\title{
HEMP USER'S MANUAL
}

E. D. Giroux

December 17, 1973

Prepared for U.S. Atomic Energy Commission under contract No. W-7405-Eng-48

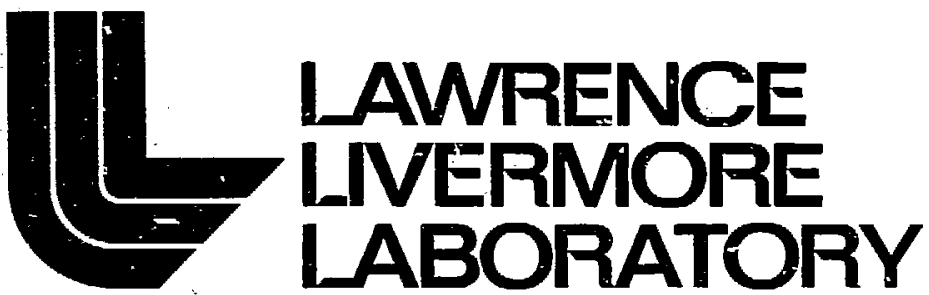

University of Calfornia/Livermore 


\section{NOTKE}

This repont wat prepated as an Jccount of wort sponsont by the United Stares Gotennecal. Noilher the Unital Statel me the United sone Alomle Enctg Commintion, nor any of their

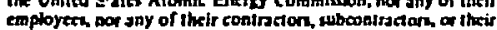

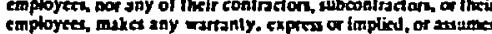

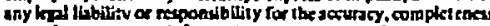

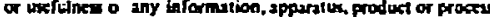

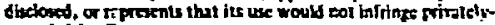
owned rithls.

Printed in the United States of America Available from

National Technical Information Service U.S. Department of Commerce 5285 Port Royal Road Springfield, Virginia 22151

Price: Printed Copy \$_ *; Microfiche \$0.95

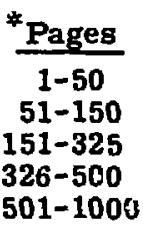

NTIS

Selling Price
$\$ 4.00$
$\$ 5.45$
$\$ 7.60$
$\$ 10.60$
$\$ 13.60$ 
TII)-4560, UC-32

Mathematics and Computers

\section{㢟 \\ LAWFENCE: LNERMMOFE LABORATOAY

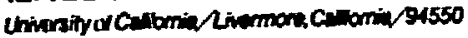

UCRL-51079 Rev. 1

\section{HEMP USER'S MANUAL}

E. D. Giroux

MS. date: December 17, 1973

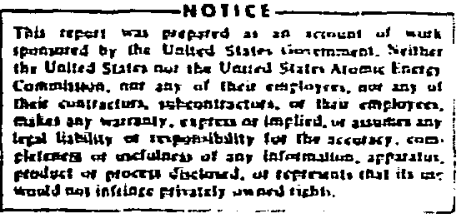

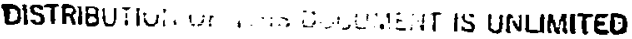

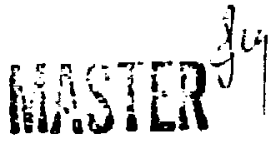




\section{Contents}

Abstract . . . . . . . . . . . . . . . . . . . . . . . . . 1

Introduction . . . . . . . . . . . . . . . . . . . . . . . 1

General Information . . . . . . . . . . . . . . . . . . . . 2

Problem Types . . . . . . . . . . . . . . . . . . . . . 2

The HEMP Grid . . . . . . . . . . . . . . . . . . . . . 2

Examples of a Two-Material Cylindrical Problem . . . . . . . . . 3

Machine and System Requirements . . . . . . . . . . . . . . . 3

Geometry . . . . . . . . . . . . . . . . . . . . . 4

Units . . . . . . . . . . . . . . . . . . . . . . 4

Zoning . . . . . . . . . . . . . . . . . . . . . 5

Boundary Conditions . . . . . . . . . . . . . . . . . . . . 6

Artificial Viscosity $\left(Q^{\prime} s\right)$. . . . . . . . . . . . . . . . . 6

The Linear-Quadratic $Q$. . . . . . . . . . . . . . . 6

Grid Distortion Q's . . . . . . . . . . . . . . . . . . . 6

Triangle Q . . . . . . . . . . . . . . . . . . . . 7

Rotational Q . . . . . . . . . . . . . . . . . . . 8

Navier-Stokes Q . . . . . . . . . . . . . . . . . . . 9

Slide-Lines . . . . . . . . . . . . . . . . . . . . 9

Volds . . . . . . . . . . . . . . . . . . . . . . . . 10

Input . . . . . . . . . . . . . . . . . . . . . . . 10

Output . . . . . . . . . . . . . . . . . . . . . . . 10

Service Routines . . . . . . . . . . . . . . . . . . . . . 11

Stability (Delta-Time) . . . . . . . . . . . . . . . . . . 12

Restart . . . . . . . . . . . . . . . . . . . . . 12

Equations of State . . . . . . . . . - . . . . . . . . . 12

Timing . . . . . . . . . . . . . . . . . . . . . . . 13

High Explosives (HE) . . . . . . . . . . . . . . . . . . . 13

Cutofis . . . . . . . . . . . . . . . . . . . . . . 14

Avallability of HEMP Program . . . . . . . . . . . . . . . . 14

Programming . . . . . . . . . . . . . . . . . . . . . . 15

Operational Flow . . . . . . . . . . . . . . . . . . . 15

The Overlay . . . . . . . . . . . . . . . . . . . . 15

LCM-SCM Transfers . . . . . . . . . . . . . . . . . . 15

Sequencing , . . . . . . . . . . . . . . . . . . . . 15

Generator . . . . . . . . . . . . . . . . . . . . 15

The Cycling Program . . . . . . . . . . . . . . . . . 17

Variable Layout . . . . . . . . . . . . . . . . . . . 17

The Grid . . . . . . . . . . . . . . . . . . . . 17

Common - . . . . . . . . . . . . . . . . . . . . 20

Table Record . . . . . . . . . . . . . . . . . . . . 20

Other Common . . . . . . . . . . . . . . . . . 20 
The Point Type Syste:s . . . . . . . . . . . . . . . . . . 20

The Equation-of-State Numbering System . . . . . . . . . . . . 20

Subroutines . . . . . . . . . . . . . . . . . . . . . 22

The Naming System . . . . . . . . . . . . . . . . . . 22

The "Main" Program . . . . . . . . . . . . . . . . . . 22

Subroutine List . . . . . . . . . . . . . . . . . . . 22

Generator Subroutines . . . . . . . . . . . . . . . 22

Subroutines Used by Both the Generator and
the Cycling Overlays . . . . . . . . . . . . . . . 24

Cyclin̨ Subroutines . . . . . . . . . . . . . . . 24

Operation . . . . . . . . . . . . . . . . . . . . . . . 28

Problem Initiation, Control and Monitoring . . . . . . . . . . . . 28

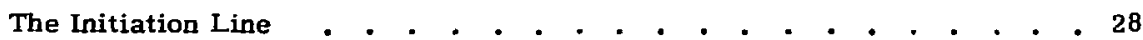

Teletype Operation . . . . . . . . . . . . . . . . . 29

Non-Teletype Operation . . . . . . . . . . . . . . . . 30

Generator Input . • . . . . . . . . . . . . . . . . . . . 30

Card Flow and Input Terminology . . . . . . . . . . . . . . . 30

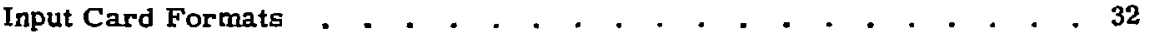

General Input Section Discussion . . . . . . . . . . . . . . 33

Name, Geometry Card . . . . . . . . . . . . . . . . 34

Delta-T Control Card . . . . . . . . . . . . . . . 35

Cutoff Card . . . . . . . . . . . . . . . . . . 35

Output Control . . . . . . . . . . . . . . . . . . . 35

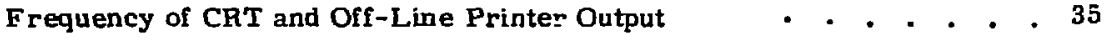

K-Line Selection . . . . . . . . . . . . . . . . . . 35

CRT Scale . . . . . . . . . . . . . . . . . . . 37

Plot Type . . . . . . . . . . . . . . . . . . . . 37

Flexible Formatted Tape Output (Binary Output) . . . . . . . . . 40

Walls, Pistons, Quadrant Control . . . . . . . . . . . . 41

Angled Rigid Walls . . . . . . . . . . . . . . . . . . 46

Quadrant Control . . . . . . . . . . . . . . . 46

Ring and Support . . . . . . . . . . . . . . . . . . . 46

VARWALL Option . . . . . . . . . . . . . . . . . 48

Pressure Profiles. . . . . . . . . . . . . . . . . . . 51

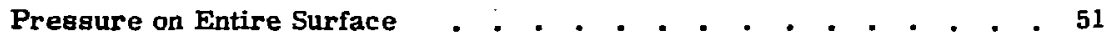

Boundary Pressures with Range and Time Controls . . . . . . . . 52

Pressure Table Input $\quad . \quad$. . . . . . . . . . . . . . . . 52

Slide-Lines and Voids . . . . . . . . . . . . . . . . . 53

Voids, Stand-Off, and Z-Factor . . . . . . . . . . . . . . 60

Tied Sliding . . . . . . . . . . . . . . . . . . . 62

Material and Material-Related Input . . . . . . . . . . . . 63

Material-Related Input Cards . . . . . . . . . . . . . . 69 
"Q" Input (Artificial Viscosity). . . . . . . . . . . . . . . 69

Special Calculations . . . . . . . . . . . . . . . . . . 71

Gravity . . . . . . . . . . . . . . . . . . . . 71

Fini Card . . . . . . . . . . . . . . . . . . . . . 73

Block Input Section Discussion . . . . . . . . . . . . . . . 73

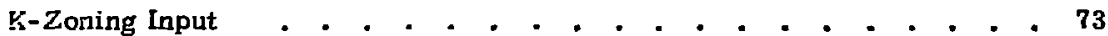

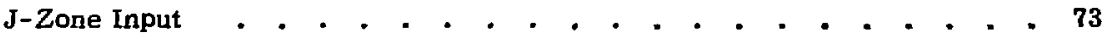

Material Number and Material-Related Input . . . . . . . . . 76

Cartesian Corner Cards . . . . . . . . . . . . . . 76

K-min of Block, Second Card . . . . . . . . . . . . . . . 79

Polar Input Cards . . . . . . . . . . . . . . . . . 80

K-Polar Input . . . . . . . . . . . . . . . . . . . . 81

J-Polar Input . . . . . . . . . . . . . . . . . . . . 83

$\mathrm{J}$-Polar Angle-K-min End . . . . . . . . . . . . . . . 83

Slide-Lines . . . . . . . . . . . . . . . . . . . 85

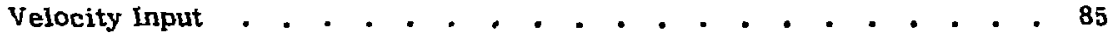

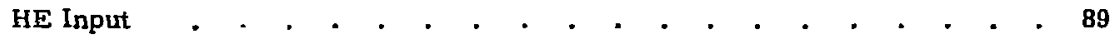

K-by-K Input . . . . . . . . . . . . . . . . . . . . 91

Fini Card . . . . . . . . . . . . . . . . . . . . . 92

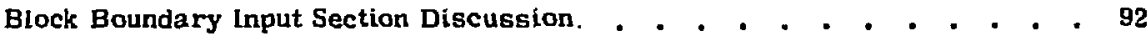

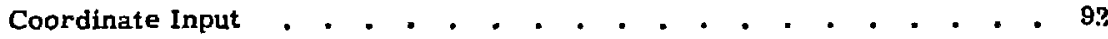

Burn Input . . . . . . . . . . . . . . . . . . . . . 92

Tied Slioing Input . . . . . . . . . . . . . . . . . . . 94

Fini Card . . . . . . . . . . . . . . . . . . . . 94

K-Line Input . . . . . . . . . . . . . . . . . . . . . 94

Data Input . . . . . . . . . . . . . . . . . . . . . 94

The Fini Card . . . . . . . . . . . . . . . . . . . . 95

K-Line Point-by-Point Input . . . . . . . . . . . . . . . . 96

Data Input . . . . . . . . . . . . . . . . . . . . 96

Fini Card . . . . . . . . . . . . . . . . . . . 97

Generator Dutput . . . . . . . . . . . . . . . . . . . 97

Teletype . . . . . . . . . . . . . . . . . . . . . . . 97

On-Line Printer . . . . . . . . . . . . . . . . . . . . 97

Off-line Printer . . . . . . . . . . . . . . . . . . . 97

Trouble Stops . . . . . . . . . . . . . . . . . . . . . 97

Main Code . . . . . . . . . . . . . . . . . . . . 97

Input to Main Code . . . . . . . . . . . . . . . . . . 97

Teletype, Sense Switch Control . . . . . . . . . . . . . . 97

Data Alteration . . . . . . . . . . . . . . . . . 98

Type Changing . . . . . . . . . . . . . . . . . 98

Gutput . . . . . . . . . . . . . . . . . . . . . 98

Teletype Output . . . . . . . . . . . . . . . . 98 
The On-Line Printer . . . . . . . . . . . . . . . 98

The Off-Line Printer . . . . . . . . . . . . . . . . 99

Tape Output . . . . . . . . . . . . . . . . . . . 102

Disk Output . . . . . . . . . . . . . . . . . . . 103

Problem Restarting . . . . . . . . . . . . . . . . . . 103

The Restart Deck . . . . . . . . . . . . . . . . . . 103

General Data Changing . . . . . . . . . . . . . . . . 104

Grid Changes . . . . . . . . . . . . . . . . . . 104

Acknowledgments . . . . . . . . . . . . . . . . . . . . . . 104

References . . . . . . . . . . . . . . . . . . . . . . 105

Appendix A: HEMP Teletype Sense Switch Controls . . . . . . . . . . 106

Appendix B: Trouble Stops and Interrupts . . . . . . . . . . . . . . 107

Appendix C: Adaptation to Other Machines and Systems . . . . . . . . . 110

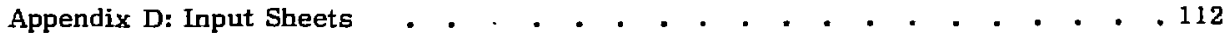

Appendix E: Sample Problem Description and Output . . . . . . . . . . 121

Appendix F: Flow Charts . . . . . . . . . . . . . . . . . . . 201 


\title{
HEMP USER'S MANUAL
}

\begin{abstract}
A computer program to solve the conservation equations of two-dimensional elastic-plastic flow has been implemented at LLL on the CDC 7600 machine. The equations are detailed in reprrt UCRL7322 Rev. 1, by Mark L. Wilkins.

Tre program, named HEMP, is written in an expanded FORTRAN IV language. This user's manual explains the operation and use of the program. A section is provided that will aid in converting the program to other machines and systems.
\end{abstract}

\section{Introduction}

The HEMP Computer Program as detailec in a report by Mark L. Wilkins 1 has been implemented at LLL, in the CHAT compiler language (LLL implementation of FORTRAN IV with extensions), for the CDC 7600 computers and associated operating system. It runs in a timesharing environment during the day and as a "stand-alone" program at night.

The HEMP code solves the conservation equations of two-dimensional elasticplastic flow, in plane $X-Y$ coordinates or in $X-Y$ coordinates with cylindrical symmetry around the $X$ axis. The solution is by the method of finite differences and uses the Lagrangian formulation. The materials within a physical system aree divided into quadrilaterals bounded by $J$ and $K$ grid lines. A decoupling of grid iines is allowed ilong $\mathrm{K}$-lines and voids may open a:ıd close between $\mathrm{K}$-lines.

Provisions for calculation of fixed boundaries, free surfaccs, pistons, and boundary slide planes have been included as well as many other special conditions.
The input system is such that the least amount of data to describe a particular physical system need be supplied. Provision is made for describing initial conditions (zonal or nodal) in great detail if required.

The HEMP code will handle large classes of problems without alteration, but it is programmed in such a way that alteration to solve many other problems is relatively convenient.

HEMP has been previously implemented in assembly program language for the IBM 7030 (Stretch) computer at LLL. The acronym HEMP is formed from the words Hyd rodynamic, Elastic, Magneto, and Plastic. The magneto portion is not presented here.

The user should be familiar with UCRL-7322 Rev. 1 (Ref. 1) before reading this menual or attempting to run problems. The user should read the "General Information and Operation" sections of this manual in their entirety before attempting to run problems. The 
"Programming" section is provided both as an aid to the user in making program changes and as a description of the pro- gram's operation. This section will greatly aid the user in finding and correcting input errors.

\section{General Information}

\section{PROBLEM TYPES}

Large classes of problems may ide solved without special program alteration. These include projectile impact problems, high explosive problems, and low energy stress-strain problems. Many problems may be solved by altering the program to include conditions not included in the standard set of options. (See "Applications to problems in two-dimensional elasticplastic nlow" section of Ref. 1.)

\section{THE HEMP GRID}

The geometry of each HEMP problem is described within the computer by a nuraber of small quadrilaterals or "zones", each containing a small quantity of mass of a particular material. The zones are separated by a segmented grid composed of two types of lines, $\mathrm{J}$-lines and $\mathrm{K}$-lines. The $\mathrm{J}-\mathrm{K}$ system of coordinates may be oriented with respect to the $X-Y$ coordinate system in any way. While certain $J-K$ lines represent real material boundaries, most $\mathrm{J}-\mathrm{K}$ lines represent physically artificial internal divisions within a material and are necessary for calculation by the finite difference method. J-lines and $\mathrm{K}$-lines may be used interchangeably in setting up a HEMP problem with certain notable exceptions:

1. Slide-lines (uncoupled grid) must be along $\mathrm{K}$-lines.
2. For some problems, input may be more conveniently written by orienting the $J-K$ system a certain way.

3. Output is generally done $\mathrm{K}$-line by $\mathrm{K}$-line so that it may be desirable to set up a problem a certain way to make the printouts easier to use, or to make linkage to other problems more convenient.

4. Small calculation speed increases and storage saving may be realized by keeping the ratio of the number of $\mathrm{K}$-lines to $\mathrm{J}$-lines low.

$\mathrm{J}$-lines are numbered in sequence from $J-\max$ at one external boundary to $\mathrm{J}$-min at the opposite external boundary. $\mathrm{I}$-max, along any $\mathrm{K}$-line, is one greater than the number of zones along that $\mathrm{K}$-line. (A problem may have several values of $J$-max, if slide lines are present, as is explanned later.) In a problem with 10 zones along a $\mathrm{K}$-line, the Jlines would be numbered from 11 to 1 .

$\mathrm{K}$-lines are numbered in a similar manner from $K-\max$ to $\mathrm{k}-\min (=1)$ with one exception. Along a slide-line (decoupled grid), there are two K-lines. The $\mathrm{K}$-line on the $\mathrm{K}$-max side of the slide surface is assigned the $\mathrm{K}$-number with a positive sign. The $\mathrm{K}$-line on the $\mathrm{K}$-min side of the slide surface is assigned the $K$ number with a negative sign. Therefore, slide-lines do not increase the size of $\mathrm{K}$-max. A problem with 10 zones in the $\mathrm{K}$ direction and no slide-lines would be 
numbered from $K$-max to $K-\min$ thus: 11 , $10,9,8,7,6,5,4,3,2,1$. If a slide-line is introduced at $K=3$, the lines would be numbered thus:

$$
11,10,9,8,7,6,5,4,3,-3,2,1 \text {. }
$$

Problems must be set up so that the following rule is observed:

The direction of increasing $J$ must be clockwise from the direction of increasing $\mathrm{K}$.

(Note: A "left-hand rule" may serve as a mnemonic device. If the left hand is thought to be placed palm down with fingers pointing toward increasing $K$, the thumb will point toward increasing $\mathrm{J}$ ).

Examples of a Two-Material Cylindrical Problem

A simple two-material cylindrical problem may be set up in four ways (Fig. 1-1) if no sliding is allowed.

If a slide line is desired between the materials, only examples (a) and (b) in Fig. 1-2 may be used because slide-lines may only be along $\mathrm{K}$-lines.

If a slide-line is introduced, the number of $\mathrm{J}$-lines may change from one material to the next. J-lines on either side of the slide-line need not meet.

MACHINE AND SYSTEM REQUIREMENTS

The HEMP implementation is for the CDC 7600 computers at LLL, Livermore. These computers are linked to each other, to the CDC 6600 computers, to large storage devices, and to remote teletype (TTY) stations throngh a time-sharing hardware system called "OCTOPUS". The software system that links the TTY's to the computers is called "F LOE." The hardware system includes cathode ray tube plotting devices (CDC 280-C) which produce a $35 \mathrm{~mm}$ film output; which is later processed to hard copy by an SC 5000 printer. Most of the HEMP alpha-numeric output is written on to a magnetic tape which is later printed using the "Radiation Printer" which prints at 30,000 lines per minute.

The CDC 7600's each have $65,536_{10}$ sixty-bit words of "small core" memory (SCM) and $512,00{ }_{10}$ sixty-bit words of a slower "large core" memory (LCM).

The HEMP main code fills the SCM with the code, working storage, library routines and system routines. This restricts the maximum number of J's in any $\mathrm{K}$-line to 101. The large core memory (LCM) portion that may be utilized by the user is approximately $400,000,10^{\circ}$

The portion of LCM that is actually used by a HEMP problem is a function of the problem size. A problem of up to about 10,000 zones may be run.

The "main" program uses about $22,500_{10}$ words of storage for coding. This does not include the generator, which has been overlaid by the main program. The generator uses about $15,000_{10}$ words.

The LLL Library routine uses about $1^{10,000} 10$ words. Twenty-five hundred words are used as a table record. The five $K$-lines that are in memory at a time use about $17,000_{10}$ words. Five thousand words are used for $J$-max long working storage and temporarily saved variables. The system uses about $8,500_{10}$ words. (The table record is the data that is written on and read from the restart tape, in addition to the grid variables.) 


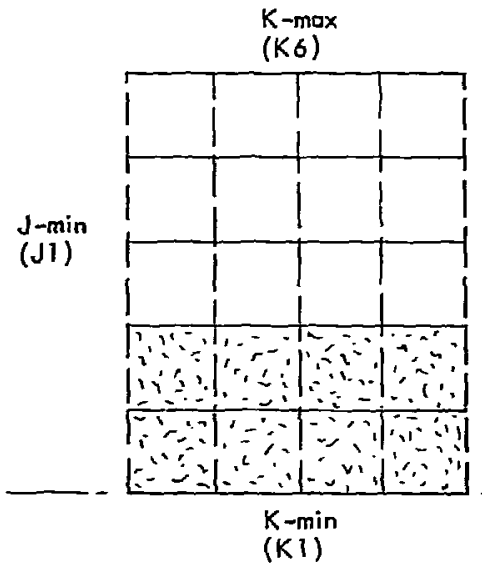

Example a.

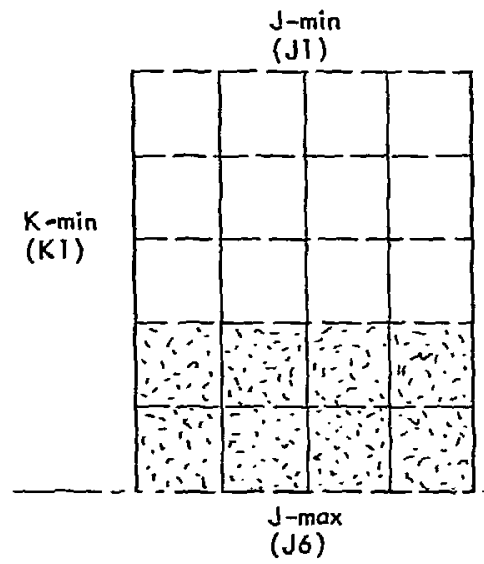

Example c.

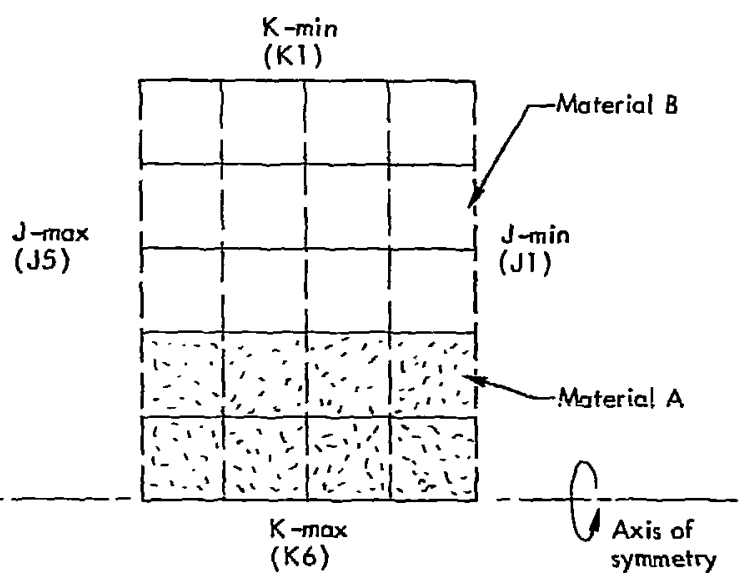

Example b.

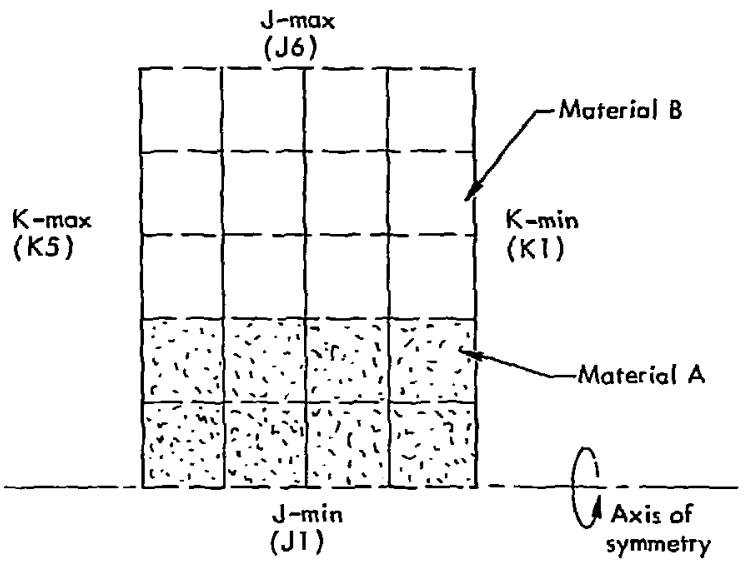

Example d.

Fig. 1-1. Four different ways to orient the grid J, K coordinate system to solve a simple cylindrical problem (without slide-lines).

\section{GEOMETRY}

The program solves problems described in the $\mathrm{X}-\mathrm{Y}$ coordinate system, either plane or cylindrical. The cylindrical case has a cylindrical symmetry around the $x$-axis.
UNITS

Tre units of the calculational quantities are as follows: Time, delta-time $-\mu$ sec $\mathrm{x}, \mathrm{y} \quad \mathrm{cm}$ 

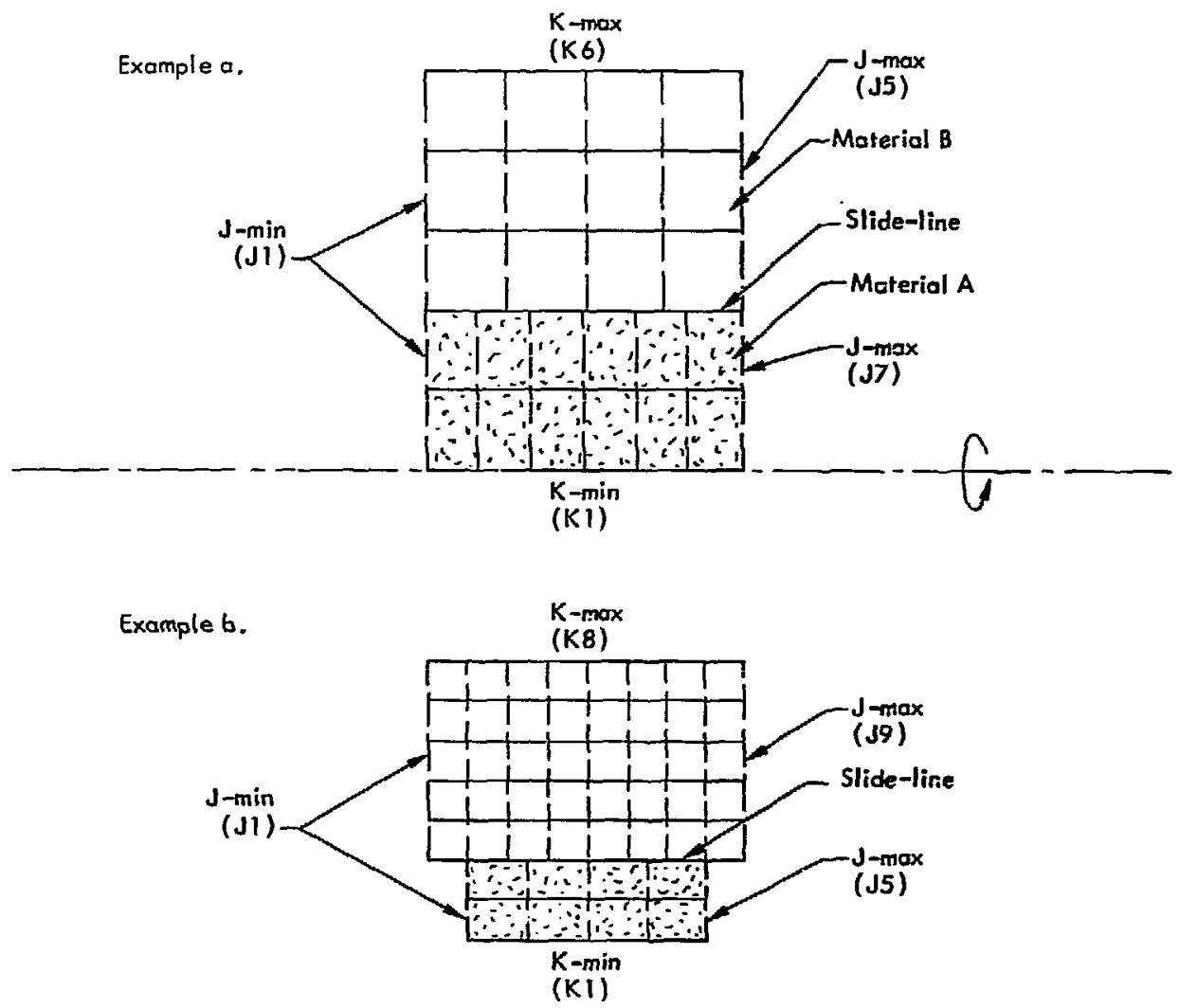

NOTE: Slide lines need not coincide with material boundaries

Fig. 1-2. Examples of problems that include a slide-line.

$\dot{x}, \dot{y}$

area (zonal)

mass (zonal)

Mu(shear modulus),

$\mathrm{Y}_{0}$ (yield point), $P$,

Q, $\mathrm{s}_{\mathrm{xx},}, \mathrm{s}_{\mathrm{yy}}, \mathrm{s}_{\theta \theta^{\prime}}$

$T_{\mathrm{xy},} \Sigma_{\mathrm{xx}} \Sigma_{\mathrm{yy}} \Sigma_{\theta \theta^{\circ}}-$ Mbar

$E$ (energy)

$\rho_{0}$

V
- $\mathrm{cm} / \mu \mathrm{sec}$

$-\mathrm{cm}^{2}$

$-\mathrm{g}$

The units of other variables on the printouts are explained in the operational output section.

\section{ZONING}

The number of mass zones into which a HEMP problem is to be divided is innuenced by a number of factors.

- The storage capacity of the machine

- The maximum number of J's allowed 
in a $\mathrm{K}$-line the maximum is 101 ).

(There is no maximum number of

K-lines)

- The calculation time

- The nature of the calculation

In general, size and time restrictions prohibit the zoning of a problem on a twodimensional coile in the same detail that would be allowed with a one-dimensional code in calculating 2 section of that same problem. A zumber of comments cen be made about zoning HEMP.

Material interfaces zoned so that the zones cn either side of the interface have similar shock transit times give the most satisfactory results.

Problems run best when the zonal aspect ratio is near 1 to 1 . When elasticplastic parameters are included, an aspect ratio of over 2 to 1 is to be discouraged, although much greater aspect ratios have been run successfully.

Cutting the zonal size by one-half will produce an eight-fold increase in running time.

\section{BOUNDARY CONDITIONS}

Provision is made for appiying rigid wall (stonewall) and piston boundary conditions for all surfaces. Various limits may be placed on the movement of selected portions of the problem (ring and support options). External pressure may be applied to part or all of each exterior surface (K-max, K-min, J-max, J-min). Provision is made to vary this pressure as a function of $X, Y$ or time.

\section{ARTIFICLAL VISCOSITY (Q'S)}

Five Q's are available by option in the program. Unless changed by input, the linear quadratic $Q$ will be automatically utilized. Also available are the NavierStokes $Q$, the triangular $Q$ and a rotational Q. Most problems need utilize only the linear-quadratic $Q$. An explanation of the various $Q^{\prime}$ 's follows:

\section{The Linear-Cuadratic $Q$}

For the calculation of shock waves, an artificial viscosity is calculated for each zone:

$$
\begin{aligned}
q^{n+1 / 2}=\left[\frac{Q_{A_{0} \rho_{0}} A^{n+1 / 2}}{v^{n+1 / 2}} \cdot\left(\frac{\dot{V}}{V}\right)^{2}\right] \\
+\frac{a Q_{B} \rho_{0} \sqrt{A^{n+1 / 2}}}{v^{n+1 / 2}}\left|\frac{\dot{V}}{V}\right|
\end{aligned}
$$

(calculate only for $\mathrm{V} / \mathrm{V}<0$ ) where $Q_{A}$ and $Q_{B}$ are constants (usually $Q_{A}=4$. and $Q_{B}=1.1$,

$$
\begin{aligned}
& a=\sqrt{\frac{P V}{\rho_{0}}}, \\
& A=\text { zone area. }
\end{aligned}
$$

The first term corresponds to a simple extension of the one-dimensional " $Q$ " of von Neumann and Richtmyer into two dimensions. The second term is a linear viscosity that damps short wavelength oscillations that occur benind shocks calculated by the $Q$ method.

\section{Grid Distortion Q's}

Fine-scale error waves of the order of zone-to-zone fluctuations can appear in finite difference hydro codes under certain boundary conditions. For example, nonphysical numerical oscillations often occur when a shearing action is introduced on the boundary of a Lagrange grid. These oscillations usually grow at a slow linear 
rate, and are not real instabilities, but nonetheless can lead to large grid distortions. In practical calculations, it is useful to be able to control the onset of grid distortion due to numerical sources and, in some cases, even to damp grid distortions that are describing real physical phenomena.

The addition of an artificial viscosity is a convenient way to control grid distortions, since it represents a physical process whose influence on a problem can be readily unde:"stood. This is in contrast to methods of damping spurious oscillations that are implicit in the finite difference scheme. In two-dimensional fluid flow calculations, a Navier-Stobes stress tensor, using linear rates of strain, can be used as an artificial viscosity. In 2-D Cartesian coordinates, there are three components of the tensor viscosity one for each of the rates of strain $\dot{\epsilon}_{\mathbf{x x}}$, $\dot{\epsilon}_{\mathrm{yy}}$, and $\dot{\mathrm{E}}_{\mathrm{xy}}$. For quadrilateral zones, the average strain in a zone is calculated from the motion of the four corners. There are more degrees of freedom than there are strain components, and it is possible to have the average rates of strain zero, even though the quadrilateral zone is distorting. The hour glass distortion shown in Fig. 1-3 is an example. No component of the rate of strain tensor is activated by such a distortion.

\section{Triangle Q}

The difficulty expressed above can be overcome by using triangles in place of quadrilaterals to calculate the rates of strain. A Navier-Stokes viscosity using triangles is formulated to prevent grid distortion and is referred to as the "triangle Q". Figurs 1-4 shows the grid

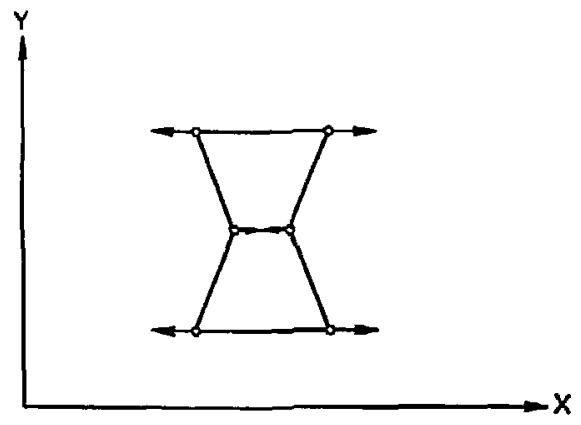

rig. 1 -3. Hourglass distortion.

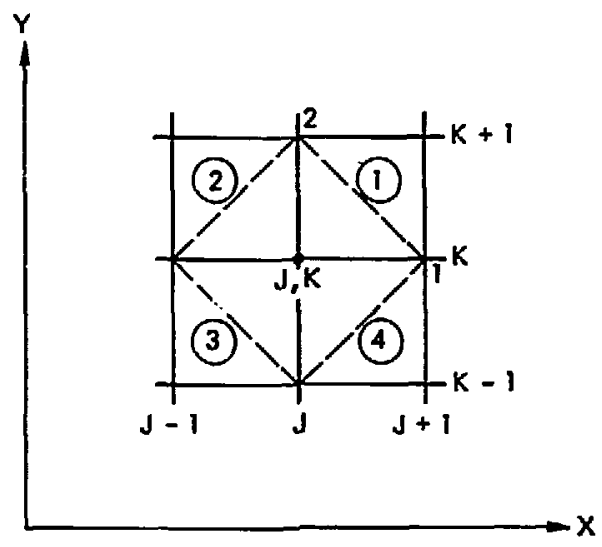

Fig. 1-4. HEMP difference scheme for accelerating point $\mathrm{J}$, $\mathrm{K}$.

for calculating the acceleration of point J, K. A "triangle $Q$ " expressed as a stress deviator is formulated for each of the triangles in the four zones surrounding point J, K. For example, the artificial viscosities for zone 1 are given by

$$
\begin{aligned}
& q_{x x}=2 \mu_{1}\left[\frac{2}{3} \dot{\epsilon}_{x x}-\frac{1}{3} \dot{\epsilon}_{y y}\right], \\
& q_{y y}=2 \mu_{1}\left[\frac{2}{3} \dot{\epsilon}_{y y}-\frac{1}{3} \dot{\epsilon}_{x x y}\right], \\
& q_{x y}=\mu_{1} \dot{\epsilon}_{x y} .
\end{aligned}
$$


where

$\mu_{1}=a\left(A_{0} / V\right)_{(1)} \sqrt{A}$.

$A=$ area of triangle $0,1,2$.

$a=$ constant $=10^{-3}$.

$\rho_{0}$ and $V$ are the zone reference density and relative volume.

Velocity strains for triangle $0,1,2$ are

$$
\begin{aligned}
& \dot{\epsilon}_{\mathrm{XX}}=\frac{\partial \dot{X}}{\partial \mathrm{X}}=-\frac{1}{\mathrm{~A}}\left\{\dot{X}_{01}\left(\mathrm{Y}_{0}-\mathrm{Y}_{1}\right)\right. \\
& \left.+\dot{x}_{12}\left(y_{1}-y_{2}\right)+\dot{x}_{20} f^{\prime} x_{2}-y_{0}\right\}^{\prime} \\
& \dot{\epsilon}_{y y}=\frac{\partial I}{\partial Y}=+\frac{1}{A}\left\{\dot{Y}_{01}\left(x_{0}-x_{1}\right)\right. \\
& \left.+\dot{y}_{12}\left(x_{1}-x_{2}\right)+\dot{y}_{20}\left(x_{2}-x_{0}\right)\right\} \text {. } \\
& \dot{\epsilon}_{x y}=\left(\frac{\partial \dot{Y}}{\partial X}+\frac{\partial \dot{X}}{\partial I}\right)=-\frac{1}{A}\left\{Y_{01}\left(Y_{0}-Y_{1}\right)\right. \\
& +\dot{\mathrm{Y}}_{12}\left(\mathrm{Y}_{1}-\mathrm{Y}_{2}\right)+\dot{\mathrm{Y}}_{20}\left(\mathrm{Y}_{2}-\mathrm{Y}_{0}\right) \\
& -\left[\dot{x}_{01}\left(x_{0}-x_{1}\right)+\dot{x}_{12}\left(x_{1}-x_{2}\right)\right. \\
& \left.\left.+\dot{x}_{20}\left(x_{2}-x_{0}\right)\right]\right\} \text {. }
\end{aligned}
$$

where

$$
\dot{x}_{01}=\frac{1}{2}\left(\dot{x}_{0}+\dot{x}_{1}\right) \text {, etc. }
$$

and

$$
\begin{aligned}
A= & \text { area of triangle } 0,1,2 \\
= & \frac{1}{2}\left[X_{1}\left(Y_{2}-Y_{0}\right)+X_{2}\left(Y_{0}-Y_{1}\right)\right. \\
& \left.+X_{0}\left(Y_{1}-Y_{2}\right)\right] .
\end{aligned}
$$

A "triangle $Q$ " for zones (2). (3), and (4) is formulated in the same manner. The components of the viscosity are added to the corresponding stress in the equations of motion for point $J, K$. The "triangle $Q$ " is actuated by introducing a value for the constant a which is designated in the program as CAQ. (See the "General Input Section Discussion," page 33. ।
Rotational Q

The rutational $Q$ of the $T$ ENSOR code ${ }^{2}$ is also available. This $Q$ is used for the same purpose as the "trlangle Q". (See Fig. 1-5.)

$w_{34}=\frac{\left(\dot{Y}_{3}-\dot{Y}_{4}\right)\left(X_{3}-X_{4}\right)-\left(\dot{X}_{3}-\dot{X}_{4}\right)\left(Y_{3}-Y_{4}\right)}{\left(Y_{3}-y_{4}\right)^{2}+\left(X_{3}-X_{4}\right)^{2}}$.

$w_{41}=\frac{\left(\dot{x}_{4}-\dot{y}_{1}\right)\left(x_{4}=x_{1}\right)-\left(\dot{x}_{4}-\dot{z}_{1}\right)\left(z_{4}-\ddot{z}_{1}\right)}{\left(Y_{4}-Y_{1}\right)^{2}+\left(x_{4}-x_{1}\right)^{2}}$.

$\omega_{21}$ is similar to $w_{34}$.

$w_{32}$ is similar to $\omega_{41}$,

$Q_{k(1)}=\operatorname{CAQ}$ a $\frac{\rho_{0}}{\sqrt{n}}\left(\frac{A}{\Delta Z}\right)\left(\omega_{34}-\omega_{21}\right)$.

$Q_{j_{(1)}}=\operatorname{CAQ} a \frac{P_{0}}{v^{n}}\left(\frac{A}{\Delta Z}\right)\left(\omega_{41}-\omega_{32}\right)$.

where

$a=$ sound speed,

$\Delta Z=$ the zone thickness from center of one side to the opposite, and is taken as the minimum of $\Delta z_{1}$ and $\Delta z_{2}$.
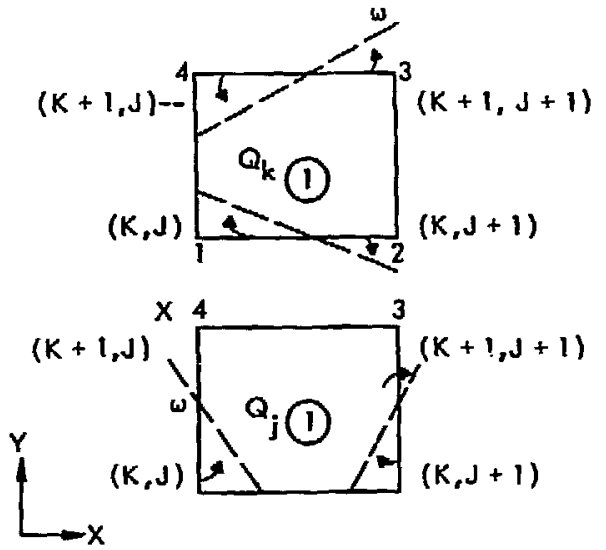

Fig. 1-5. Rotation rate, $w$, of a zone side. 

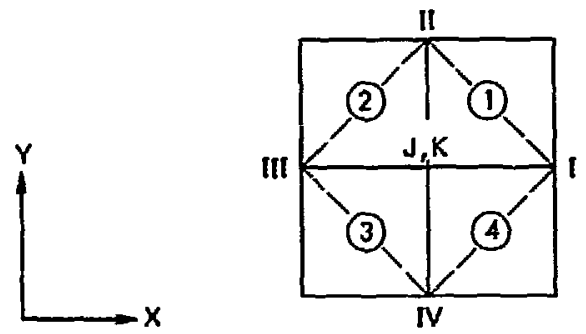

Fig. 1-6. HEMP difference scheme for accelerating point $J$, $K$.

$$
\begin{aligned}
\Delta z_{1}=\{ & {\left[\left(Y_{1}-Y_{3}\right)-\left(y_{4}-Y_{2}\right)\right]^{2} } \\
& \left.+\left[\left(x_{1}-x_{3}\right)-\left(x_{4}-x_{2}\right)\right]^{2}\right\}^{1 / 2}
\end{aligned}
$$

$$
\begin{aligned}
\Delta Z_{2}=\{ & {\left[\left(Y_{1}-Y_{3}\right)+\left(Y_{4}-Y_{2}\right)\right]^{2} } \\
& \left.+\left[\left(X_{1}-X_{3}\right)+\left(X_{4}-X_{2}\right)\right]^{2}\right\}^{1 / 2}
\end{aligned}
$$

$$
\begin{aligned}
& Q_{j(34)}=Q_{j}(3)-Q_{j}(4)^{Q_{(12)}}=Q_{j}(1)-Q_{j}(2) \\
& Q_{k(23)}=Q_{k}(2)-Q_{k}()^{Q_{k(41)}}=Q_{k}(4)-Q_{k} \text { (1) }
\end{aligned}
$$$$
Q_{X}=-Q_{k(41)} \cdot\left(Y_{I}-Y_{0}\right)-Q_{j(12)}\left(Y_{I I}-Y_{0}\right)
$$$$
+Q_{k(23)} \cdot\left(Y_{I n}-Y_{0}\right)
$$$$
+Q_{j(34)}\left(Y_{I V}-Y_{0}\right)
$$

$$
\begin{aligned}
Q_{Y}= & -Q_{k(41)}\left(X_{I}-X_{0}\right)-Q_{j(12)}\left(X_{L I}-X_{0}\right) \\
& +Q_{k(23)}\left(X_{I I I}-X_{0}\right)+Q_{j(34)}\left(X_{I V}-X_{0}\right)
\end{aligned}
$$

(See Fig. 1-6.)

The resulting accelerations from these terms are:

$$
\frac{d \dot{X}}{d t}=\frac{1}{2 \phi} Q_{X} \text { and } \frac{d \dot{Y}}{d t}=\frac{-1}{2 \phi} Q_{Y}
$$

and are included in the finite difference equation-of-motion ${ }^{*}$ for point $J, K$.

The coefficient CAQ is normally set equal to zero in the program. The rotational $Q$ is activated when an input number other than zero is used for the coefficient and when the rotation $Q$ option field on the QCONTROL card is set to non-zero, A typical value is $\mathrm{CAQ}=0.1$ to 0.5 .

Navier-Stokes Q

The $Q$ referred to as the Navier-Stokes $Q$ in Ref. 1 and in other places in this manual utilizes quadrilaterals in calculating the strain rate. It is as shown in Ref, 1 except that a limiting condition similar to the elastic yield condition has been added.

\section{SLIDE-LINES}

Sliding must be along $\mathrm{K}$-lines. A slideline should be used when 1) all the grid points on one side of a $\mathrm{K}$-line do not coincide with all the grid points on the other side, or 2) when large transverse motion along a $\mathrm{K}$-line is expected.

In this manual and on the HEMF printouts, the "slide surface" described in Ref. 1 has been named the "master" surface or line. The "sliding material" has been called the "slave" surface or line. This terminology is felt to be more distinctive and therefore easier to use in slide-line discussion. The master-slave pair is called a "slide-line".

As is explained in greater detail in Ref. 1, the "master" surface is advanced using the force field from the "slave" side

See page 70 of Ref. 1. 
and its own force field. The "slave" surface is advanced along the "master surface" by treating it as a fixed surface. When sliding is called for, lateral motion along the $\mathrm{K}$-line is uninhibited. Friction is not included (but could be readily included).

Two types of slide-lines (master-slave pairs) are allowed. When the master surface is on the higher $K$ number side of the slide-line, this is called an "upright" slide-line. When the master surface is on the lower $\mathrm{K}$ number side of the slideline, this is called an "inverted" slideline. "Upright" and "inverted" slides may be mixed in a problem. Any number of slide-lines may be in a problem (their placement must be consistent with minimum $\mathrm{K}$-zone spacing as shown below).

When possible, the master surface should be assigned to the side of the slideline that has the denser material. This is because after influencing the motion of the master side, the slide side must conform to it (except in the void case). In general, the lighter material is more likely to do this physically.

Certain minimum $\mathrm{K}$-zone spacing between $K-l i n e s$ and $K$ boundaries must be maintained.

An "upright" slide-line must be separated from:

- Any other slide-line by two zones

- K-max by one zone

- K-min by three zones.

An "inverted" slide-line must be separated from:

- Another inverted slide-line by one zone

- An upright slide-line by 2 zones

- $K$-max by one zone

- $\mathrm{K}$-min by two zones.
Figure 1-7 illustrates these minimums. For purpases of illustration, the "master" slides are shown as longer than "slave" sides of the slide-lines.

The $J$-max ends of the master and slave points may join at a single point or may be offset so that the "sliding" $J$-max point lies on the master surface or on an extension of the master surface. The $\bar{J}$-max ends are treated in a similar way. Higid wall, free surface, piston, and pressure boundary conditions may be applied to one or both sides of a slideline.

\section{VOIDS}

Provision is made for allowing a void condition between the master and slave surfaces of an "upright" slide-line. The void is treated point by point so that part of the two materials may meet while part may be in a void condition. The void may be generated open or allowed to open. It may be allowed to re-open after closing or may be forced to remain closed.

INPUT

Input is by two means, cards and teletype. The teletype is used for control and restart purposes. The generator and the restart routine use card input.

\section{OUTPUT}

Output is via five means, teletype, on-line printer, off-line printer (HSP tape), disk, and magnetic tape. The tape can contain binary output of three formats.

The disk output and part of the tape output is formatted in such a manner that 


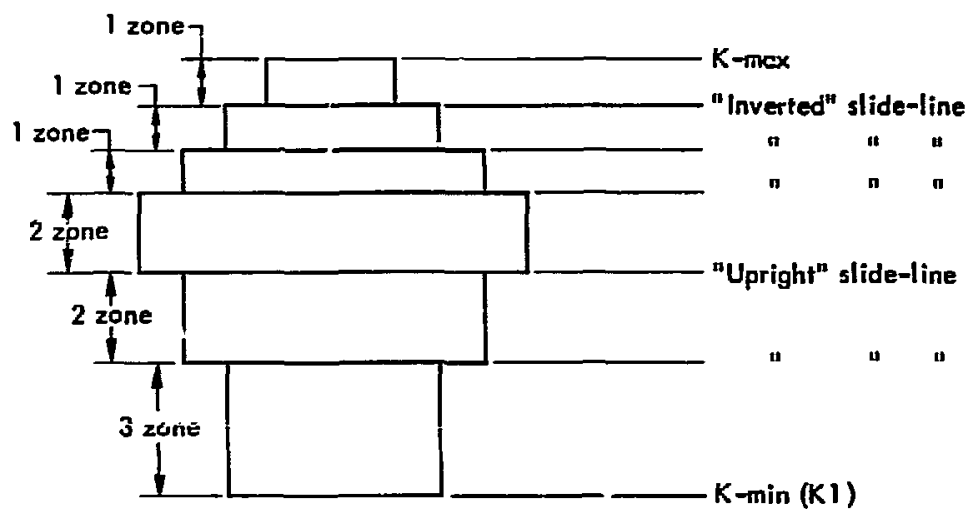

o.

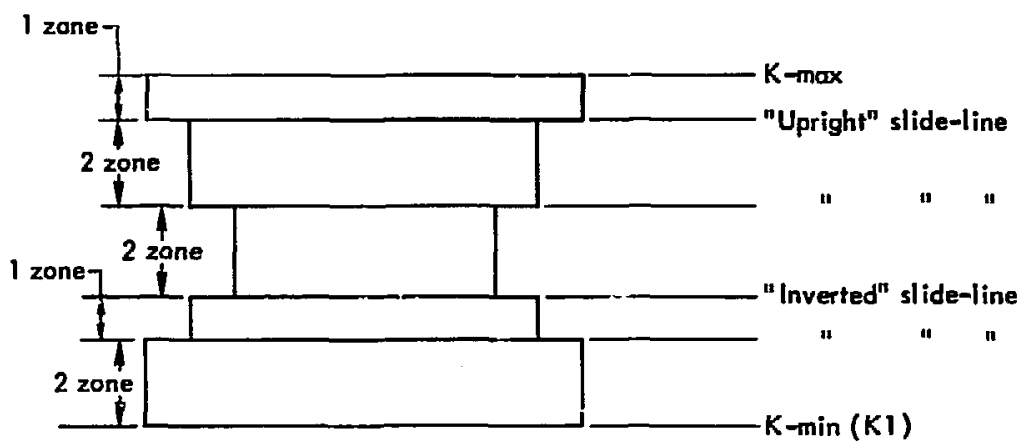

b.

Fig. 1-7. Minimum allowable K-zones in various slide-line and boundary configuraticis.

it may be processed readily by an auxiliary plot roitine which produces cathode ray tube output or Calcomp output. A second, flexible tape output format is provided so that selected variables for selected $K$-lines may be written on tape for future processing. A third tape output format is the restart dump which may also be processed by service routines.

The teletype output is restricted to supervisory type information and is under some control of sense switches. The on-line printout is also supervisury type information.
The off-line printout contains detailed zonal and nodal quantities for selected K-lines. Options are provided for calculation and printout of zonal and nodal quantities not ordinarily printed out.

\section{SER VICE ROUTINES}

A number of programs are available which process HEMP output. HEMP output is processed for three purposes.

1. Diagnostic-Provide plots of various types including configuration, with 
vector 3 , contour and others, on both cathode ray tube and "Calcomp" plotter.

2. Grid Restructuring-There are five of these. They produce a restructured restart tape.

- J Rezone-Adds J-Lines for finer zoning: each $\mathrm{J}$-zone is split into two.

- J Dezone-Removes J-Iines to make zoning coarser: two J-zones are combined into one.

- K Rezone-Adds K-lines for finer zoning: each $\mathrm{K}$-zone is split into two.

- K Dezone-Removes K-lines to make zoning coarser: two K-zones are combined into one.

- Rezoner-Generates a nicely zoner grid for a selected trouble area in the problem. The rezoner then does a remapping of the new grid over the old grid and recalculates variables so that the new data is a reproduction of the old data but with nicely formed zones.

3. Links - The restart dump may be processed to create restart dumps of other programs so that a problem may be run to an appropriate point on HEMP, and then run further by another program. For example, HEMP could be linked to an Eulerian program.

\section{STABILITY (DELTA-TIME)}

The stability calculation is substantially as written in the one-dimensional section of Ref. 1. Provision is made for adjusting all parameters by input. Problems may be run with a maximum Delta- $T$ or a constant Delta-T. If a minimum Delta- $T$ is reached, the problem will terminate.
RESTART

Provision is made for the restarting of a HEMP problem after it has run ior some time and then been removed from the machine. At periodic intervals, as a problem runs, restart dumps are automatically written on tape. When a problem has finished, or when it has used its allotted machine time and is terminated, a restart record is written. The problem may be restarted from any of these dumps.

Provision is made for altering the problem at restart time by the use of card input. The dump tape can be restructured by service routines and the problem started again from the restructured dump tape.

EQUATIONS OF STATE

Most HEMP hydrodynamic equations of state follow the form:

$\mathrm{P}=\mathrm{A}+\mathrm{B} \mu+\mathrm{C}^{2}+\mathrm{D} \mu^{3}+\left(\mathrm{E} \mu+\mathrm{F} \mu^{2}+\mathrm{G} \mu^{2}\right) \epsilon$ (if $\mu<0, \mu^{2}$ is set to 0 ), where $\mu=(1 / V-1)=\eta-1$.

If $P<P-m i n, P$ is set to $P$-min. $P$-min has a value of -0.01 for metals and is zero for non-metals, but can he changed by input. The general form appears in the program in a number of abbreviated forms so that machine time is not lost in calculating zero coefficient terms.

Certain high explosive equations of state are included that do not follow this general form. Equations of state of any form in which pressure is a function of compression, or of compression and energy, can be readily coded into the program. These may include table look-ups.

Elasticity parameters are ordinarily constant in the code (elastic mu, yield in 
tension and in compression) but may be readily programmed to be functions of variables.

Equations oi state are specified for each region in the problem by inputting an equation-of-state number. The generator then assigns the appropriate equationof-state form to each zone in that region. The coefficient and material-related properties are read in at generation time. Some of the high explosive materials have standard coefficient and material properties inclided in the generator. These materials may be used without reading in data.

\section{TIMING}

The amount of machine time that a HEMP problem uses is mainly a function of the following:

1. Machine Central Processing Unit (CPU) speed.

2. Output speed and the amount of output called for.

3 . The number of zones in the problem.

4. The number of problem cycles run.

5. The number of slide-lines in the problem.

6. Start-up and stop time.

The basic HEMP calculation speed on the CDC 7600 is about 5 points (or zones) per millisecond. Slide-lines take more time, as does writing output.

The number of problem cycles that are necessary to complete a problem is a function of the following:

1. The termination time (in microseconds) of the problem.

2. The Delta-T (time step). The time step is a function of the zone size of the problem, the material in those zones, and the activity in the problem (degree of compression, etc). Various problems may take from a few minutes to several hours to run to completion.

\section{HIGH EXPLOSIVES (HE)}

The HEMP program includes a number of high-exolosives equations of state as standard materials.

The chemical energy to be released through the hydrodynamic equation of state is stored in each high-explosive zore as an initial energy $E_{0}$. The time for the detonation front to reach a specific zone is calculated in advance from the known detoration velocity, $D$, and the distance from the point of detonation to the center of the zone. This quantity is also stored with each zone. A burn fraction, F, is calculated so as to spread the burn front over several zones analogous to the artificial viscosity " $Q$ " that spreads a shock over several zones.

For one-dimensional calculations, the burn fraction can be defined as $F=(1-V)$ / $\left(1-v_{C J}\right)$ and the burn calculation is started by setting $F=1$ in the zone that corresponds to the point of detonation. The burn calculation will proceed to around three or four times the number of zones that the artificial viscosity " $Q$ " is spread over before the detonation front is correctly established. For one-dimensional calculations, this amounts to about 16 zones. In two-dimensional calculations where there is a limit to the number of zones for a practical problem, it is usually necessary to have the correct detonation velocity established in a fewer number of zones. A convenient way to do this is to start the burn calculation at the time the detonation would reach a given zone. To allow for 
the possibility of an overdriven detonation that may arise during the calculation and result in a higher than normal detonation velocity, the burn fraction $F=(1-V) /$ $\left(1-V_{C J}\right)$ can be used in addition to the burn fraction that is based on the knoivn detonation velocity. The larger of the two is then selected for the calculation.

$$
\begin{aligned}
& \text { Burn fraction }=F_{1}^{n+1}=\left(t^{n+1}-t_{b}\right) / \Delta L \\
& \text { For } t^{n+1} \leq t_{b}: F_{1}^{n+1}=0 . \\
& F_{2}^{n+1}=\left(1-V^{n+1}\right) /\left(1-V_{C I}\right) . \\
& F^{n+1}=\text { maximum of } F_{1}^{n+1} \text { and } F_{2}^{n+1} \text {. } \\
& \text { If } F^{n+1}>1 \text {, set } F^{n+1}=1 .
\end{aligned}
$$

In the above,

$$
\begin{aligned}
\Delta L & =r \Delta x / D \\
t & =\text { actual time } \\
t_{b} & =\text { time for a zone to start burning } \\
\Delta x & =\text { grid spacing } \\
D & =\text { detonation velocity } \\
r & =\text { constant } \approx 1.5 \\
V_{C J} & =\text { Chapman-Jouguet relative } \\
& \text { volume. }
\end{aligned}
$$

The equation

$$
F=\frac{(1-V)}{\left(1-v_{C J}\right)}
$$

is calculated as $F=(1-V) B$ in the code, where

$$
\begin{aligned}
\beta & =\frac{1}{1-V_{C J}} \\
V & =\text { relative volume } \\
V_{C J} & =\begin{array}{l}
\text { relative volume at the Chapman- } \\
\text { Jouguet point. }
\end{array}
\end{aligned}
$$

The burn times are calculated in the generator. Provision is made for detonations originating from a single point, from a line, or from several points. Provision is also made for calculation of burn times around a curved HE boundary, where there is not a "line of sight" from the detonating zone to the origin of the detonation.

The input parameters to the HEMP ccde are:

- $\beta$ defined as: $B=\frac{1}{1-V_{C J}}$

- Detoration velocity D

$-\Delta \mathrm{L}$

- The type of detoration (single detonator, multiple detonators, etc)

- The location of the detonator(s).

\section{CUTOFFS}

Certain code variables have a noise cutoff test applied to them; that is, if the calculated value is lower than the cutoff test value, that variable is set to zero. The test is applied to the absolute value of the variable.

\section{AVAILABILITY OF HEMP PROGRAM}

The HEMP source program (main code and generator) is contained on over 12,000 cards. Because of its size and the length of machine time needed to compile HEMP, it is impractical to issue source cards to LLL users. A machine language version, complete with library routine, ready to use (a controllee) is available. The various subroutines that users need to have as source cards for alteration are available. The user can make alterations, compile those subroutines, and then load with the previously compiled subroutines to form a new controller. Service routines are alsc available.

Conversion of HEMP to another computer facility and system would cequire considerable programming effort because 
of differences in the facilities and equipment.

Experience has shown that a program of the size and complexity of
HEMP requires continued attention by knowledgeable programmers and physicists if it is to be an effective calculational tool.

\section{Programming}

\section{OPERATIONAL FLOW}

\section{The Overlay}

Hemp combines the generator and the cycling code as a single controllee. When the generation has completed, the cycling code overlays the generator so that no unnecessary coding remains. Level 1 consists of a small "rnain" program and any subroutines that are used by both the generator and the cycling code. The "main" program controls the overlay process.

The initial level 2 consists of those subroutines that are used only in generating or restarting. The second level 2 consists of those subroutines that are used only in the cycling process, which is used in solving the difference equations.

\section{LCMI - SCM Transfers}

The HEMP program treats large core memory (LCM) as though it were an input-output storage device. That is, it is read and written. LCM data is not directly accessed.

In the solution of the difference equations, for nonslide-line, nonboundary cases, data one point removed in four directions is needed. That is, to advance a point at $(K, J)$, nodal data at $(K+1, J)$, $(K-1, J),(K, J+1),(K, J-1)$, and zonal data at $(K+1 / 2, J+1 / 2),(K+1 / 2$,
$J-1 / 2),(K-1 / 2, J+1 / 2)$, and $(K-1 / 2$,

$J-1 / 2)$ is needed. Data is accessed to and from LCM in K-line groups. That is, all the zonal and nodal variables for all the points on a $\mathrm{K}$-line, and all the zones at $K+1 / 2$, are transfe.red as a group.

Five K-lines are in SCM at a time. Three are used in the calculations, one is to be transferred to LCM, and one is to be written over by data from LCM. If a slide-line is involved, four $\mathrm{K}$-lines are needed in the calculation. For $K-m a x$ and $K-m i n$, only two $K-l i n e s$ are reeded. The program rotates through these five K-slots as it sweeps through the grid, from K-max to K-min.

Table 2-1 shows the access sequencing used in solving one problem cycle on a $10 \mathrm{~K}$-line (9 K-zone) problem, without sliding. The number following each letter (or pair of letters) is the $\mathrm{K}$-line being operated upon. At slide tines, an extra "read" (LCM to SCM transfer) is done to bring in the necessary extra $\mathrm{K}$-line used in sliding. Later, an extra write is performed.

\section{Sequencing}

\section{Generator}

The generator first reads and interprets the "general input" cards, and stores that data away. This loop is terminated when the first "fini" card is 
Table 2-1. K-cycle sequence sequencing

$\mathrm{K}$-cycle for non-slide, $10 \mathrm{~K}$ problem.

One problem cycle is shown

\begin{tabular}{lllllllllllllllll}
\hline & \multicolumn{3}{c}{$\begin{array}{l}\text { Initial- } \\
\text { ization }\end{array}$} & & & & & & & & & & & $\begin{array}{c}\text { Final- } \\
\text { ize }\end{array}$ \\
\hline SCM & A & R10 & CU10 & UW10 & & R5 & U5 & CU5 & UW5 & & & \\
K-line & B & R9 & U9 & CU9 & UW9 & & R4 & U4 & CU4 & UW4 & & \\
Storage & C & & R8 & U8 & CU8 & UW8 & & R3 & U3 & CU3 & UW3 & \\
Slot & D & & & R7 & U7 & CU7 & UW7 & & R2 & U2 & CU2 & \\
& E & & & & R5 & U6 & CU6 & UW6 & & R1 & U1 & CU1 & W1 \\
\hline
\end{tabular}

A, B, C, D, and E are the five SCM areas that contain the five $\mathrm{K}$-lines being operated upon.

$\mathrm{C}$ - Indicates this $\mathrm{K}$-line is being calculated.

$\mathrm{U}$ - Indicates this $\mathrm{K}$-line is being used in a calculation.

$\mathrm{R}$ - Indicates that this $\mathrm{K}$-line is being read or transferred from LCM to SCM.

$\mathrm{W}$ - Indicates this $\mathrm{K}$-line is being written or transferred from SCM to LCM.

encountered. If a restart card was encountered, or if teletype input has called for a restart, the restarting sequence is initiated and no more groups of input cards are read.

If the restart sequence was not called for, the generator reads and interprets the "block" input data for the first group of $\mathrm{K}$-lines (including $\mathrm{K}$-max). Reading is again terminated by a "fini" card. Some of the "block" input data is then used in developing arrays of X's and Y's that describe the $\mathrm{K}$-outer (higher $\mathrm{K}$ number' and $\mathrm{K}$-inner (lower $\mathrm{K}$-number) boundaries of the block. There are four of these arrays, $\mathrm{X}$-outer, $\mathrm{Y}$-outer, $\mathrm{X}$-inner, and $\mathrm{Y}$-inner.

Block boundary input is then read. This reading is also terminated by a "fini" card. If block boundary input is actually present, it is used to replace some or all of the values in the boundary arrays. The generator then interpolates the boundary data to create the grid X's and $Y$ 's for each $K-l i n e$, starting with the $\mathrm{K}$-outer and proceeding to the $\mathrm{K}$-inner. As each $K$-line's $X^{\prime} ' s$ and $Y^{\prime} s$ are calculated, they are used with the preceding $1 K$-line's $X$ and $Y$ 's and with other input data to calculate the masses at $K+1 / 2$. All the nodal and zonal data for $K$ and $K+1 / 2$ is calculated or gathered in one of the five SCM K-line storage sections. This is then transferred to LCM. The generator then repeats the block, block boundary reading sequences for as many blocks as have been called for by general input. If sliding has been called for in a block, special coding is entered to generate extra data for the lower $K$ boundary of that block.

In the case of the "inverted" slide-line, the normal sequencing is changed so that the block boundary $\mathrm{X}$ and $\mathrm{Y}$ data for the following block is generated or read in before the $\mathrm{K}$-lower $\mathrm{K}$-line of the upper block is calculated. This is necessary because the lower block's boundary is 
the master surface and its positions must be known in order to calculate the slave zones in the upper block.

If "K-line" input has been called for by input within a block, "K-line" and "K-line point by point" input is read and processed as the appropriate $\mathrm{K}$-line is being calculated. The " $\mathrm{K}$-line" input, if used, overrides earlier input, and the " $\mathrm{K}$ line point by point" input overrides the "K-line" and earlier input. Important variables are printed out for each $\mathrm{K}$-line and all card input is listed off-line and on-line.

\section{The Cycling Program}

The main or cycling code advances points in the grid (at $\mathrm{J}, \mathrm{K}$ ) and calculates the zonal (at $J+1 / 2, K+1 / 2$ ) quantities. When all the points in the problem have been advanced in time, when all the zonal quantities have been calculated, and when a new time step has been calculated, a problem cycle has been completed. The program sequences through many problem cycles until the problem has been completed. At periodic intervals, the program will write output of various types. The problem will terminate when it has reached its completion time, when it gets into certain difficulties, or when it has been removed from the machine by the operator.

The main code calculates from the $K-\max , J-\max$ point to the K-min (K1), $\mathrm{J}$-min (J1) point. It operates upon $\mathrm{K}$-line groups. In preparation for advancing the $X$ and $Y$ points of a $K$-line, the code first calculates the zonal velocity force and mass terms for all the zones at $K-1 / 2$. (The zonal quantities at $K+1 / 2$ have previously been calculated and saved before the $X^{\prime} s$ and $Y^{\prime} s$ at $K+1$ had been advanced in time.) The code then saves the nodal quantities at $K, J$ for the entire $\mathrm{K}$-line, for future use. The program then loops through the $\mathrm{K}-\mathrm{line}$, calculating $X$-dot and $Y$-dot and advancing $X$ and $Y$ in time.

At this point, both $K$ and $K+1$ have been advanced in time. HEMP then calculates the zonal quantities for the $K_{5}+1 / 2$ zones. The order is as indicated by the order of the equations in UCRL7322 (see Ref. 1).

After the zonal quantities have been calculated, the code then checks to see if any type of output of that $\mathrm{K}$-line is called for. If called for, it writes it out and then proceeds to the next $\mathrm{K}$-line. When all the $\mathrm{K}$-lines have been calculated, the program checks the input data to see if output has been called for during the next cycle. If so, it sets flags to cause output during the running of the next cycle.

If a restart dump is called for, it is done for all K's at the end of the cycle. All other $\mathrm{K}$-line output is done as the program sweeps through the $\mathbf{K}$-lines. The code then calculates a new time step (Delta-T) to be used the next cycle, then loops to the beginning of the next cycle and the sequence is repeated.

\section{VARIABLE LAYOUT}

\section{The Grid}

This HEMP implem entation carries 32 variables per point-zone. Each of these 32 variable units is associated with each J, $K$ nodal point in the problem. Most of the variables carried with a nodal point do not refer to the $J, K$ point but to the zone centered at $J+1 / 2, K+1 / 2$. 
These point zone units are packed in memory in K-line long groups. Each $\mathrm{K}$-line long group is preceded with an eight word unit that carries information about that $k$-line. Therefore, a 5 zone long K-line ( $6 \mathrm{~J}$ 's) would use $(32 \times 6) \div 8$ or 200 words of storage.

The following is a list of the K-line variables and the use(s) of each. The gruup of 32 after the first eight is repeated for as many $J$ 's as there are in the $\mathrm{K}$-line. The first 32 -variable group is associated with the $\mathrm{J}$-max point, therefore it has no $\mathrm{J}+1 / 2$ or zonal quantities.

1. NZS - An integer that gives the number of zones in the $K$-line. (The number of J's is NZS + 1.)

2. MHK - A floating number that is the sum of all the zonal mass terms (MH) in the K-line. It is used in the slide-line calculation but carried for other $\mathrm{K}-\mathrm{lines}$ also.

3. JMNEX - An integer, 1 through 9, that is the direction of the slideline extension at $\mathrm{J}-\mathrm{min}$. It is carried and used only on the master side of the slide-line.

4. JMXEX - An integer that is associated with the slide-line J-max master extension in a manner similar to JMNEX above.

5. IVOIDR - An integer that indicates to the slide-line routine whether or not the void routine is called upon for that particular upright slide-line. If it is 1 , the void routine will not be used, if 2,3 , or 4, the void routine will be used.

6. TPJMAX - This decimal number is the minimum spacing allowed during the problem run between $J$-max end points when those points are on a vertical or horizontal fixed boundary as called by the "stone-wall" options. It is calculated at generation time and is $1 / 10$ th of the original point spacing. This forced sfacing may be bypassed by input.

7. TPJMIN - This decimal number is used in a manner similar to TPJMAX above but for the J-min points.

8. Word 8 is not used at present. The following 32 variables are repeated for each point.

1. KTYPE - An integer that is the point-zone type for that point-zone. It is used to control program flow.

2. EQST - An integer that is the material and equation-of-state number for the zone $J+1 / 2, K+1 / 2$,

3. BYTS - A structured word consisting of 3 integers. It is used in the slideline calculations only.

4. $X$ - The $X$ coordinate.

5. $Y$ - The $Y$ coordinate.

6. XDOT - The X velocity.

7. YDOT - The $Y$ velocity.

8. MH - This variable is equal to twice the mass of the zone."

9. RO - This variable is $\rho_{0}$ or density at zero time.

10, ALAREA - This variable is used in two ways in running through the problem cycle. At one time it carries twice the zonal area. At another time it carries the zonal sub-term of the alpha used in the velocity equations.

11. V - Relative volume

12. P - Pressure

13. E - Energy 
14. QBET - This variable is used in two ways. It contains $Q$ at one time and contains zonal sub-term of the beta used in the velocity equations at the other time.

15. F - This variable is the burn time, if it is an $\mathrm{HE}$ zone. If the value is negative, it is the burn time. If it is a positive " 1 ", it indicates that the zone has burned. This $F$ is sometimes used for non-HE materials as an indicator storage.

16. SSS - This variable is the sound speed squared.

17. SIGXXE - Contains $S_{x x}$, the elastic stress in the $\mathrm{X}$ direction.

18. SIGYYE - Contains $S_{y y}$, the elastic stress in the $\mathrm{Y}$ direction.

19. SIGTTE - Contains $\mathrm{S}_{\theta \theta}$, the "Hoop" stress.

20. TXYE - Contains TAUXY, the elastic shear stress.

21. QNSXX - This variable is used in two ways. At one time it contains the Navier-Stokes $Q$ in the $X$ direction. It includes both the deviatoric and the scalar components.

It is also used to contain SIGMAXX, the total stress in the $X$ direction during the velocity calculations.

22. QNSYY - This variable is used in two ways similar to QNSXX.

23. QNSXY - This variable is used in two ways, the Navier-Stokes XY term, and later the sum of that term and the elastic shear term.

24. QNSTTP - This variable is used in two ways. At one time it contains the Navier-Stokes $Q, \theta$ term. At the other time, it contains twice the value of the zonal sub-term used in calculating the $\phi$ used in the velocity calculations.

Variables 25 through 32 are used to carry quantities other than those needed to solve the basic HEMP equations. Some are used for a number of purposes, depending on input options. Variables with other names are equivalent to these. These variables are very useful for coding in special routines.

Var. 25 - Contains $X$ at zero time unless bypassed by an option. Contains $\mathrm{S}_{1}$ at time $\mathrm{N}$ if "lambda" calculation is called for.

Var. 26 - Contains $Y$ at zero time unless bypassed by an option. Contains $S_{2}$ at time $N$ if "lambda" calculation is called for.

Var. 27 - Contains OSS (octagonal shear stress) unless bypassed by an option. Contains $S$ at time $N+1$ if the "lambda" calculation is called for.

Var. 28 - This variable is not used unless an option is called for. Contains the term (P - SMAX) if called for. $P$ is pressure and SMAX is the maximum of $S_{1}, S_{2}$, and $s_{3}$. If the "Lambda" calculation is called for, it contains $\mathrm{S}_{2}$ at time $N+1$. It contains $E_{y y}$ if the thin plate option is called for.

Var. 29 - Contains PDI (the internal plastic distortion) unless bypassed by input.

Var. 30 - Used only for special routines. Var. 31 - Used only for special routines. 
Var. 32 - Used only for special routines.

\section{Common}

\section{Table Record}

The labeled common "A001" is the group of non-grid variables that must be saved from problem cycle to problem cycle. It is written as the first record of any restert dump.

\section{Other Common}

Numbered common " 19 " is the $5 \mathrm{~K}$-line SCM block. It also contains some of the $\mathrm{K}$-line working storages. Numbered common " 21 " is the LCM grid block. It also contains those $K$-line long working storage blocks that are used only at slide lines or when writing output. These variables are equivalenced to the first word of common "21" and are indexed with offsets calculated at problem generation time. The other commons contain variables used in linking subroutines. All of the variables in numbered common " 19 " are equivalenced to location zero and are packed in memory through the use of "offsets" which are calculated and stored at generation and restart times. The offset name is ordinarily the name of the variable with a " $K$ " as a prefix.

\section{THE POINT TYPE SYSTEM}

As the program loops through the grid, it uses the variable KTYPE that is carried with each point to control the problem flow. In the nodal loops, the KTYPE number is used to control boundary conditions and to activate the slide-line routines. In the zonal loops, the type number is used to activate slide-line routines, and to control the general flow.
As a problem is generated, a standard set of KTYPE numbers is created and stored with the grid. Allowance in the numbering system has been made to sccommodate special type numbers that can be used to control the code to do nonstandard things at a point or a zone. These special numbers are read in as input.

The following system has been established as standard and should be observed when changing to non-standard point types:

- The $\mathrm{K}$-max line uses types 40 through 49.

- The $\mathrm{K}-\mathrm{m}$ in line uses types 10 through 19.

- The "upright" master surface uses types 20 through 29.

- The "upright" slave surface uses types 60 through 69 .

- The K-line immediately below (lower $K$ number) the "sliding" surface uses types $\mathbf{5 0}$ through $\mathbf{5 9}$.

- The "inverted" master surface uses types 70 through 79 .

- The "inverted" slave surface uses types 80 through 89.

- The general lines use types 30 through 39.

The standard type number uses a "2" in the "ones" place for the J-max point. It uses a " 6 " in the "ones" place for the $\mathrm{J}$-min point. It lises a zero in the "ones" place for all the other points of a K-line.

Figure 2-1 illustrates the type numbering system. The arrow indicates the zone that is associated with each point type.

THE EQUATION OF-STATE NUMBERING SYSTEM

Equations of state numbered I through 


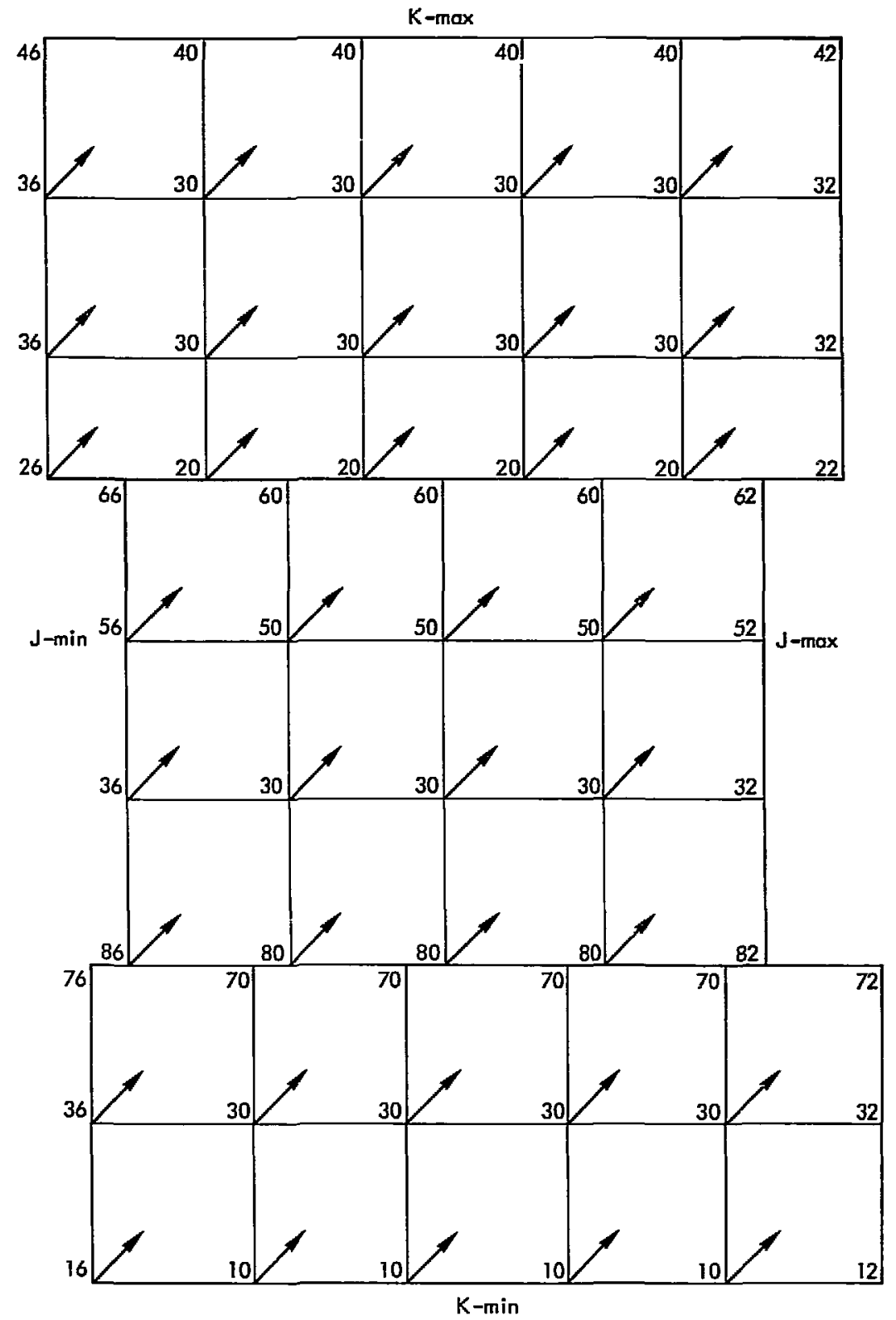

Fig. 2-1. Type numbers for points in the HEMP grid.

60 are allowed in the code. Twelve coefficients are allowed for each, and certain material-related constants are associated with each equation of state. 
These coefficients and constants are carried in the common "AOO1" which is the restart table record. Material numbers 1 through 9 are high explosives.

The equation-of-state number is carried for each zone. It is used twice in "computed go to's" in the zonal calculation. The first "computed go to" calculates or fetches the elastic terms, and certsin vther material-related properties. The second "computed go to" goes to the proper equation-of-state form for that particular equation of state. The coefficients are fetched by subscripting the various constant names with the equation-of-state number.

Equations of state of a new form can be readily added through the use of previously unused numbers. This requires recompilation of the VQPEAA subroutine. Subroutine calls to dummy entry points have been included in the zonal loops. These dummy entry points can be replaced with a new equation of state. This allows an equation of state to be added without recompiling the VQPE subroutine. This is recommended for limited use only, because of the time consumed by subroutine calls.

\section{SUBROUTINES}

\section{The Naming System}

All of the subroutines have been given six character names. The first four characters indicate the subroutine's use. The fifth and sixth character are used to identify a particular version of that subroutine. By this method, a special version of a subroutine is easily identified. The subroutines are entered at entry points so that the name changing does not interfere with the calls. The non-special subroutines have been given the suffix letters "AA".

\section{The "Main" Program}

It is named CONTAA. This routine controls the bringing in of the first level 2 (the generator) and its overlay by the second level 2 (the cycling program). It also executes the input output unit assignments and is the channel through which the program communicates with the teletrpe. The following subroutines are used by the "main" program to do these things.

LEVLAA - This is the routine that actually executes the overlays.

GETSYM and SYSTAA - Are routines that initiate the system calls that are used in program control and communication.

\section{Subroutine List}

The following is the list of the regular subroutines, their purpose, and their entry point(s).

\section{Generator Subroutines}

1. GENRAA - This is the controlling subroutine of the generating process. It calls the other generator subroutines and some subroutines used by both the generator and the cycling code. Because it is the first routine entered in the first level 1, it has no entry point. The generator reads input data and sets up the "grid" for calculation by the CYCLAA subroutine.

2. INGNAA - Its entry point is INPGEN. This subroutine reads and decodes the "general input" cards. 
3. INBKAA - its entry point is INPBLK. It reads and decodes the "block input" sub-group of cards.

4. INBPAA - Its entry point is INPBPP. It reads and decodes the "block boundary" sub-group of cards.

5. INKLAA - Its entry point is INPKL. It reads and decodes the "K-by- $\mathrm{K}^{\text {" input }}$ subgroup of cards.

6. INKPAA - Its entry point is INPKPP. It reads and decodes the "K-by-K point by point" subgroup of cards.

7. ENEMAA - Its entry point is ENMEMO. This subroutine expands SCM and LCM and sets up the data index offsets.

8. BRGNAA - Its entry point is BRGEN. The HEMP program branches to "common" A021 and then back to the proper point in the subroutine for the options that can be set once at generating or restart time. This subroutine sets the proper addresses in the "common" block A021.

9. REGOAA - The entry point is RESTRTRD. If it is called for by the generator, this routine restarts the problem from a restart dump on tape.

10. NZINAA - The entry point is NRZIN. If the block's K-min zoning is specified, this routine calculates the number of zones per K-line (as inputted by INBKAA for the $\mathrm{K}-\mathrm{min}$ boundary of the block).

11. NZOTAA - The entry point is NRZOUT. This routine calculates the number of zones per $\mathrm{K}$-line (as inputted by INPBLK) for the $K-\max$ boundary of the block. It sums the regional input to calculate this number.

12. BBOTAA - The entry point is OUTERB. This routine calculates the $X$ and $Y$ coordinates for the block $K$-max boundary from either Cartesian or Polar inp.ut.
13. BBINAA - The entry point is INERB. This routine generates the $X$ 's and $Y^{\prime}$ 's for the block $\mathrm{K}$-min boundary, from either Cartesian or Polar input. This subroutine is called only if the inside zoning has been specified explicitly.

14. BBISAA - The entry point is INERBS. If the inner zoning of the block is not specified explicitly, this subroutine uses the zoning as specified for the $\mathrm{K}$-max boundary of the block to generate the $\mathrm{K}$-min block boundary coordinates.

15. KLINAA - The entry point is KLINIP. If " $K-b y-K "$ input is read and actually contains input (other than the "fini" card), this routine uses that data to generate the point and zone variables for the $J, K$ points and the zones at $\mathrm{J}+1 / 2, \mathrm{~K}+1 / 2$.

16. NOIDAA - The entry point is NODID. This routine sets the KTYPE number that is carried with each point of the grid, which is used as a "pointer" to specify the type of calculation to use for that point and for its corresponding zone.

17. CRETAA - The entry point is CREATE. This routine uses any or all of the data inputted by the various routines to create and/or store all the point by point and zone by zone variables of the HEMP grid.

The order of priority of the input is INKPAA, INKLAA, POLJAA, INBPAA, and INBKAA.

18. POLJAA - The entry point is POLART. If J-Polar input is specified, this routine generates $X$ and $Y$ values from that input. ( $J$-Polar input is explained in the "General Input Section Discussion", page 33.)

19. GBRNAA - The entry point is GENBRN. This routine generates the 
"burn time" for HE (high explosive) zones. If Huyghens burn is called for by input, this routine calls HUYGAA.

20. HUYGAA - The entry point is HUYGEN. This routine generates burn times when a "shadow" is involved.

Subroutines Used by Both the Generator and the Cycling Overlays

1. ANGJAA - The entry point is ANGADJ. It is used iu the slidetine search routines to adjust the angle value so that the discontinuity in the angle value is $180^{\circ}$ from the direction of the line.

2. EXTNAA - The entry points are EXTSIX, and INVOLVE. This routine sets the coordinates of the master surface slide-line extensions according to the inputted directions.

3. VUPBAA - The entry point is UPVOLB. This routine does the slow, complete, methodical search (brute force) to set up the initial point ordering used in calculating the volume, area, and mass values of the "SLA VE" zones of an "upright" slide-line. This routine can be called by the main code.

An "upright" slide-line is defined as a master-slave pair which has the master line on the $\mathrm{K}$-max (higher $\mathrm{K}$ number) side.

4. VUPGAA - The entry point is UPVOLG. This routine updates the ordering used in calculating the volume, area, and mass of the slave zones of the "upright" slidetine. It uses the previous ordering as a starting point.

(The "ordering" is a set of index numbers that is created by the code to specify the logical relationship between the grid points on both sides of the slide- line. An ordering set is used in slide volume calculations.)

VUPGAA also does the final coordinate positioning and velocity calculation of the "upright" slide-line slave points.

5. VUPVAA - The entry point is UPVOL. This routire calculates the area and a volume-mass subterm that is used in calculatus the mass in the generator, and the volume $(V)$ in the main code.

6. VINBAA - The entry point is IN VOLB. This routine is similar to VUPBAA but for the "inverted" slide line. An "inverted" slide-line is defined as a master-slave pair which has the master line on the $\mathrm{K}$-min (lower $\mathrm{K}$-number) side.

7. VINGAA - The entry point is INVOLG. This routine is similar to VUPGAA but for the "inverted" slide-line. The final $X$ and $Y$ positioning and velocity calculation of the "inverted" slave points is also done by this subroutine.

8. VINVAA - The entry point is INVOL. This routine is similar to VUPVAA but for the "inverted" slide-line.

\section{Cycling Subroutines}

These routines make up the second load of the second level overlay. This group of subroutines is sometimes called the "main code" because it is the portion of the HEMP program that cycles through the grid solving the HEMP difference equations. The "main code" should not be confised with the small FORTRAN program that controls the overlay process.

The CYCLAA subroutines is the controlling subroutine of the cycling process. It can be thought of as the "Main" routine, although it is actually a subre 'rtine. It does the following principal things: 
It loops through the grid from $\mathrm{K}$-max to $\mathrm{K}-\mathrm{min}$, calculating and calling subroutines to calculate the HEIMP difference equations. This process is done in $\mathrm{K}$-I ine segments. A loop advances all of the points of a $\mathrm{K}$-line in time, then the VQPEAA subroutine is called to calculate the zonal quantities at $K+1 / 2$.

In preparation for the point advance loop and the zonal loop, two subroutines are called which do preliminary work on the variables. One of these routines is PLPZAA which calculates and moves zonal quantities. The other pre-loop subroutine is PLPNAA which moves nodal quantities. The four subroutines CYCIAA, VQPEAA, PLPNAA, and PLPZAA do nearly all of the HEMP main equation calculations, exclusive of slide-line and boundary condition calculations.

The CYCLAA subroutine moves the grid variables to LCM from SCM and to SCM from LCM. This process is discussed in "LCM - SCM Transfers", page 15.

The CYCLAA routine also calls edit and print routines, etc. The subroutine makes no subroutine calls for general interior points, but handles the boundary and slide-line calculation by subroutine calls.

The following are cycling subroutines:

1. CYCLAA - The entry point is CYCLE. It also has an entry point within it called SUB30. It controls the cycling process as described above.

2. PLPNAA - The entry point is PLOOFN. This routine saves and moves nodal (point) variables in preparation for the velocity calculation. It is called by CYCLAA.
3. PLPZAA - The entry point is PLOOPZ. This routine calculates variables for the zones at $K-1 / 2$ and moves the variables that were calculated for the previous $\mathrm{K}$-line to $\mathrm{K}+1 / 2$ storage. It is called by CYCLAA.

4. PROPAA - The entry point is PROP. This routine checks to see if surface pressure (pressure pr file) for the entire surface is called for. If it is, it calls entry points in PTABAA to calculate the pressure by table look-up. This pressure is applied to the entire surface ( $K-\max , K-m i n, J-m a x$, or $J-m i n)$. This routine is called only once per problem cycle, therefore pressure can be a function only of time, by the use of this routine.

5. PRSPAA - The entry points are PJMX, PJMN, PKMX, and PKMN. This routine can be called by the various boundary subroutines. It checks input data to select pressure areas and then can call entry poirts in PTABAA to calculate pressure as a function of $\mathrm{X}, \mathrm{Y}$, or time.

6. PTABAA - The entry points are PTJMX, PTJMN, PTKMX, and PTKMN. This routine uses table look-up data to calculate surface pressure as a function of time, of $X$, or of $Y$. This routine is called either by PROPAA or by PRSPAA. If called by PROPAA, pressure can be a function only of time.

7. UT10AA - The entry point is SUB10. This routine calculates $X, Y$. $\dot{X}$ and $\dot{Y}$ for type "10" points (K-min). It applies boundary conditions according to the input. (Used for $\mathrm{K}-\mathrm{min}$ points except $J-\max$ and $\mathrm{J}-\mathrm{min}$.)

8. UT12AA - The entry point is SUB12. Its use is the same as UT10AA 
but for type "12". (Used for the J-max point at the end of $\mathrm{K}-\mathrm{min}$.)

9. UT16AA - The entry point is SUB16. Its use is the same as UT10AA but for type "16". (Used for the K-min, $J-m i n$ point.)

10. UT20AA - The entry point is SUB20. This routine calculates the $X$, $Y, \dot{X}$, and $\dot{Y}$ 's for type " 20 " slide-line points (master side). ("Upright" slideline masters, except end points.)

11. UT22AA - The entry point is SUB22. This routine is similar to UT20AA but for type "22" points. It also applies the $J$-max boundary conditions.

12. UT26AA - The eniry point is SUB26. This routine is similar to UT20AA but for type " 26 " points. It also applies to $\mathrm{J}$ - min boundary conditions.

13. UT32AA - The entry point is SUB32. This routine is similar to UT10AA but handles type "32" points (J-max). (J-max point of ordinary interior lines.)

(NOTE: UT30AA does not exist because the general type " 30 " points are calculated in CYCLAA without a subroutine call)

14. UT36AA - The entry point is SUB36. This routine is similar to UT10AA but handles type " 36 " points $(\mathrm{J}-\mathrm{min})$. ( $\mathrm{J}-\mathrm{min}$ point of ordinary interior lines.)

15. UT40AA - The entry point is SUB40. This routine is similar to UT10AA but handles type " 40 " points. ( $\mathrm{K}-\mathrm{max}$ points except $\mathrm{J}-\max$ and $\mathrm{J}-\mathrm{min}$.)

16. UT42AA - The entry point is SUB42. This routine is similar to UT10AA but handles typ " $^{2}$ " points. (The J-max, K-max point.)

17. UT46AA - The entry point is SUB46. This routine is similar to UT10AA but handles type "46" points. (The J-min, $\mathrm{K}-\max$ point.)

18. UT60AA - The entry point is SUB60. This routine advances the "upright" slave points in time but the final position and velocity is done in the VUPGAA subroutine. (The "upright" slide-line slave points, except the end points.)

19. UT62rA - The entry point is SUB62. This routine is similar to UT60AA but handles the $J$-max slide slave point, type "62". It also applies J-max boundary conditions.

20. UT66AA - The entry point is SUB66. This routine is similar to UT60AA but handles the $\mathrm{J}-\mathrm{m}$ in slide slave point, type "66". It also applies the $J$-min boundary conditions.

21. UT70AA - The entry point is SUB70. This routine is similar to UT20AA but calculates the type 70 "inverted" slideline master points.

22. UT72AA - The entry point is SUB72. This routine is similar to UT20AA but for type 72 "inverted master" points. It also applies the $\mathrm{J}-\max$ boundary conditions.

23. UT76AA - The entry point is SUB76. This routine is similar to UT20AA but for type 76 "inverted master" points. It also applies the $\mathrm{J}-\mathrm{min}$ boundary conditions.

24. UT80AA - The entry point is SUB80. This routine is similar to UT60AA but calculates the type $\mathbf{8 0}$ "inverted slave" points. The final positioning and velocity calculation is done in VINGAA.

25. UT82AA - The entry point is SUB82. This routine is similar to UT62AA but calculates the type 82 "inverted slave", $\mathbf{J}$-max points. The final positioning and velocity calculation is done in VINGAA.

26. UT86AA - The entry point is SUB86. This routine is similar to UT66AA but 
calculates the type 86 "inverted slave" $\mathrm{J}$-min points. The final positioning and velocity calculation is done in VINGAA.

27. U01SAA, U1OSAA, U2OSAA, U30SAA, U40SAA, U60SAA, U7OSAA, and UBOSAA. These routines are linkages between the CYCLAA routine and the SUBS_._S routines listed next. These routines are called only if non-standard point types have been inputted into the problem.

28. SUBSIS, SUBS10S, SUBS20S, SUBS30S, SUBS40S, SUBS60S, SUBS70S, and SUBS80S. These subroutines contain entry points SUB _- for all of the nonstandard point type numbers from 1 through 49, and from 50 through 89. They are all dummy entries. If a special treatment of a point is to be done, it can be assigned a type number and the special coding included after ths appropriate entry point.

29. STNDAA - The entry point is STAND. This routine executes the "stand-off" option for both the "upright" and the "inverted" slide-lines, if called for.

30. VD60AA - The entry points are SUB60V, SUB62V, and SUB66V. If the void or tied sliding options are called for by input, this routine calculates the movement of the slave points. The void can only be used with the "upright" slide-line.

31. VQPEAA - The entry point is VQP. This routine is called once per $\mathrm{K}$-line by the CYCLAA subroutine. It calculates the zonal quantities volume, Q, pressure, energy and the elastic terms for all zones. The slave zones' volumes are done by calling subroutines. The equations of state are included in this subroutine. (See "The equation-of-state numbering system", page 20.) Preliminary time step calculations are also done in this routine.

32. CZNLAA - The entry points are CS123, COSS, CEDOT, CLAMBDA, EQSTHEA, EQSTA, EQSTB, EQSTC, EQSTD, and CALE. This subroutine is a collection of a number of zonal calculations. It can be called by VQPE or by the output routines. Entry CS123 calculates $S_{1}, S_{2}$, and $S_{3}$. Entry Coss calculates "OSS," the octagonal shear stress. Entry CEDOT calculates E-dot- 1 and E-dot-2. Entry CLAMBDA calculates Lambda-1 and Lambia-2. Entry CALE calculates $E_{1}$ and $E_{2}$ - The entries beginning with EQST are dummy entry points to allow the programmer to add equations of state without recompiling the VQPEAA routine.

33. BRHEAA - The entry point is BURNHE. This routine is called by the HE (high explosive) equations of state. It calculates the "burn fraction".

34. BINOAA - The entry point is BINO. If called for by input, this routine writes out selected variables for a $\mathrm{K}$-line(s) on the "dump" tape that can later be processed by service routines. (See pages 10 and 11.)

35. CHSPAA - The entry points are CHGHSP, NMFIL and CRETFL. The entry CHGHSP is not used. The NMFIL entry is used to name the CRT disk files. The CRETFL entry is used to create the "CRT" disk file. NMFIL and CRETFL. are called by the subroutine PRNTAA.

36. PRNTAA - The entry point is PRINT. This subroutine writes the "CRT" record on to tape or disk if called for, and it writes the high speed printer 
output if called for. It is entered once per K-line if called for by input.

37. EDITAA - The entry point is EDIT. This routine is entered once each problem cycle. It interrogates the input in order to set up "flegs" to control the output during the running of the next cycle, and to force the restart dump at the end of the present cycle.

38. DELTAA - The entry point is DELTAT. This routine is entered once each problem cycle, at the end of the cycle. It calculates the time step based on zonal information obtained during the running of the previous cycle. (That information is compiled by the VQPEAA subroutine.)

39. DUMPAA - The entry point is SAVDAT. When called upon to do so by the EDITAA routine, this routine writes a restart "dump" on the output tape. Each dump consists of a "table" record (A001) and a record for each $\mathrm{K}$-line. This routine is entered once per problem cycle, if called for by input.

40. U22CAA - The entry point is 022CM. This routine is entered from UT22AA. It calculates the centers of mass for the zones on both sides of an "upright" slide-line. It also sets the extra centers of mass for the sliding-zones according to the slide-line extension input.

41. U22BAA - The entry point is U22BF. This routine does the slcw, methodical (brute force) search to set up the ordering used in the "upright" slide surface velocity calculations. It is used during the running of the first problem cycle only, or after the grid has been altered by a service routine.

42. U22GAA - The entry point is U22GS. This routine updates the ordering used in the "upright" velocity calculations. Lt uses the ordering from the previous cycle as a first try. During the running of the first cycle, there will be no change from the ordering set up by the U22BF sweep.

43. U72CAA - The entry point is U72CM. This routine is similar to the U22CAA, routine but is used in the "inverted" slideline calculation.

44. U72BAA - The entry point is U72BF. This routine is similar to tr:e U22BAA routine but is used in the "inverted" slideline calculation.

45. U72GAA - The entry point is U72GS. This routine is similar to the U22GAA routine but is used in the "inverted" slideline calculation.

\section{Operation}

\section{PROBLEM INITIATION, CONTROL,} AND MONITORING

HEMP problems are run in two different ways, through teletype (TTY) control, or through ORDER-ABKCON control. When running under teletype control, the user is able to monitor the progress of the problem and control some output through the use of sense switches. The ORDER-ABKCON control system simulates the teletype input lines after reading that input from cards.

The Initiation Line

The control input line that starts or restarts a HEMP problem consists of a 
series of input fields. The fields must be in the proper order, but certain ones need not be included. The fields are recognized by name and order. A space is the delimiter.

The fields, in order, are:

-Controllee Name. This field contains the file name of the HEMP controllee. -Output Field. Output field controls all output except HSP output and has three possible forms:

a. If a tape vault name is entered, all tape output (except HSP) will be written on that tape: CRT dumps, restart dumps, and binary output is requested by input. This is the option normally used for production runs. The tape vault name must consist of two alphabetic characters followed by three numeric characters (Example: EB644).

b. If the name DISK is entered the CRT dumps will be written on a disk file, but no restart dump or BINARY OUTPUT will be written and restarts will be impossible. This option is often used for daytime debug and trial runs.

c. If nothing is entered in the field, no tape or disk output is written (except HSP): no CRT dumps, no restart dumps and no binary output.

-User's Name Field. This may consist of any name of up to 10 characters that does not conflict with the output field ahead of it, and the "box" field following it. This field need not be entered. If used, this name ap- pears as part of the label on the printed output.

-Box Field. This field is used to label the printed output so that it may be separated and placed in the user's output box. This field must always be present. It must consist of the three characters "BOX" followed immediately by three alpha-numeric characters (Example : BOXC99). -Input Field. This field may be inputted in three ways. If it is left blank, this indicates to the HEMP program that this is a restart and that the program should read the dump tape listed in the output field and restart the problem from the last dump on that tape. If the field contains purely numeric data, this indicates to the HEMP program that this is a restart and that HEMP should read the dump tape listed in the output field and restart the problem from the dump whose cycle number is equal to the numeric data. If the field contains an alpha-numeric name, this indicates to the program that an input file is to be read. The file name must begin with an alphabetic character. The input file may be either new problem data or it may be restart file data. These fields are followed by $\mathrm{a}$ " $\mathrm{T} \mathrm{V}$ " in the standard LLL teletype input marner.

\section{Teletype Operation}

After the initiation line has been entered, the computer will run the problem to completion, or until trouble is encountered, or until the computer time has run out. No further teletype entries need be made. When the problem has finished 
generating, or when the restart dump has been read in, a message "problern generated or restarted" will be typed out on the teletype. When the run has terminated for any reason, a message "all done" will be printed. If the problem has terminated due to an error, a message will print out. If the termination is due to a standard HEMP error stop, a short stop message will be printed. These messages are listed and further explained in Appendix $B$. If the stop is due to a machine interrupt, an error number and location will be printed out. The trouble must be diagnosed by reference to the loading "map". Often the difficulty can be found by studying the input and the regular HEMP output.

Further problem monitoring and output control is possinle through the use of the "sense switch" options (discussed in the next paragraph). If a problem is running with a tape, when that tape has been filled the program will increment the tape number by one and will request that the operator hang that tape. The problem will switch tapes and proceed.

Output can be partially controlled through the use of the "sense switch" options, during restart, generation and cycling. The letters " $S W$ " followed immediately by a number from 1 through 6 and a period, will cause the appropriate switch to be reversed from its previous position. All six sense switches are "off" initially. After a sense switch message has been received by the computer, it will respond with a message on the teletype that teils the user which switches are on. Thus a message "on" that is not followed by numbers means that no switches are on.

The options are shown in Appendix A.
Non-Teletype Operation

HEIIP runs under ABKCON control which in turn runs under ORDER control. ORDER and ABKCON are LLL job control languages that serve as communication links between the user and the operating system and the controllee program.

When the user wishes to run problems at night, he submits a card deck that contains both his input or restart data and control cards. The job control languages use many of these cards as though they were teletype input and output lines to initiate and control the job and to receive messages. The user receives an on-line print-out of all messages sent and received by ORDER and ABKCON.

\section{GENERATOR INPUT}

Laput is by means of cards which have been collected into an input file on a disk. The teletype input can control certain output but cannot influence the basic HEMP calculations.

\section{Card Flow and Input Terminology}

The generator proceeds from the general to the specific. That is, the input that pertains to the whole problem or to numerous regions of the problem is read first. Then input of finer and finer detail is read. The finest detailed input overrides any previous input when there is a conflict. Input is read and processed by the generator in three groups. The three groups are called 1. General, 2. Block, and $3 . K$-by-K. The first and second groups are always used. The third is used only when needed. The second and third input groups are each divided into two sub-groups. The Block group's two 
subgroups are the "Block Input" subgroup and the "Block Boundary" subgroup. The K-by-K group's two subgroups are: "K-Line Input," and "K-Line Point-by-Point Input." Each subgroup is separated in the input deck by a "fini" card.

A discussion of the characteristics and use of each subgroup follows.

General Input-This group includes input that applies to the whole problem or to material that may be in a number of regions of the problem. This includes such items as boundary conditions, output control and material-related input. This is the first set of cards encountered by the generator. General input reading is terminated when the first "fini" card is encountered.

Block Input-A block is defined as a number of $K$-lines that have the same materials in corresponding J-zones. A region is a group of zones (within a block) that are of the same material and whose coordinates are generated from the same "corner" points. (See Fig. 3-1.) Regions always run from the higher $K$ ( $K$-high is the $\mathrm{K}$ with higher $\mathrm{K}$-number) to the lower $\mathrm{K}$ (K-low is the $\mathrm{K}$ with lower $\mathrm{K}$-number):

The Block in Example 1 (Fig. 3-1) has four regions. The points marked with $X$ are the boundary points that have been specified in the Block input. The Block in Example 2 (Fig. 3-1) has two regions,

(JI)

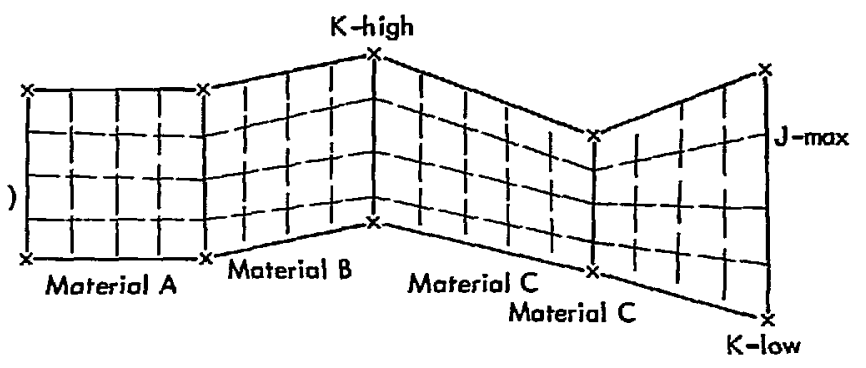

Example 1.

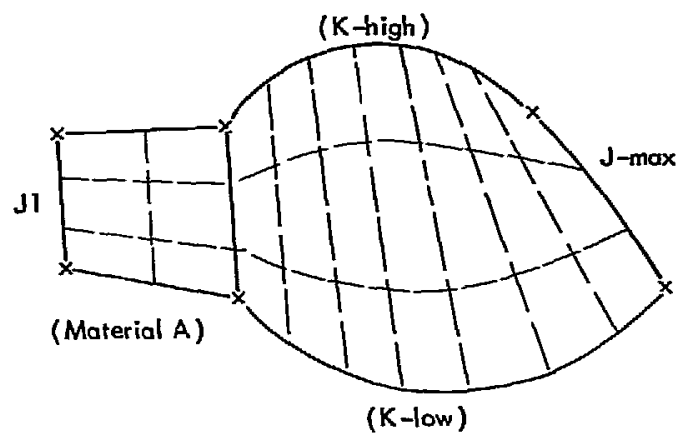

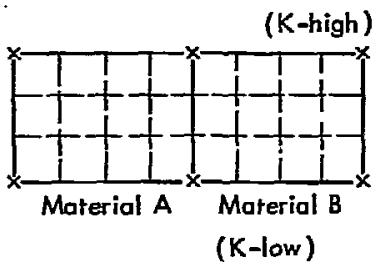

Example 3.

Example 2.

Fig. 3-1. Block input with more than one region. 
both of the same material. (The region on the right ( $J$-max) end was generated with K-polar input).

The zoning in Example 3 (Fig. 3-1) is uniform. The reason for generating it as two regions was because of the material change from one region to the next.

Block input includes the regional corner points (or polar data), the zoning counts, the material assignment, certain material-related properties, as well as other data.

The Block Boundary subgroup allows for the point by point input of the K-high and $\mathrm{K}$-low block surfaces by either Cartesian or Polar input. If used, it overrides the surfaces generated by the Block input. Each Block subgroup is terminated by a "fini" card. Block input always contains two "fini" cards, one terminating the first Blcek Ir.put subgroup, and the second terminating the Block Boundary subgroup. A problem may have as many blocks as are necessary to describe it. There may be up to eight regions within a block.

The "K-by-K" and "K-by-K Point-ByPoint" subgroups are used only if this finer detailed input is needed. It is called for by an input card in the Block Input subgroup that precedes the $\mathrm{K}-\mathrm{by}-\mathrm{K}$ cards. The $K-b y-K$ and $K-b y-K$ Point-By-Point subgroups are always read in pairs. For example, if $K$-by- $K$ input is called for, for the fifth $K$ of the second block, both $\mathrm{K}-\mathrm{by}-\mathrm{K}$ and $\mathrm{K}-\mathrm{by}-\mathrm{K}$ Point-By-Point input will be read.

The K-by-K subgroup allows the user to respecify the characteristics of a particular $\mathrm{K}$-line. $\mathrm{K}$-line regional information is inputted much as if the user is writing the input for a one-dimensional code. The zonal quantities that are specified are for the zones centered at $\mathrm{K}+1 / 2$.

The K-by-K Point-By-Point subgroup enables the user to respecify the coordinates and input velocities for any or all nodal points on that K-line. Likewise, the user may respecify most zonal quantities for the zones centered at $\mathrm{K}+1 / 2$.

If the user wishes to specify Point-ByPoint input or zone by zone input but does not wish to use the $K-b y-K$ subgroup capability, he should supply only the "fini" card to the K-by-K subgroup. The generator will recognize that this $K$-by-K input is not intended and will skip the portion of the program that decodes that input. (See Figs. 3-2 and 3-3.)

Input Card Formats

Most HEMP input cards have a name in the first eight or ten columns. If these first columns are blank, the card is accepted as a continuation of the data of the previous card. Within each of the five input groups or subgroups is a card vocabulary. As a card is read, its first eight or ten columns is matched against the vocabulary of that group (or subgroup). If it matches, the input is decoded and stored in the proper places. If it does not match, the offending card and an error message is printed out and the run is terminated. All card names start in column 1. Cards within a subgroup may be in any order. Only those cards that actually contain input need be used.

Integer input must be right-adjusted. Floating point input must include a decimal point but must be right-adjusted only 
The card order of a deck to generate a three block problem, with no finer input, would be as follows.

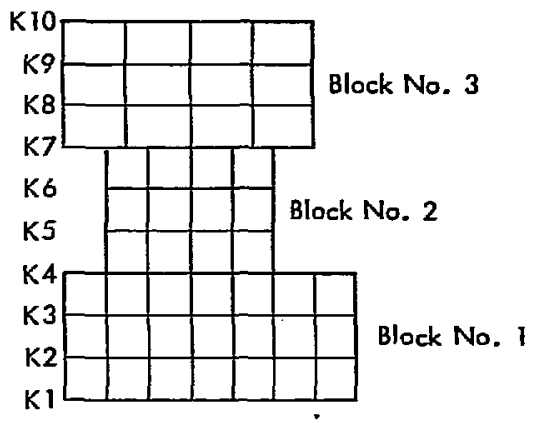

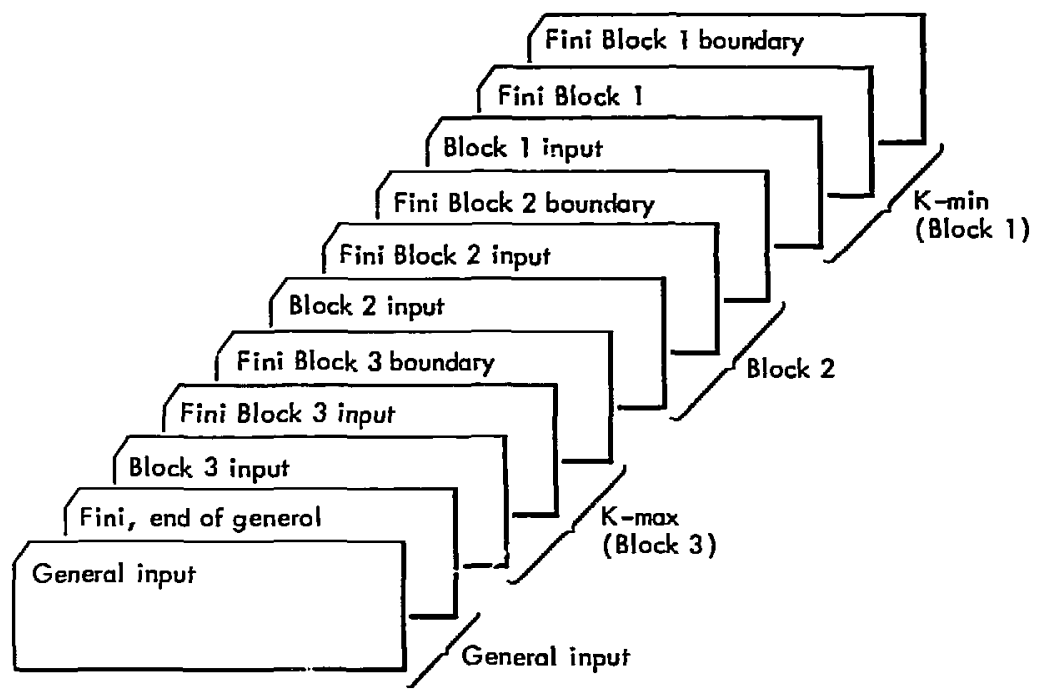

Fig. 3-2. Card order of three-block problem.

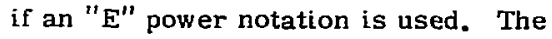
FORTRAN " $F$ " format is used. In this write-up, if the variable to be inputted is an integer, the word "integer" will follow the column listing. If "integer" is not present, the input if floating point.
General Input Section Discussion

The input in this section is input that applies to the entire problem or to some areas or boundaries of a wider scope than that included in Block input. This includes materiai related input becarise 
The card order of a deck to generate a problem similar to the example in Fig. 3-2 but with speciol zonal input at $K$-number $5+1 / 2$ and nodal input at $K-5$ would be as follows.

$x$ Zones to be input point by point

o Nodes to be input
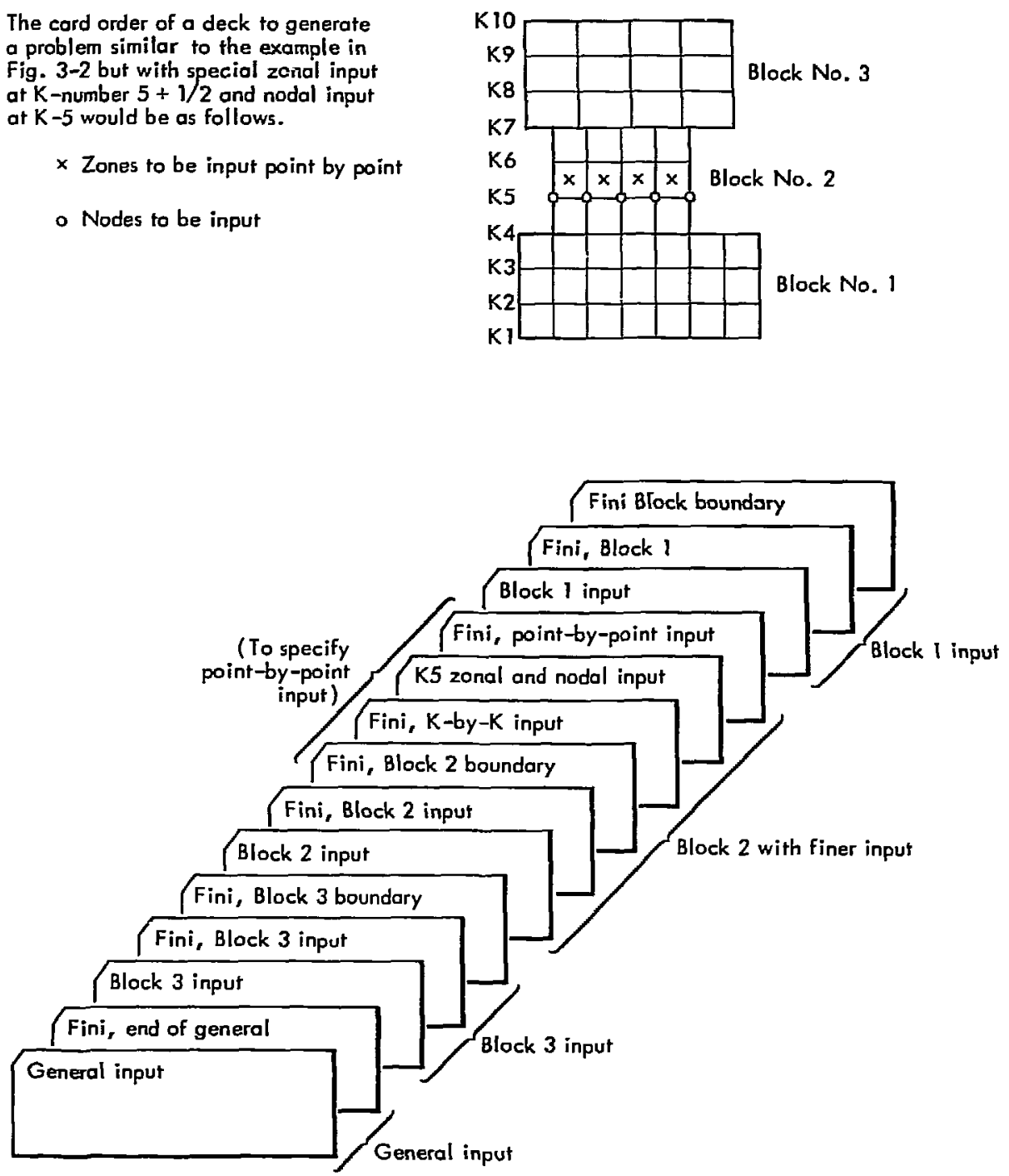

Fig. 3-3. Three-block problem with more detailed input.

the same material may appear in more i'tan one region and/or Block of the Froblem.

Tite card names have been selected to give indications of the general use of the input on that card. In certain cases, this is not true, however.

\section{Name, Geometry Card}

This card is customarily the first card in the deck after the file "ID" card. The card format is as shown in Table 3-1. 
Table 3-1. Name, geometry card format.

\begin{tabular}{|c|c|c|}
\hline $\begin{array}{l}\text { Field } \\
\text { use }\end{array}$ & Columns & Input and explanation \\
\hline $\begin{array}{l}\text { Card } \\
\text { name }\end{array}$ & $1-10$ & GENERAL \\
\hline Blocks & $11-12$ & Integer. The number of Blocks in the problem. \\
\hline$K^{\prime} \mathbf{S}$ & $13-15$ & $\begin{array}{l}\text { Integer. The number of K's in the problem. } \\
\text { (The total number of } K-\text { zones plus one.) }\end{array}$ \\
\hline $\operatorname{Max}-J$ & $16-18$ & $\begin{array}{l}\text { Integer. The number of } \mathrm{J}^{\prime} \mathrm{s} \text { in the longest } \mathrm{K} \text {-line in the } \\
\text { problem. (The total number of J-zones in the } \mathrm{K} \text {-line, plus } \\
\text { one.) }\end{array}$ \\
\hline \multirow[t]{2}{*}{ Geometry } & $19-20$ & $\begin{array}{l}\text { Integer. Enter " } 1 \text { " if the problem is the plane case. Enter } \\
\text { " }+2 \text { " if problem is cylindrical in quadrants } 1 \text { or } 2 \text {. Enter } \\
\text { "-2" if the problem is cylindrical in quadrants } 3 \text { or } 4 \text {. The } \\
\text { quadrant notation automatically prevents points from cross- } \\
\text { ing through the } x \text { axis. Complete control of this test is pro- } \\
\text { vided by use of the XYQUAD card in boundary control. }\end{array}$ \\
\hline & $21-24$ & Not used. \\
\hline $\begin{array}{l}\text { Problem } \\
\text { natae }\end{array}$ & $25-54$ & $\begin{array}{l}\text { The problem name is entered here. Any group of } 30 \text { charac- } \\
\text { ters and spaces can be entered. }\end{array}$ \\
\hline
\end{tabular}

These thirty spaces are printed as the problem name on the printouts. Only the first 20 columns of this group are put on the "CRT" tape.

\section{Delta-T Control Card}

The follow card allows changing of Delta-T control parameters. It also can be used to control the frequency of restart dumps. This card need not be used if "standard" numbers are to be used." (See the card format as shown in Table 3-2.)

\section{Cutoff Card}

The normal cutoffs are $1 \times 10^{-10}$ except XYCUT which is $1 \times 10^{-8}$. The card format is shown in Table 3-3.

\footnotetext{
See Appendix A, Section I of Ref. 1.
}

\section{Output Control}

Certain output can be controlled in frequency and character by input cards. Sense-switch-controlled output is in addition to the card-controlled output. The types of output that are controlled by cards are CRT tape output, off-line printer output, flexibly formatted (binary) tape output, and restart dump output. Teletype and on-line output cannot be controiled by input cards.

\section{Frequency of CRT and Off-Line Printer Oatput}

The frequency of CRT (cathode ray tube) and off-line printer output is controlled by a card whose format is shown in Table 3-4. (Times are in microseconds.)

\section{K-Line Selection}

The selection of $\mathrm{K}$-lines that are written out when off-line printouts are 
Table 3-2. Della-T control card format.

\section{Field}

use

\begin{tabular}{ll}
\hline Card name & $1-10$ \\
Fixed & $11-15$ \\
Delta-T &
\end{tabular}

Initial

Deita-T

$16-20$

Delta-T

$\max$

21-25

Delta- I

stop

Shear

coefficicnt

Minimum

Delta-T

factor

Maximum

Delta-T

factor

"b"

coeficient

First dump

cycle

Second dump $\quad 57-6:$
" $\mathrm{B}$ ":

"A"

Dump

frequency

$63-68$

"C"

(NOTE)

Dump

with CIIT

$69-70$

Courant

number
Input and explanation

\section{DELTAT}

If this is left blank, the time step will be calculated in the usual manner.

If not zero, the value will be used to run the problem at that fixed time step. This overrides the other Delta-T input.

If this is left blank, the initial time step will be equal to $1 \times 10^{-4}$

If not blank, the value will be used as the initial Delta-T

If this is left blank, the larg sst value that the time step (Delta-T) will be allowed to reach will be one (1.). If not zero, the largest value $w$ ill be that value.

If this is left blank, the problem will terminate when the Delta-T has reached I $\times 10^{-5}$. If not zero, the problem will terminate when that value is reached.

31-35 If this is left blank, the sound speed calculation will include the tern1, $4 / 3$ times the shear modulus. If not zero, the $4 / 3$ will be replaced by the inputted number.

If this is left blank, the minimum factor that the time step (1)elta-T) can raise from one cycle to the next (if it is to raise at all) is 1.1 . If it wants to raise less than that, it will not raise at all.

If not zero, the factor is the value oi the inputted number.

If this is leit blank, the maximum factor that the Delta-T can raise from une cycle to the next is 1.2 . If it wants to raise more than that, the Jelta- $T$ at $N+1 / 2$ \%ll be set equal to the Delta-T at $\mathrm{i}-1 / 2$ times the ractor.

If not zero, the ractur is replaced by the inputted value.

If this is left blank, the coefricient in the " $b$ " calculation as shown in the stability calculation will be 8 .

If not zero, the inputted value will be used.

Integer. If this is left blank, the first restart dump will be taken at cycle number 100. If not zero, the dump will be taken at tinat cycle number.

Integer. If this is left blank, the second restart dump will be taken 400 eycles aiter the first restart dump. If not zero, the dump will be taken that numbur of cycles after the: firtil clump.

Integer. If this is left blark, restart dumps will be taken at $\mathbf{5 0 0}$ cycle increments afte $r$ the second restart dump. If not zero, the restart dumps will be taken at the new increment.

When the program is running, " $\Lambda$ " is counted down to zero, the " $13^{1 "}$ is put into " $A$ " and " $C$ " into " $B$ ". Therefore " $A$ " always contains the number of cycles to the next dump.

If left blank, a rcstart dump will not be taken with each regular C.RT. If set to "1.", a dump will be taken with each regular (IRT. I'orcing a CIT' with the sense switches will not cause the dump.

If this is loft ilank, $2 / 3$ will be useri as the coefficient (Courant number) in the final l)elta-T calculation. If not blank, the inputted value will be used. 
Table 3-3. Cutoffs card iormat.

\begin{tabular}{|c|c|c|}
\hline $\begin{array}{l}\text { Field } \\
\text { use }\end{array}$ & Columns & Input and explanation \\
\hline Card name & $1-10$ & CUTOFFS \\
\hline $\begin{array}{l}\text { Ger sral cut } \\
\text { change }\end{array}$ & $11-17$ & $\begin{array}{l}\text { If not zero, the inputted value } w i l l \text { replace the cut-off } \\
\text { values for } Q, E, P, \dot{X}, \dot{Y} \text {, and } \dot{V} / V \text {. }\end{array}$ \\
\hline $\begin{array}{l}X \text {-dot, } Y-\text { dot } \\
\text { cut }\end{array}$ & $18-74$ & $\begin{array}{l}\text { If not } z e r o_{2} \text { the inputted value will become the cut-off value } \\
\text { for } \dot{X} \text { and } Y \text {. It overrides the column } 11-17 \text { input. }\end{array}$ \\
\hline$Q$-cut & $25-31$ & $\begin{array}{l}\text { If not zero, the inputted ralue will replace the cut-off value } \\
\text { for } Q \text {. It overrides the coiumn } 11-17 \text { input. ( } Q \text { is not } \\
\text { allowed to be negative.) }\end{array}$ \\
\hline E-cut & $32-38$ & $\begin{array}{l}\text { If not zero, the inputted value will replace the cut-off value } \\
\text { for energy. It overrides the column } 11-17 \text { input. }\end{array}$ \\
\hline P-cut & $39-45$ & $\begin{array}{l}\text { If not zero, the inputted value will replace the cut-off for } \\
\text { pressure. It overrides column 11-17 input. }\end{array}$ \\
\hline $\begin{array}{l}\mathrm{V}-\operatorname{dot} / \mathrm{V} \\
\text { cut }\end{array}$ & $46-52$ & $\begin{array}{l}\text { If not zero, the inputted value will replace the cut-off value } \\
\text { for } V \text {-dot over } V \text {. It overrides column } 11-17 \text { input. }\end{array}$ \\
\hline$X, Y$ cut & $53-59$ & $\begin{array}{l}\text { If not zero, the inputted value will replace the cut-off value } \\
\text { for } X \text { and } Y \text { that is used in the generator. }\end{array}$ \\
\hline
\end{tabular}

written is controlled by a card whose format is shown in Table 3-5.

\section{CRT Scale}

Two types of cards are used to control the scale and types of the CRT plota. They are not used by HEMP but are put on the CRT output tape so that it may be conveniently plotted. This input can be altered by other input when the plotting is being done. The CRT scale card format is shown in Table 3-6.

Three scales are allowed as input at one time. The second and third cards are similar to the card above but with a scale number of 2 or 4 (not 3 ), and the classification fields are ignored. The card name PLOTSCALE may be left off if these cards immediately follow the number 1 scale card in the input deck.

\section{Plot Type}

The card (format is shown in Table $3-7$ ) is used by the plot routine to determine the nature of the plots, using the scales inplitted with the PLOTSCALE cards. A number of options are available for each plot and may be called for use with any or all scales. Ten sets of options are allowed and each may apply to any or all of the three scales. Therefore, it is possible to produce as many as 30 plots per output time. Six options are available.

The option field "G", when set to " 1 ", causes all of the $J$ - and $K$-lines in the scale area to be plotted. The option "B", when set to " 1 ", causes all of the boundary lines in the scale area to be plotted (including material boundaries). The option " $V$ ", when set to " 1 ", causes all of the elastic vectors in the scale area to be plotted (for elastic materials only). The option " $Q$ ", when set to " 1 ", causes zones with " $Q$ ' $s$ " above a certain value to be shaded in direct proportion to the magnitude of the " $Q$ ". The option "RX", when set to "I", causes the plot. 
Table 3-4. CRT and off-line printer card format.

\begin{tabular}{lll}
\hline $\begin{array}{l}\text { Field } \\
\text { use }\end{array}$ & Columns & Input and explanation \\
\hline Card name & i-10 & EUITFREO \\
Increment 1 & $11-15$ & $\begin{array}{l}\text { The problem will write CRT output at this frequency until } \\
\text { "Time I" is reached. }\end{array}$
\end{tabular}

Time $1 \quad 16-20$

When the problem has reached this time, it will change frequency to "Increment 2 ". If "increment 2 " is zero, the problem will terminate.

Increment 2 21-25 After "Time $I$ " is reached, but before "Time 2 " is reached, the problem will write CRT output at this frequersy.

Time $2 \quad 26-30$

After "Time 1 " has been reacined, the problem will run to "Time $1 "$ " "Time $2 "$ and write CRT output at time intervals equal to "Increment 2"; if "Increment 3 " is zero, the problem will terminate.

Increment 3 31-35 After "Time 1" plus "Time 2 " is reached, but before the sum of all three "times" is reached, the problem will write CRT output at this frequency.

Time $3 \quad 36-40$

After the sum of "Time 1", "Time 2", and "Time 3 " is reached, the problem will terminate.

(NOTE)

Concerning

changing

output

Irequency or

time at restart

time.

If changes are tu be made in the CRT output requency or time at restart time, helullewing explanation of how the IIL:MP code operates must be understood by the user.

When the problem reaches a CRT output time point, and edits, it auds that time to "Increment 1 " and then runs until it reaches that time. When "Time 1 " is reached, "Time " 1 " is added to" "Time 2 " and replaces "Time 1 ". "increment 2 " replaces "Increment $1 "$ " "lime $3 "$ and "Increment 3 " replace "Time 2" and "Increment 2". "Time 3" and "Increment $3 "$ are then set to zero. Therefure, the current problen time is always compared with the time in "Time l" to sice when to change edit frequencies or when to terminate the problem.

The next lime to write C $R T$ is s:arried in a storage location that can bo changed by input at restart time.

When a problem has finished by reaching its termination time, it can be extencled by putting the new output increment in "Incroment 1 ", the next change time in "Time 1 " etc.

Prints/CRT 41-45

If this field is lelt blank, off-line printer output will be written rach time regular CIT output is writter. If a number " $n$ " is entered, off-line printer output will be written each "nth" time. (This value " $n$ " is put in a counter and counted down to "I", then a priniout is written.)

Debug

printout

$46-50$

If set to non-zorn, the "Debug" print out will be written. This prints out the velocity sub-terms. This is described in the main code output section.

(Used only at restart time.)

Next Cir $\quad 51-55$

time

if a number is entered herc when restarting, the next CRT output will be written at that problem time. It replaces tine previous value.

(Used only at restart time.)

Print $\quad 56-60$

if a number is entered here at restart time, the current

counter print per C'RT counter will be roplaced by this value. (See prints, ic:RT above.) 
Table 3-5. K-line selection card format.

\begin{tabular}{|c|c|c|}
\hline $\begin{array}{l}\text { Field } \\
\text { use }\end{array}$ & Columns & Input and explanation \\
\hline Card name & $1-10$ & PRINT-OUT \\
\hline $\begin{array}{l}\text { Interface } \\
\text { option }\end{array}$ & 11 & $\begin{array}{l}\text { Integer, If set to "1" just } K-\max , K-\min \text {, and the slide- } \\
\text { lines will be printed out. }\end{array}$ \\
\hline Higher $\mathrm{K}$ & $12-14$ & $\begin{array}{l}\text { Integer. If not zero, this is the highesi } K \text {-number that will } \\
\text { be printed out except for interfaces if called for. }\end{array}$ \\
\hline Lower K & $15 \cdot 17$ & $\begin{array}{l}\text { Integer. If not zero, this is the lowest } \mathrm{K} \text { number that will } \\
\text { be printed out except for interfaces if interface edits are } \\
\text { called for. }\end{array}$ \\
\hline
\end{tabular}

Table 3-6. CRT scale card format.

\begin{tabular}{|c|c|c|}
\hline $\begin{array}{l}\text { Field } \\
\text { Use }\end{array}$ & Columns & Input and explanation \\
\hline Card name & $1-10$ & PLOTSCALE \\
\hline Classification & n 11 & $\begin{array}{l}\text { Integer. If left blank, the CRT output will be labeled } \\
\text { "secret". If not zero, the CRT will not be so labeled. }\end{array}$ \\
\hline $\begin{array}{l}\text { Scale } \\
\text { number }\end{array}$ & $12-15$ & $\begin{array}{l}\text { Integer. } 1,2 \text {, or } 4 \text {. This is the number assigned to this } \\
\text { scale. It must be present. See explanation below. }\end{array}$ \\
\hline $\mathrm{Xm}$ in & $16-25$ & The minimum value of $\mathrm{X}$ to be plotted. \\
\hline$x \max$ & $26-35$ & The maximum value of $X$ to be plotied. \\
\hline Ymin & $36-45$ & The minimum value of $Y$ is be plotted. \\
\hline Ymax & $46-55$ & The maximum vacie of $Y$ to be plotted. \\
\hline $\begin{array}{l}\text { Vector } \\
\text { length }\end{array}$ & $56-65$ & $\begin{array}{l}\text { If a vector plot of elastic zones is called for, this number } \\
\text { must be entered. It is the length of the vector in cm. It } \\
\text { is usually entered as } 1 / 2 \text { to } 3 / 4 \text { of the original thicknees of } \\
\text { a typical zone of the elastic regions in the problem. }\end{array}$ \\
\hline $\begin{array}{l}\text { Multiplier } \\
\text { factor }\end{array}$ & $66-75$ & $\begin{array}{l}\text { If not zero, the grid points' displacement from their position } \\
\text { at time zero will be multiplied by this number. (This } \\
\text { exaggerates the motion. Used for very small displacement } \\
\text { problems.) }\end{array}$ \\
\hline (NOTE): & & $\begin{array}{l}\text { The CRT plot is linear in each scale in each direction. The } \\
\text { difference between } X \text {-min and } X \text {-max determines the scaling } \\
\text { in the } x \text { direction and the difference between } Y-m i n \text { and } \\
Y \text {-max determines the scaling in the } Y \text { direction. }\end{array}$ \\
\hline
\end{tabular}

image as determined by the previously set options to be reflected across the $X$ axis.

Allowance must be made for this reflected image when selecting the scales. The option "RY" is similar to " $R X^{\prime}$ but for the $Y$ axis. If both are set to " 1 ", the image will be reflected both ways. On the input card, a seventh column in each set of options is used to determine which scales that the option set applies to. The sum of the scale numbers is entered; thus a " 5 " would call for that set of options to apply to scale 1 and scale 4 and would 
Table 3-7. Plot type card format.

\begin{tabular}{|c|c|c|}
\hline $\begin{array}{l}\text { Field } \\
\text { use }\end{array}$ & Columns & Input and explanation \\
\hline \multirow[t]{3}{*}{ Card name } & $1-10$ & PLOTTYPE \\
\hline & 11 & Integer. Set to I to call grid "G" plot \\
\hline & 12 & Integer. Set to 1 to call Border "B" plot \\
\hline \multirow{2}{*}{$\begin{array}{l}\text { Option } \\
\text { group }\end{array}$} & 13 & Integer. Set to 1 to call Vector " $\mathrm{V}$ " plot \\
\hline & 14 & Integer. Set to 1 to call $Q$, "Q" plot \\
\hline \multirow[t]{5}{*}{1} & 15 & Integer. Set to 1 reflect around the $x$ axis \\
\hline & 16 & Integer. Set to 1 reflect around the $y$ axis \\
\hline & 17 & Integer. Enter the sum of the scale card numbers \\
\hline & 18 & Integer $\mathbf{G}$ \\
\hline & 19 & Integer $\mathbf{B}$ \\
\hline \multirow{2}{*}{$\begin{array}{l}\text { Option } \\
\text { group }\end{array}$} & 20 & Integer V \\
\hline & 21 & Integer $Q$ \\
\hline \multirow[t]{5}{*}{2} & 22 & Integer $\mathbf{R X}$ \\
\hline & 23 & Integer RY \\
\hline & 24 & Integer SUM \\
\hline & 25 & Integer. $\mathbf{G}$ \\
\hline & 26 & Integer B \\
\hline \multirow{2}{*}{$\begin{array}{l}\text { Option } \\
\text { group }\end{array}$} & 27 & Integer. $\mathrm{V}$ \\
\hline & 28 & Integer $Q$ \\
\hline \multirow[t]{5}{*}{3} & 29 & Integer $\mathbf{R X}$ \\
\hline & 30 & Integer $\mathbf{R Y}$ \\
\hline & 31 & Integer SUM \\
\hline & 32 & Integer $\mathbf{G}$ \\
\hline & 33 & Integer B \\
\hline \multirow{2}{*}{$\begin{array}{l}\text { Option } \\
\text { group }\end{array}$} & 34 & Integer $\mathrm{V}$ \\
\hline & 35 & Integer $\mathbf{Q}$ \\
\hline \multirow[t]{3}{*}{4} & 36 & Integer, RX \\
\hline & 37 & Integer RY \\
\hline & 38 & Integer SUM \\
\hline
\end{tabular}

produce two plots per option. The option groups may be repeated to fill the card, so that ten groups are allowed.

Flexible Formatted Tape Output (Binary Output)

This output capability allows the user to cause any code quantity to be written on tape or to be calculated and written on tape. This can then be processed by other programs. (The information is written in binary format.)

Two types of frequency control are provided. The one using the card REG. BIN (Table 3-8) is similar to the frequency 
Table 3-8. Frequency control (regular) card format.

\begin{tabular}{|c|c|c|}
\hline $\begin{array}{l}\text { Field } \\
\text { use }\end{array}$ & Columns & Input and explanation \\
\hline Card name & $1-10$ & REG.BIN \\
\hline Time step 1 & 11-15 & Write the binary tape output at these timestep intervals. \\
\hline Time 1 & $16-20$ & Use the step 1 until this time. \\
\hline Time step 2 & $21-25$ & $\begin{array}{l}\text { When time } 1 \text { is reached, write at intervals of this time } \\
\text { step. }\end{array}$ \\
\hline Time 2 & $26-30$ & $\begin{array}{l}\text { Use time step } 2 \text { until a time of time } 1 \text { plus time } 2 \text { is } \\
\text { reached. }\end{array}$ \\
\hline Time step 3 & $31-35$ & $\begin{array}{l}\text { When time } 1 \text { plus time } 2 \text { is reached, then write at intervals } \\
\text { of this time step. }\end{array}$ \\
\hline Time 3 & $36-40$ & $\begin{array}{l}\text { Write binary output until time } 1 \text {, plus time } 2 \text {, plus time } 3 \\
\text { is reached. }\end{array}$ \\
\hline High K-1 & $41-43$ & $\begin{array}{l}\text { Integer. Write binary output from this } \mathrm{K} \text { number down to } \\
\text { the low } \mathrm{K}-1 \text { number. If this is blank, } \mathrm{K}-\mathrm{max} \text { is assumed. }\end{array}$ \\
\hline Low $\mathrm{K}-1$ & $44-46$ & $\begin{array}{l}\text { Integer. Write binary output from the high } \mathrm{K}-1 \text { above down } \\
\text { to this number. If blank, } \mathrm{K} \text {-min assumed. }\end{array}$ \\
\hline High $\mathbf{K - 2}$ & $47-49$ & $\begin{array}{l}\text { Integer. High } K \text { number } 2 \text {. This must be lower than the } \\
\text { above numbers. If blank, just the above numbers are used. }\end{array}$ \\
\hline Low $\mathbf{~ K - 2}$ & $50-52$ & $\begin{array}{l}\text { Integer. Low } K \text { number } 2 \text {. This must be lower than the } \\
\text { above numbers. }\end{array}$ \\
\hline High $\mathbf{K}-3$ & $53-55$ & $\begin{array}{l}\text { Integer. High } K \text { number } 3 \text {. This must be lower than the } \\
\text { above numbers. If blank, just the above numbers are used. }\end{array}$ \\
\hline Low $\mathrm{K}-3$ & $56-58$ & $\begin{array}{l}\text { Integer. Low } K \text { number } 3 \text {. This must be lower than the } \\
\text { above numbers. }\end{array}$ \\
\hline
\end{tabular}

and $K$-line control of the off-line printer output. The other, using the card called SEIS. BIN (Table 3-9), puts out selected $\mathrm{K}$-lines every problem cycle after starting at the selected start time. Both use the card VAR. BIN (Table 3-10) to determine which variables to write out. Both frequency control options may be used in the same problem. (The name SEIS.BIN is used because this type of output is used in analysis of seismological problems.)

A second card may be used with a format the same as in Table 3-10. Up to 40 variables may be put out at a time. Table 3-11 is the variable number list.
Walls, Pistons, Quadrant Control

A group of options are provided that allow for controlling the motion of boundary (and sometimes interior) J, K points.

The most used options are those called for on the STONEWALLS card. These options bypass the $\mathrm{X}$ or $\mathrm{Y}$ (or both) velocity calculation on the K-max, K-min, J-max and/or J-min exterior boundaries. Because the velocity calculation is bypassed, the initial velocity remains. Therefore, if the initial velocity is zero, a rigid wall condition is set up. If the initial velocity is not zero, a constant velocity or "piston" condition is set up (a constantly moving surface). This card 
Table 3-9. Frequency control (SEISMO) card format.

\begin{tabular}{|c|c|c|}
\hline $\begin{array}{l}\text { Field } \\
\text { use }\end{array}$ & Columns & Input and explanation \\
\hline Card name & $1-10$ & SEIS. BIN \\
\hline Start time & $1 \pm-15$ & $\begin{array}{l}\text { This is the time that the cycle by cycle "seismo" binary } \\
\text { tape output is to begin. (It must be nonzero to use this } \\
\text { routine.) }\end{array}$ \\
\hline \multirow{10}{*}{$\begin{array}{l}\text { K's to } \\
\text { write out }\end{array}$} & $16-18$ & \multirow{10}{*}{ List number of $K^{\prime} s$ to output. } \\
\hline & $19-21$ & \\
\hline & $22-24$ & \\
\hline & $25-27$ & \\
\hline & $28-30$ & \\
\hline & $31-33$ & \\
\hline & $34-36$ & \\
\hline & $37-39$ & \\
\hline & $40-42$ & \\
\hline & $43-45$ & \\
\hline
\end{tabular}

Table 3-10. Variable list card format.

(Use this card with REG.BIN card and/or SEIS.BIN card.)

\begin{tabular}{lcl}
\hline $\begin{array}{l}\text { Field } \\
\text { use }\end{array}$ & Columns & Input and explanation \\
\hline $\begin{array}{l}\text { Card name } \\
\begin{array}{l}\text { Output } \\
\text { variable } \\
\text { number }\end{array}\end{array}$ & $1-10$ & $\begin{array}{l}\text { VAR.BIN } \\
\text { Integer. List variable numbers in any order. Leave no } \\
\text { blanks. }\end{array}$ \\
& $14-16$ & $\begin{array}{l}\text { Integer. Second variable to output } \\
\text { Integer. Third variable to output } \\
\text { Integer. Fourth variable to output }\end{array}$ \\
& - & \\
& - & Integer. Twentieth variable to output \\
\hline
\end{tabular}

(format shown in Table 3-12) is useful only for vertical or horizontal walls.

A rigid wall may be specified at any angle by the use of the angle-wall cards. The XYQUAD card provides for restricting the motion of all points within certain quadrants. The RING card allows for the restriction of motion of all points between certain $\mathrm{X}, \mathrm{Y}$ limits. The VARWALL card allows for the restriction of motion of points of certain $\mathrm{K}-\mathrm{lines}$ between $\mathrm{X}$ or $\mathrm{Y}$ limits. 
Table 3-11. Variable number list.

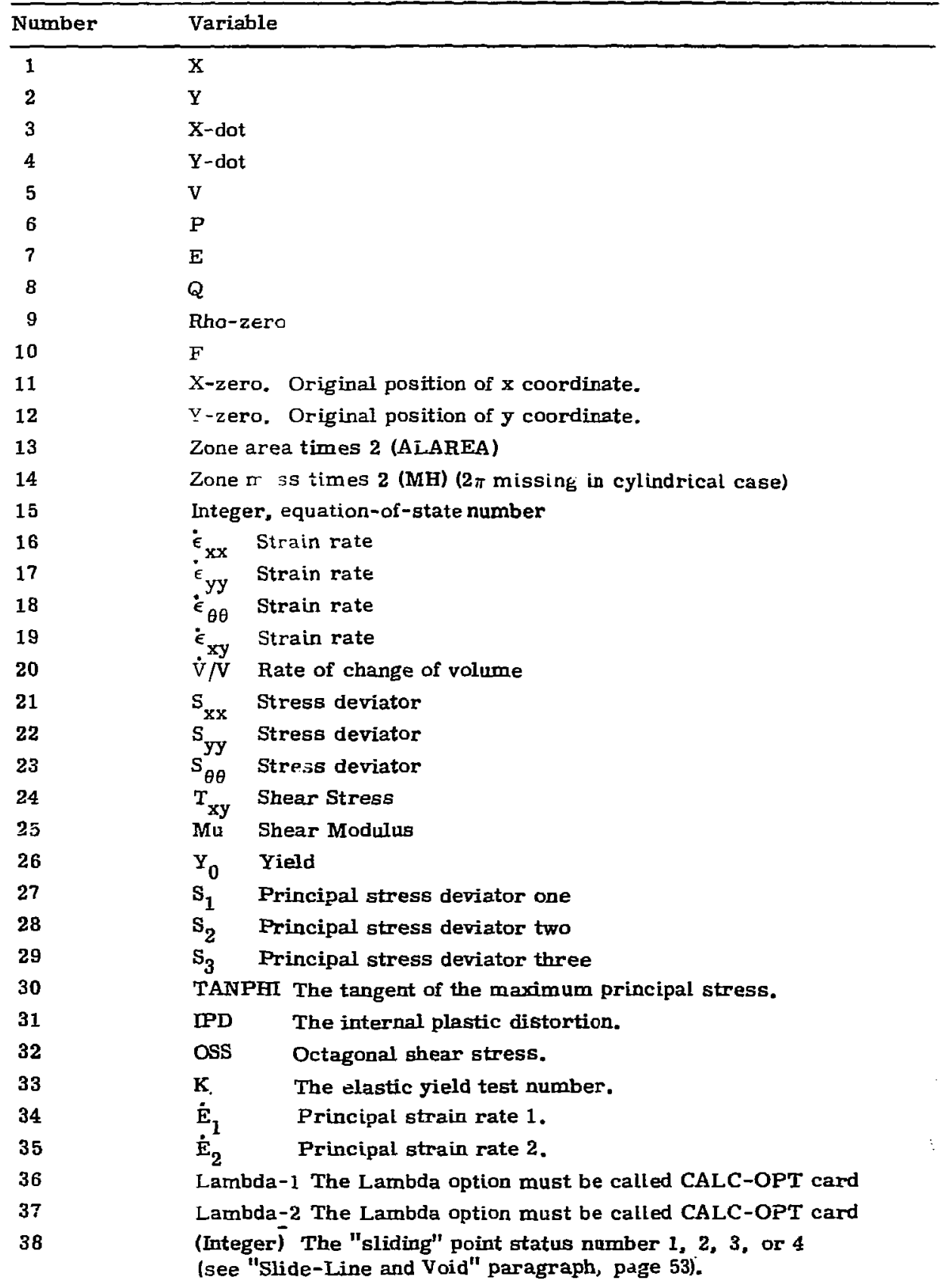


Table 3-11. (Continued).

\begin{tabular}{|c|c|}
\hline Number & Variable \\
\hline 39 & Not used. \\
\hline 40 & SIGMA-D The Sigma-D used in the slide calculations* \\
\hline 41 & $\dot{\mathrm{X}}(\mathrm{X}$ acceleration) \\
\hline 42 & $\dot{\mathbf{Y}}(\mathrm{Y}$ acceleration $)$ \\
\hline 43 & Not used \\
\hline 44 & Not used \\
\hline 45 & Not used \\
\hline 46 & Not used \\
\hline 47 & Not used \\
\hline 48 & Not used \\
\hline 49 & Not used \\
\hline 50 & Not used \\
\hline 51 & $Q_{x x}$ Navier-Stokes $Q$ \\
\hline 52 & $Q_{\mathrm{yy}}$ Navier-Stokes $\mathbf{Q}$ \\
\hline 53 & $Q_{\theta \theta}$ Navier-Stokes $Q$ \\
\hline 54 & $Q_{x y}$ Navier-Stokes $Q$ \\
\hline 55 & Linear part of Navier-Stokes $Q$ \\
\hline 56 & DS-rate \\
\hline 58 & $\begin{array}{l}\text { Strain rate composite term. } \\
+2\left(\dot{\epsilon}_{\mathrm{xx}}^{2}+\dot{\epsilon}_{\mathrm{yy}}^{2}+\dot{\epsilon}_{\theta \theta}^{2}+\dot{\epsilon}_{\mathrm{xy}}^{2}\right) \\
\text { Sound Speed squared }\end{array}$ \\
\hline 59 & Not used \\
\hline 60 & (Integer) The number of the point type \\
\hline 61 & Variable 25 This will put out whatever is in the variable \\
\hline 62 & Variable 26 This will put out whatever is in the variable \\
\hline 63 & Variable 27 This will put out whatever is in the variable \\
\hline 64 & Variable 28 This will put out whatever is in the variable \\
\hline 65 & Variable 29 This will put out whatever is in the variable \\
\hline 66 & Variable 30 This will put out whatever is in the variable \\
\hline 67 & Variable 31 This will put out whatever is in the variable \\
\hline 68 & Variable 32 This will put out whatever is in the variable \\
\hline 69 & $\partial \Sigma_{x x} / \partial x$ \\
\hline 70 & $\partial \Sigma_{\mathrm{xy}} / \partial \mathrm{YY}$ \\
\hline 71 & ALPHA $=T_{x y} / Y$ \\
\hline 72 & $\partial \Sigma_{\mathrm{YY}} / \partial \mathrm{Y}$ \\
\hline 73 & $\partial T_{x y} / \theta Y$ \\
\hline 74 & BETA $=\Sigma_{y y}-\Sigma_{\theta \theta} / Y$ \\
\hline 75 & $\begin{array}{l}\text { The non-compression rate term of the } Q \text { equation. } \\
=C_{0}^{2} \rho_{0} A^{n+1 / 2} / N^{n+1 / 2}\end{array}$ \\
\hline
\end{tabular}


Table 3-11. (Continued).

\begin{tabular}{lll}
\hline Number & Variable \\
\hline 76 & $1 / 2 \phi$ \\
77 & Not used \\
78 & Not used \\
79 & Not used & \\
80 & Not used \\
81 & Not used \\
82 & Not used \\
83 & Not used \\
84 & Not used \\
85 & $\mathrm{E}_{1}$ \\
86 & $\mathrm{E}_{2}$ & \\
87 & $\mathrm{E}_{3}\left(=\mathrm{E}_{\mathrm{zz}}\right)$ & Principal strain 3. \\
88 & $\mathrm{E}_{1}-\mathrm{E}_{2}$ & \\
89 & Not used & \\
90 & Not used & \\
\hline
\end{tabular}

*Appendix B, Section I of Ref. 1 .

Table 3-12. Vertical and horizontal walls (or piston) ${ }^{\frac{1}{*}}$.

\begin{tabular}{|c|c|c|}
\hline $\begin{array}{l}\text { Field } \\
\text { use }\end{array}$ & Columns & Input and explanation \\
\hline Card name & $1-10$ & STONEWALLS \\
\hline$K-\max \dot{X}$ & 11 & Integer. If set to "1", $\dot{\mathrm{X}}$ at $\mathrm{K}-\mathrm{max}$ is not calculated. \\
\hline$K-\max \dot{Y}$ & 12 & Integer. If set to " 1 ", $\dot{\mathrm{Y}}$ at $\mathrm{K}-\max$ is not calculated. \\
\hline $\mathrm{K}-\mathrm{min} \dot{\mathrm{X}}$ & 13 & Integer. If set to "1", $\dot{X}$ at $K$-min is not calculated. \\
\hline$K-\min \dot{Y}$ & 14 & Integer. If set to "1", $\dot{Y}$ at $K-m$ in is not calculated. \\
\hline$J-\max \dot{x}$ & 15 & integer. If set to "1", $\dot{X}$ at $J-\max$ is not calculated. \\
\hline$J-\max \dot{\mathrm{Y}}$ & 16 & Integer. If set to "1", $\dot{Y}$ at $J-\max$ is not calculated. \\
\hline$J-\min \dot{\mathrm{X}}$ & 17 & Integer. If set to " $1 ", \dot{\mathrm{X}}$ at $\mathrm{J}-\mathrm{min}$ is not calculated. \\
\hline $\mathrm{J}-\mathrm{min} \dot{\mathrm{Y}}$ & 18 & Integer. If set to "1", $\dot{\mathrm{Y}}$ at $\mathrm{J}$-min is not calculated . \\
\hline $\begin{array}{l}\text { Boundary } \\
\text { point spacer } \\
\text { fraction }\end{array}$ & $19-26$ & $\begin{array}{l}\text { All vertical and horizontal boundary points are forced to be } \\
\text { spaced from their neighboring boundary points by } 1 / 10 \text { of } \\
\text { the original spacing. This is to prevent crossover. If a } \\
\text { number is entered here, the fraction will be changed to the } \\
\text { new value. It can not be changed to zero. }\end{array}$ \\
\hline $\begin{array}{l}\text { Skip } \\
\text { spacing }\end{array}$ & $27-29$ & $\begin{array}{l}\text { Any number entered here will cause the spacing routines to } \\
\text { be skipped. }\end{array}$ \\
\hline
\end{tabular}

These options apply the rigid wall condition to the entire $\mathrm{K}-\mathrm{max}, \mathrm{K}-\mathrm{min}, \mathrm{J}-\mathrm{max}$ or $\mathrm{J}-\mathrm{m}$ in surface. 


\section{Angled Rigid Walls}

Each problem exterior boundary may have applied to it an angled rigid wall. No boundary apacing is forced. Four cards may be used, one for each surface. The card format is shown in Tables 3-13 through 3-16. The slope of the surface may be inputted by two means, the angle of the slope from a zero angle to the right of the end point, or by the inputting of the end points. (See Fig. 3-4.)

\section{Quadrant Control}

Cylindrical case problems will automatically be run with the condition that a J, K grid point can not pass through $Y=0$. This condition can be removed by input in column 13 on the XYQUAD card. (See Table 3-17J All other quadrant controls are not exercised unless called for by input.

\section{Ring and Support}

The "ring" and "support" options (Fig. 3-5) limit the motion of the grid points in the $X-Y$ plane by setting $X$ or $Y$ to zero when any point reaches specified values. In effect, these options set up stone walls of limited length that will stop the motion of any point that attempts to pass through the line segment.

Table 3-13 shows the ring and support card format.

The ring option limits the horizontal motion of all grid points. It can be used in eitaer plane or cylindrical geometry. The support option limits the vertical motion of all points. For each option, an $\mathrm{X}$-min, $\mathrm{X}$-max, $\mathrm{Y}$-min, and $\mathrm{Y}$-max must be entered on the ring card. These values must lie outside of the initial position of the grid, so that the grid is enclosed by the ring or support.

Table 3-13. K-max angle boundary wall card format.

\begin{tabular}{|c|c|c|}
\hline $\begin{array}{l}\text { Field } \\
\text { use }\end{array}$ & Columns & Input and explanation \\
\hline Card name & $1-10$ & KMAX-ANG \\
\hline Input option & $11-12$ & $\begin{array}{l}\text { Integer. If set to }+1 \text {, take angle as inputted. If set to }-1 \text {, } \\
\text { the end points are inputted. }\end{array}$ \\
\hline Angle & $13-20$ & $\begin{array}{l}\text { If columns } 11-12 \text { are set to }+1 \text {, this angle (in degrees) will } \\
\text { be used in calculating the surface velocities. The angle is } \\
\text { measured from a line extending directly to the right of the } \\
\mathrm{K}-\mathrm{max}, \mathrm{J}-\mathrm{min} \text { corner of the problem, around counterclock- } \\
\text { wise to the K-max line. If columns } 11-12 \text { are set to }-1 \text {, the } \\
\text { generator will calculate the angle from the end points } \\
\text { entered below. }\end{array}$ \\
\hline$\underset{J-\max X}{K-\max }$ & $21-28$ & $\mathrm{X}$ of $\mathrm{K}$-max, $\mathrm{J}$-max point \\
\hline $\begin{array}{l}K-\max - \\
J-\max Y\end{array}$ & $29-36$ & $\mathrm{Y}$ of $\mathrm{K}-\mathrm{max}, \mathrm{J}-\mathrm{max}$ point \\
\hline $\begin{array}{l}\mathrm{K}-\max - \\
\mathrm{J}-\min \mathrm{X}\end{array}$ & $37-44$ & $\mathrm{X}$ of $\mathrm{X}$-mas, $\mathrm{J}$-min point \\
\hline $\begin{array}{l}\text { K-max- } \\
J-\min Y\end{array}$ & $45-52$ & $Y$ of $K-r i a x, J$-min point \\
\hline
\end{tabular}


Table 3-14. K-min angle boundary wall card format.

\begin{tabular}{|c|c|c|}
\hline $\begin{array}{l}\text { Field } \\
\text { use }\end{array}$ & Columns & Input and explanation \\
\hline Card name & $1-10$ & KMTN-ANG \\
\hline Input option & $11-12$ & $\begin{array}{l}\text { Integer, if set to }+1 \text {, the angle is inputted. If set to }-1 \text {, } \\
\text { the end points are inputted. }\end{array}$ \\
\hline Angle & $13-20$ & $\begin{array}{l}\text { If columns } 11-12 \text { are set to }+1 \text {, this angle (in degrees) will } \\
\text { be used in calculating the surface velocities. The angle is } \\
\text { measured from a line extending directly to the right of the } \\
\mathrm{K}-\mathrm{min}, \mathrm{J}-\mathrm{min} \text { corner of the problem around counterclock- } \\
\text { wise to the K-min line. If columns } 11-12 \text { are set to }-1 \text {, the } \\
\text { generator will calculate the angle from the end points } \\
\text { entered below. }\end{array}$ \\
\hline $\begin{array}{l}\text { K-min- } \\
\text { J-max } X\end{array}$ & $21-28$ & $X$ of $K-m i n, J-m a x$ point \\
\hline $\begin{array}{l}\text { K-min- } \\
\mathbf{J}-\max \mathbf{Y}\end{array}$ & $29-36$ & $\mathrm{Y}$ of $\mathrm{K}-\mathrm{min}, \mathrm{J}-\mathrm{max}$ point \\
\hline$\underset{J-\min }{K} x$ & $37-44$ & $\mathrm{X}$ of $\mathrm{K}-\mathrm{min}, \mathrm{J}-\mathrm{min}$ point \\
\hline $\begin{array}{l}\text { K-min- } \\
\text { J-min } Y\end{array}$ & $45-52$ & $Y$ of $K-\min , J-m$ in point \\
\hline
\end{tabular}

Table 3-15. J-max angle boundary wall card format.

\begin{tabular}{|c|c|c|}
\hline $\begin{array}{l}\text { Field } \\
\text { use }\end{array}$ & Columns & Input and explanation \\
\hline Carà Name & $1-10$ & JMAX-ANG \\
\hline Input Option & $11-12$ & $\begin{array}{l}\text { Integer. If set to }+1 \text {, the angle is inputted. If set to }-1 \text {, } \\
\text { the end points are inputted. }\end{array}$ \\
\hline Angle & $13-20$ & $\begin{array}{l}\text { If columas } 11-12 \text { are set to }+1, \text { this angle (in degrees) will } \\
\text { be used in calculating the surface velocities. The angie is } \\
\text { measured from a line extending directly to the right of the } \\
\mathrm{K}-\text { min, } J \text {-max corner of the problem, around counterclock- } \\
\text { wise to the } J-m a x \text { line. If columns } 11-12 \text { are set to }-1 \text {, the } \\
\text { generator will calculate the angle from the end points } \\
\text { entered below. }\end{array}$ \\
\hline $\begin{array}{l}\mathrm{K}-\max - \\
\mathrm{J}-\max \mathrm{X}\end{array}$ & $21-28$ & $X$ of $K-\max , J-\max$ point \\
\hline $\begin{array}{l}\text { K-max- } \\
\text { J-max } Y\end{array}$ & $29-36$ & $Y$ of $K-\max , J-\max$ point \\
\hline $\begin{array}{l}\mathrm{K}-\min - \\
\mathrm{J}-\max \mathrm{X}\end{array}$ & $37-44$ & $\mathrm{X}$ of $\mathrm{K}-\mathrm{min}, \mathrm{J}$-max point \\
\hline $\begin{array}{l}K-\min - \\
J-\max Y\end{array}$ & $45-52$ & $\mathrm{Y}$ of $\mathrm{K}-\mathrm{min}, \mathrm{J}-\mathrm{max}$ point \\
\hline
\end{tabular}


Table 3-16. J-min angle boundary wall card format.

\begin{tabular}{|c|c|c|}
\hline $\begin{array}{l}\text { Field } \\
\text { use }\end{array}$ & Columns & Input and explanation \\
\hline Card name & $1-10$ & JMIN-ANG \\
\hline Input option & $11-12$ & $\begin{array}{l}\text { Integer. If set to }+1 \text {, the angle is inputted. If set to }-1 \text {, } \\
\text { the end points are inputted. }\end{array}$ \\
\hline Angle & $13-20$ & $\begin{array}{l}\text { If columns } 11-12 \text { are set to }+1 \text {, this angle (in degrees) will } \\
\text { be used in calculating the surface velocities. The angle is } \\
\text { measured from a line extending directly to the right of the } \\
\mathrm{K}-\mathrm{min} \text {, J-min corner of the problem, around courterclock- } \\
\text { wise to the J-min line. If columns } 11-12 \text { are set to }-1 \text {, the } \\
\text { generator will calculate the angle from the end points } \\
\text { entered below. }\end{array}$ \\
\hline $\begin{array}{l}\mathrm{K}-\max - \\
\mathrm{J}-\min \mathrm{X}\end{array}$ & $21-28$ & $\mathrm{X}$ of $\mathrm{K}-\mathrm{max}, \mathrm{J}-\mathrm{min}$ point \\
\hline$\underset{J-\min }{K} \mathrm{Y}$ & $29-36$ & $\mathrm{Y}$ of $\mathrm{K}-\max , \mathrm{J}-\mathrm{min}$ point \\
\hline$\underset{J-\min }{K-\min }$ & $37-44$ & $\mathrm{X}$ of $\mathrm{K}-\mathrm{min}, \mathrm{J}-\mathrm{min}$ point \\
\hline $\begin{array}{l}\mathrm{K}-\min - \\
\mathrm{J}-\mathrm{min} \mathrm{Y}\end{array}$ & $45-52$ & $\mathrm{Y}$ of $\mathrm{K}-\mathrm{min}, \mathrm{J}-\mathrm{m}$ in point \\
\hline
\end{tabular}

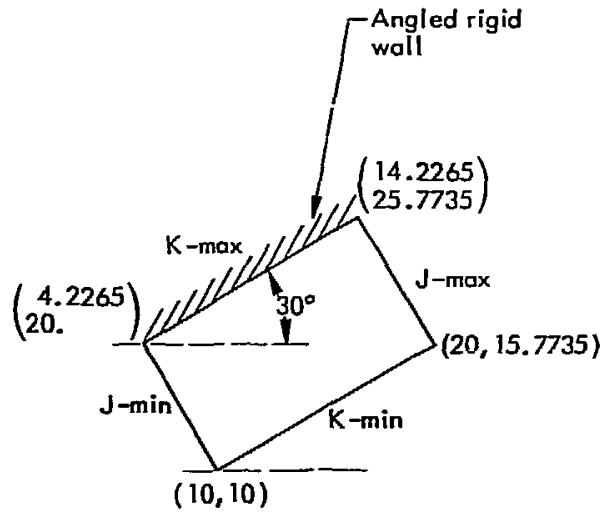

The example could be inputted in two ways:

1 . by a -1 in columns $11-12,14.2265$ in columns $21-28,25.7735$ in columis 29-36, 4.2265 in columns $37-44$, and 20 . in columns 45-52

or by

II. +1 in columns $11-12$ and +30.0 in columns 13-20.

Fig. 3-4. Angled rigid wall example.
All four input numbers must be specified for the option that is being used. For example: If you use the ring option and you want 2 ring only on the left side of the grid, you should specify a large positive $\mathrm{X}$-max in order to place the right hand ring far way from the grid. If you leave $X$-max blank, the code will use an $\bar{X}$-max of zero which may cause difficulty (iepending on the problem).

\section{VARWALL Option}

The VARWALL option resembles the ring and support options in setting up stone walls to stop motion. However, in this option the stone wall lines aro of infinite length and they will stop the motion of only specified parts of the grid-the parts whose $K$-number corresponds to or are between the input $\mathrm{K}$-numbers. (Appropriate interior points are tested in addition to the boundary points. ) 
Table 3-17. Quajrant control card format.

\begin{tabular}{|c|c|c|}
\hline $\begin{array}{l}\text { Field } \\
\text { use }\end{array}$ & Columns & Input and smisation \\
\hline Card name & $1-10$ & XYQUAD \\
\hline No-Y's & 11 & $\begin{array}{l}\text { Integer. A "1" will restrain any grid point from getting a } \\
\text { negative } Y \text { value. This is automatic for cylinder above } \\
X \text {-axis proolems, unless bypassed by input. }\end{array}$ \\
\hline $\mathrm{Nc}+\mathrm{Y}^{\prime} \mathrm{S}$ & 12 & $\begin{array}{l}\text { Integer. A "1" will restrain any grid point frorn getting a } \\
\text { positive } \mathrm{Y} \text { value. This is automatic for cylinder below } \\
\mathrm{X} \text {-axis problems, uniess bypassed by input. }\end{array}$ \\
\hline $\begin{array}{l}\text { Allow All } \\
Y^{\prime} s\end{array}$ & 13 & $\begin{array}{l}\text { Integer. A "1" will remove the automatic restraint on } \mathrm{Y} \\
\text { irom the cylindrical case problems. }\end{array}$ \\
\hline No-X's & 14 & $\begin{array}{l}\text { Integer. } A \text { " } 1 \text { " will restrain any grid point from getting a } \\
\text { negative } X \text { value. }\end{array}$ \\
\hline $\mathrm{No}+\mathrm{X}^{1} \mathrm{~s}$ & 15 & $\begin{array}{l}\text { Integer. A " } 1 \text { " will restrain any grid point from Eetting a } \\
\text { positive X value. }\end{array}$ \\
\hline $\begin{array}{l}\text { Keep Y } \\
\text { at zero }\end{array}$ & 16 & $\begin{array}{l}\text { Integer. A "1" will restrain any grid point (except a slave } \\
\text { point) from moving in the } Y \text { direction if its } Y \text { coordinate is } \\
\text { equal to zero. }\end{array}$ \\
\hline
\end{tabular}

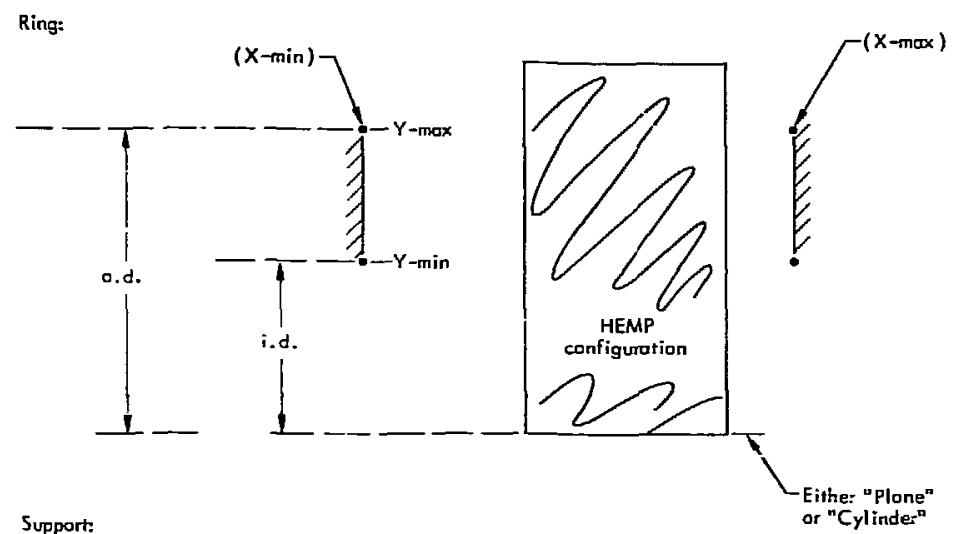

Support:
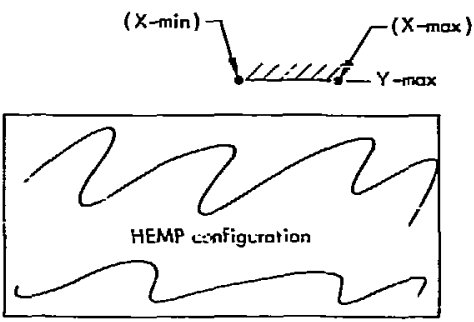

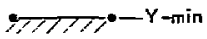

Fig. 3-5. Examples of ring and support options. 
Table 3-18. Ring and support card format.

\begin{tabular}{|c|c|c|}
\hline $\begin{array}{l}\text { Field } \\
\text { use }\end{array}$ & Columns & Input and expianation \\
\hline Card input & $1-10$ & RING \\
\hline o.d. of ring & $11-17$ & $\begin{array}{l}\text { If not zero, the "ring" routine is activated. The "o.d." } \\
\text { (outside diameter) of the limiting boundaries is this value. } \\
\text { Any point that is below this } Y \text { and above the "i.d." will be } \\
\text { stopped when it reache either the maximum X input value } \\
\text { or the minimum X input value. This is for both cylindrical } \\
\text { case and plane case problems. This value applies to both } \\
\text { the right ring boundary and the left ring boundary. }\end{array}$ \\
\hline i.d. of ring & $18-24$ & $\begin{array}{l}\text { If the "ring" option is activated by "o.d." above, the lower } \\
\text { edge of both the right hand and left hand ring is this value. }\end{array}$ \\
\hline $\begin{array}{l}X-\max \text { of } \\
\text { ring }\end{array}$ & $25-31$ & $\begin{array}{l}\text { If the ring option is called for, no point with a }{ }^{\text {"t }} \mathrm{Y}^{\mathrm{rl}} \text { between } \\
\text { the o.d. and the } \mathrm{i} . \mathrm{d} \text {. will be permitted to have an } X \text { value } \\
\text { greater than this input } X \text {. }\end{array}$ \\
\hline $\begin{array}{l}\mathrm{X}-\mathrm{min} \text { of } \\
\text { ring }\end{array}$ & $32-38$ & $\begin{array}{l}\text { If the ring option is called for, no point with a " } \mathrm{Y}^{\text {" }} \text { between } \\
\text { the o.d. and the i.d. will be permitted to have an } \mathrm{X} \text { value } \\
\text { smaller (or more negative) than this input } \mathrm{X} \text {. }\end{array}$ \\
\hline $\begin{array}{l}\text { " } \mathrm{X} \text { " of } \\
\text { right end } \\
\text { of "Support" }\end{array}$ & $39-45$ & $\begin{array}{l}\text { If not zero, the "support" routine is activated. The right } \\
\text { end (highest } X \text { value) of the limiting boundaries is this } \\
\text { value. Any point that is to the left of this } X \text { value and to the } \\
\text { right of the left end value will be stopped when it reaches } \\
\text { either the maximum } Y \text { or the minimum } Y \text {. This } X \text { input } \\
\text { value appites to both the maximum } Y \text { input value and the } \\
\text { minimum } Y \text { input value. }\end{array}$ \\
\hline $\begin{array}{l}\text { "X" of left } \\
\text { end of support }\end{array}$ & $46-52$ & $\begin{array}{l}\text { If the "support" option is activated, the left edge of both } \\
\text { the upper and the lower support is this value. }\end{array}$ \\
\hline $\begin{array}{l}\text { Maximum "Y" } \\
\text { allowed in the } \\
\text { "support" regior }\end{array}$ & $\begin{array}{l}53-59 \\
\text { on }\end{array}$ & $\begin{array}{l}\text { No point with an } X \text { between } X-\text { left and } X \text {-right (above) will } \\
\text { be permitted to have a } Y \text { value greater than this input } Y \text {. }\end{array}$ \\
\hline $\begin{array}{l}\text { Minimum "Y" } \\
\text { allowed in the } \\
\text { "support" regior }\end{array}$ & $\begin{array}{l}\text { 60-67 } \\
\text { on }\end{array}$ & $\begin{array}{l}\text { No point with an } X \text { between } X \text {-left and } X \text {-right (above) will be } \\
\text { perm itted to have a } Y \text { value smaller than this input } Y \text {. }\end{array}$ \\
\hline
\end{tabular}


Table 3-19. Maximum and minimum X's and $Y^{\prime} s$ for selected K's card format.

Field

use Columns Input and explanation

\begin{tabular}{|c|c|c|}
\hline Card name & $1-10$ & VARWALL \\
\hline $\begin{array}{l}\text { Higheat } \mathrm{K}- \\
\text { number to } \\
\text { control } \mathrm{X} \text {. }\end{array}$ & $11-13$ & $\begin{array}{l}\text { Integer. If not zero, this } K \text {-number and those of smaller } \\
\text { value down to and including "lower } K{ }^{\prime \prime} \text { (below) will have the } \\
\text { ma-imum } X \text { and minimum } X \text { tests applied. }\end{array}$ \\
\hline $\begin{array}{l}\text { Lowest } \mathrm{K}- \\
\text { number to } \\
\text { control X }\end{array}$ & $14-16$ & $\begin{array}{l}\text { Integer. This } K \text {-number will be the lower boundary to } \\
\text { which the } X \text { maximum and } X \text { minimum tests will be applied }\end{array}$ \\
\hline Maximum $\mathrm{X}$ & $17-28$ & $\begin{array}{l}\text { Points on or between } K \text {-numbers " } K \text {-highest" and " } K \text {-lowes } \\
\text { will be restrained from having an } X \text { value greater than this } \\
\text { input value. }\end{array}$ \\
\hline Minimum X & $29-40$ & $\begin{array}{l}\text { Points on or between } K \text {-numbers "K-highest" and } K \text {-lowest } \\
\text { will be restrained from having an X value smaller (more } \\
\text { negative) than this input value. }\end{array}$ \\
\hline $\begin{array}{l}\text { Highest K- } \\
\text { number to } \\
\text { control Y. }\end{array}$ & $41-43$ & $\begin{array}{l}\text { Integer. If not zero, this } K \text {-number and those of smaller } \\
\text { value down to and including "Iower } K^{\prime \prime} \text { (below) will have the } \\
\text { maximum } Y \text { and minimum } Y \text { tests applied. }\end{array}$ \\
\hline $\begin{array}{l}\text { Lowest } \mathrm{K}- \\
\text { number to } \\
\text { control } \mathrm{Y} \text {. }\end{array}$ & $44-46$ & $\begin{array}{l}\text { Integer. This } \mathrm{K} \text {-number will be the lower boundary that th } \\
\text { Y maximum tests (below) will be applied. }\end{array}$ \\
\hline Maximum $\mathrm{Y}$ & $47-58$ & $\begin{array}{l}\text { Pnints on or between "K-inighest" and "K-lowest" will be } \\
\text { rt -trained from having a } Y \text { value greater than this input } \\
\text { value. }\end{array}$ \\
\hline Minimum $\mathrm{Y}$ & $59-70$ & $\begin{array}{l}\text { Points on or between " } K \text {-highest" and "K-Iowest" will be } \\
\text { restrained from having a } \mathrm{Y} \text { value smaller (more negative) } \\
\text { than this input value. }\end{array}$ \\
\hline
\end{tabular}

Table 3-19 shows the VARWALL card format.

A certain part of the grid, say from $\mathrm{K} 21$ to $\mathrm{K} 12$, can have its $\mathrm{X}$-motion limited by this option while the same, or different, or overlapping part of the grid can have this $\mathrm{Y}$-motion limited.

On slide surfaces whose $\mathrm{K}$-number corresponds to one of the input $\mathrm{K}$-numbers (highest or lowest $\mathrm{K}$ ), only the side of the master-slave pair that is on the restricted side is held.

\section{Pressure Profiles}

Pressures may be applied on all or part of all exterior boundaries. Two routines for each boundary (K-max, K-min, J-max, J-min) are provided. A table look-up input system is provided for each boundary. It may be used by the routine that applies pressure as a function of time to the entire boundary, or it may be used by the more gereral routine. The more general routine will apply pressure to a selected region of a boundary as a function of Time, of $X$, or of $\mathrm{Y}$.

\section{Pressure on Entire Surface}

This card (format shown in Table 3-20) activates the four routines that apply pressure as a function of time to any or 
Table 3-20. Pressure on entire surface card format.

\begin{tabular}{|c|c|c|}
\hline $\begin{array}{l}\text { Field } \\
\text { use }\end{array}$ & Columns & Input and explanation \\
\hline Card name & $1-10$ & PBOUNDARY \\
\hline $\begin{array}{l}\text { K-max } \\
\text { pressure }\end{array}$ & 11 & $\begin{array}{l}\text { Integer. If set to "1", the code will use the table input } \\
\text { from cards VARPKMAX and PRESKMAX to apply pressure } \\
\text { as a function of time to the entire K-max boundary. }\end{array}$ \\
\hline $\begin{array}{l}\mathrm{K}-\min \\
\text { pressure }\end{array}$ & 12 & $\begin{array}{l}\text { Integer. If set to " } 1 \text { ", the code will use the table input } \\
\text { from cards VARPKMIN and PRESKMIN to apply pressure } \\
\text { as a funetion of time to the entire K-min boundary. }\end{array}$ \\
\hline $\begin{array}{l}\mathrm{J}-\max \\
\text { boundary }\end{array}$ & 13 & $\begin{array}{l}\text { Integer. If set to " } 1 \text { ", the code will use the table input } \\
\text { from cards VARPJMAX and PRESJMAX to apply pressure } \\
\text { as a function of time to the entire J-max boundary. }\end{array}$ \\
\hline $\begin{array}{l}\mathrm{J}-\min \\
\text { boundary }\end{array}$ & 14 & $\begin{array}{l}\text { Integer. If set to "1", the code will use the table input } \\
\text { from cards VARPJMIN and PRESJMIN to apply pressure } \\
\text { as a function of tirue to the entire J-min boundary. }\end{array}$ \\
\hline $\begin{array}{l}\text { J-max } \\
\text { "overhang" } \\
\text { pressure }\end{array}$ & 15 & $\begin{array}{l}\text { integer. If set to " } 1 \text { ", the } \vec{J} \text {-max pressure profile (from } \\
\text { all input) will be applied to the portion of the "master" } \\
\text { surface that overhangs the } J \text {-max end of the "slave" surface }\end{array}$ \\
\hline $\begin{array}{l}\text { J-min } \\
\text { "overhang" } \\
\text { pressure }\end{array}$ & 16 & $\begin{array}{l}\text { Integer. If set to " } 1 " \text {, the } J \text {-min pressure profile (from all } \\
\text { input) will be applied to the portion of the "master" surface } \\
\text { that overhangs the } J-m \text { in end of the "slave" surface. }\end{array}$ \\
\hline
\end{tabular}

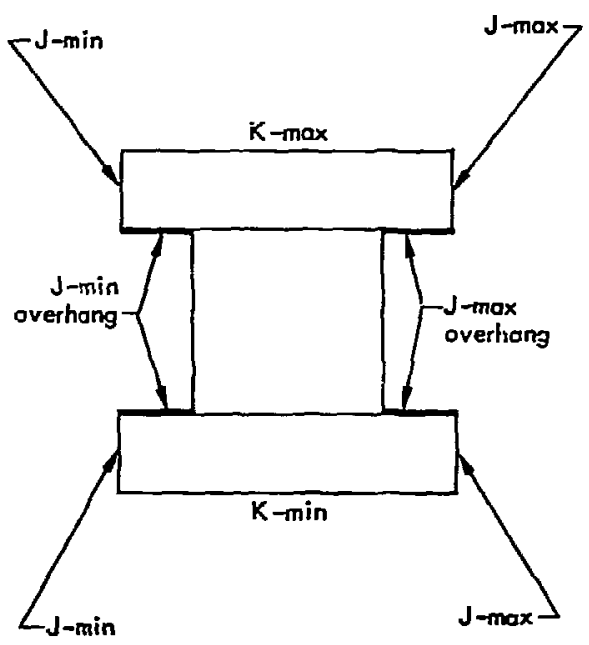

Fig. 3-6. Pressure applied to slideline overhang.

all of the exterior boundaries. The pressure is constant for a particular time for every point on the boundary.
Figure 3-6 shows how the pressure is applied to the "Overhang".

\section{Boundary Pressures with Range and Time Controls}

These cards (Tables $3-21$ inrough 3-32) allow the user to specify surface pressure as a function of time, of $\mathrm{X}$, or of $\mathrm{Y}$ and permits the use of this pressure to be limited by $J$ and $K$ number restrictions, by time restrictions, by $\mathrm{X}$ restrictions, and by $Y$ restrictions.

Pressure Table Input (Fig. 3-7)

This input requires three kinds of cards for each boundary that is to have a pressure applied (K-max, K-min, J-max or $\mathrm{J}$-min boundaries).

EXAMPLE: To specify pressure as a function of time on the K-max boundary, with $J$ limits, these cards are required (the PBOUNDARY card is not used). 
Table 3-21. Controlled $\mathrm{K}$-max boundary pressure card format.

(Values on VARPKMAX and PRESKMAX cards will be used.)

\begin{tabular}{|c|c|c|}
\hline $\begin{array}{l}\text { Field } \\
\text { use }\end{array}$ & Columns & lnput and explanation \\
\hline Card name & $1-10$ & PKMAX \\
\hline $\begin{array}{l}\text { P varies } \\
\text { with time }\end{array}$ & 11 & $\begin{array}{l}\text { Integer. If set to " } 1 \text { ", the values on VARPKMAX will be } \\
\text { problem "times". Pressure will be a furction of time. }\end{array}$ \\
\hline $\begin{array}{l}P \text { varies } \\
\text { with } X\end{array}$ & 12 & $\begin{array}{l}\text { Integer. If set to " } 1 \text { ", the values on VARPKMAX will be } \\
\text { X's. Pressure will be a function of X. }\end{array}$ \\
\hline $\begin{array}{l}\text { P varies } \\
\text { with } \mathrm{Y}\end{array}$ & 13 & $\begin{array}{l}\text { Integer. If sat to " } 1 \text { ", the values on VARPKMAX will be } \\
Y \text { 's. Pressure wrill be a function of } y \text {. }\end{array}$ \\
\hline $\begin{array}{l}\text { J-upper } \\
\text { limit }\end{array}$ & $14-16$ & $\begin{array}{l}\text { Integer. If entered, this is the upper J point boundary of } \\
\text { the area to which the pressure will be applied. If not } \\
\text { entered, there will be no J test. }\end{array}$ \\
\hline $\begin{array}{l}\text { J-lower } \\
\text { limit }\end{array}$ & $17-19$ & $\begin{array}{l}\text { Integer. This is the lower } J \text { point boundary to which the } \\
\text { pressure will be applied. }\end{array}$ \\
\hline $\begin{array}{l}\text { Time to } \\
\text { start } \\
\text { pressure }\end{array}$ & $20-2 B$ & $\begin{array}{l}\text { This is the start time of the pressure. If the "stop time" } \\
\text { is not entered, the pressure will be on at all times. }\end{array}$ \\
\hline $\begin{array}{l}\text { Time to } \\
\text { stop } \\
\text { pressure }\end{array}$ & $29-37$ & $\begin{array}{l}\text { If not zero, the pressure will start at tine time above and } \\
\text { will be set to zero at this time, regardless of the table } \\
\text { input data. If this is zero, the start and stop tests are not } \\
\text { made. }\end{array}$ \\
\hline Lower $\mathrm{x}$ & $38-46$ & $\begin{array}{l}\text { If this input is nonzero, the boundary zones with an } X \\
\text { smaller (more negative) than this will be assigned a pres- } \\
\text { sure of zero. }\end{array}$ \\
\hline Upper X & $47-55$ & $\begin{array}{l}\text { If an } X \text { boundary test is called for by Lower } X \text { (above), the } \\
\text { boundary zones with an } X \text { greater than this will be assigned } \\
\text { a pressure of zero. }\end{array}$ \\
\hline Lower Y & $56-64$ & $\begin{array}{l}\text { If this input is nonzero, the boundary zones with a Y } \\
\text { smaller (more negative) than this will be assigned a pres- } \\
\text { sure of zero. }\end{array}$ \\
\hline lipper $\mathrm{Y}$ & $65-73$ & $\begin{array}{l}\text { If a } Y \text { boundary test is called for by Lower } Y \text { (above), the } \\
\text { boundary zones with a Y greater than this will be assigned } \\
\text { a pressure of zero. }\end{array}$ \\
\hline
\end{tabular}

- A PKMAX card to identily the independent variable (time, in this case), and the $\mathrm{J}$ limits.

- One or two VAR PKMAX cards with a lisî of times.

- One or two PRESKMAX cards with a list of pressures.

As a practical matter, it is usually wise to extend the tables beyond the expected independent variable boundaries to avoid difficulty if the problem is ex- tended in time or if $\mathrm{X}$ or $\mathrm{Y}$ exceeds its expected values.

\section{Slide-Lines and Voids}

The HEMP program allows the uss to specify any type of boundary conditions for the ends of $\mathrm{K}$-lines. This flexibility requires that some system be provided for describing the motion of the "slave" points beyond the ends of the "master" line. For this purpose, the code extends 
Table 3-22. K-max table, independent variable card format.

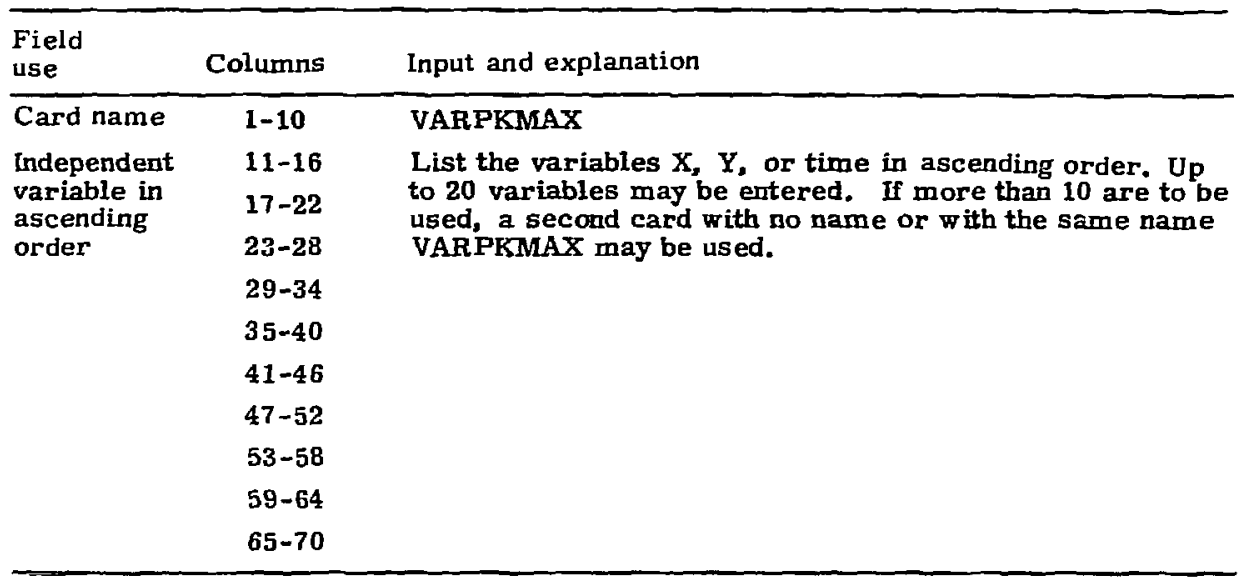

Table 3-23. K-max table, pressure card format.

\begin{tabular}{lcl}
\hline $\begin{array}{l}\text { Field } \\
\text { use }\end{array}$ & Columns & Input and explanation \\
\hline Card name & $1-10$ & PRESKMAX \\
Pressure & $11-16$ & $\begin{array}{l}\text { List the pressures that correspond to the independent } \\
\text { vasle }\end{array}$ \\
& $17-22$ & List up to 20 pressures on up to two cards. \\
& $23-28$ & \\
& $29-34$ & \\
& $35-40$ & \\
$41-46$ & \\
& $47-52$ & \\
$53-58$ & \\
$59-64$ & \\
$65-70$ &
\end{tabular}

the "master" line with a very long line segment at each end. The slave points are constrained to move $a^{7}$ ong these extended lines when they are beyond the
$\mathrm{J}-\mathrm{max}$ or $\mathrm{J}$-min points. A similar device is used by the program to pick up zonal information from the "slave" side when advancing the "master" points in time. 
Table 3-24. Controlled K-min boundary pressure card fc t.

(Values on VARPKMIN and PRESKMIN cards will be used.)

\begin{tabular}{|c|c|c|}
\hline $\begin{array}{l}\text { Field } \\
\text { use }\end{array}$ & Columns & Input and explanation \\
\hline Card name & $1-10$ & PKMIN \\
\hline $\begin{array}{l}\text { P varies with } \\
\text { tina: }\end{array}$ & 11 & $\begin{array}{l}\text { Integer. If set to "1", the values on VARPKMnN will be } \\
\text { problem "times". Pressure wil be a function of time. }\end{array}$ \\
\hline $\begin{array}{l}\text { P varies with } \\
X\end{array}$ & 12 & $\begin{array}{l}\text { Integer. If set to " } 1 \text { ", the values on VARPKMnN will be } \\
X^{\prime} \text { 's. Pressure will be a fanction of } X \text {. }\end{array}$ \\
\hline $\begin{array}{l}\text { P varies } \\
\text { with } Y\end{array}$ & 13 & $\begin{array}{l}\text { Integer. If set to "1", the values on VARPKMn will be } \\
\text { Y's. Pressure will be a function of Y. }\end{array}$ \\
\hline $\begin{array}{l}\text { J-upper } \\
\text { limit }\end{array}$ & $14-16$ & $\begin{array}{l}\text { Integer. if entered, this is the upper } \mathrm{J}, \cdot \pm \text { boundary of } \\
\text { the area to which the pressure will be appiled. If not } \\
\text { entered, there will be no J test. }\end{array}$ \\
\hline $\begin{array}{l}\text { J-lower } \\
\text { limit }\end{array}$ & $17-19$ & $\begin{array}{l}\text { Integer. This is the lower } J \text { point boundary to which the } \\
\text { pressure will be applied. }\end{array}$ \\
\hline $\begin{array}{l}\text { Time to } \\
\text { start } \\
\text { pressure }\end{array}$ & $20-28$ & $\begin{array}{l}\text { This is the start time of the pressure. If the "stop time" } \\
\text { is not entered, the pressure will be on at all times. }\end{array}$ \\
\hline $\begin{array}{l}\text { Time to } \\
\text { stop } \\
\text { pressure }\end{array}$ & $29-37$ & $\begin{array}{l}\text { If not zero, the pressure will start at the time above and } \\
\text { will be set to zero at this time, regardless of the table } \\
\text { input data. If this is zero, the start and stop tests are not } \\
\text { made. }\end{array}$ \\
\hline Lower $\mathrm{X}$ & $38-46$ & $\begin{array}{l}\text { If this input is nonzero, the boundary zones with an } X \\
\text { smaller (more negative) than this will be assigned a pres- } \\
\text { sure of zero. }\end{array}$ \\
\hline Upper X & $47-55$ & $\begin{array}{l}\text { If an } \mathrm{X} \text { boundary test ls cailed for by Lower } \mathrm{X} \text { (above), the } \\
\text { boundary zones with an } \mathrm{X} \text { greater than this will be assigned } \\
\text { a pressure of zero. }\end{array}$ \\
\hline Lower Y & $56-64$ & $\begin{array}{l}\text { If this input is nonzero, the boundary zones with a } Y \\
\text { smaller (more negative) than this will be assigned a pres- } \\
\text { sure of zero. }\end{array}$ \\
\hline Upper Y & $65-73$ & $\begin{array}{l}\text { If a Y boundary test is called for by Lower Y (above), the } \\
\text { boundary zones with a } \mathrm{Y} \text { greater than this will be assigned } \\
\text { a pressure of zero. }\end{array}$ \\
\hline
\end{tabular}

Table 3-25. K-min table, independent variable card format.

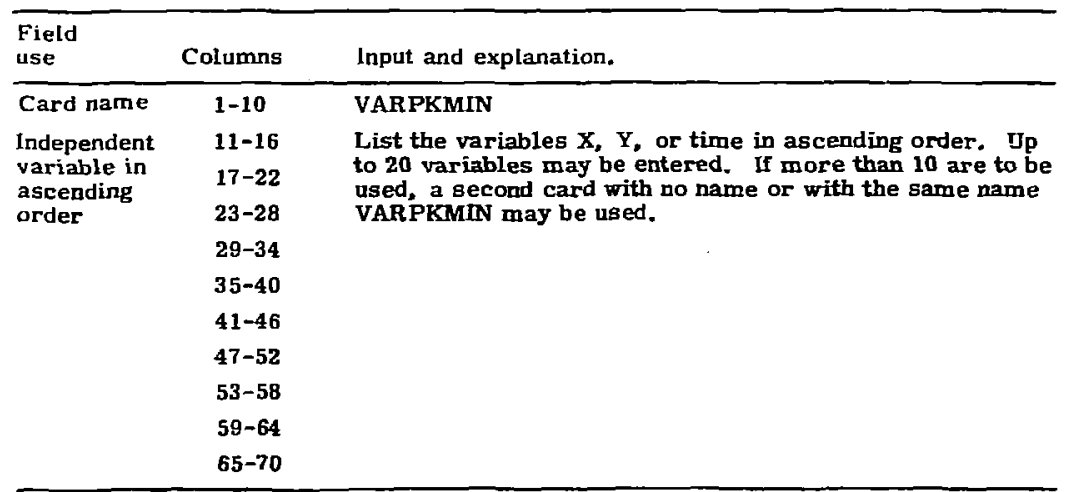


Table 3-26. K-min table, pressure card format.

\begin{tabular}{lcl}
\hline $\begin{array}{l}\text { Field } \\
\text { use }\end{array}$ & Columns & Input and explanation \\
\hline Card name & $1-10$ & PRESKMIN \\
$\begin{array}{l}\text { Pressure } \\
\text { table }\end{array}$ & $11-16$ & $\begin{array}{l}\text { List the pressures that correspond to the independent vari- } \\
\text { ables, The code will interpolate between input points. List }\end{array}$ \\
& $17-22$ & $\begin{array}{l}\text { up to } 20 \text { pressures on up to two cards. } \\
23-28\end{array}$ \\
& $29-34$ & \\
& $35-40$ & \\
& $41-46$ & \\
& $47-52$ & \\
& $53-58$ \\
& $59-64$ \\
\end{tabular}

Table 3-27. Controlled J-max boundary pressure card format.

(Values on VARPJMAX and PRESJMFX cards will be used.)

\begin{tabular}{|c|c|c|}
\hline $\begin{array}{l}\text { Field } \\
\text { use }\end{array}$ & Columns & Input and explanation \\
\hline Card name & $1-10$ & PJMAX \\
\hline $\begin{array}{l}\text { P varies } \\
\text { with time }\end{array}$ & 11 & $\begin{array}{l}\text { Integer. If set to "1", the values on VARPJMAX will be } \\
\text { problem "times". Pressure will be a function of time. }\end{array}$ \\
\hline $\begin{array}{l}\text { P varies } \\
\text { with } X\end{array}$ & 12 & $\begin{array}{l}\text { Integer, If set to " } 1 \text { ", the values on VARPJMAX will be } \\
X^{\prime} s \text {. Pressure will be a function of } X \text {. }\end{array}$ \\
\hline $\begin{array}{l}\text { P varies } \\
\text { with Y }\end{array}$ & 13 & $\begin{array}{l}\text { Integer. If set to " } 1 \text { ", the values on VARPJMLX will be } \\
Y^{\prime} \text { 's. Pressure will be a function of } Y \text {. }\end{array}$ \\
\hline $\begin{array}{l}\text { K-upper } \\
\text { limit }\end{array}$ & $14-16$ & $\begin{array}{l}\text { Integer. If entered, this is the upper } K \text { point boundary of } \\
\text { the area to which the pressure will be applied. If not } \\
\text { entered, there will be no K test. }\end{array}$ \\
\hline $\begin{array}{l}\text { K-lower } \\
\text { limit }\end{array}$ & $17-19$ & $\begin{array}{l}\text { Integer. This is the lower } K \text { point to which the pressure } \\
\text { will be applied. }\end{array}$ \\
\hline $\begin{array}{l}\text { Time to } \\
\text { start } \\
\text { pressure }\end{array}$ & $20-28$ & $\begin{array}{l}\text { This is the start time of the pressure. If the "stop time" } \\
\text { is not entered, the pressure will be on at all times. }\end{array}$ \\
\hline $\begin{array}{l}\text { Time to } \\
\text { stop } \\
\text { pressure }\end{array}$ & $29-37$ & $\begin{array}{l}\text { If not zero, the pressure will start at the time above and } \\
\text { will be set to zero at this time, regardless of the table input } \\
\text { data. If this is zero, the start and stop tests are not made. }\end{array}$ \\
\hline Lower $\mathrm{X}$ & $38-46$ & $\begin{array}{l}\text { If this input is nonzero, the boundary zones with an } X \\
\text { smaller (inure negative) than this will be assigned a pres- } \\
\text { sure of zero. }\end{array}$ \\
\hline Upper X & $47-5 \bar{\jmath}$ & $\begin{array}{l}\text { If an } X \text { houndary test is called for by Lower } X \text { (above), the } \\
\text { boundary zones with an } X \text { greater than this will be assigned } \\
\text { a pressure of zero. }\end{array}$ \\
\hline Lower Y & $56-64$ & $\begin{array}{l}\text { If this input is nonzero, the boundary zones with a } Y \\
\text { znaller (more negative) than this will be assignerl a pres- } \\
\text { sure of zero. }\end{array}$ \\
\hline upper $\mathrm{Y}$ & $65-73$ & $\begin{array}{l}\text { If a } Y \text { boundary test is called for by l-ower } Y \text { (above), the } \\
\text { boundary zones with a } Y \text { greater than this will be assigned } \\
\text { a pressure of zero. }\end{array}$ \\
\hline
\end{tabular}


Table 3-28. J-max table, independent variable card format.

\begin{tabular}{lcl}
\hline $\begin{array}{l}\text { Field } \\
\text { use }\end{array}$ & Columns & Input and explanation \\
\hline Card name & $1-10$ & VARPJMAX \\
$\begin{array}{l}\text { Independent } \\
\text { variable in }\end{array}$ & $11-16$ & List the variables $X, Y$, or time in ascending order. Up \\
ascending & $17-22$ & to 20 variables may be entered. If more than 10 are to be \\
order & $23-28$ & used, a second card with no name or with the same name \\
& $29-34$ & \\
& $35-40$ & \\
& $41-46$ & \\
& $47-52$ & \\
& $53-58$ & \\
& $59-64$ & \\
$65-70$
\end{tabular}

Table 3-29. J-max table, pressure card format.

\begin{tabular}{lcl}
\hline $\begin{array}{l}\text { Field } \\
\text { use }\end{array}$ & Columns & Input and explanation \\
\hline Card name & $1-10$ & PRESJMAX \\
Pressure & $11-16$ & List the pressures that correspond to the independent \\
table & $17-22$ & variables. 7he code will interpolate between input points. \\
& $23-28$ & \\
& $29-34$ & \\
& $35-40$ & \\
$41-46$ & \\
$47-52$ & \\
& $53-58$ & \\
$59-64$ & \\
$65-70$
\end{tabular}


Table 3-30. Controlled J-min boundary pressure card format.

(Values on VARPJMIN and PRESJMIN cards will be used.)

\begin{tabular}{|c|c|c|}
\hline $\begin{array}{l}\text { Field } \\
\text { use }\end{array}$ & Columns & Input and explanation \\
\hline Card name & $1-10$ & PJMIN \\
\hline $\begin{array}{l}\text { P varies } \\
\text { with time }\end{array}$ & 11 & $\begin{array}{l}\text { Integer. If set to "1", the values on VARPJMn will be } \\
\text { prcblem "times". Pressure will be a function of time. }\end{array}$ \\
\hline $\begin{array}{l}\text { P varies } \\
\text { with } X\end{array}$ & 12 & $\begin{array}{l}\text { Integer. If set to "1", the values on VARPJMnN will be } \\
\text { X's. Pressure will be a function of X. }\end{array}$ \\
\hline $\begin{array}{l}\text { P varies } \\
\text { with } Y\end{array}$ & 13 & $\begin{array}{l}\text { Integer. If set to "1", the values on VARPIMIN will-be } \\
Y^{\prime} 6 . \text { Pressure will be a function of } Y \text {. }\end{array}$ \\
\hline $\begin{array}{l}\text { K-upper } \\
\text { limit }\end{array}$ & $14-16$ & $\begin{array}{l}\text { Integer. If entered, this is the upper } \mathrm{K} \text { point boundary of } \\
\text { the area to which the pressure will be applied. If not } \\
\text { entered, there will be no } \mathrm{K} \text { test. }\end{array}$ \\
\hline $\begin{array}{l}\text { K-Iower } \\
\text { limit }\end{array}$ & $17-19$ & $\begin{array}{l}\text { Integer. This is the lower } \mathrm{K} \text { boundary point to which the } \\
\text { preesure will be applied. }\end{array}$ \\
\hline $\begin{array}{l}\text { Time to } \\
\text { start } \\
\text { pressure }\end{array}$ & $20-28$ & $\begin{array}{l}\text { This is the start time of the pressure. If the "stop time" } \\
\text { is not entered, the pressure will be on at all times. }\end{array}$ \\
\hline $\begin{array}{l}\text { Time to } \\
\text { stop } \\
\text { pressure }\end{array}$ & $29-37$ & $\begin{array}{l}\text { If not zero, the pressure will start at the time above and } \\
\text { will be set to zero at this time, regardless of the table } \\
\text { input data. If this is zero, the start and stop tests are not } \\
\text { made. }\end{array}$ \\
\hline Lower X & $38-46$ & $\begin{array}{l}\text { If this input is nonzero, the boundary zones pith an } X \\
\text { smaller (more negative) than this will be assigned a pres- } \\
\text { sure of zero. }\end{array}$ \\
\hline Upper $\mathrm{X}$ & 47-55 & $\begin{array}{l}\text { If an } X \text { boundary test is called for by Lower } X \text { (aboue), the } \\
\text { boundary zones with an } X \text { greater than this will be asgigned } \\
\text { a pressure of zero. }\end{array}$ \\
\hline Lower Y & $56-64$ & $\begin{array}{l}\text { If this input is nonzero, the boundary zones with a } Y \\
\text { smaller (more negative) than this will be assigned a pres- } \\
\text { sure of zero. }\end{array}$ \\
\hline Upper Y & $65-73$ & $\begin{array}{l}\text { If a } Y \text { boundary test is called for by Lower } Y \text { (above), the } \\
\text { boundary zones with a } Y \text { greater than this will be assigned } \\
\text { a pressure of zero. }\end{array}$ \\
\hline
\end{tabular}

Table 3-31. J-min table, independent rariable card format.

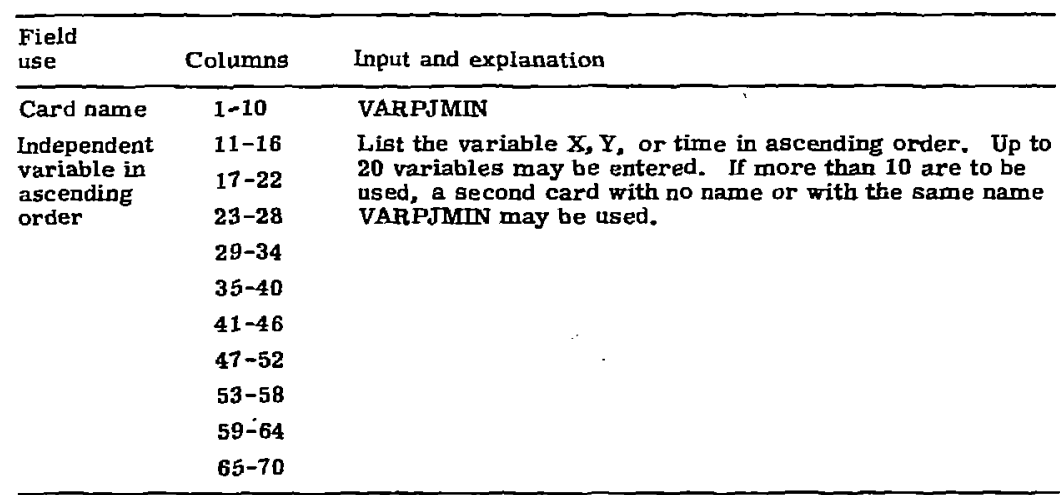


Table 3-32. J-min table, pressure card format.

\begin{tabular}{|c|c|c|}
\hline $\begin{array}{l}\text { Field } \\
\text { use }\end{array}$ & Columns & Input and explanation \\
\hline Card name & $1-10$ & PRESJMIN \\
\hline \multirow{10}{*}{$\begin{array}{l}\text { Pressure } \\
\text { table }\end{array}$} & $11-16$ & \multirow{9}{*}{$\begin{array}{l}\text { List the pressures that correspond to the independent } \\
\text { variables. The code will interpolate between input points. } \\
\text { List up to } 20 \text { pressu'es on up to two cards. }\end{array}$} \\
\hline & $17-22$ & \\
\hline & $23-28$ & \\
\hline & $29-34$ & \\
\hline & $35-40$ & \\
\hline & $41-46$ & \\
\hline & $47-52$ & \\
\hline & $53-58$ & \\
\hline & $59-64$ & \\
\hline & $65-70$ & . \\
\hline
\end{tabular}

Input

\begin{tabular}{|c|c|c|c|c|c|c|c|c|}
\hline$X, Y$, or Time & 0 & 3. & 5. & 7.5 & 9. & 10. & 15 & 1000 \\
\hline Pressure & 0 & 0 & .1 & .1 & .4 & .1 & 0 & 0 \\
\hline
\end{tabular}

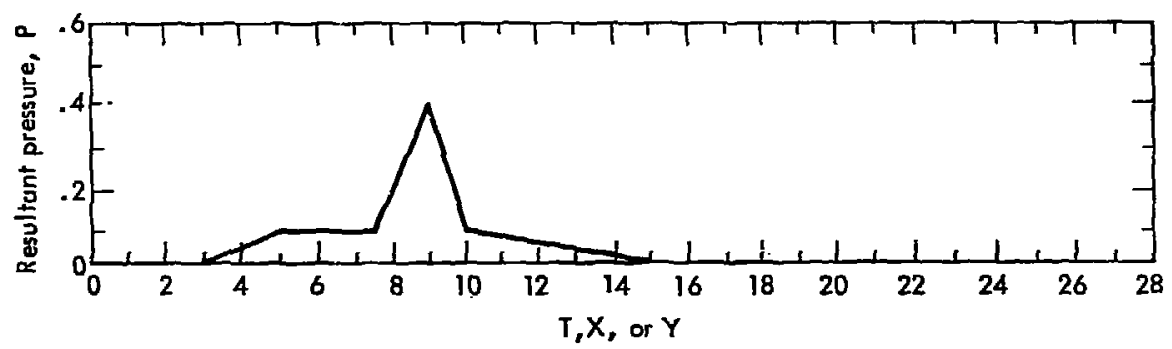

Fig. 3 7. Example of pressure profile data use.

Slide-lines are specified in "block input." However, the slide-line extension directions mag be inputted in general input, and will apply to all the slide-lines in the problem, unless overridden by block input for a particular slide-line.

The direction that is chosen is ordinarily at about a right angle to the J-max or 
$\mathrm{J}$-min surface. A numbering system is used to describe this direction to the code.

Direction " 1 " is at zero degrees, direction " 2 " is at 45 degrees, etc. (see Fig. 3-8).

An input number " 9 " allows the user to specify the extreme end points of the

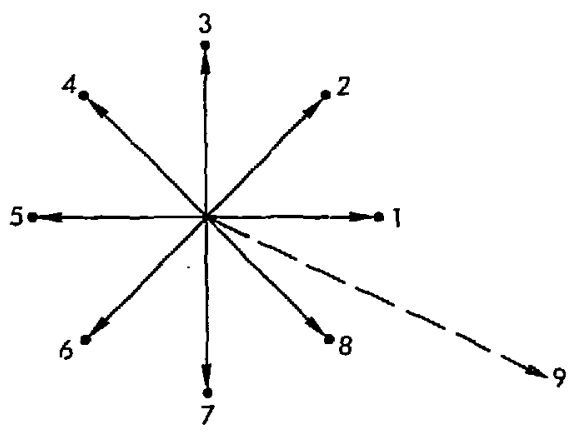

Fig. 3-8. Standard slide-line extension directions. extensions instead of the generator placing them at the standard angles. For almost all proolems, the standard angle works well even though the slide-lire is not quite at that angle. If type " 9 " is inputted, the coordinates must be supplied with a SLIDE-ANG card with the block input. (See p. 86.) If the type " $g$ " is inputted with block input the $X, Y$ coordinates should be placed out at distances like 10,000 or greater to avoid a twisting effect when the "master" $\mathrm{J}$-max or $\mathrm{J}$-min point moves. Table 3-33 shows the card format.

Fig. 3-9 illustrates the slide-line extension use.

Voids, Stand-Off, and Z-Factor

$A$ void routine may be implemented for any or all "upright" slide-lines. No provision is made for voids in the "inverted" slide line.

The void routine is called for in "block input." The void may be generated

Table 3-33. Slide-line extension angle input card format.

\begin{tabular}{lcl}
\hline $\begin{array}{l}\text { Field } \\
\text { use }\end{array}$ & Columns & Input and explanation \\
\hline $\begin{array}{l}\text { Card name } \\
\text { J-max } \\
\text { direction }\end{array}$ & 110 & $\begin{array}{l}\text { SLIDE-ANG } \\
\text { Integer. This is the direction number }(1-9) \text { that will be } \\
\text { used by the code to set up the J-max extension, This is } \\
\text { overridden by block input, if ised. }\end{array}$ \\
$\begin{array}{l}\text { J-min } \\
\text { direction }\end{array}$ & 12 & $\begin{array}{l}\text { Integer. This is the direction number }(i-9) \text { that will be } \\
\text { used by the code to set up the J-min extension. This is } \\
\text { overridden by block input, if used. }\end{array}$
\end{tabular}




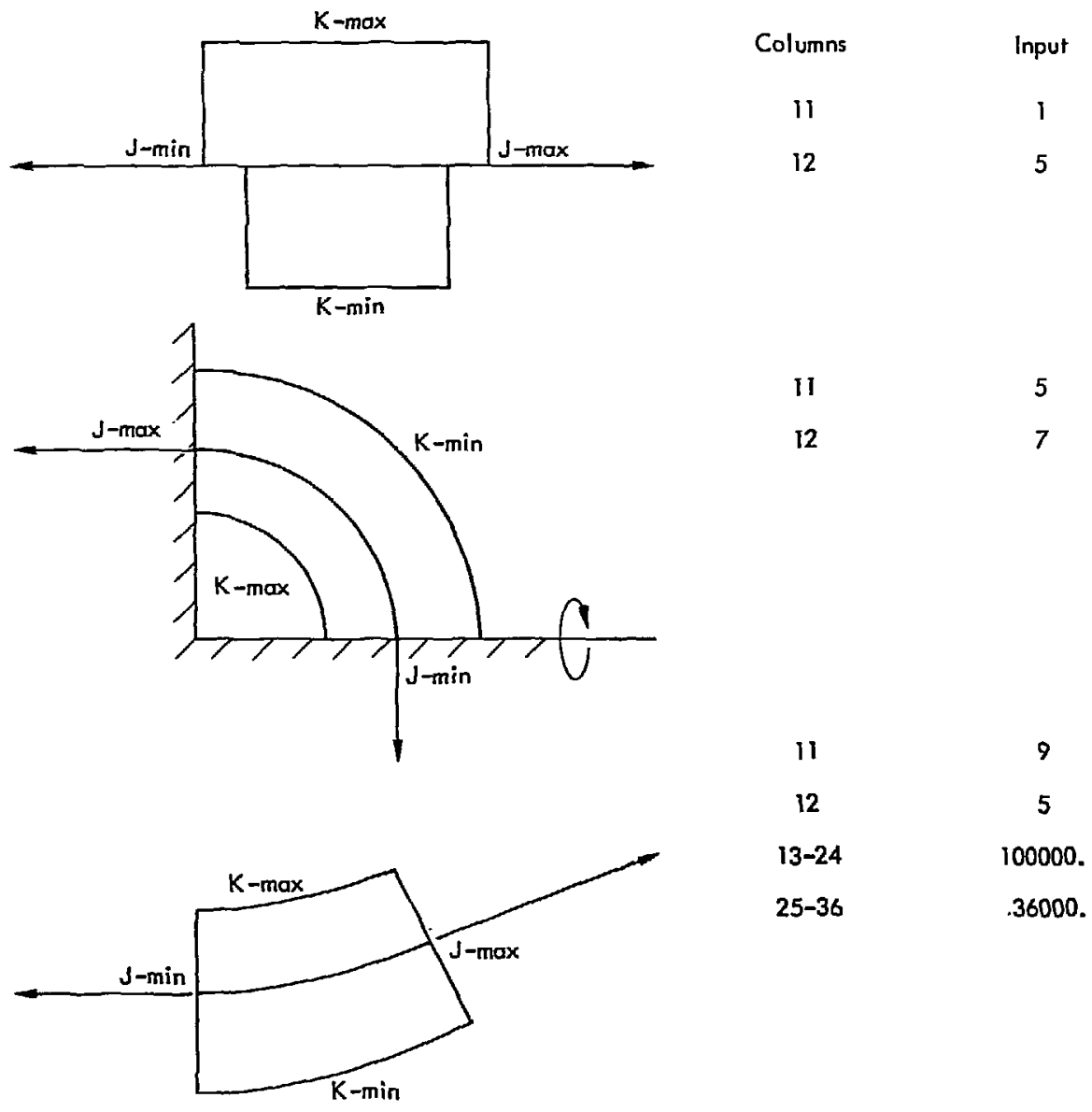

Fig. 3-9, Slide-line extension use.

either open or closed and may be allowed to open or restrained from opening.

On certain types of problems, a point one K-line away from the "slave" points may pass through the "master" side. This can be prevented by implementing the "stand-off" routine. When it is used, these points are forced to stay a - certain distance away from the master surface.
The $\mathrm{Z}$-factor ${ }^{*}$ is used in calculating the effective mass associated with a master $J, K$ point. The acceleration of this point is composed of a component perpendicular to the slide-line, and a component parallel to the slide-line. The perpendicular component includes the mass of the material beneath the slide-line while the parallel

\footnotetext{
Appendix B, I, 3, e, - vi- in Ref. 1 .
} 
component does not. The $\mathrm{Z}$-factor is calculated by first summing the masses of the zones in the $\mathrm{K}$-line on each side of the slide surface. These sums are then used to calculate the multiplier term, $\mathrm{Z}$. For the upright slide-line, the term ( $Z$-factor) is the $K+1 / 2$ mass sum. The inverted slide-line term is the same, except that the denominator is the $\mathrm{K}-1 / 2$ mass sum.

As implemented in the program, the $Y$ (radial) terms are included in the calculation of these sums in the cylindrical case, rather than as shown in Ref. 1, without the $\mathbf{Y}$ terms.

For a problem with like materials and zoning on both sides of the slide-line, this $Z$-factor is equal to 2 .

This Z-factor is calculated automatically at generation time, but may be overridden by input for special applications. Provision is made on this card for inputting these numbers. A number inputted for the upright slide line will apply to all upright slide lines. A number inputted for the inverted slide-line will apply to all inverted slide-lines. Table 3-34 shows the card format.

\section{Tied Sliding}

Regular sliding surfaces offer no resistance to lateral motion along the slideline. Sometimes it is desirable to have some or all points along a slide-line be treated as though they were general interior points for all time, or until certain criteria are met. This can be done with an upright slide-line by calling for tied sliding by specifying which points are tied and specifying the release criteria. These criteria are specified on the TIEBREAK card.

Tied sliding is calleo for in block input. It uses the void routine so void opening and closing is allowed with tied sliding. See paragraphs "Slide-Lines," page 85, and "Tied Sliding Input," page 94.

Table 3-34. Voids, stand-off and Z-factor card format.

\begin{tabular}{|c|c|c|}
\hline $\begin{array}{l}\text { Field } \\
\text { use }\end{array}$ & Columns & Input and explanation \\
\hline Card name & $1-10$ & SP-SLIDE \\
\hline $\begin{array}{l}\text { Void opening } \\
\text { control }\end{array}$ & $11-18$ & $\begin{array}{l}\text { Used with void routine only. If this card is not used, this } \\
\text { number is set to } 100000 \text {. which won't allow a void to open } \\
\text { at all. A void can close but will not reopen. If this card is } \\
\text { used and this input is left blank or set to zero, the distance } \\
\text { squared that a point must pull away from the slide "master" } \\
\text { to open a void will be set to } 0.00001 \mathrm{~cm}^{2} \text {. This is the } \\
\text { normal value for void opening. If any other number is used } \\
\text { this will be the distance squared (in } \mathrm{cm}^{2} \text { ) to open a void at } \\
\text { a point. }\end{array}$ \\
\hline $\begin{array}{l}\text { Stand-off } \\
\text { distance }\end{array}$ & $19-26$ & $\begin{array}{l}\text { If not zero, the stand-off routines will be used. This numbe } \\
\text { is the distance (in cm) that the next } \mathrm{K}-\text { line will be forced to } \\
\text { stay away from the master line. The number that is often } \\
\text { used is about } 1 / 10 \text { th of the usual zone thickmess. }\end{array}$ \\
\hline $\begin{array}{l}\text { Z-factor } \\
\text { upright }\end{array}$ & $27-34$ & $\begin{array}{l}\text { If not zero, the } \mathrm{Z} \text {-factor for all "upright" slide-lines will } \\
\text { be this number. }\end{array}$ \\
\hline $\begin{array}{l}\text { Z-factor } \\
\text { inverted }\end{array}$ & $35-42$ & $\begin{array}{l}\text { If not zero, the } Z \text {-factor for all "inverted" slide-lines will } \\
\text { be this number. }\end{array}$ \\
\hline
\end{tabular}


The points that are to be tied ("master" and "slave"), must meet at generation time.

If any points of a particular slide line are not tied at generation time, "block boundary" input must specify which points are tied. In that case, the closed void (number 2) is called for with block input, and tied sliding (number 4) is inputted for the tied points with boundary input. If part of the line is initially open, a " 3 " is used with the block input. The status numbers are explained in the paragraphs mentioned above. Table 3-35 shows the card format.

Material and Material-Related Input Provision has been made in the program for 60 equations of state. The practice has been to use numbers 1 through 9 for high explosives and numbers 10 through 60 for non-HE materials.

The equation forms are listed below by letter. Then the equation-of-state numbers are listed along with its form, its coefficients (if $\mathrm{HE}$ ) and any special information. No non-HE coefficients are included. The user must input the coefficients for all non-HE equations of state and may change the $\mathrm{HE}$ coefficients if desired. Longer forms may be used by leaving appropriate coefficients at zero.

\section{Form A (HE,Wilkins Form)-}

$P=a \eta^{a}+b\left(1-\frac{\omega}{\bar{R}} \eta\right) e^{-\frac{R}{\eta}}+w \eta \epsilon$ where $\eta=\frac{1}{v}$ and $\epsilon$ is energy. In HEMP input terms the equation is written as: $P=C_{1} \eta^{C_{2}}+C_{3}\left(1-C_{4} \eta\right) e^{\frac{C_{5}}{\eta}}$

$$
+C_{6} \eta \in \text { if } v>C_{8^{2}}, P^{n+1}=P^{n} \text {. }
$$

For thesound speed calculations a representative garama-1 is put in $C_{7}$.

\section{Form B (Gamma Law HE)-}

$$
P=(\gamma-1)(1+\mu) \epsilon
$$

or

$$
P=C_{1}(1+\mu) \epsilon
$$

where

$$
\mu=\frac{1}{v}-1 \text { and } \epsilon \text { is energy }
$$

Form C (HE, JWL Form) (Bee Table 3-36) -

$$
\begin{aligned}
P=A & \left(1-\frac{\omega}{R_{1} V}\right) e^{-R_{1} V} \\
& +B\left(1-\frac{\omega}{R_{2} v}\right) e^{-R_{2} V}+\omega \eta \epsilon
\end{aligned}
$$

where

$$
\eta=\frac{1}{\nabla} \text { and } \epsilon \text { is energy. }
$$

in HEMP input terms,

$$
\begin{aligned}
P=C_{1} & \left(1-\frac{C_{3}}{V}\right) e^{-C_{2} v} \\
& +C_{4}\left(1-\frac{C_{6}}{V}\right) e^{-C_{5} v}+C_{7} \eta \epsilon
\end{aligned}
$$

if $\mathrm{V}>\mathrm{C}_{8}, \mathrm{P}^{\mathrm{n}+1}=\mathrm{P}^{\mathrm{n}}$.

For the sound speed calculation, a representative gamma-1 is put in $\mathrm{C}_{9}$.

Form D-Inputting a form $D$ equationof-state number causes subroutine calls to be made to entry point EQSTHE in CZNLAA. The user can supply any HE form there. (See "Equation-of-State" paragraph, page 12 and "Equation-ofState Numbering System paragraph", page 20. 
Table 3-35. Tied sliding card fortaat.

\begin{tabular}{|c|c|c|}
\hline $\begin{array}{l}\text { Field } \\
\text { use }\end{array}$ & Columns & Input and explanation \\
\hline Card name & $1-10$ & TIEBREAK \\
\hline OsS test & $11-18$ & $\begin{array}{l}\text { If the OSS (octagonal shear stress) is greater than this } \\
\text { number, the point being tested will be allowed to slide. If } \\
\text { zero or blank, this test is not made. }\end{array}$ \\
\hline IPD test & $19-26$ & $\begin{array}{l}\text { The P - S-max and this test are applied in an "or" test todeter- } \\
\text { mine if the point is to be released. If the P - S-max input is } \\
\text { not zero, both tests are used. If the IPD (internal plastic } \\
\text { distortion) is greater than this value, the tied point wil be } \\
\text { reieased. Seting this to a large positive value will frevent } \\
\text { a point from being released by this IPD test and, in efrect, } \\
\text { only the } P \text { - S-max test will cause release. }\end{array}$ \\
\hline$P$ - S-max & $27-34$ & $\begin{array}{l}\text { If this is not zero, both the } I P D \text { and the } P-S \text {-max tests are } \\
\text { applied. } P \text { - } S-\text { max is not normally calculated but is auto- } \\
\text { matically called for when this test on tie breaking is used. } \\
\text { Setting this input number to a targe negative value will pre- } \\
\text { vent a point irom being released by this } P \text { - S-max test } \\
\text { and, in effect, only the IPD test will cause release. Setting } \\
\text { both values large will cause the points to be tied for all } \\
\text { time. ( } P \text { minus } S-m a x \text { is the pressure minus the maximum } \\
\text { of } S_{1}, S_{2} \text {, and } S_{3} . \text { ) }\end{array}$ \\
\hline $\begin{array}{l}\text { Time to } \\
\text { begin } \\
\text { relcase } \\
\text { on velocity } \\
\text { test. }\end{array}$ & $35-42$ & $\begin{array}{l}\text { If this is not zero, the routine that releases points along the } \\
\text { slide line at a certain time determined by a velocity (below) } \\
\text { will be activated. This is the time to start the release. }\end{array}$ \\
\hline Velocity & $43-50$ & $\begin{array}{l}\text { This is the release velocity (the velocity that the crack is } \\
\text { forming). }\end{array}$ \\
\hline $\mathrm{X}$ or start & $51-58$ & $\begin{array}{l}\text { This is the } X \text { coordinate of the start of the release line. } \\
\text { It is used with } Y \text { and the velocities to calculate release } \\
\text { times for all tied points. }\end{array}$ \\
\hline$Y$ or start & $59-66$ & This is the $Y$ coordinate of the start of the release line. \\
\hline \multirow[t]{2}{*}{$\begin{array}{l}\text { Release } \\
\text { fraction }\end{array}$} & $67-74$ & $\begin{array}{l}\text { If this is zero, tied points when released by any of the } \\
\text { criteria wiil be released at once. If not zero, the } \\
\text { acceleration on the sliding side will be gradually applied. } \\
\text { The number should be about equal to } 1-1 / 2 \text { times the distance } \\
\text { between tied points, divided by the release velocity. }\end{array}$ \\
\hline & & $\begin{array}{l}\text { The use of this option (release (raction) allows the user to } \\
\text { allow the velocity of a released point to build up over a } \\
\text { period of time. By setting it as described above, the point } \\
\text { will be fully released about the same time that the next } \\
\text { point in the slide line is released. This option more closely } \\
\text { simulates a continuous medium and may prevent local } \\
\text { instabilities. }\end{array}$ \\
\hline
\end{tabular}




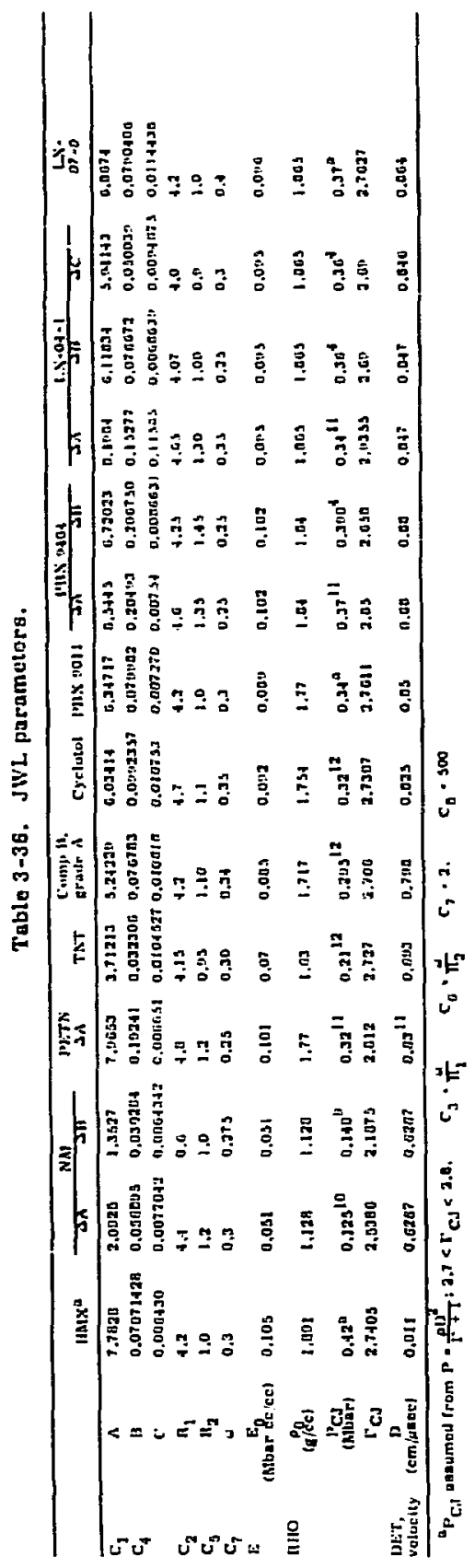




$$
\begin{aligned}
& \text { Form E- } \\
& P=C_{1} \mu+C_{2} \mu^{2}+\left(C_{3}+C_{4} \mu\right) \epsilon ; \\
& \text { if } \mu<0, C_{2} \mu^{2} \text { is set to zero. }
\end{aligned}
$$

Here.

$$
\mu=\frac{1}{v}-1, \epsilon \text { is energy. }
$$

\section{Form F-}

$P=C_{1} \mu+C_{2} \mu^{2}$;

if $\mu<0, C_{2}{ }^{2}$ is set to zero.

\section{Form G-}

$\mathrm{P}=\mathrm{C}_{1} \mu+\mathrm{C}_{2} \mu^{2}+\mathrm{C}_{3} \mu^{3}+\left(\mathrm{C}_{4}+\mathrm{C}_{5} \mu\right) \epsilon_{;}$

if $\mu<0, \mathrm{C}_{2} \mu^{2}$ is set to zero.

Form H-

$P=C_{1} \mu+C_{2} \mu^{2}+C_{3} \mu^{3}$

if $\mu<0, C_{2} \mu^{2}$ is set to zero.

$$
\begin{gathered}
\text { Form J- } \\
P=C_{1}(I+\mu) \epsilon .
\end{gathered}
$$

$$
\begin{aligned}
\text { Form K- } \\
\begin{aligned}
P= & C_{1}+C_{2} \mu+C_{3} \mu^{2}+C_{4} \mu^{3} \\
& +\left(C_{5}+C_{6} \mu+C_{7} \mu^{2}\right) \epsilon ;
\end{aligned}
\end{aligned}
$$

if $\mu<0, C_{3} \mu^{2}$ and $C_{7} \mu^{2}$ are set to zero.

\section{Form L-These equations of state} call dummy entry points in the CZNLAA subroutine. See the write-up of form D.

Form M-Multiphase. See the writeup of equation-of-state 59.

Table 3-37 lists the 60 equations of state, their form, material (for some
HE's), the coefficients in the code, and the material-related properties. The burn velocity for HE's is not carried or used with material input but is listed as a convenience to the user. It is needed in "block input" for mosr tie burn schemes.

$C_{1}$ through $C_{12}$ are the various coefficients. ELMU is the shear modulus. YELT is the yield in tension, YELC is the yield in compression. RHO is the density. $E$ is the initial energy. $V$ is the initial relative volume. PMIN is the minimum pressure that will be allowed, $Q_{A}$ and $Q_{B}$ are the $Q$ coefficients. CANS is the $C_{a}$ of the Navier-Stokes $Q$. CSNS is the $C_{\mathbf{g}}$ of the Navier-Stokes Q. YNS is the Naviar-Stokes "yield" number.

BETA is the number used in calculating the burn for HE's (for Gamma-Law HE's, it is set to Gamma + 1). CAQ is the coefficient for the triangle or rotational $Q$. The units of ELMU, YELT and YELC are megabars.

Equations of state 10 through 60 have coefficients of zero; $V, Q_{B^{\prime}}$, and RHO for these equations are set to 1. PMIN is set to -0.01 and $Q_{A}$ is set to 4. All of the other input numbers are preset to zero. Table 3-38 lists the form numbers.

Equation-of-state number 59 is a five-part multiphase equation of state. It uses the five general equations of state 35 through 39. All material-related properties are tnputted using the number " 59 " except the coefficients to be used for the fivo: phases and PMIN, which must be inputted for numbers 35 through 39 bit need not be inputted for 59. The phase change is a function of $\mu$ whtch is equal to $1 / N-1$. 
Table 3-37. HE equation of state.

\begin{tabular}{|c|c|c|c|c|c|c|c|c|c|c|}
\hline \multirow{2}{*}{\multicolumn{2}{|c|}{ Number }} & \multicolumn{9}{|c|}{ HE material } \\
\hline & & 1 & 2 & 3 & 4 & 5 & 6 & 7 & 8 & 9 \\
\hline & Form & A & $\mathbf{B}$ & $\mathbf{B}$ & $\mathrm{C}(\mathrm{JWL})$ & C(JWL) & A & $\mathrm{D}$ & $\mathbf{D}$ & $\mathbf{D}$ \\
\hline & Material & 9404 & Cyclotol & Comp B & - & - & $\mathrm{LX}-04$ & -- & - & - \\
\hline \multirow{27}{*}{ 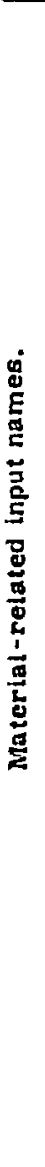 } & $\mathrm{Cl}$ & -0.0034844 & 1.85 & 1.77 & $0^{*}$ & \multicolumn{3}{|c|}{$0^{7}-0.0008335$} & & \\
\hline & $\mathrm{Cz}$ & +4. & & & & \multicolumn{3}{|c|}{4.} & & \\
\hline & C3 & 6.43536 & & & & \multicolumn{3}{|c|}{5.943} & & \\
\hline & $\mathrm{C}_{4}$ & 0.0875 & & & & \multicolumn{3}{|c|}{0.1} & & \\
\hline & $\mathrm{Cs}$ & 4. & & & & \multicolumn{3}{|c|}{4.} & & \\
\hline & C6 & 0.35 & & & & \multicolumn{3}{|c|}{0.4} & & \\
\hline & $\mathrm{C7}$ & 2. & & & & \multicolumn{2}{|r|}{2.} & & & \\
\hline & $\mathrm{Cs}$ & 100. & & & & \multicolumn{2}{|c|}{100.} & & & \\
\hline & $\mathrm{Cg}$ & 2. & & & & \multirow{2}{*}{\multicolumn{2}{|c|}{2.}} & & & \\
\hline & $\mathrm{ClO}$ & & & & & & & & & \\
\hline & \multicolumn{10}{|l|}{ Cil } \\
\hline & \multicolumn{10}{|l|}{$\mathrm{CI2}$} \\
\hline & ELMU & 0 & 0 & 0 & D & 0 & 0 & 0 & $\mathbf{0}$ & 0 \\
\hline & YELC & 0 & 0 & $\mathbf{0}$ & o & o & o & 0 & 0 & 0 \\
\hline & YELT & $\mathbf{0}$ & 0 & 0 & 0 & 0 & 0 & 0 & $\mathbf{0}$ & 0 \\
\hline & RHO & 1.84 & 1.755 & 1.715 & 1. & 1. & 1.865 & 1. & 1. & 1. \\
\hline & $\mathbf{E}$ & 0.139852 & 0.0836 & 0.082 & o & 0 & 0.1126 & 0 & 0 & $\mathbf{0}$ \\
\hline & v & 1. & 1. & 1. & 1. & 1. & 1. & 1. & 1. & 1. \\
\hline & PMIN & 0 & 0 & 0 & 0 & 0 & 0 & 0 & 0 & 0 \\
\hline & $Q_{A}$ & 4. & 4. & 4. & 4. & 4. & 4. & 4. & 4. & 4. \\
\hline & $\mathbf{Q}_{\mathbf{B}}$ & 1. & 1. & 1. & 1. & 1. & 1. & 1. & 1. & 1. \\
\hline & CANS & o & o & 0 & 0 & 0 & 0 & 0 & 0 & 0 \\
\hline & CSNS & 0 & 0 & 0 & 0 & o & 0 & 0 & 0 & 0 \\
\hline & YNS & 0 & 0 & $\mathbf{0}$ & o & 0 & 0 & 0 & 0 & $\mathbf{0}$ \\
\hline & CAQ & 0 & 0 & 0 & 0 & 0 & 0 & 0 & 0 & 0 \\
\hline & BETA & 3.658 & 3.85 & 3.77 & 0 & 0 & 3.726 & 0 & 0 & 0 \\
\hline & $\begin{array}{l}\text { Burn } \\
\text { velocity }\end{array}$ & 0.88 & 0.83 & 0.8 & & & 0.848 & & & \\
\hline
\end{tabular}

Sce Table 3-36 (JWL materials).

$\mu$ is tested against the equation-of-state input values for number 50.

If $\mu<C_{1}$, use equation-of-state number 35 .

If $C_{1}<\mu<C_{\eta}$, use equation-of-gtate number 36.
If $\mathrm{C}_{2}<\mu<\mathrm{C}_{3}$, use equation-of-state number 37.

If $C_{3}<\mu<C_{4}$, use equation-of-state number 38 .

If $\mu>C_{4}$, use equation-of-state number 39. 
Table 3-38. Non-HE material form number table.

\begin{tabular}{ll}
\hline Form & Number \\
\hline $\mathrm{E}$ & $10,11,12,13,14,15$ \\
$\mathrm{~F}$ & $16,17,18,19,20$ \\
$\mathrm{G}$ & $21,22,23,24,25$ \\
$\mathrm{H}$ & $26,27,28,29,30$ \\
$\mathrm{~J}$ & $31,32,33,34$ \\
$\mathrm{~K}$ & $35,36,37,38,39$, and 40 \\
& (40 allows an energy leak or sink term, see below) \\
L & Dummy equation-of-state calls \\
& 52 calls EQSTA in CZNLAA \\
& 53 calls EQSTB in CZNLAA \\
& 54 calls EQSTC in CZNLAA \\
& 55 calls EQST D in CZNLAA \\
$M$ & 59. See the write-up on 59, above. \\
& Number 60 can be used at present time to make a form "inert." \\
& See the write-in below. \\
& All other numbers arE not used.
\end{tabular}

Table 3-39. Material-related input cards.

\begin{tabular}{|c|c|c|}
\hline $\begin{array}{l}\text { Field } \\
\text { use }\end{array}$ & Columns & Input and explanation \\
\hline Card name & $1-8$ & MATINPUT \\
\hline $\begin{array}{l}\text { Material } \\
\text { number }\end{array}$ & $9-10$ & $\begin{array}{l}\text { Integer. The material number of the values that are to be } \\
\text { inputted or changed (right-adjusted). }\end{array}$ \\
\hline $\begin{array}{l}\text { Variable } \\
\text { name }\end{array}$ & $11-14$ & $\begin{array}{l}\text { Any of the names in the vocabulary list. it must be left- } \\
\text { adjusted. }\end{array}$ \\
\hline Value & $15-24$ & The value of the input. \\
\hline Name & $25-28$ & \\
\hline Value & $29-38$ & \\
\hline Nañse & $39-42$ & \\
\hline Value & $43-52$ & \\
\hline Name & $53-56$ & \\
\hline Value & $57-66$ & \\
\hline Name & $67-70$ & \\
\hline Value & $71-80$ & \\
\hline
\end{tabular}

The current equation-of -state number for the various phases is printed out in the "F" column.
Equation of state 60 sets all calculated zonal quantities to zero except $V$. It may be used occasionally in an active problem 
to make a zone "inert." Equation of state $\mathbf{4 0}$ is of the general form and may be used just like the other general equations of state 35 through 39 . To implement the leaksink term, put a nonzero start time in $C_{8}$. After that time energy will be leaked or added according to the equation Eleaksink $=\left(\left(C_{9}+C_{10} *\right.\right.$ Time $) \neq$ Delta- $\left.T\right)$.

Material-Related Input Cards (see Table 3-39)

The following is the material input vocabulary:

$$
\begin{aligned}
& \mathrm{C} 1 \\
& \mathrm{C2} \\
& \mathrm{C} 3 \\
& \mathrm{C} \\
& \mathrm{C} 5 \\
& \mathrm{C} 6 \\
& \mathrm{C} \\
& \mathrm{C} 8 \\
& \mathrm{C} 9 \\
& \mathrm{C} 10 \\
& \mathrm{C} 11 \\
& \mathrm{C} 12
\end{aligned}
$$

Coefficiest input of the equations of state

ELMU - Shear modulus

YELT - Yield in tension

YELC - Yield in compression

$Q_{A} \quad$ - A term of $Q$ calculations

$Q_{B} \quad$ - B term of $Q$ calculations

$C A Q$ - Angle $Q$ coefficient

V - Volume (relative)

E - Energy

RHO - Reference density

PMIN - Minimum pressure

CANS - Ca Navier-Stokes $Q$ coefficient

CSNS - $C_{5}$ Navier-Stokes $Q$ coefficient

YNS - Yield Navier-Stokes Q.

BETA - Equivalent to gamma + I.

The vocabulary can be entered in any order and blank fields are allowed.
Cards may be added with or without the card name but all cards must include a material number in columns 9-10.

"Q" Input (Artificial Viscosity)

Unless otherwise changed by input, the HEMP program will automatically utilize the linear-quadratic $Q$ for all zones. The standard nronbers for $Q_{A}$ and $Q_{B}$ will be used unless changed by materialrelated input cards. (The standard numbers for $Q_{A}$ and $Q_{B}$ are 4. and 1. respectively. )

The Navier-Stokes $Q$ is as written in Ref. 1 except that a limiting condition similar to the elastic yield condition has been added. If no limit is desired, putting a one (i.) in YNS will effectively remove the test. $C_{a}$ is entered as CANS and $C_{s}$ is entered as CSNS. The values to be used may depend on the problem but a CANS of .125 and a CSNS of .25 have been utilized. Experience with a particular problem may dictate adjustments of these values.

The triangular $Q$ input is materialrelated. To use this $Q$, the input value for the term " $a$ " is entered as CAQ on a material-related input card. A value of about . 001 has been used; however, the user may find that other values may be used to advantage in certain cases.

The rotational $Q$ uses the same input name CAQ to input the material-related constant. A value of about . 1 to . 5 has Deen employed. In addition, the rotational $Q$ flag word on the QCONTROL card must be set to non-zero. The rolational $Q$ and the triangular $Q$ may not both be used in the same problem.

An upper limit of the value of the Linear-Quadratic $Q$ is used to stop a problem that has become unstable. This 
Table 3-40. $Q$ input card format.

\begin{tabular}{|c|c|c|}
\hline $\begin{array}{l}\text { Field } \\
\text { use }\end{array}$ & Columns & Input and explanation \\
\hline Card name & $1-10$ & QCONTROL \\
\hline $\begin{array}{l}\text { Rotational Q } \\
\text { flag }\end{array}$ & $11-18$ & $\begin{array}{l}\text { If set to non-zero, the Ro'ational } Q \text { will be used for sny } \\
\text { material for which a CAQ has been entered (instead of } \\
\text { the Triangular } Q \text { ). }\end{array}$ \\
\hline Q-stop & $19-26$ & $\begin{array}{l}\text { If zero or blank, the problem will terminate when the } Q \\
\text { reaches } 100 \text {. If not zero, the problem will stop when the } \\
Q \text { reaches that value. }\end{array}$ \\
\hline Q-max & $27-34$ & $\begin{array}{l}\text { If zero or blank, the maximum } Q \text { that will be allowed will } \\
\text { be } 100,000 \text {. If not zero the maximum will be that number. } \\
\text { The } Q-\text { stop and } Q \text {-max tests are applied only on the linear- } \\
\text { quadratic } Q \text {. }\end{array}$ \\
\hline
\end{tabular}

Table 3-41. Special calculations card format.

\begin{tabular}{|c|c|c|}
\hline $\begin{array}{l}\text { Field } \\
\text { use }\end{array}$ & Columns & Input and explanation \\
\hline Card name & $1-10$ & CALC-OPT \\
\hline OSS & $11-13$ & $\begin{array}{l}\text { If not zero, the OSS (Octagonal Shear Stress) calculation } \\
\text { will be bypassed. If zero or blank, the calculation will be } \\
\text { done, (OSS is stored in variable } 27 \text { ). }\end{array}$ \\
\hline$P-S-\max$ & $14-16$ & $\begin{array}{l}\text { If not zero, pressure minus the maximum of } \mathrm{S}_{1}, \mathrm{~S}_{2} \text {, and } \\
\mathrm{S}_{3} \text { is stored in variable } 28 \text {. If zero or blank, it will not be } \\
\text { calculated unless "tied sliding" has been called for. }\end{array}$ \\
\hline IPD & $17-19$ & $\begin{array}{l}\text { If not zero the IPD (Internal Plastic Distortion) calculation } \\
\text { will be bypassed. If zero, the IPD calculation will be done. } \\
\text { (Uses variable } 29 . \text { ) }\end{array}$ \\
\hline$s_{1}, s_{2}, s_{3}$ & $20-22$ & $\begin{array}{l}\text { If not zero, the } S_{1}, S_{2}, S_{3} \text { calculation will be bypassed. } \\
\text { If zero, the } S_{1}, S_{2}, S_{3} \text { will be done. These terms are } \\
\text { needed to calculate } P^{-}-\mathrm{S} \text {-max. The only reason to bypass } \\
\text { this calculation would be to save computer tirule because } \\
\text { no grid variable storage is used. }\end{array}$ \\
\hline Lambda & $23-25$ & $\begin{array}{l}\text { If not zero, the Lambda calculation will be done. Lambda } \\
\text { is a scalar plastic flow-rate parameter (Ref. } 1 \text { equations } \\
\text { of state, plastic flow region). If zero, the calculation will } \\
\text { not be done. This calculation uses variables } 25 \text { through } 28 \text {, }\end{array}$ \\
\hline $\begin{array}{l}\text { X-zero and } \\
\text { Y-zero }\end{array}$ & $26-28$ & $\begin{array}{l}\text { If zero, the initial } X \text { and } X \text { coordinate values for all } \mathrm{J}, \mathrm{K} \\
\text { points will be saved in variables } 25 \text { and } 26 \text {. If not zero, } \\
\text { they will not be saved. }\end{array}$ \\
\hline
\end{tabular}

prevents wasted machine time and usually stops a problem shortly after it has gotten into trouble. The stardard number that it is automatically set to is 100 (arbitrarily). It may be changeo by input (QCONTROL card). Some problems may have legitimate $Q^{\prime}$ 's this high, so the value must be raised by input. (See Table 3-40.)

In certain cases, the user may wish to set an upper limit that the LinearQuadratic $Q$ may reach (but continue 
running). 'ithe Q-max option on the QCONTROL card allows this. Unless inputted, it is automatically set to a huge value (larger than $Q$ stop) so that it has no effect. To have an effect, it must be set lower than the value in $Q$ stop, and the $Q$ must reach that value. Care should be exercised in employing this technigue.

Special Calculations (see Table 3-41)

A number of special calculations are optional. In general, these are not used in the usual problem but have been included because of their usefulness for special purposes or for outputting. Because some of these calculations use the bame storage location, there are restrictions on their concurrent use. The "tied sliding" routine, if used, does require certain of these calculations. If used, certain of these options store quantiries in variables 25 through 29 of the HEMP grid.

Table 3-42 shows the uses of grid variables 25 through 32. An " $X$ " means the variable is used unless bypassed by input. A. "O" means that it is used if called for.

Gravity (see Table 3-43)

The gravity routine not only applies the gravity force to the grid but calculates

Table 3-42. Uses of grid variables 25 through 32 .

\begin{tabular}{|c|c|c|c|c|c|}
\hline & $\begin{array}{l}\mathrm{X}, \mathrm{Y} \\
\mathrm{zero}\end{array}$ & oss & IPD & P-S-max & Lambda \\
\hline Variable 25 & $\mathrm{x}$ & & & & 0 \\
\hline Variable 26 & $\mathrm{x}$ & & & & 0 \\
\hline Variable 27 & & $\mathrm{x}$ & & & 0 \\
\hline Variable 28 & & & & 0 & 0 \\
\hline Variable 29 & & & $\mathrm{x}$ & & \\
\hline \multicolumn{6}{|l|}{ Variable 30} \\
\hline \multicolumn{6}{|l|}{ Vartabl = 31} \\
\hline Variable 32 & & & & & \\
\hline
\end{tabular}

Table 3-43. Gravity card format.

\begin{tabular}{|c|c|c|}
\hline $\begin{array}{l}\text { Field } \\
\text { use }\end{array}$ & Columns & Input and explanation \\
\hline Card name & $1-10$ & GRnVITY \\
\hline Gravity & $11-17$ & The acceleration in $\mathrm{cm} / \mu \mathrm{sec}^{2}$. \\
\hline $\operatorname{Sin} \phi$ & $18-24$ & $\begin{array}{l}\text { The sin of the angle between a line running directly to the } \\
\text { right and the line representing a flat "water plane" surface } \\
\text { This should be zero if the gravity is directed in the }-Y \\
\text { direction. }\end{array}$ \\
\hline $\operatorname{Cos} \phi$ & $25-31$ & $\begin{array}{l}\text { The cos of the above described angle. This should be one } \\
\text { (1.), if the gravity is directly in the - } Y \text { direction }\end{array}$ \\
\hline Bulk Modulus & $32-38$ & $\begin{array}{l}\text { The equation of state used for the material must be } \\
P=K_{t h} \text { The } K \text { is also entered here. }\end{array}$ \\
\hline $\mathrm{X} 1$ & $39-45$ & Enter the $X$ of one end of the "water plane surface" line. \\
\hline $\mathbf{Y} 1$ & $46-52$ & Enter the $Y$ that goes with $X 1$. \\
\hline $\mathbf{X 2}$ & $53-59$ & Enter the $X$ of the other end of the surface line. \\
\hline Y2 & $50-66$ & Enter the $\mathrm{Y}$ that goes with $\mathrm{X} 2$. \\
\hline Delta-Z & $67-73$ & Enter the zone thickness in the gravity direction. \\
\hline Y offset & $74-80$ & $\begin{array}{l}\text { Enter the distance of offset negative } Y^{\prime} \text { 's below the } X \text { axis. } \\
\text { Zones below will be assigned equation of state } 60 \text { and a } \\
\text { density of } 1 \times 10^{-6} \text {. }\end{array}$ \\
\hline
\end{tabular}


the initial V so that the gravity is in balance with the pressure at start time. A rectangular grid (plane case) is generated. It must have equal thickness zoning in the downward direction. The grid can be oriented at any angle. Provision is also made to offset any negative $Y$ 's by an additional distance so that sloping boundaries can be set up. The negative zones are offset, the equation of state is automatically changed to number 60 (inert) and their density is set at $1 \times 10^{-6}$. These zones are, in effect, removed from the prublem so that a boundary sloping through the original grid is established. If this sloping boundary is utilized, the user should also call for the XYQUAD option that keeps $\mathrm{Y}$ at zero if it is at zero.

Two examples are shown in Fig. 3-10 following the card format explanation.

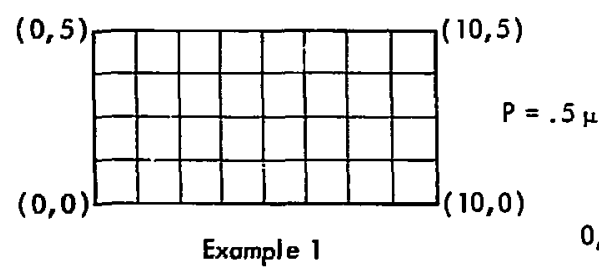

Example 1

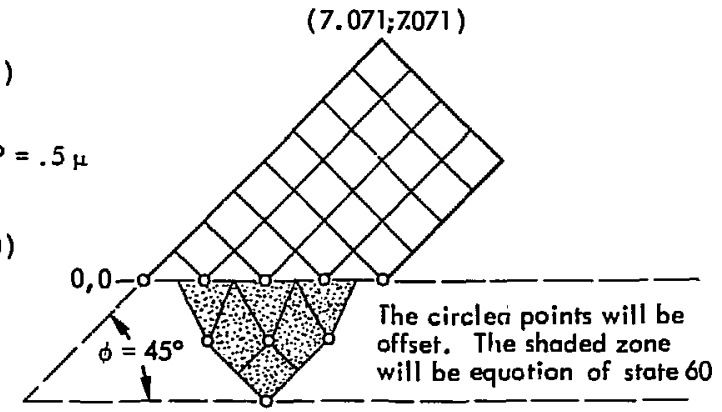

$(3.5355 ;-3.5355)$

\begin{tabular}{l|c|c|c}
\hline \multicolumn{1}{c|}{ Field } & Columns & $\begin{array}{c}\text { Input } \\
\text { Example 1 }\end{array}$ & $\begin{array}{c}\text { Input } \\
\text { Example 2 }\end{array}$ \\
\hline Card name & $1-10$ & Grovity & Grovity \\
Gravity & $11-17$ & 9.8 E-10 & 9.8 E-10 \\
Sin $\phi$ & $18-24$ & 0. & .707 \\
Cos $\phi$ & $19-31$ & 1. & .707 \\
Bulk modulus & $32-38$ & .5 & .5 \\
X1 & $39-45$ & 0. & 0. \\
Y1 & $46-52$ & 5. & 0. \\
X2 & $53-59$ & 10. & 7.071 \\
Y2 & $60-66$ & 5. & 7.071 \\
Del ta Z & $67-73$ & 1.25 & 1.25 \\
Y OFF & $74-80$ & - & 100. \\
\hline
\end{tabular}

Fig. 3-10. Examples of gravity input. 
Fini Card (see Table 3-44)

This card must be the last card in the general input group.

\section{Block Input Section Discussion}

Block input includes those items that are related to the regions within the block. These items include boundary coordinates (Cartesian or Polar), zone counts, material selection, volume, energy, density, velocity, and $\mathrm{HE}$ parameters.

Block input also is used to call for and describe slide-lines and to call for $\mathrm{K}-\mathrm{by}-\mathrm{K}$ and point-by-point input for the $K{ }^{\prime} s$ within the block.

\section{K-Zoning Input}

$A$ card that must be included in every block is the $\mathrm{K}-\mathrm{z}$ nne count card. (See Table 3-45.)
J-Zone Input (see Tables $3-46$ through 3-49)

The number of zones in the $J$ direction for each region must be inputted. If the lower- $K$ boundary of the block is zoned in the same manner as the higher-K boundary, the lower- $K$ input need not be specified; the generator will accept the higher-K zoning for both surfaces. Cards with blank data need not be included in the block.

If both the higher- $K$ and lower $-K$ zoning is specified, the sum of all zones in the regions of each must be equal.

The total number of $J$-zones in a $K$-line of a block must be less than (by one or more) the number entered in the Max-J field on the GEN ERAL card..

There can be up to eight regions in a block. Each region requires a J-zone

Table 3-44. Fini card format.

\begin{tabular}{lll}
\hline $\begin{array}{l}\text { Field } \\
\text { use }\end{array}$ & Columns & Input and explanation \\
\hline $\begin{array}{l}\text { Card name } \\
\text { Comments }\end{array}$ & $1-10$ & FINI \\
& $11-80$ & $\begin{array}{l}\text { The user may put anything in these columns. They are } \\
\text { ignored by the generator. It is useful in card handling to } \\
\text { have the words "Of General" in these columns. }\end{array}$ \\
\hline
\end{tabular}

Table 3-45. K-zone count card format.

\begin{tabular}{lcl}
\hline $\begin{array}{l}\text { Field } \\
\text { use }\end{array}$ & Columns & Iaput and Explanation \\
\hline $\begin{array}{l}\text { Card name } \\
\begin{array}{l}\text { Number of } \\
\text { K-zones }\end{array}\end{array}$ & $11-10$ & NKZONESBLK \\
\end{tabular}

The block shown would have a K-zone count of 3 .

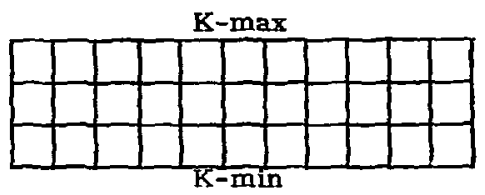


Table 3-46. J-zoning Cartesian, higher-K boundary card format.

\begin{tabular}{|c|c|c|}
\hline $\begin{array}{l}\text { Field } \\
\text { use }\end{array}$ & Columns & Input and Explanation \\
\hline Card name & $1-10$ & JZOUTC \\
\hline \multirow[t]{2}{*}{$\begin{array}{l}\text { J-min region } \\
\text { zoning } \\
\text { Cartesian } \\
\text { (higher-K) }\end{array}$} & $11-13$ & $\begin{array}{l}\text { Integer. The number of Cartesian zones in the region of } \\
\text { the higher-K boundary at the J-min end of the block. If } \\
\text { zero, the first region is polar. If the JZINNC or the } \\
\text { JZINNP cards are not used, this zoning applies to the } \\
\text { lower-K boundary also. }\end{array}$ \\
\hline & & The corner card's values are interpolated. \\
\hline Second region & $14-16$ & Integer. The second region Cartesian zone count. \\
\hline Third region & $17-19$ & Integer. The third region Cartesian zone count. \\
\hline Fourth region & $20-22$ & Integer. The fourth region Cartesian zone count. \\
\hline Fifth region & $23-25$ & Integer. The fifth region Cartesian zone count. \\
\hline Sisth region & 26-28 & Integer. The sixth region Cartesian zone count. \\
\hline Seventh region & $29-31$ & Integer. The seventh region Cartesian zone count. \\
\hline Eighth region & $32-34$ & Integer. The eighth region Cartesian zone count. \\
\hline
\end{tabular}

Table 3-47. J-zoning Polar, higher-K boundary card format.

\begin{tabular}{|c|c|c|}
\hline $\begin{array}{l}\text { Field } \\
\text { use }\end{array}$ & Columns & Input and Explanation \\
\hline Card name & $1-10$ & JZOUTP \\
\hline $\begin{array}{l}\text { First region } \\
\text { Polar }\end{array}$ & $11-13$ & $\begin{array}{l}\text { Integer. The number of Polar zones in the region of the } \\
\text { higher-K boundary at the J-min end of the block. Must } \\
\text { not be zero if the first region of the JZOUTC card is blank } \\
\text { or zero. This will apply to the lower-K boundary also if } \\
\text { the JZINNC or JZINNP cards are not used. }\end{array}$ \\
\hline Second region & $14-16$ & Integer. The second region Polar zone count. \\
\hline Third region & $17-19$ & Integer. The third region Polar zone count. \\
\hline Fourth region & 20-22 & Integer. The fourth region Polar zone count. \\
\hline Fifth region & $23-25$ & Integer. The fifth region Polar zone count. \\
\hline Sixth region & $26-28$ & Integer. The sixth region Polar zone count. \\
\hline Seventh region & n $29-31$ & Integer. The seventh region Polar zone count. \\
\hline Eighth region & $32-34$ & Integer. The eighth region Polar zone count. \\
\hline
\end{tabular}

input number that specifies the number of J-zones in that region.

If that number is entered on a Cartesian card, that segment of the boundary (or boundaries) will be generated using the
Cartesian corner points and interpolating linearly. If that number is entered on a polar card, that segment of the boundary (or boundaries) will be generated using the polar input data and interpolating 
Table 3-48. J-zoning Cartesian, lower-K boundary card format.

\begin{tabular}{|c|c|c|}
\hline $\begin{array}{l}\text { Field } \\
\text { use }\end{array}$ & Columns & Input and explanation \\
\hline Card name & $1-10$ & JZINNC \\
\hline $\begin{array}{l}\mathrm{J} \text {-min } \\
\text { region zoning } \\
\text { Cartesian } \\
\text { (lower-K) }\end{array}$ & $11-13$ & $\begin{array}{l}\text { Integer. If zero, the JZINNP input is used, or the } \\
\text { higher-K input is used. }\end{array}$ \\
\hline Second region & $14-16$ & Integer. The second region lower-K Cartesian zone count. \\
\hline Third region & $17-19$ & Integer. The third region low-K Cartesian zone count. \\
\hline Fourth region & 20-22 & Integer. The fourth ragion low-K Cartesian zone count. \\
\hline Fifth region & 23-25 & Integer. The fifth region low-K Cartesian zone count. \\
\hline Sixth region & 26-28 & Integer. The sixth region low-K Cartesian zone count. \\
\hline Seventh region & 29-31 & Integer. The seventh region low-K Cartesian zone count. \\
\hline Eighth region & $32-34$ & Integer. The eighth region low-K Cartesian zone count. \\
\hline
\end{tabular}

Table 3-49. J-zoning Polar, lower-K boundary card format.

\begin{tabular}{|c|c|c|}
\hline $\begin{array}{l}\text { Field } \\
\text { use }\end{array}$ & Columns & Input and explanation \\
\hline Card name & $1-10$ & JZINNP \\
\hline $\begin{array}{l}\mathrm{J} \text {-min region } \\
\text { zoning Polar } \\
\text { (lower-K) }\end{array}$ & $11-13$ & $\begin{array}{l}\text { Integer. If zero, the JZINNC input is used, or the } \\
\text { higher-K input is used. }\end{array}$ \\
\hline Second region & $14-16$ & Integer. The second region low-K Palar zone count. \\
\hline Third region & $17-19$ & Integer. The third region low-K Polar zone count. \\
\hline Fourth region & 20-22 & Integer. The fourth region low-K Polar zone count. \\
\hline Fifth region & 23-25 & Integer. The fifth region low-K Polax zone count. \\
\hline Sixth region & 26-28 & Integer. The sixth region low-K Polar zone count. \\
\hline Seventh region & $29-31$ & Integer. The Beventh region low-K Polar zane count. \\
\hline Eighth region & 32-34 & Integer. The eighth region low-K Polar zone count. \\
\hline
\end{tabular}




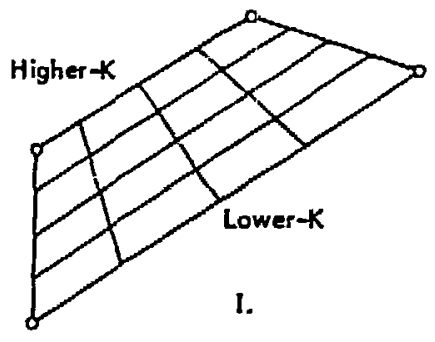

Higher $-K$

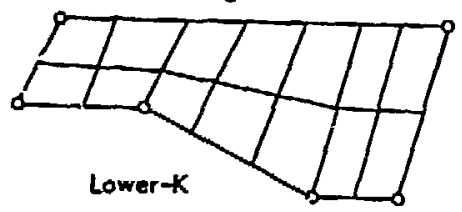

III.

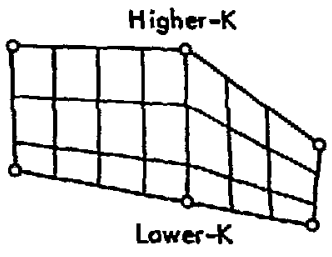

II.

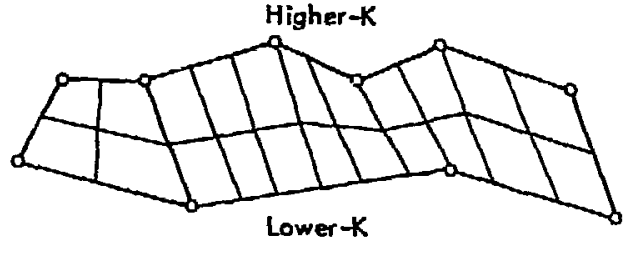

IV.

Higher-K

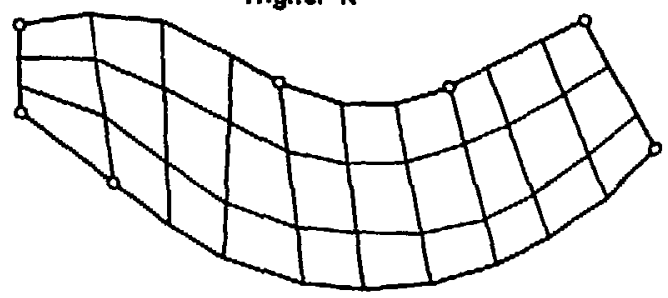

Lower-K

v.

Fig. 3-11. Examples of regional mixed Polar and Cartesian inputs.

equally along the arc.

Figure 3-11 and Table 3-50 show the use of these cards. (The other boundary data is not shown.)

\section{Material Number and Material- kelated Input (See Tables 3-51 through 3-57}

The material regions are associated with the J-zoning high-K cards. An equation-of-state number must be entered for each higher-K region.
Energy, volume and density may be entered by region. These numbers will override the general input numbers only for the region of input.

\section{Cartesian Corner Cards (See Table 3-55)}

If there are more than four regions in the block, and the additional regions are Cartesian input, follow the above card with another card, with or without 
Table 3-50. J-zonal input used to generate examples.

\begin{tabular}{|c|c|c|c|c|c|c|c|c|c|c|}
\hline \multirow[b]{3}{*}{ Example } & \multirow[b]{3}{*}{ Cards } & \multicolumn{9}{|c|}{ Regions and columns } \\
\hline & & 1 & 2 & 3 & 4 & 5 & 6 & 7 & 8 & \\
\hline & & $11-13$ & $14-16$ & $17-19$ & $20-22$ & $23-25$ & $26-28$ & $29-31$ & $32-34$ & \\
\hline \multirow{4}{*}{$\mathbf{I}$} & JZOUTC & 4 & & & & & & & & \\
\hline & JZOUTP & & & & & & & & & 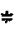 \\
\hline & JZ ENNC & & & & & & & & & $\because$ \\
\hline & JZINNP & & & & & & & & - & $\mp$ \\
\hline \multirow{4}{*}{ II } & JZOUTC & 4 & 3 & & & & & & & \\
\hline & JZOUTP & & & & & & & & & * \\
\hline & J2INNC & & & & & & & & & $\div$ \\
\hline & JZINNP & & & & & & & & & $\mp$ \\
\hline \multirow{4}{*}{ III } & JZOUTC & 7 & & & & & & & & \\
\hline & JZOUTP & & & & & & & & & $\neq$ \\
\hline & JZ INNC & 2 & 3 & 2 & & & & & & \\
\hline & JZINNP & & & & & & & & & $=$ \\
\hline \multirow{4}{*}{ IV } & JZOUTC & 2 & 3 & 2 & 2 & 2 & & & & \\
\hline & JZOUTP & & & & & & & & & $*$ \\
\hline & JZINNC & 2 & 6 & 3 & & & & & & \\
\hline & JZINNP & & & & & & & & & * \\
\hline \multirow{4}{*}{$\mathbf{v}$} & JZOUTC & & & 3 & & & & & & \\
\hline & JZOUTP & 4 & 3 & & & & & & & \\
\hline & JZINNC & 1 & & & & & & & & \\
\hline & JZINNP & & 9 & & & & & & & \\
\hline
\end{tabular}

\footnotetext{
"Don't need the card.
}

Table 3-51. Material card format.

\begin{tabular}{|c|c|c|}
\hline $\begin{array}{l}\text { Field } \\
\text { use }\end{array}$ & Columns & lnput and explanation \\
\hline Card name & $1-10$ & MATNO \\
\hline $\begin{array}{l}\text { Material } \\
\text { number }\end{array}$ & i $1-13$ & $\begin{array}{l}\text { Liteger. Equation-of-state number }(1-60) \text { of material in } \\
\text { region at } \mathrm{J}-\mathrm{min} \text { end. }\end{array}$ \\
\hline $\begin{array}{l}\text { Material } \\
\text { number }\end{array}$ & $14-16$ & Integer. Equation-of-state, region 2. \\
\hline $\begin{array}{l}\text { Material } \\
\text { number }\end{array}$ & $17-19$ & Integer. Equation-of-state, region 3. \\
\hline $\begin{array}{l}\text { Material } \\
\text { number }\end{array}$ & $20-22$ & Integer. Equation-of-state, region 4. \\
\hline $\begin{array}{l}\text { Material } \\
\text { number }\end{array}$ & $2 j-25$ & Integer. Equation-of-state, region 5. \\
\hline $\begin{array}{l}\text { Material } \\
\text { number }\end{array}$ & 26-28 & Integer. Equation-of-state. region 6. \\
\hline $\begin{array}{l}\text { Material } \\
\text { number }\end{array}$ & $29-31$ & Integer. Equation-of-state, region 7. \\
\hline $\begin{array}{l}\text { Material } \\
\text { number }\end{array}$ & $32-34$ & Integer. Equation-of-state, region 8. \\
\hline
\end{tabular}


Table 3-52. Volume card format.

\begin{tabular}{lcl}
\hline $\begin{array}{l}\text { Field } \\
\text { use }\end{array}$ & Columns & Input and explanation \\
\hline Card name & $1-10$ & volUME \\
$\begin{array}{l}\text { Volume, } \\
\text { J-min region }\end{array}$ & $11-18$ & $\begin{array}{l}\text { If not zero, the relative volume (V) of the J-min region } \\
\text { will be this number. }\end{array}$ \\
Region 2V & $19-26$ & V, region 2. \\
Region 3V & $27-34$ & V, region 3. \\
Region 4V & $35-42$ & V, region 4. \\
Region 5V & $43-50$ & V, region 5. \\
Region 6V & $51-58$ & V, region 6. \\
Region 7V & $59-66$ & V, region 7. \\
Region 8V & $67-74$ & V, region 8. \\
\hline
\end{tabular}

Table 3-53. Energy card format.

\begin{tabular}{|c|c|c|}
\hline $\begin{array}{l}\text { Field } \\
\text { use }\end{array}$ & Columns & Input and explanation \\
\hline Card name & $1-10$ & ENERGY \\
\hline $\begin{array}{l}\text { Energy } \\
\mathrm{J}-\text { min region }\end{array}$ & $11-18$ & $\begin{array}{l}\text { If not zero, the initial energy }(\epsilon) \text { of the } \mathrm{J}-\mathrm{m} \text { in region } w \text { ill } \\
\text { be this quantity. }\end{array}$ \\
\hline Region $2 \epsilon$ & $19-26$ & e, region 2 . \\
\hline Region $3 \epsilon$ & $27-34$ & $\varepsilon$, region 3 \\
\hline Region $4 \epsilon$ & $35-42$ & $\epsilon$, region 4 \\
\hline Region $5 \epsilon$ & $43-50$ & $\epsilon$, region 5 \\
\hline Region $6 \epsilon$ & $51-58$ & c. region 6 \\
\hline Region $7 \mathrm{E}$ & $59-66$ & $\epsilon$, region 7 . \\
\hline Region $8 \epsilon$ & $67-74$ & $\epsilon$, region $B$. \\
\hline
\end{tabular}

Table 3-54. Density card format.

\begin{tabular}{|c|c|c|}
\hline $\begin{array}{l}\text { Field } \\
\text { use }\end{array}$ & Columns & Input and explanation \\
\hline Card name & $1-10$ & DENSITY \\
\hline $\begin{array}{l}\text { Density } \\
\text { J-min region }\end{array}$ & $11-18$ & $\begin{array}{l}\text { If not zero, the density (Rho-Zero) of the } \mathrm{J} \text {-min regian } \\
\text { will be this quantity. }\end{array}$ \\
\hline Region 2 Rho & $19-26$ & Rho-Zero, region 2. \\
\hline Region 3 Rho & $27-34$ & Rho-Zero, region 3. \\
\hline Region 4 Rho & $35-42$ & Rho-Zero, region 4. \\
\hline Region 5 Rho & $43-50$ & Rho-Zero, region 5. \\
\hline Region 6 Rho & $51-58$ & Rho-Zero, region 6. \\
\hline Region 7 Rho & $59-66$ & Rho-Zero, region 7 . \\
\hline Region 8 Rho & $67-74$ & Rho-Zero, region 8. \\
\hline
\end{tabular}


Table 3-55. K-max (K-outer) of block card format.

\begin{tabular}{|c|c|c|}
\hline $\begin{array}{l}\text { Ficld } \\
\text { use }\end{array}$ & Columns & Input and explanation \\
\hline Card name & $1-10$ & CORNRMAX \\
\hline$\underset{K-\max x}{J-\min }$ & $11-17$ & $\begin{array}{l}\text { Enter the J-min, K-outer } X \text { if the J-min region has } \\
\text { K-outer Cartesian ingut. }\end{array}$ \\
\hline$\underset{K-\max Y}{J-\min }$ & $18-24$ & $J-\min -K-\max Y$ \\
\hline \multirow[t]{2}{*}{ Second $x$} & $25-31$ & $\begin{array}{l}\text { Input the second } X \text { (the } X \text { of the } J-\max \text { end of the } \mathrm{K} \text {-outer } \\
\text { Cartesian segment). }\end{array}$ \\
\hline & & $\begin{array}{l}\text { The } X \text {, Y pairs must be inputted for both ends of each } \\
\text { Cartesian segment. This input is unnecessary if the point } \\
\text { is bounded by Polar regions or if block boundary input is } \\
\text { to be used for the regions on either side of the point. }\end{array}$ \\
\hline Second $Y$ & $32-38$ & Second $Y$. \\
\hline Third $x$ & $39-45$ & $\mathrm{X}$ of third point. $\mathrm{J}-\max$ end of region 2 . \\
\hline Third Y & $46-52$ & $\mathrm{Y}$ of third point. $\mathrm{J}-\max$ end of region 2. \\
\hline Fourth $\mathrm{X}$ & $53-59$ & $X$ of fourth point. $J$-max end of region 3 . \\
\hline Fourth $Y$ & $60-66$ & $Y$ of fourti point. $J-\max$ end of region 3. \\
\hline Fifth $x$ & $67-73$ & $X$ of fifth point. $J-\max$ end of region 4 . \\
\hline Fifth $\mathbf{Y}$ & $74-80$ & $Y$ of fifth point. $\mathrm{J}-\mathrm{mex}$ end of region 4. \\
\hline
\end{tabular}

Table 3-5o. Additions to K-max (K-outer) of block card format.

\begin{tabular}{lcl}
\hline $\begin{array}{l}\text { Field } \\
\text { use }\end{array}$ & Columns & Input and explanation \\
\hline Card name & $1-10$ & CORNRMAX or blank \\
Sixth $X$ & $11-17$ & X of sixth point. J-max end of region 5. \\
Sixth $Y$ & $18-24$ & $Y$ of sixth point. J-max end of region 5. \\
Seventh $X$ & $25-31$ & $X$ of seventh point. J-max end of region 6. \\
Seventh $Y$ & $32-38$ & $Y$ of seventh point. J-max end of region 6. \\
Eighth $X$ & $39-45$ & $X$ of eighth point. J-max end of region 7. \\
Eighth $Y$ & $46-52$ & $Y$ of eighth point. J-max end of region 7 \\
Ninth $X$ & $53-58$ & $X$ of ninth point. J-max end of region 8. \\
Ninth $Y$ & $59-66$ & $Y$ of ninth point. J-max end of region 8. \\
\hline
\end{tabular}

the name, with the additional point. (See Table 3-56.)

K-min of Block, Second Card (See Table 3-57)
This card is the same format as the second card of the $\mathrm{K}$-outer input. Use only if there is Cartesian input for the fifth, sixth, seventh, or eighth regions. 
Table 3-57, K-min (K-Inner) of block card format.

\begin{tabular}{|c|c|c|}
\hline $\begin{array}{l}\text { Field } \\
\text { use }\end{array}$ & Columns & Input and explanation \\
\hline Card name & $1-10$ & CORNRMIN \\
\hline$\underset{K-\min X}{J-\min }$ & $11-17$ & $\begin{array}{l}\text { Enter the } J-m i n, K \text {-inner } X \text { if the } J \text {-min region has } \\
K \text {-inner Cartesian input. }\end{array}$ \\
\hline 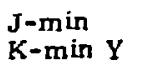 & $1 B-24$ & $\mathrm{~J}-\mathrm{min}-\mathrm{K}-\mathrm{min} \mathrm{Y}$ \\
\hline Second $\mathrm{X}$ & $25-31$ & $\mathrm{X}$ of second point, $\mathrm{K}$-inner boundary. \\
\hline Second $Y$ & $32-38$ & $Y$ of seceunu püint, $k$-inner boundary. \\
\hline Third $\mathrm{X}$ & $39-45$ & $\mathrm{X}$ of third point, $\mathrm{K}$-inner boundary. \\
\hline Third Y & $46-52$ & $Y$ of third point, $K$-inner boundary. \\
\hline Fourth $\mathrm{X}$ & $53-58$ & $\mathrm{X}$ of fourth point, $\mathrm{K}$-inner boundary. \\
\hline Fourth Y & $59-66$ & $\mathrm{Y}$ of fourth point, $\mathrm{K}$-inner boundary. \\
\hline Fifth $\mathrm{X}$ & $67-73$ & $X$ of fifth point, $K$-inner bouridary. \\
\hline Fifth $Y$ & $74-80$ & $Y$ of fifth point, $K$-inner boundary. \\
\hline
\end{tabular}

Table 3-58, K-Polar radius, outer $K$ card fornat.

\begin{tabular}{|c|c|c|}
\hline $\begin{array}{l}\text { liield } \\
\text { use }\end{array}$ & Columns & input and explanation \\
\hline Card name & $1-10$ & RADIUSOUTR \\
\hline $\begin{array}{l}\text { Radius of } \\
\text { first region }\end{array}$ & $11-18$ & $\begin{array}{l}\text { Enter the radius of the arc centered at XKMAXSHIFT, } \\
\text { YKMAXSHIFT, for the first region. }\end{array}$ \\
\hline $\mathrm{R}$ region 2 & $19-26$ & Radius of arc, region 2. \\
\hline$R$ region 3 & $27-34$ & Radius of arc, region 3 . \\
\hline$R$ region 4 & $35-42$ & Radius of arc, region 4 . \\
\hline $\mathbf{R}$ region 5 & $4.3-50$ & Radius of arc, region 5 . \\
\hline R regirn 6 & $51-58$ & Radius of arc, region 6 . \\
\hline R region $?$ & $59-6 f i$ & Radius of arc, region 7 . \\
\hline R region 8 & $67-74$ & Radius of arc, region 8 . \\
\hline
\end{tabular}

Polar Input Cards

$\mathrm{K}$-Polar input is input that causes a region (or regions) within a block to have its $\mathrm{K}$-ruter or $\mathrm{K}$-inner boundary generated as points on an arc.

$\mathrm{J}$-Polar input is input that causes a .J-boundary between regions to be generated as points on an arc.
$\mathrm{J}-$ Pular and $\mathrm{K}$-Polar can not be used in the same block.

To generate the desired arc, the user specilies radius, $x$ ans! $y$ ur the center, and beginning and endir: angles (deg).

Points that are common to both Carlasian and li-Hblar inpul must bre described in both ways. 
Table 3-59. K-Polar angle, outer $\mathrm{K}, \mathrm{J}$-min end of arc card format.

\begin{tabular}{|c|c|c|}
\hline $\begin{array}{l}\text { Field } \\
\text { use }\end{array}$ & Columns & Input and explanation \\
\hline Card name & $1-10$ & JMN-KX-ANG \\
\hline $\begin{array}{l}\mathrm{J} \text {-min angle } \\
\text { first region }\end{array}$ & $11-18$ & $\begin{array}{l}\text { Enter the angle (in degrees) for the J-min end of the first } \\
\text { region arc. The angle is measured counterclockwise } \\
\text { from a line directly to the rigit of the center. }\end{array}$ \\
\hline $\mathrm{J}-\mathrm{min}$ angle 2 & $19-26$ & Angle of $\mathrm{J}$-min end of arc, region 2 . \\
\hline $\mathrm{J}-\mathrm{min}$ angle 3 & $27-34$ & Angle of J-min end of arc, region 3 . \\
\hline $\mathrm{J}-\mathrm{min}$ angle 4 & $35-42$ & Angle of $\mathrm{J}-\mathrm{min}$ end of arc, region 4 . \\
\hline $\mathrm{J}-\mathrm{m}$ in angle 5 & $43-50$ & Angle of $\mathrm{J}-\mathrm{min}$ end of arc, region 5 . \\
\hline $\mathrm{J}-\mathrm{min}$ angle 6 & $51-58$ & Angle of $\mathrm{J}-\mathrm{min}$ end of arc, region $\overline{6}$. \\
\hline $\mathrm{J}-\mathrm{m}$ in angle 7 & $59-66$ & Angle of $\mathrm{J}-\mathrm{min}$ end of arc, region 7 . \\
\hline $\mathrm{J}-\mathrm{min}$ angle $\mathrm{B}$ & $67-74$ & Angle of $\mathrm{J}-\mathrm{min}$ end of arc, region $\mathrm{B}$. \\
\hline
\end{tabular}

Table 3-60. K-Polar angle, outer $K, J-m a x$ end of arc card format.

\begin{tabular}{|c|c|c|}
\hline $\begin{array}{l}\text { Field } \\
\text { use }\end{array}$ & Columns & Input and explanation \\
\hline Card name & $1-10$ & JMXX-KX-ANG \\
\hline $\begin{array}{l}\mathrm{J}-\max \text { angle } \\
\text { first region }\end{array}$ & $11-18$ & $\begin{array}{l}\text { Enter the angle (in degrees) of the J-max end of the first } \\
\text { region arc. }\end{array}$ \\
\hline $\mathrm{J}$-max angle 2 & $19-26$ & Angle of $\mathrm{J}$-max end of arc, region 2. \\
\hline $\mathrm{J}$-max angle 3 & $27-34$ & Angle of J-max end of arc, region 3 . \\
\hline $\mathrm{J}$-max angle 4 & $35-42$ & Angle of J-max end of arc, region 4. \\
\hline $\mathrm{J}-\max$ angle 5 & $43-50$ & Angle of $\mathrm{J}$-max end of arc, region 5 . \\
\hline$J$-max angle 6 & $51-58$ & Angle of $\mathrm{J}$-max end of arc, region 6 . \\
\hline $\mathrm{J}$-max angle 7 & $59-66$ & Angle of J-max end of arc, region 7 . \\
\hline $\mathrm{J}$-max angle 8 & $67-74$ & Angle uf $\mathrm{J}-\max$ end of arc, region 8 , \\
\hline
\end{tabular}

K-Polar Input

To describe the arc of the K-Polar regions, five cards are used for each K-boundary. Three of these cards are normally used for all arcs. Two cards describe the angles of the $\mathrm{J}$-min and the $\mathrm{J}$-max ends of the arc, and one card describes the radius of the arc. Two of the cards describe the $X$ and $Y$ of the center of the arc. If the center is at zero, these cards need not be used.
Following is a description of the five cards used to describe K-Polar input for the $\mathrm{K}$-outer boundary. The $\mathrm{K}$-inner boundary cards are the same except that the card names are changed. These names will be given following the $K$-outer card descriptions. (See Tables 3:58 through 3-61.)

The $Y$ of the center of the outer region is inputted in a similar manner using the card name YKMAXSHIFT. 
Table 3-61. K-Polar, $X$ - center, outer $K$ card format.

\begin{tabular}{|c|c|c|}
\hline $\begin{array}{l}\text { Field } \\
\text { use }\end{array}$ & Columns & Input and explanation \\
\hline Card name & $1-10$ & XKMLAXSHIFT \\
\hline $\begin{array}{l}X \text { of center } \\
\text { first region }\end{array}$ & $11-18$ & $\begin{array}{l}X \text { of center of the arc. If zero, } X \text { equals zero will be the } \\
\text { center. }\end{array}$ \\
\hline$X$ region 2 & $19-26$ & $X$ of the center of region 2. \\
\hline $\mathrm{X}$ region 3 & $27-34$ & $X$ of the center of region 3 . \\
\hline$x$ region 4 & $35-42$ & $X$ of the center of region 4 . \\
\hline $\mathbf{X}$ region 5 & $43-50$ & $X$ of the center of region 5. \\
\hline$X$ region 6 & $51-58$ & $X$ of the center of region 6 . \\
\hline $\mathrm{X}$ region 7 & $59-66$ & $\mathrm{X}$ of the center of region $\mathrm{Z}$. \\
\hline$x$ region 8 & $67-74$ & $\mathrm{X} \mathrm{a}$ : the center of region 8 . \\
\hline
\end{tabular}

Table 3-62. K-Polar example.

\begin{tabular}{|c|c|c|c|c|c|c|c|c|c|c|}
\hline \multicolumn{5}{|l|}{ CORNRMAX } & $\mathrm{x}_{\mathrm{C}}$ & ${ }^{Y_{C}}$ & $\mathbf{Y}_{\mathbf{D}}$ & $\mathbf{Y}_{\mathbf{D}}$ & $\mathrm{X}_{\mathrm{E}}$ & $\mathrm{Y}_{\mathrm{E}}$ \\
\hline CORNRMIN & $\mathbf{X}_{F}$ & $\mathrm{Y}_{\mathrm{F}}$ & $x_{G}$ & $\mathbf{Y}_{\mathbf{G}}$ & $\mathbf{X}_{\mathrm{H}}$ & $\mathbf{Y}_{\mathrm{H}}$ & $\mathbf{x}_{\mathbf{J}}$ & $\mathbf{Y}_{\mathbf{J}}$ & & \\
\hline NZONESBLK & 1 & & & & & & & & & \\
\hline JZINNC & & & 3 & 2 & & & & & & \\
\hline JZINNP & 8 & 4 & & & & & & & & \\
\hline JZOUTC & 5 & & 6 & & & & & & & \\
\hline JZOUTP & & 6 & & & & & & & & \\
\hline MATNO & 17 & 17 & 20 & 20 & & & & & & \\
\hline XKMAXSHIFT & $\mathrm{x}_{\mathrm{r}}$ & $\mathrm{x}_{\mathrm{II}}$ & & & & & & & & \\
\hline YKMAXSHIF T & $\mathbf{Y}_{\mathrm{I}}$ & $\mathbf{Y}_{\text {II }}$ & & & & & & & & \\
\hline RADIUSOUT & $\mathbf{R}_{\mathbf{I}}$ & $\mathbf{R}_{\mathrm{II}}$ & & & & & & & & \\
\hline $\mathrm{JMN}-\mathrm{KX}-\mathrm{ANG}$ & $\phi_{I J-m i n}$ & $\phi_{\text {II J-min }}$ & & & & & & & & \\
\hline $\mathrm{JMX}-\mathrm{KX}-\mathrm{ANG}$ & $\phi_{[\mathrm{J}-\max }$ & $\phi_{\text {II J-max }}$ & & & & & & & & \\
\hline XKMINSHIFT & & $\mathrm{x}_{\text {III }}$ & & & & & & & & \\
\hline YKMINSHLFT & & $Y_{\text {III }}$ & & & & & & & & \\
\hline RADIUSIN & & $\mathbf{R}_{\text {III }}$ & & & & & & & & \\
\hline JMN-KN-ANG & & $\phi_{\text {III J-min }}$ & & & & & & & & \\
\hline JMX-KN-ANG & & $\phi_{\text {II J-max }}$ & & & & & & & & \\
\hline
\end{tabular}

The five cards that describe the

$\mathrm{K}$-inner boundary in a manner similar to the $\mathrm{K}$-outer boundary are called XKMINSHIFT, YKMINSHIFT, RADIUSIN, JMNKN-ANG, and JMX-KN-ANG.
Figure 3-12 illustrates the input of a block of mixed $K$ Polar and Cartesian input. The various fields are shown as columns (see Table 3-62). 


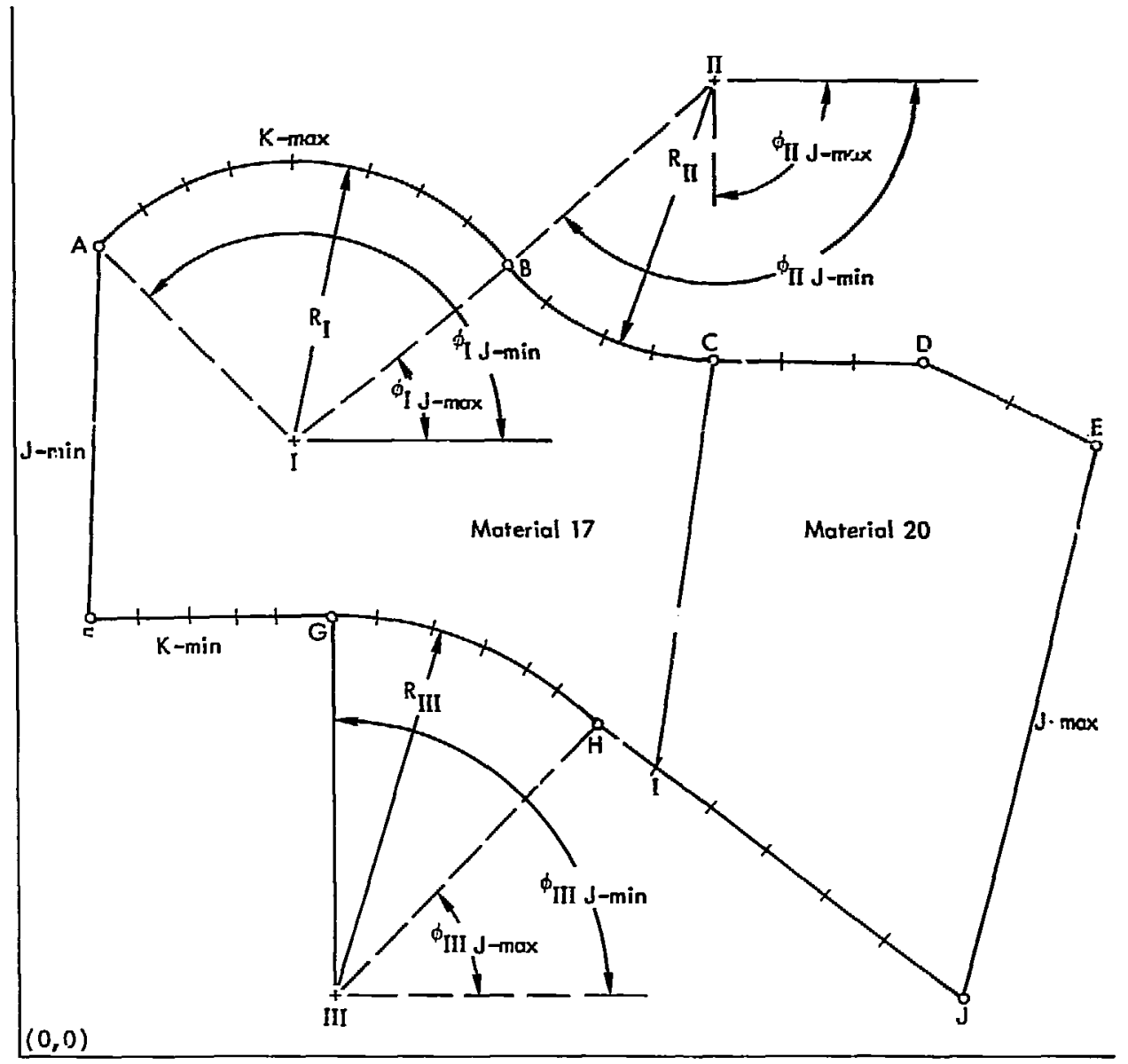

Fig. 3-12. Block of mixed Polar and Cartesian inputs.

\section{J-Polar Input (See Tables 3-63 through 3-65)}

The J-Polar input uses some of the same cards as the K-Polar input so that the card names are not meaningful. To use J-Polar input, a card called JPOLAR is included in the block. This signals to the generator that the data on the cards is to be used in J-Polar generation.
The data is inputted by regional boundaries. If $\mathrm{J}$-Polar data is not specified for a particular J-boundary, Cartesian input is used to generate the points.

\section{J-Polar Angle-K-min End}

The format is the same as the $K$-max end but the card is called JMN-KN-ANG. 
Table 3-63. J-Polar flag card format.

\begin{tabular}{lcl}
\hline $\begin{array}{l}\text { Field } \\
\text { use }\end{array}$ & Columns & Input and explanation \\
\hline Card name & $1-10$ & $\begin{array}{l}\text { JPOLAR } \\
\text { Integer. A "1" signals to the generator that this is a } \\
\text { Signal }\end{array}$ \\
\hline
\end{tabular}

Table 3-64. J-Polar radius card format.

\begin{tabular}{|c|c|c|}
\hline $\begin{array}{l}\text { Field } \\
\text { use }\end{array}$ & Columns & Input and explanation \\
\hline Card name & $1-10$ & RADIUSOUTR \\
\hline $\mathrm{J}-\mathrm{min}$ radius & $11-18$ & $\begin{array}{l}\text { Radius of the J-min boundary of the block. If zero, the } \\
\mathrm{J}-\mathrm{min} \text {, K-max, and the J-min, K-min Cartesian points } \\
\text { will be used to linearly interpolate a straight line. }\end{array}$ \\
\hline Radius & $19-26$ & Radius of the J-max end of region 1 . \\
\hline Radius & $27-34$ & Radius of the J-max end of region 2 . \\
\hline Radius & $35-42$ & Radius of the $J-\max$ end of region 3 . \\
\hline Radius & $43-50$ & Radius of the $J$-max end of region 4 . \\
\hline Radius & $51-58$ & Radius of the $J$-max end of region 5 . \\
\hline Radius & $59-66$ & Radius of the J-max end of region 6 . \\
\hline Radius & $67-74$ & Radius of the J-max end of region 7 . \\
\hline Radius & $\begin{array}{c}11-18 \\
\text { (ncxt card) }\end{array}$ & Radius of the $\mathrm{J}-\max$ end of region 8 . \\
\hline
\end{tabular}

Table 3-65. J-Polar angle, K-max end card format..

\begin{tabular}{|c|c|c|}
\hline $\begin{array}{l}\text { Field } \\
\text { use }\end{array}$ & Columns & Input and explanation \\
\hline Card name. & $1-10$ & $J M N-K X-A N G$ \\
\hline $\begin{array}{l}\text { Angle of } \\
\mathrm{K}-\mathrm{max} \text { and } \\
\mathrm{J}-\mathrm{min} \text { line }\end{array}$ & $11-18$ & $\begin{array}{l}\text { The angle measured counter clockwise from } 0 \text { degrees to } \\
\text { the } K \text {-max end of the arc. }\end{array}$ \\
\hline Angle $\mathrm{K}-\max$ & $19-26$ & Angle to $\mathrm{K}$-max end of arc, J-max of region 1 . \\
\hline Angle $\mathrm{K}-\max$ & $27-34$ & Angle to $K-\max$ end of arc, $J-\max$ of region 2 . \\
\hline Angle $\mathrm{K}-\mathrm{max}$ & $35-42$ & Angle to $\mathrm{K}$-max end of arc, J-max of region 3 . \\
\hline Angle $K-\max$ & $43-50$ & Angle to $\mathrm{K}-\max$ end of arc, J-max of region 4 . \\
\hline Angle $K-\max$ & $51-58$ & Angle to $\mathrm{K}$-max end of arc, J-max of region 5 . \\
\hline Angle $K-\max$ & $59-66$ & Angle to $\mathrm{K}$-max end of arc, J-max of region 6 . \\
\hline Angle $\mathrm{K}-\max$ & $67-74$ & Angle to K-max end of arc, J-max of region 7 . \\
\hline Angle $\mathrm{K}-\mathrm{max}$ & $\begin{array}{c}11-18 \\
\text { (next card) }\end{array}$ & Angle to $\mathrm{K}-\max$ end of arc, $\mathrm{J}$-max of region 8 . \\
\hline
\end{tabular}



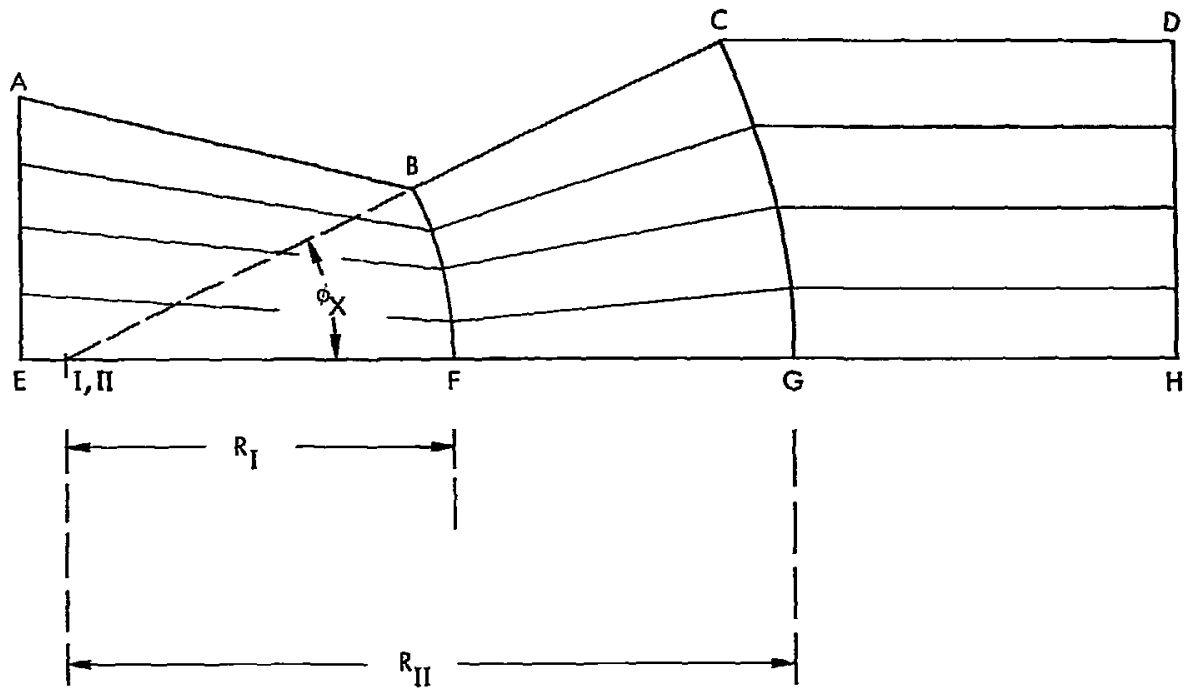

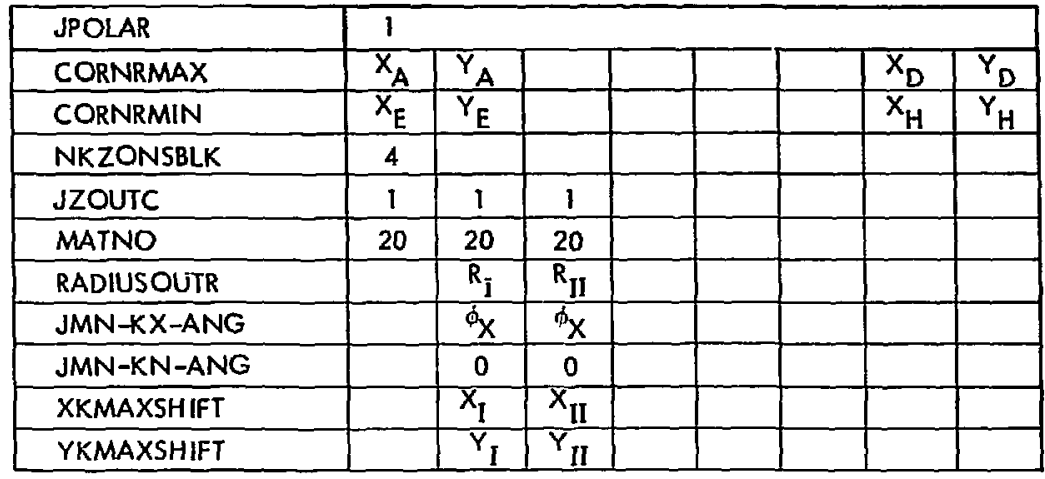

Fig. 3-13. Block of combined J-Polar and Cartesian inputs.

The centers of the arcs are given on the XKMAXSHI F'T and the YKMAXSHIFT cards using the formats as used in K-polar input.

Figure 3-13 shows a block generated by combined J-Polar and Cartesian input.

Slide-Lines (See Tables 3-66 and 3-67)

A card called SLIDE-TYPE is used to call for sliding at the $K$-min boundary of the block. The slide extension angle may also be inputted with block input if desired.

Velocity Input (See Tables 3-68 through 3-71)

Seven cards enable users to input velocities by regions, at boundaries between regions, and at boundaries between blocks. There is a hierarchy of card use whereby the regional boundary. 
Table 3-66. Slide-type card format.

\begin{tabular}{|c|c|c|}
\hline $\begin{array}{l}\text { Field } \\
\text { use }\end{array}$ & Columns & Input and explanation \\
\hline Card name & $1-10$ & SLIDE-TYPE (See footnote to this table. \\
\hline \multirow[t]{2}{*}{$\begin{array}{l}\text { "Upright" } \\
\text { sliding }\end{array}$} & 11 & $\begin{array}{l}\text { Integer. If } 1,2,3 \text {, or } 4 \text { the K-min boundary of this block } \\
\text { will have "upright" sliding. (The "mester" surface will be } \\
\text { the K-high side of the line; the "slave" surface will be the } \\
\mathrm{K}-\mathrm{lower} \text { side of the line.) }\end{array}$ \\
\hline & & $\begin{array}{l}\text { If set to "1", the non-void routine will be used. If set to } \\
2,3 \text {, or } 4 \text {, the void routine will be used. If set to " } 2 \text { ", all } \\
\text { points will be generated in the closed position. The gen- } \\
\text { erator will place the "slave" point exactly on the "master" } \\
\text { line. If set to " } 3 \text { ", the points are assumed to be open and } \\
\text { the "slave" points are not extrapolated to the surface. If } \\
\text { set to "4", all points are "tied". (See the "Slide-Lines and } \\
\text { Voids," page } 53 \text {, and "Tied Sliding Input," page 94.) }\end{array}$ \\
\hline $\begin{array}{l}\text { "Inverted" } \\
\text { sliding }\end{array}$ & 12 & $\begin{array}{l}\text { If set to " } 1 \text { " the } K \text {-min boundary of this block will have } \\
\text { "inverted" sliding. (The "master" surface will be the } \\
\text { K-lower side of the line; the "slave" surface will be the } \\
\text { K-high side.) }\end{array}$ \\
\hline
\end{tabular}

This card goes in the block on the $K$-max side of the slide.

Table 3-67. Slide line extension direction card format. (See Fig. 3-8 for directions.)

\begin{tabular}{|c|c|c|}
\hline $\begin{array}{l}\text { Field } \\
\text { use }\end{array}$ & Columns & Input and explanation \\
\hline Card name & $1-10$ & $\begin{array}{l}\text { SLIDE-ANG (Note: This card goes with the block that has } \\
\text { the master surface as a boundary.) }\end{array}$ \\
\hline$J-\max$ ext & 11 & $\begin{array}{l}\text { Integer. If } 1 \text { through } 9 \text {, this slide-line direction will over- } \\
\text { ride the } J \text {-max direction inputted with the general input. }\end{array}$ \\
\hline$J-$ min ext & 12 & $\begin{array}{l}\text { Integer. If } 1 \text { through } 9 \text {, this stide-line direction will over- } \\
\text { ride the J-min direction in general input (see p. 60). }\end{array}$ \\
\hline $\begin{array}{l}\text { J-max X } \\
\text { (direction } \\
9 \text { only) }\end{array}$ & $13-24$ & $\begin{array}{l}\text { If direction " } 9 \text { " has been called for at } \mathrm{J} \text {-max, this } \mathrm{X} \text { will } \\
\text { be used. }\end{array}$ \\
\hline $\begin{array}{l}\text { J-max Y } \\
\text { (direction } \\
9 \text { only) }\end{array}$ & $25-36$ & $\mathrm{~J}-\max \mathrm{Y}$, cirection " $\mathrm{g}$ ". \\
\hline$J-\min x$ & $37-48$ & $\begin{array}{l}\text { If direction " } \mathrm{g} \text { " has been called for at } \mathrm{J}-\mathrm{min} \text {, this } \mathrm{X} \text { will } \\
\text { be used. }\end{array}$ \\
\hline$x-\min Y$ & $49-60$ & $\mathrm{~J}-\mathrm{min} \mathrm{Y}$, direction " $9 "$ ". \\
\hline
\end{tabular}

cards override all other cards, and the block boundary card overrides the region input cards. Specifically the hierarchy is this:

First priority - Lower $J$ of region Second priority - J-max end of block Third priority - Lower $\mathrm{K}$ of region
Fourth priority - K-max of block Fifth priority - Velocity of region Point-by-point input will, of course, override all of these.

To input a zero to override previous input, put in $1 \mathrm{E}-30$. This will be recognized as an input number and stored, 
Table 3-68. Regional X-dot card format.

\begin{tabular}{|c|c|c|}
\hline $\begin{array}{r}\text { Field } \\
\text { use }\end{array}$ & Columns & Input and explanation \\
\hline Card name & $1-10$ & XVELMAT \\
\hline $\begin{array}{l}\text { X-dot } \\
\text { region } 1\end{array}$ & $11-18$ & $\begin{array}{l}\text { If not zero, this velocity will be assigned to all the points } \\
\text { in, and all boundary points of, the first region. Where a } \\
\text { boundary conflict occurs, the J-min end region will over- } \\
\text { ride the next higher region and the } K \text {-min end region will } \\
\text { override the } K-\text { max end region. }\end{array}$ \\
\hline $\begin{array}{l}X \text {-dot of } \\
\text { region } 2\end{array}$ & $19-26$ & X-dot of region 2 \\
\hline $\begin{array}{l}x \text {-dot of } \\
\text { region } 3\end{array}$ & $27-34$ & $\mathrm{X}$-dot of region 3 \\
\hline $\begin{array}{l}X \text {-dot of } \\
\text { region } 4\end{array}$ & $35-42$ & $\mathrm{x}$-dot of region 4 \\
\hline $\begin{array}{l}X \text {-dot of } \\
\text { region } 5\end{array}$ & $43-50$ & $\mathrm{X}$-dot of region 5 \\
\hline $\begin{array}{l}X \text {-dot of } \\
\text { region } 6\end{array}$ & $51-58$ & $\mathrm{X}$-dot of region 6 \\
\hline $\begin{array}{l}X \text {-dot of } \\
\text { region } 7\end{array}$ & $59-66$ & $\mathrm{x}$-dot of region 7 \\
\hline $\begin{array}{l}X \text {-dot of } \\
\text { region } 8\end{array}$ & $67-74$ & X-dot of region 8 . \\
\hline
\end{tabular}

Table 3-69. X-dot at J-min of the regions card format.

\begin{tabular}{|c|c|c|}
\hline $\begin{array}{l}\text { Field } \\
\text { use }\end{array}$ & Columns & Input and explanation \\
\hline Card name & $1-10$ & XVEIMATJ \\
\hline $\mathbf{J}$-min of block & $11-18$ & $\begin{array}{l}\text { If non-zero, this velocity will be assigned to the J-min end } \\
\text { of the block. }\end{array}$ \\
\hline $\begin{array}{l}\mathrm{J}-\mathrm{min} \text { of } \\
\text { region } 2\end{array}$ & $19-26$ & $\mathrm{X}$-dot of the J-min end region 2 . \\
\hline $\begin{array}{l}\mathrm{J}-\mathrm{min} \text { of } \\
\text { region } 3\end{array}$ & $27-34$ & $\mathrm{X}$-dot of the J-min end region 3. \\
\hline $\begin{array}{l}\mathrm{J}-\text { min of } \\
\text { region } 4\end{array}$ & $35-42$ & $X$-dot of the J-min end region 4. \\
\hline $\begin{array}{l}J-m i n \text { of } \\
\text { region } 5\end{array}$ & $43-50$ & $\mathrm{X}$-dot of the J-min end region 5. \\
\hline $\begin{array}{l}\mathrm{J}-\mathrm{min} \text { of } \\
\text { region } 6\end{array}$ & $51-58$ & $X$-dot of the $J-\min$ end region 6 . \\
\hline $\begin{array}{l}\mathrm{J} \text {-min of } \\
\text { region } 7\end{array}$ & $59-66$ & $X$-dot of the $J-\min$ end region 7 \\
\hline $\begin{array}{l}\text { J-min of } \\
\text { region } 8\end{array}$ & $67-74$ & $\mathrm{X}$-dot of the J-min end region 8 . \\
\hline
\end{tabular}


Table 3-70. $\mathrm{X}$-dot at the $\mathrm{K}-\mathrm{min}$ of the regions card format.

\begin{tabular}{|c|c|c|}
\hline $\begin{array}{l}\text { Field } \\
\text { use }\end{array}$ & Columns & Input and explanation \\
\hline Card name & $1-10$ & XVELMATK \\
\hline $\begin{array}{l}\text { Z-dot, first } \\
\text { region, K-min }\end{array}$ & $11-18$ & $\begin{array}{l}\text { If non-zero this } \mathrm{X} \text {-dot will be assigned to the } \mathrm{K}-\mathrm{min} \\
\text { boundary of this region of this block. }\end{array}$ \\
\hline $\begin{array}{l}\mathrm{X} \text {-dot, } \mathrm{K}-\mathrm{min} \\
\text { region } 2\end{array}$ & $19-26$ & $\mathrm{X}$-dot of the $\mathrm{K}$-min boundary of region 2 . \\
\hline $\begin{array}{l}\mathrm{X} \text {-dot, } \mathrm{K}-\mathrm{min} \\
\text { region } 3\end{array}$ & $27-34$ & $\mathrm{X}$-dot of the $\mathrm{K}-\mathrm{min}$ boundary of region 3 . \\
\hline $\begin{array}{l}\mathrm{X} \text {-dot, } \mathrm{K}-\mathrm{min} \\
\text { region } 4\end{array}$ & $35-42$ & $\mathrm{X}$-dot of the $\mathrm{K}-\mathrm{m}$ in boundary of region 4 . \\
\hline $\begin{array}{l}\mathrm{X} \text {-dot, } \mathrm{K}-\mathrm{min} \\
\text { region } 5\end{array}$ & $43-50$ & $\mathrm{X}$-dot of the $\mathrm{K}-\mathrm{m}$ in boundary of region 5 . \\
\hline $\begin{array}{l}X \text {-dot, } K-\text { min } \\
\text { region } 6\end{array}$ & $51-58$ & $\mathrm{X}$-dot of the $\mathrm{K}-\mathrm{min}$ boundary of region 6 . \\
\hline $\begin{array}{l}\mathrm{X} \text {-dot, } \mathrm{K} \text {-min } \\
\text { region } 7\end{array}$ & $59-66$ & $\mathrm{X}$-dot of the $\mathrm{K}$-min boundary of region 7 . \\
\hline $\begin{array}{l}X-\text { dot, } K-m i n \\
\text { region } 8\end{array}$ & $67-74$ & $\mathrm{X}$-dot of the $\mathrm{K}$-min boundary of region 8 . \\
\hline
\end{tabular}

Table 3-71. Velocities at $J-\max$ and $K-\max$ of the block card format.

\begin{tabular}{|c|c|c|}
\hline $\begin{array}{l}\text { Field } \\
\text { use }\end{array}$ & Columns & Input and explanation \\
\hline Card Name & $1-10$ & VELBLOCK \\
\hline $\begin{array}{l}\text { X-dot at } \\
\text { J-max of block }\end{array}$ & $11-18$ & $\begin{array}{l}\text { If not zero, this } \mathrm{X} \text {-dot will be assigned to all } \mathrm{J} \text {-max points } \\
\text { of this block. }\end{array}$ \\
\hline $\begin{array}{l}\text { Y-dot at } \\
\text { J-max of block }\end{array}$ & $k^{19-26}$ & $\mathrm{Y}$-dot at J-max end of block. \\
\hline $\begin{array}{l}\mathrm{X}-\mathrm{dot} \text { at } \\
\mathrm{K}-\max \end{array}$ & $27-34$ & $\begin{array}{l}\text { If not zero, this } X \text {-dot will be assigned } t \text {, the entire } K \text {-max } \\
\text { boundary of this block. }\end{array}$ \\
\hline $\begin{array}{l}\text { Y-dot at } \\
\mathrm{K}-\max \end{array}$ & $35-42$ & $\mathrm{Y}$-dot for entire $\mathrm{K}$-max of block. \\
\hline
\end{tabular}

then set to zero by the cutoff during the running of the first cycle. If a rigid wall boundary condition has been called for at the boundary where the $1 \mathrm{E}-30$ has been read in, the number will not be cut off but is so small that its use will not adversely affect the running of the problem.

The regional $Y$-dot is inputted in an identical fashion to the $\mathrm{X}$-dot except that the card is called YVELMAT. See Table 3-68.

The $\mathrm{Y}$-dot at the $\mathrm{J}$-min end of the regions is inputted in a manner similar to XVELMATJ except that the card is called YVELMATJ. See Table 3-69.

The Y-dot of the K-min boundary of the regions in the block is inputted in a manner similar to the $\mathrm{X}$-dot except that 
Table 3-72. Burn type card format.

\begin{tabular}{|c|c|c|}
\hline $\begin{array}{l}\text { Field } \\
\text { use }\end{array}$ & Columns & Input and explanation \\
\hline Card name & $1-10$ & HEBURN \\
\hline $\begin{array}{l}\text { I-min end } \\
\text { burn type, } \\
\text { region } 1\end{array}$ & $11-13$ & $\begin{array}{l}\text { Integer. Enter numbers } 1 \text { through } 5 \text { to indicate the appro- } \\
\text { priate burn time calculating routine for the zones in this } \\
\text { region. }\end{array}$ \\
\hline $\begin{array}{l}\text { Burn type, } \\
\text { region } 2\end{array}$ & $14-16$ & Integer. Regional burn type, region 2 . \\
\hline $\begin{array}{l}\text { Burn type, } \\
\text { region } 3\end{array}$ & $17-19$ & Integer. Regional burn type, region 3 . \\
\hline $\begin{array}{l}\text { Burn type, } \\
\text { region } 4\end{array}$ & $20-22$ & Integer. Regional burn type, region 4. \\
\hline $\begin{array}{l}\text { Burn type, } \\
\text { region } 5\end{array}$ & $23-25$ & Integer. Regional burn type, region 5 . \\
\hline $\begin{array}{l}\text { Burn type, } \\
\text { region } 6\end{array}$ & $26-28$ & Integer. Regional burn type, region 6 . \\
\hline $\begin{array}{l}\text { Burn type, } \\
\text { region } 7\end{array}$ & $29-31$ & Integer. Regional burn type, region 7 . \\
\hline $\begin{array}{l}\text { Burn type, } \\
\text { region } 8\end{array}$ & $32-34$ & Integer. Reglonal burn type, region 8 . \\
\hline
\end{tabular}

the card name YVELMATK is used. Ses Table 3-70.

HE Input (See Tables 3-72 through 3-74)

Five ypes of burn time generating routines are available. Some of the input is for the entire block (not by region) so that some restriction on the multiple use of burn types and different HE's within a block may be found. Burn times can be read in as zonal input with the "pointby-point" input subgroup.

The five burn types are as follows:

Number 1. Burned HE-The burn fraction for all zones in the region is set to " 1 " so that-all of the energy is released at once. No HEPARAM inp'it is necessary.
Number 2. Simple Single-Point Detonation-The HE in the region is detonated from a single point and the burn time is calculated directly, without reference to boundaries. The velocity, burn constant and the detonation point must be entered on the HEPARAM card. The burn may be offset in time by entering a time increment in "time subtract." A positive entry will make the burn time sooner. A negative burn time will make the burn time later (delay). Figure 3-14 shows a simple single-point detonation.

Number 3. Line Detonation-The burn time is calculated from the zone center to the nearest point on a line runaing through the input points 1 and 2 as entered on the HEPARAM card. The line is infinitely long and does 
Table 3-73. HE input parameters card format.

\begin{tabular}{|c|c|c|}
\hline $\begin{array}{l}\text { Field } \\
\text { use }\end{array}$ & Colurnns & Input and explanation \\
\hline Card name & $1-10$ & HEPARAM \\
\hline $\begin{array}{l}\text { Detonation } \\
\text { velocity }\end{array}$ & $11-18$ & $\begin{array}{l}\text { Enter the detonation velocity for the } \mathrm{HE} \text { in all the regions } \\
\text { of this block. }\end{array}$ \\
\hline Burn constant & $19-26$ & $\begin{array}{l}\text { Enter the burn constant. This number is used in cal- } \\
\text { culating the burn fraction from the burn time. Its value } \\
\text { is quite noncritical. It is about equal to one and onethalf } \\
\text { times the average zone thickness, divided by the detonation } \\
\text { velocity. }\end{array}$ \\
\hline$x_{1}$ & $27-34$ & $\begin{array}{l}X \text { of the detonation point of all single detonator burns. } \\
X_{3} \text { of one end of the detonation line for line detonation burns. }\end{array}$ \\
\hline $\mathbf{Y}_{1}$ & $35-42$ & $Y$ corresponding to $X_{I}$. \\
\hline$x_{2}$ & $43-50$ & The $X$ of the second end of the type 3 line. \\
\hline $\mathbf{Y}_{2}$ & $51-58$ & The $Y$ of the second end of the type 3 line. \\
\hline Time subtract & $59-66$ & $\begin{array}{l}\text { This time increment will be subtracted from the calculated } \\
\text { burn time for type } 2,3 \text {, and } 4 \text { burns. }\end{array}$ \\
\hline $\begin{array}{l}\text { Number of } \\
\text { multiple points }\end{array}$ & $67-69$ & $\begin{array}{l}\text { Integer. Number of detonation points in multiple point } \\
\text { detonation. }\end{array}$ \\
\hline
\end{tabular}

Table 3-74. Shadow card format.

\begin{tabular}{|c|c|c|}
\hline $\begin{array}{l}\text { Field } \\
\text { use }\end{array}$ & Columns & Input and explanation \\
\hline Card name & $1-10$ & SHADOW \\
\hline $\begin{array}{l}\text { K-max- } \\
\text { shadow }\end{array}$ & 11 & $\begin{array}{l}\text { Integer. Set to "1" if the K-max boundary of the block is } \\
\text { Huyghens shadow surface. }\end{array}$ \\
\hline $\begin{array}{l}\text { K-min- } \\
\text { shadow }\end{array}$ & 12 & $\begin{array}{l}\text { Integer. Set to " } 1 \text { " if the K-min boundary of the block is } \\
\text { the Huyghens shadow surface. }\end{array}$ \\
\hline$J$-max-end & 13 & $\begin{array}{l}\text { Integer. Set to " } 1 \text { " if the } J-\max \text { end of the shadow surface } \\
\text { is the nearest to the detonation point. }\end{array}$ \\
\hline J-min-end & 14 & $\begin{array}{l}\text { Integer. Set to " } 1 \text { " if the J-min end of the shadow surface } \\
\text { is nearest to the detonation point. }\end{array}$ \\
\hline Read shadow & 15 & $\begin{array}{l}\text { Integer. Set to " } 1 \text { " if the shadow points and delay times } \\
\text { are to be read in with block boundary input. }\end{array}$ \\
\hline
\end{tabular}




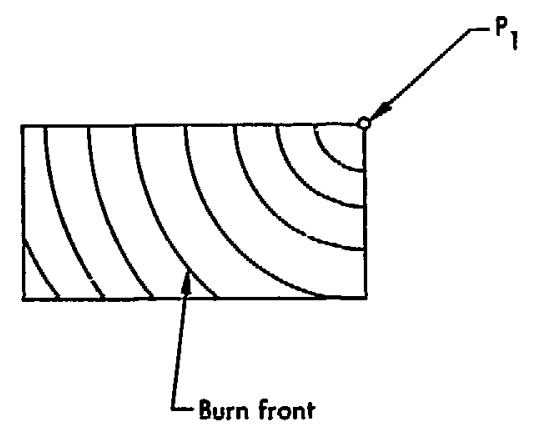

Fig. 3-14. Simple single-point detonation.

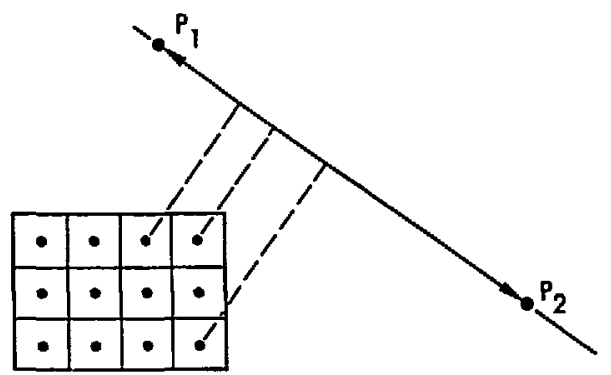

Fig. 3-15. Line detonation.

not terminate at the end points. (See Fig. 3-15.)

Number 4. Huyghens Detonation-The Huy ghens routine enables the user to run HE burns from a single point that is not in "line of sight" of all zones. The intruding "shadow boundary" (Fig. 3-16) ordinarily is the $K-\max$ or $K$-min boundary of the blo:k. Only a simple curve is allowed, no "s" shadow lines, and only one shadow. The SHADOW card must be used. If the $K-\max$ or $K-m i n$ boundary are not the shadow, the shadow points may be read in with block boundary input. If read in, as many points must be read in as there are $\mathrm{J}$ 's in a $\mathrm{K}$-line of that block. Delay time may be read in also.

Number 5. Multiple Point DetonationMany detonators can be used at once in simple detonations. (See Fig. 3-17.) The code calculates the "line-of-sight" burn time from each zone to all of the detonators and keeps the minimum time. A "subtract time" can be entered with each detonator. The points and delay times are entered with block boundary input. A burn velocity may be supplied with each detonator.

K-by-K Input (See Table 3-75)

The following card is used to call for

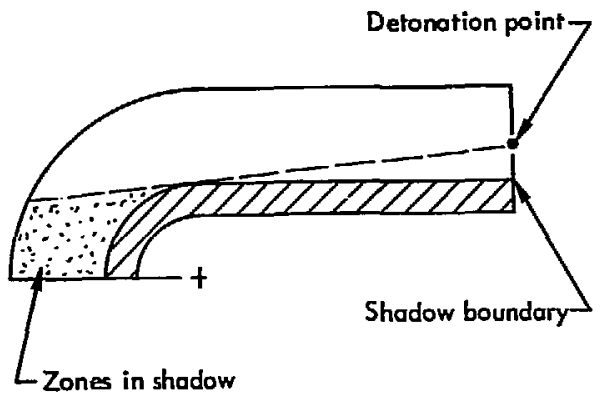

Fig. 3-16. Example of Huyghens detonation.

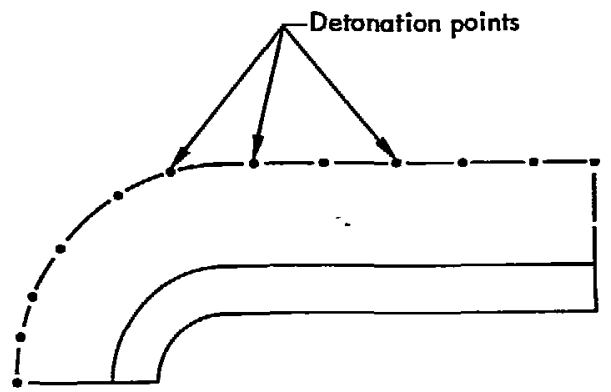

Fig. 3-17. Multiple point detonation. 
the reading in and interpretation of $\mathrm{K}-\mathrm{by}-$ $\mathrm{K}$ and point-by-point input. This input is always read in pairs.

\section{Fini Card (See Table 3-76)}

This card must be the last card in the block input subgroup.

\section{Block Boundary Input Section Discussion}

Coordinate Input (See Table 3-77)

The following cards may be used, if desired, to modify the block generated arrays of X's and Y'S for the higher-K and lower-K boundaries of the block. They also may be used to input certain Huygheng burn data, burn delay data, and tiej sliding data.

Block boundary coordinates may be inputted either as Cartesian data or as radius-angle data. The points in a line may be mixed Cartesian and Polar input.
This is also true tor the Huyghens shadow line input.

All point-by-point and zone-by-zone input starts at the $J$-max end of the K-lines.

This card may be followed by similar cards with or without the card name for all $X$ 's to be inputted at $K$-outer.

All boundary input uses a similar format. Table 3-78 shows the cards' names and uses.

\section{Burn Input}

Huyghens Shadow Input - If the "shadow" boundary of the block does not coincide with the K-max or K-min block boundary, the shadow points may be read in as input, with either Cartesian or radius-angle coordinates. The format is the same as that for the boundary point data. The first point listed should be the end nearest

Table 3-75. K-by-K input card format.

\begin{tabular}{lll}
$\begin{array}{l}\text { Field } \\
\text { use }\end{array}$ & Columns & Input and explanation \\
\hline $\begin{array}{l}\text { Card name } \\
\begin{array}{l}\text { Higher } \\
\text { K-number }\end{array}\end{array}$ & $11-10$ & KTOK \\
$\begin{array}{l}\text { Lower } \\
\text { K-number }\end{array}$ & $14-16$ & $\begin{array}{l}\text { Integer. Enter the number of the upper K (in the block) } \\
\text { for which K-by-K input is to be read. This is the number } \\
\text { of the K in the block not in the entire problem. } \\
\text { Integer. Enter the number of the lower K (in the block) } \\
\text { for which K-by-K input is to be read. }\end{array}$ \\
\hline
\end{tabular}

Table 3-76. Fini card format.

\begin{tabular}{lcl}
\hline $\begin{array}{l}\text { Field } \\
\text { use }\end{array}$ & Columns & Input and explanation \\
\hline $\begin{array}{l}\text { Card name } \\
\text { Comments }\end{array}$ & $1-10$ & FINI \\
$11-80$ & $\begin{array}{l}\text { The user may put anything in these columns. They are } \\
\text { ignored by the generator. It is useful in card handling to } \\
\text { have the words "of block number input" in tbese } \\
\text { columns. }\end{array}$ \\
\hline
\end{tabular}


Table 3-77. Higher-K boundary input card format.

\begin{tabular}{|c|c|c|}
\hline $\begin{array}{l}\text { Field } \\
\text { use }\end{array}$ & Columns & Input and explanation \\
\hline Card name & $1-8$ & BBPPXOUT \\
\hline$J-\max x$ & $9-16$ & $\begin{array}{l}\text { List the } X \text { for the } J \text {-max point of } K \text {-outer boundary. If this } \\
\text { is radius-angle input, this is the radius. If zero is to be } \\
\text { inputted, use a very small number, such as } 1 \mathrm{E}-10 \text {. }\end{array}$ \\
\hline Second $\mathrm{X}$ & $17-24$ & $X$-value at $J-\max -1$ \\
\hline Third X & $25-32$ & $\mathrm{X}$-value at $\mathrm{J}$-max -2 \\
\hline Fourth X & $33-40$ & $\mathrm{X}$-value at $\mathrm{J}-\max -3$ \\
\hline Fifth $\mathrm{X}$ & $41-48$ & $X$-value at $J$-max -4 \\
\hline Sixth X & $49-56$ & $X$-value at $J$-max - 5 \\
\hline Seventh X & $57-64$ & $\mathrm{X}$-value at J-max - 6 \\
\hline Eighth X & $65-72$ & $X$-value at $J-\max -7$ \\
\hline Label & $73-80$ & $\begin{array}{l}\text { This field is not used by the generator so may be used for } \\
\text { labeling. }\end{array}$ \\
\hline
\end{tabular}

Table 3-78. Boundary input cards.

\begin{tabular}{lcll}
\hline & $\begin{array}{c}\text { Cartesian } \\
\text { input use }\end{array}$ & $\begin{array}{c}\text { Polar input } \\
\text { use }\end{array}$ & $\begin{array}{l}\text { Card } \\
\text { name }\end{array}$ \\
\hline Outer $\mathrm{K}$ & $\mathrm{X}$ & Radius & BBPPXOUT \\
& $\mathrm{Y}$ & X-shift & BBPPYOUT \\
& - & Angle & BBPPANGO \\
Inner K & - & Y-shift & BBPPSFTO \\
& $\mathrm{X}$ & Radius & BBPPXIN \\
& $\mathrm{Y}$ & X-shift & BBPPYIN \\
& - & Angle & BBPPANGI \\
& - & Y-shift & BBPPSFTI \\
\hline
\end{tabular}

Table 3-79. Huyghens shadow input cards.

\begin{tabular}{lll}
\hline $\begin{array}{l}\text { Cartesian } \\
\text { coordinates }\end{array}$ & $\begin{array}{l}\text { Polar } \\
\text { coordinates }\end{array}$ & $\begin{array}{l}\text { Card } \\
\text { name }\end{array}$ \\
\hline X coordinates & Radius & BBPPXHYG \\
Y coordinates & X-shift & BBPPYHYG \\
- & Angle & BBPPANGH \\
- & Y-shift & BBPPDELY \\
\hline
\end{tabular}

to the detonator. Table 3-79 shows the names and uses of the cards.
Multiple Point Data Input-If multiple point input is used, the cards BBPPXHYG, 
BBPPYHYG, and BBPPDELY are used to input the $X, Y$, and delay times for each detonator. The card BBPPBRNV may be used with each burn time and each detonator. If a velocity is not entered for a point, the block detonation velocity will be used. This card is therefore not necessary if all velocities are the same.

The number of detonators must be entered on the HEPARAM card in block input. Th? maximum number of detonators that may be used is equal to the number of $\mathrm{J}^{\mathrm{t}} \mathrm{S}$ in the longest (in J count) $\mathrm{K}$-line in the problem.

\section{Tied Sliding Input (See Table 3-80)}

If all points are not tied at generation time, or any special status is desired for some points, the status $(2,3$, or 4$)$ may be inputted point-by-point at input time. (See "Slide-Lines and Voids, " p. 53, and "Tied Sliding," p. 62.)

Follow this card with similar cards, with or without the name, until the statis of all points has been described. The status of a point need not be redescribed if it is the same as that entered on the SLIDE-TYPE card of block input.

This card is put in the block boundary input of the block whose $\mathrm{K}$-max slave nodes are to be tied.
Fini Card

This card is similar in format to the previously shown fini cards. Columns 11 - 80 could contain the message "of block boundary input."

This card must be present for all blocks, whether a not block boundary input is actually present.

$\underline{\text { K-Line Input }}$

Data Input (See Table 3-81)

This data input should be present only if the KTOK input card in block input is present. As noted previously. if " $K-b y-K$ " input is called for, both " $K$-by- $K$ " and "point-by-point" input is read for the appropriate $\mathrm{K}$-lines.

This input generates $\mathrm{J}, \mathrm{K}$ points at $K$, and zonal data at $K+1 / 2$. If no zoning data is present in this sub-section, this input will not be used (except for the FINI card). This input overrides previous input.

The material number card is the same format as the KLINENZ card but is called KLINEMN.

The $X$ and $Y$ coordinates are read in using cards of the same format as the

Table 3-80. Tied sliding input card format.

\begin{tabular}{|c|c|c|}
\hline $\begin{array}{l}\text { Field } \\
\text { use }\end{array}$ & Columns & Input and explanation \\
\hline Card name & $1-8$ & BBTIED \\
\hline \multirow[t]{6}{*}{$\begin{array}{l}\text { Status J-max } \\
\text { sliding point }\end{array}$} & 9 & $\begin{array}{l}\text { Integer. List the status number }(2,3 \text {, or } 4) \text { for the J-max } \\
\text { sliding point. }\end{array}$ \\
\hline & 10 & J-max-1 point status. \\
\hline & 11 & J-max-2 point status \\
\hline & - & -- \\
\hline & - & - \\
\hline & 72 & $J-\max -63$ point status. \\
\hline
\end{tabular}


Table 3-91. K-line zoning card format.

\begin{tabular}{|c|c|c|}
\hline $\begin{array}{l}\text { Field } \\
\text { use }\end{array}$ & Columns & Input and explanation \\
\hline Card name & $1-10$ & KLINENZ \\
\hline Zones region 1 & $1 \quad 11-13$ & $\begin{array}{l}\text { Integer. If zero or blank, K-line input will not be used, } \\
\text { even though the KTOK card in block input called for this } \\
K \text { number. If not zero, this integer is the number of zones } \\
\text { in the first region. }\end{array}$ \\
\hline Zones region 2 & $214-16$ & Second regional zoning, Cartesian or Polar. \\
\hline Zones region 3 & $3 \quad 17-19$ & Third regional zoning, Cartesian or Polar. \\
\hline Zones region 4 & $420-22$ & Fourth regional zoning, Cartesian or Polar. \\
\hline Zones region 5 & $523-25$ & Fifth regional zoning, Cartesian or Polar. \\
\hline Zones region 6 & $626-28$ & Sixth regional zoning, Cartesian or Polar. \\
\hline Zones region 7 & $729-31$ & Seventh regional zoning, Cartesian or Polar. \\
\hline Zones region 8 & $832-34$ & Eighth regional zoning, Cartesian or Polar. \\
\hline
\end{tabular}

Table 3-82. $\mathrm{K}$-line input cards.

\begin{tabular}{lll}
\hline & Card name & Use \\
\hline KLINEDEN & Density \\
KLINEE & Energy \\
KLINEVOL & Volume \\
KLINEXVE & X-dot for points in K-region. \\
KLINEYVE & Y-dot for points in K-region. \\
KLINER & Radius (if Polar input). \\
KLINEINC & The angle increment (in degrees) in this region. \\
KLINEANG & (One increment per zone.) \\
KLINEXS & Angle (in degrees) of the J-min end of the region. \\
KLINEYS & Y shift or offset from zero.
\end{tabular}

Cartesian corner cards (CORNRMAX and CORNRMIN) in block input. The card name to use is KLINEXY. This card specifies the points $J, K$ on the $K$-line being generated. The points at $\mathrm{J}, \mathrm{K}+1$ are accepted from the previously generated K-line.

All of the other cards (except the Fini card) use the same format as the energy, volume, density cards (and others) in block input. Table 3-82 shows the uses and card names.

\section{The Fini Card}

The Fini card is the same format as the other Fini cards. It may be convenient to include a message "of K-line number " on the card.

If $K-b y-K$ input is called upon for a $K-l i n e$, this card must be present, even 
Table 3-83. X input card format.

\begin{tabular}{|c|c|c|}
\hline $\begin{array}{l}\text { Field } \\
\text { use }\end{array}$ & Columns & Input and explanation \\
\hline Card name & $1-8$ & KLPPX \\
\hline$J-\max X$ & 9-I6 & $\begin{array}{l}\mathrm{X} \text { of the J-max point. Radius if Polar. (Use } 1 \mathrm{E}-10 \text { to read } \\
\text { in a zero. A blank will leave the previously generated } \mathrm{X}^{\prime} \mathrm{s} \text {. }\end{array}$ \\
\hline$J-\max -1 X$ & $17-24$ & $\mathrm{X}$ of the $\mathrm{J}-\max -1$ point. \\
\hline$J-\max -2 x$ & $25-32$ & $X$ of the $J-\max -2$ point. \\
\hline$J-\max -3 x$ & $33-40$ & $\mathrm{X}$ of the $\mathrm{J}-\max -3$ point. \\
\hline$J-\max -4 x$ & $41-48$ & $\mathrm{X}$ of the $\mathrm{J}-\max -4$ point. \\
\hline$J-\max -5 x$ & $49-56$ & $\mathrm{X}$ of the $\mathrm{J}$-max - 5 point. \\
\hline$J-\max -6 x$ & $57-64$ & $X$ of the $J-\max -6$ point. \\
\hline$J-\max -7 x$ & $65-72$ & $X$ of the $J-\max -7$ point. \\
\hline
\end{tabular}

though no K-line data cards precede it. The point-by-point input subgroup must follow this.

\section{K-Line Point-by-Point Input}

This option allows the user to input detailed data for specific nodes and/or zones of the problem. Data is inputted in $\mathrm{K}$-line groups, i.e., if nodal data for a $\mathrm{J}, \mathrm{K}$ point, or zonal data for a $\mathrm{J}+1 / 2$, $\mathrm{K}+1 / 2$ zone is to be inputted; the appropriate $\mathrm{K}$-line is called for on the KTOK input card in Blcrk Input. The data is then listed on the appropriately labeled card (below). The data is listed with the $\mathrm{J}$-max end data first, the zonal data is listed with the $K+1 / 2, J-\max -1 / 2$ zone first.

Only the zones or nodies whose values are to be different than that described by previous input need be entered. A blank field will lez.ve the previously generated value, a zero must be entered by inputting an extremely small value such as $1 \mathrm{E}-30$.
Data Input (See Table 3-83)

If $\mathrm{K}-\mathrm{by}-\mathrm{K}$ input was called for with the KTOK card in block input, this input must be present. It need only consist of a Fini card, if no nodal or zonal quantities are to be read in. This input overrides all other input.

If more than the first $8 X^{\prime}$ 's are to be read in, this card is followed by similar cards, with or without the card name.

Table 3-84 shows all of the point-bypoint cards that use this same format.

Table 3-84. Point-by-point input cards, decimal format.

\begin{tabular}{ll}
\hline Card name & Use \\
\hline KLPPX & $\begin{array}{l}\text { X if Cartesian, radius if Polar. } \\
\text { Start at J-max point. }\end{array}$ \\
KLPPY & Y if Cartesian input. \\
KLPPXVEL & X-dot \\
KLPPYVEL & Y-dot \\
KLPPE & $\begin{array}{l}\text { Initial energy in the zone. } \\
\text { Starts at J-max - 1/2 zone. }\end{array}$ \\
KLPPVOL & Volume \\
KLPPDEN & Rho-zero \\
KLPPANGL & Angle of point if Potar input. \\
KLPPXSFT & X-shift if Polar input. \\
KLPPYSFT & Y-shift if Polar input. \\
KLPPBURN & Burn times. \\
\hline
\end{tabular}


Table 3-85. Point-by-point input cards, integer iormat.

\begin{tabular}{ll}
\hline Card name & Use \\
\hline KLPPMAT & $\begin{array}{l}\text { Integer. The material number } \\
\text { starts with J-max - } / / 2 \text { zone. }\end{array}$ \\
KBKTYP & $\begin{array}{l}\text { Integer. The point type number } \\
\text { starts with J-max point. }\end{array}$ \\
\hline
\end{tabular}

Two card types use the same columns as those shown in Table 3-85 but require integer input. The material number may be specified zone by zone. The first data field applies to the $J$-max - $1 / 2$ zone.

The calculation type number may be assigned point-by-point using a card of the same format but with integer input.

\section{Eini Card}

A Fini card must follow the point-bypoint input. (If the $\mathrm{K}-\mathrm{b} y-K$ input was called for by the KTOK card in block input, two Fini cards must be present for each K-line for which data is to be read. The first terminates the reading of the " $K-l i n e "$ input, and the second terminates the reading of the "point-by-point" input.)

\section{GENERATOR OUTPUT}

\section{Teletype}

When the problem has finished generating, the message "problem generated or restarted" $w$ ill be sent to the teletype. If sense switches 3 or 4 are on, the program $w$ ill send a message to the teletype after each block is generated, informing the user that the block has been gererated. For this purpose, the blocks are numbered in order of input so that the first block encountered will be number one.

Trouble messages print out on the teletype. If a card name does not match a vocabulary name, it is printed out. The error messages are shown in Appendix $B$ along with further explanation.

\section{On-Line Printer}

All of the above teletype messages are automatically printed on the on-line printout. In addition, all cards are printed out. A sequence of column numbers is periodically printed out between card printouts as an aid in card column checking.

\section{Off-Line Printer}

Everything that is printed on the online listing also appears on the off-line listing. In addition, important zonal and nodal data is printed in $\mathrm{K}$-line groups. The columns are labeled with headings that are largely self-explanatory. The quantity in the $\mathrm{MH}$ column is equal to twice the mass at $\mathrm{J}+1 / 2, \mathrm{~K}+1-1 / 2$ (as shown in the equation write-up in Ref. 1). MH does not include the $2 \pi$ term for cylindrical problems.

The last column (I-J) is the index value used to fetch and store the quantities in the $5-\mathrm{K}$ storage. It is useful in program dubugging.

Trouble Stops

The trouble stops are listed and explained in Appendix $\mathbf{B}$.

\section{MAIN CODE}

\section{Input to Main Code}

\section{Teletype, Sense Switch Control}

Certain modifications in frequency and type of output can be made while running through the use of the "sense switch" options. These are tabulated in Appendix A. 
Data Alteration

Service routines are required if alteration of the grid data is required (see "Service Routines," page 11. The data that is read in and processed by the "general input" section of the generator can be altered by those cards at restart time. The restart procedure is described in "Problem Restarting, "page 103.

\section{Tape Changing}

As the problem runs, it may fill the tape with the various types of output records. When it does, it adds one to the tape vault. A tape can be changed immediately after the restart dump is read in by setting that option on the restart card; see "Problem Restarting," page 103.

Output

\section{Teletype Output}

After tile problem has generated or restarted, the program will send teletype messages to the user under the following conditions.

(1) The problem has finished. An "all done" will be sent.

(2) The problem has terminated due to an error condition. Error stops are of two types, programmed stops and system interrupts. The program stops occur when certain tests show that the problem is in difficulty. An error message prints out, followed by an "all done." These error messages tell the nature of the difficulty. They are further explained in Appendix B. The system interrupts occur when the computer has difficulty in executing the instructions.
This may be due to faulty data, or machine error. An interrupt of this type will occur, for example, when division by zero is attempted. These errors are listed in LTSS (Livermore Time Sharing System) publications as Refs. 3 and 4.

\section{The On-Line Printer}

Certain key data is sent to the on-line printer to be printed out every problem cycle. This print-out can be studied after the problem has run to ascertain the problem's history.

In addition to the every cycle line, lines are printed whenever other types of output are written, when a pressure profile is used, and when a programmed interrupt occurs.

The eight columns of the every cycle line contain these numbers.

Column 1. The cycle number

Column 2. The problem time

Column 3. The delta-t (at $N+1 / 2$ )

Column 4. The $K$-number of the zone $(K+1 / 2)$ that is controlling the time step.

Column 5. The $J$-number $(J+1 / 2)$ of the time step zone.

Column 6. The sound speed in the zone that was used in time step calculation.

Column 7. The characteristic zone thickness of the zone that was used in calculating the time step.

Column 8. The actual calculation time of the previous problem cycle (in microseconds). 
This line is printed at the beginning of the problem cycle. The delta-T zonal information is the result of the running of the previous cycle.

Every 50 cycles, a problem name line is written (which includes the controller name and the load (map) name). This is follow ed by a line listing the headings of the every cycle line.

The programmed interrupts are listed in Appendix B.

The pressure profile line lists a pressure value for each surface if there is a pressure on any boundary. Only one number is listed for each boundary. It is the last nonzero pressure on each boundary (in order of calculation). Thus the $\mathrm{K}-\max$ and $\mathrm{K}-\mathrm{min}$ pressure listed will be at the $J$-max end of the pressure surface. The $J$-max and $J-m i n$ pressures listed will be at the $\mathrm{K}-\mathrm{min}$ end of the pressure surface.

\section{The Off-Line Printout}

The frequency and $K$-number of the on-line printout is controlled by input, see "General Input Section Discussion," page 33. Certain extra printouts can also be caller for by input.

The on-line supervisory line is also printed ofi-line.

For a K-line, the following types of off-line output may occur. The output is listed, in general, in the order that it would occur, along with an c..planation. The zonal data that is listed with a $\mathrm{J}, \mathrm{K}$ number is centered at $J+1 / 2, K+1 / 2$.

Name Line-For each $\mathrm{K}-\mathrm{l}$ ine printed, the paper is restored, and the problem name line is printed out. If the problem name begins with a "1", it is a plane case problem. If it begins with a "2" or " 2 ", it is a cylindrical case problem.
The name of the code file that was used to run the problem is listed, and the name that was assigned to the controllee at load time is listed.

Slide Z-Factor and Slide Labeling-If the $\mathrm{K}$-line to be printed is a "master" surface, a number labeled "Z-factor" will be printed out. This is the $Z$ described in Ref. 1.

If the $\mathrm{K}$-line to be printed is either surface of a decoupled boundary (slide-line), the message "slave surface(n)" or "master surface $(n)^{\text {it }}$ will be printed out. The message is bounded by asterisks. The number " $n$ " in the message is the calculational type number of the $J$-max point of that

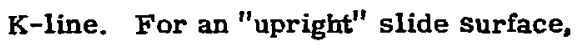
the "master" line will be printed out before the "slave" line. For in "inverted" slide surface, the "slave" line will be printed out before the "master" line.

Heading and Data Line - The beading and data line is similar to the supervisory line. It includes the $\mathrm{K}$-number of the $\mathrm{K}$-line to be printed, but it does not include the machine running time.

Eydro Nodal and Zonal Listing-For all of the $\mathrm{K}$-lines called for, the following columns for the entire $\mathrm{K}$-line are labeled and listed.

Column 1. J. The J number. Nodal variables on this line are centered at this $J$ and the $\mathrm{K}$ number of this $\mathrm{K}$-line. Zonal variables on this line are centered at $\mathrm{J}+1 / 2$,

\footnotetext{
Appendix B, Section I, 3, e, vi of Ref. 1.
} 
$K+1 / 2$. The zonal variables are listed as zero for those nodes for which there is no associated zone at $\mathrm{J}+1 / 2$, $\mathrm{K}+1 / 2$.

Column 2. RHO. The rho-zero of the material in the zone.

Column 3. $\mathrm{X}$. The $\mathrm{X}$ coordinate.

Column 4. $\mathrm{Y}$. The $\mathrm{Y}$ coordinate.

Column 5. X-DOT. The velocity in the $\mathrm{X}$ direction. A positive $X$-dot indicates that a point $X$ is increasing in value (moving to the right). A negative $X$-dot indicates that the $\mathrm{X}$ is decreasing in value.

Column 6. Y-DOT. The velocity in the $\mathrm{Y}$ direction. A positive $\mathrm{Y}$-dot indicates that a point $Y$ is increasing in value (moving up). A negative $\mathrm{Y}$-dot indicates that the $\mathrm{Y}$ is decreasing in value.

Column 7. V. The relative volume. It is equal to one over the compression.

Column 8. P. Pressure (megabars).

Column 9. E. Energy (megabar-cc per original cubic centimeter).

Column 10. Q. The artificial viscosity term.

Column 11. F. The burn column. If the zone is $\mathrm{HE}$, and the quantity is negative, $F$ is the burn time. If it is a plus one, the zone was burned. This column is sometimes used for special purposes for non-HE zones.
Elastic Listings - If the K-line being printed has zones associated with it, and if it includes a zone(s) of elastic material, two sets of zonal quantities will be printed out. The first set of columns contain the following data.

Column 1. J. The J number.

Column 2. RHO. The density.

Column 3. EDXX. E-dot-xx. The velocity strain in the $X$ direction.

Column 4. EDYY E-dot-yy. The velocity strain in the $\mathrm{Y}$ direction.

Column 5. EDTT. E-dot-theta-theta. The velocity "hoop" strain.

Column 6. EDXY. E-dot-xy. The velocity shear strain.

Column 7. VDOT/V. V-dot over V. The rate of change of the volume.

Column 8. SXXE. The elastic stress in the $X$ direction (stress deviator).

Column 9. SYYE. The elastic stress in the $\mathrm{Y}$ direction (stress deviator).

Column 10. STTE. The elastic hoop stress deviator.

Column 11. TXYE. The elastic shear stress deviator.

The second zonal elastic printout has the following columns.

Column 1. $\mathrm{J}$

Column 2. RHO

Column 3. MU. The shear modulus.

Column 4. Y-ZERO. The yield number.

Column 5. S1. Principal stress deviator one.

Column 6. S2. Principal stress deviator two. 
Column 7. S3. Principal stress deviator three.

Column 8. IPD. Internal plastic distortion.

Column 9. OSS. Octagonal shear stress. Column 10. Not used.

Column 11. K-ELASTIC. The $\mathrm{K}$ used in the Von Mises yield condition. If it is negative, the zone has not yielded. If it is positive, the zone has yielded.

Column 12. TANPHI. The tangent of the angle of the vector of the maximum principal stress. (This number is used to plot the vector on the CRT plot output.)

Navier-Stokes Printout-If the K-line includes any zone that is using the NavierStokes $Q$, the following printout will be written.

The first seven columns are identical to the first seven columans of the first elastic printout. The last four columns are as follows:

Column 8. QXX. The Navier-Stokes deviatoric component in the $\mathrm{X}$ direction, plus the scalar component.

Column 9. QYY. The Navier-Stokes deviatoric component in the $\mathrm{Y}$ direction, plus the scalar component.

Column 10. QXY. The Navier-Stokes "theta" deviatoric component, plus the scalar component.

Column 11. QXY. The Navier-Stokes shear deviatoric component, plus the scalar component.
Debug Printout-If the debug printout has been called for by input, the following columns will be written for all $\underline{\mathrm{K}}$-lines.

Column 1. J

Column 2. RHO

Column 3. P-SIGX/X. The sum of the sigma-x's times the $X$ arms.

Column 4. P-TXY/Y. The sum of the $T$-xy's times the $X$ arms.

Column 5. ALPHA. The sum of the alpha zonal subterms divided by four.

Column 6. P-SIGY/Y. The sum of the sigma-y's times the $X$ arms.

Column 7. P-TXY/X. The sum of the $T$-xy's times the $Y$ arms.

Column 8. BETA. The sum of the beta zonal sub-terms, divided by four.

Column 9. AREA. Twice the area at time $n+1$ of the zone.

Column 10. QCOEF. The $Q_{A}$, rho, area, $V$ terms used in the quadratic portion of the $Q$. (All terms except the $V-\operatorname{dot} / \mathrm{V}$ term of the quadratic portion.)

Column 11. 1/TWOPHI. One divided by two phi used in the velocity calculations.

Column 12. SOUND-SPD. The sound speed squared in the zone.

Energy-Mass Summation-At the end of each cycle for which printouts have been called, an energy-mass summation for the entire problem will be written.

Problem name and cycle links will be written. These will be followed by a line with the following data.

Column 1. (TOTAL E.) The total energy in the problem at this time. In cylindrical problems, $\because$ 
is the total energy with the zones rotated completely around the $X$ axis.

Column 2. (E-ZEROJ The total energy at time zero.

Column 3. (E-CHANGE) The percent of change in the total energy from time zero to the present. If it is negative, energy has been lost. If it is positive, energy has been gained.

Column 4. (KE SUM) The total kinetic energy in the problem.

Column 5. (IE SUM) The total internal energy in the problem.

Column 6. (MASS-SUM) The total mass (in grams) in the problem. In cyclindrical problems, this is the rotated mass, including the Pi terms.

The problem total line is followed by lines that list mass and energy by material numbers. If a material number in a problem is separated by at least one $\mathrm{K}-\mathrm{zone}$, it is listed separately (see Fig. 3-18a). If a material number appears in two consecutive $\mathrm{K}$-lines, it is treated as one material even though the zones may not actually touch (see Fig. $3-18 b$ ). The following columns are printed.

Column 1. (MATERIAL) The material number.

Column 2. (MASS) The mass of the material (rotated around the $\mathrm{X}$ axis and including $\mathrm{Pi}$ terms if cylindrical).

Column 3. (TOTAL ․) The total energy in the material.

Column 4. (KINETIC E.) The total kinetic energy in the material.
Example a.

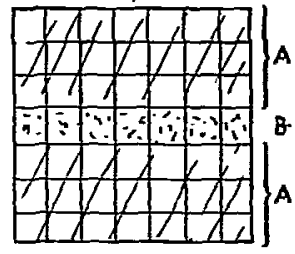

Material A will be listed twice
Exomple b.

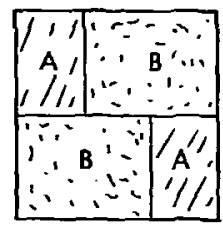

Both material A and material $B$ will be listed only once
Fig. 3-18. Examples of mass energy summation.

Column 5. (INTERNAL E) The total internal energy in the material.

\section{Tape Output}

If a tape vault number is entered in the output field of the initiation line, tape output will be written. If a tape number is not entered, no tape output will be written.

Three types of binary output are written on the tape. They are identified on the tape by identification words at the start of certain records, and by the record order. The last HEMP record on a tape is a short "end sentinel" record that is used to indicate that the preceding record was the last record written. The first word of the end sentinel record is the ASCII representation of the alpha-numeric characters "END SEN'TIN." This end sentinel record is always preceded immediately by an "end of fille" mark.

Restart Dumps - The restart dump consists of a group of records, one for each K-line, plus a control or "Table" record. The control record is first, followed by the $K$ records in a descending $K$ order. For each slide boundary, two records are 
written. The first word of the Table record is the problem cycle number in fixed format. The Table record is all of the common block "A001". The K-line format is identical to the grid layout for a $\mathrm{K}$-line ("The Grid", page 17). The restart dump is always preceded and followed by an "end-of-file" mark. Other types of records are never mixed in with the restart records between "end-of-file" marks.

CRT Output - The cathode ray tube records are written in $\mathrm{K}$ descending order in a manner similar to the restart records. They are preceded by a control cecord. The first word of the control record is the octal word 2777777777777777777.

The first word of each $K$ record is the number of zones in that $\mathrm{K}$-line (an integer). The second word is the $K$-type of the $\mathrm{J}$-max node of the $\mathrm{K}$-line (an integer). The nodal data follows in groups of five for each node (or zone) in the $Y$-line. The five words of data in the group are: $X, Y$, Q, TANPHI, and the equation-of-state number.

The CRT records may be mixed with "binary output" records if both are called for at the same cycle.

The CRT records are preceded and followed by "end-of-file" marks.

Binary-Output - The flexibly formatted output is referred to as "binary-Jutput" although all of the tape data is in binary format. The nature of the content of this output is described in "Output Control, " page 35.

Each K-line of output called for produces two or more records. The first record is a contrel record of which the first word is the octal word 00000000000007654321 .
Each group of ten output variables produces a record consisting of the ten variables for all the J's of the $\mathrm{K}$-line, plus an initial identification word (octal 000000000000 1234567).

The K-1ines from this binary-output will be intermixed with CRT K-lines if both are written the same cycle. These records are preceded and followed by an "end-oź-file" mark.

\section{Disk Output}

Disk output is written only for CRT output, and only when called for by the word "disk" in the output field of the initiation line. It produces a group of files named "CRTHM-...-.-." The dashes represent the right-adjusted cycle number of the first cycle written in that file. About 20 output cycles are contained in each file.

These files can be plotted later by the plot routine. This disk output is very useful for the initial trial runs of a problem because no tape need be mounted but plots can be produced.

Trouble Stops-The trouble stops are listed and explained in Appendix B.

\section{PROBLEM RESTARTING}

"The Overlay", page 15, explains the ways in which a problem may be restarted from a dump on the dump tape.

If data is to be changed, or if a tape is to be changed immediately after restarting, a restart file must be used.

The Restart Deck

The file's L.D. card is followed by a group of general input cards that make 
Table 3-86. Restart card format.

Field

use

Card name

Cycle number

11-15

Tape change $\quad 16-20$
Input and explanation

RESTART

Integer. Enter the cycle number of the dump to be restarted. Leave blank if the last dump on the tape is to be restarted.

Integer or tape number. Set not zero to cause an immediate tape change after restarting. If set to 1 (column 20), the tape number will be upped by one (1). If a tape formatted name is entered (example AB401), the code will switch to that tape number. the desired changes, if any, and includes a "restart" card of the following format (see Table 3-86).

A "fini" card must terminate the deck.

\section{General Data Changing}

All general data cards may be used at restart time to change data.

\section{Edit Change}

Frequently output frequency and termination time are changed at restart time. The card input and prosedure to do this is explained in "Output Control", page 35.

\section{Dump Frequency Change}

Dump frequency changing is explained in "Output Control", page 35.

\section{Grid Changes}

The data of the HEMP grid may be changed by "service routines" which read a dump, alter the grid data, and write a new dump. This new dump is then read and restarted by the HEMP program. A number of types of service routines are discussed in "Service Routines 2. Grid Restructuring", pages 11, 12.

\section{Acknowledgments}

A number of programmers in addition to myself have been associated with this HEMP programming effort. Tokihiko Suyehiro has worked directly with the HEMP program. Allen Leibee has programmed aii of the plot and service routines. Jack Almstead (then of Sandia Laboratories) did much of the early programming.

Mark L. Wilkins originated HEMP and has directed all HEMP activities. 


\section{References}

1. Mark L. Wilkins, Calculation of Elastic-Plastic Flow, Lawrence Livermore Laboratory, Rept. UCRL-7322, Rev. 1 (1969).

2. G. Maenchen and S. Sack, "The Tensor Code," in Methods in Computational Physics, B. Alder, S. Fernbach, and M. Rotenberg, Eds. (Academic Press, New York, 1964), Vol. 3, pp. 181-210.

3. H. Gin, Livermore Time-Sharing System, M-026, Chapter 107, "Standard Error Procedure," Lawrence Livermore Laboratory, LTSS-107 (1968).

4. P. DuBois, H. Coverston, D. Storch, and G. Powles, Livermore Time-Sharing System, M-026, Chapter 10, "7600 System Calls and I/O Requests," Lawrence Livermore Laboratory, LTSS-10 (1970). 


\section{Appendix A}

\section{HEMP Teletype Sense Switch Controls}

Table A1. HEMP telerype sense switch controls.

\begin{tabular}{llll}
\hline Control & Switch & \multicolumn{1}{c}{ Use } & \multicolumn{1}{c}{ Explanation } \\
\hline $\begin{array}{l}\text { Restart } \\
\text { dump } \\
\text { control }\end{array}$ & SW1. & $\begin{array}{l}\text { Dump and } \\
\text { terminate } \\
\text { Dump and go. }\end{array}$ & $\begin{array}{l}\text { Dump a restart file and terminate the run as } \\
\text { soon as this switch is detected on. } \\
\text { Dump a restart file and run in a tight loop } \\
\text { until sw2. is taken off. Then proceed with } \\
\text { the run. (The tight loop wastes time.) }\end{array}$ \\
$\begin{array}{llll}\text { Teletype } \\
\text { supervisory } \\
\text { control }\end{array}$ & SW3. & $\begin{array}{l}\text { Cycle by cycle } \\
\text { and messages } \\
\text { when editing }\end{array}$ & $\begin{array}{l}\text { Write on TTY a cycle by cycle message giving } \\
\text { cycle, time, etc. } \\
\text { Write a special message on TTY (Teletype) } \\
\text { when a dump, printout or CRT is written. }\end{array}$ \\
& SW4. & $\begin{array}{l}\text { Messages } \\
\text { when editing }\end{array}$ & $\begin{array}{l}\text { Write a special message on TTY when a } \\
\text { restart dump, off-line printout or CRT } \\
\text { output is written. }\end{array}$ \\
$\begin{array}{l}\text { Printout } \\
\text { and CRT } \\
\text { control }\end{array}$ & SW5. & Write CRT & $\begin{array}{l}\text { Write CRT output every cycle as long as this } \\
\text { switch is on. } \\
\text { Write off-line output and CRT output every } \\
\text { cycle as long as this switch is on. }\end{array}$ \\
\hline
\end{tabular}




\section{Appendix B \\ Trouble Stops and Interrupts}

System interrupts occur when the computer has difficulicy in executing the instructions of the program. These difficulties may accur due to faulty data, due to machine error, or due to programming error. These errors are of two types and are listed in Refs. 3 and 4. A common error is "202" which occurs when division by zero is attempted. It usually occurs at generation time and is usually due to faulty input.

The system interrupts are printed out on the teletype along with the adiresses where they occurred. If the trouble can not be found by a study of the input, the address can be used with the load map to ascertain the exact nature of the difficulty.

The programmed trouble stops list out a message on the teletype, on the on-line printout and on the off-line printout. The message may be somewhat briefer on the TTY than on the other output devices.

Listed below are the messages and a further explanation of the difficulty. Where two messages are listed, the shorter one is the teletype message. The name of the subroutine that sends the message is listed.

\section{TROUBLE MESSAGES FROM THE GENERATOR}

- Number of $\mathrm{K}$-zones in a block is zero." The user failed to correctly provide a NKZONESBLK card in each block. GENRAA.

" Sum of block K-zones greater than input NL - 1." The sum of the values on all of the NKZONESBLK cards is greater than the number of K-lines entered on the GEN ERAL card minus one. GENRAA.

- "Number of J-zones in a block is zero." The JZOUTC and/or JZOUTP card is missing or incorrect. GENRAA.

- "Too many zones in this block." The sum of the J-zones called for in a block is greater than the number entered in the "Max-j" field or the GENERAL card minus one. GENRAA.

- $V=0$ at mass calculation time. Material number . $\mathrm{V}=0$ has been inputted for material number - GENRAa.

-"Sum of block K-zone input less than NL - 1." The sum of the values on all of the NKZONESBLK cards is less than the number of $\mathrm{K}$-lines entered on the GENERAL. card minus one. GENRAA.

-"Error - card not found in GEN input vocabulary." A card in the general input group is not in the vocabulary list. The card is printed out. INGNAA.

-"Error - card not found in block input vocabulary." A card in the block input subgroup is not in the vocabulary list. The card is printed. INBKAA.

-"Error = card not found in block boundary PT-BY-PT." A card in the block boundary subgroup is not in the vocabulary list. The card is printec.. INBPAA. 
-"Error - card not found in K-line input vocabulary." A card in the K-BY-K input subgroup is not in the vocabulary list. The card is printed. INKLAA.

-"Error - card not found in K-line PT-BY-PT vocabulary." A card in the

$\mathrm{K}-\mathrm{BY}-\mathrm{K}, \mathrm{PT}-\mathrm{BY}-\mathrm{PT}$ input subgroup is not in the vocabulary list. The card is printed. INKPAA.

-"First call trouble." Machine error, try again. ENEMAA.

-"Second call trouble." Machine error, try again. ENEMAA.

-"Third call trouble." Machine erros, try again. ENEMAA.

-"THEMP to THEMPA." Machine error, try again. ENEMAA.

-"THEMPA to THEMPB." Machine error, try again. ENEMAA.

-"THEMPB to THEMPA." Machine error, try again. ENEMAA.

-"SCM goof." Machine error, try again. ENEMAA.

-"Number of zones inner edge of block does not equal number of zones in outer edge". "Inner zone number does not match outer." NZINAA.

-"Input for a region specifies zone count for both Cartesian and Polar." "Inner block input has both Cartesian and Polar for a region." NZINAA.

-"Input for a region specifies zone count for both Cartesian and Polar." This message refers to the $K$-higher input. NZOTAA.

-"Block I/P. A block has too many $\mathrm{J}$-zones per $\mathrm{K}$-line." This message refers to the K-higher input. NZOTAA.

- Input error-number of zones in a specified $\mathrm{K}$-line does not equal number zones per $\mathrm{K}$ in this block zone." "Zone count in a $\mathrm{K}$-line does not match block count." KLINAA.

- "Equation-of-state input number is zero or over 60." A material number is missing or faulty. CRETAA.

-"Huyghens shadow surface is not properly described to the generator." The SHADOW card in general input is missing or incorrect. HUYGAA.

-"Unable to create a tape file." Machine error. Try again. CONTAA.

-"Lab error." Machine error. Try again. CONTAA.

- "Trouble in brute force sweep, upright volume VUPB." This stop indicates that the initial, methodical search to determine which line (from the "slave" point to $\mathrm{K}-1$ ) intersects which slide "master" segment has not been able to find a solution. This is usually due to input error. (The line from the sliding point to K-1 must not be of zero length.) VUPBAA.

-"Trouble in brute force sweep, inverted volume. VINB." This message is similar to the one for VUPB but for inverted slide-line. VINBAA.

-"J-min upright slide-line extension input is faulty." The user did not correctly specify the J-min upright extension direction. U22CAA.

- "J-max upright slide-line extension input is faulty." The user did not correctly specify the J-max upright extension direction. U22CAA.

- "J-min inverted slide-line extension input is faulty." Similar to above but for inverted slide-line. U72CAA. 
- "J-max inverted slide-line extension input is faulty." Similar to above but for inverted slide-line. U72CAA.

\section{THE FOLLOWING MESSAGES MAY BE PRINTED OUT DURING GENERATION,} OR WHILE RUNNING THE CYCLING CODE

\footnotetext{
-"General uprigft $U$ search trouble. No intersection." The line from an upright "slave" point to $\mathrm{K}-1$ does not intersect a "master" segment. Usually indicates a scrambled grid. VUPBAA.

-"General inverted V search trouble. No intersection." VING. The line from an inverted "slave" point to $\mathrm{K}-1$ does not intersect a "master" segment. Usually indicates a scrambled grid. VINBAA.
}

\section{THE FOLLOWING STOPS MAY OCCUR DURING THE RUNNING OF THE CYCLING "MAIN" PROGRAM}

-"Upright slide-line velocity brute force failure." The line that must intersect the line segment from "slave" zone center tc "slave" zone center fails to find a solution. If this stop occurs during the running of the first cycle, input is faulty. U22BAA.

-"Inverted slide-line brute force search failure." Similar to above but for inverted slide-line. U7 2BAA.

-"General upright slide velocity search failure." The intersection used in the upright slide-line calculation can not be found. Usually indicates scrambled slide-line. U22GAA.

-"Slide-line velocity search failed. Inverted general sweep." Similar to above but for inverted slide-line, U72GAA.

-Record length error. PRNT. Machine or tape trouble. PRNTAA.

-Tape trouble ICRT = PRNT. Tape trouble. PRNTAA.

"No output types specified for binary output." Binary output was called for but no type numbers were inputted. An input error, but it will not be evident until the first time that "Binary" output is to be written. BINOAA.

-(EOF ICRT). Taje trouble or machine trouble. BINOAA.

-"Tape trouble ICRT = Binary." Tape trouble or machine trouble. BINOAA.

- "Binary output list number too big." A number called for as a binary output type is too big. BINOAA.

-" $Q$ has reached limit at $K=$ $J=$ QSTOP." The $Q$ at the zone listed has reached 100 or the value inputted as the $Q$ stop value. EDITAA.

-"Minimum Delta-T has been reached." The Delta-T (Time Step) has gone below the lower value permitted. DELTAA.

-"Tape trouble ICRT = Dump:" Tape trouble during the restart dumping procedure. DUMPAA. 


\title{
Appendix C \\ Adaptation to Other Machines and Systems
}

\author{
SPECIAL CHARACTERISTICS OF LLL FORTRAN (CHAT)
}

CHAT is an extension of Fortran IV. It includes a number of capabilities that are not available in Fortran IV.

The "cliche" capability (macro) allows the user to define and assign a name to a block of coding. Whenever that name appears in the program, the compiler inserts that block of coding. In HEMP it is used only to set aside the "common" blocks as a cliche (named HEMP). Each subroutine includes a card "use HEMP" which inserts the commons in each subroutine. This enables the user to compile many or all of the subroutines at once with only one set of common cards. A user at a facility without this feature will have to provide a common for each subroutine.

Shift instructions are provided in CHAT. These are used by HEMP in decoding the teletype input. Because other computer facilities do not have identical TTY hardware and interfaces, this section will have to be removed; therefore, the shift instructions will not be needed.

Many "system calls" are used by HEMP in teletype communication (CONTAA), in memory expansion (ENEMAA) and in changing high speed output tape (CHSPAA). As the HEMP program generates or restarts a problem, it calls for more and more of the large core memory (LCM). For a machine without an LCM (extended core) the expansion will not be necessary. The ENEMAA subroutine also sets up the index increments for the various $\mathrm{K}$-line long arrays of variables.

CHAT has a "logical if" teat that is an extension of the FORTRAN IV logical if test. The Statement:

IF (NUMBER1) NUMBER2 = NUMBER1

will leave "NUMBER2" unaltered if NUMBER1 is equal to zero, but will set NUMBER2 equal to NUMBER1 if NUMBER1 is not equal to zero. These tests are used in the subroutine "INGNAA."

CHAT allows the use of a "parameter" card which defines the value of the named parameter. Whenever the name is encountered, the assigned value is substituted.

\section{TO CONVERT TO RUN ON DISK, DRUM OR TAPE}

The HEMP program treats the LCM (large core memory) much as if it were an external storage device. The LCM is read and written, but no calculations are done directly with the grid as it resides in LCM. LCM is read and written a K-line at a time. Data is transferred between LCM and the area laid out for the five K-lives in SCM (small core memory). The $\mathrm{K}$-line that is being read in is not used by the $\mathrm{K}-1$ ine being calculated at that time. The LCM reads and writes may therefore be converted 
to disk, drum, or tape reads and writes and be fully buffered. Conversion to tapes is not desirable because of the high frequency of tape reading and writing errors. If tapes are used, four working (scratch) tapes must be provided with the code reading and writing a pair on alternate cycles. Four are used so that the first half of the $\mathrm{K}$-lines may be written on and read from two tapes and those tapes rewound, while the second half of the $\mathrm{K}$-lines are being read and written on the other two tapes. The firsthalf tapes are then ready to be read and written at the start of the next cycle while the second-half tapes are being rewound. Reads and writes and calculations are done simultaneously.

If conversion to disk or drum is to be done, two independent units and exchanges should be utilized. Then the reads, writes, and calculations can be done simultaneously. Read-write heads should have to be repositioned only once per cycle per disk. If only one disk or drum is available, the K-lines should be arranged in the file in such a manner that after each access, the proper $\mathrm{K}$-line follows immediately. This requires a rotation of $\mathrm{K}$-line through the various $\mathrm{K}-\mathrm{line}$ slots on the unit so that a particular $\mathrm{K}$-line is moved from position to position as the problem cycles through its run.

LCM read-writes are done in the generation (GENRAA), the cycling routine (CYCLAA), the dump (DUMPAA), and the restart (REGOAA) routines.

\section{THE OVERLAY}

The overlays can be combined into a single load if space is available and the overlay system is not available. The generator overlay can be separated from the cycling overlay and each treated as a separate program. If so, a restart tape could be written by the generator, and the main code would read this and run, just as if it were restarting from a running dump. Subroutines used by both the generator and the cycling code must be provided to both. This would include those routines now in level one, except the present control (CONTAA) routine.

\section{CONVERSION PROCEDURE}

A method to proceed with a conversion to another machine would be to make the necessary decisions on methods based on the above information, convert the CLI routine to commons, then compile all routines. The incompatible statements will appear as errors on the compilations. These can then be corrected individually. 


\section{Appendix D: Input Sheets}

The input sheets serve $\varepsilon$ s a convenient means of inputting much of the most common input.

Several block input sheets are shown because all of the types of input could not be included on one sheet. These block input sheets can be combined in any way to run problems.

\section{K-Line}

No input sheet for K-line input has been made because of the infrequency of its use. 


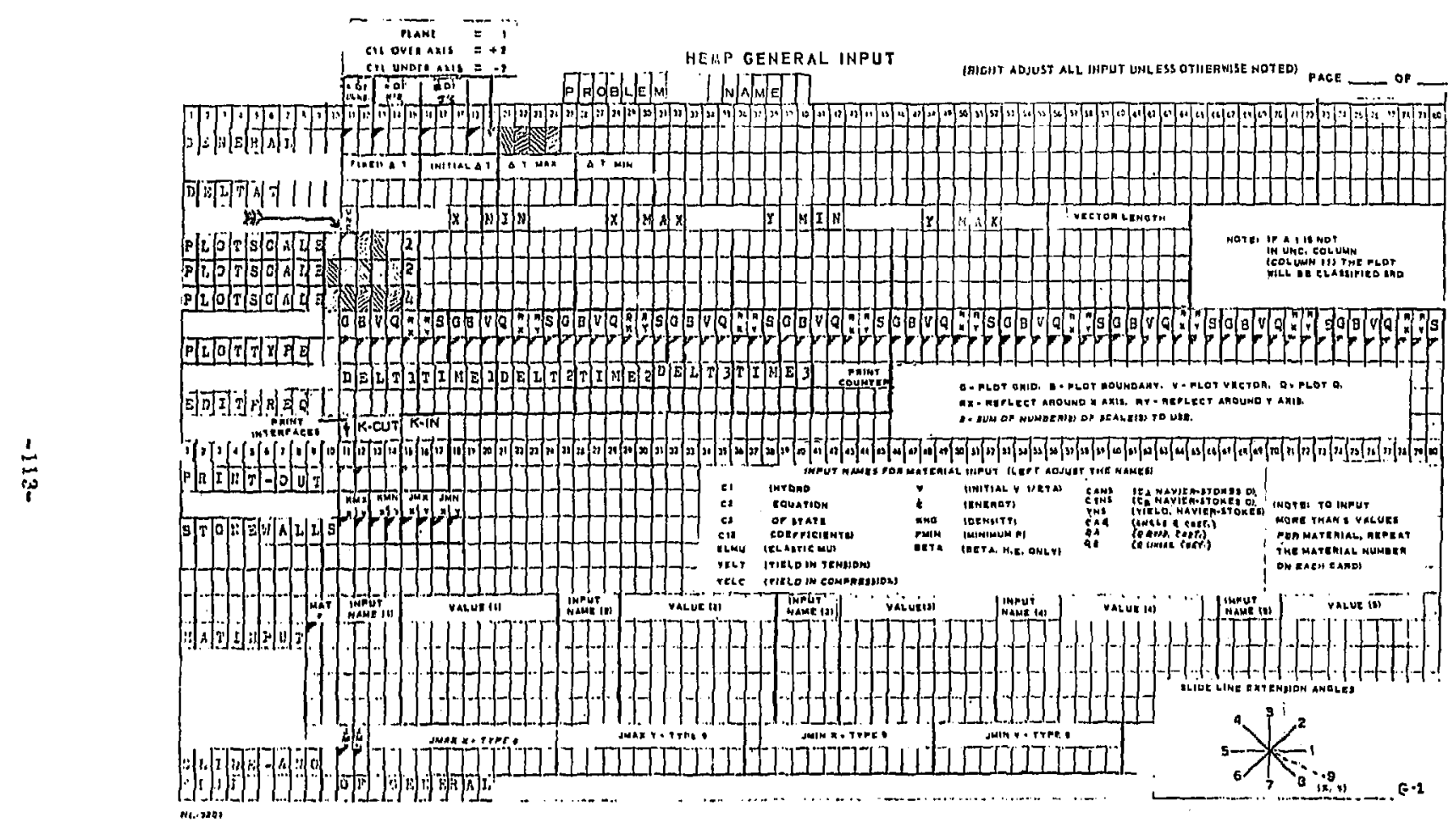


โว่'38

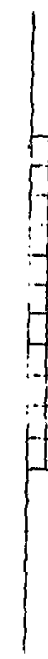

(1)

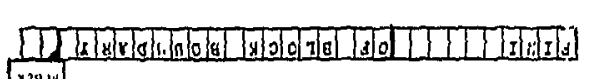
ining

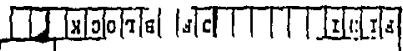

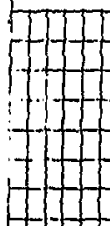

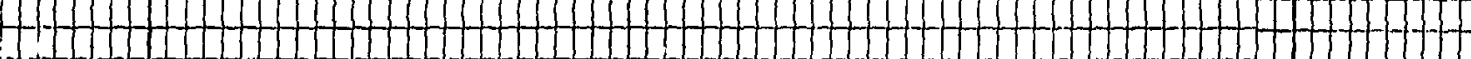
-

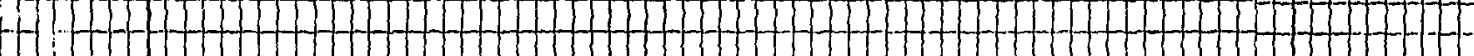
(i)<smiles>CC(C)(C)C(C)(C)C</smiles>

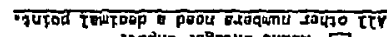

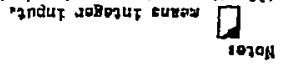

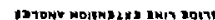

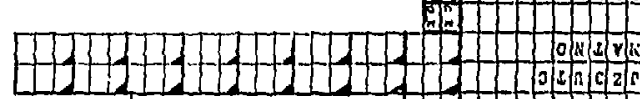

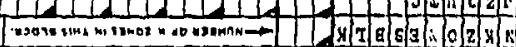

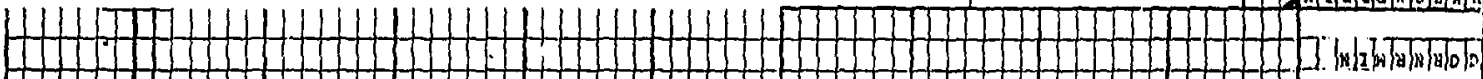

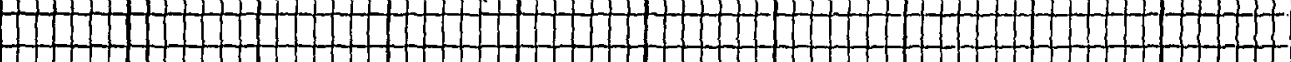

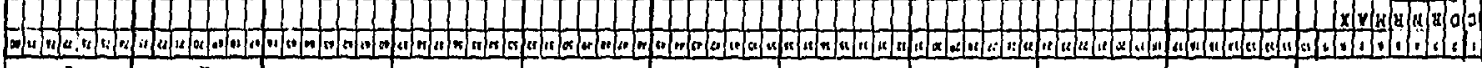

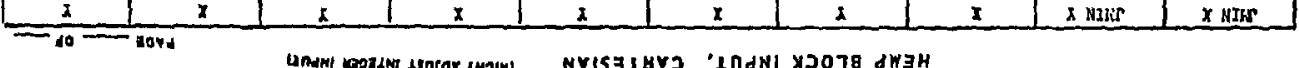




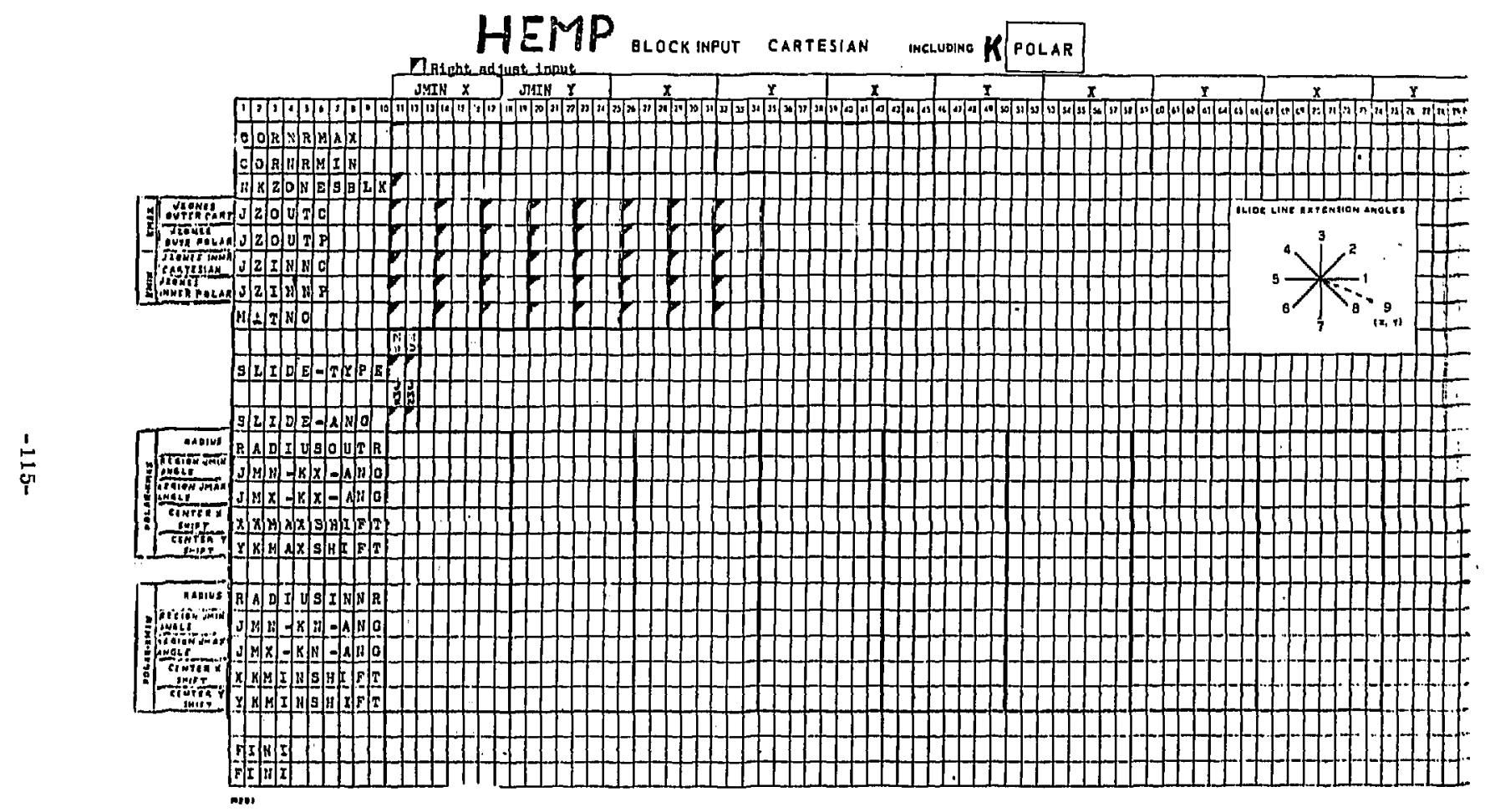




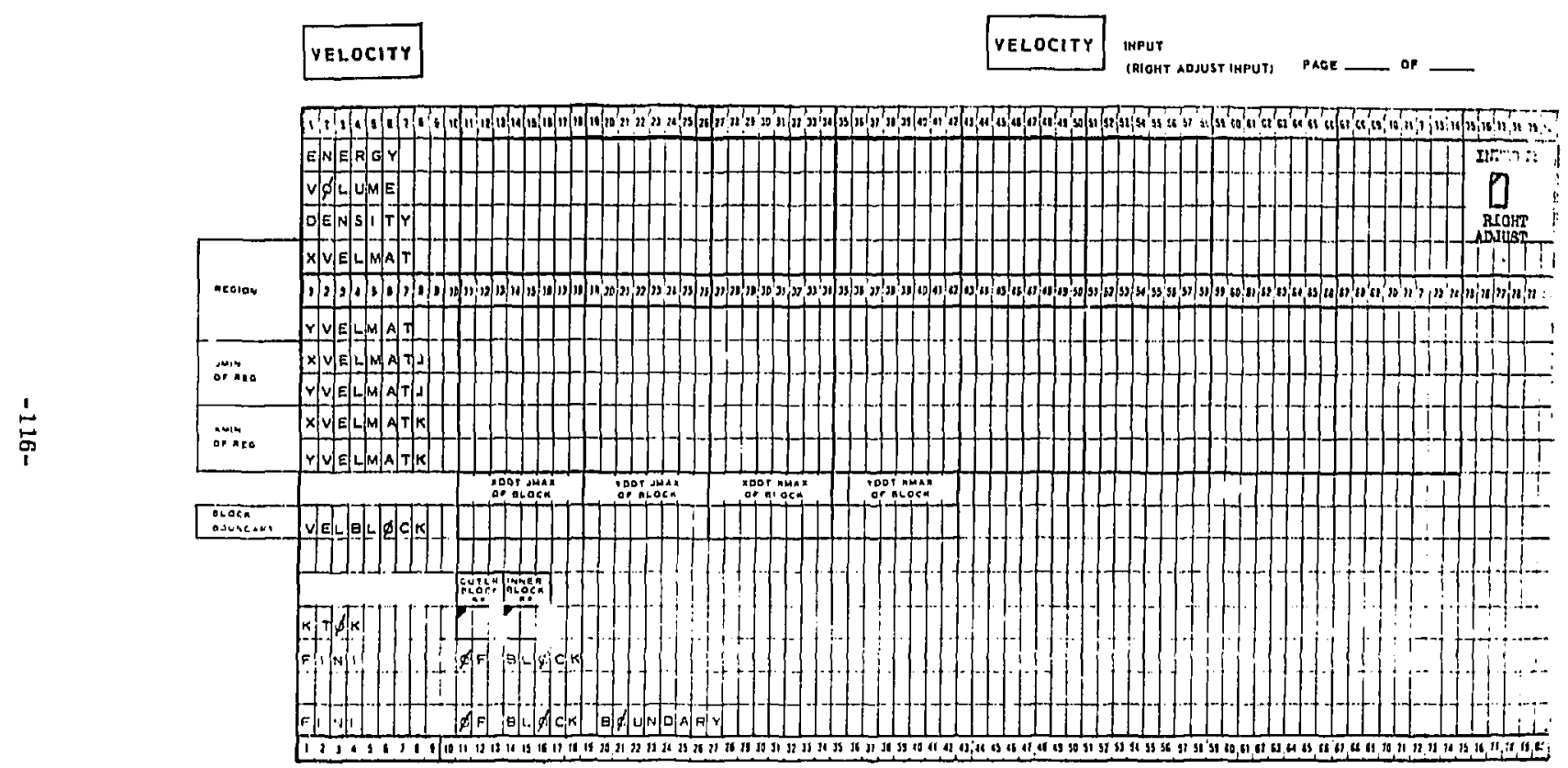




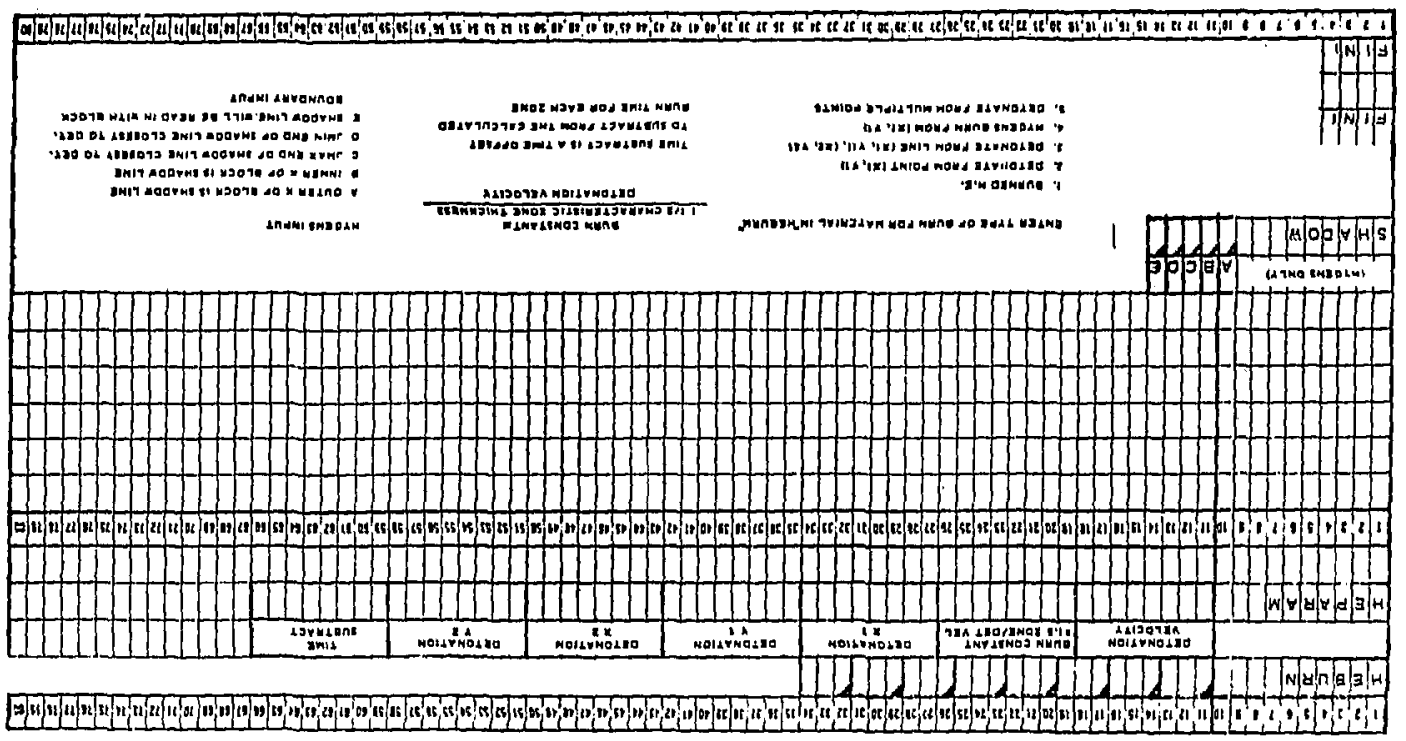

ED.

$$
\exists \cdot H \text { dW } \exists H
$$




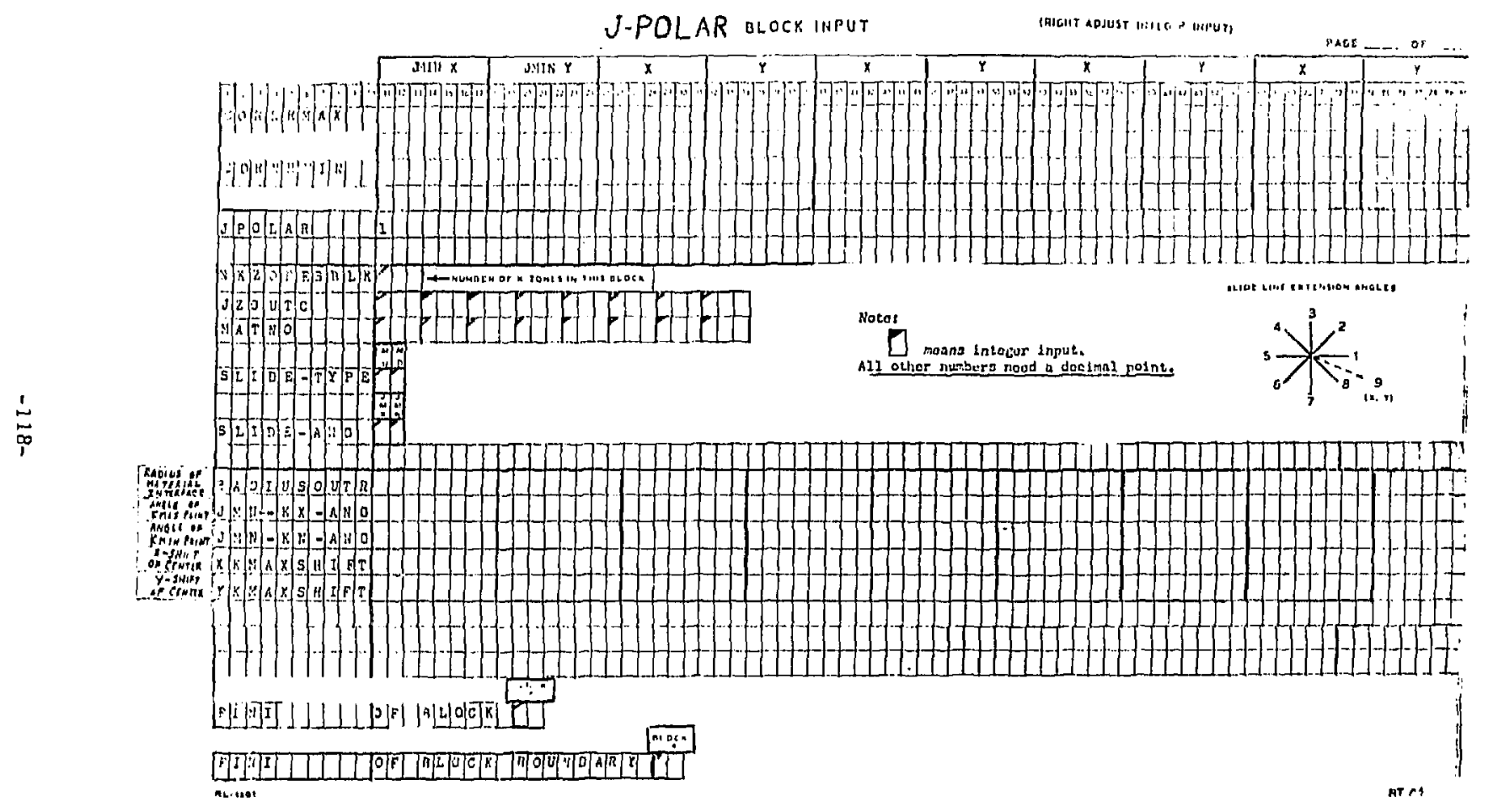




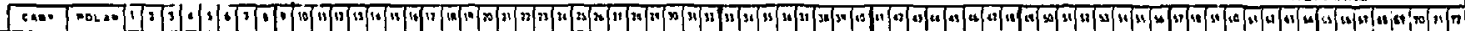

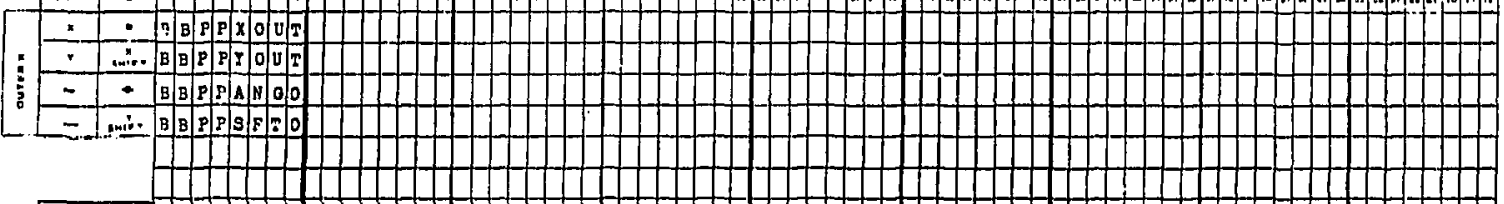

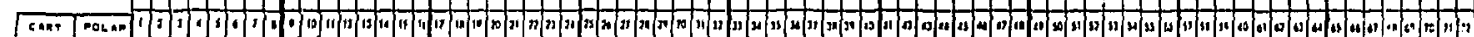

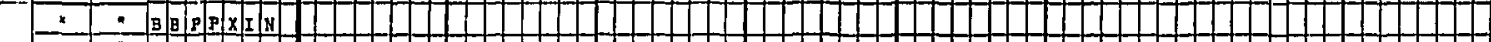
:

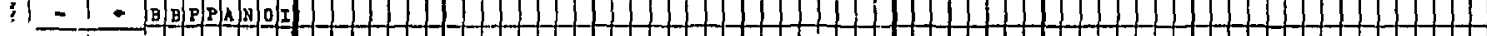
$\stackrel{i}{\varphi_{i}^{\prime}}$

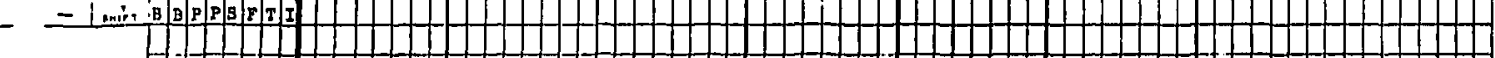
anc

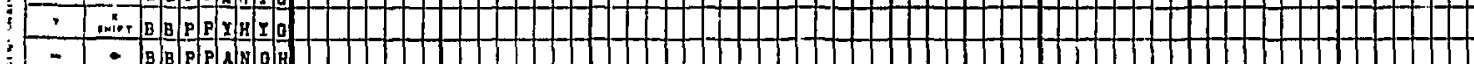

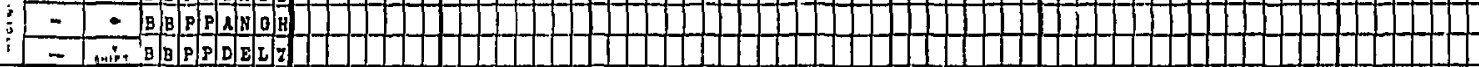

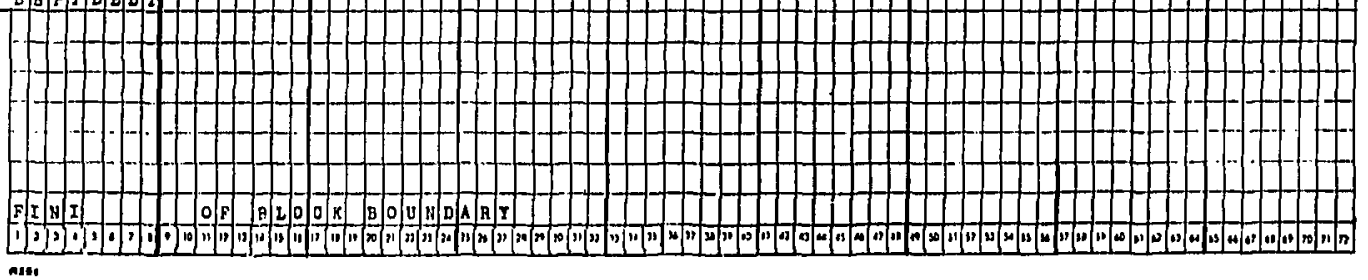


K.LINE POIIIT GY POINT IOA ZONEQY ZONE) INPUT

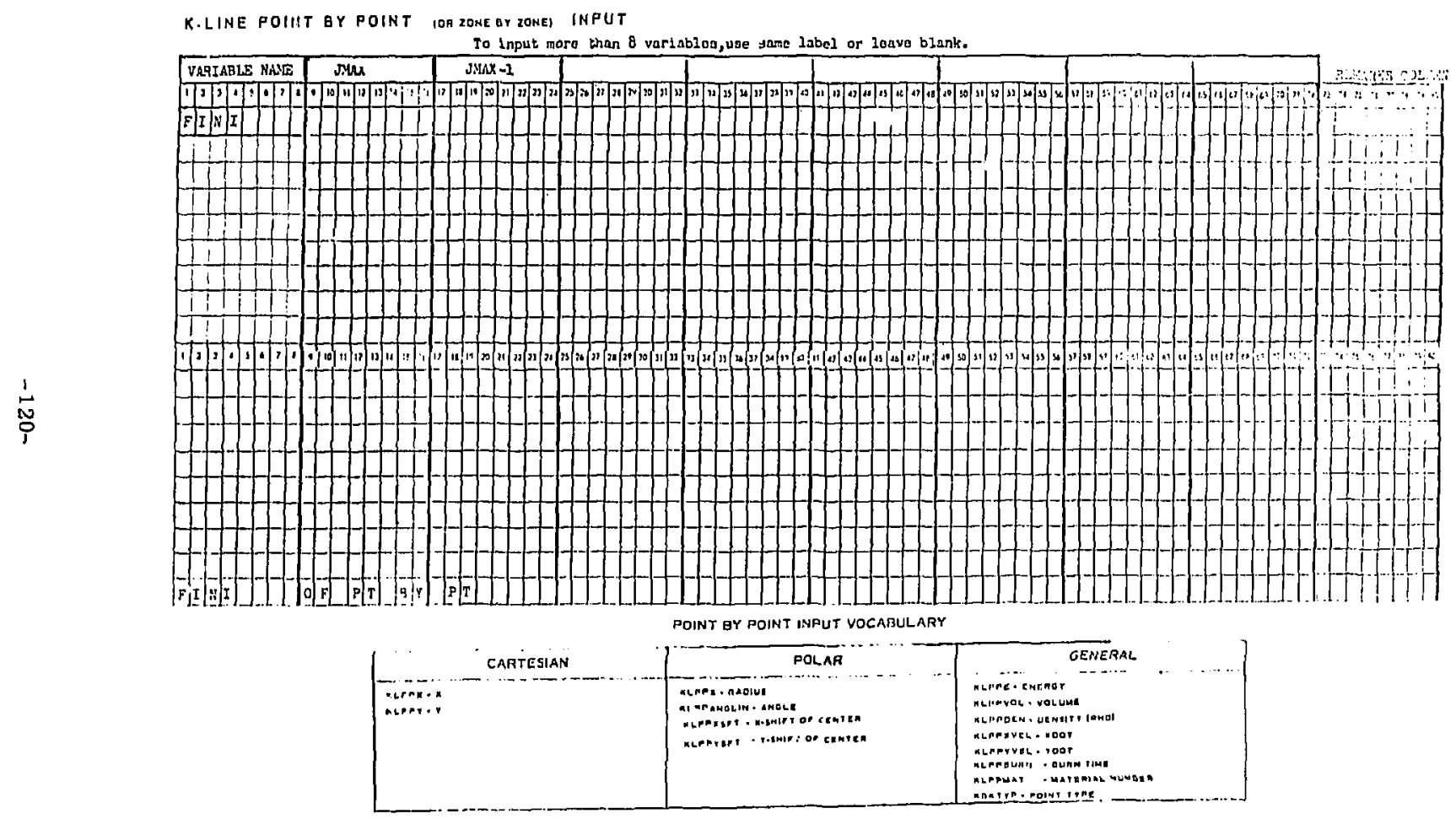




\section{Appendix E: \\ Sample Problem Description and Output}

The sample problem is the problem named LIP 0.01 that is shown in Ref. $1^{\frac{*}{*}}$. That problem was run on an earlier version of HEMP (assembly language coded) an the IBM 7030 (Stretch) computer. This is why the cycle count and time do not correlate exactly.

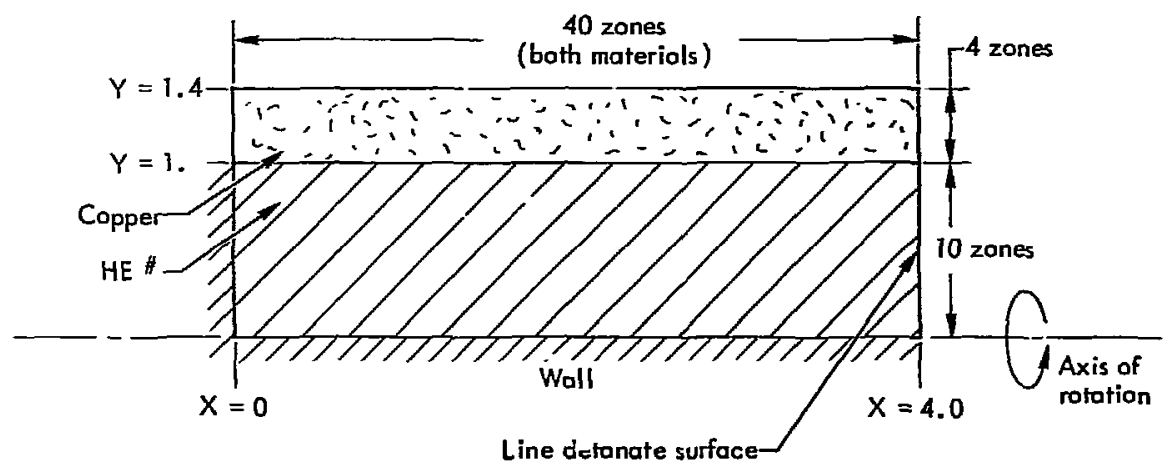

Equations of state:

$$
\begin{aligned}
& \text { Copper } \quad P=1.88 \mu \quad \text { Shear modulus }=.46 \\
& \text { (Use Form E, No. 10) } \\
& \text { Yield }=.01 \\
& \rho_{0}=7.85 \\
& \mathrm{P}-\min =-.01 \\
& \text { HE }{ }^{*} 1 \text { Standard } \quad \text { Det velacity }=.88 \\
& \text { Burn constant }=.17
\end{aligned}
$$

Fig. E-1. Specifications of example problem LIP .01.

\footnotetext{
Page 49 of Ref. 1.
} 


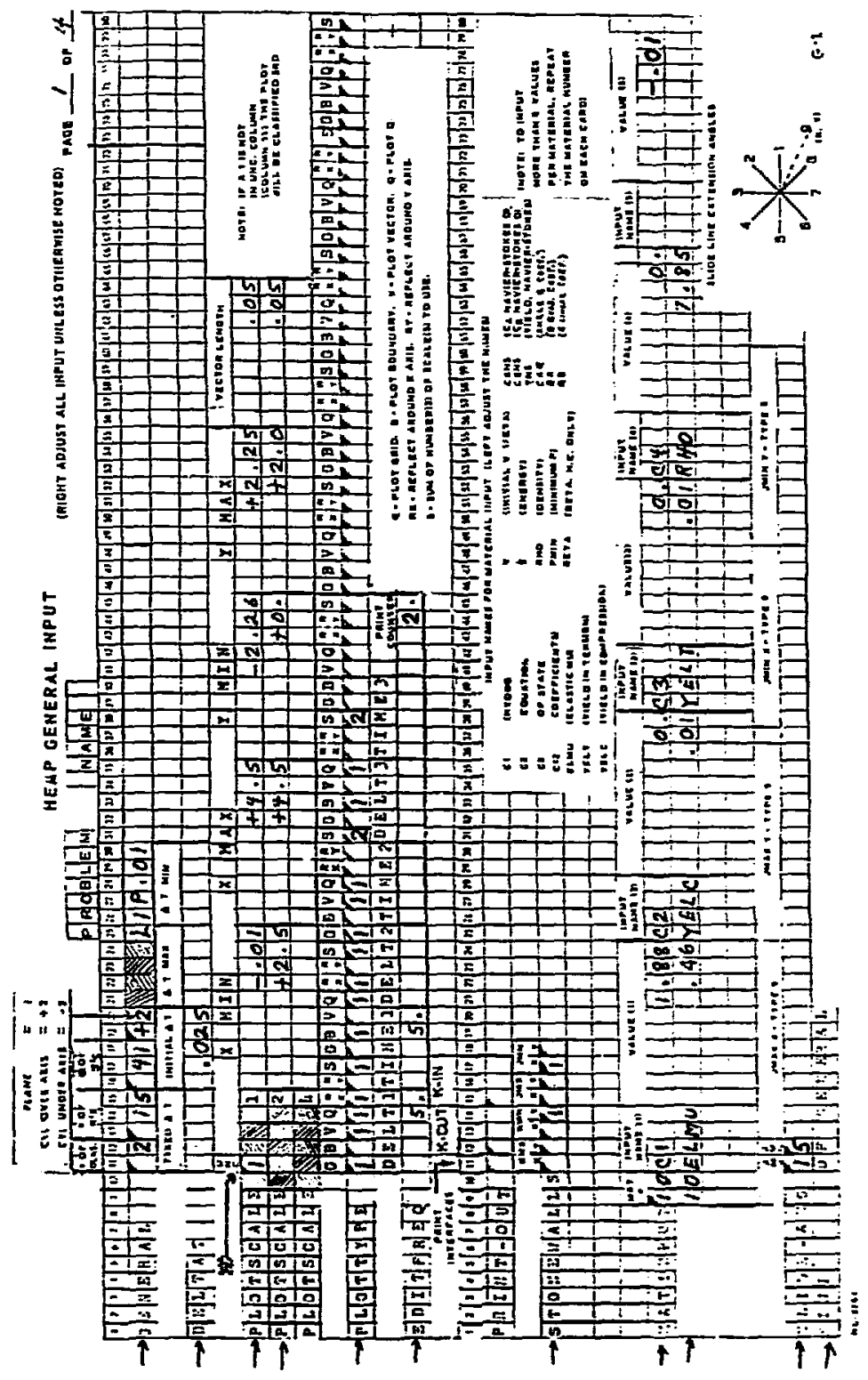




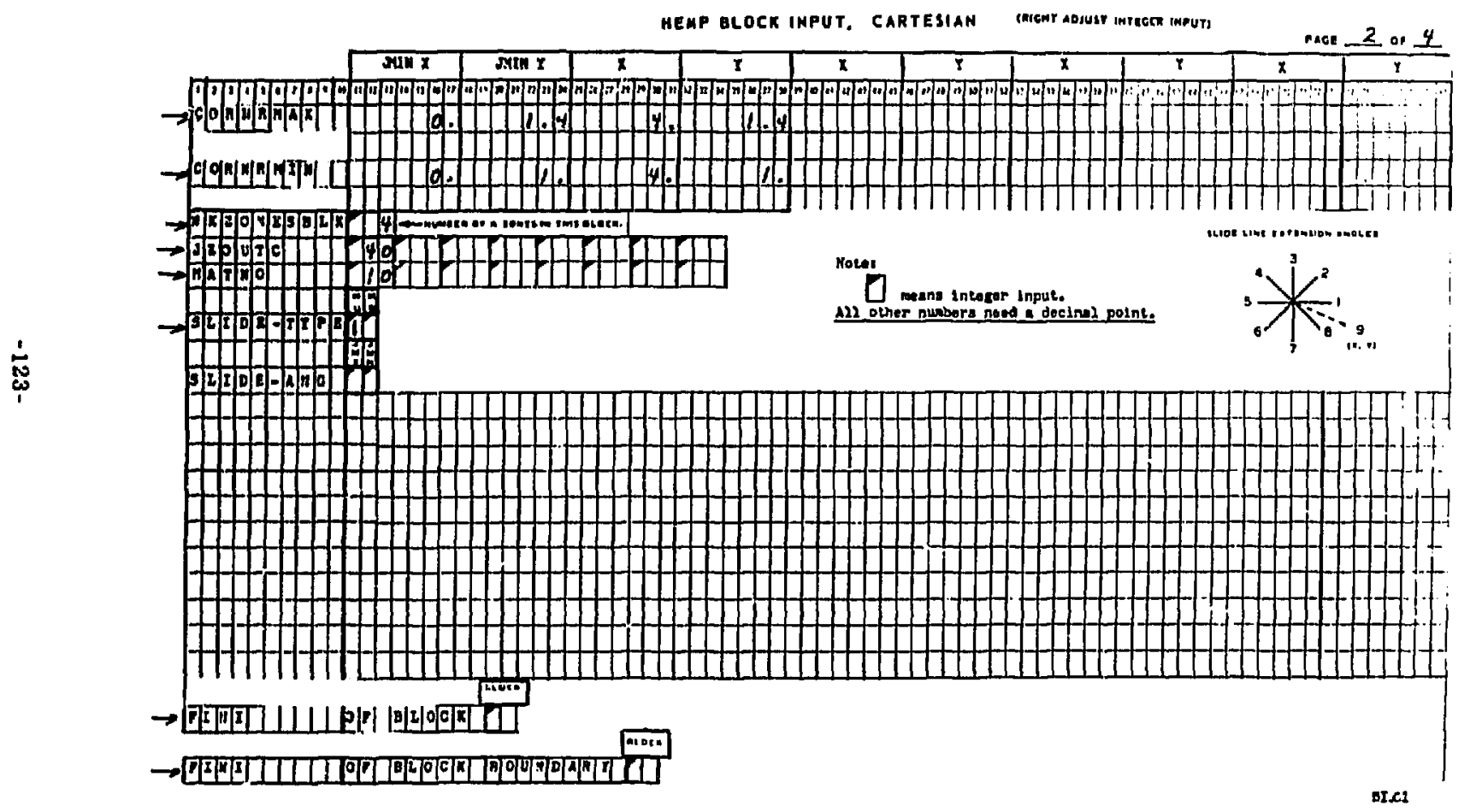




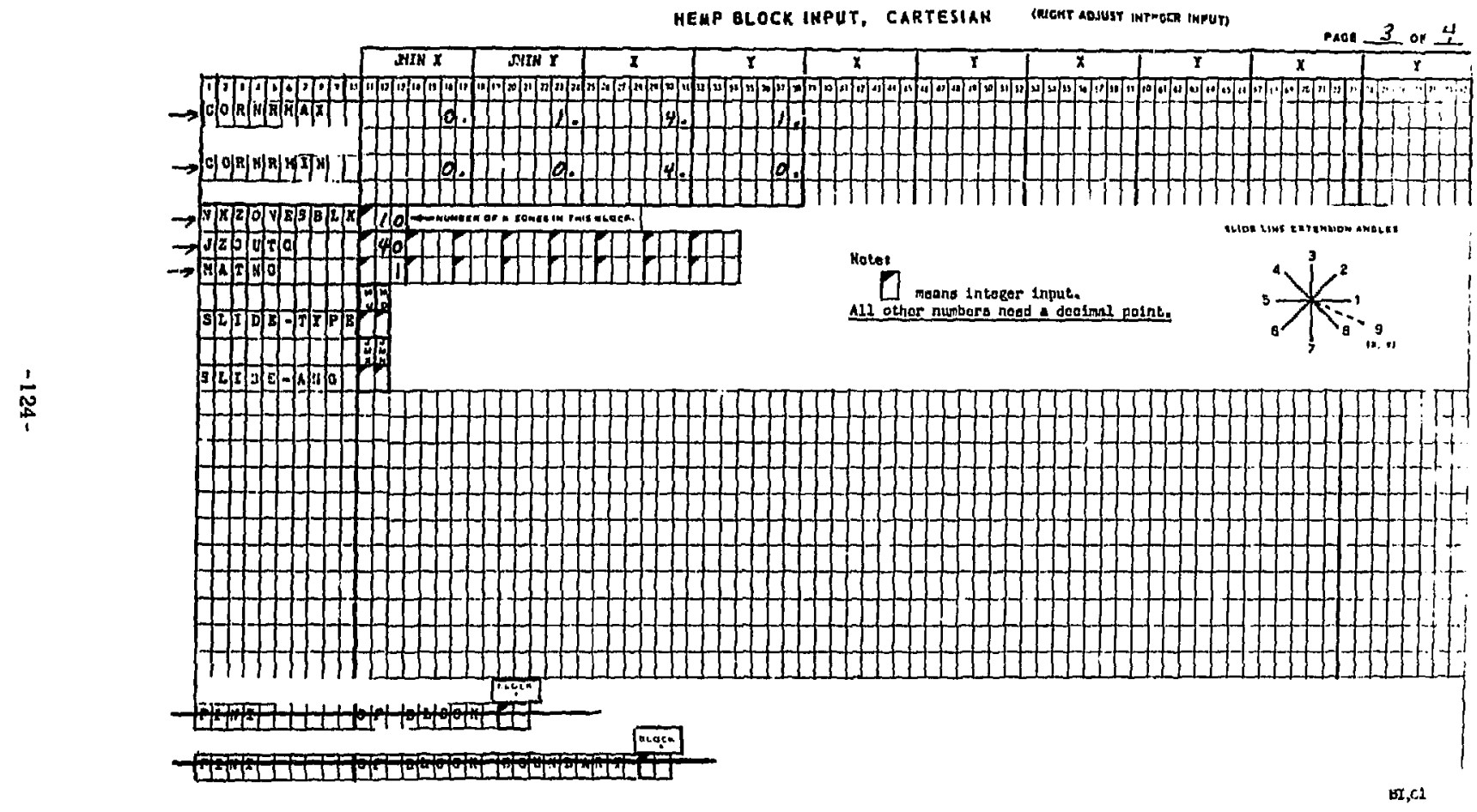




\section{HEMP H.E. 뚀․ㅗ}

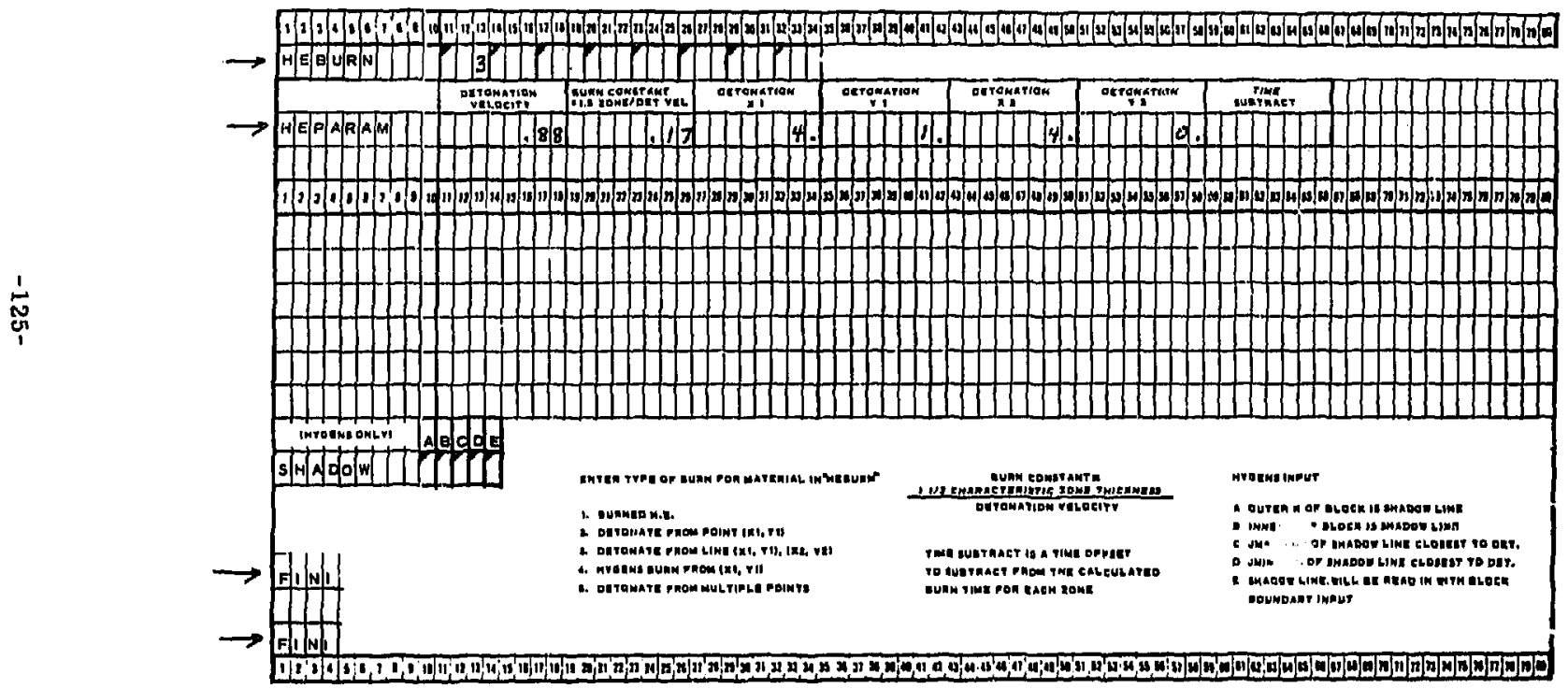



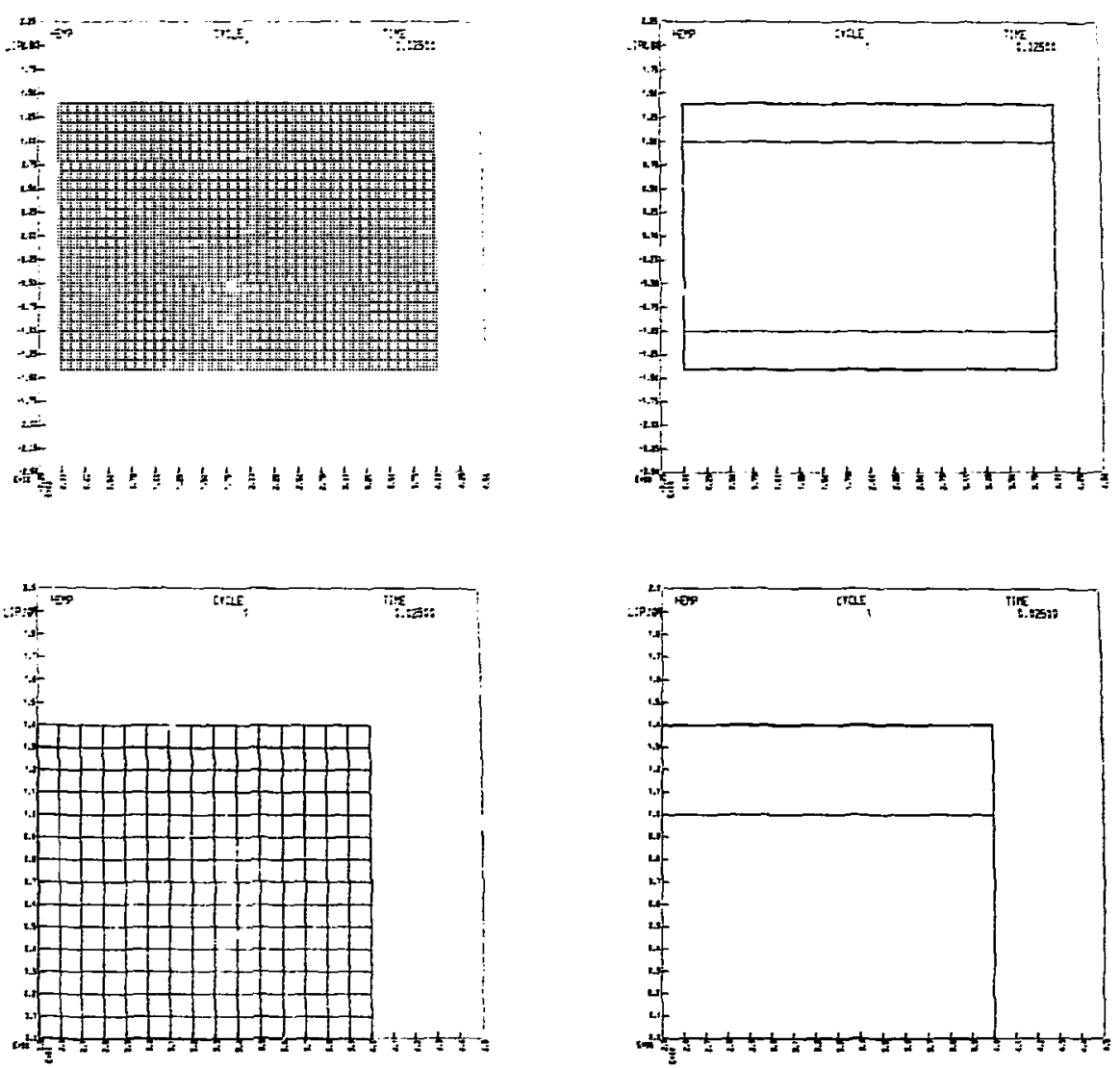

Sample problem CRT output, cycle $=1$, time $\approx 0$. 

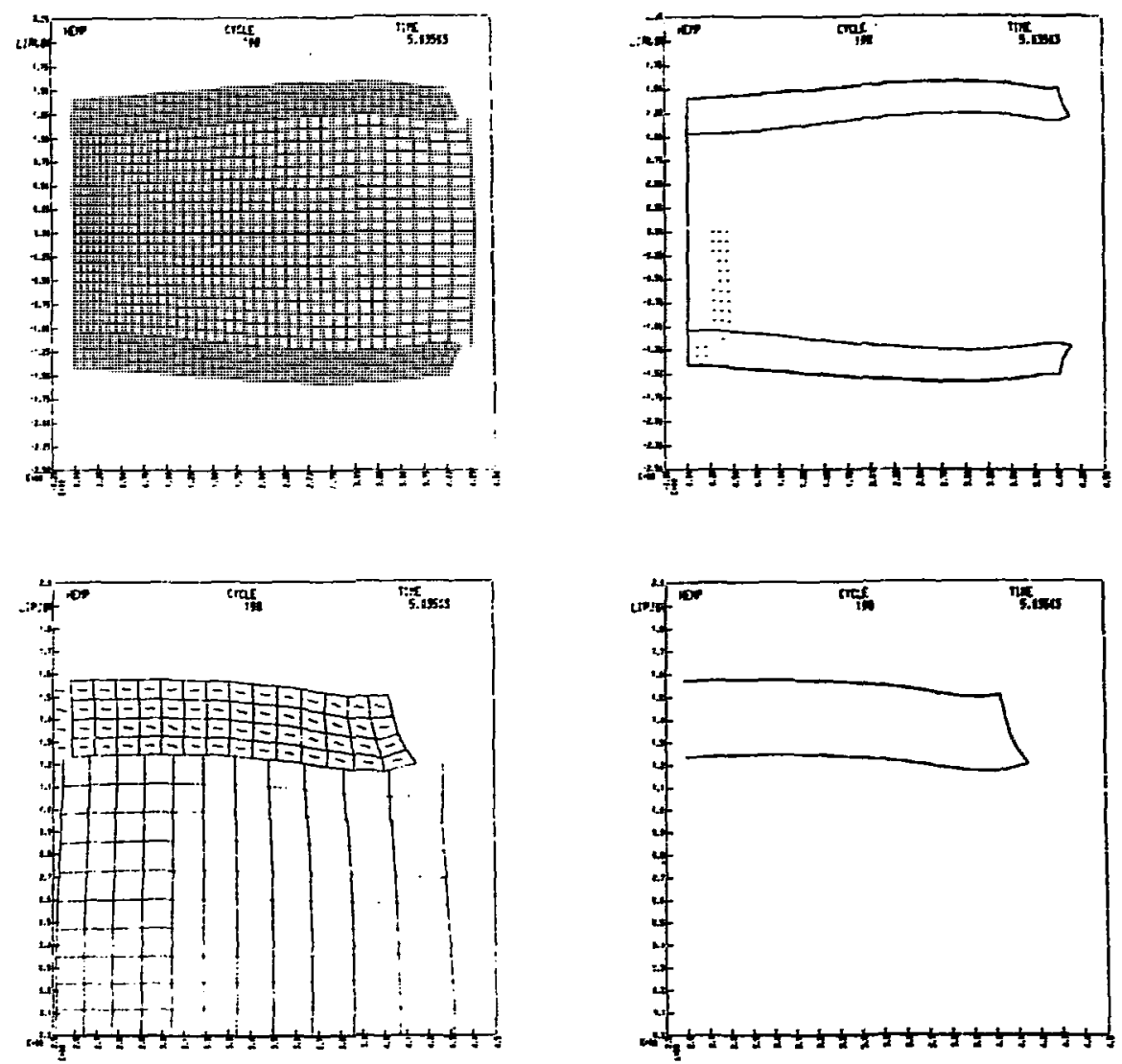

Sample problem CRT output, cycle $=198$, time $=5$. 
2345678901234567490123456789012345678901234567896123456789012345678901234567890 GENERAL 2 L $15 \quad 41+2 \quad$ LIP.0I

OELTAT .025

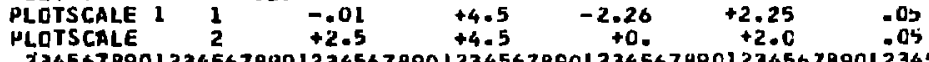

7345678901234567890123456789012345678001234567890123456789012345674901234567490

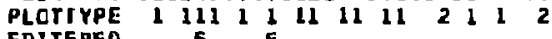

EDITFREO 1.5

STONE WALLS 2345678901234567890123456789012345678901234567890123456789012345678901234567890 MATINPUTIOELAU

SLIDE-ANG 15

FINI OF GENERAL

2345678901234567890123456789012345678901234567890123456789012346678901234567890

CORMRMAX

CORNRMIN

0

NKZONESBLK 4

J20UTC 234567890123

(1)

MATNO 10

SLIOE-TYPEI

FINI OF BLOCK

$234567690123456789012345678901234567890123436784 C 123456709012343678901234567890$

灾

FINI OF BLOCK BUUNOARY 


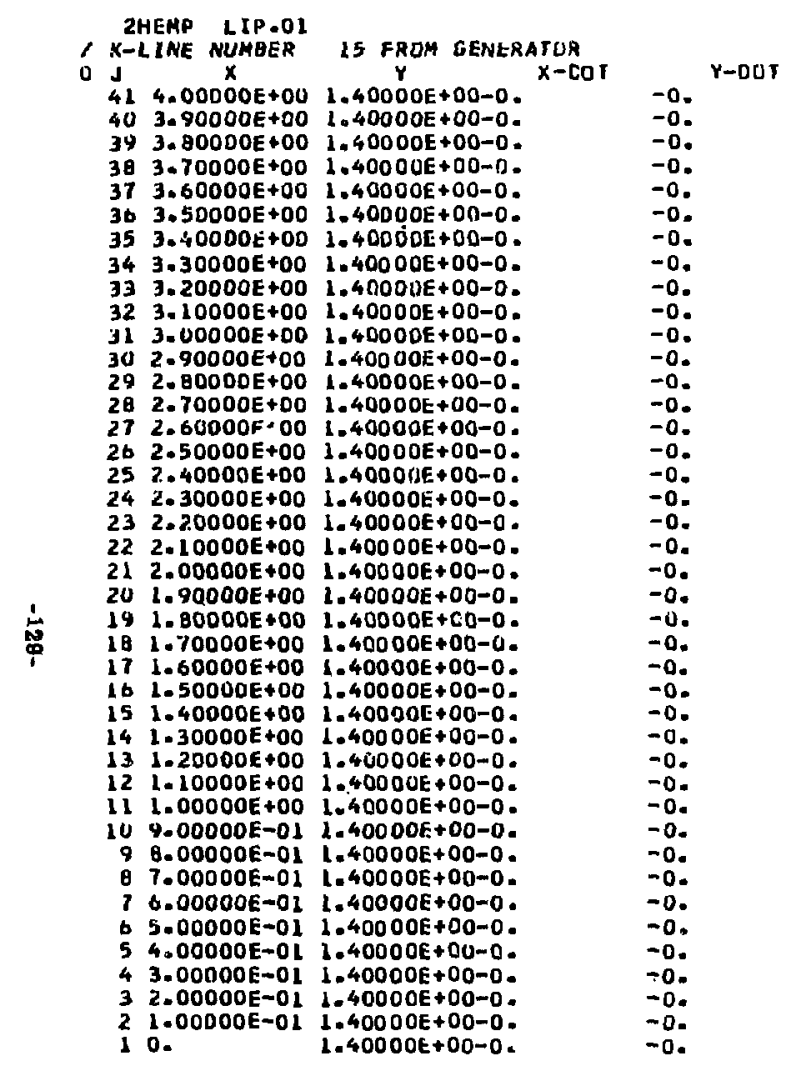

CODE FILE

F

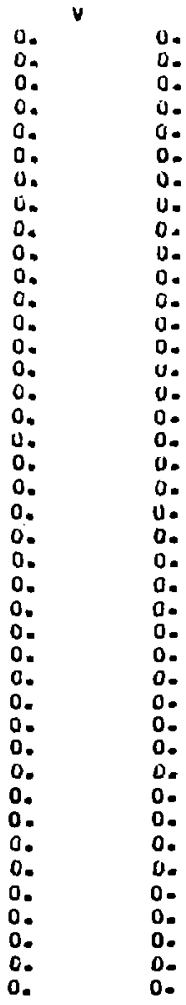

E

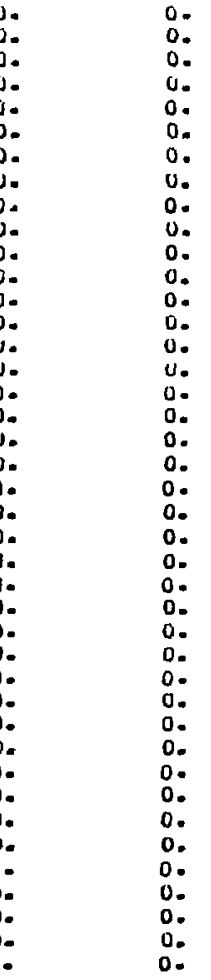

REMPDG MAP

HEHPOG

MH

0.
0.
0.
0.
0.
0.
0.
0.
0.
0.
0.
0.
0.
0.
0.
0.
0.
0.
0.
0.
0.
0.
0.
0.
0.
0.
0.
0.
0.
0.
0.
0.
0.
0.
0.
0.
0.
0.
0.
0.
0.

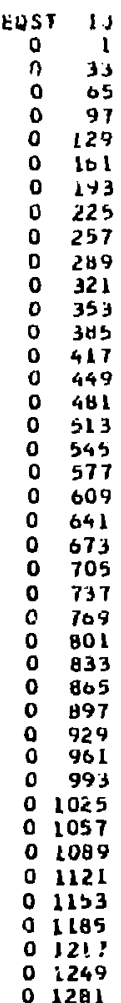


2HENP LIP.01

K-L INE NUMGER 14 FROM GENERATU

L 4.00000E+00 1.30000E+00-0

40 3.90000E+DO 1.30000E+00-0.

$393.80000 E+00$ 1.30000E+D0-0.

38 3. $30000 E+00$ 1.3000OE+00-0.

37 3. $60000 E+00$ 1.30000E + 00-0.

$363.50000 E+00$ 1. $30000 E+U 0-0$.

$353.40000 E+001.30000 E+00-0$.

34 3.3000UE+00 1.30000E+00-0.

$333.20000 E+00$ 1.30000E+00-0.

$323.10000 E+00$ 1.300 OOE +00-0.

$313.00000 E+00$ 1. 300 OOE $+00-0$.

$302.90000 E+001.30000 E+00-0$.

$292.80000 E+001.30000 E+00-0$.

28 2.70000E+00 $1.30000 E+00-0$.

27 $2.600006+00$ la $300005+00-0$.

27 2.60000E+00 l. $30000 \mathrm{E}+00-0$.

$26 \quad 2.50000 E+00$ L. $30000 t+00-0$.

25 2.40000E+00 1. $30000 E+00-0$.

24 2. 30000 toO 1.3000 OE+00-0.

$23 \mathrm{2} .20000 \mathrm{E}+00 \mathrm{O} 1.3000 \mathrm{O}+00-0$.

22 2. $10000 E+001.30000 E+00-0$.

$212.00000 E+001.30000 E+00-0$.

$201.90000 E+00$ 1.30000E+00-0.

禹 $191.80000 E+00 \quad 1.30000 k+00-0$.

$181.70000 E+00 \quad 1.3000 U E+00-0$.

$171.60000 E+001.30000 E+00-0$.

$161.50000 E+001.30000 E+00-0$.

$151.40000 E+001.30000 E+00-0$.

14 1.30000E +00 l.3000UE + 00-0.

13 1. 20000E +00 1. J0OOOE +00-0.

$121.10000 E+00$ 1. $30000 E+00-0$.

il 1.0000OE+00 1. $30000 \mathrm{E}+00-0$.

I0 9.00000E-01 1.30000E $+00-0$.

9.00000-01 1.30000E+00-0.

Q. 00000E-OL L. 30000E+00-0.

$1.00000 \mathrm{E}-01 \mathrm{~L} 1.30000 \mathrm{O}+00-0$.

6.00000E-01 1. 30000E+00-0.

5.0000E-01 1.30000E+00-0.

4.00000E-01 I.300NOE+00-0.

3.00000E-01 1. 30000E+00-0.

$32.00000 E-0 L$ L. $30000 E+00-0$.

C $1.00000 \mathrm{E}-01 \mathrm{~L} 1.30000 \mathrm{E}+00-0$.

10.

1. 300 OOE + 00-0. $x-c 01$

\section{$-0$}

-0.
-0.

$-0$.

-0 .

-0 .

-0 .

-0 .

-0 .

$-0$

-0 .

-0 .

$-0$.

$-0$.

-0 .

$-0$.

-0 .

$-0$.

$-0$.

$-0$.

-0 .

-0 .

-0 .

-0 .

$-0$.

-0.
-0.

-0 .

$-0$

$-0$.

- 0 .

$-0$.

$-0$

-0 .

-0.
-0.

CODE FILE HEMPDL MAP

HEMPOG

0.

1. OOOOE+UO C.

$1.000 E+00$ O.

$1.000 E+000$.

$1.000 \mathrm{E}+00 \mathrm{U}$.

$1.000 E+00$ O.

$1.000 E+00$ O.

$1.000 E+00$ U.

1.000E+00 U.

$1.000 E+00$ O.

$1.000 E+00 \mathrm{U}$.

$1.000 E+00 \mathrm{O}$.

$1.00 u t+00 \mathrm{U}$.

$1.0006+40$ u.

1.000eavo u.

$1.000 E+00$.

1.000 t

1.000 e.0O 0 .

1.000e+00 O.

$1.000 \varepsilon+00$
$1.0005+00$
1.000

1.000E+00 0.

1.VOOE $+00 \mathrm{O}$.

1. ODOE + DO U.

1. UUOE +UOO 0 .

1. OOOE+UO O.

$1.000 E+000$.

1. 000E+00 U.

1. $000 \mathrm{t}+00 \mathrm{O} 0$.

1. UDOE $+00 \mathrm{U}$.

$1.000 E+00 \mathrm{U}$.

1. 000E+00 U.

1.000 E

1. 0006t00 0.

$1.000 E+00$ O.

1.000E+00 U.

1.00E+0O

L. OCOE+Do D.

I. OOOE+0O O.

L.000E+00 O.

$1=000 E+00$ O.

l. UOOE+OU O.

1. 000E+00 U.
HH

2. $11950 \mathrm{E}-01$ 1.05000E+00 (2.11345 2.1 . 1950 - 1 1.85000E+00 10149 $2.11950 E-017.85000 E+00 \quad 101481$ 2.11950e-OI 7.45000E+00 10 15L 2.11950E-01 7.85000E+00 101545 2.11950E-017.85000E+00 $10\lfloor 577$ 2.11950E $017.85000 E+00 \quad 101609$ $2.11950 E-01 \quad 7.85000 E+00 \quad 10 \quad 1041$ $2.11950 E-017.85000 E+0 n \quad 101705$ 7.119 CEE-01 7.85000E+00 101737 $2.119506017 .85000+00101737$ $2.119501-01$ 7.05000 101769 2.11950E-OR 7.85000eto0 10 1801 -11950E-01 7.85000e+00 101833 2.119SOE-O1 7.85000E+00 101865 2.11950e-OI 7.85000+00 10 1897

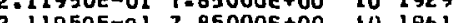
2.11950E-OL 7.6500E+00 lO 1961 2.1195OE-OI 7.BSOOOE+0O 101943 $2.11950 E-01 \quad 7.85000 E+00102025$ $2.11950 E-01 \quad 7.85000 E+00 \quad 102057$ $2.12950 E-0 L \quad 7.85000 E+00102089$ $2.11950 \mathrm{E}-01 \quad 7.85000 \mathrm{E}+00 \quad 102121$ $2.11950 E-02$ 7.85000E+00 102153 $2.11950 E-01 \quad 7.85000 E+00 \quad 102185$ $2.11950 E-017.85000 E+00102217$ $2.11950 E-017.05000 E+00102244$ $2.11950 E-01705000 E+00$ 1O 224 $2.11950 E-017005000 E+00$ 10231 2.1ISOE OI T.85000 $2.19500017 .050000+00102377$ C. 1195een 2.11950e-01 7.85000 +00 102409 2.1195OE-OI 7.85OCOE+00 102441 2.11950E-OI 7.85000E+00 102473 2.11950E-01 7.85O00E+00 102505 2. $11950 E-017.85000 E+00102537$ $2.11450 E-01 \quad 7.05000 E+00$ 10. 2569 $2.11950 E-D 1$ 7.85OPOE+DO 102001 
2HEMP LIP.OL 13 FROM GENERATOR

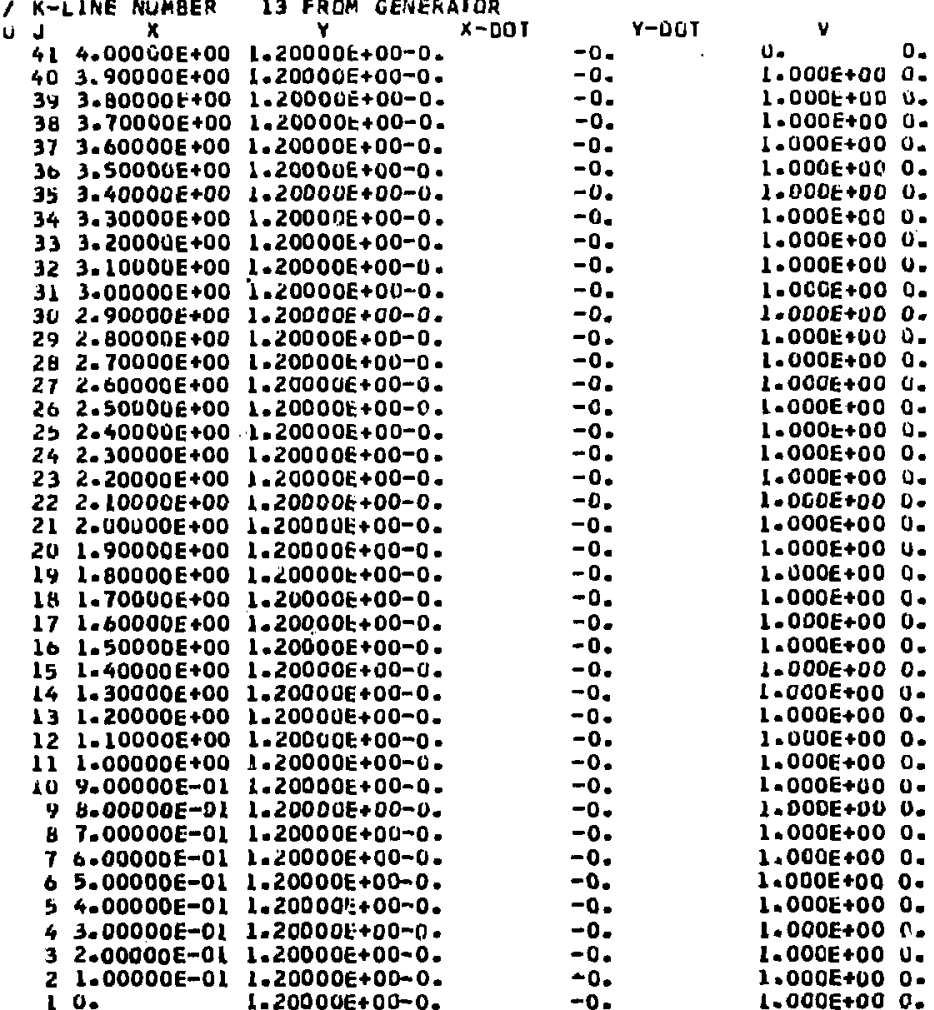

COCE FILE HEMPDG MAP

HEMPDG
MH

0. $1.96250 E-01$ 7.85000E+00 $1.96250 E-01 \quad 7.85000 E+00$ $1.96250 E-017.85000 E+00 \quad 102737$ $1.96250 E-017.85000 E+00102769$ $1.96250 E-017.85000 E+00102601$ $1.96250 E-017.85000 E+00102833$ $1.96250 E-01 \quad 7.85000 E+00 \quad 102065$ $1.96250 E-01 \quad 7.85000 E+00 \quad 102897$ $1.96250 E-01 \quad 7.85000 E+00 \quad 102929$ $1.96250 \mathrm{E}-01 \quad 7.85000 \mathrm{E}+00 \quad 102961$ $1.96250 \mathrm{E}-01 \quad 7.85000 \mathrm{E}+00 \quad 102943$ $1.96250 E-01 \quad 7.85000 E+00 \quad 103025$ $1.96250 \mathrm{E}-01$ 7.85000E+00 103057 1.96250E-01 7.85000E+00 103089 $1.96250 E-01 \quad 7.85000 E+00 \quad 103121$ $1.96250 \mathrm{E}-01 \quad 7.85000 \mathrm{E}+00 \quad 103153$ $1.96250 E-017.85000 E+00 \quad 103165$ $1.96250 E-01$ 7.ASOOOE+00 103217 $1.96230 E-017.85000 E+00103249$ $1.96250 E-017.85000 E+00$ 10 3281 $\begin{array}{llll}1.96250 E-01 & 7.85000 E+00 & 10 & 3313 \\ 1.96250 E-01 & 7.65000 E+00 & 10 & 3345\end{array}$ $1.96250 E-01 \quad 7.85000 E+00 \quad 103377$ $1.96250 E-01 \quad 7.85000 E+00$ 10 3409 $1.96250 \mathrm{E}-01 \quad 7.85000 \mathrm{E}+00 \quad 103441$ $1.96250 E-01 \quad 7.85000 E+00 \quad 103473$ $1.96250 E-01 \quad 7.85000 E+00 \quad 103505$ $1.96250 E-01 \quad 7.85000 E+00 \quad 103537$ $1.96250 E-017.85000 E+00 \quad 103564$ $1.96250 E-017.85000 E+00$ 10 3601 $1.96250 E-017.85000 E+00 \quad 10365$ $1.96250 E 017.8500 \%+00103665$ $1.96250 E-0 L$ T.8500 103697 1.96250E-OL 7.85000E+00 103729 $1.96250 E-017.85000 E+00$ 10 3793 $\begin{array}{llll}1.96250 E-01 & 7.85000 E+00 & 10 & 3793 \\ 1.96250 E-02 & 7.65000 E+00 & 10 & 3825\end{array}$

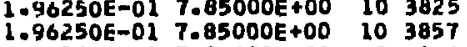
$1.96250 E-01 \quad 7.85000 E+00 \quad 103889$ $1.96250 E-01$ 7.65000E+0D 103921 
2HEMP LIP.OL

I k-LINe numaer

$\mathrm{J}$

11 from generator

4.

(3)

3.80000 400 l.0000E

$37.60000 \mathrm{E}+00 \mathrm{O}-0000 \mathrm{OE}+00-0$

$363.50000 E+001.00000 E+00-0$

35 .

$34.40000 E+001.00000+00-0$

33 3.20000E+00 $1.00000 E+00-0$

$323.10000 E+001.00000 E+00-0$.

31 3. $00000 E+00$ 1.000DOE $+00-0$.

$302.90000 E+00$ 1.00000E $+00-0$.

$292.80000 E+00$ 1.00000E $+00-0$.

28 Z. TOOOOE +00 1.000 OOE + 00-a.

$272.60000 E+001.00000 E+00-0$.

b $2.50000 E+001.00000 E+00-0$.

$252.40000 E+00$ 1.0OOOOE $+00-0$

$242.300005+001.00000 E+00-0$

$332.20000 E+00 \quad i .00000 E+00-0$

22 2-10000E+00 1.00000E+00-0.

$21 \quad 2.00000 E+00$ l.0000DE $+00-0$.

$201.90000 E+00 \quad 1.00000 E+00-0$

$191.80000 E+00$ 1. $00000 E+00-0$.

18 1.70000E +00 1.00000E $+00-0$.

$171.60000 E+00$ 1.00000E $+00-0$.

161 -50000E +00 I. OODOOE $+00-0$.

$151.40000 E+00$ l.00000E $\$ 00-0$.

$141-30000 E+00 \quad 1.00000 E+00-0$

13 1. $20000 \mathrm{E}+00 \mathrm{I}, 00000 \mathrm{0}+00-0$

12 1.20000E 00 L

12 1.

10.000

$1.00000+00-0$

8.00000E-0L L.00000E+00-0

Q 7.00000E-0L 1.00000E $+00-0$

6.00000E-01 $1.00000 E+00-0$

$65.00000 E-01$ 1.00000E $+00-0$.

5 4.00000E-01 1. $00000 E+00-0$

3.00000E-01 1.00000E+00-0.

$32.00000 E-01$ i $1.00000 E+00-0$.

2 1.00000E-01 1.00000E+00-0.

$1.00000 E+00-0$
Y-DOT

-0 .

-0.
-0.

$-0$.

-0 .

-0.
-0.
-0.

-0 .

-0.
-0.
-0.

-0 .

$-0$.

$-0$.

-0 .

$-0$.

$-0$.

-0.
-0.

-0 .

-0 .

$-0$.

$-0$.

-0.
-0.
-0.

$-0$.

$-0$.

...

$-0$.

$-0$.

$-0$.

-0.
-0.

$-0$.

-0 .

-0 .

-0.
-0.

COCE P ILE

HEMPUG MAP

HEAPDG

0.

$.0005+00$. $.000 E+00$ U. $1.000 t+000$. $1.000 E+00$ O. 1.000 t O O 1. OOOE+UO L. $1.000 E+00$ O. 1.000E+00 O. 1. OOOE+DOO 0 . L. OOOE+00 O. $1.000 E+00$ O. $1.000 \mathrm{E}+00 \mathrm{O}$

$1.000 E+00$ O.

1.000 CO

l.000eroo

1.000 .

$1.000 E+00$.

1.000 tod

$1.000 E+00$.

$1.000 E+00 \mathrm{O}$.

$1.000 E+00$ O.

$1.000 E+000$.

$1.000 E+000$.

$1.000 E+000$.

$1.000 E+000$.

1.000E+00 O.

1.000E+00 0.

L. DOOE +00 O.

$1.000 E+00$ O.

$1.000 E+00$ O

$1.000 E+00$ O

1.000 .

$1.000 E+000$.

$1.000 E+00$ O.

1.000E+

L. UUOE +000 O.

$1.000 E+00$ O.

L. OOOE $+00 \mathrm{O}$.

$1.000 E+000$.

$1.000 F+000$.

$\begin{array}{lll}1.000 E+00 & 0 . \\ 1.000 E+00 & 0 .\end{array}$
0.
0.
0.
0.
0.
0.
0.
0.
0.
0.
0.
0.
0.
0.
0.
0.
0.
0.
0.
0.
0.
0.
0.
0.
0.
0.
0.
0.
0.
0.
0.
0.
0.
0.
0.
0.
0.
0.
0.
0.
0.0
MH .. $1.04850 E-01$ T.85000E+00 1.64850E T.85OOE+00 1.04850E OL $1.64850 E-01$ 7. $85000 E+00$ $1.64850 \mathrm{E}-017.85000 \mathrm{E}+00$ $1.04850 E-01$ T.85000E +OO $1.64850 E-01 \quad 7.85000 E+00$ 1.64850E -01 7. $05000 E+00$ $1.64850 E-017.85000 E+00$ $1.64850 E-017.85000 E+00$ $1.64850 E-017-85000 E+00$ $1.64850 E-017005000 E+00$ $1.64850 E 017.050000$ $1.64850 E-017.85000$ t $1.64850 E-017.05000 E+00$ $1.64850 E 01$ T. $1.64850 E-01$ T. $25000 E+00$ $1.64850 E-01$ TasoOeE+OD 1.648 SOE-O1 T.QSOOOE+00 $1.64850 E-01$ 7.85000E +00 $1.64650 \mathrm{E}$ OI $7.8500 \mathrm{E}+00$ $1.64850 \mathrm{E}-01 \quad 7.85000 \mathrm{E}+00$ $1.64850 E-01$ 7.85000E +00 $1.64850 E-017.85000 E+00$ $1.64850 E-01$ 7.85000E +00 $1.64850 E-01 \quad 7.85000 E+00$ $1.64850 E-01 \quad 7.85000 E+00$ $1.64850 E-017.85000 E+00$ 1.64850E-01 7.85000E 400 1.6485OE-01 7.85O0O +00 1.64850E-OL $7.85000 E+00$ $1.64850 E-01$ 7.85000E+00 $1.64050 E-O 1$ T.QSOOE $1.640502-01$ T.85ODOE +OD 1.6485OE-01 TaBSODOE+00 $1.64850 \mathrm{E}-01$ 7.85000E+00 $1.64850 E-02$ T.85000E+00 $1.64850 E-01 \quad 7.85000 E+00$ 1.6485OE-01 7.85000E+00 $1.64850 E-01 \quad 7.85000 E+00$

$1.64850 E-01 \quad 7.65000 E+00$
EOST IJ 105313 105345 $10 \quad 3377$ 105409 10 3441 105305 105537 105569 105601 10 56bs 105697 105729 105701 105793 105825 10 5089 205921 105953 105985 106017 106049 106113 $10 \quad 6145$ 106177 106241 106273 106305 106337 106401 106433 106465 106497 106529 
BLCCK 2 DOME

2345676901234567890123436789012345678901234567890123456789012345676901234567890

0. 1. 4. 4. 1.

NKLONESELK 10

JLOLTC

$234567890123456789012345678901234567890223456789 C 123456789 C 12345678901234567890$ MATHD

HEPARAR

08

.17

4. 1.

4.

D.

Of BLCC

AL OLOCK GCUNCARY 


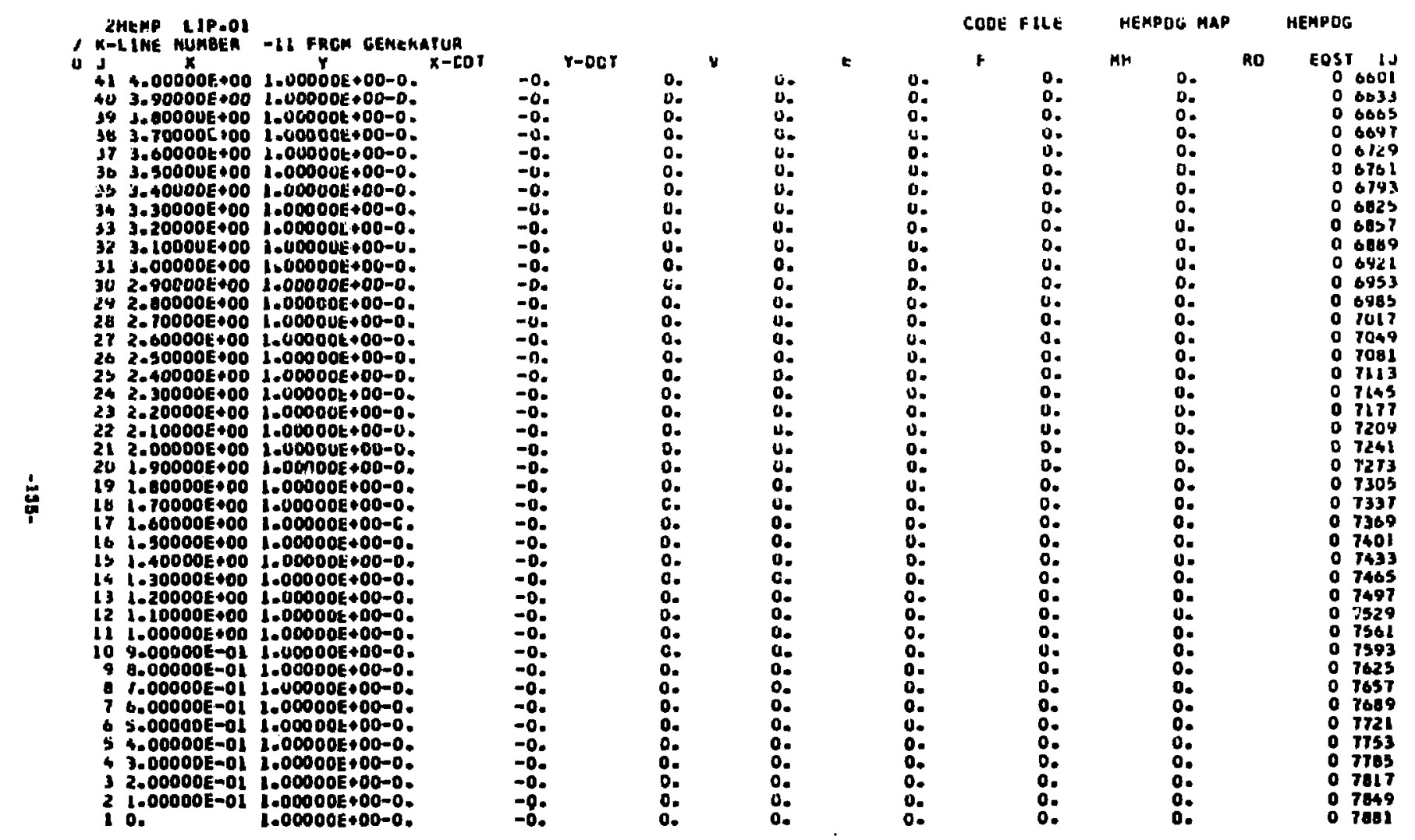




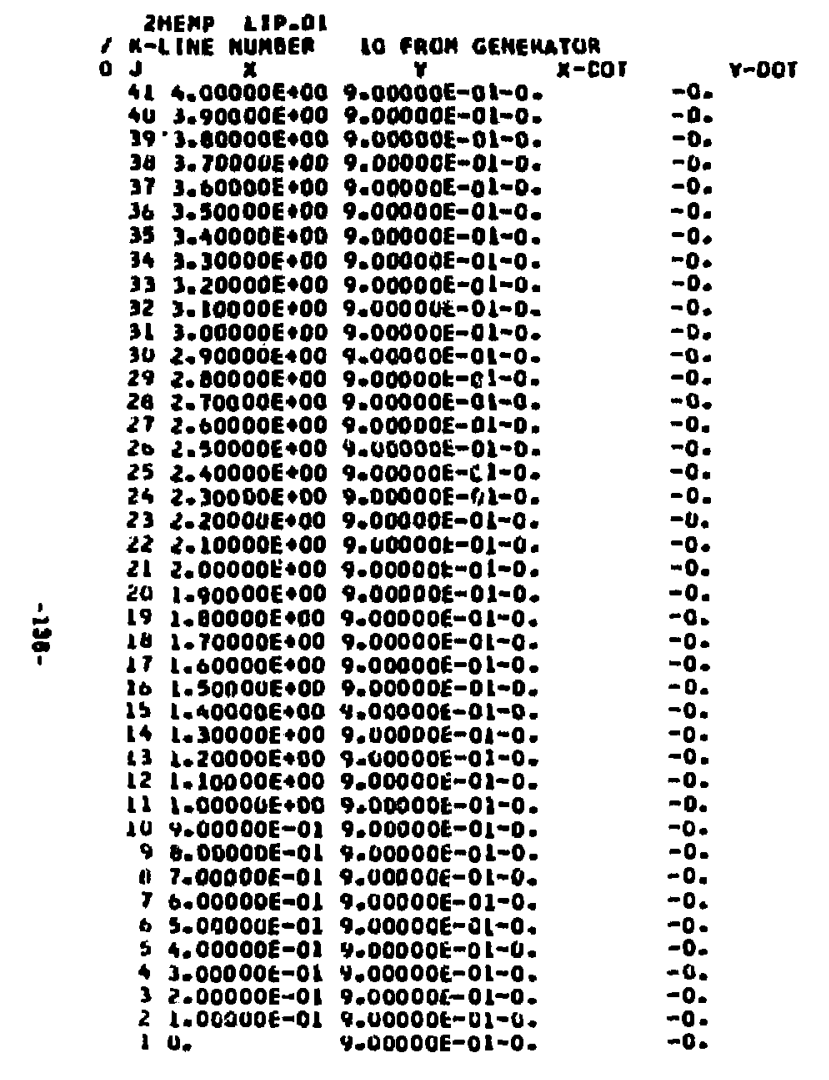

code f ILE HEMPOG MAP HEAPdG

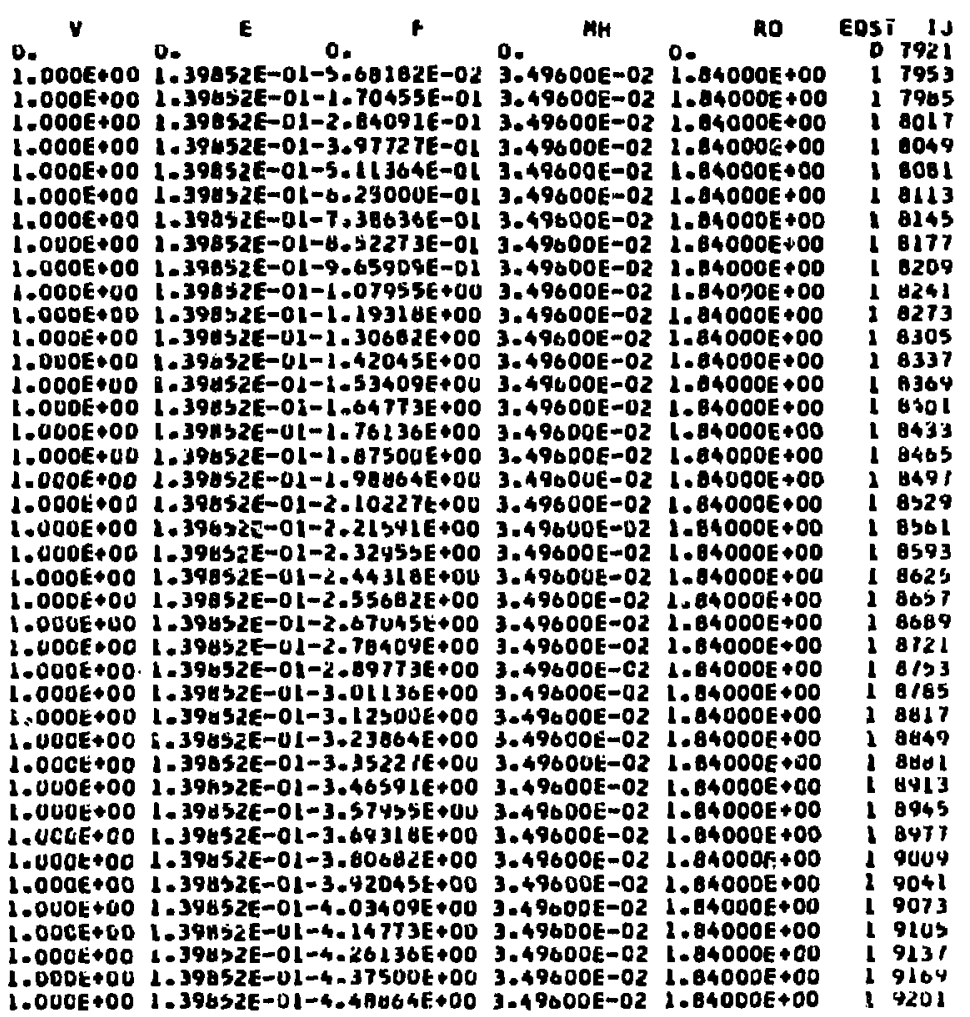


2HEMP LIP.01

0

it $4.0000^{X}$$$
\text { (1) }
$$

9 fron generatoa

6.00000E-01-0. $403.90000+00$ Q.00000E $=01-0$ 39 3.8000OE+OD $\quad$-ODDODE-DL-O. 31 3. 37 3. 34 3. $30000 E+00$ B.0000OE-0L -0 . 35 3.40000E400 C.00000E-01-0. 343.300005400 a.0OOOOE-OL-O. 333.200005400 8.00000E-01-0. 32 3.10000E 400 a.00000E-01-0. $313.00000 E+00$ B.00000E-01-0. $302.900006+00 \quad 8,00000 E-01=0$. 24 2.00000E\$00 6.000005-01-0. 28 2.T0000E $\$ 00$ 8.00000E-01-0. $272-00000 E+00$ 8.00000E-DI-0. 26 2.50000E +00 8.00000E-0I-0. 25 2. $40000 E+00$ o.00000E-01=0. 24 2.30000 +00 0.00000E-0I-0. 23 2.20000E +00 \&.00000E-02-0. 22 2.100005 400 a $000005-01-0$. $212.00000 E+00$. $00000=02=0$. 20 1. 00000500 . $\therefore \quad 191.00000 E+00$ B.00000E-01-0. 18 1. TODOOE 100 8.00000t-01-0. 17 l.60000Ex00 8.00000E-01-0.

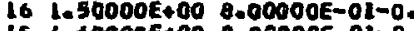

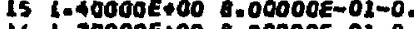
14 L.30000E+00 8.00000E-01-0. 13 1.20000E+00 $0.00000 E-01-0$. $121.10000 E+00$ G00000E-01-0. 11 1.00000E+00 6.00000E-OL $=0$. IU 4.00000E-01 B.0000OE-OL-O. 9 B.00000E-01 8.00000E-0L-D. C T.00000E-01 B.00000E=0L-O. T $6.00000 E-01$ 0.00000E-01 $=0$. 6 3.00000E-01 6.000001-01-0. 5 T.000D0E-OI B.00000E-01-0. $+3.00000 E-01$ B.00000E-01-0. 3 L.00000E-0 Q.0000OE-OL -0. 2 L.00000E-01 9.00000E-01-0. 8.00000E-01-0. $x \rightarrow 0$ in

-
$=$
$=$
CCIE FILE HEMPOG MAP HEMPOC
Y-DOT

(1.

10

$\dot{E}$

0.

mit

RO

EUST I J

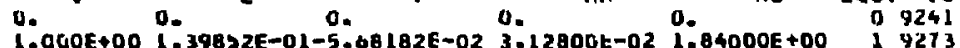
1.000E-00 1.39852E-01-5.681825-02 3.12800t-02 1.84000E+00 19273 1.000E+U Im

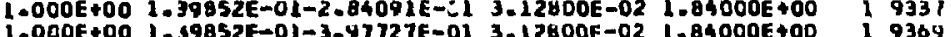
1.000 CO $1.000 E+00$ 1.398S2E-0L-3.

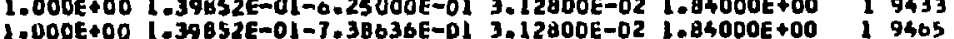

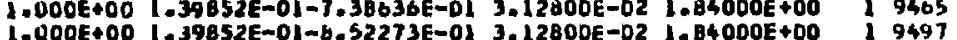
$1.000 E+00$
1.0008

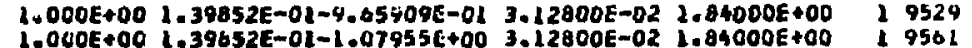

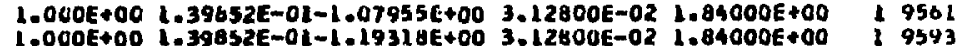
$\begin{array}{llllll}1.000 E+00 & 1-39852 E-01-1.19314 E+00 & 3.12800 E-02 & 1.84000 E+00 & 1 & 9593\end{array}$ $\begin{array}{llllll}1.000 E+00 & 1-39852 E-01-1.30682 E+00 & 3.12800 E-02 & 1.64000 E+00 & 1 & 9625\end{array}$

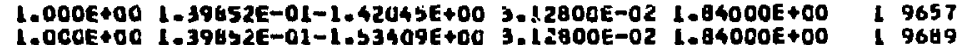
$1.000 E+00$ L.39852E-01-1.647T3E+00 3.128NOE-02 $1.84000 E+00$ I 9121 $1.000 E+00$ 1.39452E-01-1.76136E+00 3.12800E-02 $1.84000 E+00 \quad 19753$ $1.000 E+00$ 1.398S2E-01-1.8750OE+00 3.12800E-02 1.84000E+00 19785 $1.000 E+00 \quad 1.39852 E-0 L-1.98664 E+00 \quad 3.12800 E-02 \quad 1.64000 E+00 \quad 19817$ $1.000 E+00 \quad 1.39652 E-01-2.10227 E+003.12600 E-02 \quad 1.64000 E+00 \quad 19844$ $1.000 E+001.39852 E-01-2.22591 E+00$ 3.12000E-02 1.84000E+00 19881 $1.000 E+001.39852 E-0 I-2.32955 E+00$ 3.12800E-02 $1.84000 E+00 \quad 19913$ $1.000 E+00$ 1.39452E-01-2.4431 10 +00 3.12800E-02 $1.84000 E+00$ 19945 $1.000 E+00$ 1. $1.000 E+00$ 1. $1.000 E+00$ 1.39452E-01-2.67045E+00 $3.12600 E-02$ 1.84000E+00 110009 $1.000 E+00$ 1.39652E-01-2.76409E+00 3.12800E-02 1.84000E+00 110041 $1.000 E+00$ 1.39652E-aL-2.89773E+00 3.12800E-02 $1.64000 E+00 \quad 110073$ 1.000E400 1.39052E

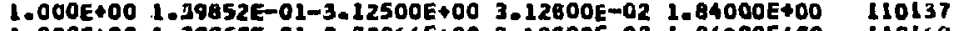
$1.000 E+00$ 1.39as2E-01-3.238B4E+00 3.12000E-02 1.04000E\$d0 110169 $1.000 E+001.39652 E-01-3.35227 \mathrm{~K}+00$ 3.12800E-02 $1.84000 E+00$ 110201

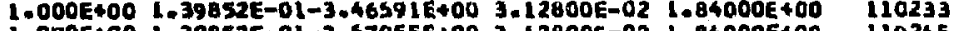
$1.000 E+00$ 1.39852E-0L-3.57455E+00 3.12800E-02 $1.04000 E+00 \quad 110265$ L.000E\$00 1.39852E-01-3.693186+00 3.12800E-02 $2.84000 E+00 \quad 110297$

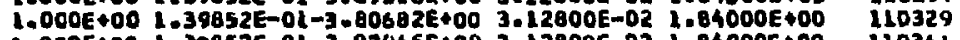
$1.000 E+00$ i. 398\$2E-01-3.92045E 400 3.12800E-02 1.84000E +00 110361 $1.000 E+001.39652 E-01-4.03409 E+00$ 3.12800E-02 $1.84000 E+00$ 110393 $1.000 E+00$ 2-39852E-01-4. $44773 E+00$ 3.12800E-02 $1.84000 E+00 \quad 110425$ 1.UOOE +00 2.3P4S2E-01-4.26136E+00 3.12800E-02 1.84000E+00 110457 $1-000 E+00$ l-39E52E-01-4-37500E+00 3.12800E-02 $1-04000 E+00 \quad 110489$ $1.000 E+00$ i. 39852E-0I-4.48864E+00 3.12800E-02 I.84000E+00 110S2L 
2HEMP LIP $=01$

t $\mathrm{d}$

8 FROH GENERATOR

41 4.00000E+00 7.00000E-01-0. $401.90000 E+00$ 7.00000E-al-0. $393.80000 E+00$ J.00OOOE-OL-O. 36 3.70000E 400 7.0000OE-0L-0. 17 \$.60000E $\$ 00$ 7.0000UE-01-0. 3t 3.50000E+00 7.00000E-01-0. 3S 3.40000E +00 7.00000E-01-0. 34 3.30000E +00 7.00000E-01-0. 33 3.20000E+OQ 7.000DOE-DI-D. $323.20000 E+00$ 7.00000t-0l-0. 31 3.00000E $\$ 00$ 7.00000E-01-0. SC Z-90000E +00 T. $70000 E-01-0$. $292.80000 E+00$ 7.00SUUE-01-0. 28 2-70000E +00 7.00000E-01-0. $27<.60000 E+00$ 7.00000E $-01-0$. $202-50000 E+00$ T.00000E-01-0. 24 $2040000 \mathrm{E}+007.40000 \mathrm{E}=01=0$ $24.3000 \mathrm{C} 00$. 24 2.30000E 23 2.20000E+00 7.00000 -01-0 22 2. $10000 \mathrm{E}-00$ T.00000E-02-0. 21 2.00000E $1.00000 E-01-0$. 20 1.90000E+DO T.00000E-OL-U. 19 1.80000E+00 7.00000E-01-0. 19 C.TOOOOE+00 7.00000E-01-0. $171.60000 E+00$ T.00000E-01-0 16 $1.90000 E+00$ 7.00000E-01-0. is $1.40000 E+00$ 7.00000E $=01=0$ 14 T. 3000OE 00 7-UDODDE-DI=0 13 1.2000UE+00 7.00DOOE-01-0. $121.10000 E+00 \quad 1.00000 \mathrm{E}-01=0$. It 1.00000E+00 7.00000t-01-0. 104.00000 E-01 7.UODUOE-01-0.

H.00000E-01 7.00000E-0L-U.

r.000DOE-01 7.000000-01-0

1.00000E-01 7.000005-01-0.

2.00000E-OL T.00000r-01-

2.00000e-OI 7.00000z=01-B.

4.00000E-OL T.OUOOOE-01-0.

$3.00000-01$ 7.00000E-01-0. 2.0000et r.0000t-ot-o. 1 U. $7.00000-01=0$.
CCCE FILE HEHPDG MAP

HEMPQG

$Y$-DOT $Y$ E

E

MH

RO

EUST IJ

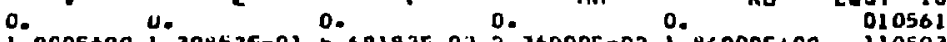
1.000E $1.000 E 001.39852 E-01-1.7045 S E-012.76000 E-021.84000 E+00 \quad 110625$ 1.000E

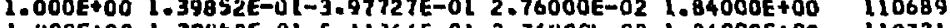
$1.000 E+00$ l.39852E-01-5.11364E-C1 2.76000t-02 1.84000e+no 110721 1.0OOE+UO 1.398S2E-OL-6.25000E-OL 2.76000E-02 1.84000E+00 110753 $1.000 E+00$ L.39832E-01-7.38636E-01 2.76000E-02 1.84000E+00 1.10785 1. ODOE+DO 1.398S2E-U1-8-32273E-01 2.76000E-02 1.84000E+00 110817 1.000E+00 L.398j2E-01-4-65409E-01 2.76000E-C2 L.84000E+00 110849 $1.000 E+00$ 1.39852E-01-1.07955E+00 2.76000E-02 1.84000E+00 110881 $1.000 E+00 \quad 1.39852 E-U L-1-19318 E+002.76000 E-02 \quad 1.84000 E+00 \quad 110413$ $1.000 E+001.39832 E-01-1.30682 E+002.76000 E-02 \quad 1.64000 E+00 \quad 110445$ 1. DUOE+0D 1.39432E-01-1.4204SE+00 2.J6000E-02 1.84000E+00 11097 $1.000 E+00 \quad 1.39852 E-01-1.53409 E+002.76000 E-02 \quad 1.84000 E+00 \quad 111009$ $1-000 E+001.39852 E-01-1.64773 E+00 \quad 2.76000 E-02 \quad 1.64000 E+0 D \quad 112041$ $1-600 E+00$ I.39852E-01-1.76136E +00 2.76000E-02 1.84000E+00 IilO

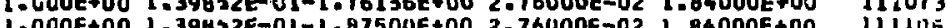
$1.000+00$ 1. 111201 . $1.000 t+001.39852 E-01-2.44318 E+00$ 2.76000E-02 $1.84000 E+00$ 111203 1.000E+00 1.39832E-01-2.55642E+00 2.76000E-02 $1.84000 E+00 \quad 111297$ $1.000 E+00$ 1.396\$2E-01-2.67045E+00 2.76000E-02 1.84000E+00 111329 1.OCOE+00 1.39bS2E-0I-2-78404E+00 2.76000E-C2 $1.84000 E+00$ 1L 1361 $1.000 E+00$ L.394S2E-UL-2.897T3E+00 2.76000E-02 $1.84000 E+00 \quad 111393$ $1.000 E+001.39652 E-01-3.01136 E+00$ 2.760U0E-U2 1.84000E+00 $11142 b$ $1 . C O O E+D O 1.39832 E-D L-3.22500 E+00 \quad 2.76000 E-02 \quad 1.84000 E+00 \quad 1114 b 7$ $1.0 C 0 E+00$ l. $398>2 E-01-3.23464 E+002.76000 E-02 \quad 1.84000 E+00 \quad 111444$ $1.000 E+00$ 1.39852E-01-3.35227C+00 2.76000E-02 $1.84000 E+00$ 111.2 $1.000 E+00$ L.396S2E-0L-3.46b9LE+00 2.76000E-02 1.84000E+00 LILSS $1.000 E+001.398>2 E-01-3.3795 \supset E+00 \quad 2.76000 E-02 \quad 1.84000 E+00$ 111585 $1.000 t+001.396 ! i 2 E-01-3.69318 E+00 \quad 2.16000 E-02 \quad l-84000 E+00 \quad 111017$

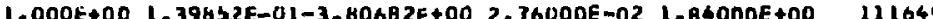
L. 1.000 . $1.000 E 00$ 1.39452E C1-4.0340E+O0 $2.76000 E-021.8400 E+00 \quad 11111$ $\begin{array}{lllll}1.000 E+00 & 1.39452 E-U L-4.14773 E+00 & 2.76000 E-02 & 1.84000 E+00 & 111745 \\ 1.000 E+00 & 1.39 H \$ 2 E-01-4.26136 E+00 & 2.76000 E-02 & 1.84000 E+00 & 111777\end{array}$ $1.000 E+001.398>2 E-01-4.37500 E+002.76000 E-02$ 1.84000E+00 IIIBU $1.600 E+001.39832 E-01-4.48864 E+002.76000 E-021.84000 E+00$ 111841 
2HEPP LIP.O1

K-L LAE HUABER

(1) 7 FROM GENERATOR

41 4.00000E $\$ 00$ \&.00000E-01-0. 40 \$.90000E $\$ 00$ 6.00000t-01-0. 39 3.800DOE +00 B.0DODOE-01-0. 38 3. $70000 \%+00$ 6.00000t-0I-0. $38.10000 \div+00$
37
$3.00000 E+00$
$36.00000 E-02=0$. 36 3.60000E+00 $6.00000 E-01-0$. 35 3. $40000 E+00$ 6.000OOE-01-0.

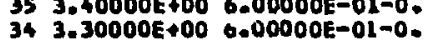
$343.30000 E+00$ 0.00000E-01-0.

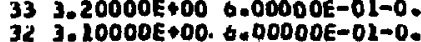

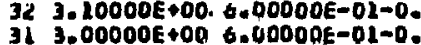
302.90000 E 00 6.0000OE-0L-0. 24 2. $00000 E+00$ 8.00000E-0L -0 . $242.70000 E+00$ b.00000t-01-0. $272.80000 E+006.000005-01-0$. 20 2050000E 00 0.000005-01-0. 25 2.40000E 000 O.00000 $-01-0$. $243-30000500$ o. $23230000 E 00$. 22 2. 100008000 o 22 2. 21 2.00000 20 1.

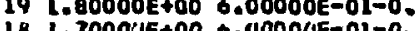
18 1. TOODJe+00 0.00000E-01-0. 17 l. $60000 E+00$ 6.00000E-01-0. 16 I SOOOOE $\$ 00$ 6.00000E-0L-D. 15 1.40000E $\$ 00$ 6.00000t $=01-0$. 14 1. 30000E+00 6. U0000E-01-0. $131.20000 E+006.00000 \mathrm{k}-01-0$. 12 1. If $1.00000 \mathrm{E}+00$ 6.000006-01-0. 10 9.00000E-01 6.00000E-C1-0. 9 0.00000E-01 6.00000E-01-0. 7 7.00000E-01 6.00000E-01-0. 5.00000E-01 G.UODOUE $=01-0$. 5 4.00000E-01 6.00000E-01-0. $3.000005-01$ b.000005-01-0. 3 2.00000e-01 3 2.00000E-0. G.00000E-01-0. $\begin{array}{lll}2 & 1.00000 E-01 & 6,00000 E-01-0 . \\ 1 & 0 . & 6,00000 E-01-0 .\end{array}$
COCE FILE

HEAPOG MAP

HEMPDG
r-DOT

$-0$.

$-0$

$-0$.

$-0$.

$-0$

$-0$.

$-0$.

$-0$.

$-0$.

$-0$.

$-a$.

$-0$.

$-0$.

-0 .

$-0$.

$-0$

$-0$.

-0 .

$-0$

$-0$

$-\infty$.

$\cdots$

-0.
-0.

-0 .

$-0$.

$-0$.

-0 .

-0 .

$-0$.

- 0 .

$-0$.

$-0$.

$-0$

-

-0 .

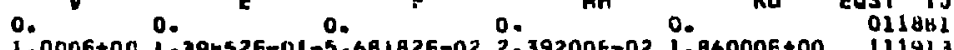

E

5

MH

RO

$\operatorname{cosT} 1 \mathrm{~J}$ $1.000 E+00 \quad 1.39652 E-01-5.66182 E-02 \quad 2.39200 E-02 \quad 1.04000 E+00 \quad 111413$ $1.000 E+00$ l.39852E-01-1.7045SE-01 2.39200E-02 1.84000E+00 111945 1.0OOE+00 1-39852E-01-2-84091E-01 2-39200E-U? 1.84000E +00 11147I $1.000 E+112004$ 1.00OE+CO I.39652E-01-3.123G4E-01 2.39200E-02 1.64000E+00 112041 $1.00 n E+00$ l.3.3.52E-01-6.25000E-01 $2.39200 E-021.64000$ + 112003 $1.000 E+001.39652 E-01-7.38636 E-01$ 2.39200E-02 $1.84000 E+00112105$ $1.000 E+001.39632 E-01-8.52273 E-012.39200 E=021.84000 E+00 \quad 112137$ $1.000 E+001.39452 E-01-9.65909 E-012.39200 E-021.84000 E+00 \quad 112169$ $1.000 E+00$ l. 39852E-0I-1.074b5E+00 $2.39200 E-02$ 1.84000E+00 112201 $1.000 E+001.39452 E-01-1.19318 E+002.39200 E-021.04000 E+00 \quad 112233$ $1.000 E+00 \quad 1.39852 E-01-1.30602 E+002.39200 E-021.04000 E+00 \quad 112265$ $1.0 U O E+001.39852 E-0 L=2.42045 E+002.392 U 0 E-021.04000 E+00112297$ $1.000 E+00$ l.39852E-0L-L.53409E+00 2.39200E-02 l-84000E+00 112329 $1.0005+001-39652 E-01-1.64773 E+002.39200 E-02 ~ 1-04000 E+00$ L 112361

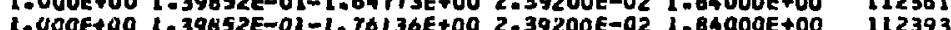
$1.0005+C 0$ L $39025-01-1.075005+00230200 E-02$ l $84000 E+00$ $1.000+60$ l.

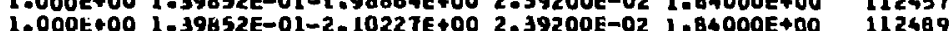
$1.0005+00113952 E-01-2.21501 E+00$ 1.2489 1.000E+00 1.39852E-01-2.21391E+00 2.39200E-02 1.84000E+00 112521 1. OCGE+00 1.39852E-01-2.32955E+00 2.39200E-02 $1.04000 E+00 \quad 112553$

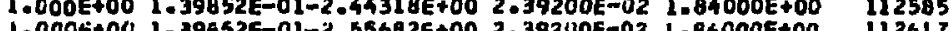
$1.000 E 400$ l.3965LE 112617 J.000E+00 1.39652E-01-2.67U45E+00 2.39200E-02 1.84000E+00 112649 1.0COE+00 1.39652E-01-2.79409E+00 2.34200E-02 1.84000E+00 112681 1. DOLE+00 1.39ES2f $-01-2.89773 E+00 \quad 2.39200 E-02 \quad 1.84000 E+00 \quad 112113$ $1.000 E+00$ l-398BZE-01-3.01136E+00 2.39200E-02 $1.64000 E+00 \quad 112745$ $1.000 E+00$ 1.39852E-01-3.12500E+00 2.39200E-02 1.84000E+00 112777 $1.000 E+001.39452 E-U 1-3.23864 E+002.39200 E-02 \quad 1.84000 E+00 \quad 112809$ $1.000 E+00$ I. 39852E-0I-3.35227E+00 2-39200E-02 1. $34000 E+00 \quad 112841$ $1.000 E+00$ l. 39852E-U]-3.46591E+00 2-39200E-02 $1.84000 E+00 \quad 112873$ $1.000 E+001.39652 E-01-3.57955 E+002-39200 E-02 \quad 1 . B 4000 E+00 \quad 112905$ $1.0 C O E+O C$ I.3985ZE- $01-3.69318 E+00$ 2.3920DE-02 1.8400OE+0O 112937 $1.000 E+001.39852 E-01-3.80682 E+002.39200 E-02 \quad 1-B 4000 E+00 \quad 112964$ $1.000 E+00 \quad 1.39852 E-01-3.92045 E+00 \quad 2.39200 E-02 \quad 1.84000 E+00 \quad 113001$ $1-000 E+00$ 1.39852E-01-4.03409E+00 2.39200E-02 1-84000E+00 113033

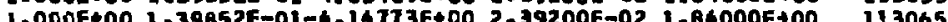
$1.000 E 00$ 1.39652E 113065 $1.000 E+00$ 1.39ASAE-02

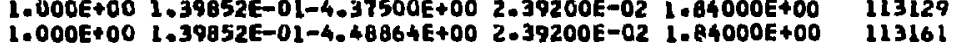




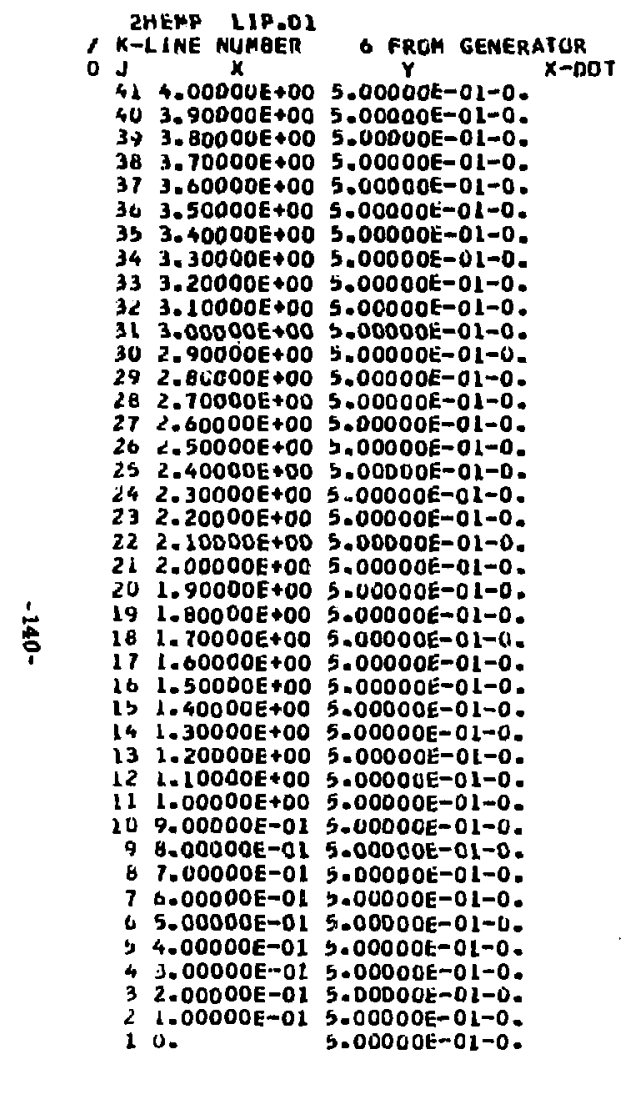

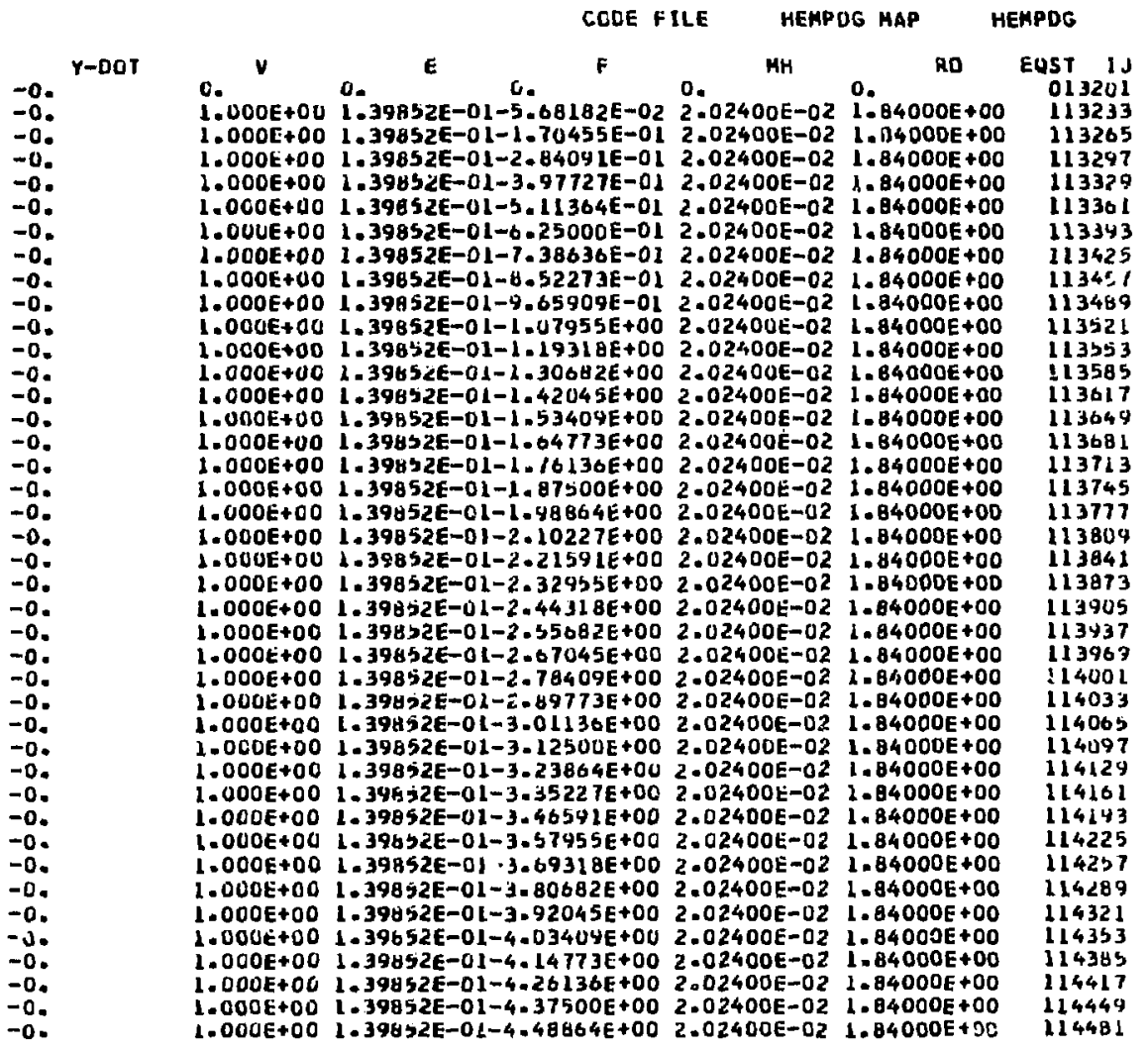


2HEMP LIP.OL K-LINE NUMBER

0 $X \quad Y$ X-DOT 4.00000E+00 4.00000E-01-0. $40 \quad 3.90000 E+00 \quad 4.00000 E-01-0$. $393.00000 \mathrm{E}+00 \quad 4.00000 \mathrm{E}-01-0$. $383.70000 E+00$ 4.000 OOE-01-0. $373.60000 E+00$ 4.00000E-O1-0. $363.50000 E+00$ 4.00000E-01-0. 35 3.40000E $\times 00$ 4.00000E-01-0. 34 3.30000E+00 4.00000E-01-0. 33 3.200DOE $\$ 00$ 4.00000E-01-0. 32 3.10000E +00 4.00000t-01-0. 31 3.000OOE+00 4.0000OE-01-0. $30 \quad 2.90000 E+00$ 4.00000E-0I-0. 29 2.80000E+00 4.0000 $\dot{\varepsilon}-01-0$. $282.70000 \mathrm{E}+00$ 4.00000E-02-0. $272.60000 E+00$ 4.00000E-01-0. $26 \quad 2.50000 E+00$ 4.00000E-01-0. 25 2.40000E+00 4.00000E-01-0. $24 \quad 2.30000 E+00$ 4.000005 $-01-0$. 23 2.20000E +00 \&.,00000E-01-0. $222.10000 E+00$ 4.000OOE-01-0. $212.00000 E+00$ 4,000O0E-01m0. $202.90000 E+00 \quad 4,00000 E-01-0$. $191.80000 E+00 \quad 4.00000 E-01-0$. I) $1.70000 E+00$ 4.00000E-01-0. 17 1.60000E+00 4.00000E-01-0. $161.50000 E+00 \quad 4.00000 E-01-0$. is $1.40000 E+00$ 4.000OOE-0I-0.

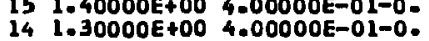
13 1.2000OE+00 4.00000E-01-0. $121.10000 E+00$ 4.0000UE-01-0. 11 1. $00000 E+00$ 4.0000UE-01-0. 10 9.00000E-01 A.00000E-0L-0. 9 8-00000E-01 4-00000E-01-0. $4700000 \mathrm{0}-014000005-01-0$ 7 6.00000E-OL $4.00000 E-01-0$. 6 5.00000E-01 4.00000E-0L-0. 5 \$.00000E-02 4.00000E-01-0. 4 3.00000E-02 4.00000E-01=0. 3 2.00000E-01 4.00000E-01-0. $21.000001=014.000005-01-0$. 10. $4.00000 \mathrm{E}-01-0$.
Y-DOT

-0 .

-0.
-0.

-0 .

-0 .

-0 .

-0 .

-0 .

-0 .

-0 .

-0 .

-0 .

$-0$.

-0 .

-0 .

$-0$.

-0 .

-0 .

-0 .

-0 .

-0 .

-0 .

-0 .

-0 .

-0 .

-0 .

-0 .

$-0$.

0 .

-0 .

$-0$.

-0 .

-0 .

-0 .

-0 .

-0 .

-0 .

$-0$.

-0 .

$-0$.
0.
0.
0.

E

F

0 .

$\mathrm{MH}$

a.

RO

EUST IJ 014521 $1145 \mathrm{b3}$ 114585 114617

114681

114713

$114 / 45$

114777

114609

114841

114813

114905

114937

114969

115001

115033

115047

115129

115161

115193

115225

115257

115289

$115+21$

115353

115385

115417

115449

115481

115513

115545

115577

$11560 \%$

12564

115673

215705

$\begin{array}{llllll}1.000 E+00 & 1.39852 E-01-4.26136 E+00 & 1.65600 E-02 & 1.84000 E+00 & 115737 \\ 1.000 E+00 & 1.39852 E-01-4.37500 E+00 & 1.65600 E-02 & 1.84000 E+00 & 115769\end{array}$

$\begin{array}{llllll}1.000 E+00 & 1.39852 E-01-4.26136 E+00 & 1.65600 E-02 & 1.84000 E+00 & 115737 \\ 1.000 E+0 Q & 1.39852 E-01-4.37500 E+00 & 1.65600 E-02 & 1.84000 E+00 & 115769\end{array}$ $1.0 D 0 E+00$ 1. $39852 E-01-4.48864 E+001.65600 E-02$ 1.64000E+00

115801 
2HEMP LIP.OI $K-L$ INE NUMBER 0 s 4 From generator

$424.00000 E+00$ 3.00000E-01-D. 40 3.90000E+00 3.000OCE-OL-O. J9 $3.80000 E+00$ 3.00000E-01-0. $383.70000 E+00$ 3.00000E-0L -0 . $373.60000 E+003.00000 t-01-0$. $363.50000 E+00 \quad 3.00000 \mathrm{E}-0 \mathrm{I}-0$. $353.40000 E+00 \quad 3.00000 E-01-0$. 34 3.30000E +00 3.00000E-OL-O. $333.20000 E+00$ 3.0000 $0 E-01-0$. 32 3. $20000 E+00$ 3.00000E-01-0. $313.00000 \mathrm{E}+00 \mathrm{U}$ 3.00000E-01-0. $30<-90000 E+00$ 3.00000E-01-0. 29 2.80000E+DO 3.00000E-01-0. 28 2. $70000 E+00$ 3.00000E $=01-0$. $272.60000 E+00$ 3.00000E-01-0. $202.50000 E+00 \quad 3.00000 E-01-0$. $25 \quad 2.40000 E+00$ 3.00000E-01-0. $242.30000 E+00$ 3.00000E-0L -0. $232.20000 E+00$ 3.00000E $-01-0$. 22 2. $10000 E+00$ 3.00000E-01-0. 2L. $2.00000 E+00$ 3.0000 OE-0L-0. 2J $1.90000 E+00$ 3.00000E $=0$ L-O. 1. I. $80000 E+00$ 3.00000E $01-0$. IB $1.70000 E+00$ 3.00000t-01-0. 27 L. $40000 E+00 \quad 3.00000 t-01-0$ 16 L.50000E+00 3.00000E-0L-0. I $1.40000 E+00$ 3.00000E-01-U. $14.300006+00$ 3.00000E $01-0$. $13.30000 \mathrm{e}+00$ 3.00000 13 1.20000E 12 1. 10000 E 3.00000 O $01-0$ If 1.0U000E+00 3.00000F-Át-0. $109.00000 E-O L$ 3.00000E $-0 \mathrm{~L}=0$ $98.00000 \mathrm{E}-01$ 3.00000E-01-0. B 7.00000E-01 3.00000E-01-0. $\gamma$ 6.00000E-01 3. U0000E-0l-0. b $5.00000 E-02$ 3.00000t-01-0. 4.00000E-01 3.00000E-01-0. 3.00000E-01 3.00000E-01-0. 3 2.00000E-01 3.00000E-01-0. $21.00000 E-013.00000 E-01-0$. 10 . $3.00000 t-01-0$
$Y-00 r$

-0 .

$-0$

-0 .

-0.
-0.

-0 .

$-0$

$-0$

$-0$.

$-0$

$-0$

$-0$

.

$-0$

$-0$.

$-0$.

-0 .

$-0$.

$-0$.

$-0$.

.

-0 .

-0 .

$-0$.

-0 .

-0 .

-0 .

-0 .

$-0$.

-0 .

-0 .
0.

0. 0.

MH

ENST IJ D) 5842 115873 115905 115937 115969 126001 116033 116065 116097 116129 116101 116193 116225 116225 116251 116289 116321 116353
116385 116417 116449 $1164 \mathrm{Bl}$ 116513 116545 116577 116004 116641 116641 116705 116705 116731 116769 116001 116833 116805 116897 116929 $1269 b 1$ 110793 117025 117057 - 117089 117121 
2HEMP LIP.01

$k-L$ INE NUMBER

0.1

$x$

3 from genERATOR

$403.90000 \mathrm{E}+00$ 2.00000E-0L-0.

$343.00000 \mathrm{E}+00$ 2.

38 .

37 3.600OOE+00 2.000OOE-OL-0.

36 3. 50OOOE +00 2.000OOE-01-0.

$353.40000 E+002.00000 E-0 L-0$.

$343.30000 E+00$ 2.00000E-0I -0 .

$333,20000 E+D 0 \quad 2.00000 k-01-0$.

32 3. $10000 E+002.0000$ OE-01-D.

31 3.00000E +00 2.00000E-01-0.

$302.90000 E+00 \quad 2.00000 E-01-0$.

29 2.80000E+00 2.00000E-01-0.

28 2.70000E+00 2.000 OLE-01-0.

$272.60000 E+00$ 2.00000E-01-0.

26 2.50000E+00 2.00000E-01-0.

2S $2.40000 E+00$ 2.00000E-01-0.

24 2. 30000E +00 2.0000 OE-01-0.

23 2.20000E+OO 2.000COE-O1-0.

22 2. $10000 E+00$ 2.00000E-01-0.

$212.00000 E+00$ 2.00000t-01-0.

$201.90000 E+00 \quad 2.00000 E-01-0$.

$191.80000 E+00$ 2.00000E-01-0.

$181.70000 E+002.00000 E-01-0$.

$171.60000 E+00 \quad 2.00000 E-01-0$.

Le $1.50000 E+00 \quad 2.00000 E-01-0$.

is $1.40000 E+00$ 2 $-000005-01-0$.

$14.30000+00$ 200000E-01-0.

14 1.

$131.20000 E+00$ 2.00000E-01-0.

12 l.

11 1.00000 000 2.00000E-01-0.

-

7.0000E-O1 2.00000E-D1-0.

?.0000e

6.00000E-01 2.00000E-01-0.

6 5.00000E-01 2.00000E-01-0.

5 4.00000E-QL 2.00000E-01-0.

3.00000E-01 2.00000E-01-0.

2.00000E-01 2.00000E-01-0.

$21.00000 E-01$ 2.00000E-01-0.

10.

2.00000E-01-0.
CODE FILE

HEMPDG MAP

HEMPDG

0.

0. $E$ o.

F

MH

RO

EOST IJ

017161

117193

217225

127257

117289

217321

117353

117385

117417

117449

117481

117513

217513

117545

11757

117609

117641

117673

117705

117737

117769

117801

117833

117865

117897

117929

117961

117993

117993

118025

118057

128089

118121

118153

118185

118217

118244

118281

218313

118345

118377

118409

118441 
2HEMP LIP.OI

K-LINE NUMBER 2 FROM GENERATOR

0 $\mathrm{X}$

$4 \mathrm{C} 4.000005400$ 1.000005-01-0.

40 4.00000E400 1.00000E-01-0.

40 3.

39 3. B0000E+00 1.00000E-01-0

38 3. 30000E+00 1.00000E-01-0

37 3.60000E +00 1.00000E-01-0.

36 3.50000E +00 1.00000E-01-0.

35 3.40000E+00 1.00000E-01-0.

34 3.30000E +00 1.00000E-01-0.

$333.20000 E+001.00000 E-01-0$.

32 3.10000E+00 1.00000E-01-0.

31 3.00000E+00 1.00000E-01-0.

30 2. $90000 \mathrm{E}+00$ 1.00000E-01-0

OEE +00 L.00000E-01-0

24 2.70000E+00 1.00000E-01-0.

$272.60000 E+00$ L.00000E-02-0.

26 2.50000E+00 1.00000E-01-0.

25 2.40000E+00 1.00000E-01-0.

$242.30000 E+00$ 1.00000E-01-0.

$232.20000 E+00$ 1.00000E-01-0.

22 2. $10000 E+00$ 1.00000E-0I-0.

$212.00000 E+00$ 2.00000E-01-0.

20 I. $90000 E+00$ 1.00000E-01 $=0$.

$191.80000 E+00$ 1.00000E $-01-0$

18 1. $70000 E+00$ 1.00000E-01-0.

$171.60000 E+00$ 1.00000E-0I-0.

$161.50000 E+00$ 1. $00000 E-01-0$.

$152.40000 E+00$ 1.00000E-01-0.

1.00000 +00 I. 000 $-01=0$.

$131.20000 E+00$ 1.00000E-01-0.

$121-10000 \mathrm{E}+00 \quad 1.00000 \mathrm{E}-01-0$.

11 1. $00000 \mathrm{E}+00 \mathrm{O} 1.00000 \mathrm{E}-0 \mathrm{~L}-0$.

$109.00000 E-01$ l.00000t-0L-0.

4 H.00000E-OL 1.0OOOOE-OL-0.

G 7.00000E-01 1.00000E-01-0.

$T$ 6.00000E-01 1.00000E-01-0.

- 5.00000E-01 1.00000E-01-0.

4.0000UE-01 1.00000E-01-0.

4.00000 E 01 l.00000E-01-0.

4 3. OODOOE OL 1 OOOOE-01-0.

3 2.00000E-01 $1.00000 E-01-0$.

$\begin{array}{lll}2 & 1.00000 E-01 & 1.00000 E-01-0 . \\ 1 & 0.0 & 1.00000 E-01-0 .\end{array}$

1-00t
0.
0.
0.
0.
0.
0.
0.
0.
0.
0.
0.
0.
0.
0.
0.
0.
0.
0.
0.
0.
0.
0.
0.
0.
0.
0.
0.
0.
0.
0.
0.
0.
0.
0.
0.
0.
0.
0.
0.
0.

COCE FILE HEAPDG MAP

HEAPOG

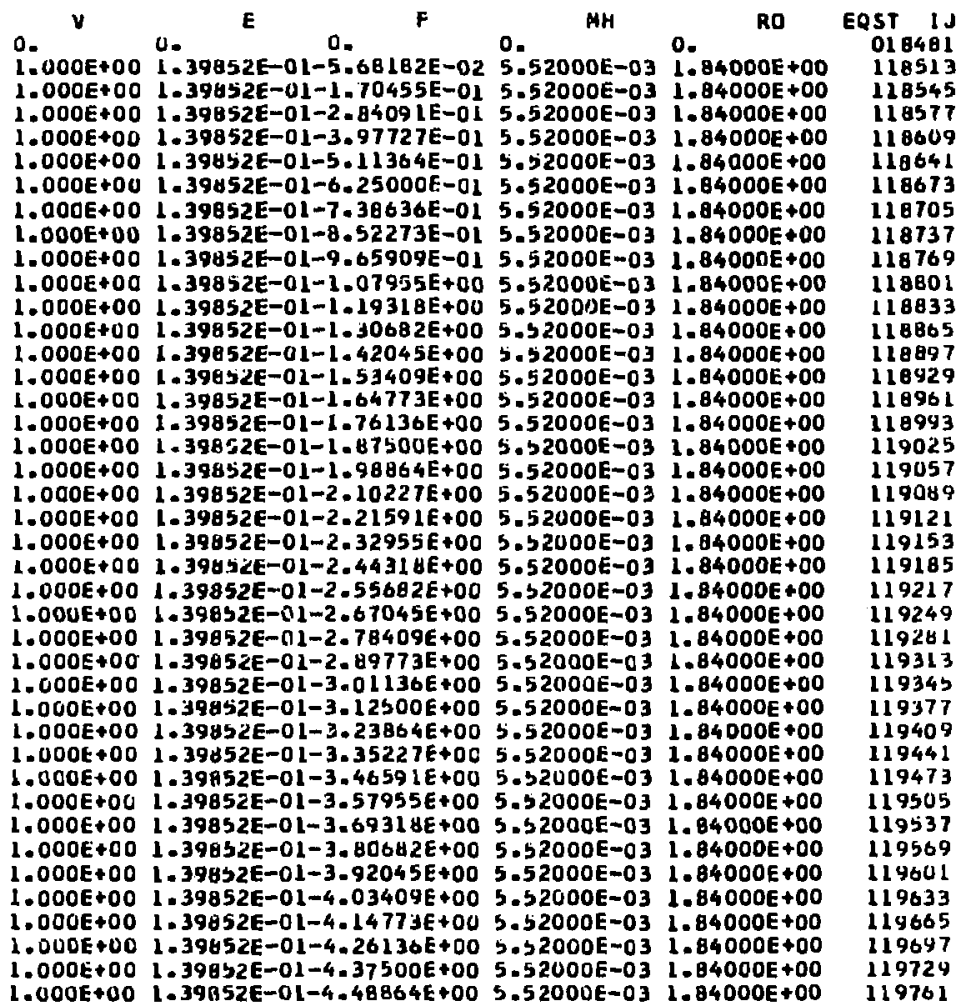

$1.000 E+00$

$1.000 E+00$ I.39R52E-0L-4.48864E+00 $5.52000 E-03$ 1.84000E+00

119761 
2HEMP LIP.OI I K-LINE MUMBER

D J

$414.00000 E+00$ 0.

$393.90000 \mathrm{C}+00$.

$383.8000+00$.

$38 \mathrm{~T}$. TOO0OE+00 $\mathrm{d}$

37 .

36 3.50000e 00 O

$353.400005+000$

$343.30000 E+00 \mathrm{O}$

33 3. $20000 E+00$ O.

$323.10000 E+000$.

$313.00000 E+000$.

$302.90000 E+00$ O.

$202.80000 E+000$.

$283.70000 E+00 \quad 0$

$272.60000 E+00 \mathrm{O}$

21 $2060000+00$ 0.

28 2. $20000 E+00 \mathrm{a}$

$252.40000 E+00$ O.

$242.30000 E+00$ O.

$232.20000 E+000$

22 2.10000E $\$ 00$ O

$212.00000 E+00 \mathrm{O}$.

$201.90000 E+000$.

$191.60000 E+000$.

$181.70000 E+00$ O.

$171.60000 E+00 \mathrm{O}$.

$161.50000 E+00$ o.

15 L.400soe $400 \mathrm{O}$.

$141.30000 E+00$ O.

$131.20000 E+000$.

$121.10000 E * 00$ D.

is $1.00000 \mathrm{E}+00$ 0.

10 g.000005-01

10 9.00000E-01 0.

7.00000E-01

$7.00000 \mathrm{E}-01 \mathrm{O}$.

6.00000E-02
$5.00000 E-01$

5.00000E-01 0.

3.00000E-01 0 .

$3.00000 E-012$

$2.00000 E-01$
2 l. $00000 E-01$

10.

BLOCK 1 DONE

$\begin{array}{ll}0 . & -0 . \\ 0 . & -0 . \\ 0 . & -0 .\end{array}$

FROM GENEKATOR

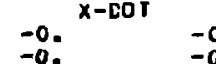

$Y-001$

$\begin{array}{ll}-0.0 & -0 . \\ -0.0 & -0 .\end{array}$

-

-0.0 -

$-0 . \quad-0$.

-

-0.
-0.

-0 .

-0 .

-0 .

-0.
-0.

$-0$.

-0 .

-0 .

-0.
-0.
-0.
-0.

-0 .

-0.
-0.

-0.

-0.

-0.

-0.
-0.
-0.

-0.

-0.
-0.

$-0$.

-0.

-0.
-0.

-0 .

areo

2HEMP LIP.OI

ICYCLE I TIH

IHE

1 I DELTA-T

.500000E-02
CCLE FILE

HEMPOG MAP

HEMPDG

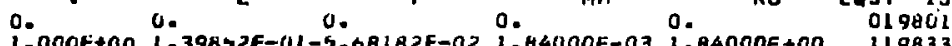

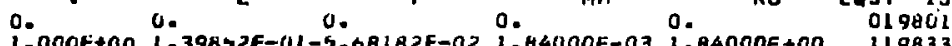

E

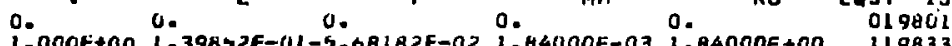

$\mathbf{F}$

MH

RO

EUST IJ 1.000E 00 L 1.0OE $1.000 \%$ 119841 $1.000 E+00$ 1.39852E-OL-3.97T2 TE-01 $1.84000 E-03$ 1.84000E $400 \quad 119924$ $1.000 E+00$ 1.3965e-OL-5.11364E-OI $1.84000 E-031.84000 E+00 \quad 119901$ $1.000 E+00$ 1.3985E 119543 $1.000 E+00$ 1.39652E-0L-1.36636E-01 1.84000E-03 1.84000E $+00 \quad 120025$ 1. $000 E+00$ 1.39AS2E-OL-H.52273E-01 1.84000E-03 1.84000E+00 120051 $1.000 E+001.39852 E-01-9.05909 E-01$ 1.84000E-03 $1.84000 E+00 \quad 120089$ $1.000 E+001.39832 E-01-1.07955 E+001.84000 E-031.84000 E+00 \quad 120121$ $1.000 E+001.39452 E-0 I-1.19318 E+00 \quad 1.84000 E-03 \quad 1.84000 E+00$ 1.201b3 1.000E+00 1.39852E-01-1.30682E+00 1.84000E-03 1.84000E+00 1.20145 $1.000 E+00$ 1.39852E-01-1.4204bE+00 1.64000E-03 1.84000E +00 12011 $1.000 E+001.39052 E-01-1-53409 E+00$ L $04000 E-03$ I $04000 E+00$ L 12021 $1.000 E+001.30452 E-01-1.53773 E+001.04000-032.84000 E+00 \quad 120249$ $1.000 E+001.20281$ $1.000 E+120313$

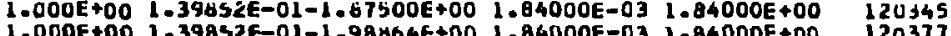
1.000 (1.8400E-03 1.84000 +00 12037

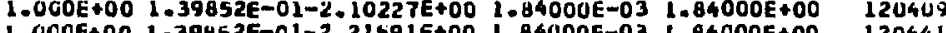
l.0O0E+00 1.39852F-01-2.21591E+00 1.0400E-03 1.64000+00 120441 $1.000 E+00$ 1.39852E-01-2.32955E+00 1.84000E-03 1.64000E+OD 120473 $1.000 E+00 \quad 1.39852 E-02-2.44318 E+001.84000 E-03 \quad 1-84000 E+00 \quad 120505$

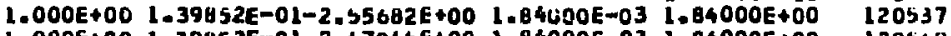
$1.000 E+001.39852 E-02-2.6704 S E+001.84000 E-03 \quad 1.84000 E+00$ 120569

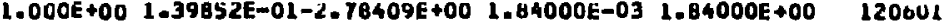
$1.000 E+00$ 1-39852E-0L-2.89773E+00 L.84000E-03 $1.84000 E+00 \quad 120633$ $1.000 E+001.39852 E-01-3.01136 E+00 \quad 1-84000 E-03 \quad 1.84000 E+00 \quad 120605$ $1.000 E+001-39852 E-01-3-12500 E+00 \quad 1-84000 E-03 \quad 104000 E+00 \quad 120697$ $1.000 E+00$ l 1.000 (120129 1.00000120161 1.00000120793

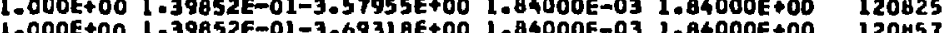
1.0004047 $1.0006+00$ Lajaster 120269 $1.000 E+00$ l.39852E-01-3.9204sE 120921 $1.000 E+00$ 1.39652E-01-4.03409E400 1.64000E-03 $2.84000 E+00 \quad 120453$ $1.000 E+00$ l.39852E-01-4.24773E+00 1.64000E-n3 $1.84000 E+00$ 120945 1.000E+00 1.39852E-01-4.26136E+00 1.84000E-03 L.84000E+00 121017 $1.000 E+001.39852 E-01-4.375 J O E+00$ 1. B4OOOE-03 1.84000E+00 121049 $1.00 O E+O Q \quad 1.39852 E-01-4.48864 E+00$ 1.8400OE-03 1.84000E+OD 121081

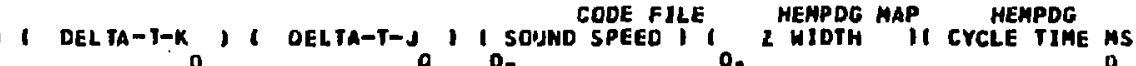


ZHEMP ITP.01

(CYCLE) (K-NUMGER) I TIME

15 2.300000E-0C

1 DELTA-T . SOODUOE-02

31

CCOE FILE

HEHPOG MAP HEKPOG

RHO

$x(2)$

$Y|R|$

$x-001$

$\begin{array}{ll}41 & 0 . \\ 40 & 0 .\end{array}$

390.

380.

370.

so 0.

350.

340.

330.

310 .

30 .

290.

290.

270.

260 .

250.

240.

230 .

$\therefore \quad 220$.

210.

200.

$\begin{array}{ll}19 & 0 . \\ 18 & 0 .\end{array}$

if 0 .

is 0.

is 0.

140.

130.

il 0 .

100.

40.

8.

0

00

20.

40.

20.

$4.0000 E+00$ I. $3.9000 E+00 \quad 1.4000 E+000$. 3. 3.7000 . $3.6000 E+00$ 1.4000t+00 O. $3.6000 E+00$
$3.5000 E+00$ $3.5000 E+00$ 1.
$3.4000 E+00$ I. $4000 E+000$. $3.3000 E+U D$ 1.4UODE $+O C \mathrm{O}$. $3.2400 E+001.4000 k+000$. 3. $1000 E+001.4000 \mathrm{~L}+00 \mathrm{O}$. 3.0000 E +00 1.40UOE 400 D. $2.9000 E+00 \quad 1.4000 E+00$ C. $2 . \forall 000 E+00 \quad L-4000 E+00$ O. $2.7000 E+00$ l. $4000 E+00 \mathrm{D}$. $2.6000 E+0 U, \quad 4000 E+000$. $2.5000 E+00$ L $4000 E+0 \mathrm{C}$. $2.4000 E+00$ L $4000 E+00$. $2.30005+00$ l. 40UDe+00 2. $20005+00$ L $40006+000$. 200 - 2000 D 1.4000 to 2. 1.9000 toO 1.4000E +00 0. $1.8000 E+00$ l. $4000 t+00$ O. $1.7000 E+00$ l.400OE +OC C. l.6000E+RO l.40UDE +DO O. I.5O0OE 400 1.4000E+OU D. 1.4000 etaO l.4000E+00 O. 2.3UOOE +UO I. 4 UOOE+OC C. 1.2U0DE $\$ 00$ I. 4 UUDE +00 O. $1.1000 E+00$ I.4UOOE +1)O O. $1.0000 E+00$ 1.4OUOE+100 0 . 9.0000E-UI I.4GUOE+OC O. U.0000E-UL L 4 UUOt +00 D. $7.0000 E-01$ 1. 4 UOOE +00 0. 6.UU00E-01 l.4UUOE +00 0 . 5.000OE-01 I. 4 UOOE +OU C. S.c000 1.4000 . 4.0000 E 3.0000E-OI l.4U0OE +OU 0. 2.0000E-OL 1.4000E +00 0. 1.

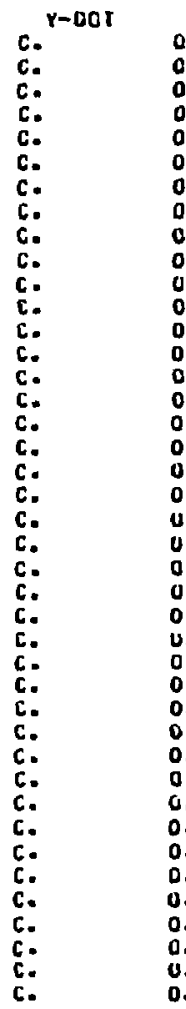

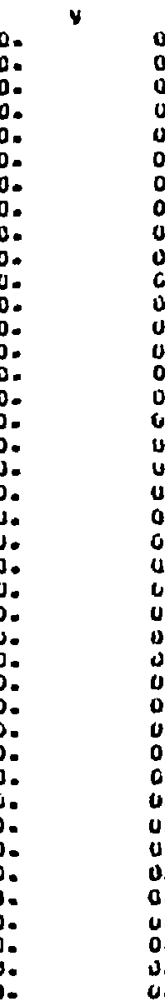

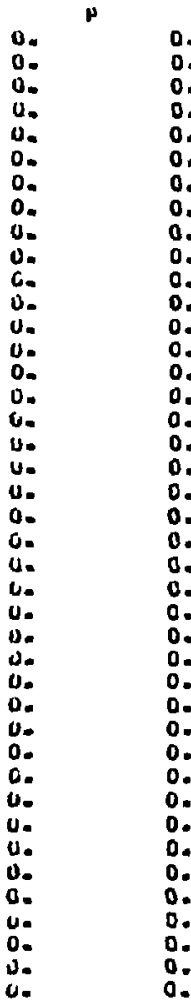

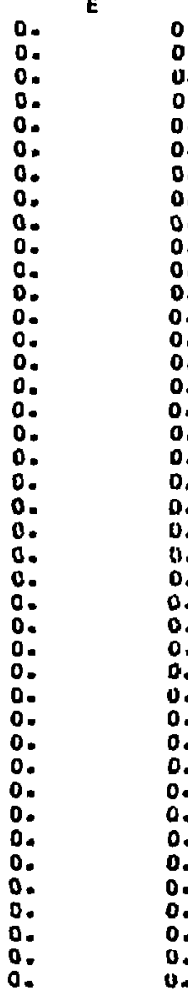

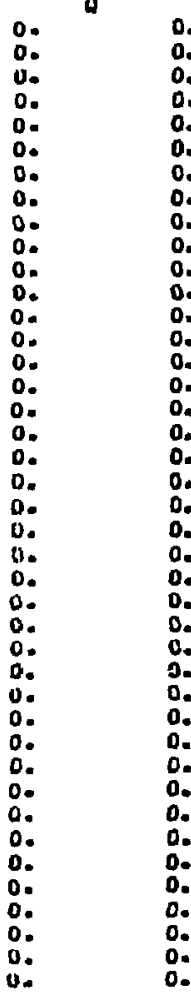

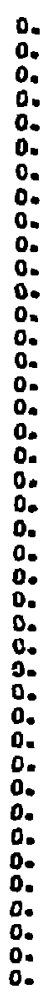




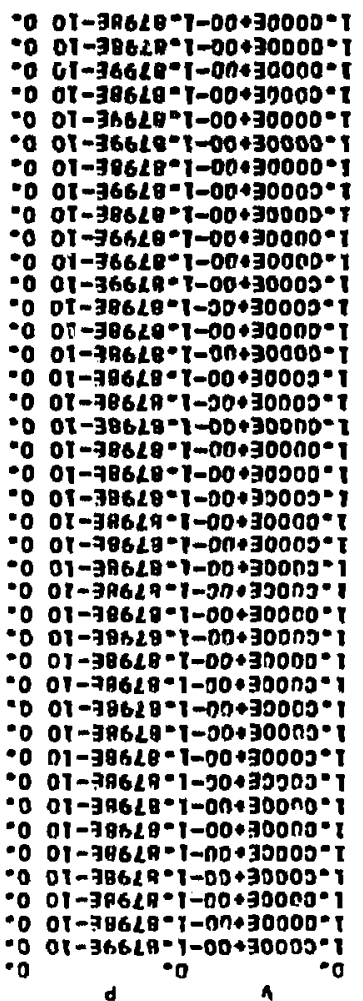

- ol ol-3a6L8-1-00+30000-1

-0-00+70005-1 - $00+30058 \cdot 1$ - 0 00+30005*1 10-30000*t 00+30058* z

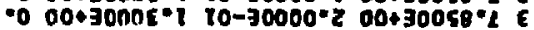

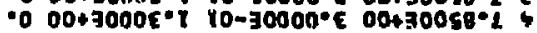
-0 00+30006*1 10-30000* 00+30058 थ 1 s

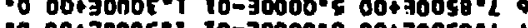
-0 00+3000E-1 10-30000.4 00+30058-2 L - 0 00+3000E-T 10-30000\%L 00030058-L - O D0+3000e*T 10-30000-8 00+70058*L A - o oot30noe-1 10-30000\%h 00+3005a-l ol -0 00+300ne-1 00+30000-1 00+30050-L il

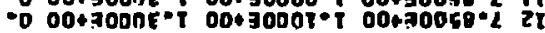
- $00+30006 \cdot 1$ 0n*30002-1 00+70058*I EI - 00 007000E-1 00+3000E*T 00+30058*1 +1

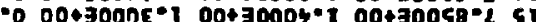
- 004zonar.1 00+30005-1 00+30050\% - 00430ner

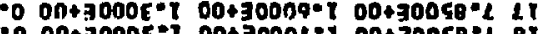
-O O0+300DE"1 00+3000L"I 00+3005D'L BI -O O0+300nE.1 00+30008\%1 00+30058-2 61

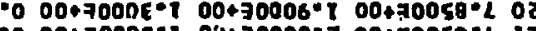

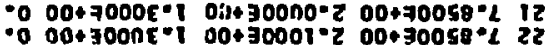

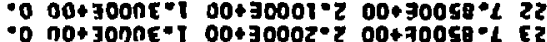
O no+jonne-1 00+3000z-z 00+70058-L Ez

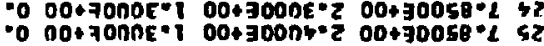

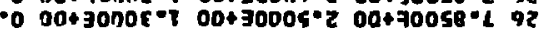

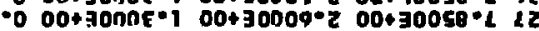
- D Do+300ne-1 00+30002-2 $00+70058 \cdot 2$ a? -0 30+7000E-1 00+30008*2 00+30048 - 62 - $000+700 n c * 100+30008=200+30058 \cdot \%$ of

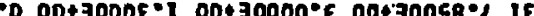
-

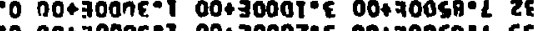

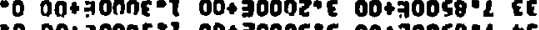

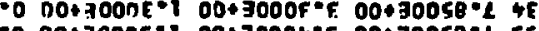

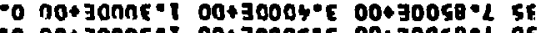

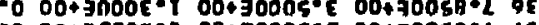
- O 00+3000E-I 00430009.e 00+30058.L LE

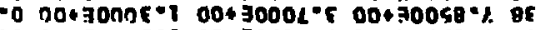
-O not 30nDE"l 00+30009-E 00+30058- $L$ be - O not30nDF-1 00+3000s-E $00+30058-i$ or $100-x$

ixIA




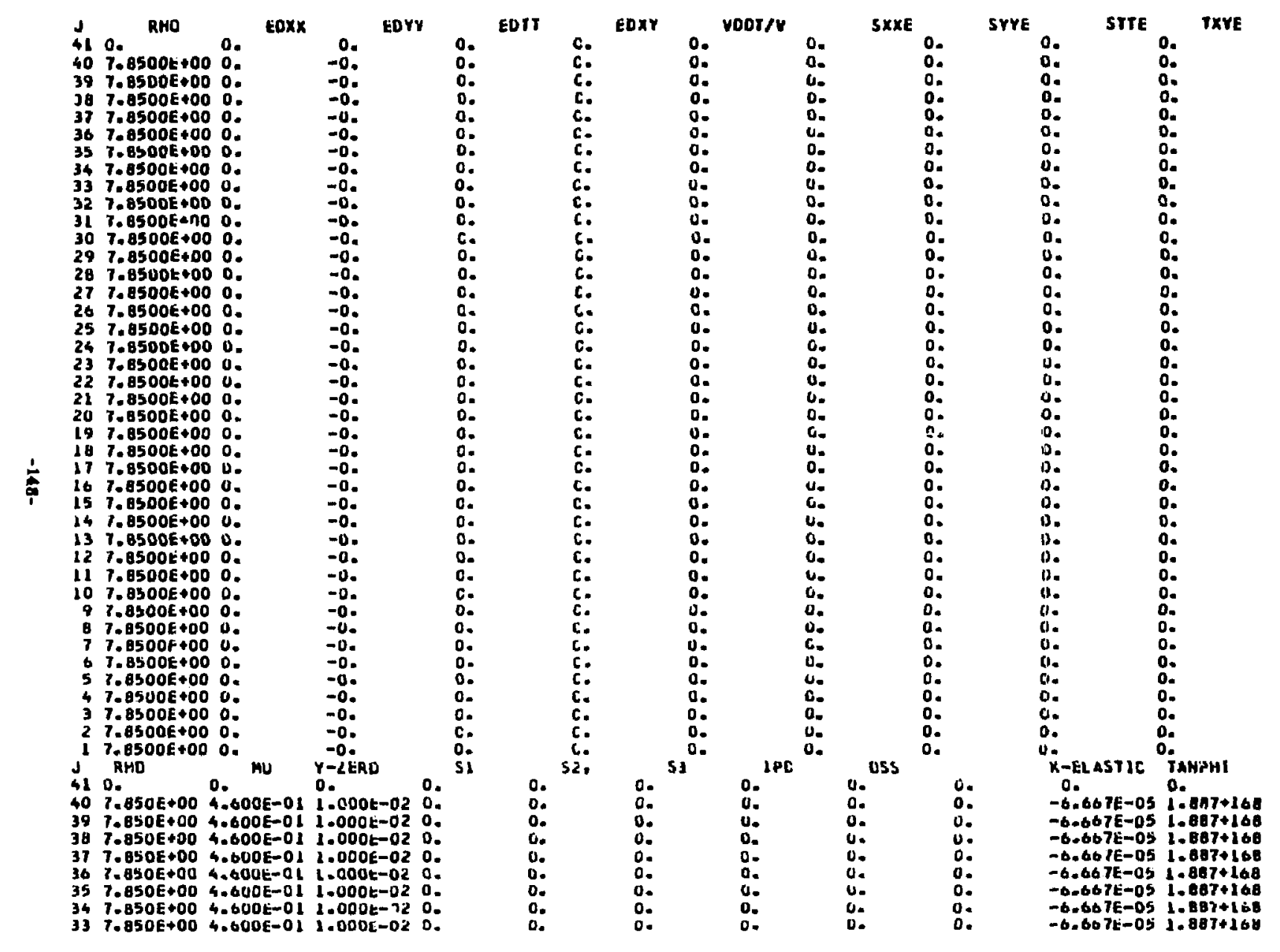




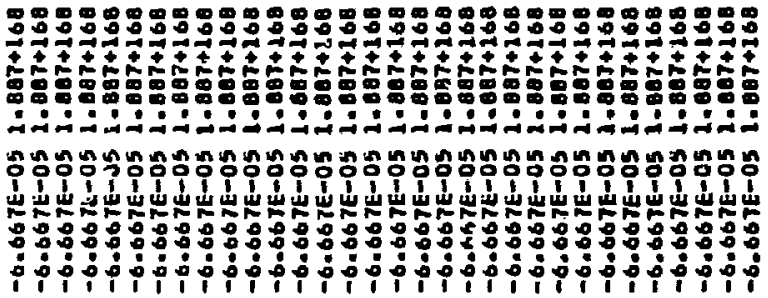

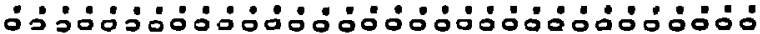

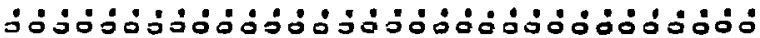

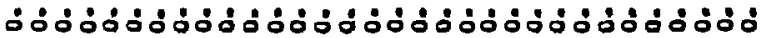

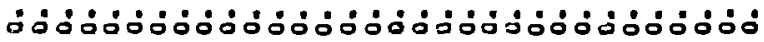

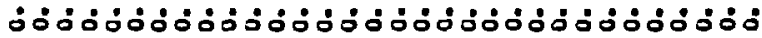

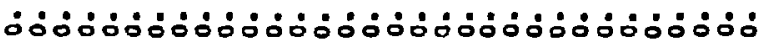

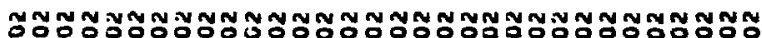
ílilipili

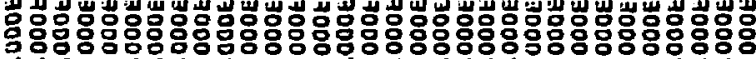
4.

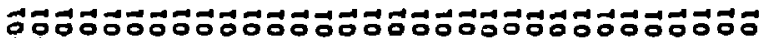
I lululd

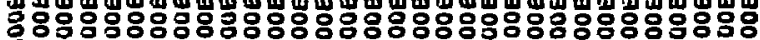

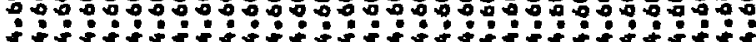

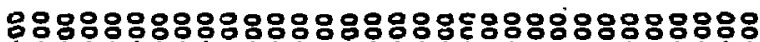

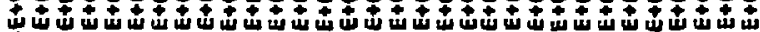
○

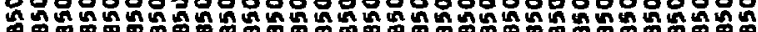

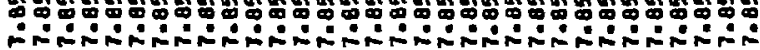

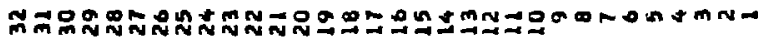


2HENP LIP.OL (CYCLE) IK-NUMAER)

TIME 11 DELTA-T $132.500000 E-02 \quad 2.500000 E-02$

1 OELTA-T-K

1

CODE FILE

HEMPOG MAP

HENPOG

RHD

$x(2)$

$Y(R)$

$x-00 T$

42 D. 4.00OOE +00 $1.2000 E+0 C O$. 40 7.850OE $+00 \quad 3.9000 E+00 \quad 1.2000 E+00$ O. $397-8500 E+00 \quad 3.8000 E+00 \quad 1.2000 E+000$. 38 7.85OOE+00 3.7000E+00 $1.2000 \mathrm{E}+00 \mathrm{O}$. 37 T-ESOOE+OO $3.6000 E+00$ 1.2U0OE+00 0 . $367.0500 E+003.5000 E+Q 0$ L l.2UOUE+OQ 0 . 35 7.8500E +00 3.400OE +00 L.200OE+0O C. $347.8500 E+00^{\circ} 3.3000 E+00 \quad 1.2000 E+00 \quad 0$. $337.8500 \mathrm{t}+00 \quad 3.2000 \mathrm{E}+00$ i.2U00E+00 C. $327.8500 E+003.1000 E+00$ 1.2 $2000+000$. $317.8500 t+003.0000 E+U 01.2000 t+000$. $307.8500 E+00 \quad 2.9000 E+00 \quad 1.20001:+000$. $297.8500 E+00$ 2.800OE +00 1.2000E+0C 0 . $287.8500 \mathrm{E}+00 \mathrm{2}-7000 \mathrm{E}+00 \mathrm{O} 1.2000 \mathrm{E}+00 \mathrm{O}$. $287.8500 E+00$ 2.7000E+00 $1.2000 E+000$. 27 . $267.8500 E+00$ 2.5UOOE $\$ 00$ l.2000E+00 0. 25 T.ASOCE 2.4000 C +00 1.2 24 7. 23 T.8500E+00 2.2000E+00 1.2U00E+TO O.

$\therefore \quad 22$ T.8SOOC+00 2.IUODE +00 1.20UOE+100 O. $217.8500 t+00$ 2. $0000 E+00$ I.2U00E+UO O. $207.8500 E+00$ 1.4000E +00 1.2UDOE+OC 0 . $197.8500 E+00$ L.BODOE +00 I.2UDOE +OU 0 $187.8500 E+00 \quad 1.7000 E+00 \quad 1.2000 E+000$. $171.8500 E+00$ I. $6000 \mathrm{E}+00$ l.2U00t $+00 \mathrm{G}$

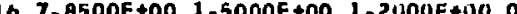
7 . $7500 E+00$ d $4000 E+00$ l. is 7-esogetod 1. $47.0500 E+00$ l.3000E+UO 1.200OE +00 O $37.0500 E+00$ l.2000e+00 $1.2000 t+00$ O 12 7. II 7.85ODE 7.00 1.0000E+00 1.2000E+00 O. 10 7.0SODE $\$ 00$ 9.0000E-01 1.2000E+00 0. 4 7.05OOE+O0 8.0000e-01 l.2000E+00 D. 7 7. BSOOE+00 7.0000E-OL L.2UUUE +OU O. $77.8500 E+00$ 6.UUOOE-OL L.2UOOE+0U O. $67.8500 E+00$ S.0000E-01 $\quad$ - 2 -2UOOE +00 O. $57.8500 \mathrm{E}+00 \quad 4.0000 \mathrm{E}-01 \quad 1.2000 \mathrm{E}+0 \mathrm{C} \quad 0$. $47.8500 E+00$ 3.000OE-D1 1.2UUDE+DO O. $37.8500 E+00$ 2.0000E-02 $1-2000 E+00$ O. $27.8500 t+001.0000 E-02$ l. $2000 E+040.0$ $17.8500 \mathrm{t}+00 \mathrm{U}$. L.2UOOE+OC -0 .

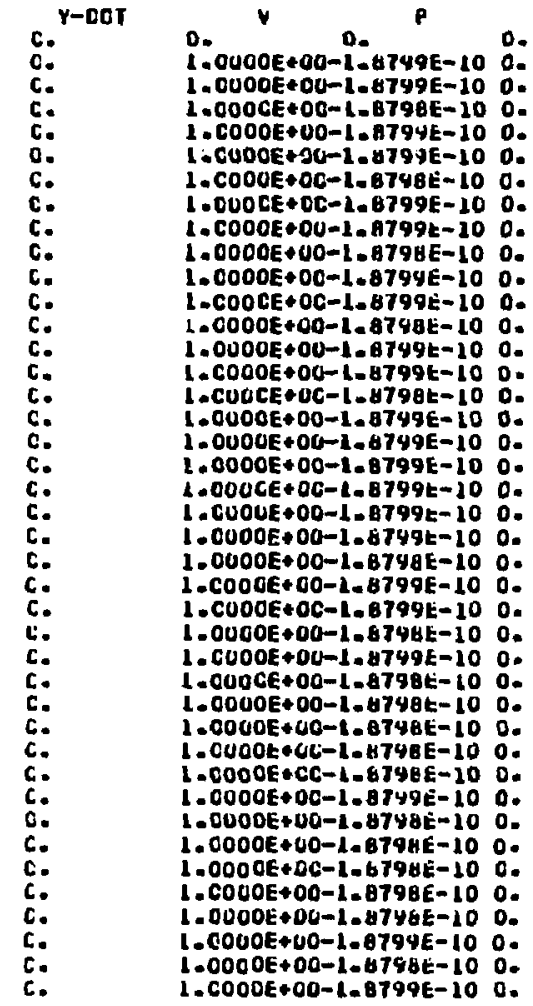

o.

E

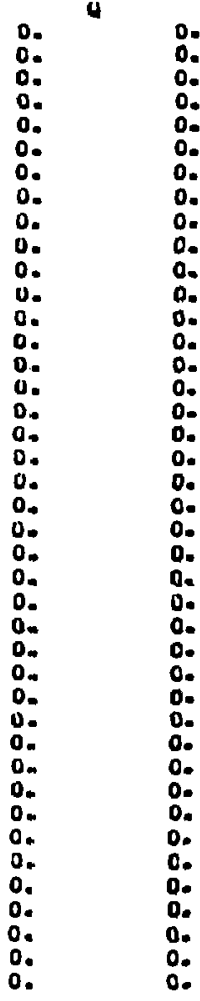

0.
0.
0.
0.
0.
0.
0.
0.
0.
0.
0.
0.
0.
0.
0.
0.
0.
0.
0.
0.
0.
0.
0.
0.
0.
0.
0.
0.
0.
0.
0.
0.
0.
0.
0.
0. 


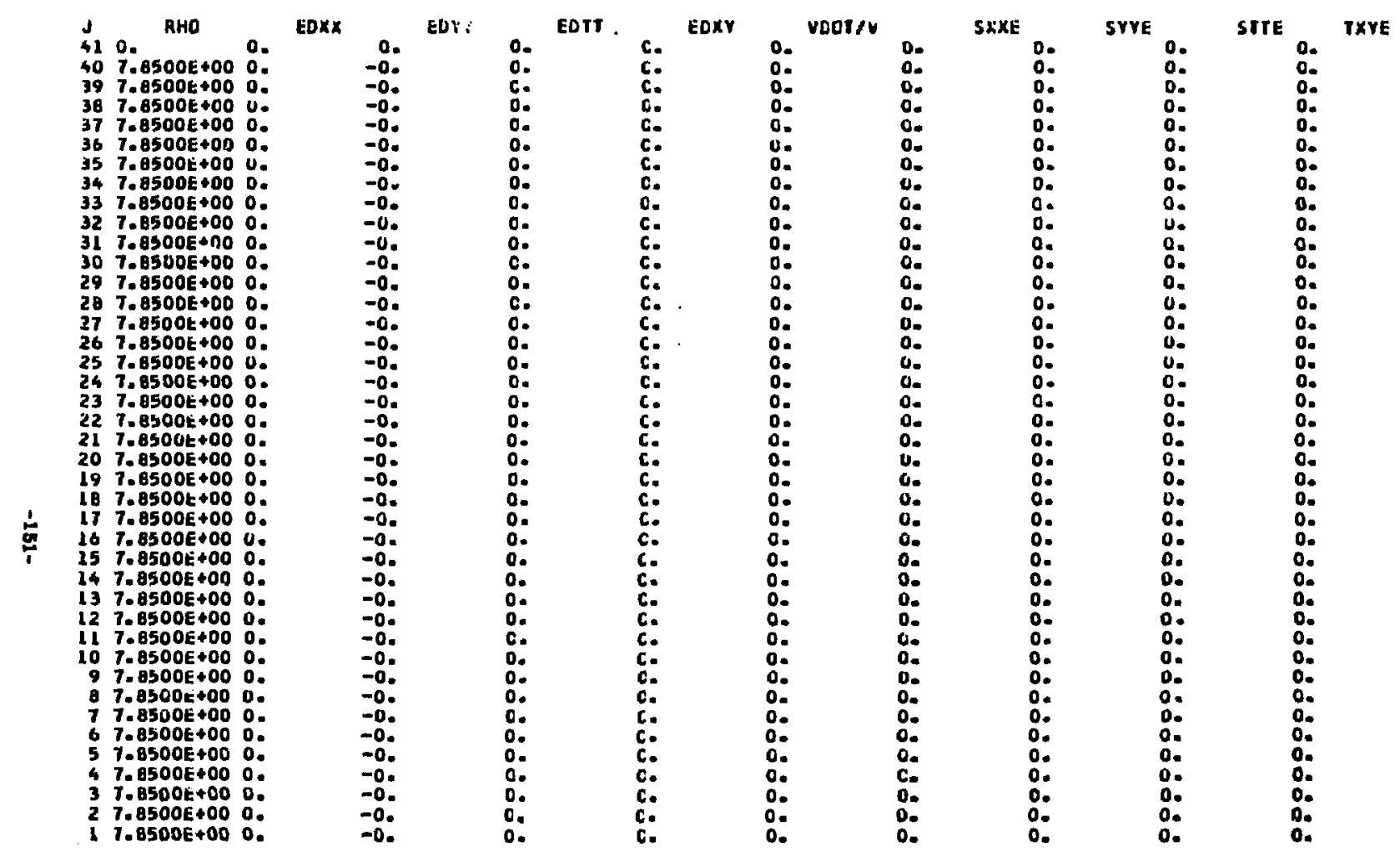




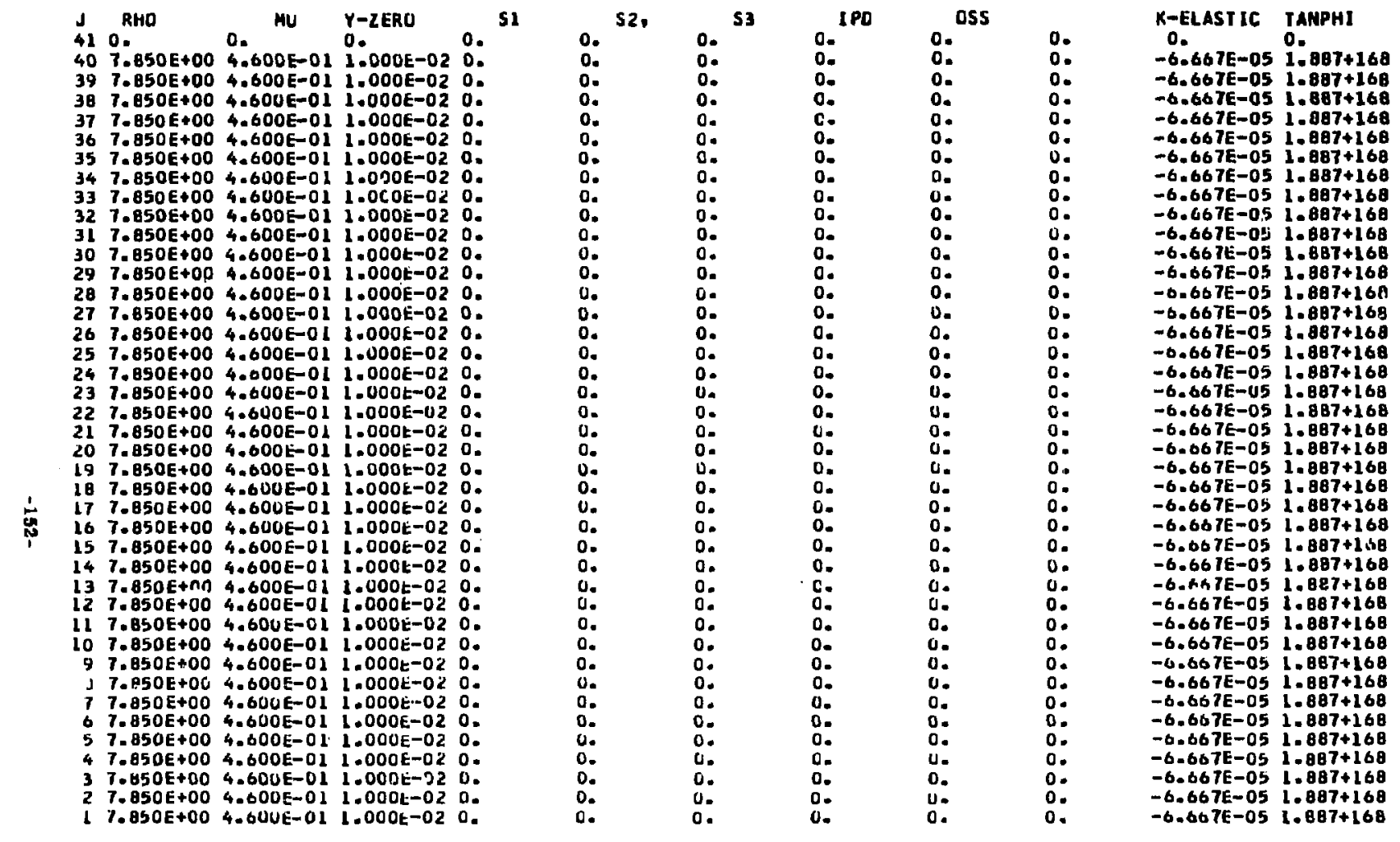


2HEMP LIP.OL (CYCLE) (K-NUMBER

1

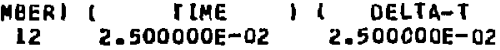

I I DELTA-T-K

| Uelta-t-j, I I SDUhD

HEMPDG MAP

HEMPDG

0.

0 .

0.

2 HIDTH

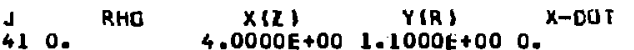

40 T.B500E+00 $\begin{array}{llll}4.0000 E+00 & 1.1000 E+00 & 0 . \\ 3.900 E+00 & 1.1000 E+00 & 0 .\end{array}$

$397.6500 E+00 \quad 3.8000 E+00 \quad 1.1000 E+000$.

$38 \mathrm{~T}$.8500E $+00 \quad 3.7000 E+00 \quad 1.1$ ULOEE $+00 \quad 0$.

$377.8500 E+00 \quad 3.6000 E+00 \quad 1.1 U 00 E+000$.

36 T.8bOOE +00 3.50OOE +00 1. $1000 t+000$.

$357.8500 E+003.4000 E+00$ 1. $2000 E+000$.

$347.8500 E+00 \quad 3.3000 E+00$ L. LUOOE +00 0 .

$337.8500 E+00 \quad 3.2000 E+00 \quad L .1000 E+00 \quad 0$.

$327.8500 E+00 \quad 3.1000 E+00 \quad 1.1000 E+000$.

31 7. $8500 E+00$ 3.0000E+00 1. LOODE+OC 0 .

$307.8500 E+00 \quad 2.9000 E+00 \quad 1.1000 E+000$.

29 7.6500E +00 2.8000E +00 - $.1000 \mathrm{E}+000$.

$287.85 \cap 0 E+002.7000 E+00$ I. 2 UOOE +00 O.

$277.8500 E+002.6000 E+00 \quad 1.1000 E+000$.

$267.8500 E+00$ 2.5000E +00 L.1OOOE +00 O.

$257.8500 E+00$ 2.4000E +00 1. 1000E +00 0 .

$247.8500 E+002.3000 E+00 \quad 1.1000 E+000$.

$237.8500 E+00 \quad 2.2000 E+00$ 1. $1000 E+000$.

$1 \quad 227.8500 E+002.1000 E+00 \quad 1.1000 E+000$.

$217.8500 E+00$ 2.0000E +00 l. $1000 E+00$ O.

$207.8500 E+00 \quad 1.9000 E * 00 \quad 1.1000 E * 000$.

$197.8500 E+00 \quad 1.8000 E+00 \quad L .1000 E+00 \quad 0$.

$187.8500 E+00 \quad 1.7000 E+00 \quad$ LE $1000 E+00 \quad 0$.

17 T. $8500 E+00 \quad 1.6000 E+00 \quad 1.1000 E+00 \quad 0$.

$167.8500 E+00 \quad 1.5000 E+00 \quad 1.1000 E+000$.

$157.8500 E+00 \quad 1.4000 E+00 \quad 1-1000 E+000$.

$147.8500 E+00 \quad 1.30006+00 \quad 1.1000 E+000$.

$137.8500 E+001.2000 E+001.1000 E+000$

$127.8500 E+001.1000 E+00 \quad 1.1000 E+000$.

$117.8500 E+00 \quad 1.0000 E+001.1000 E+000$.

$107.8500 \mathrm{E}+0$ N 9.0000E-01 l. $2000 \mathrm{E}+00 \mathrm{O}$.

$97.6500 E+00$ 8.0000E-01 I. $1000 E+000$.

$87.8500 E+007.0000 E-021.1000 E+000$.

$7.8500 E+006.0000 E-01 \quad 1.1000 E+000$

b 7.8500E+00 5.0000E-01 1.1.000E+00 0 .

5 7.6500E+00 4.0000E-CI $1.1000 t+000$.

$47.8500 E+013.0000 E-011.1000 E+000$.

3 7. $8500 E+002.0000 E-01 \quad 1.1000 E+000$.

$27.8500 E+00$ L.0000E-0L $1.1000 E+000$.

$17.8500 E+000 . \quad 1.1000 E+00-0$.

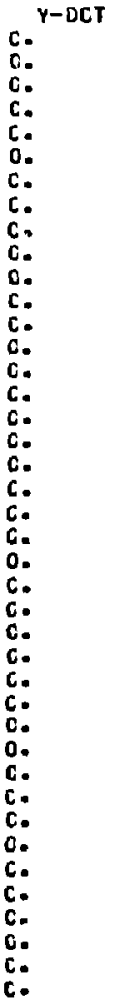

$0 . \quad 0 . \quad$ P 0. $1.0000 E+00-1.8799 E-100$. $1.0000 E+00-1.8799 E-100$. 1. COOOE+0O-1.8798E-10 O. $1.0000 E+00-1.8799 t-100$. $1.0000 E+00-1.8799 E-100$. 1.0000E+00-1.8798E-10 O. 1. $0000 E+00-1.8799 E-100$. $1.0000 E+00-1.6799 E-100$. $1.0000 E+00-1.6798 \mathrm{t}-10$ O. $1.0000 E+00-1.8799 E-100$. 1. $C 000 E+00-1-8799 E-10$ o. 1. DOOOE+UO-1.8798E- 10 O. 1. $0000 E+00-1.8799 E-100$. $1.0000 E+00-1.8799 E-10$ 0. 1.COOCE+ 0C-1.8798E-10 O. $1.0000 E+00-1.8798 \mathrm{E}-100$. 1.0000E+00-1.8798E- 100. $1.000 C E+00-1.8794 E-100$. $1-0000 E+0 C-1.8798 E-100$. $1.0000 E+00-1.8798 E-100$. $1.0000 E+00-1.4798 E-100$. $1.0000 E+00-1.8798 E-100$. 1. COOOE $>00-1.6799 E-100$. $1.0000 E+00-1.8798 E-100$. $1.0000 E+00-1.8798 E-100$. 1. COODE+00-1. -8798E-10 0. 1. COOOE+00-1.8798E-10 n. 1.C000F+00-1 - $8798 E-100$. $1.0000 E+20-1.8799 \mathrm{E}-100$. $1.0000 E+00-1.8799 \mathrm{E}-100$. 1. CUOOE+0O-1 - 8794E-10 O. 1. DOQ0E+00-1.8794E- 10 O. $1.0000 E+00-1.8749 E-100$. $1.0000 E+00-1.8798 E-10$ o. 1. COOOE+OO-L - B799E- 100 . $1.0000 E+00-1.8799 E-100$. 1. $0000 E+00-1.8799 E-100$. 1. $0000 E+00-1.8-98 E-10$ D. $1.0000 E+00-1.8799 E-100$. $1.0000 E+00-1-8799 E-100$.

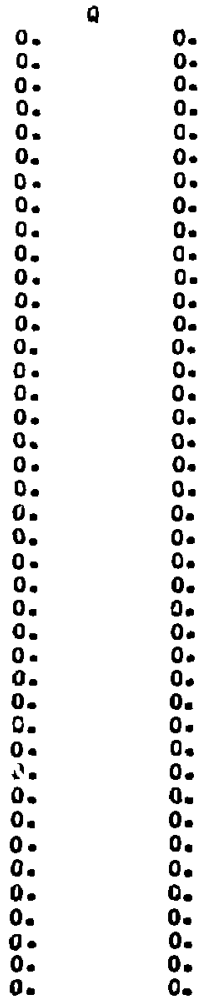

$F$

0.
0.
0.
0.
0.
0.
0.
0.
0.
0.
0.
0.
0.
0.
0.
0.
0.
0.
0.
0.
0.
0.
0.
0.
0.
0.
0.
0. 


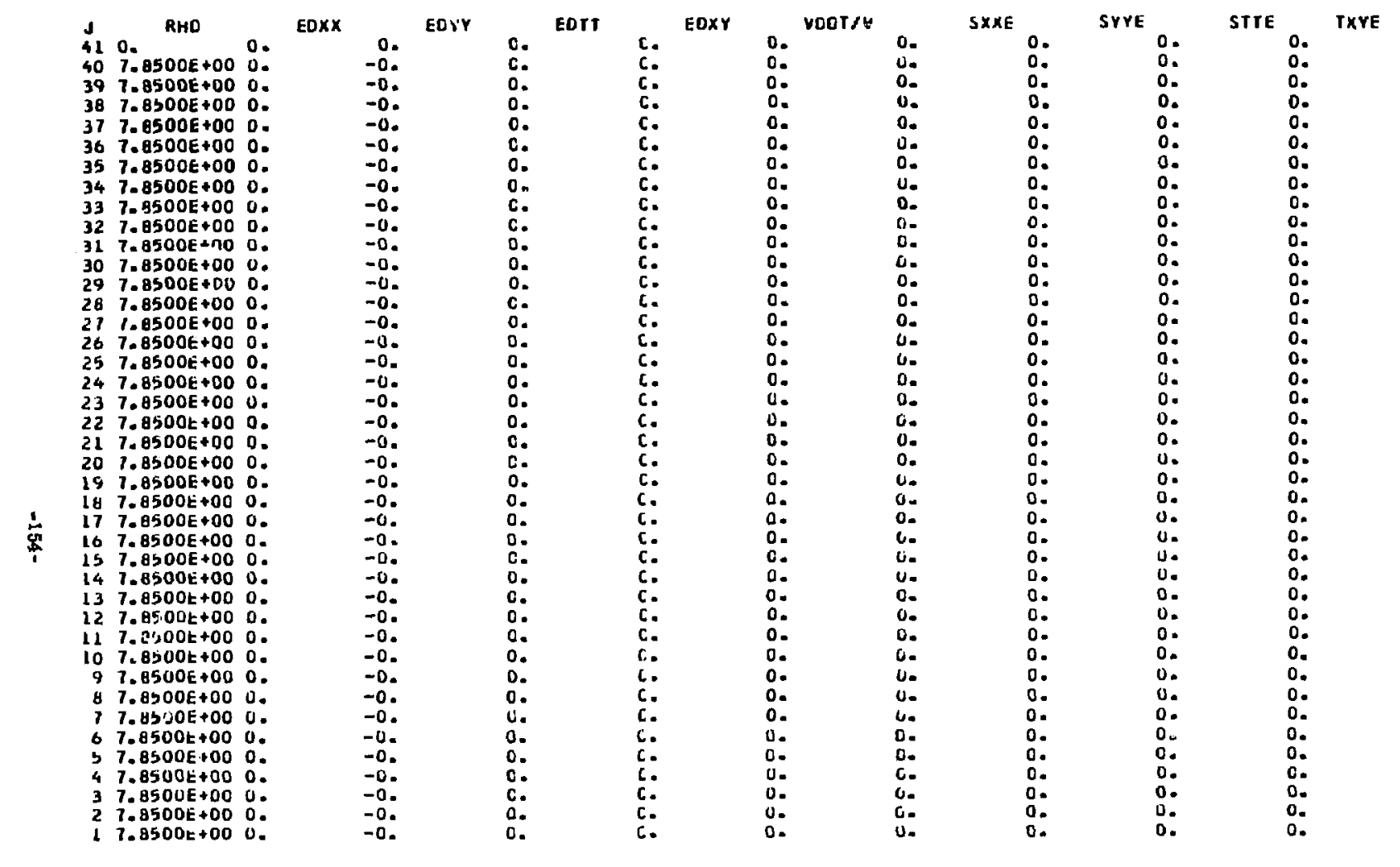




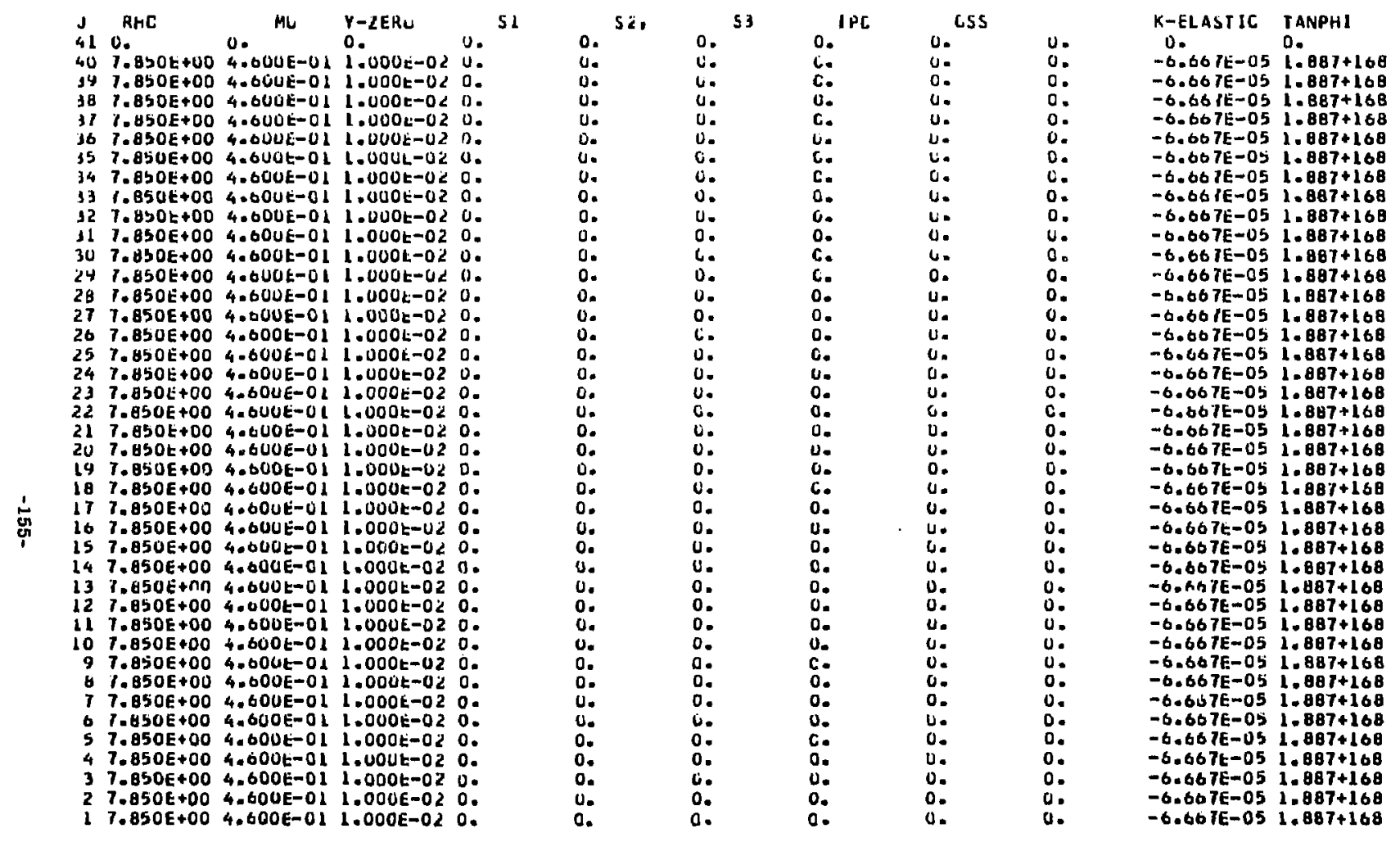


2HEMP LIP.OL

1 DELTA-I DELTA- T 1 11. UEL TA-T T-K 11 Lie ᄂIA-TーA 11 0 . 410. $x(2)$ $Y(R)$ $x-D O T$ 40 T. 39 . $397.8500 t+00 \quad 3.4000 E+00 \quad 1.0000 E+000$. 38 7.8500E+00 3.7000E +00 1.UUUDE +00 O. $37 \% .8500 E+00$ 3.0UOOE +0D 1.0UOUE +OC 0 . $367.8500 E+00$ 3.bOOOE +00 1.0UUOt+00 C. 15 $7.8500 E+00$ 3.4UDOE +00 1.0UCOE +000 . $347.8300 E+00$ 3.3000E+0O 1.0 OCOE +00 O. $3+1.8500 E+00$ 3.2UOOE +00 I. OULOE+OU O. $327.8500 E+00$ 3. $1000 E+00$ 1.00UOE+OD 0 . 31 $1.8500 E+00$ 3.0U0OE +00 1.0LUOE + UC O. $307.8500 E+002.4000 t+00$ I. UUDOE +00 O. $247.8500 E+00$ 2.800OE+UO $1.0000 E+00$ O. $28 \% .8500 E+002.7000 E+00 \quad 1.0000 E+00$ O.

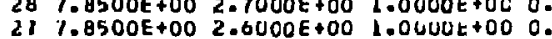
$267.8500 E+00$ 2.5UUOE+UD 1.OUUUE +OU 0 . $257.8500 E+002.4000 E+00 \quad 2.0000 E+000$. $247.8500 E+00$ 2.400OE +00 $2.0000 E+000$. $\begin{array}{llll}24.8300 E+00 & 2.3000 E+00 & 1.0000 t+00 & 0 .\end{array}$

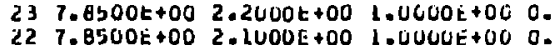
$217.8500 E+00 \quad 2.0000 E+00$ L. ULUOE $+00 \quad 0$. $207.8500 E+00 \quad$ L.9OUOE $+00 \quad$ I.000OE $+0 \mathrm{C} C$. $191.8500 E+00 \quad 1.8000 E+00 \quad 1.0660 t+000$. I $7.8500 E+00 \quad 1.7000 E+00 \quad 1.0400 t+000$.

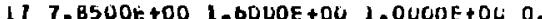
$167.8500 E+00$ L 5000 E 400 1.0UUDt +00 O

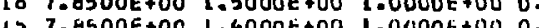
is T.ESOOE $147.8500 E+00$ l.3UOOE 00 L.OUUUE +00 O. $\begin{array}{llll}\text { li } 7.8500 E+00 & \text { l. } 2000 E ~ 100 & \text { l. UUUOt }+0 U & 0 .\end{array}$ $127.8500 E+001.1000 E+00$ L. UUUOt + DL C.

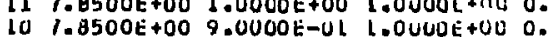
$97.8500 E+00$ B. $0000 E-O L$ L. OUUDE+1JU 0. 7. 7.85ODE +00 7.0UOOE-DL L. OULOL+OU O. $77.8500 t+00$ G. UUNOE-OL $1.0000 t+0 C 0$. 6 7.8500E+00 3.0000E-UL L.OUUUE+0O O. $57.8500 E+00 \quad 4.0000 E-01$ L.00UOE+00 O. $47.8500 E+00 \quad 3.0000 E-0 L \quad 1.0$ OUOL +0U C. $7.8500 E+00$ 1.00OOE-OL 1.UUUDE+UO O.
$17.8500 E+00$ O.

I T.8500t +00 O. $Y-D C I$

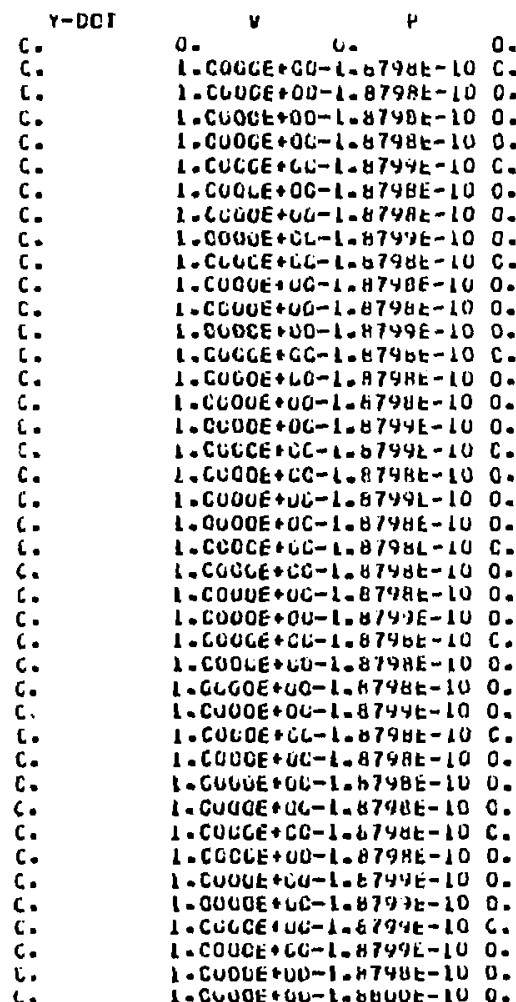

.

t

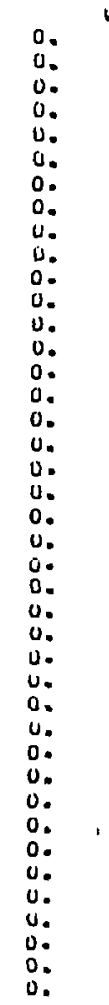

0.
0.
0.
0.
0.
0.
0.
0.
0.
0.
0.
0.
0.
0.
0.
0.
0.
0.
0.
0.
0.
0.
0.
0.
0.
0.
0.
0.
0.
0.
0.
0.
0.
0.
0.
0.
0.
0.
0.
0.
0.
0. 


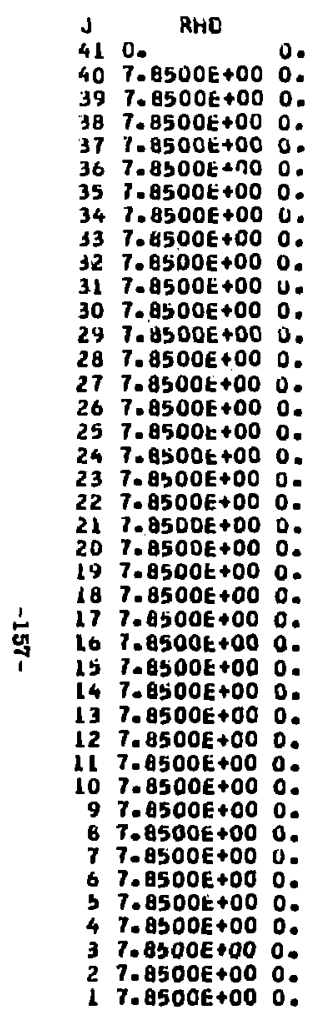

$\operatorname{toxx}$

EDYY

EDT T

c. ECXY 0.
-0.
-0.0.

-0 .

-0.
-0.

$-0$.

-0.
-0.

-0.
-0.

-0 .

0 .

-0 .

-0.
-0.

$-0$.

$-0$.

-0.
-0.

-0 .

-0.
-0.

-0.
-0.

-0.
-0.

-0.

-0 .

-0 .

$-0$.

-0 .

-0 .

-0.
-0.

-0 .

-0 .

-0.
-0.

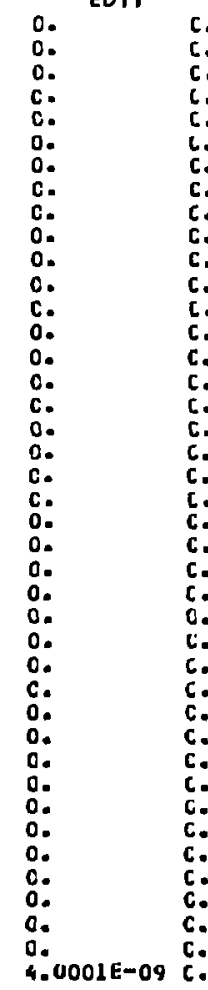

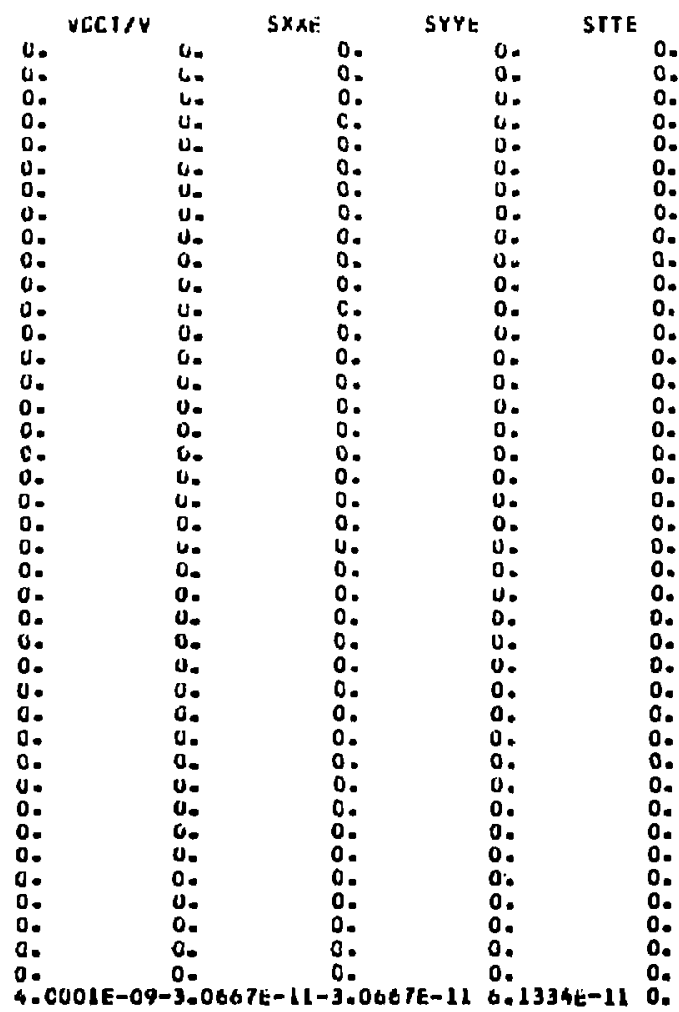

0.
0.
0.
0.
0.
0.
0.
0.
0.
0.
0.
0.
0.
0.
0.
0.
0.
0.
0.
0.
0.
0.
0.
0.
0.
0.
0.
0.
0.
0.
0.
0.
0.
0.
0.
0.
0.
0.
0.
0.
0.

TXYE

c.

:

c.

c.

c.

:

c.

C.

c.

c.

c.

c.

.

C.

c.

C.

c.

c.

4.C0OLE-09-3.0667t-11-3.0667E-11 6.1334t-11 0. 


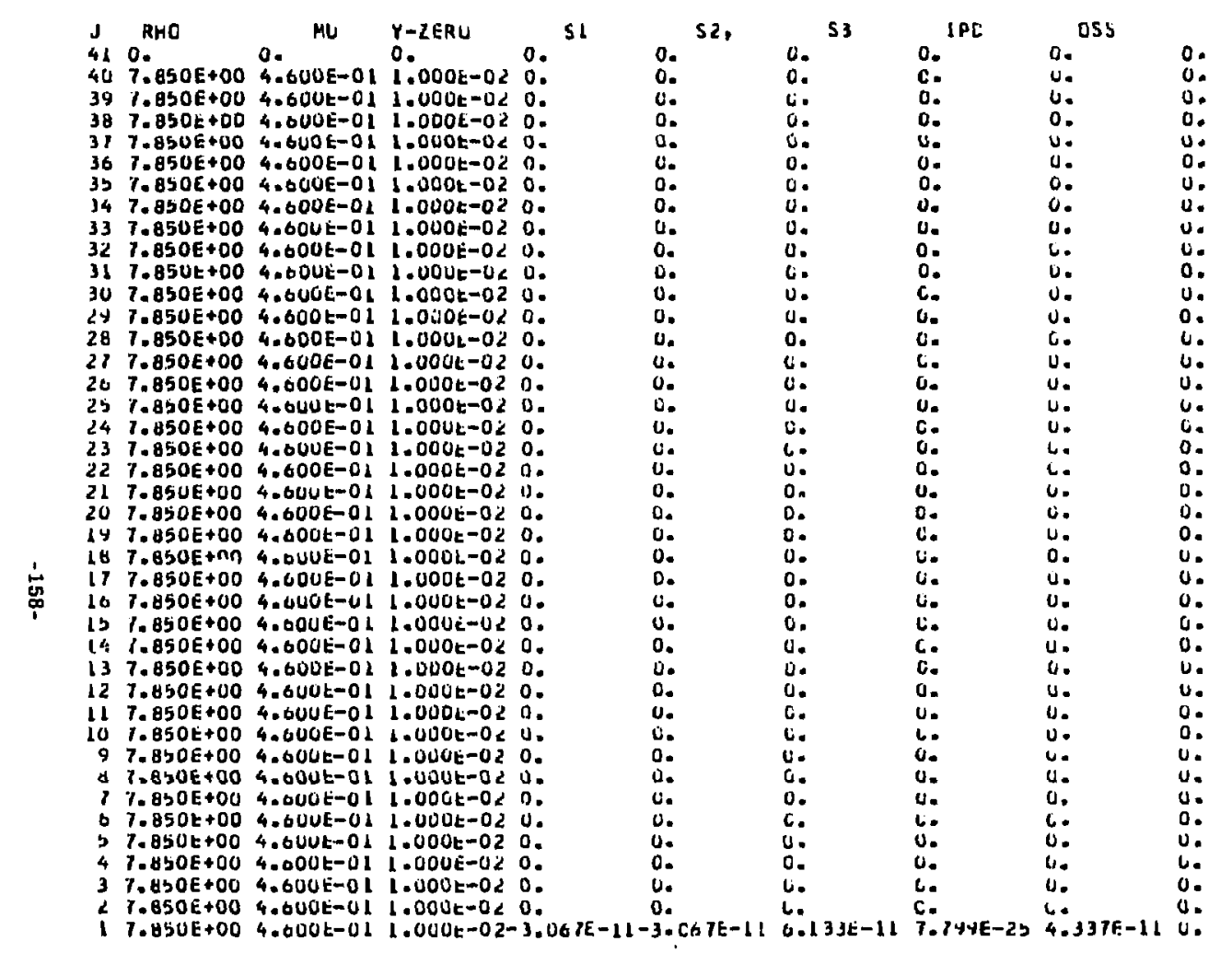

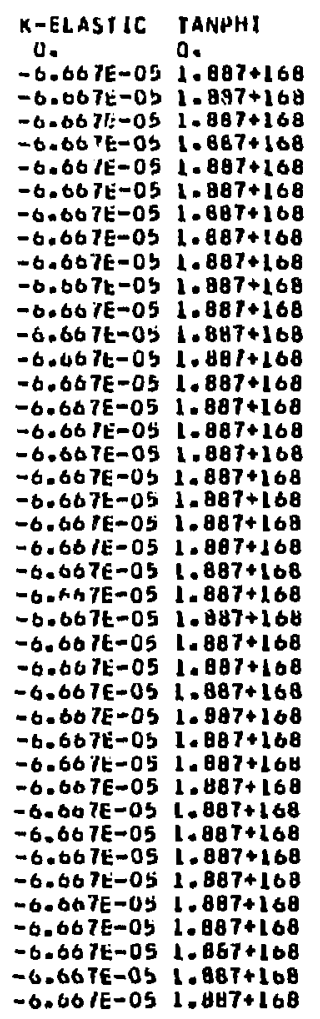


2HEYP LIP.OI

- SLAVE IUPGIGtI

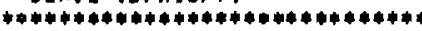

(CYCLE) (K-NUMGER) I TIME

UEL TA- I-K

1 CELTA-I-J

1 SOUNC SPEEC 11

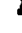

VCIL STATLS

RC VCIC RLCTINC

AC veic acurint

AC VCIL RLUTINE

AC VCIC RCUTINF

NC VCIC RCUTINE

AO VCli aCUIint

AC VLLC RLUTINE

AC VCIL RCUTINE

AT; V[IL RCUTINE

AO velC RCUTIAt

AU veli acur Int

AO VCIC ACUTINE

AC YCIC RLUTINE

no Vete RCUTINE

AC VCIO RLCTINL

AC VCIC RCLTINE

AL VCIC RLUTINE

NO VCLE RCLIINE

No VCIL RCUTINE

AL VCIC RULIINE

NU VClO RCLTINH

NO voll RCLI INE

2. 1 UOOE +00 1. $1.000 E+O C$ O.

$1.9000 \mathrm{t}+00$ 1.000E +

$1.40005+00$ d. OUUOE $+0 \mathrm{C}$

$1.7000 t+00$ l.uUutos

$1.7000 \mathrm{t}+\mathrm{O}$ 1.0000E+00 0

1.6000e tho l. UOUOL+00 a.

$1.50004+00$ I. OCOOE +000 a.

$1.4000 E+00$ I. UUCOE $+0 \mathrm{C}$ C.

1.3000E+00 I.OUDOE+00 0 .

$1.2000 E+00$ 1.0UOOE +00 O.

L. LUOOE+CO 1. UOUOE +0O O.

$1.0000 E+00$ L.OUUOE + OC 0 .

$9.0000 E-01$ 1-OUOOE +00 O.

Q.00ODE-U1 L.OUUOE+OU O.

7.000OE-01 L.OUUOE +000 .

$0.0000 E-01$ L. $0000 E+0 C$ C.

$5.0000 E-01$ 1.0000E +00 O.

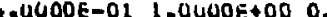

3.0000E-OI 1.0000E +00 O.

2.0000E-UL 1.000OE+OC C.

2.0000E-CL 1.0000E+OC C.

u.

$1.0000 \mathrm{E}+000$.

AO VCIC RCLTINE

AC VCIL RCUTINE

MU VCIC RLuTINL

NO VCIC RCLT INE

ho velC Routine

AL VCID RLUTJNL

ho VelC acuTine

AO VOIC ACUI INE

AO VCIL ROUTINE

AC VCIU ACUT IAE

ho vCID acurinE

AO YCIC RCLIINE

NO VCLG RUUTINE

AO VCIC RUUTINE

AO VOIO RCLTIHE

no velc alurint

NO VCIC RLUTINE

AC YCIC ROUTINE

miora 1

30 .

$\begin{array}{ll}20 . \\ 1 & 0 .\end{array}$

c.

C. 

2HENP LIP.OL
(CYCLE) (K-NUNBER

(O) I TIME

1 DELTA-T - SUOCOOE-OS

1 DELIA- T-K

U.

$x-001$

420.

RHO

$x(2)$

$Y-\operatorname{cCr}$

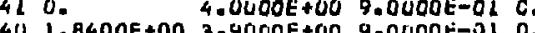

$401.8400 E+003.9000 E+009.00005-010$

$391.8400 E+00$ 3. $3000 E+00$ 9.OUOOE-0l 0

$361.8400 E+00$ 3.7000E +00 9.UGUOE-01 0 .

$371.8400 E+00$ 3.6UOOE +UO 9. UUUOE-OL C.

$361.8400 E+00$ 3.5000E +00 9.000OE-OL 0.

$35 \quad 1.8400 t+00 \quad 3.4000 E+00$ 9. UOUOE-01 0 .

34 L.8400E+00 3.3000E+00 9.0UUOE-01 O.

$33 \quad 1.8400 t+00$ 3. $2000 E+009.000 \mathrm{C}-01 \mathrm{C}$

31 I. $8400 E+00$ 3.00OOE +00 9.0UGUE-01 0.

$301.8400 E+00 \quad 2.9000 E+U 0$ 9.UUUOE-01 0 .

$241.8400 t+00 \quad 2=4000 E+009.0400 E-01 \mathrm{C}$.

2甘 $1.8400 E+002.7000 E+00$ T-0 ONODE-0L 0 .

$271.8400 E+00$ 2.6000E+00 7.4UOOE-01 0 .

$261.8400 t+00$ 2.5000E+UO $9.04 U 0 E-0 L \mathrm{C}$.

$251.8400 E+00 \quad 2.4000 E+00$ 4.00U0L-OL C.

$241.8400 t+002.3000 E+00$ \%.0COOE-OL 0 .

$231.8400 t+002.2000 t+00$ H. OUUDE-OL 0 .

i. $22 \quad 1.8400 E+00$ 2.1600E+00 y. $0000 E-n ! 0$.

21 1.8400t+00 2.0000E+00 \$.0U0OL-01 C.

20 L.8400E $+00 \quad 1.4000 E+00$ 4.0000t-0L 0.

IY 1.84OUE+CO 1.8000E+00 9.0LLUE-01 0.

IB $1.0400 E+00$ 1.7000E+00 9.0000E-1) C.

11 1. $8400 \mathrm{t}+00$ l.6000E +00 9.0U60t-UI C.

16 1. $8400 E+00$ I.5UOOE +00 Y.UUUUE-UI O.

1) $1.8400 E+00$ 1.4U0OE +0O 9.UCUOE-U1 O.

$141.8400 E+00$ I.3U00E + U0 9.0UUOE-OL C.

13 L. $4400 E+00$ 1.20COE+UO H.0LUOE-OL C.

$121.84 U 0 E+00$ L. $1000 E+00$ 9.ULUOE-UI 0 .

Il I.8400E+00 I-UUOUE+00 9.0UVOE-01 0 .

IU 1.8400E+00 9.0000E-01 9.0060E-0I 0 .

$41.8400 t+00$ H.0000E-01 $9.4000 t-01$ C.

d 1.8400E+00 7.0000E-OL 4.0000E-01 O.

$11.8400 t+00 \quad 6.0000 E-01$ 9.0600E-01 O.

- 1.84DOE+00 \$.UUVOE-OL 4.0UOUt -11 O.

3 1. B4OOE +00 4.0000E-01 4.0UNOt=01 C.

$41.8400 E+00$ 3.0UODE-01 9.0UUOL-OL O.

$3 \quad 1.8400 t+002.0000 E-01$ 4.0UUOE-OL 0.

1 1.8400t+00 U. H. UUUOE-OL $-C_{\text {. }}$.

11

c.

CLCE Filt

0 .

HEPPDG MAP 0

0.

0. 0.

L. OUUUE +00 D.

1. CUUOE $P$ OC O.

l. CUUDE 0 O.

1.0000 +00 O.

I. GOUUE +UC U.

1.0UDUE+UC U.

1. CUCOE+OU U.

1. COUUE +UC U.

1. OLUOE+OC C.

- ouout +uo u.

CUNOE OC

- CUGGE+OC U.

- Cuderco

1. OLOUE+CU

CuOue 40 co

- Cungeruc d.

l-cuvos+oc $\mathrm{C}$.

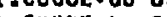

- COUOE+OU O.

1. CUOOE+ UO O.

L. CUUCE OOC U.

1. CUOOE+UC U.

- DUUGe+0U O.

- CULOE + 40 U.

1. COUOE + UC C.

L. CULAOE+ OC li.

1. OUUCE +UD C.

1. CUOCE+UC U.

1. CHUGE +OO O.

l-ccuutruo u.

1. CuUueruo la

1. CUUOE+CL U.

1. COUOE +UC O.

1. CUOOE+UO D.

1. CUOUE +UU U.

.CONOE+OC L.
0.

E

1.3985t-01 0 .

1.39BSt-01 0 .

1.394SE-OL 0 .

1.398SE-01 0 .

1. 3485E-01 0 .

l. 34 ust-01 0 .

1.3485E-01 0 .

1.348bt-01 0 .

1. $3985 \mathrm{EL}-01 \mathrm{U}$.

I. 34 6St-01 C.

1. $348 b E-01$ U.

$1.3465 t=01$ u.

1.348zt-01 U.

1.3985E-01 0 .

1.39Bbt-01 0 .

$1.398 \mathrm{BE}-01 \mathrm{U}$.

$1.3485 \mathrm{E}-010$.

1.3965E-01 U.

1.398SE-01 O.

1.34 ASE-01 U.

1.348SE-OL U.

1. 348bt-01 0 .

1.3945E-01 0 .

2. 348JE-01 U.

1. 3485t-01 0 .

1. $348 b \mathrm{C}-01 \mathrm{u}$

$1.3485=010$

1.3985E-01

$1.3485 \mathrm{E}-01 \mathrm{U}$

1.

1.398se-or U.

1. $3985 \mathrm{t}-01 \mathrm{O}$.

1. 3463t-01 0.

l. 3485t-01 O.

1.3985t-01 U.

$1.3985 k-01 \mathrm{U}$

1.39BSE-0L O.

1. 39 BSE-OL 0 .

$1.3485 t-02 \mathrm{u}$

1.39dat-01 0.
1.3985E-01 U.
0.

$-5.6018 \mathrm{E}-02$ -1. 7045E-01 $-2.8409 E-01$

$-3.9773 E-01$

$-5.1136 E-01$

$-6.2500 \mathrm{E}-01$

$-7.3864 E-01$

$-8.5227 E-0 L$

$-9.6591 \mathrm{~K}-01$

$-1.0195 E+00$

$-1.1932 E+00$

$-1.3068 E+00$

$-1.4205 E+00$

$-1.5341 E+00$

$-1.6477 \mathrm{E}+00$

$-1.8750 E+00$

-

-

- $2.10235+00$

-2.32

$-2.4432 E+00$

$-2.5568 \mathrm{E}+00$

$-2.6705 E+00$

$-3.1250 E+00$

$-3.2386 E+00$

$-3.3523 E+00$

$-3.5795 E+00$

$-3.6932 E+00$

$-3.80 s \theta E+00$

$-3.9205 E+00$

$-4.0341 E+00$

$-4.1477 E+0 D$

$-4.2614 E+00$

$-4.3750 E+00$
$-4.4886 E+00$ 
ZHENP LIP.OL (CYCLE) (K-NUMELR)

\section{RHO}

410.

$x(2)$

$Y(R)$

$x \rightarrow \operatorname{DOT}$

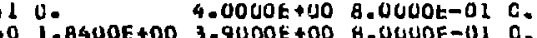
39 l. $381.8400 t+00 \quad 3.7000 E+00$ g. OUUOE-01 0 . $371.8400 \mathrm{t}+00$ 3.6000E+00 8.0000E-0L 0 . $361.8400 \mathrm{E}+00$ 3. $5000 E+00$ G. UUDOE -010 . $351.8400 t+00$ 3.4UOQE +0O B. U600t-0L C. $141.8400 \mathrm{E}+00 \quad 3.3000 E+00$ 8.0000E-01 0 . $33 \quad$ L.8400E +00 3.2000E +00 8.0UUOE-0L 0 . $322.8400 E+003.1000 E+00 \quad \theta .0400 t-010$. 31 L.8400E +00 3.00OOE +00 B. OUUOL-OL C. $302.8400 E+002.9000 E+00$ 8.0UUUE-0L 0 . 24 L.8400E+00 2.8000E +00 8.0000E-01 D. $2 \theta 1.8400 E+00 \quad 2.7000 E+00$ 8.0UCOE -01 O. 21 1.8400t+00 2.6000E+00 \&. U0OUt-01 0 . $26 \quad 1.8400 E+00$ 2.5UOOE +00 B.0OUOE-01 0 . 25 L. $8400 E+00 \quad 2.4000 E+00$ 8.0VUOE-01 0 . $241.8400 E+00$ 2.3000E+00 B.0U0OE-01 0. $231.8400 \mathrm{e}+00$ 2.2000E +00 8.0000e-01 0 . $1 \quad 221.8400 E+00$ 2.1000E+00 8.0000E-OL O.

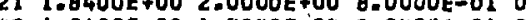
$20 \quad 1.8400 E+00$ 1. $4000 E+00$ 8.0UDUE $-01 \quad 0$ 19 L.84DOE+OD I. $8000 E+00$ 8.0000E-01 0. $181.8400 E+00 \quad 1.7000 E+00 \quad 8.0000 E-010$. If $1.8400 E+00$ 1.6000E+00 B.0UOOE-01 O. It $1.8400 E+00 \quad 1.5000 E+00$ H.OOUOE-OL O. $15 \quad 1.8400 E+00$ I. $4000 E+00$ B. DUDUE-01 C. $141.8400 E+00 \quad 1.3000 E+00 \quad 8.0000 E-01$ O. 13 I. $8400 E+00$ I.2000E+00 8.0000E-01 O. 13 I. 2 I. IL 1.8400E+OO L. Ia $1.8400 E+00$ 9.0000E-0L B.0000E-OL 0 . 1.8400E+OO 8.0000E-OL 8.0000E-UL Q

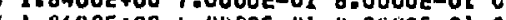
1.84OOE 400 6.00COE-U1 8.0LUOE-0L C. 1.8400E+00 3.000OE-01 B.UOUDE-02 O $1.6400 t+00$ 4.0000E-0L 6.0000E-01 O. $4.8400 t+00$ 3.0000E-01 B.0000t-01 0

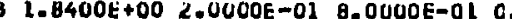
$1.8400 E+001.0000 E-01$ 8.0UUOE-DL O.

$11.8400 E+00$ 0. B.ULUOE-OL-O.

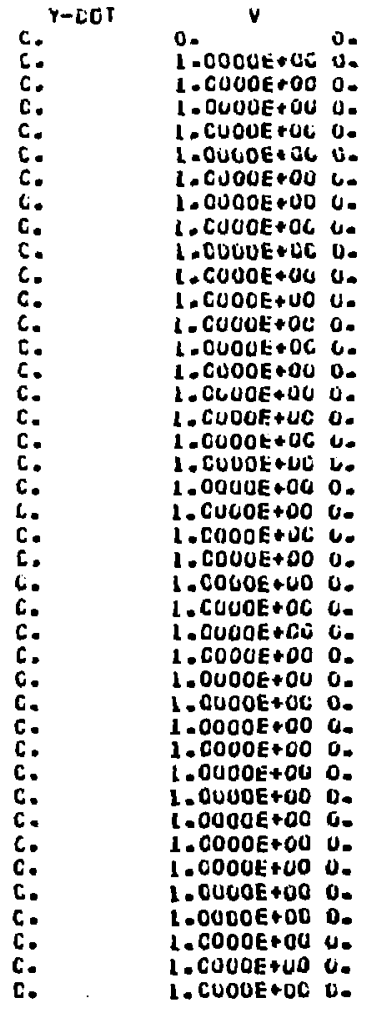

LtLIA-T-J I I SOUNC SPELC I 1
.
F

$-5.6818 \mathrm{~B}-02$ $-1.7045 E-01$ $-2.8409 E-01$ $-3.9773 E-01$ $-5.1136 \mathrm{E}-01$ $-6.2500 E-01$ -7.3864E-01 -8.5227E-01 $-9.6591 \mathrm{E}-02$ $-1.0795 E+00$ $-1.1932 \mathrm{E}+00$ $-1.3068 E+00$ $-1.4205 E+00$ $-1.4205 E+00$ $-1.5341 E+00$ $-1.6477 E+00$ $-1.7614 E+00$ $-1.87506+00$ $-1.9886 E+00$ $-2.1023 E+00$ $-2.2159 E+00$ $-2.3295 E+00$ $-2-4432 E+00$ $-2.5568 E+00$ $-2.6705 E+00$ $-2.7841 E+00$ $-2.8977 E+00$ $-3.0114 E+00$ - $3.1250 E+00$ $-3.1250 E+00$ $-3.2386 E+00$ $-3.3523 E+00$ $-3.4659 \epsilon+00$ $-3.5795 E+00$ $-3.6932 E+00$ $-3.8068 E+00$ $-3.9205 E+00$ $-4.0341 E+00$ $-4.1477 E+00$ $-4.2614 E+00$ $-4.3750 E+00$ $-4.4886 E+00$ 
2HENP LIP.OI (CYCLE) IX-NuRgent

5 RHL

410 . A.0UOOE+00 7. OLDOE 01 C 39 1.840 OE 400 3.4000E+U0 7.0UUOE $=01$ O. $38 \quad$ 1.8400E+U0 3.7000E+U0 7.0UUOT-01 C. Il l.8400E+00 3.4000E+00 T.0U0OE-OL C. 36 I.84OOE+00 3.5OOOE+UD 7.0UUOE-OI Q. $J 51.8400 E+00 \quad 3.4000 E+00$ 7.00UOE-01 0 . $341.8400 t+003.3000 E+00$ 7.04JOE-0. 0 . $341.8400 E+00$ 3.3000E +00 7.0UWOE-O\& 0 . $33 \quad 1.8400 E+00$ 3.2000E+00 7. ULUDE-OI 0 . $321.8400 E+00$ 3.1000E+00 7.0000E-02 0 . 11 $1.8400 t+00 \quad 3.0000 E+00 \quad 7.0600 t-010$. 3U $1.8400 \mathrm{t}+00$ 2.9000E +00 7. U0U0t-01 C. $29 \quad 1.8400 t+002.8000 t+00$ 1.0000t-01 C. $281.8400 t+00 \quad 2.7000 E+00 \quad 1.0000 t-01$. $27 \quad 1.8400 E+002.6000 E+00$ 1.ULUOE-OL C. $201.8400 E+00 \quad 2.5 U 00 E+00 \quad$ 1.0UODE-OL O. C3 $1.8400 t+00$ 2.4000t+00 7. UUGUt $-01 \mathrm{C}$. 24 L. 8400E +00 2.3000E+UO 7.0UUOL-01 0. $231.8400 E+00 \quad 2.2000 E+00$ 7.0LUOE-OL C.

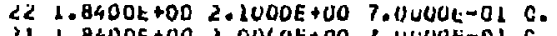
21 L.BHDOE +00 2.00COE +00 R.UUUOE-01 C. $201.8400 E+00 \quad 1.9000 E+007.046 U E-D 1$ D. It 1. $8400 t+00$ 1.8UOOE +UO 7.0UUDE-01 C. Lt $1.8400 E+00$ 1.7U0OE +00 7. UUUOL -01 O.

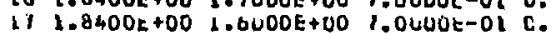
It $1.5400 E+00$ i.SUOOE +0O $7.04 U 0 E-01$ a. is $1.8400 t+00$ T. $4000 E+00$ 7.0U00e-0I C

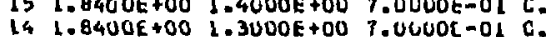
is $1.8400 \mathrm{0}+00$ i.

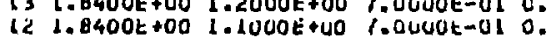
li $1.8400 t+00$ 1. 1000E +UO r. QuUat -01 O.

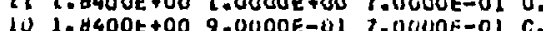
IJ 1. $4400 t+00$ 9.00ODE-OL T.0UUOE-OL C. 4 L.840UE +0O G.0UNDE-UA 7.0UCOE-UL C.

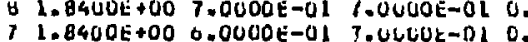
$71.8400 E+000.0000 E-01$ T.UULOE-DI O

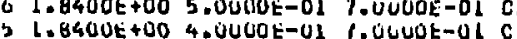
3 I. $8400 E+00$ 4. UUCOE-OI Y.UUUDE-OL C. 1.8400t+U0 3.0000E-01 T. GuUOE-01 2 1.8400t+00 l.0000E-UI 1.0U00t-al C. I. $1.4400 t+00$ U. 1. OuCOL-OL-C.

$x-D O I$

0.

1.3485t-0 0. $1.3485 \mathrm{E}-01 \mathrm{O}$. $1.3985 E-010$. $1.3485 E-O L O$ O. $1.3985 E-01$ U. l. 3985E-01 0. 1.3985t-01 0. $1.3485 t-01$. $1.3983 t-01$ 0. $1.3983 E-02$ O. 1. 34 YSt 01 D. $1.3985 E-01$ O. 1. $399 B E-0 L$ U. 1.39 BSE-01 0. 1.3485E-01 U. 1. $3485 E-01$ a. $1.3485 E-010$. $1.3485 E-01$ O $1.3985 t-010$ $1.3905 E-01$ a. $1.3485 \mathrm{E}-01$ o. $1.3435 \mathrm{JE}-01 \mathrm{O}$ 1.34 1.3985E-0L 1.3485e-ar do. 1. 3985 son $1.3985 \mathrm{r}-0 \mathrm{O}$. $1.3985 \mathrm{E}-01 \mathrm{O}$. 1.3UBBE-01 0. $1.398 b E=010$. I. 348SE-01 U. $1.3985 t-01 \quad 0$. $1.3985 E-01$ U. $1.3485 t-010$. $1.398 \mathrm{bf}-010$. 1.398 jt -010 . $1.3945 E-010$. 1.399SE-01 0 . 1.398bt-01 a. 1.38Bbt-01 0.
$\mathbf{F}$

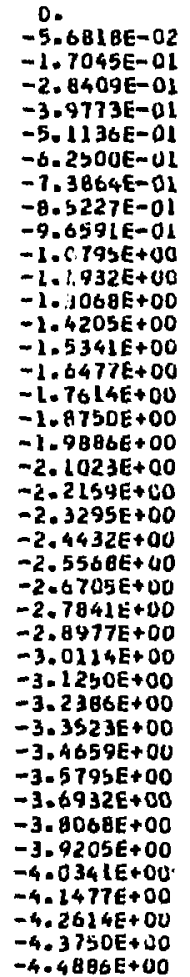

$-5=6$ ( $-2.8409 E-01$ $-3.9773 \mathrm{E}-01$ -6.2300E-UI $-7.3864 E-01$ $-8.3227 E-01$
$-9.6591 E-01$ - I. C. T9SE+00 $-1.10698+00$ $-1.4205 E+00$ $-1.64776+00$ $-1.7614 E+00$ - 1. ล750E+ $-2.1023 E+00$ $-2.2154 E+C 0$ $-2.3295 E+00$ $-2.4432 E+00$ $-2.6705 E+00$ $-2.7841 E+00$ $-3.0114 E+00$ $-3.12 b 0 E+00$ $-3.3523 E+00$ $-3.4659 E+00$ -3. $6932 \mathrm{E}+00$ $-4.0341 E+00$ -4. $2471 E+00$

$-4.4886 E+00$ 
ZHENP LIP.OL (CYCLE) (K-NUMBER)

CUCE FILL DELIA-I-K, I'
C.

0 .

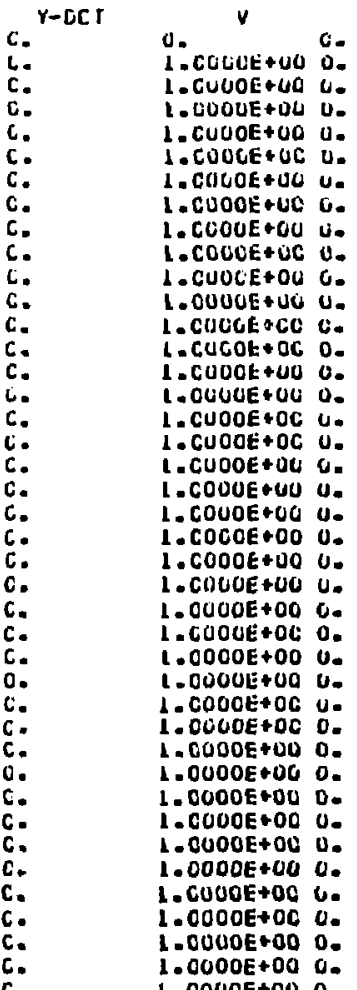

HEMPDG MAP
1 RHC $x(2) \quad Y(R) \quad X-D O T$

4L O. 4.UUUUE+OO 6.0UGOE-OL C. 40 L.B400E $+00 \quad 3,9000 F+00$ 6.0U00t-01 C. 3. L.8400E +00 3.8000t +00 0.0U00t $=01$ C

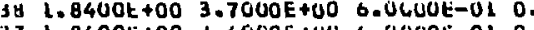
$371.8400 E+00$ 3.6U0OE+UU 6.0000E-01 0 . 34 L. $8400 E+00$ 3. $3000 E+00$ 6.0GUOE- 11 O. $331.8400 t+00$ 3. $2000 E+00$ 6.0000t-01 C. $321.8400 \mathrm{t}+00$ 3.1000E +00 6.04U0E-OL C. $31 \quad 1.8400 E+003.0000 t+00$ 6.0GUDE-01 C. $301.8400 t+002.4000 t+00$ 6.0UUOE-OL O. $241.8400 E+002.8000 E+00$ 6.0 2 CUE-OI O. $\angle 8 \quad 1.4400 E+00$ 2. 7UOOE +00 Q.0UOOE-UL O. L 1 84UOE +00 2-6U0OE+U0 6.UCUOE-UI O. 26 L. $8400 E+00$ 2.3000E +00 6.00UOE-0I D. 25 I. $8400 \mathrm{t}+00$ 2.4000E +00 6.0000t-01 0 I4 $231.8400 E+00$ 2 $2000 E+00$ O. OUNOE-OL E 21 1.8400t+00 2.0000E+00 6.0U00E-01 0. $201.8400 E+00$ 1.900OE +UO B.0UUOL -01 O. $191.8400 E+00$ 1.800OE + OU O.0UUOE-01 O. $181.8400 E+00 \quad 1-7000 E+00 \quad 6.0 U U O E-U 10$. $171.8400 E+00 \quad 1.6000 E+00$ 6.UUNOE-UL 0 16 l.

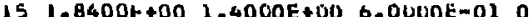

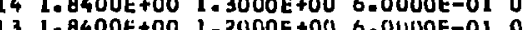
13 l. 2 1.8400E too a.000e-Ol 6.0000e-OL O. 1.8400E+00 7.0000E-OL 6.0000E-01 0. $1.8400 E+00$ 6.0000E-OL 6.00uDe-OL O 1.8400E+00 B.UOUOE-D 1 G.0UOUk-02 0 . $1.8400 \mathrm{k}+00$ 4.0000E-01 6.0000Em01 0 . $41.8400 \mathrm{E}+00$ 3.0000E-01 6.0000E-01 0 . $31.8400 E+00$ 2.0000E-01 6.0U00E-01 C. $1.8400 E+00$ 1.VOOOE-OL $1.000 U E-01$ O.

1 1.8400E+DO D. $361.8400 \mathrm{E}+00 \quad 3.5000 \mathrm{E}+00 \quad 6.0000 \mathrm{~L}-010$ $351.8400 E+003.40 C O E+00 \quad 6.0000 E-01 \quad 0$

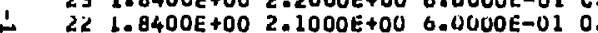
$14100400 E+00$ l $30008+00$ 6.0UUOt-01 0

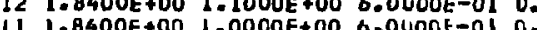
1 1. 

4. RHE
$x(2)$
$Y(R)$
$x-D 01$

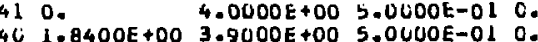
SU $1.8400 E+00$ 3.9O0DE 36 . 12 1. $4400 \mathrm{t}+00$ 3. 1. $1.8400 E+00$ 3.6000 +00 5.0 30 $1.8400 E+00$ 3.SOOOE $+00 \quad 5.0000 E-010$. IS $1.8400 E+003.4000 E+003.0000 \mathrm{k}-01 \mathrm{O}$.

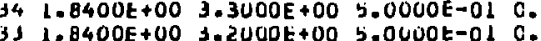
12 1.B4OOE +00 3.10ODE + OO 5.UUOOE-OL O. II L. B4CDE +0O $3.0000 E+00$ b.ULOOE-OL C. $301.8400 E+00 \quad 2.9000 E+00$ 5.000DE-0I C. 29 1.840OE +00 2. BOUOE +0O S.00UOE-OL O. IH I. $8400 E+002.7000 E+00$ 5.0000E-01 0. 27 I. $8400 t+00$ 2.6000E +00 b.UCOOt-0l 0. $\therefore$ I.8400E+00 2-SOUOE+00 S.0UUOE-0I C Cb $1-8400 t+00$ 2-4000E+00 b.0UODE-OI 0 .

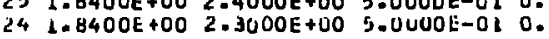
i) $1.8400 E+00$ 2.2000E+00 5.0000E-01 0 . \% $221.8400 E+00 \quad 2.1000 E+00$ S.OUNOE-OL C. $211.8400 E+00 \quad 2.0000 E+00$ S.UUUUE-OI C. $191.8400 \mathrm{E}+00$ 1.80OOE+OO S.OLLOUE-OL 0 . It $1.8400 t+00$ L. $7000 E+00$ b. DUUOt-0I O. $171.8400 t+00$ 1.6U0OE +UO 3.0UUUt-0L C. l6 $1.8400 t+00$ 1.5000E+00 3.0UU0E-0L 0 . i. $1.8400 E+00 \quad 1.4$ NOOE+00 3.UUNOE-01 O. 14 1.8400E+00 1.3000E+00 3.0UUUE-DI O. $131.8400 E+00$ 1.2UOOE +OU 3.ULUOE-DI 0.

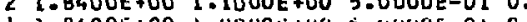

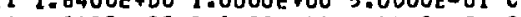
L 1.8400t+00 9.0000E-UL 3.0LUCt-01 C.

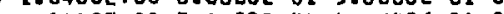
$1.8400 E+00$ T.UUOOE-UI S.UUUOE-01 O. $1.8400 E+00$ 6.0000E-OL 5.0LOUE-OL O. 1.840DE+00 \$.0UOOE-OL B. OUUOE-01 C. 1. $8400 t+00$ 4.0NOOE-01 S.UUUOL-01 C. 1. $8400 E+00$ 3.0UUOE-0L 5.0UUOt-0L O. 1.84OOE+00 2.0UUOE-U1 5.UUUUE-01 0.

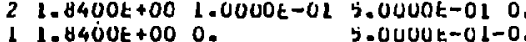
S.0UUUt-0l-0. c.

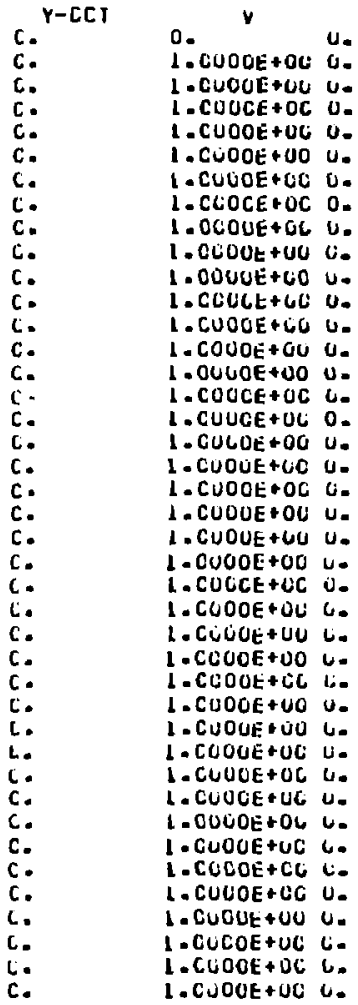
$1.3085 E^{\circ}-010$ 1.398מE-01 0 $1.3985 \mathrm{E}-01 \mathrm{U}$ 1. $3985 E-010$ $1.3485 \mathrm{E}-01 \mathrm{U}$ $1.3985 E-01 \mathrm{U}$. $1.3985 E-01 \mathrm{U}$. 1.3985E-01 0 . $1.3485 t-010$. $1.3983 \mathrm{~L}-01 \mathrm{U}$. $1.3485 E-01$ U. 1.398SE-01 U. 1.3yoje-Ol 0 . 1.34 4SE-01 0 . 1. 39BSE-CI 0 . 1. 3985 SE-01 0 . 1.3945E-01 0. 1.39BSE-OL 0 . 1.3985E-01 0 . $1.3965 E-01$
$1.3485 E-01$ 1. 398DE-OL U. 1.3985t-01 0. $1.3965 E-010$. 1.396SE-OL 0 . 1. $398 \mathrm{BE}-01 \mathrm{~L}$ O. 1.3985E-01 0 . 1. 3 पु 1.3 1 CEE-OL 0. - 3yase ar 0. 1.3985t-01 0. 1.398SE 01 r. 1. $398 \mathrm{se}-010$. - Jy dis-ar o. l. 3985t-01 0. 1.3985F-OL U. 1.3985E-0I U. 1. 3485t-01 0 . 1.3485t-01 0 . l. $3985 E-01$ U.

0.
$-5.6818 E-02$ -1.7045E-01 $-2.8409 \mathrm{E}-01$ $-3.9773 E-0$ $-5.1136 E-01$ -6.2万OOE-OL $-7.3864 E-01$ $-0.5227 E-D I$ $-9.6591 E-U 1$ $-1.0793 E+00$ $-1.1932 E+00$ $-1.3068 E+D 0$ $-1.4205 E+00$ $-1.5341 E+00$ $-1.6477 E+00$
$-1.7614 E+00$ $-1.8750 E+00$ $-\mathrm{L} .9886 \mathrm{E}+00$ $-2.1023 E+U O$ $-2.2159 E+00$ $-2.3295 E+00$ $-2.4432 E+00$ $-2.5568 E+00$ $-2.6705 E+0 U$ $-2.7941 E+00$ - 2. $-3.0114 E+U D$ - $3.2386 E+U 0$ $-3.3+3 \mathrm{E}+00$ - $3.4659 E+00$ 3. $-3.8068 F+00$ $-4.0341 E+00$ $-4.2614 E+00$ $-4 \cdot 3730 E+O 0$ $-4.4880 E+00$ 


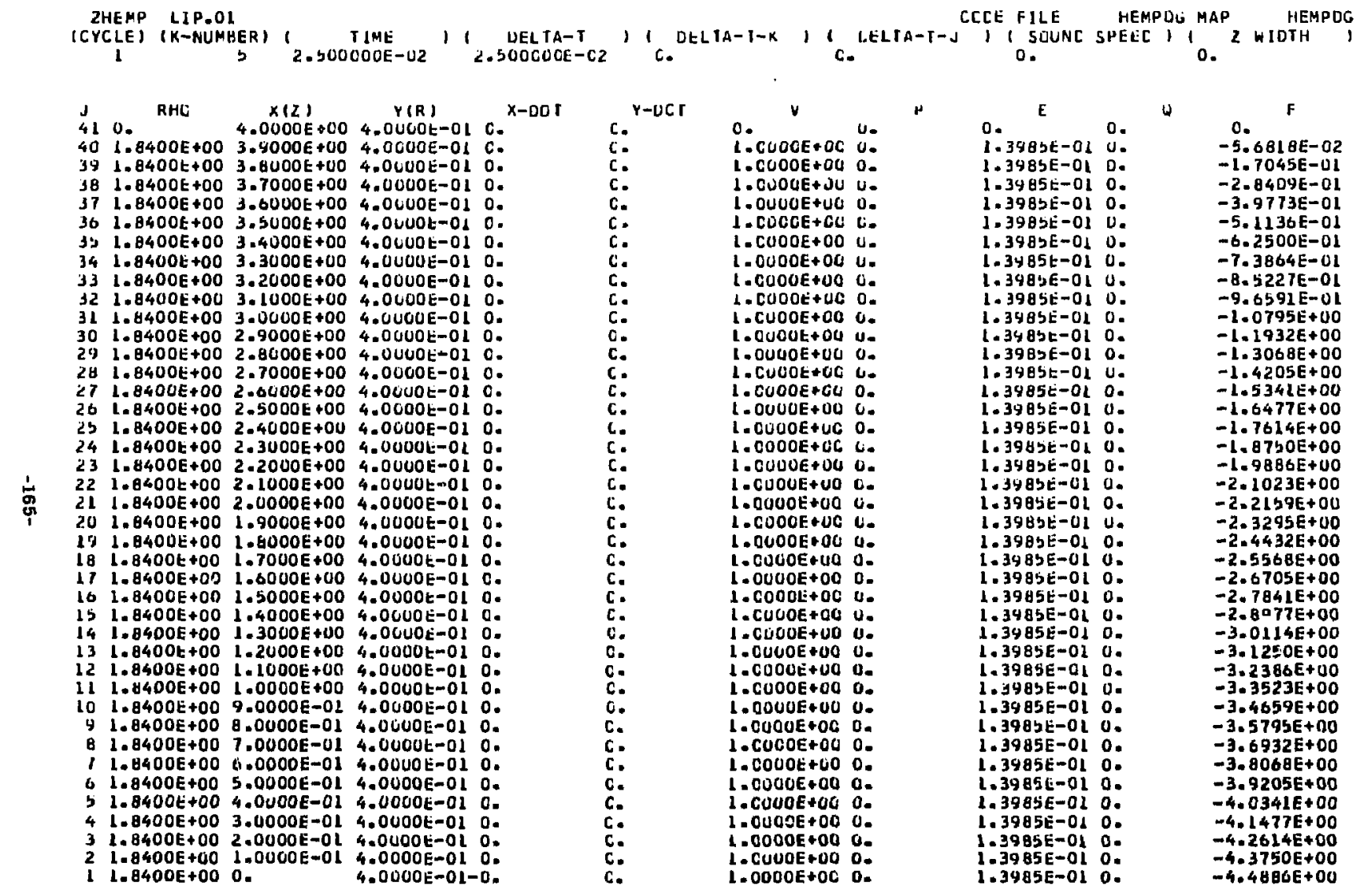


ZHEFP LIP.OL

(CYCLE) (K-NUHBER)

1

IIME

IME

11 DELIA-T

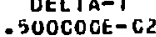

1 DELTA-T-K

11

c.

CCLE + ILE

HEMPOG MAP 0 .

410.

$4.00005+00$ J OCOOL-OL 0.

$40 \cdot 1.8400 E+00 \quad 3.4000 E+00$ 3. OUNOE-01 0

$391.8 ;, 00 \mathrm{k}+00 \quad 3.8000 \mathrm{E}+00$ 3.0UU0k-01 0

$381.8400 E+00$ 3.7000E+00 3.0U0OE-01 C

31 1. $8400 t+003.6000 \mathrm{t}+00$ 3.0000t-01 0 .

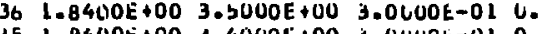

$351.84100 E+00 \quad 3.4000 E+00$ 3.0UUNE-01 0 .

34 L.840OE +00 3.3000E +00 3.0UOOE-01 O.

33 I. $8400 E+003.2 U 00 E+00$ 3.0UOOE-01 0 .

32 1.8400E+00 3.1000E+1)0 3.0UUDE-01 O.

I1 1.8400 t +00 3.UUOUE +UO 3.UUUOt-01 C.

30 1.8400E+00 $2.4000 \mathrm{E}+100$ 3.0U6Dt-01 C.

24 1.64U0E+00 CAUOUE +UD 3.006Ut-UI O.

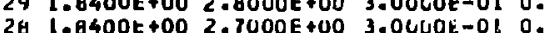

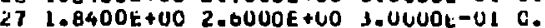

LA $10400 E+00$ 2. $000 t+00$ t.0LUOE-0I $c$

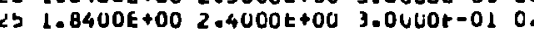

74 1.8400t +00 2.3000t +00 \$.0U0Ut -010

$231.8400 t+00$ Z.2U0UE +UO S.UUUUt-0I C.

$1 \quad 22 \quad 1.0400 k+00 \quad 2.1000 E+00 \quad 3.0000 t-01 \quad 0$.

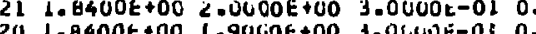

IY $1-84005+00$ L $80005+00$ 3.0000E-01

I I I. B4UOE +00 1. $7000 E+00$ 3. UUOOE-UI C

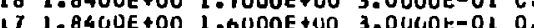

16 lo

26 1.8400E 100 l.

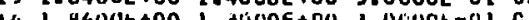

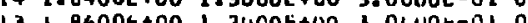

13 l.8400E +0O l.2UCOE+UO s.OLUOE-OI O.

12 1.8400E +00 1.1000E+00 3.0LOOE-01 0 .

11 1.8400E

$101.8400 E+009.0000 E-013.0000 E-01 \mathrm{C}$

1. $4400 t+00$ B.OUDOE-UL 3.00UOt-01 O

$1.8400 E+00$ T.UOUOE-UL 3.0UUOt-UL O

$1.8400 t+006.0000 E-U 1$ 1.0UUOE-01 0 .

$1.8400 E+00$ 3.UDUOE-OL 3. UUUUt-UL C

1. $6400 E+00$ 4.UUDOE-OL S.OLUCRE-OL O.

$1.8400 t+003.0000 E-013.06 U 0 t-010$

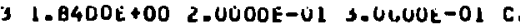

$21.8400 t+001.0000 t-01$ 1.0LUOE-OI C.

1 1. $8400 t+00 \mathrm{U}$.
0.

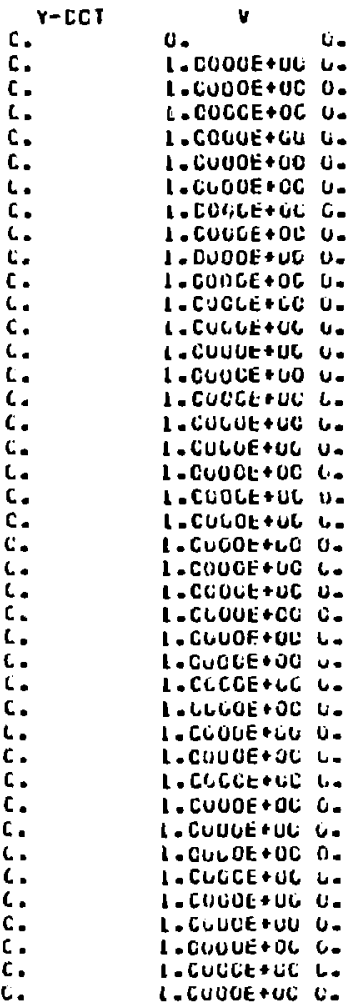

0.

$1.39055-010$. 1.3985E-OR 1.3485E-01 $U$. 1. 348SE-01 0 . 1.3985t-01 0 . 1. उYUSE-0I U. 1. 3YBSE-OI U. 1.3985E-01 0 . 1.3985E-01 U. l. 398SE-0L U. 1.3985E-0I U. 1.39日DE-OL U. 1.3905E-01 0. 1.3985E-01 0 . 1. 398bE-01 j. 1. 39ABE-OL U. $1.3985 t-010$. 1. JY8SL-OL U. 1.394bt-01 U. 1. 348st-01 U. 1.3985E-0l U. 1. 348DE-01 0 . 1. 3985E-01 0 . I. J985E-0L U. I. $3485 E-U 1$ O. 1.348be-01 U. 1. $198 \mathrm{st}=010$. $1.34856-010$. 1.3485t-01 0 . 1.3485E-01 0. 1. 348jE-01 0. 1. $34855-010$. 1. 398SE-OL 0 . 1.3985E-0I 0 . 1.398SE-O1 0. 1.3945 tol 0 . 1. 34805-01 0 .
HEMPOG 
ZHENP LIP.OL (CYCLE) (KTHULE)

$$
\text { I }
$$

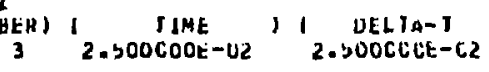

\begin{abstract}
1 DELTA-J 2. BOOCCLE-C2
\end{abstract} 1 C. $D L L I A-J-x$

CCCE PILE

HEMPDL MAP

0 .

i.

HEMPDO

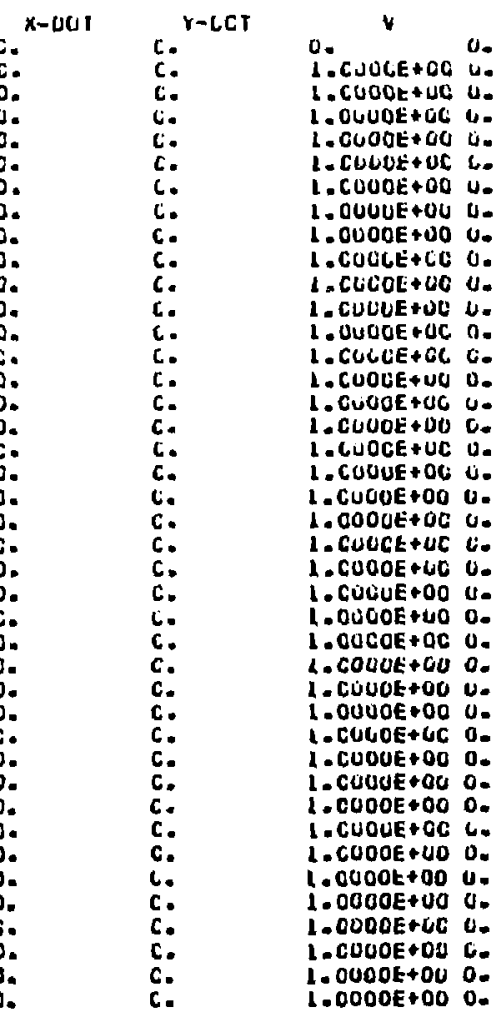

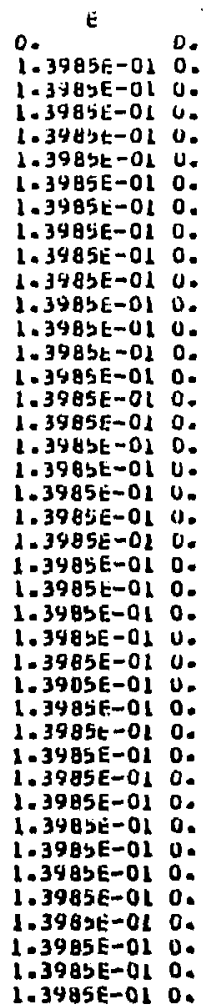

4 D. $-5.6828 E-02$ $-1.7045 E-01$ $-2.8409 E-01$ $-3.9773 \mathrm{E}-01$ $-5.1136 E-01$ $-6.2500 E-01$ $-7.3864 E-01$ $-8.5227 E-01$ $-9.6591 \mathrm{E}-\mathrm{OL}$ $-1.079 b E+00$ $-1.1932 E+00$ $-1.3068 E+00$ $-1.4205 E+00$ $-1.5341 E+00$ $-1.6477 \mathrm{~T}+00$ $-1.7624 E+00$ $-1.8750 E+00$ $-1.9886 E+00$ $-2.1023 E+00$ $-2.2159 E+00$ $-2,3295 E+00$ $-2.4432 E+00$ $-2.556 B E+00$ $-2.6705 E+00$ $-2.7841 E+00$ $-2.8977 E+00$ $-3.1250 E+00$ $-3.1250 E+00$ $-3.2386 E+00$ $-3.4659 E+00$ $-3.4659 E+00$ $-3.5795 E+00$ $-3.80685+00$ -3.8008E+00 $=3.9205 E+00$ $-4.0341 E+00$
$-4.1477 E+00$ $-4.2614 E+00$ $-4.3750 E+00$ 
2HEHP LIP.OI

CCCE FILE

HEMPDG MAP HEMPOG

(CYCLE) (K-MUYY

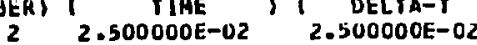

1 I DELIA-IAK , I

0.

0.

YIR) $\quad x-00 T$

410.

$x(2)$

41) $1.0400 E+004.0000 E+001.0000 E-010$. 40 1.8400E +OD

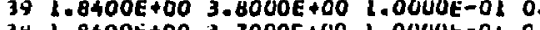
$361.8400 E+003.7000 E+00$ 1. OOUOE-OL 0 .

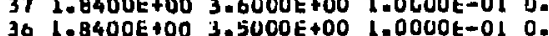
$36 \quad 1-8400 E+00 \quad 3.50 C 0 E+00 \quad 1-0000 t-01 \quad 0$. $\begin{array}{lllll}15 & 1-8400 E+00 & 3.4000 E+00 & 1.0000 E-01 & 0 .\end{array}$ $\begin{array}{lllll}34 & 1.8400 \mathrm{E}+00 & 3.3000 E+00 & 2.0000 \mathrm{E}-01 & 0 \\ 33 & 1.8400 \mathrm{O}+00 & 3.2000 \mathrm{E}+00 & 1.0000 \mathrm{E}-01 & 0\end{array}$ $321.8400 E+003.1000 E+00$ L.0000E-01 0 $311.8400 E+00 \quad 3.0000 E+00$ 1.0000E-01 0 . 30 $1.8400 E+00$ 2.9000E +00 1.0000E-01 C. 29 I. B4OOE +00 2.8DUOE +00 L.OUUDE-OL 0. $2 B 1.8400 \mathrm{t}+00$ 2.7000E+00 1.0000E-01 0 . $271.84 D 0 E+002.6000 E+00$ L.0OUOE-OL 0 . $261.8400 t+002.5000 E+00$ I.0UUOE-01 C. $261.8400+002.500 E+00$ 1.0000E-01 C. $251.0400 E+002.4000 E+00$ 1.0000E-01 0 . $231.8400 E+002.2000 E+00$ 1.0000t-0I C. $\therefore \quad 22$ I. $6400 E+00$ 2.2UOUE + UO L.OLUOt-OL C.

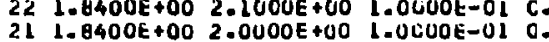
2U 1.8400E +00 1.9000E+00 L.0UUOE-01 O.

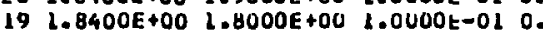
$18 \quad$ I. $8400 E+00$ 1. $7000 E+00$ L.0000E -01 C. $17 \quad 1.8400 E+00 \quad 1.6000 E+00$ I. OUDOE-UL 0. $16 \quad 1.8400 \mathrm{E}+00$ 1.5000E +00 1.0000E-01 0 . Is $1.8400 E+00 \quad 1.4000 E+00 \quad 1.0000 t-010$. $141.8400 E+001.3000 E+00$ L.UUUOE-OL C. $131.8400 E+00$ 1.2U0OE +00 I. $1.0000 \mathrm{t}-01 \mathrm{O}$. $121.8400 E+00$ 1.1000E+00 1.UUUOE-OL 0 . 12 . $11400 \mathrm{C}$. 10 1. B400E+00 9.0OCOE-O1 1.0CUOE-OL C. 10 1.8400E+00 9.00COE-01 1.0CUOE-01 C. 4 . 7 . 7 1.6400E+00 6.0000E-0l l.0000E-Dl 0. $1.6400 t+00$
5 5 1. $8400 E+00$ 4.0000E-OL 1.0U0OE-O1 0 .

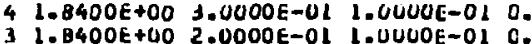

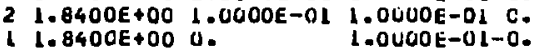

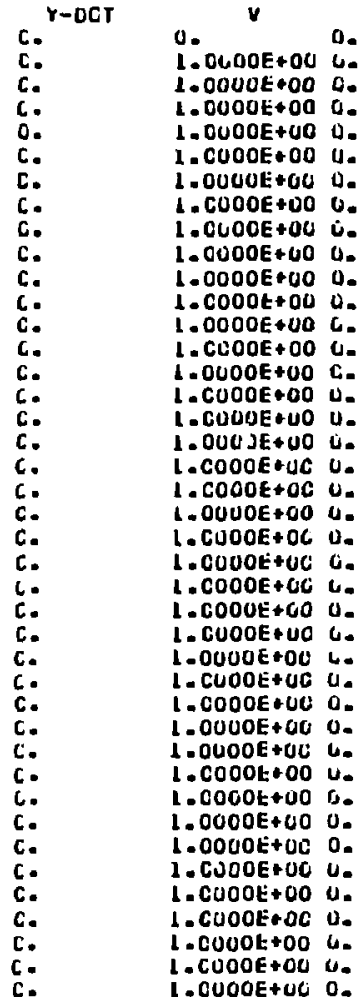

I. CUOOE+OU U.

0. $3985 \mathrm{E}-01$ O. l. $3985 E-01$ O. $1.3985 E-010$. 1.3985E-OL 0 . 1. 398BE-01 0 . 1. 3985E-01 0 1. $3985 t-010$. $1.3985 \mathrm{E}-01 \mathrm{U}$ $1.3985 E-010$. $1.3985 \mathrm{t}-010$. 1. $3985 E-010$ $13905 \mathrm{~B}-010$ 1.3985E-01 0. $1.3983 \mathrm{bE} 01 \mathrm{u}$ 1.3485501 . $1.3485-010$ 1.3485E-01 $1.3985 E-01$ O. $1.3985 E-010$. 1. $3985 E-010$ 1.398SE-OL U 1.3985E-OL O 1.3985E-UL U. 1. $3985 E-010$. 1.3985E-OL O. 1.3985E-01 O. 1.3985E-01 0. $1.34850-010$ 1.3985E-01 0 . $1.3485 t-010$. 1. $3985 E-01$ o. $1.3483 t-010$ $1.3985 \mathrm{E}-01 \mathrm{O}$ - 3985e-O 0 . 1.3985t-01 0. $1.3985 \mathrm{E}-01 \mathrm{O}$ $1.3985 \mathrm{E}-01 \mathrm{O} 0$. 1. $3985 E-010$. 1. $348 S E-01$ D. L.3985t-0L $U$. 1.348 be-Ol 0 . 1.398at-01 O. - 5 . $-2.7045 E-01$ $-2.8409 E-01$ $-3.9773 E-01$ $-5.1136 E-01$ $-6.2500 E-01$ $-7.3864 E-01$ $-8.5227 E-01$ $-9.6591 \mathrm{E}-01$ $-1.0795 E+00$ $-1.1932 E+00$ $-1.3068 E+00$ $-1.4205 E+00$ $-1.5341 E+00$ $-1.6477 E+00$ $-1.7614 E+00$ $-1.8750 E+00$ $-1.9806 E+00$ $-2.1023 E+00$ $-2.2159 E+00$ $-2.3295 E+00$ $-2.4432 E+00$ $-2.5568 E+00$ $-2.6705 E+00$ $-2.7841 E+00$ $-2.8977 E+00$ $-3.1250 E+00$ $-3.2386 E+00$ -3.3523E+OA - 4 . - $3.46598+00$ -3. $-3.6932 E+00$ $-3.9205 E+00$ $-4.0341 E+00$ $-4.1477 E+00$ $-4.2614 E+00$ $-4.3750 E+00$ $-4.4886 E+00$ 
2HEPP LIP.OL (CYCLE) (K-NUPBERI

1

(K-NUPBERI I TIME

11 OELTA-T

COCE FILE

hEMPOG MAP

HEMPDG

1

410.

AHO

$x(2)$

4.000OE+OO 0

$401.8400 \mathrm{t}+00 \quad 3.9000 \mathrm{E}+000$. 39 I. $3400 E+003.6000 E+00$ O

37 .

37 I. $4400 \mathrm{E}+00$ 3.0000e+00 0.

3o I-B4OOE

35 l.

34 1.8400E +00 3.3000E 100 O.

33 1. $0400 E+00$ 3.2000E+00 0 .

$321.8400 E+003.1000 E+000$.

31 1. $8400 E+003.0000 E+000$.

$301.8400 E+00$ 2.900OE +000 .

$29 \quad 1.8400 E+002.8000 E+000$.

$26 \quad$ L.8400E+00 $2.7000 E+00 \quad 0$.

$27 \mathrm{~L}-8400 \mathrm{E}+00 \mathrm{Z}-6000 \mathrm{E}+00 \mathrm{O}$

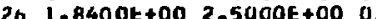

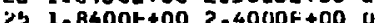

24 1.

23 $1.8400 E+00$ a.

$\therefore \quad 221.8400 \mathrm{t}+002.1000 \mathrm{E}+00 \mathrm{O}$

\$ 21 l. $4400 E+002.0000 E+00$ O 20 L. $8400 E+00$ 1.9000E+00 O. $191.8400 E+001.8000 E+00$ o. $191.8400 E+001.8000 E+000$. 17 1.8400E+00 1.TOOOE +00 0 . 27 l. 8 HOOE +00 L.6OOOE +00 O. 16 L.8400E +00 \&. $5000 E+000$. 15 L. $8400 E+00$ l. $4000 E+00$ D. $141.8400 E+001.3000 E+000$. $131-8400 E+00 \quad 1-2000 E+000$. $121.8400 E+00$ 1. $1000 E+000$. ll $1.8400 E+001.0000 E+000$. 10 I. $8400 E+00$ 9.0000E-01 0

9 1.B4OOE+00 8.0000E-01 0

$1.0400 E+007.0000 E-01$ O

$1.04005+00$ 0.0400E-01 0

1.

1.0400E+00 $5.000 \mathrm{CO}$ O

l.

1.6400E+00 3.0000E-01 0.

1.6400E+00:2.0000E-01 0.

1.8400E+00 0 .

(CYCLE) (K-RUMBEK) I TIME
$Y(R)$

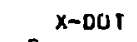

c.

c.

0 .

0.

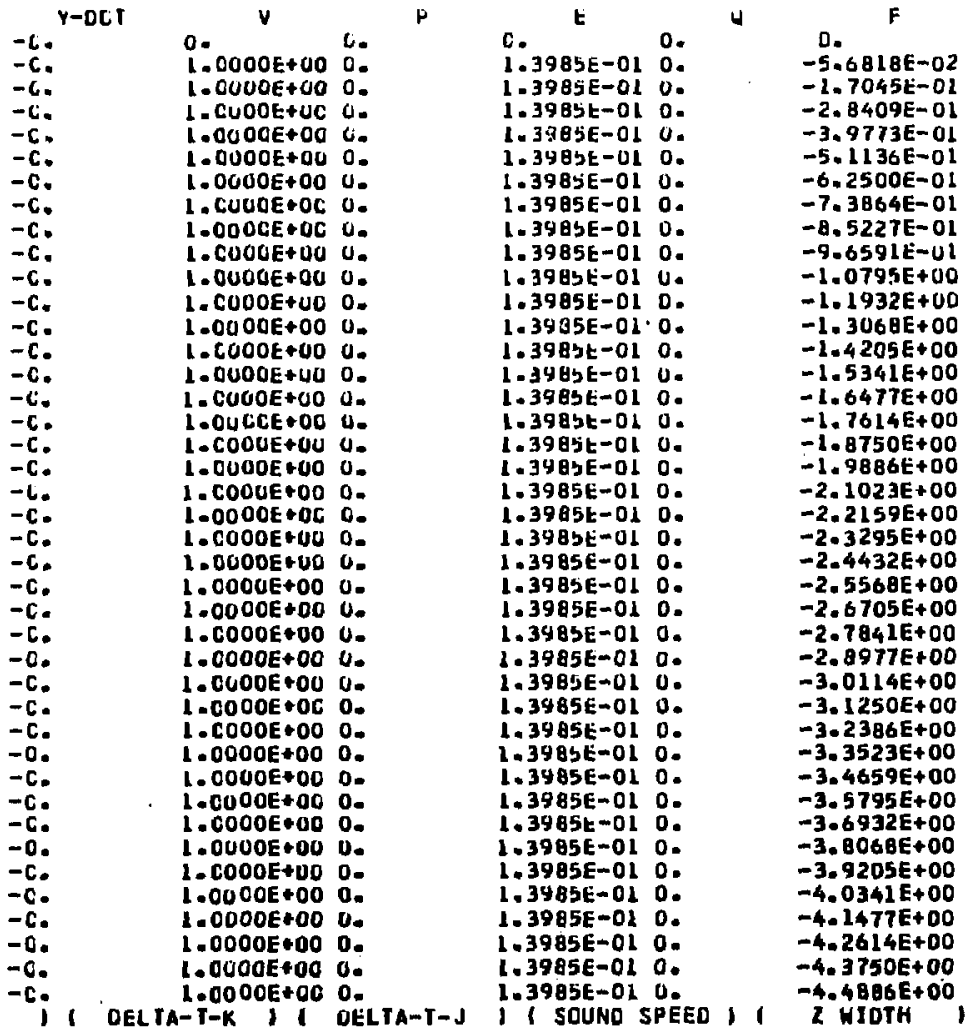


2HEMP LIP.OL

(CYCLE) (K-NUMBER) ( TIME

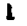

T IME

1 OLLTAC-

1 1 DELTA-T- 1 CGDE FILE

HEMPDG MAP HEMPDG

$\begin{array}{cc}\text { (TOTAL E) } & \text { (E-2ERU) } \\ \text { 1.757432E }+00 & 1.757432 E+00 \\ \text { (MAIERIAL) } & \text { (MAS5) }\end{array}$

$\begin{array}{rl}10 & 9.47001 T E+01 \\ 1 & 2.312212 E+01\end{array}$

(E.-CHANGE)

L. $100000 E+01$

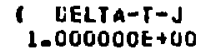

1 So

SPEEC I 1 WIOTH

TH

l.757432E+00

\begin{tabular}{|c|c|}
\hline $0 . .^{(K . E .5 U H)}$ & $\begin{array}{r}(I-E \text {. SUN) } \\
(-7 b 7432 E+00\end{array}$ \\
\hline (KINETIC E) & $\begin{array}{l}\text { (INTERNAL EI } \\
1.757432 \mathrm{t}+\text { UO }\end{array}$ \\
\hline
\end{tabular}




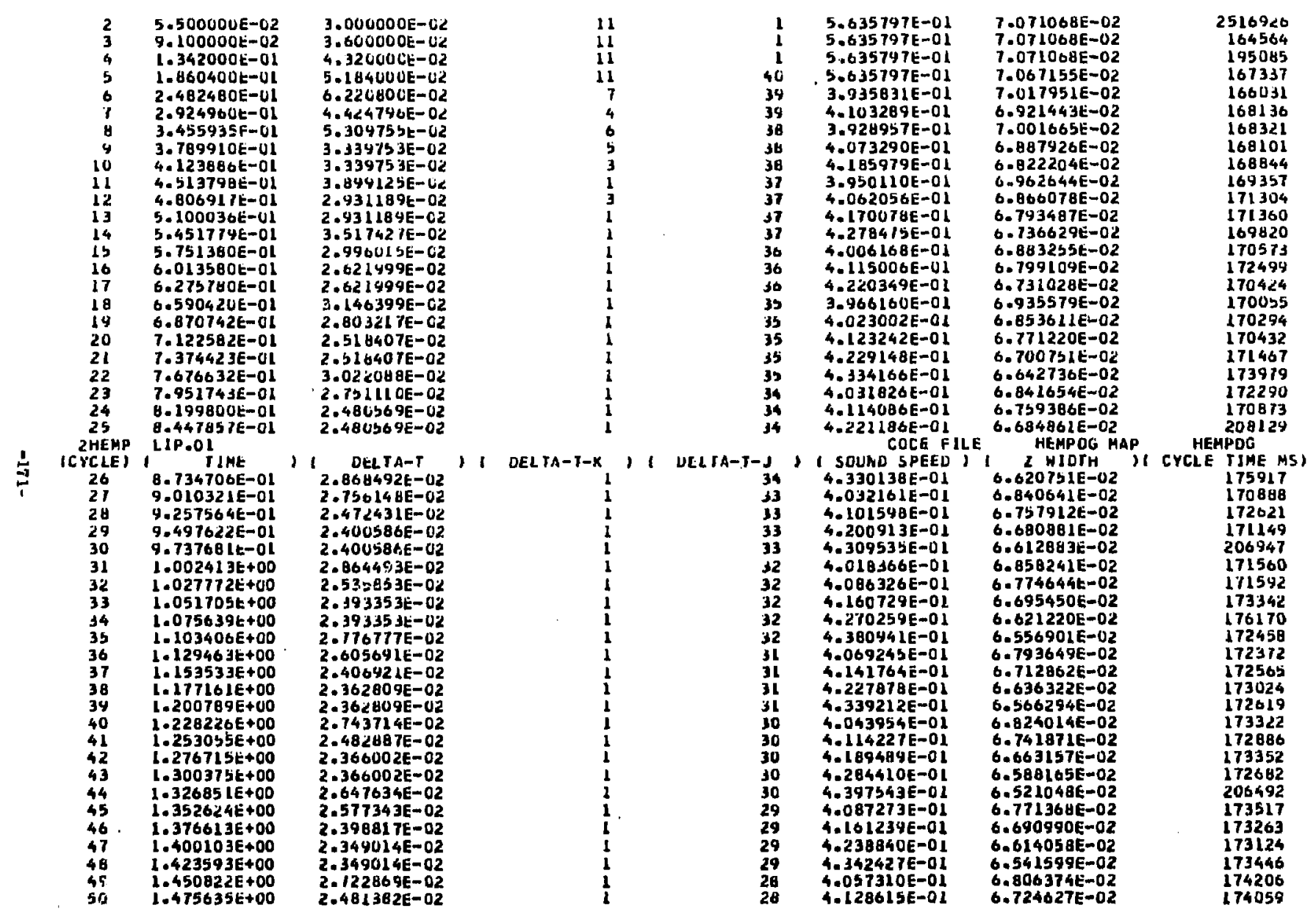




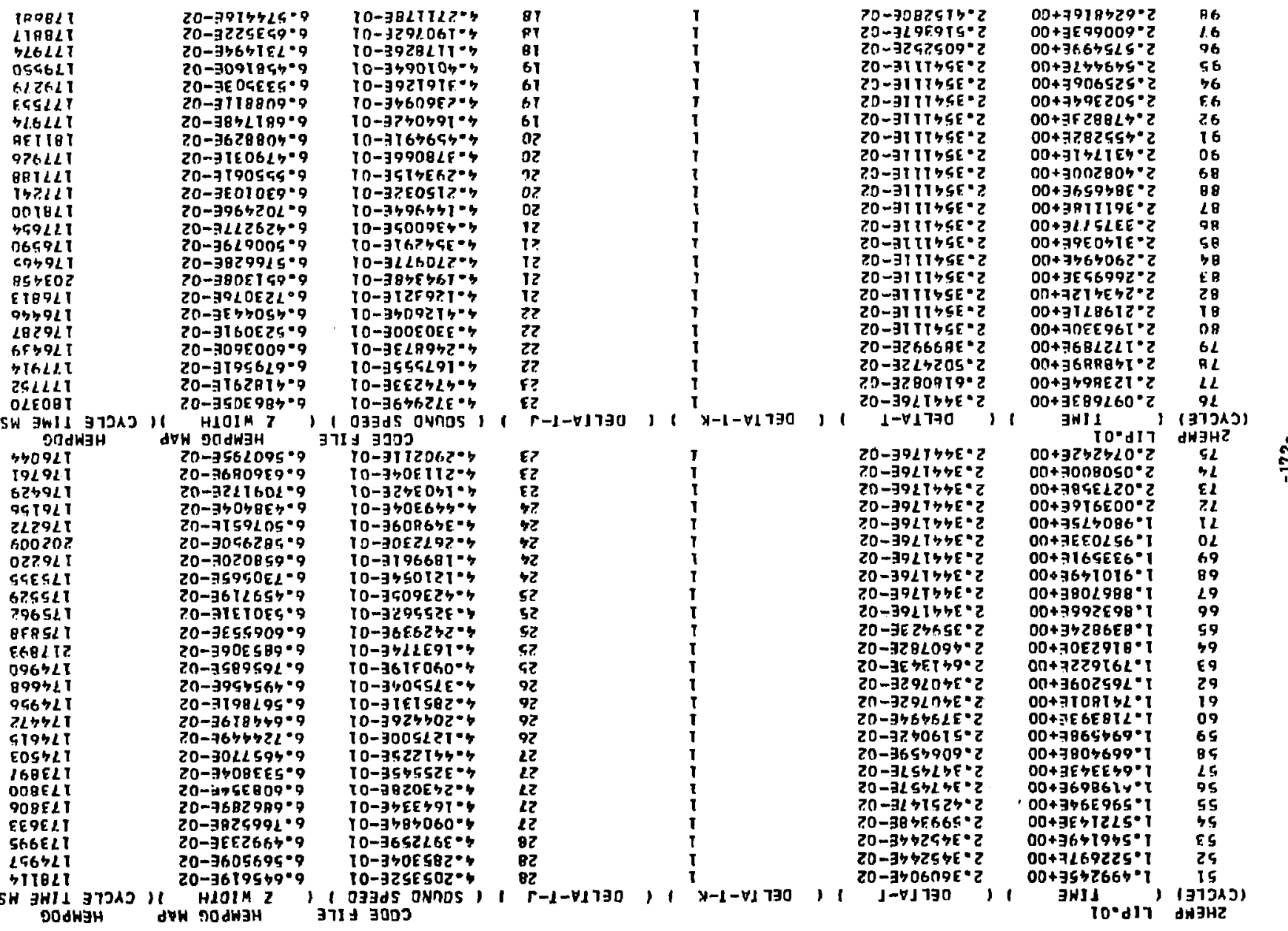




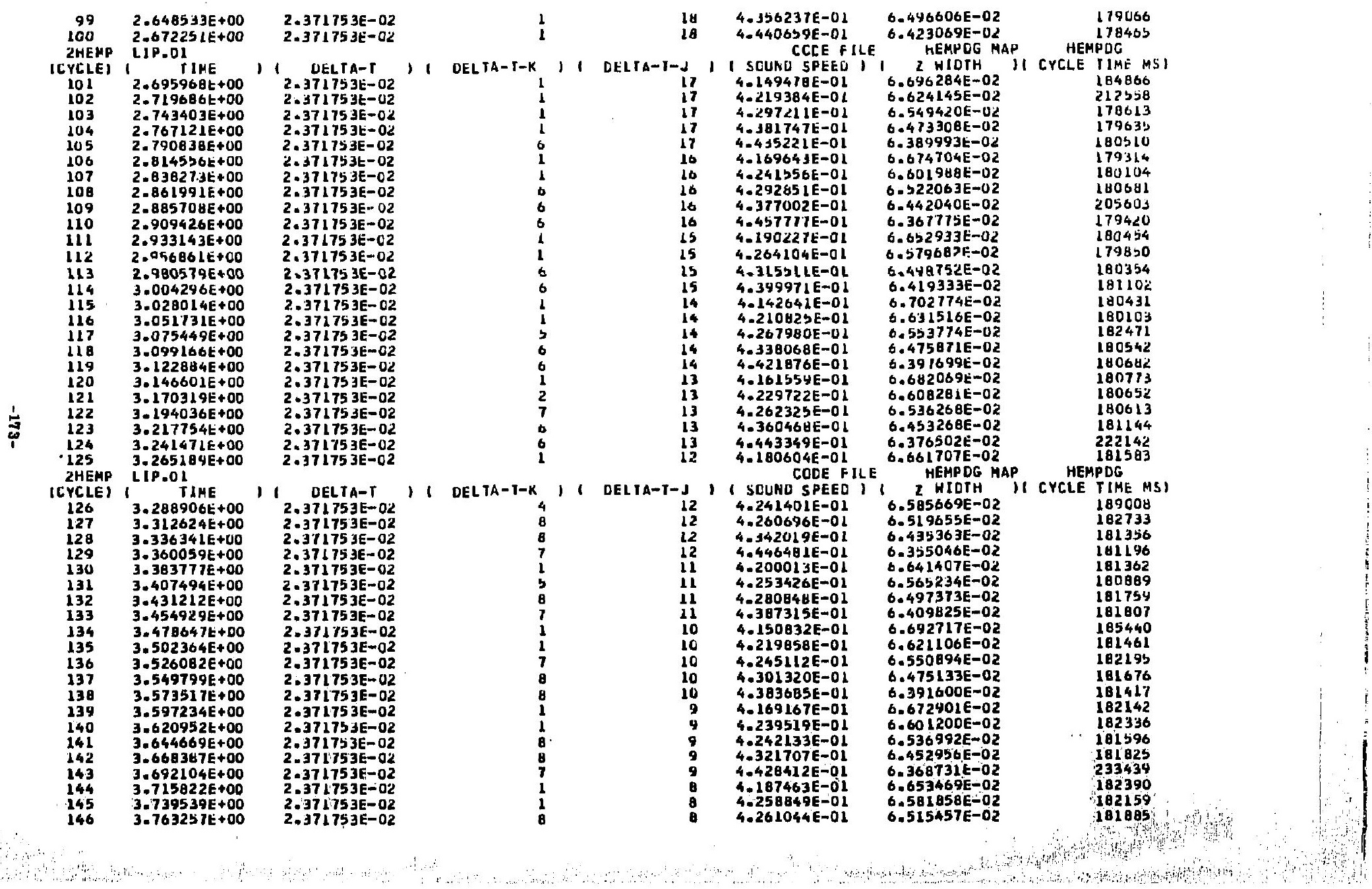




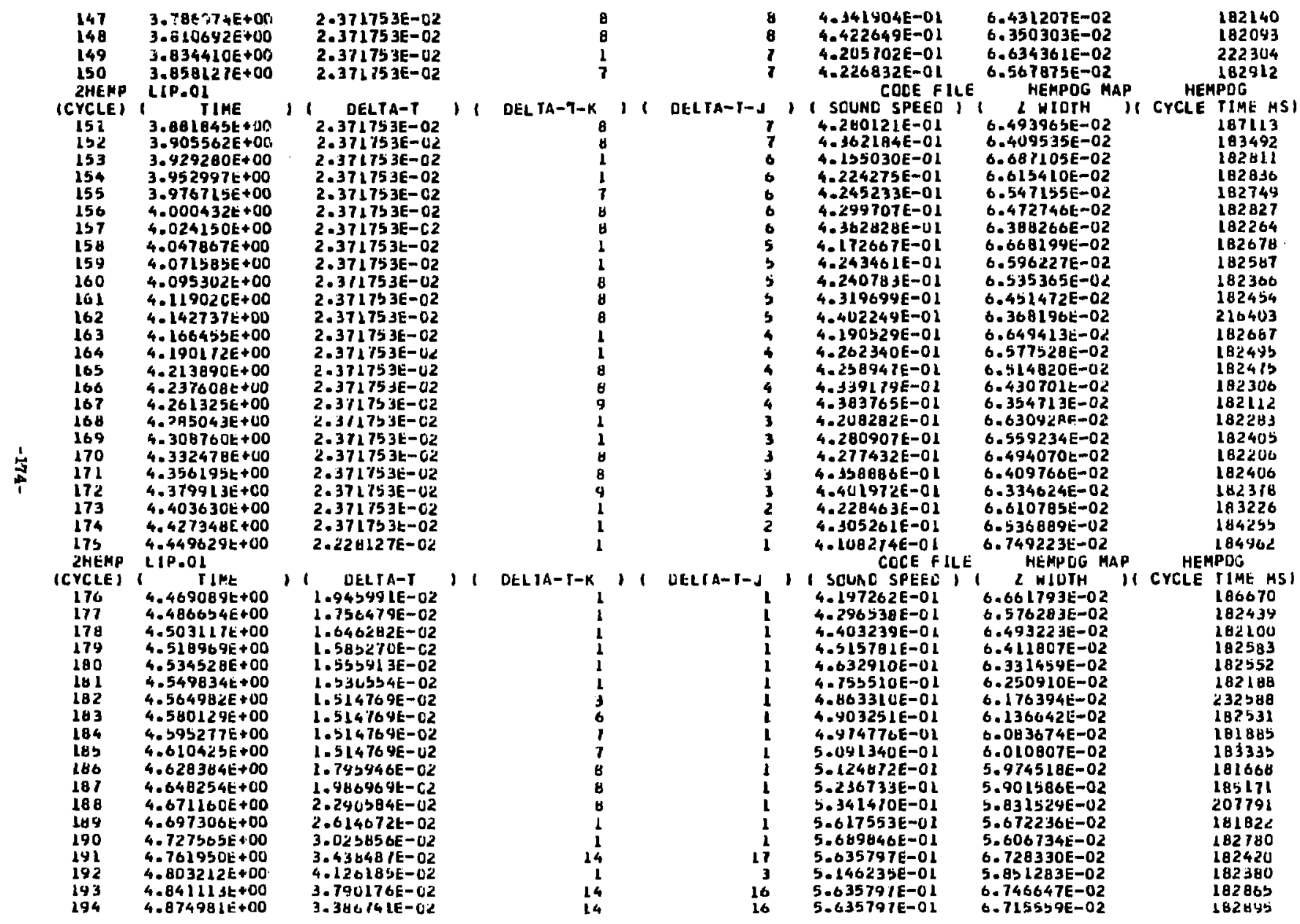




$\begin{array}{lll}195 & 4.915622 E+00 & 4.064089 t-02 \\ 196 & 4.95277 \mathrm{bE}+00 & 3.716291 \mathrm{E}-02 \\ 197 & 4.996268 \mathrm{0}+00 & 4.349386 \mathrm{O}-02 \\ 198 & 5.035024 E+00 & 3.370045 E-02\end{array}$

$996268 E+00$

3. $870045 t-02$

41 $5.635797 \mathrm{E}-0$

it $\quad 5.635797 \mathrm{E}-01$

$5.635797 E-01$

$6.473698 E-02$

$6.737087 E-02$

18280

182830

$0.523595 E-02$

184013

198

13

3c $5.635797 \mathrm{E}-0$ I

$6.443454 \mathrm{E}-02$

184013

: 
2HEMP LIP.OL

ICYCLE) (K-NUMUER)

1 OELTA-T OELIA-T
3. $876095 E-C 2$

11 UELTA-I-K 1.30000OE+G

14 COCE FILE

HEMPDG MAP J. 000000E+0

1 SOUND SPEED)

2 WIDTH
$6.493454 E-02$

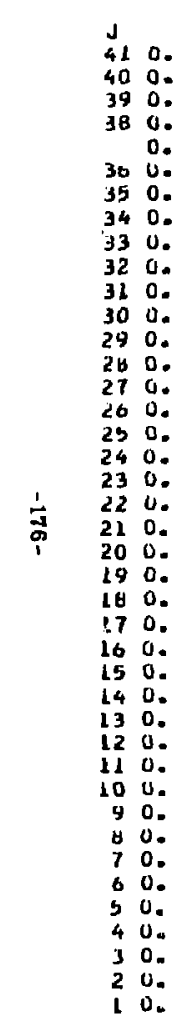

RHO

$x(2)$

$Y\langle R\}$

$x-001$

$Y-D C T$

4.024IE+0O L.SO33E+OU 7.666UE-0J 3.6372E-02 O. $3.4334 E+00$ 1.444LE+00 $9.6527 t-03$ j. $1508 E-02$ C. $3 . H 396 E+00 \quad 1.4483 t+00 \quad 1.1759 t-02 \quad 3.3662 t-02 \quad 0$. $3.7406 E+00$ 1.b15OE+0C 1.3951E-02 3.5148t-02 0. $3.6337 E+00 \quad 1 . \$ 328 E+00$ 1.4918E-02 4.1263E-U2 0. $3.3261 \mathrm{t}+00$ 1.5460t OD 1.3095E-02 4.6668E-U2 0. $3.4186 E+00 \quad 1.5367 \mathrm{E}+00 \quad 1.1969 \mathrm{E}-02 \quad 5.1483 E-020$ $3-3116 E+00$ L $4441+0 C$ B. $2505-035.34 B 0 E-020$ $3.316 E+00$ 1. 3.2064E too l.5 $3.1011 E+00$ 1.5739E+00 7.1066E-03 6.0878t-C2 0 . $2.9968 E+00$ L.S758E+00 $4.1813 \mathrm{~L}-03 \quad 6.2260 \mathrm{E}-02 \mathrm{U}$ $2.6927 E+00 \quad 1.5766 t+0 C \quad 3.888 L E-03 \quad 6.2914 E-02 \quad 0$. $2.7891 t+00 \quad 1.5 \% 63 t+002.1799 E-03 \quad 6.4046 E-02 \quad 0$. $2.6864 E+00 \quad 1.5748 E+00 \quad 5.8495 E-04 \quad$ E.4446E-02 C. $2.5840 E+00$ 1.57262+00 1.57CSE-04 t.5395E-02 0. $2.4621 E+00$ 1.5696t+OL-5.5627t-04 6.7564E-02 0. $2.3605 E+001.5658 t+00-1.615 L E-03 \quad 7.0149 E-020$. $2.2793 E+00$ 1.5U12E+00-2.7311E-03 7.2687t-02 C. $2.1785 E+00$ l.bbb9t+00-3.4463E-03 7.528CE-02 O. $2.0760 E+0 D \quad 1.5499 E+0 C-5.3042 E-037.7463 t-02 \quad 0$. $1.4777 E+001.5432 t+00-6.7297 t-03$ E. $6626 t-020$. $1-8778 E+00$ l $5+0 E+0 U-7-7878 E-0180+3475-U 2$ O

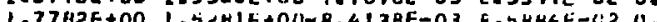

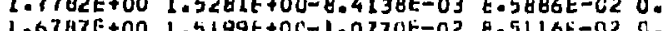
$1.6787 e+00$ l.s 1.3796 to $1.5117 E+00-1.2318 E-027.8861 E-020$. $1.4806 \mathrm{E}+00 \quad 1.3041 \mathrm{E}+00-1.1978 \mathrm{E}-02 \quad 6.9512 \mathrm{t}-020$. L. 38 L6E +00 $1.4413 E+00-8.2375 E-03 t .24 b L E-020$. $1.2422 E+001.4909 E+00-6.0015 t-03$ t.1710t-02 0. $1.1828 E+00 \quad 1.4643 t+0 U-6.0386 E-03$ t. $271 B E-020$. $1.0633 E+00 \quad 1.4776 t+00-6.6520 E-03 \quad t-4160 t-02 \mathrm{C}$ $9.8402 E-U L 1.4706 E+0 U-7.7620 t-01 t .5959 t-020$. H. $8406 E-O 1 \quad 1.4634 E+O C-9.173 B t-03$ k. $8040 E-U 2$ O. 7.8b88t-01 l.4559t+00-1.0684t-02 $1.0433 t-020$. $0.8709 t-01 \quad 1.4480 t+00-1.2023 t-027.281$ Bt - 020. b.6B43E-01 $1.4348 F+00-1.2402 E-02 \quad 7-3008 E-1,20$. $4.8995 \mathrm{E}-01$ 1.4314E+00-1.5050k-02 $7.4225 \mathrm{E}-02 \mathrm{U}$ $3.9174 E-O L$ L $42.45+00-1.0027 t-02$ to $3.9174 E-01$ l.4234E $00-1.6027 E-02$ C.QL2OE-O2 O. 2.9370E-01 1.4164t+00-1.4734t-02 $3.8666 \mathrm{t}-02 \mathrm{O}$ L.9571E-OL l.4111E+00-1.1473E-02 4.9308E-02 U. $\begin{array}{lllll}9.7809 E-02 & 1.4079 t+0 C-6.4196 E-U^{3} & 4.3220 E-02 & 0 . \\ 0 . & 1.4070 E+00-0 . & 4.1740 E-02 & 0 .\end{array}$

$\checkmark$

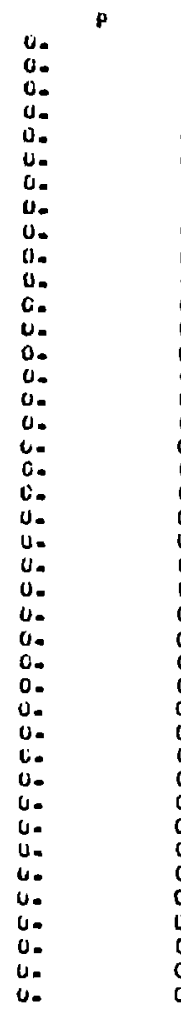

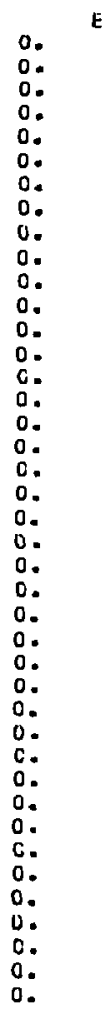

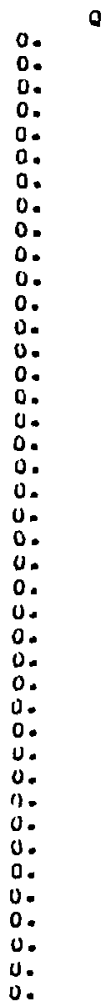

\section{F}

.

.

0.

0.

0.

a.

0.

0.

0.

0.

0.

0.

0.

0.

0.

.

0 .

o.

0.

0 . 
2HEPP LIP.OI

(CYCLE) (K-NUH

198
TIME

11 DELTA-T 3.076095E-02
COCE FILE

HENPDG MAP

I I DELIA- I-K 1. 30UCUOE+OL

PEEC 11 ( SUUNC SPEEC
$3.6337 y 7 E-01$
E

0. $x$-DOT Y-DOT J RHO $x(2)$ $Y(R)$ $4.0424 E+00$ 1.4111E+00 1.0B49E-02 3.4136E-02 0. $.4111 E+00$ 1.0B49E-02 3. $136 E-02$ O. 0. a. $E$. 0 . $6.4934545-02$ $6.493454 E-02$ $40 \quad 7.8500 E+00 \quad 3.4389 E+00$

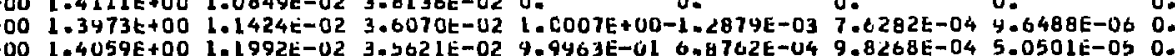
7. 75OOE+00 $\quad I .7309 E+00$ 1.4243E+00 1.0375E-02 3.4879E-02 L.0010E+00-1.4283E-03 1.4432E-03 2.5940E-05 0. $377.8500 E+003.6282 E+00.1 .4474 E+00 \quad 1-2023 E-02 \quad 4.4881 E-02 \quad 1-0.41 E+0 G-7-0923 E-03 \quad 1.7734 E-03 \quad 1.3508 E-04 \quad 0$.

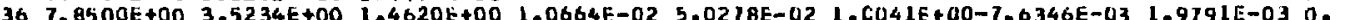
15 $347.8500 E+00 \quad 3.3126 E+00$ l.4805E+00 $9.0457 E-035.91 / 8 E-02$ l.0028E+00-5.3137E-03 2.1278E-03 0. $307.8500 E+00 \quad 2.8960 E+00 \quad 1.4919 E+00 \quad 3.1922 E-036.4673 E-02$ 9.9473E-01 $3.0350 E-042.2841 E-030$.

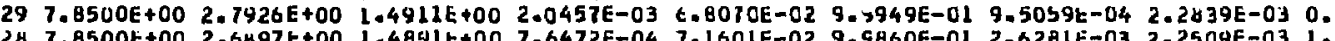
$277.8500 E+002=5875 E+00 \quad 1.4860 E+00$ B.3274E-05 7.4718E-02 1.CUOSE+00-9.4658E-04 2.1963E-03 5.7352E-04 0. $267.8500 E+00 \quad 2.4857 E+00 \quad 1.4820 E+00-7.2442 E-04 \quad 7.6907 E-02 \quad 1-0050 E+00-9.3600 E-03 \quad 2.1385 E-03 \quad 8.1319 E-04 \quad 0$. $257.8500 E+00$ 2.3645E+00 1.4772E+00-1.5732t-03 1.8B89E-02 1.CLOLE+00-2.0000E-02 2.0939E-03 S.9125E-04 0.

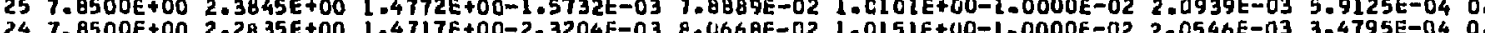

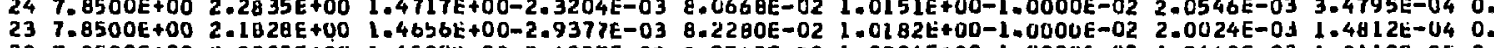
$227.8500 E+002.0823 E+00 \quad 1.4584 E+00-3.4337 E-03 \quad 6.3763 E-02 \quad 1.0204 E+00-1.0000 E-02 \quad 1.9468 E-03 \quad 1.8110 E-05 \quad 0$.

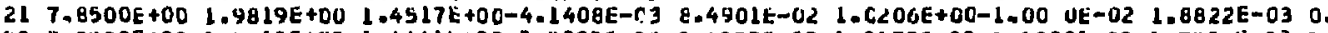
$207.8500 E+00$ 1. 8 \& LEE+00 $1.4441 t+00-5.2095 E-03$ e.4872E-02 $1.0179 E+00-1.0000 E-02 \quad 1.7886 E-03 \quad 0=$ $147.85 D O E+00 \quad 1.7820 E+00 \quad 1.4363 E+00-6.3510 E-03 \quad 8.3156 E-02 \quad 1.0124 E+00-1.0000 E-02 \quad 1.7037 E-030$. $187.8500 E+D 0$ 1.6824E+00 1.4263E+00-8.7381E-0j 6.1170E-02 1.0029E+00-3.491SE-03 1.5751E-03 0. $177.8500 t+00$ l.583LE+00 1.4204E+00-1.0927E-02 8.0508E-02 9.5UTOE-01 1.7642E-02 1.6341E-03 0. 15 7. $.0500 E+00 \quad 1.3452 E+00 \quad 1.4040 E+00-1.0659 E-02 \quad 7.9148 E-02 \quad 9.4919 E-01 \quad 2.05541:-02 \quad 1.4934 E-03 \quad 7.8490 E-03 \quad 0$. $147-8500 E+00 \quad 1.2861 E+00 \quad 1-3459 E+00-9.0002 E-03 \quad 7-3366 E-02 \quad 1-0036 E+00-6-7037 E-03 \quad 1-1804 E-03 \quad 4.9608 E-03 \quad 0$. $137.0500 E+001.1969 E+001030$ $137.8500 E+00$ 1.1369E+00 $1.3881 E+00-7.5311 E-03 \quad 7.1913 E-02$ 1.C159E+00-1.0000E-U2 $1.1220 E-031.8130 E-030$.

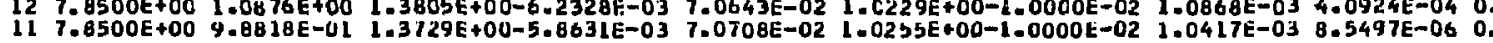

$107.8500 E+00$ B.8876E-01 l.36b2E+00-5.4493E-03 7.1116E-02 L.0251E+00-1.0000E-02 9.7607E-04 0. 9 7.8500E+00 7.8927E-01 1.3574E+00-4.7434E-03 7.1903E-02 2.0226E+00-1.0000E-02 8.9497E-04 0. B ?. B500E +00 6.8970E-02 $1.3494 E+00-3.6267 E-03 \quad 7.3156 E-02 \quad 1.0179 E+00-1.0000 E-02 \quad 7.9251 E-04$ 0. 7 7.8500E+00 5.9004E-01 L.3412E+0U-3.8038E-03 7.4030E-02 L.01 15E+00-1.0000E-02 6.5050E-04 0. $67.0500 E+00$ 4.9057E-DL 1.3330E+00-7.2935E-03 7.2349E-02 L.002 IE+00-4.0284E-03 5.3L32E-04 0. $57.8500 E+00$ 3.9163E-01 L.3 $2 b 2 E+00-1.0508 E-02$ 6.7056E-02 9.8985E-01 $1.9277 E-026.2185 E-040$. 4 7. $8500 E+00$ 2.y324E-01 $1.3183 E+00-1.0923 E-02$ 5.9615E-02 9.7903E-01 4.0277E-02 9.1169E-04 0. $37.850 U E+00 \quad 1.9526 E-01$ l.31J0E+00-6.5270E-03 $5.2593 E-02 \quad 9.7176 E-015.4643 E-02 \quad 1.1929 E-03 \quad 5.9167 E-040$. 2 7.8500E+00 9.7590E-02 1.3098E+00-4.5525E-03 4.8128E-02 9.6712E-01 6.3907E-02 1.42 12E-03 4.3726E-03 0. $17.8500 E+000$. $1.30896+00-0$. $4.7220 E-029.6494 E-01$ b.8309E-02 l.5413E-03 7.0789E-03 0. 

$397.8500 E+00-1.316 b E-02-2.3491 t-022.3420 E-02-5.0767 E-03-1.3136 E-0<-<-0107 E-03-403997 E-030.4104 E-03-1.0425 E-03$ $347.8500 E+007.3531 t-04-3.4667 t-02$ 2.4474t-02-1-6247E-02-9.4374E-0 J-9.4HI 7t-04-4-8704E-015.8686E-03-1.4376E-03 $377.8500 t+00-5.8034 E-03-4.3169 E-02$ 2.1243E-02-2.2b32t-02-2.1/79E-U2 4.77I7t-04-5.6476E-01 4.8194E-03-2.25A6E-03 $367.8500 E+00$ 1.8943E-02-3.9436E-02 3.0393E-02-2.3924E-02 9.580IE-0S 1.63726-03-6.0001E-01 4.3624E-03-2.1154E-03

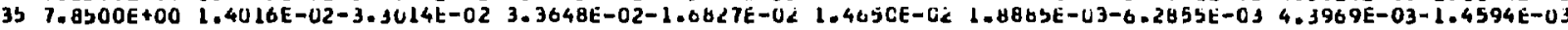
$347.8500 E+00$ 1.8685E-02-3.4376t-02 3.6480E-02-1.0887t-02 2-C790E-02 2.4858t-U3-6-3946E-03 3.408BE-03-1.4695E-03 $337.6500 E+00$ 1.4I26E-02-0.1174E-0L 3.87SOE-02-3.4648E-02-3.2482E-01 1.3434t-03-6.2971E-01 4.7531E-03-1.0082E-01 12 7.8500t +00 1.6348t-02-5.5342t-02 4.0218E-02 1.5961t-U2 1.423IE-03 1.6436E-U3-6.4931E-01 3.8475t-03 1.1626E-03

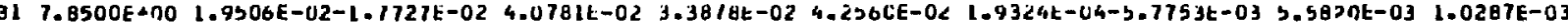

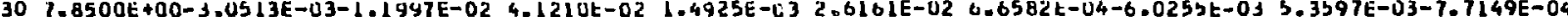

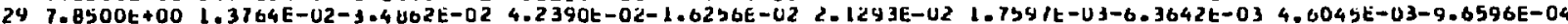

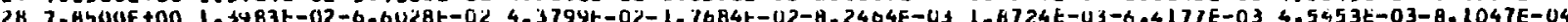
27 7

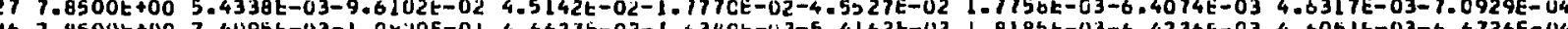

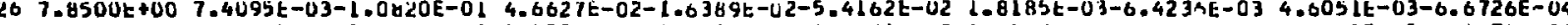
$237.8500 t+00$ 9.338st-03-1.0370t-01 4.8224t-02-1.0494t-022-4-6121t-02 1.058/t-03-6.3708t-03 4.7121E-U3-7.4970E-04 $247.8400 E+009.3236 E-03-9.4477 t-02$ 4.9831E-02-1.8716t-C2-1-5123E-02 1.4010t-03-6.2662t-03 4.8632E-03-9.4393E-04 $237.8500 t+009.5144 t-03-8.3449 t-02$ 3.1428t-02-2.3518t-02-2.300JE-02 1.034 1t-01-6.0446t-03 b.0460t-03-1.2456t-U3 $227.8500 t+001.0200 E-02-1.1263 E-025.3037 E-02-3.1553 t-C 2-H . C 26 U t-03$ 5.18L6t-04-5.7930t-0 3.2748t-03-1.5836E-03 $217.6500 t+001.2291 E-02-5.3634 E-025.4242 E-02-3.6426 t-021.1 U 50 E-02<-1.4432 t-04-5.4242 E-03 \quad 3.6226 t-03-1.6721 E-03$ $20 \% .0500 E+00$ 1.2696E-02-3.2102E-02 5.3899E-02-1.6664E-02 3.6493E-02-1.2324E-03-4-4317E-03 6.1645E-03-1.1883E-03

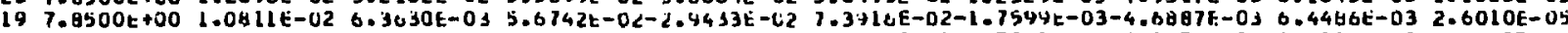
$187.8500 E+00$ 2.5565E-02 3.6663t-0< 5.6767t-0?-1.64SCE-62 1.19LI9E-01-8-7295t-04-5.1079E-03 5.9809t-03 L.4219E-0S

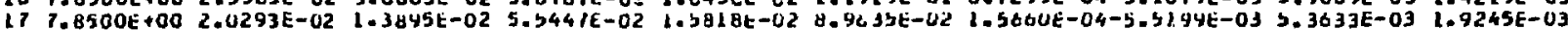

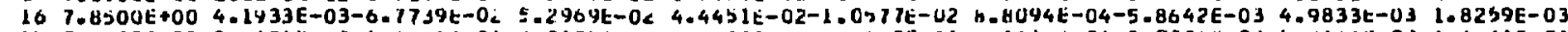

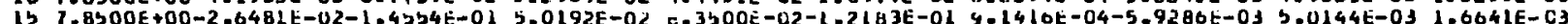
14 1 $0504 t+00-2-1043 E-02-1$ 14 ( 13 . E-03-8.9294E-U4 $117.8500 E+00$ 4.3862E-0J-3.7042t-02 4.1734t-02-1.0719t-c2-3-3021E-03 1.6311t-04-5.3404E-03 3.2173E-03-2.2881E-U3 $107.4500 E+00$ 7.1058E-03-4.0644E-02 4.8776E-02-3. 8C92t-42 1.5H37t-02-3.59b5t-04-4.4654t-03 4.8249t-01-3.4145E-03 $47.8500 E+00$ 7.6469E-03-2.3346t-02 5.0070t-02-6.2b3bt-02 9.4321E-02-1.7130t-04-3.6376E-03 4.4151E-03-4.0827E-03

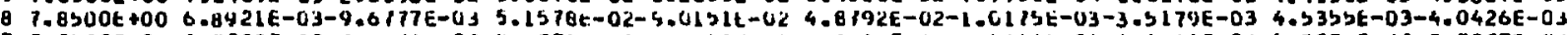

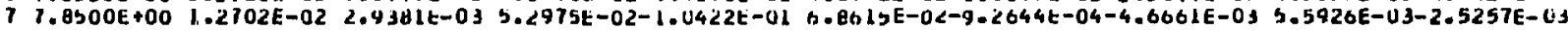

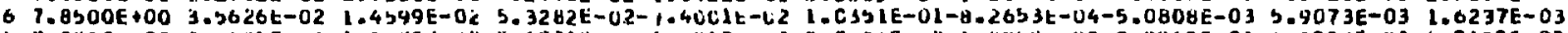
$37.8500 t+00$ 2.663BE-02 1.5U20E-02 5.1031E-DL-1.0843E-02 9.2086E-U2-1.2465t-03-3.0940E-03 4.3925E-03 4.2493E-03 4 7. $8500 t+00-1.1767 t-03$ 2.4317t-04 4.6172t-02 3.6453t-02 4.524CE-U2-1-6 736E-US-2.2b31E-0J J.928Jt-03 4.6556E-US 3 7.8500E+00-2.7076E-02-2.2U15E-02 4.0320t-02 3.C394t-02-8.7707E-63-1-9845t-03-2.3460t-03 4.3145é-03 4.3824E-0J

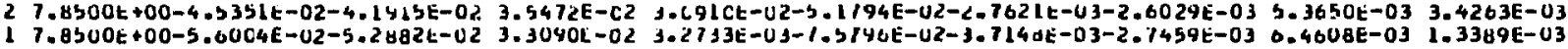


J RHO 0. 0 O.

St 0. Si, 0. I Bc 0. is 0. $7.050 E+00$ GUOt-01

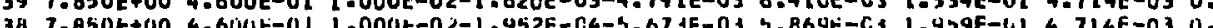

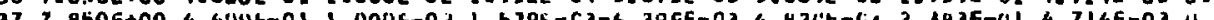

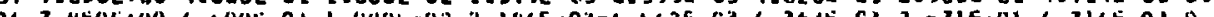
S5.

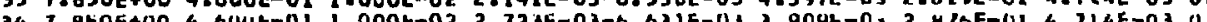

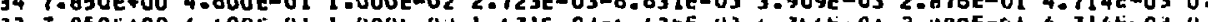

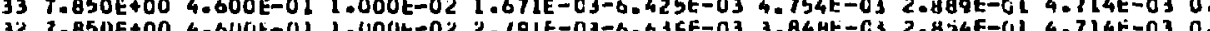
32 1.850E+00 4.6UUE-01 1.U0UE-02 2.191E-03-6.635E-03 3.84tE-C3 2.854E-01 4.714E-03 0

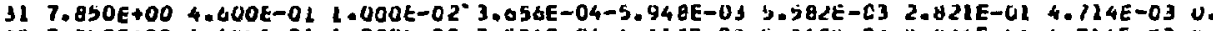
10 7.8DOE+00 4.6UUE-02 1.000E-02 1.536E-04-6.11 3E-03 5.36CE-CS 2.6J6E-UL 4.714E-03 U. $297.850 t+00$ 4.600E-02 1.000E-02 1.873E-03-6.417E-03 4.605E-03 2.801E-01 4.714E-03 0. 28 1.850E +00 4.600E-01 I.000t-02 1.45IE-03-6.44tE-US 4.34St-CS 2.734E-01 4.714t-03 0. $277.850 E+00$ 4.6UUE-01 l.0OUE-02 1.837E-03-6.468E-03 4.632E-0S 2.644E-01 4.714E-03 U. 26 7.850E+00 4.69UE-01 1.000E-02 1.672E-03-6.4/7E-0 J 4.60SE-CS 2.342E-UL 4.714E-03 0.

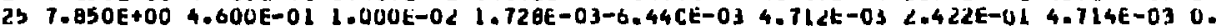
$247.850 t+00 \quad 4.600 E-01 \quad 1.000 t-02 \quad 1.517 t-03-6.341 E-014.86 J E-C 3$ L. $06 E-01 \quad 4.714 E-03 \quad 0$.

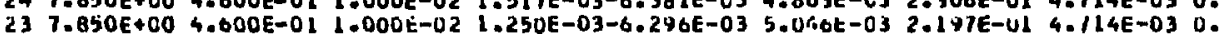
$227.850 E+004.600 t-01$ 1.000E-02 B.932E-C4-6.16EE-03 3-275E-CS $2.093 E-G 1$ 4. $714 E-03$ U. 22 . $850 E+00$ 4.600E-01 1.000E-02 6.932E-C4-6.16EE-03 $3.275 E-C 3$ 2.093E-G1 4.714E-03 U.

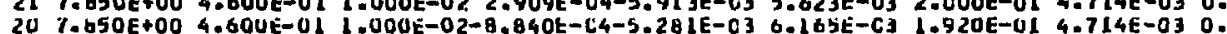
$197.850 E+00$.

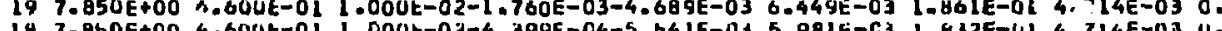
$187.850 E+00$ 4.600t-0I 1.000t-02-4.399E-04-5.34 LE-03 5.9AIE-C3 L.832E-U1 4.714E-03 U $\rightarrow \quad 17$ 7.85OE+00 4.600E-01 1.000E-02 7.475E-04-6.111E-03 5.363E-CS L.EI7E-01 4.714E-03 0. $167.850 E+00$ 4.00UE-01 $1.000 E-02 \quad 1.343 E-03-6.327 E-03$ 4.983E-C3 1.762E-G1 $4.714 E-03 \quad 0$. 15 7. B5OE+00 4.600E-01 1 - .00E-02 1.297E-03-6.312E-U3 3.014E-CS 1.628E-01 4.714E-03 0. $147.850 E+00$ 4.600t-01 1.000t-02 1.422E-0S-6-3bLE-03 4.930E-CS 1.442E-01 4.714E-03 0.

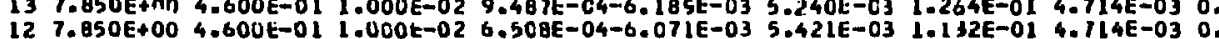
$117.850 E+00 \quad 4.600 E-01$ 1.000E-02 9.855E-04-6.203E-03 3.217E-61 1.034E-U1 4.714E-03 0. $107.850 E+00$ 4.60Ut -01 l.000t-02 l.572t-03-6.3HIE-03 4.82ht-C3 9.494E-02 4-714E-03 0 $97.050 E+00$ 406GUE-01 L. 7 .050E 7 7.85OE+C0 4.600E-C1 1.000E-02 1.964E-03-6.499E-03 4.3JSE-03 7.8OLE-02 4.714E-03 0 $77.850 E+00$ 4.600E 5 T. 2. T. 7.850E+00 4.600E-01 1.000t-02 2.700E-03-6.629E-03 3.929E-03 5.021E-02 4.114E-03 0. 3 7.B50E+00 4.600E-01 l.000E-02 $2.219 E-03-6.554 E-03$ 4.335E-C3 4.635E-02 $4.714 E-03 \quad 0$. 1 7.850E+00 4.600E-01 1.000E-02-1.407E-03-4.654E-03 6.461E-C3 1.732E-02 4.714E-0J 0
K-ELASTIC TANPHI

0.

2.064E-05-1.153E-01 2.2 70E-05-3.750E-01 $2.652 E-05-4.144 E-01$ 3. 3bIE-05-3.104E-01 $3.66 j E-05-2.385 E-01$ $3-213 E-05-1.732 E-01$ $3.6+44 E-05-1.612 E-01$ S.237E-05-1.263E-U2 $4.729 E-05$ 1.252E-DI $2.844 E-05 \quad 1.675 E-01$ $2=17$ SE-0S-1. 13BE-OI 3.6SUE-OS-1.173E-U1 $5.569 E-05-9.683 E-02$ $1.409 E-0 S-6.604 E-02$ 6.326E-05-8.043E-02 Q.129E-05-9.257t-0. 7.h92E-05-1 213E-01 $7.013 E-05-1.213 E-01$ $7.0135-05-1.698 \mathrm{E}-01$ $6.386 E-05-2.368 E-01$ $3.027 E-05-2.926 E-01$ $4.287 E-05-2.936 E-01$ 2.3 4 E-05 8.8BOE-03 $7.898 \mathrm{E}-06 \quad 3.046 \mathrm{E}-01$ $1.914 E-05$ 3.071E- OI $0.380 E-05$ 2.533E-01 $1.125 E-04$ 2.303E-01 $1.199 E-04 \quad 1.665 E-01$ Q.An 3E-05 7.930E-02 $6.077 E-05-1.353 E-01$ $4.886 E-05-3.594 E-01$ 4. 379E-05-5-656E-O1 $4.553 E-05-7-093 E-01$ 5. $172 \mathrm{E}-05-7.3755-01$ 5.172E-05-7.375e-01 $3.933 E-05-5.039 E-01$ 1.211E-06 3.38le-OI $6.305 E-06$ 8.108E-01 2.796E-05 9.399E-01 $4.001 E-05$ 9.600E-01 $4.250 E-05$
$4.662 E-05$
$1.425 E+00$ 
ZHEMP LIP.0I

(CYCLE) (M-NUNBER

198

13

7 IME

11 DELTA-T

1 DELTA-T-K

1. 3 COOOOE +0 L

CCLE FILE

HEAPOG MAP

HEHPDG

RHO 3.876095E-62

Y-CCT

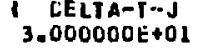
I SOUAD SPEEC
$5.635797 E-01$

$6.493454 E-02$

410.

$x(2)$

$Y(R)$

$x-001$

.2112E-02 0.

0.

$E$

a

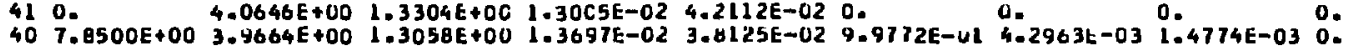

$397.8500 E+003.8 b 35 E+00$ 1.3215E+00 1.4b38E-02 3.7526t-02 1.CU23E+CC-4-36bbE-03 2.7331E-03 6.0285E-06 0.

$38 \quad 7.8500 E+00$ 3.7375E $\$ 00 \quad 1.34 \angle 8 E+00$ 9.6575E-03 4.2196E-02 1.CO1LE+00-2.0903E-03 3.0291E-03 0.

$377.8500 E+00$ 3.6241E+DO 1.362BE+0C 9.6002E-03 4.7450E-02 9.9950E-01 9-4084E-04 2.6509E-03 3.1852E-05 0.

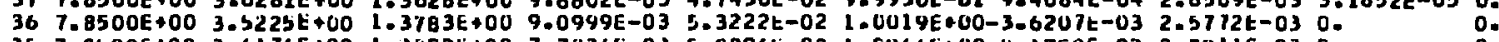

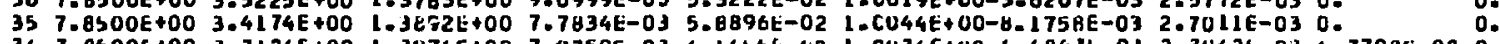

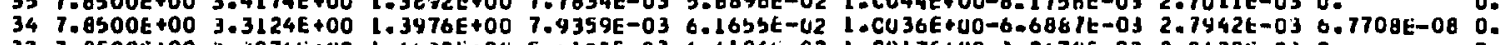

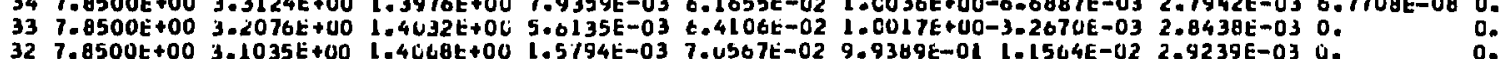

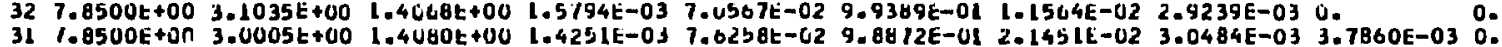

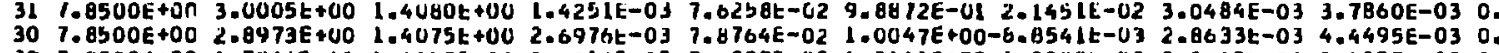

$297.8500 E+00 \quad 2.7944 E+001.4059 E+002.0010 E-03 \quad 7.4809 E-02 \quad 1.0141 E+00-1.0000 E-02 \quad 2.8562 E-032.3397 E-03 \quad 0$.

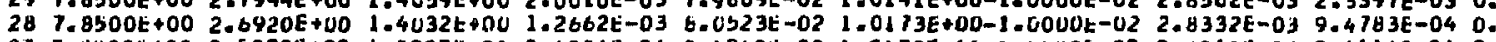

27 7.4500E+00 2.5898E+00 1.3997E+00 8.4284E-04 E.1042E-C2 1.C1 78E+CO-I. UUUOE-02 2.8019E-03 2.41L4E-04 0.

$267.8500 E+00 \quad 2.4679 E+00$ 1.3952E+00 6.9064E-04 E.175SE-02 1.0173E+00-1.0000E-02 2.7790E-0J 5.1441E-06 0.

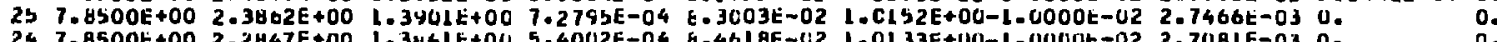

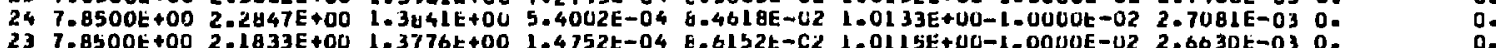

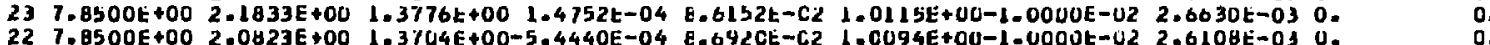

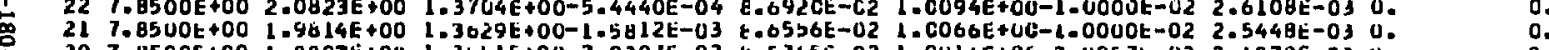

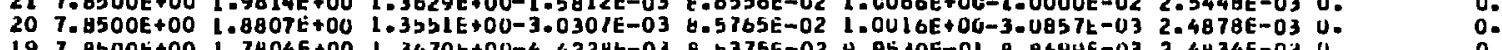

$197.8300 E+00 \quad 1.7804 E+00 \quad 1.3470 E+00-4.4228 t-038.3375 E-02$ 9.9530E-01 8.8694E-03 2.4834E-03 U.

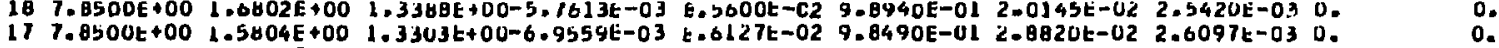

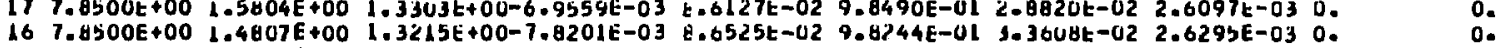

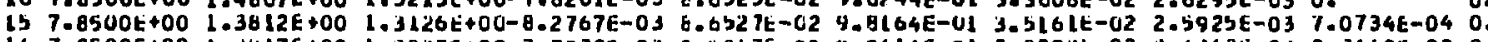

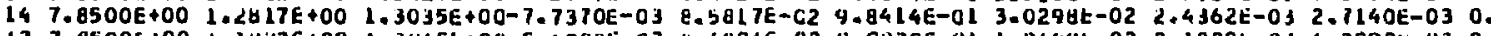

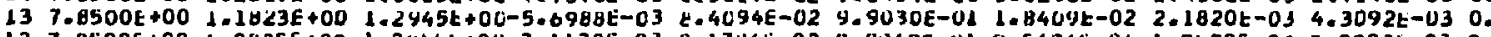

12 7.8500E +00 1.0825E +00 1.24bbE+0U-3.1138E-03 8.1746E-02 9.9449E-U1 9.5634E-04 1.9b90E-0J 2.0903E-03 0.

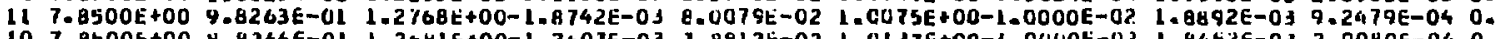

10 7.8BOOE+00 8.8266E-01 1.2081E+00-1-7007E-03 7.8812E-02 1.0127E+CO-1-0UUOE-02 1.8452E-03 2.9080E-04 0.

$47.4500 E+00$ 1.8212E-01 1.2b9bE+00-2.3883E-03 7.636LE-02 1.0156E+U0-1.000UE-02 1.8181E-03 b.2468E-06 0.

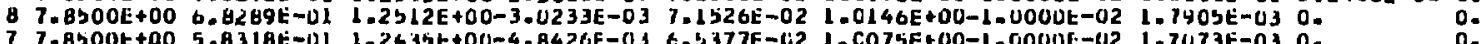

$67.8500 E+004.8385 E-01 \quad 1.2364 E+00-8.9661 E-03$ t.0731t-02 9.9058E-01 1.7816E-02 $1.7094 \mathrm{E}-0303$.

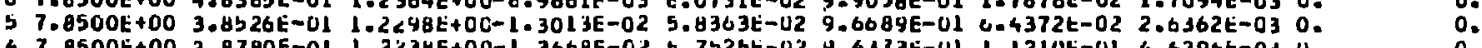

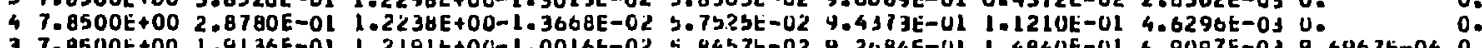

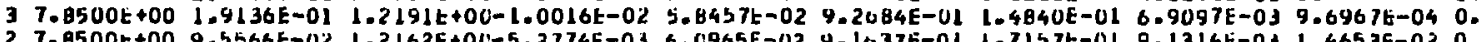

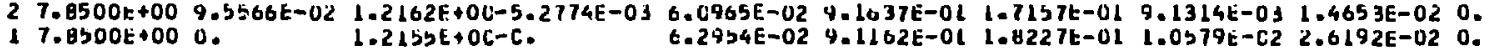




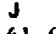

EOXX
EDYY
EDIT

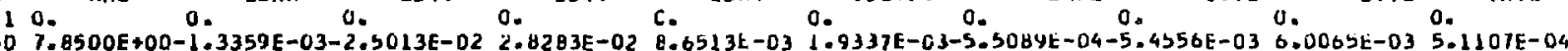
0.

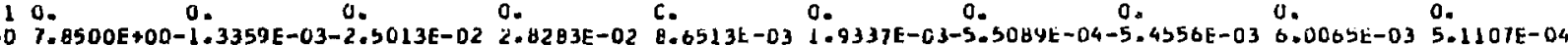

EDXY
VLCIR

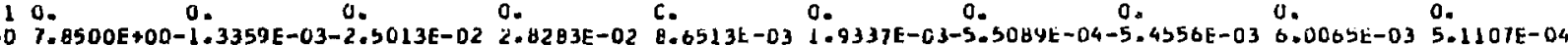

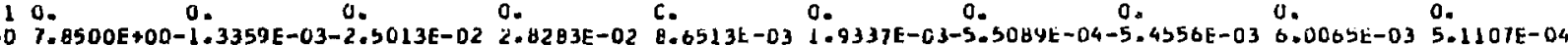
$347.8500 E+00-9.8726 E-03-2.1043 t-02$ 2.7140E-02-2.7533t-02-4.5656E-03-4.7040t-05-5.2306t-03 5.2776t-03-2.3929E-03

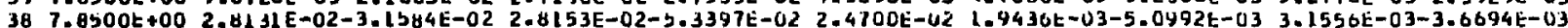
377

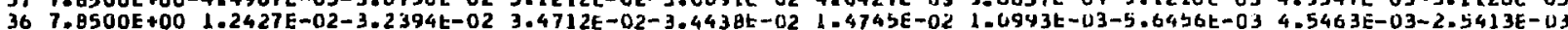
$357.00 E$ (a)

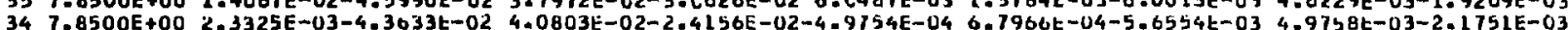
$337.0 C E+00$ 2. $327.8500 E+00$ 3.4286E-02-4.06b9t-02 4.5378E-02-1.5620E-02 3.9006E-02 2.6825E-03-6.5949t-03 3.9125t-03-5.1854E-04

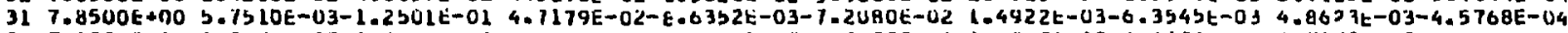
$307.8500 E+00-1.0736 E-02-1.6633 E-01$ 4.87L6E-02-1.5295E-02-1.2835E-01 l.0962E-03-6.410LE-03 4.7139E-03-4.8945E-04 $297.8300 E+00$ B.8957E-03-1.5224E-01 5.0321E-02-1.6363E-02-9.3027E-02 1.8383E-03-6.4338E-03 4.5956E-03-6.2211E-04 $287.8500 E+00$ 9.8755E-03-1.2092E-01 5.1889E-02-2.0290E-02-5.9L53E-02 1-3751E-03-6.2548E-01 4-8797E-03-9.5938E-04 27 7.8500E+00 5.6386E-03-8.8/81E-02 5.3344E-02-2-2056E-02-2-9799E-02 7-0524E-04-5.9322E-03 5.2269t-03-1.3524E-03

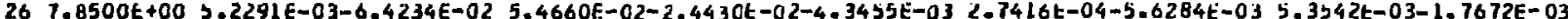
(1) 作

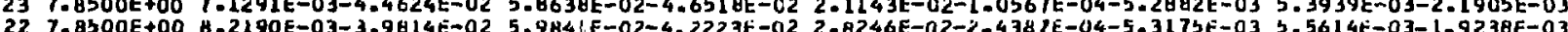
22 7.

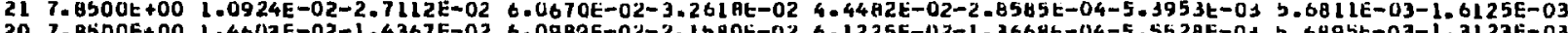
$201.0500 E+00$ l. 19 7.85O0E+00 1.4496E-02-1.7635E-02 6.0622E-02-1.134CE-02 5.7683E-02 3.6717E-04-5.

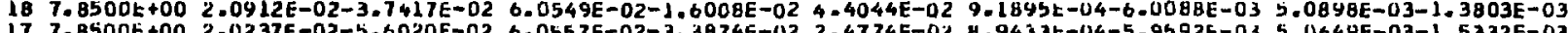

17 7.850E 16 7. $157.8500 E+00-2.2741 E-03-7.3024 E-020.2055 E-02-2.2172 E-02-1.3243 E-02$ 3.9612E-04-5.4579E-03 5.5818t-03-2.0009E-04 $147.8500 t+00-9.4049 E-03-9.0028 E-02$ 6.0374E-02 1.1909E-02-4-7058t-02 6.0186t-04-6.0315E-03 3.4296t-03 4.7150E-04 $137.8500 E+00-1.6314 E-02-1.2316 E-01$ 5.4039E-02 2.062 7E-02-8.0435E-02 6.5538E-04-6.0647E-03 5.4091E-03 3.1429E-04 12 7. B5OOE+0O-1-7412E-02-1.2485E-0I 5.7804E-02 2.9997E-03-8-4454E-02 0-4568E-04-6.0639E-03 5.4162E-03-2.4639E-04 $117.8500 t+00-5.0494 t-03-1.0409 t-01$ 5.7155t-02-1.9735t-02-5.5486E-02 3.5565E-04-5.9141E-03 5.5585E-03-5.7755E-04 $107.8500 t+00$ 6.1517E-04-8.887LE=02 5.6966E-02-2.8091E-02-3.1240E-02-9.4029t-04-5-2454E-03 6.1857E-03 4.9910E-05 $97.8 \zeta 00 E+00$ 2.16U9E-03-6.3125E-02 5.6774E-02-1-7562E-02-4.1896E-03+3-5506E-03-2.6467E-03 6-1973k-03 2.0794E-03 8 7. $8500 E+00-1-2520 E-03-1.5727 E-02 \quad 5.6093 E-02 \quad 4.2934 E-03$ 3.9114E-02-5-0327E-03 2.0480E-03 2-9847E-03 3.7574E-03

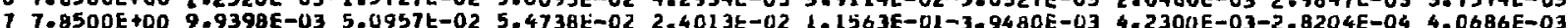
$67-8500 E+00$ 3.7457E-02 1.028IE-0 $5.2881 E-02$ C $57.8500 E+00$ 3.5380E-02 l.038BE-01 5.0445E-02 5-0687E-02 1.8971E-01-2-11941-03 1.9975E-0. $1.2181 E-045.3930 E-03$ $470500 E+00$ 3.6905E-03 5.447F-02 $37.8500 E+00-3.2317 E-02-2.1619 E-02 \quad 4.5089 E-02$ 5.6464E-02-8.0472E-03-1-3296E-03-3.3472E-03 $4.6768 E-03$ - $3.9880 E-03$ 2 7. 1 7. $1500 E+00-5.0878 E-02-1.5238 E-01$ 4.3480E-02 1.0157E-04-1.5977E-01 L.0855E-04-5.8147E-03 5.7061E-03 3.7705E-04 
055

40 7.850E+00 4.600E-01 I.000E-02-4.982E-04-5.50EE-03 6.006E-C3 2-025E-01 4. $414 E-03$ 0. 39 7.BSOE+00 4.600E-01 1.000E-02 8.8B7E-04-6.16EE-03 5.27HE-CJ J.7b9E-01 4.714E-03 0. $387.650 E+00$ 4.600E-01 l.000E-02 3.508E-03-6.664E-03 3.156E-0J 4.115E-01 4.714E-03 0. 37 7.85OE+00 4.600E-01 1.000t-02 L.939E-03-6.493E- C3 4.5S5E-C 3.485E-01 4.114E-03 0. 36 T.850E+00 4.600E-01 l.000E-02 1.950E-03-6.496E-03 4.546E-C3 3.233E-01 4.714E-03 0. $357.850 E+00$ 4.000E-0I 1.000E-02 $1.648 E-03-6.471 E-03 \quad 4.623 E-03 \quad 3.217 E-014.714 E-030$. $347.850 E+00 \quad 4.600 t-01$ 1.000E-02 $1.35 S E-03-6.330 E-0 S$ 4.976E-03 3.244E-01 4.714E-03 0. $337.850 E+00$ 4.600E-01 1.000E-02 1.989E-03-6.SO5E-C3 4.516E-C3 3.276E-01 4.714E-03 0. 32 7.BSOE+00 4.6OUE-OL 1.0DUE-02 2.71 31 7.850E+U0 4.6UUE-01 1.000E-02 l.514E-03-6.381E-03 4.862t-0J 3.663E-01 $4.714 E-030$. $307.850 E+00$ 4.600E-0I 1.000t-02 1.726E-03-6.44CE-03 4.714E-0S 3.13SE-01 4.714E-03 0. 29 7.85OE+00 4.60CE-01 1.000E-02 1.885E-03-6.48CE-03 4.59CE-C3 3.C46E-01 4.714E-03 0. $287.850 E+00$ 4.600t-01 1.000t-02 1.454E-03-6.374E-03 4.88CE-C3 2.463E-01 4.114t-03 0. $277.850 E+00$ 4.6UUt-01 1.000t-02 9.702E-04-6.197E-03 5.227E-CS 2.696E-C1 4.714E D3 U. 26 7.650E+00 4.600E-01 1.000E-02 7.628E-04-6.117E-03 S.354E-0\$ 2.846E-01 4.714E-03 0. 2b 7.650E+00 4.600t-01 1.000t-02 7.763E-C4-6.L2ZE-C3 3.346E-C3 2-b04E-01 4.714E-C3 0. $247.850 E+004.600 E-01$ 1.000E-02 $8.250 E-04-6.142$ E-03 5.31JE-C3 $2.756 E-014.114 E-03$ O.

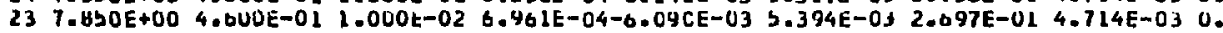
$227.850 E+00$ 4.600E-01 1.00UE-02 4.031E-04-5.964E-03 3.561E-C3 2.031E-01 4.114E-03 0. 21 7.850E+00 4.0UUE-01 1.000t-02 1.80SE-C4-5.662E-C3 5.68LE-CS 2.571E-01 4.714E-03 0.

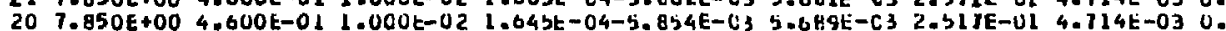
$197.830 E+00$ 4.00UE-01 l.0OUt-02 b. $040 E-04-6.043 \mathrm{E}-03$ 5.454t-0J 2-473E-01 4.714E-03 0. 18 T.850E+00 4.000E-01 1.000E-02 1.184E-03-6.214E-03 5.090E-03 2.423E-01 4.114E-03 0.

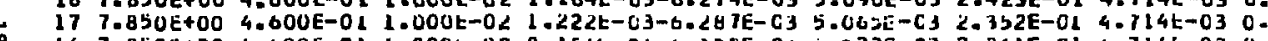
16 7.850E+00 4.600E-01 1.000L-02 0.156t-04-6.13EE-03 3.322E-C3 2.261E-01 4.714E-03 0. 13 7.85UE+00 4.00UE-01 1.000L-02 4.024E-04-5.464E-03 3.b62E-0S 2.163E-01 4.714E-03 0.

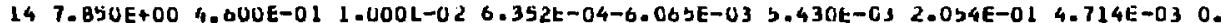

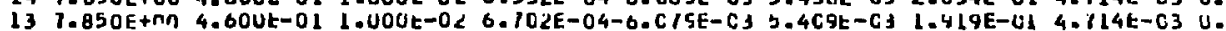
12 7.850E+00 4.600E-01 1.000E-02 6.34JE-C4-6.673E-C3 5.41EE-C3 $1.706 E-014.714 E-03 \quad 0$.

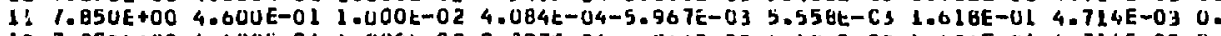

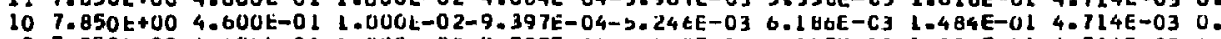
$97.850 t+004.600 t-01 \quad 1.000 t-02-4.707 E-C 4-3.227 E-036.197 t-031.3 B b E-014.714 E-030$.

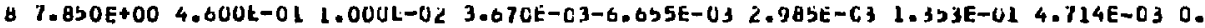
7 7.B5OE+00 4.6U0t-01 l.000E-02 5.904E-03-3.62 IE-03-2.82CE-04 1.339E-01 4.714E-03 U. $07.850 E+00$ 4.600t-01 l.00Ut-02 6.264E-0J-b.10EE-03-1.1bIE-CJ I.796E-01 4.714t-03 0.

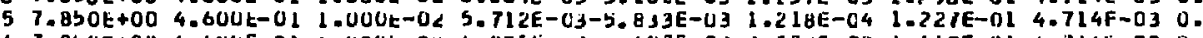

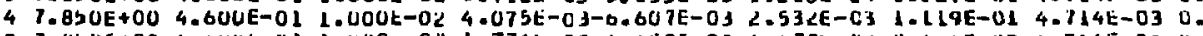

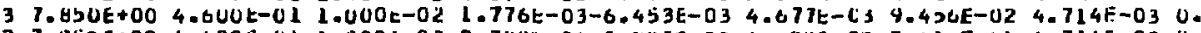

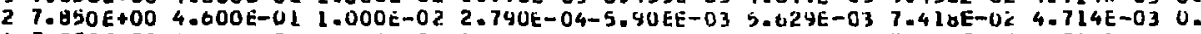

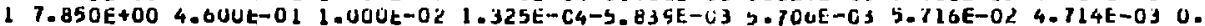

K-ELASTIC TANPHI O. 0.

$406 \mathrm{E}-05$ 1.031E-01 $2.497 \mathrm{E}-05-3.910 \mathrm{E}-01$ $4.040 E-05-4.263 E-01$ $3.229 E-05-4.409 E-01$ 3.524E-05-3.346E- Ul 4.31 $3 E-05-2.447 E-U 1$ $4.069 E-05-3.103 E-01$ 2.849E-05-1 $932 \mathrm{E}-01$ 4. 460 - $55-6-216 E-02$ 4.466E-05- $-2.216 \mathrm{E}-02$ $9.423 \mathrm{E}-05-5.813 \mathrm{E}-02$ $1.231 E-04-6.016 E-02$ $1.173 \mathrm{E}-04-7.479 \mathrm{E}-02$ T. $480 E-05-1.238 E-01$ 7.304E-05-1.959E-01 5.896E-05-2. $765 E-01$ $5.414 \mathrm{E}-05-3.480 \mathrm{E}-U \mathrm{I}$ $5.429 E-05-3.748 E-01$ $3.473 E-05-3.660 E-01$ $5.187 E-05-3.363 E-01$ 4.40TE-05-2.892E-01 $3.616 \mathrm{E}-U 5-2.295 \mathrm{E}-01$ 3.012E-05-1.839E-01 $4.719 E-05-1.919 E-01$
$6.029 E-05-2.135 E-01$ $0.495 E-05-1$. $717 E-01$ $0.681 E-05-3.146 E-02$ 8.164E-05 7.073E-02 $9.715 E-05 \quad 4.667 E-02$ $9.672 \mathrm{E}-05-3.667 \mathrm{E}-02$ 8.65AE-05-9.135E-02 $6.814 \mathrm{E}-05$ 1.159E-02 3.178E-05 1.241E+00 8.237E-06 2.316E+00 $1.896 \mathrm{E}-05 \quad 2.423 \mathrm{E}+00$ $3.087 E-0 S 1.969 E+0 U$ $3.056 E-051.452 E+00$ $3.271 E-051.125 E+00$ 4.422E-05 7.786E-OL 7.238E-05 3.613E-01 1.040E-04 6.340E-0.2 
ZHENP LIP. 01

198
TIME $5.035029 E+00$
11 LELIA-T
CCOE FILE

HEMPQG MAP

HEMPDG

J 1 SOUNO SPEED 11 I WIDTH
J

$r(R)$

$x-D 0 t$

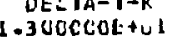

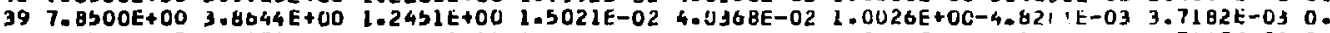
$367.8500 E+003.7459 E+00 \quad 1.2442 E+0 C \quad 1.0639 t-02 \quad 4.5693 t-C 2$ 9.9968E-0L 0.1032t-04 3.7669E-03 0. $377.8500 t+00$ 3.63 16E+00 1.2827E+00 8.6404E-03 3.2614E-02 9.9943E-01 1.3904E-04 3.5672E-015.0261E-05 0. $367.8500 t+00 \quad 3.3219 E+00 \quad 1.2972 E+00 \quad 7.3922 E-03 \quad 5.7487 E-02 \quad 1.0012 E+00-2.2508 E-03$ 1.346E-03 $2.2127 E-05$ O. $347.8500 E+00$ 3.

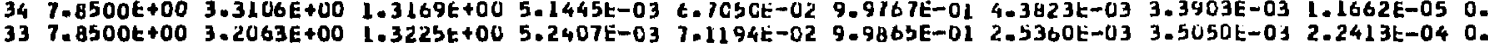
33 .

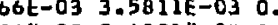
$317.8500 E+00$ 2. $395 E+00$ 1.3266t+ 00 2.76C6E-03 7.9417E-02 9.9b41E-01 1.7184E-03 3.b291E-03 0. $307.8500 E+00$ 2.0967E to0 1.3259t+00 3.0240E-03 8.24C6E-02 9.9828E-01 3.2456E-03 3.6598E-03 0. $297.8500 t+002.7939 E+00 \quad 1.3239 t+002.5464 E-03 \quad 8.4250 E-02$ 9.984SE-01 2.9267t-03 3.7U21E-03 0. $247.8500 t+002.6414 E+001.3209 E+002.2106 t-03 \quad 8.0069 t-029.9774 E-014.2583 t-03 \quad 3.7305 t-010$.

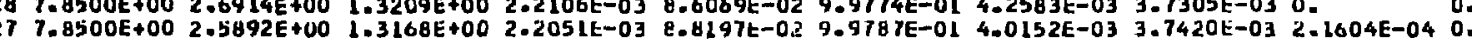
$267.8500 E+00$ 2.4872t+00 1.3117E+00 2.2412t-03 5.C148t-02 9.9950E-01 9.4027t-04 3.7365t-03 2.2151E-04 0. $257.8500 E+002.3854 t+00 \quad 1.3057 t+002.2360 E-03 \quad 5 . C 977 E-02 \quad$ L.CU26t+U0-4.7910t-03 3.71B2E-03 2.7987E-04 0. $247.8500 E+002.2437 E+00 \quad 1.2491 E+00 \quad 2.1268 E-03 \quad 9.0492 E-02 \quad 1.0055 E+00-1.00001-02 \quad 3.7013 E-03 \quad 5.3033 E-05 \quad 0$. $237.8500 E+00$ 2. $1821 E+00$ l.2920E+00 2.0959E-03 $8.9407 E-02$ L-0Ub2E+0C-1.00G0E-02 $3.6790 E-030$.

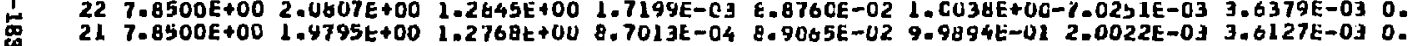

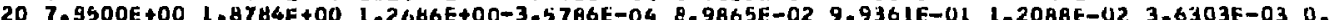
$197.0500 E+001077775+00$ l $2001 E+00-15499 E-03)$ 19 . $177.8500+00$ L $7.576 \mathrm{E}+00$ 1.25 $177.8500 E+00$ l.5768E+00 $1.2422 E+00-3.0639 E-03$ S.1137E-02 4.8337E-01 3.1796E-02 3.7328E-03 0. $167.8500 E+00 \quad 1.4765 E+00 \quad 1.2329 E+00-3.4705 E-03$ S.2565E-02 4.80SOE-01 3.7394E-02 3.7811E-01 0. $157.0500 E+00 \quad 1.3765 E+00 \quad 1.2232 E+00-4.0842 E-03$ 9.4657E-02 9.7667E-01 4.0980E-02 3.7901E-0J 0. $147.8500 E+00 \quad 1.2765 E+00 \quad 1.2131 t+00-4.7339 E-03$ S.6L7CE-02 9.7906E-01 4-0204E-02 3.6958E-03 $1.5910 E-03$ 0. $137-8500 t+00 \quad$ L. $1767 E+00 \quad$ I.2028t+00-4.6681E-03 9.5600E-02 9-8289E-01 3-2723E-02 3.4547E-03 3.5350E-03 0. $127.8500 E+00 \cdot 1.0769 E+00 \quad 1-1426 E+00-3.6165 E-03$ 9.2213E-02 9.8982E-01 1.9333t-02 3.146 $117.8500 E+009.7697 \mathrm{E}-01$ 1.1428E+00-2.2057E-03 8.7073E-02 9.9656E-01 6.4821E-03 $2.9411 \mathrm{E}-031.1196 \mathrm{E}-03$ 0. $107.8500 t+00$ 8.769be-01 l.1734t+00-1.6379t-03 8.2175E-02 9.9931E-01 1.2972t-03 2.8456t-03 0.

$97.8500 E+00 \quad 7.7699 E-01 \quad$ lo45E+00-2.8443E-03 7.7699E-02 4.96HLE-0L $0.023 L E-032.79 \forall 3 E-03 \quad 0$. $87.8500 E+00 \quad 6.7724 E-01$ L.1561E+00+5.3157E -03 7.2083E-02 9.9030E-01 1.8028E-02 2.0310E-03 0. 7 7.8SOOE+00 5.7782E-0I L.1484E+00-8.2178E-03 6.4298E-02 9.8280E-01 3.2909E-02 2.9766E-03 0. $67.8500 E+00$ 4.78 84E-01 1.1416E+00-1.0600E-02 5.5932E-02 9.7216E-U1 5-3834E-02 3.3795E-03 0. $57.0500 E+00$ 4.784E-

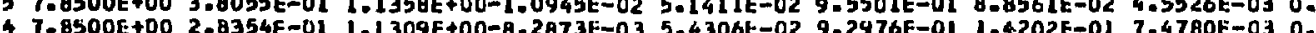
4 7.

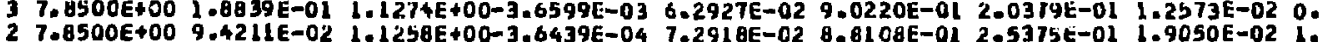

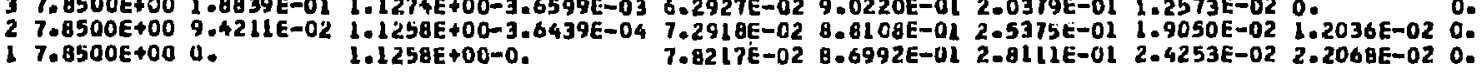
0. 0. . 


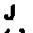
410. RHO $\operatorname{ED} \times x$ 0. 39700 T. $387.8500 E+00$ 3.6727E-02-4.7179E-02 37 7.

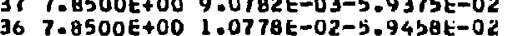
$357.8500 E+00$ 1.2960E-02-4.t.942E-02 $347.8500 E+00 \quad 7.2232 E-03-5.4047 E-02$ $337.8500 \mathrm{E}+00$ 1. $1674 \mathrm{E}-02-7.6618 \mathrm{E}-02$ $337.8500 E+00 \quad 1.1674 \mathrm{E}-02-7.6618 \mathrm{E}-02$ 32 7.85OOE +00 $2.5838 E-02-7.6<32 E-02$ $307.8500 E+00-7$. 39.39E-03-4. 1420E-02 $297.8500 E+003.8101 E-03-4.9285 E-02$ 28 T.8500E +00 b.4803E-03-6.065lt-0.2 $277.8500 t+002.6225 \mathrm{E}-03-7.6696 \mathrm{t}-02$ $267-8500 t+00 \quad 1.3877 E-03-9.3227 t-02$ 25 7-BSOOE+OD $0.4695 E-04-9.7308 E-02$ $247.8500 E+00 \quad 2.5456 E-03-8.1628 E-02$ $227.8500 E+007.0444 E-03-2.4713 E-02$ 2 : 7.8500E+00 1.1429E-02-2.5317E-02 $207.8500 E+00 \quad 1.5664 E-02-3.8343 E-02$ $197.8500 E+00 \quad 1-5320 E-02-3.2768 \mathrm{t}-02$ EOIT
VDUT/V 0.
SXXE
SYYE (1) 作 5741E-02-6.3637E-02-1.4356E-02 1-5019E-03-5.3710E-03 3.8691E-03-3.2089E-03 (1)

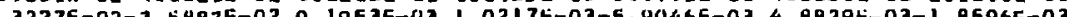

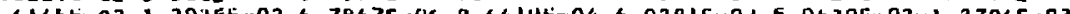
(1.3935e 4. $1669 E-02-6.431 C E-C 2 \quad 6.2553 E-C 3 \quad 1.3574 t-03-5.5642 E-03 \quad 4.2063 t-03-2.8434 E-03$ $.5145 E-02-1.0928 E-02$ 1.3454E-02-3.5844E-04-4.7891E-03 5.3476E-03-2.7223E-03 796UE-02-3.6524E-02 9.1404E-03-3-55UbE-04-5-4275E-03 5.7826E-03-2.3498E-03 9610E-02-1.854LE-U2 $1.6135 E-02$ 4.1473E-04-5.8900E-03 3.4752E-03-9.5527E-04 (1) $18265-02-2040375-02-1.027502$ 0.9570E-04-6.0005E-03 $503047 t-03-1.0093 E-03$ 6. (6.

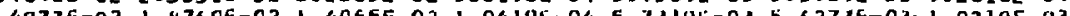
(1) (1) 作 $6.6844 E-02-2.7063 \mathrm{t}-02$ 4.4162E-02 3.88CIL-U4-5.76 L6E-03 3.3736E-03-1.4908E-03 $6.7289 E-02-2.8807 t-02$ 3.C041E-02 3.3724t-04-5.8212E-03 5-2839t-03-1.5120E-03 .7849E-02-3.3158t-02 2.4311E-02 b.1014t-U4-5.7553E-03 5.245LE-03-1.6987E-U3 17 7.8500t+00 1.2724t-02-5.7056t-02 6.8598E-02-4.1718E-02 2.4271E-02 4-6818E-04-5.6723E-0J 5.2042E-03-1.8959E-03 16 T.85UOE $+00 \quad 1.0623 E-02-6.2284 E-02 \quad 6.9635 E-02-5.0542 E-02 \quad 1.7974 E-02$ 3.5736E-04-5.1336E-0S b.1760E-03-1.8290E-03 $157.8500 t+009.8406 E-03-7.9291 E-027.0879 E-02-5.1466 t-02 \quad 1.4784 E-03 \quad 325 H E-04-5.4540 E-03 \quad 5-2014 E-03-1.3409 E-03$

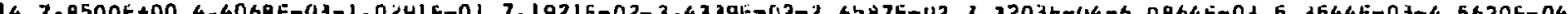
14 7.

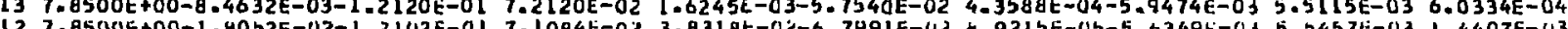
12 7. 11 7. BSOOE+00-1.37bet 10 7.8500E

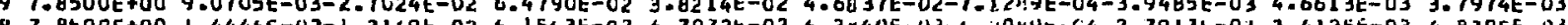
7.8SOUE+00 1.4446E-02-1.3169t-02 6.1563E-02 E.7072t-02 6.2040E-02-0.2084E-C4-2.7911E-03 3.4125E-03 4.8395E-03 $7.8500 E+00$ 2.1543E-02-1.2771E-03 5.6930E-02 9.8690E-02 7.7196E-02-5.5217t-04-1.6958E-03 2.2480E-03 5.4052E-03 7.8500E +00 3.1128E-02 2.7534E-02 5.1807E-02 6.6480E-U2 1.1047E-UL-1.1185E-U3-5.5180E-04 l.6703E-03 5.5B22E-U3 7.8SO0E+0D 2.2530E-02 6.0121E-02 4.8028E-02 2.7708E-02 4.3128E-01-2.7928E-03-3.2019t-04 1.1130t-03 4.6461E-03 7.85INOE+00-8.085ZE-03 5.51SSE-02 4.7219E-02-5.3170E-02 9-42BdE-UL-4.63L/E-03-1.8197E-03 6.4324E-03 3.6080E-04

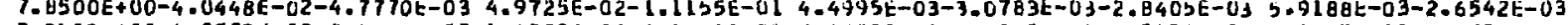
$7.8300 t+00-4.0755 t-02-8.8476 t-02$ 3.4393E-02-1.241IE-01-1.4808E-02-0.7942t-04-4.565It-03 b.4445t-03-2.775BE-03

I 7.8500t+00-2.4595t-02-1.5038t-01 5.8444E-02-6.4696E-C2-1.21 b3E-01 4.5060E-04-5.8303E-03 5.3795E-03-1.3290E-03 


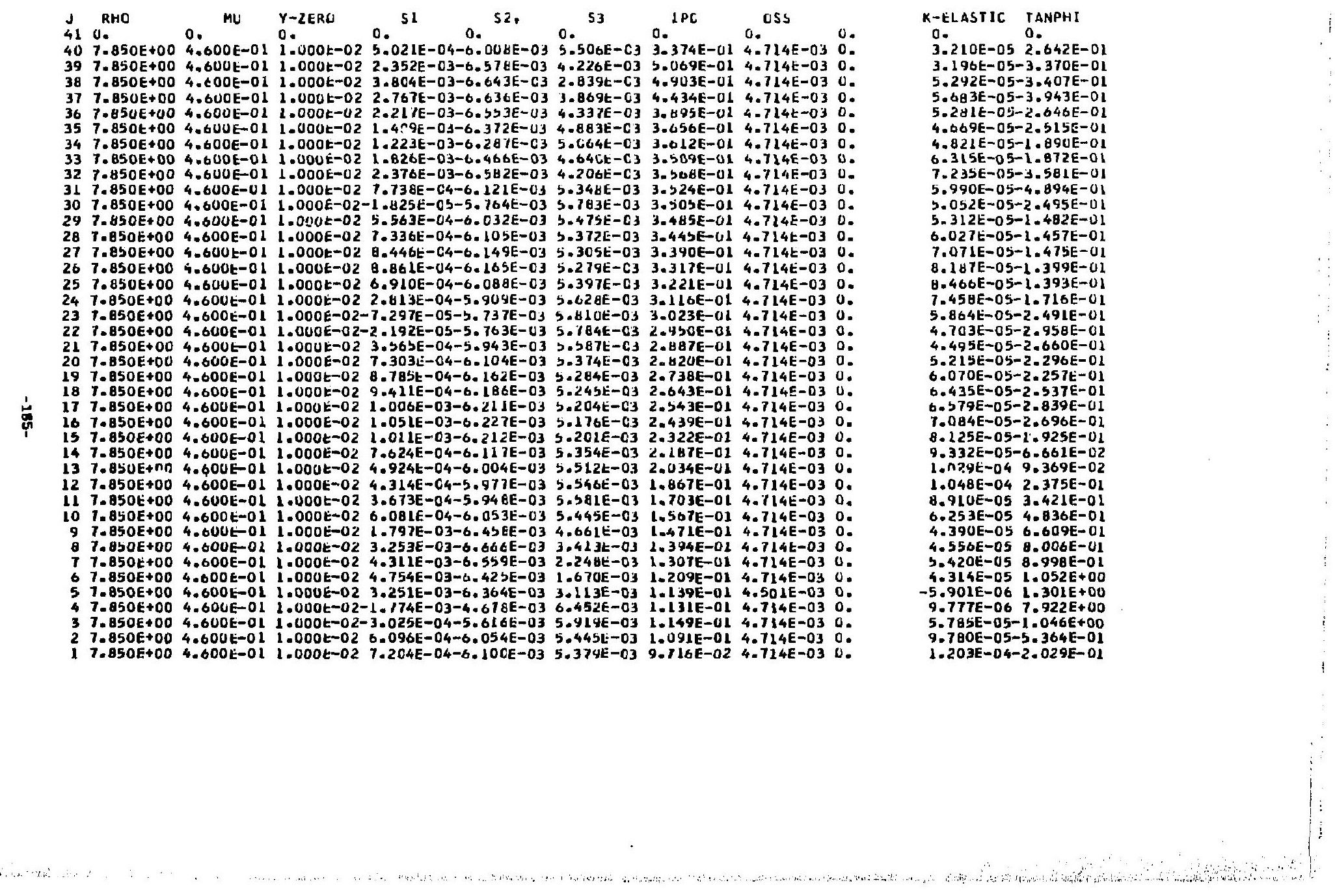


2HEMP LIP.OL

- haster (UPa IGHT) *

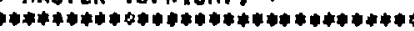

CYCLE) (K-NUMBER)

TIME

1 DELTA-T

1. 3 COCLCE +OI

3. DOO000L+OL

( SOUNC SPEEC, I 2 HIOTH,

J RHO

$x(2)$

$r(R)$

$x-00 t$

$Y$-UOT

P

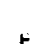

$6.493454 E-02$

4100

$4.1502 E+00$

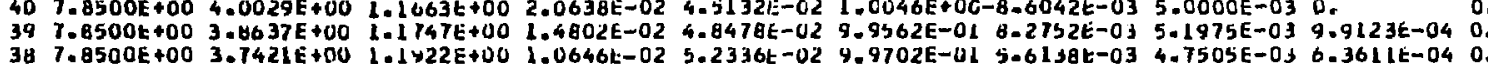

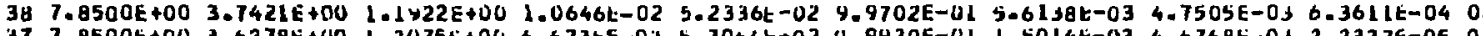

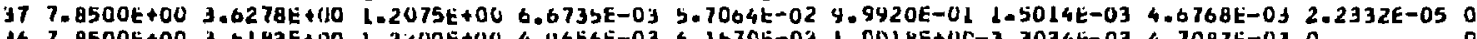

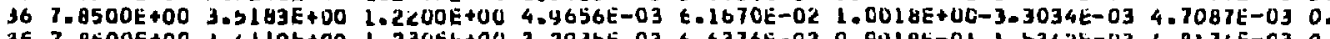

$357.8500 E+00 \quad 3-4119 t+00 \quad 1.2305 t+00 \quad 3.293 b E-03 \quad 6.6376 E-02$ 9.9418t-01 $1 . b 342 t-03 \quad 4-8174 E-03 \quad 0$.

$347.8500 \mathrm{t}+00$ 3.3078E+00 1.2 S44t+00 2.8442E-03 7.1307E-02 4.4800E-01 3.76H2t-03 4.9101E-03 0.

$337.8500 E+00$ 3.2U44E+0U $1.2437 t+00$ 2.8677E-0 $7.3236 E-02$ 4.976SE-01 4.4262E-03 5.1369E-03 0 .

$327.8500 E+00 \quad 3.1014 E+00 \quad 2.2467 t+00 \quad 2.6376 E-03 \quad 7.476 C E-02 \quad 9.9122 E-025.2414 E-03 \quad 5.2824 E-03 \quad 0$.

$317.8500 t+00 \quad 2.9985 t+00 \quad 1.2417 t+00$ 2.1785E-03 t. $2760 t-02$ 9.9S18E-U1 9.112SE-03 5.4334E-03 0.

$307.8500 E+00$ 2.8958E+00 $1.2470 E+00$ 2.3052E-03 b. $7028 E-029.9383 E-61$ 1.1680E-02 5.5580E-0S 0.

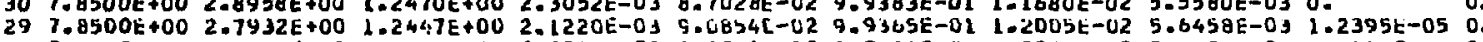

$287.8500 E+00$ 2.6909E +00 I. $241 L t+00$ 2.2200t-03 5.3961t-C2 9.942IE-01 1.0956E-02 5.6886t-03 0.111LE-04 0.

$277.8500 t+00 \quad 2.5888 E+00 \quad 1.2364 E+00$ 2.6793E-03 9.26LOE-02 9.9640E-01 6.789LE-03 5.6867E-03 6.3842E-U4 0.

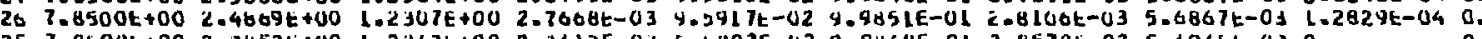

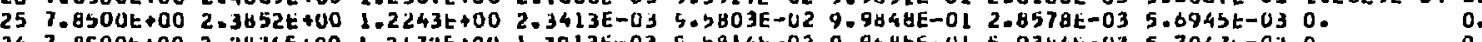

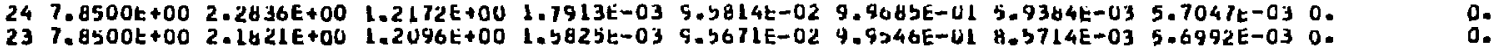

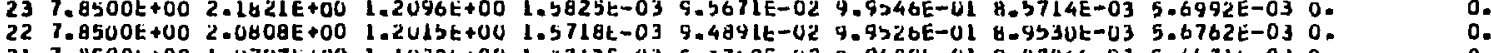

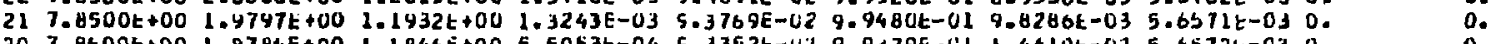

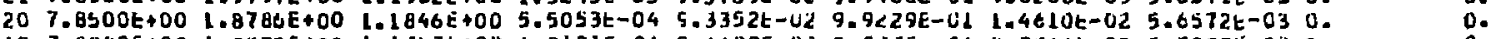

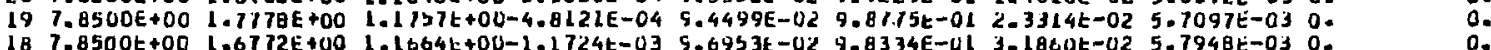

$177.8500 t+00$ l $3767 E+00$ l

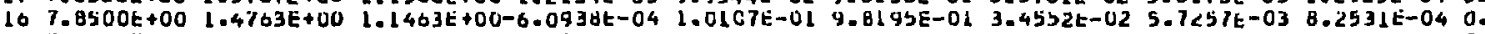

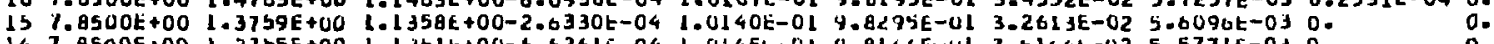

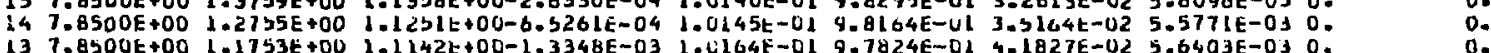

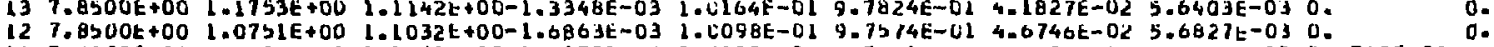

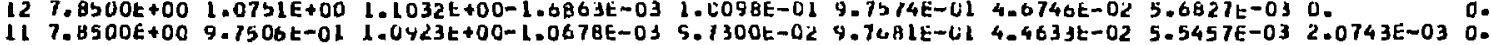

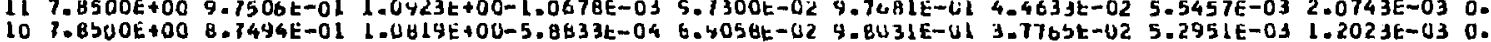

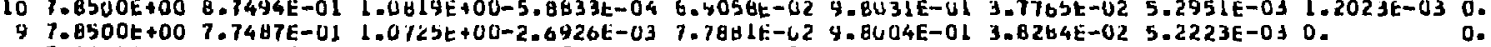

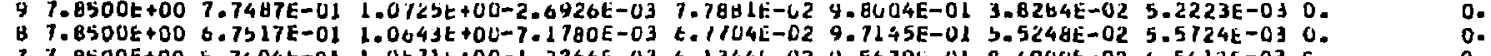

$17.8500 E+005.7604 t-01$ l.0b $51 t+00-1.2266 E-02$ 6.1344t-02 4.5679t-01 $8.4909 t-02 \quad 6.5613 E-030 . \quad 0$.

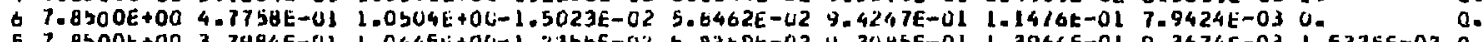

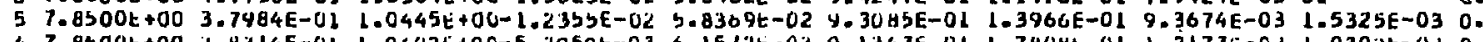

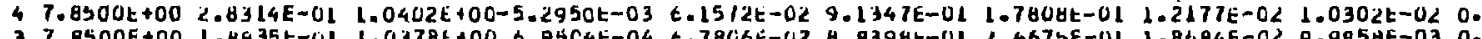

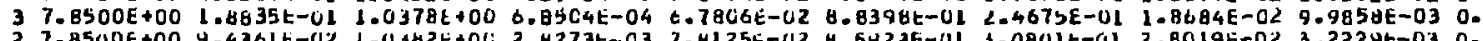

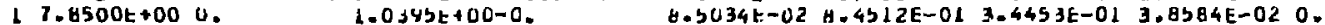


410 HHC

40 0. 0

EOXX

0 .

tory

o.

EOT T

c.

EDXY

0.

SXXE

0.

SYYE 0.

STTE TXYE 3甘 7.8b00t +00 3.5655E-02-1.0168E-01 3.8424E-02-5.3384E-02-2.7b97E-02 3.0543E-03-0.3100E-03 3.2558E-03-1.0603E-03 37 7. BSOOE +00 2. $1860 \mathrm{E}-02-7.2085 E-02$ 4.2001E-02-4.9642E-02-2.2243E-03 2.475 3E-03-6.2365E-03 3.7613E-03-1.9363E-03

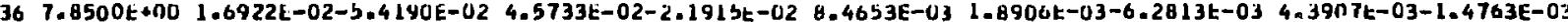

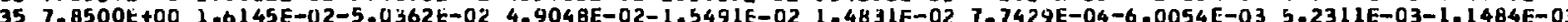
34 7. 347.002 . 33 7. 32 7. 31 7. 30 7. $297.8200 E+003.0695 E-03-1.0629 E-02$ 6.7114E-02-1.8917E-02-4-4353E-04 4.4735E-04-5.9404E-03 5.4931E-03-7.0858E-04 28 7.8500t +00 1.0754E-03-9.0831E-02 6.9336E-02-1.8450E-02-2.0440E-02 4.8239t-04-5.9696E-03 5.4871E-03-5.8733E-04 27 7.85UOE +00-2.0911E-03-4.5264E-02 7.1249E-02-1.7352t-02-2-6106E-U2 2-4926E-04-5-8941E-03 5.6048E-03-6.6294E-04 $267.0500 E+00-2.0021 E-04-8.1479 E-02$ 7.2684E-02-1.2962E-02-9.0752E-03 4-4469t-05-5.7934E-03 5.7439E-03-2.3354E-04 $257.8500 E+002.3524 E-03-6.5136 E-02$ 7.3581E-02-3.4201E-03 1.0798E-02-1-1346E-04-5.7147E-03 5.8282E-03 1.1800E-04 $247.8500 E+00$ 3.1486E-03-6.2090E-02 7.4017E-02 7.9285t-03 l-507bE-02-7-b780E-05-5.7204E-03 5.7962E-03 4-1312E-04 23 7.8500E+00 \&.0549t-04-7.0467t-02 7.4114t-02 1.6329E-02 4.4529E-03 l-4b44E-05-5.7606E-03 5.7459E-03 4.8282E-04 $227.8500 E+00$ l $0028 E-03-7.4638 E-027.4052 E-02 \quad 10743 E-02$ O 22 7

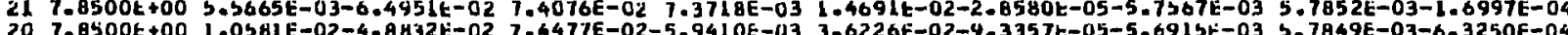

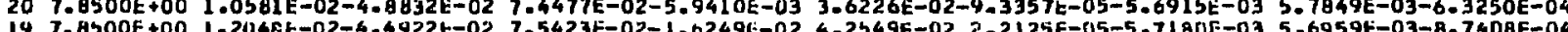
$197.8500 E+001.2048 E-02-4.4922 t-02$ 7.5423t-02-1.6249t-02 4.2549E-02 2-2125E-05-5.718UE-03 5.6959t-03-8.7408E-04 18 7. 17 7.850E $167.8500 E+00$ 1.6927E-03-9.8087E-02 8.0624E-02-3.2469E-02-1.5770E-02 3.6930E-04-5.0259E-03 5.4566E-03-1.1664E-03 15 7.8500E+00 3-2206E-03-8.7543E-02 0.2425E-02-4.15E5E-02 1.0212E-04 2. 1693E-04-5-7077E-03 5.4908E-03-1.3951E-03 14 7.8500E +00 9.8702E-03-6.84b1E-02 8.3957E-02-4.3779E-02 2-53775-02 S-3554E-06-5.6408E-03 5-6355E-03-1-2428E-03 $137.8500 E+00$ 7.5208E-03-6.4108E-02 8.4923E-02-3.3316E-02 2-8335E-02-7-4834t-05-5.7196E-03 5.7944E-03-4.3102E-04 $127.8500 t+00-3.6389 E-04-8.351 L E-02$ 8.4709E-02-4.30ESE-04 B.13bIE-04 4.8374E-05-5.7527E-03 5.7043E-03 7-1848E-04

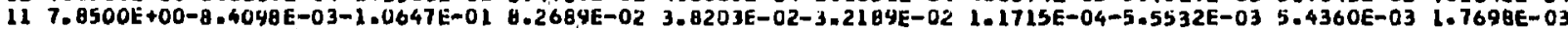
$107.8500 t+00-4.0724 t-03-9.5452 E-02 \quad 7.8582 t-02$ 6.3037t-02-2.0943E-02 4.3453t-05-4.9852E-03 4.9418E-03 2.9488E-03

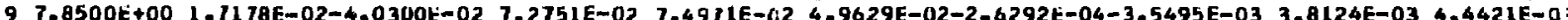
$47.0500 E+00305$ (1) 2.6890E-03 5.1036E-03 $6 \quad 7.8500 E+00$ 2.2052E-02 1.42L2E-03 5.4638E-02 1.0294E-01 1.9011E-02 b-2340E-04-4.3696E-03 3.8462E-03 4.0315E-03 5 7.8500E +00-1.3749E-02-5.2189E-02 5.1551E-02 5.8645E-02-1.4387E-02 3.7234E-05-5.5951E-03 5.5576E-03 1.4952E-03 4 7.850E+00-4.9719E-02-7.7412E-02 5.22 3 7. 5 SOE +00-5.4468E-02-0.7019E-02 5.7021E-02-1.1641E-01-6.4466E-02-2.4373E-03-2.6023 E-03 5.0397E-03-3.7786E-03 $27.8500 t+00-2.8523 E-02-3.6840 E-02$
$17.8500 E+00$ 1.295SE-02-6.9082t-02 7.2465E-02-1.49.3490E-02 1.6338E-02 3.0578t-04-5.3043t-03 4.9985E-03-2.5935E-03 
$J$ RHC

410.

$407.850 E+00$

0.

$347.650 E+00 \quad 4.600 E-01$ l.

$147.950 t+0040000$

77 7.

$367.050 E+0040005-01$ L $0005-02$ 2.

$367.850 t+004.0001-01$.

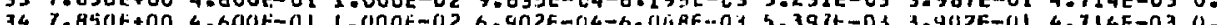
337 SSUE 00 .

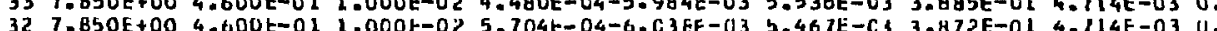
J1

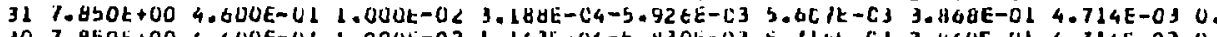

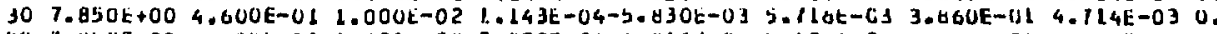

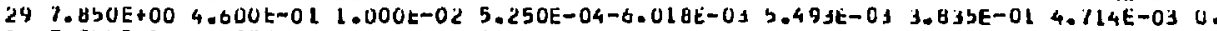

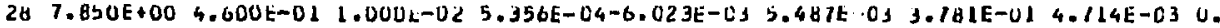

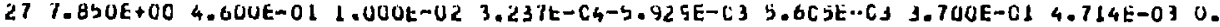

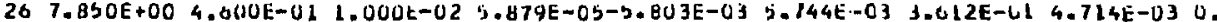

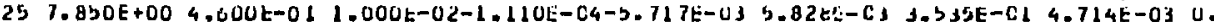

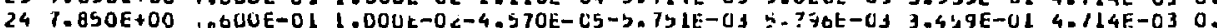
$237.850 E+004.000 E-01$ l. $000 t-025.473 E-C 5-j-00 I E-C 3$.

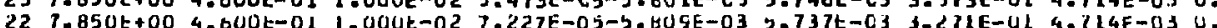
22 1.

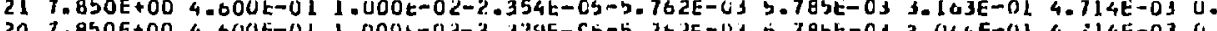
20 7.

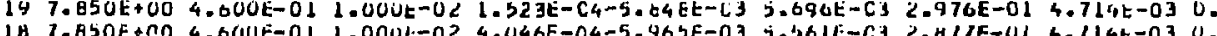
2.687E-04-6.045E-03 $2.431 E-03$ 2.012E-OL 4.714E-03 0.

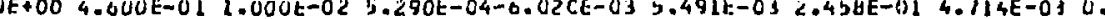

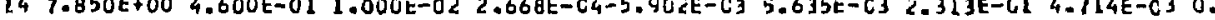

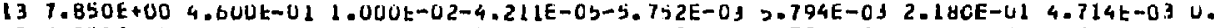

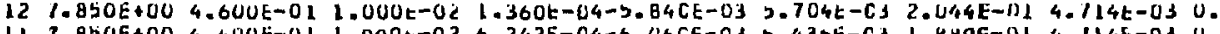

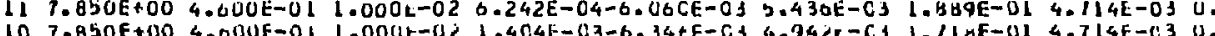

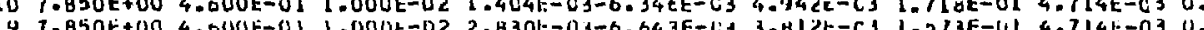

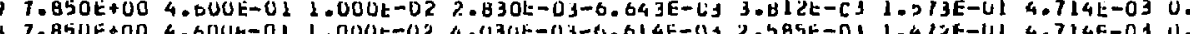

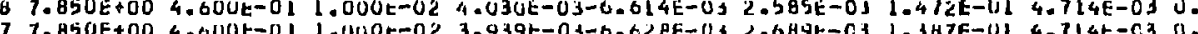

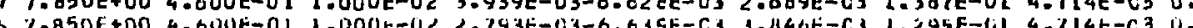

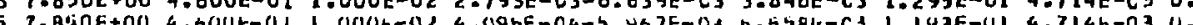
7 4 7.

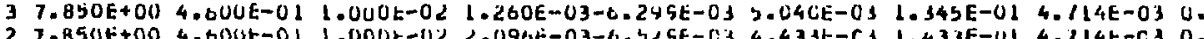

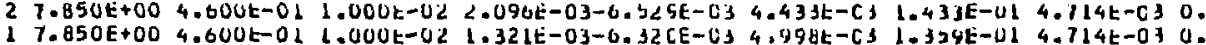

K-ELASTIC TANPHI

3.510E-05 1.881E-O 0.280E-05-1.620E-01 Q. Q.766E-OS-1.914E-O $6.647 \mathrm{E}-05-2.122 \mathrm{E}-0$ S.OL $4.859 E-05-1.648 E-C 1$ $5.025 E-05-1.226 E-C$ . 15 R $05-1.359 E-0$ $3.132 t-05-1.830 E-0$ $5.25 b t-0 b-2.400 E-0$ 2. 711E-05-1.819E-U $6.955 E-05-1.096 E-01$ $8.326 \mathrm{E}-05-9.024 \mathrm{E}-\mathrm{U2}$ $8.691 \mathrm{E}-0 \mathrm{~S}-7.445 \mathrm{E}-02$ 7. 8 100E-05-3. $091 \mathrm{E}-0$ $0.927 \mathrm{t}-052.106 \mathrm{E}-02$ 6.927 -05 2.l $06 E-0$ 6.79E-0S 1.280E-U 7.332E-OS 8. 303E-02 1. 6.92JE-05-2.965E-02 $6.035 E-05-1.116 E-01$ $3.934 t-05-1.489 E-0$ r.nate-05-1.477t-0 $6.666 E-05-1.533 E-0$ 4.545E-05-1. B49E-O $9.163 t-05-2.237 E=01$ 8.122E-Db-2.104E-D 7.D2SE-UY-7.392E8 b96t-O5 L.220E-UI - . $14 E-042.865 E-U 1$ $9.469 E-05$ 4.615E-OI 0.2 IIE-05 $6.403 E-01$ 6. $4.614 E-05$ O $509 E-01$ 4.5 C 3. $130 \mathrm{C}-05$ S.6Re 3. $444 E-05$ 2.490E-UL $6.940 E-05-3.544 E-U$ $9.408 \mathrm{E}-05-9.784 \mathrm{E}-0 \mathrm{I}$ $1.035 E-04-8.220 E-0$ B.4I IE-05-3.91SE-O 
ZHERP LIP.O

- Slave (UPRIghII

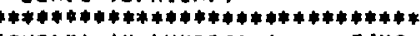

(CYCLE) (K-NUMBER) । T IV

$11 x^{*}$

11 DELTA-T

1 I DEL TA- 1-K

1. 300 OCOOE +OL

1 [ELSA-T-J

RHO $-115.035024$

3.876C9SE-C2

3. CUUOOOE tol

SOUNC SPEEC
$5.635747 t-01$ WIDTH
$0.493454 E-02$

410.

$x(2)$

$Y(R) \quad x-D O T$

$r-00 T$

vere status

$6.0831 E+00$ 1.2U12E+00 5.1088E-0 $15.3315 \mathrm{E}-02$ $4.9701 E+00$ 1.2012t+0D 3.0815E-01 5.3315t-02 4.5S62E+0O 1.2012E+OC 2.3432E-OI 5.3315E-02 $4.2704 E+001.2012 E+00 \quad 1.9859 t-015.3315 t-02$ $4.0241 E+001.1713 t+001.6579 t-018.0445 t-02$ $3.8178 E+00 \quad 1.1 \mathrm{U1} 3 \mathrm{E}+00 \quad 1.2820 \mathrm{E}-01 \quad 3.3499 \mathrm{E}-02$ $3.6433 t+00$ L.2US4E +OC $1.1122 t-01 \quad 4.2663 t-02$ $3.4832 E+00 \quad 1.2234 E+001.0018 E-01$ 3. $3946 E-02$ $3.3331 E+00$ 1.2365E+00 9.1281E-02 6.3343E-02 $3.1904 E+00 \quad 1.2441 E+00 \quad 0.4125 E-02 \quad 7.3435 E-02$ $3.0 b 33 E+00 \quad 1.2472 E+0 C \quad 7.7342 E-02$ E.CC35t-U2 $2.9207 E+00 \quad 1.2472 E+00 \quad 7.0873 E-02 \quad 8.6604 E-L$ 2.7921E+00 1.2447L+00 6.4897L-02 9.3184E-02 $2.6667 E+00$ 1.2400t+0U 5.9121E-02 9.7025t-02 2.5444E +00 1.2339E +0C 5.35C0E-02 9.6557t-02 $2.4249 E+00$ 1.2268E+00 4.8057E-02 9.671 7E-02 $2.3077 E+00 \quad 1.2189 E+00 \quad 4.2847 E-02$ 5. $4660 \mathrm{OE}-02$ $2.1925 E+00 \quad 1.2104 E+00 \quad 3.7631 E-02 \quad 9.4395 t-02$ $2.0192 E+00 \quad 1.2014 t+0 C \quad 3.2561 E-02 \quad 4.7415 t-02$ $1.9677 E+00 \quad 1.1922 E+00 \quad 2.7549 E-02 \quad 9.5953 t-02$ $1.4578 E+00 \quad 1.1828 t+00 \quad 2.2674 E-02 \quad 9.5572 t-02$ $1.7493 E+00 \quad 1.17 J 1 E+00 \quad 1.7674 E-02 \quad 9.6911 E-02$ $1.6422 E+00 \quad 1.1630 E+D C \quad 1.2494 E-02 \quad 5.9204 E-02$ $1.5364 E+O D \quad 1.1525 E+007.0146 E-03 \quad 1.00+8 E-01$ $1.4318 E+001.1417 t+001.4162 E-031.0142 t-U 1$ $1.3284 E+00$ 1. $1307 E+00-4.7802 E-03 \quad 1.0096 E-01$ $1.2203 E+001.1197 t+00-1.1547 E-021.004 \mathrm{CE}-01$ $1.1254 \mathrm{E}+00$ 1.10a7e+00-1.8768E-02 9.9419E-02 $1.0257 E+00$ 1.0978E+00-2.6752E-02 $9.6429 E-02$ $9.2729 \mathrm{E}-01$ 1.0673E $+00-3.6112 \mathrm{E}-02 \quad 8.9814 \mathrm{E}-02$ 8.3018E-01 1.0777E+00-4.5908E-02 8.COBLE-02 $7.3447 E-01 \quad 1.0692 E+00-5.624 \mathrm{BE}-02 \quad 6.4701 E-02$ $0.4021 E-01$ 1.06L7E+00-6.659LE-02 $\quad=1397 t-02$ $3.4732 E-01 \quad 1.0351 t+00-7.4932 t-02 \quad 5.6385 E-02$ $4.5613 E-01 \quad 1.0491 E+00-7.5531 E-02 \quad 5.4733 E-02$ $3.6913 E-01 \quad 1.0440 E+00-5-3401 E-02 \quad 5.6829 E-02$ 2.8727E-01 $10404 E+00-2.3211 E-02,6.0637 E-02$ $2.1058 E-01 \quad 1.0384 E+001.9682 E-03 \quad 6.6472 E-02$ $1.3850 E-01 \quad 1.0340 E+00$ 1.7464E-02 $7.3285 \mathrm{E}-02$ $\begin{array}{llll}1.3850 E-01 & 1.0340 E+00 & 1.7464 E-02 & 7.3285 E-02 \\ 6.9264 E-02 & 1.3966 E+00 & 1.3796 E-02 & 7.4827 E-02\end{array}$ $\begin{array}{llll}6.9264 E-02 & 1.9966 E+00 & 1.3796 E-02 & 7.9827 t-02 \\ 0 . & 1.495 E+00 & 0 . & 8.5034 t-02\end{array}$ NO VCIO RELTINL AD VOIC RUUTIAL ho VEIO ALUTINE AC VCID AOUIINE NO VEIU RGUTINE NO VOIC ROUTINL NO VCIO RUUT IME AC VCIO ACUTINE AO VGIO ACUTINE AO VOIC RGUTINE NO VCJU RCUTINE AC VCIO RCUTINE NO VOLO RGUTJNE hO VOLC Rourline Ad Vole Rourine AC VCIC RCUTINE NU VOID RCUTIRE ho VCIC RCUTJNE AC VCIL RCUTIAE AC YCIC RCUTINE NC VOIO ROUTINE ND VCIC RCUT INE RO VEIG RUUTINE RU VCIU RCUTINE MO VOIO RGUTINE MO VOC ROUT INE AL VCIU RGLITNE AL VCIU RCUIINE NO VEII) ROUTINE NO VCIC RCUTINE AO VEIC ROUTINE AC VCIL RGUTINE NO VDCO RQUT INE NO VDIO ROUT INE NU VOLL ROUT IME AL VOLL AOUT INE NO VOID ROUIINE NO VCIC ROUTINE MU VCIO ROUT INE MO VCIO ACUTINE NO VCID RGUTINE 


$$
x(2)
$$

YIRI DELTA-T
3.876095E-O

1 DELIA-T-K

3.00QUOOE +

3.635797E-01

$6.493454 \mathrm{E}-02$

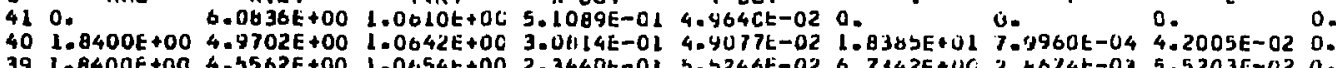
$392.8400 E+004.3562 E+00 \quad 1.0654 t+00$ 2.3440E-01 $3.3246 E-02 \quad 6.7342 E+U C$ 2.64/4E-03 $5.5203 E-02 \quad 0$. 38 1.8400E+00 4.270IE+00 1.0381E+00 1.9920E-01 2.4449E-02 4.7508E+00 4.4126t-03 6.0602t-02 0. $371.8400 t+00 \quad 4.0243 t+00 \quad 1.0525 t+00 \quad 1.6378 E-01 \quad 3.389 C t-02 \quad 4.029 \quad+00 \quad 3.5242 t-1336.3738 t-02 \quad 0$.

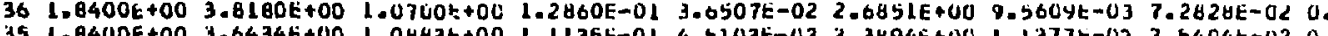
$351.8400 E+00 \quad 3.6434 t+00$ 1.06t3t+00 L.1135t-0L 4.\$103t-02 2.3894E+00 1.1377t-02 7.5404t-02 0. $341.8400 E+00 \quad 3.48 j 3 E+00 \quad 1.1015 E+00 \quad 1.0020 E-01 \quad 5.4679 t-02 \quad 2.3323 E+00 \quad 1.1704 t-02 \quad 1.5675 t-02 \quad 0$. 33 L. $8400 t+003.3333 E+00$ L.1LUTE+0C $9.1399 E-02 \quad c .2246 t-02 \quad 2.2936 t+00 \quad 1.2084 t-02 \quad 7.3809 t-02 \quad 0$.

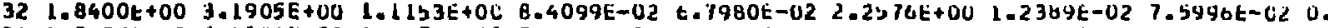
$31 L .8400 E+00 \quad 3.0534 t+00 \quad 1.1173 t+00 \quad 7.7362 t-02 \quad 7.24 C 5 E-02 \quad 2.2 L 12 t+00 \quad 1-2826 E-02 \quad 7.6326 t-02 \quad u$. $30 \quad 1.8400 t+00 \quad 2-9207 E+00 \quad 1.1 .166 t+00 \quad 7.0912 t-02 \quad 7.5645 t-02 \quad 2-153 \theta E+00 \quad 1-3434 t-02 \quad 7.6924 t-02 \quad 0$. $291.840 U t+002.7921 E+00 \quad 1.1144 E+00 \quad 6.48 C 9 E-U 2 \quad 7.03585-022.0470 t+001.4302 t-02 \quad 7.7668 t-02 \quad 0$.

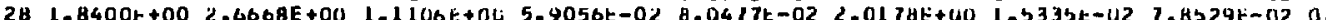

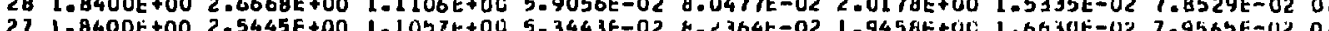
26 1. 25 1.8400E

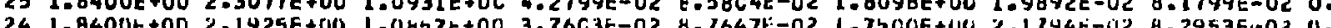

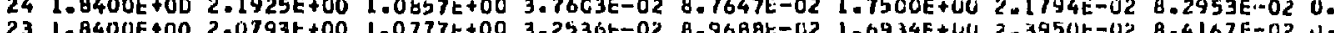

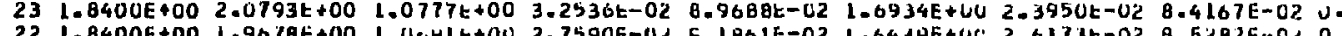

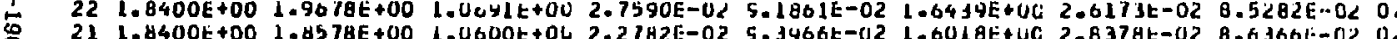

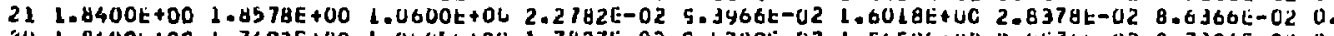
$201.8400 t+00 \quad 1.7493 E+00$ 1.0bUSt+0U $1.7827 t-02 \quad 9.5709 t-02 \quad 1.5650 t+00 \quad 3.057 t t-02 \quad 8.7394 E-02 \quad 0$. $19 \quad 1.8400 t+00 \quad 1.6422 t+00 \quad 1.0405 t+00 \quad 1.2687 E-02 \quad 9.6795 t-02 \quad l .5 J 00 t+40 \quad 3.2940 E-02 \quad 0.8450 E-02 \quad 0$.

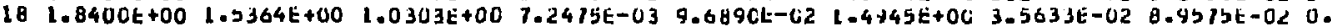

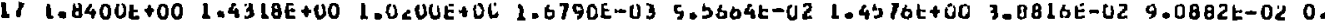

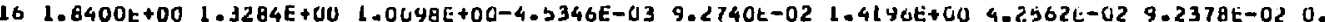

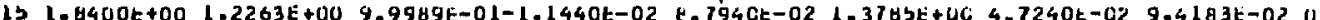

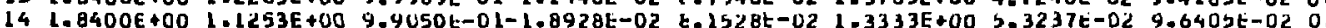

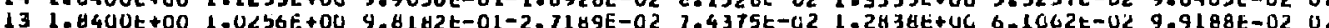
13 1.

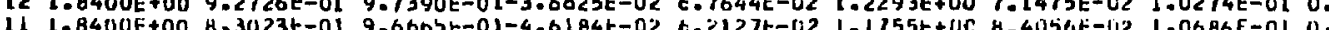
11 1.

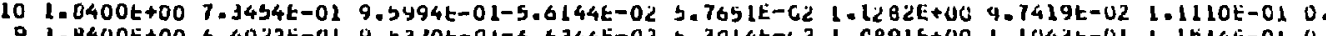
(1.

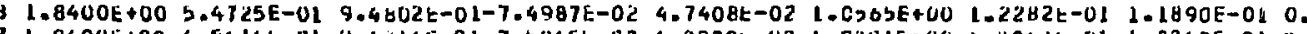
$11.8400 E+00$ 4.5016t-0I 4.4316E-01-7.5045t-02 4.3970t-02 1.0201E+00 1.3803E-01 1.2362E-01 0.

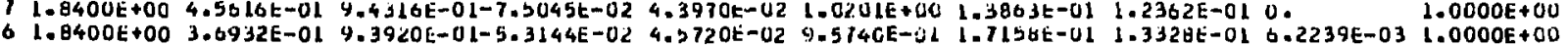

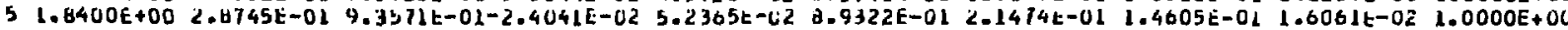

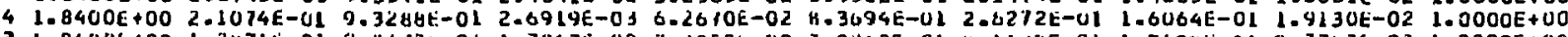

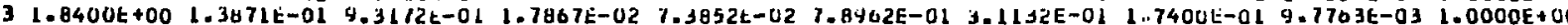
$21.8400 t+00$ b.9578E-02 $9.3196 t-01$ 1.3b63t-02 0.1281E-02 7.6301E-0L 3.4300t-01 1. $3308 E-010$.
1 L. $3400 E+000$.

$4 . J \angle 2 O E-0 I-C$

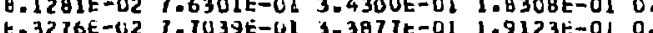
$1.0000 E+00$ 1. $0000 E+00$ $1.0000 E+00$ $1.0000 E+00$ 1. $0000 E+00$ 1. $0000 E+00$ $1.0000 E+00$ $1.0000 E+00$ $1.0000 E+D O$ $1.0000 E+\cup O$ $1.0000 E+D D$ 1. $0000 E+00$ $1.0000 E+00$ 1.0000E + DO 1. $0000 E+00$ $1.0000 E+00$ 2. $0000 E+00$ l. $0000 E+00$ 1. $0000 \mathrm{E}+00$ $2.0000 E+00$ $1.0000 E+00$ $1.0000 \mathrm{E}+00$ 1.0000E+ $1.0000 E+00$ $1.0000 E+0 O$ $1.0000 E+00$ $1.0000 E+00$ $1.0000 E+00$ $1.0000 E+00$ 1. $0000 E+00000$ 1. ONODE+O $1.0000 E+00$ I. OOOOE + UO 
$Y(R)$

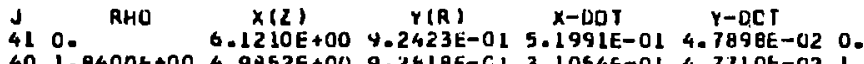

1 DELIA-1-K

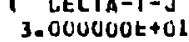

$5.635797 E-01$

$6.493454 \mathrm{E}-02$

$401.8400 t+00 \quad 4.9852 E+00$ 9.261日E-C L $3.1054 E-01 \quad 4.7710 t-02 \quad 1.7934 E+01$ U.242Ut-04 4.2235E-02 U.

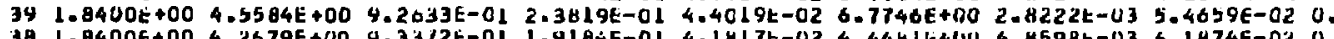

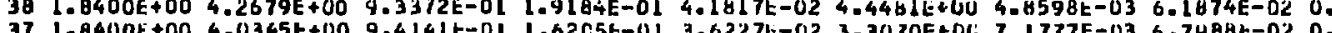

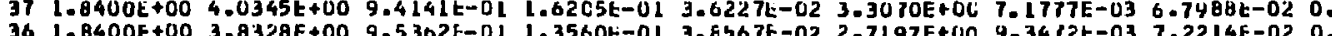

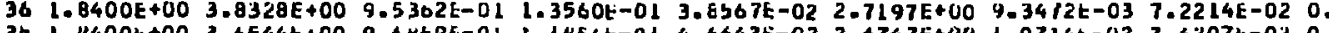
$3 b 1.3400 t+00$ 3.6544t+00 9.6639t-01 1.1654t-01 4.6643t-02 2.4747t+00 $1.0714 t-02 \quad 7.4207 t-02 \quad 0$. 34 1.8400E+00 3.4913E+00 9.7908E-DI 1.06ELE-01 5.3152E-02 2-3659E+00,1-1480E-02 7.5102E-02 U. 33 1. $8400 E+00$ 3.3380E+00 9.8553E-01 9.6845E-02 5.4232k-02 2.2996E+00 1.2003t-02 7.5563E-02 0. $321.8400 t+00 \quad 3.1926 E+00 \quad 9.8448 t-01 \quad 8.8539 E-02 \quad 6.4226 E-02 \quad 2.2319 t+00 \quad 1.2624 t-02 \quad 7.6194 E-02 \quad 0$. $31 \quad 1.8400 t+00 \quad 3.0532 t+00 \quad 9.9050 t-01$ 8.1023E-02 $6.8261 t-02 \quad 2.1635 t+00 \quad 1.3353 t-02 \quad 7.6866 t-02 \quad 0$. $101.840 U E+00 \quad 2.4189 E+00 \quad 9.8975 E-01 \quad 7.4050 E-02 \quad 7.1847 E-02 \quad 2 . C+77 t+00 \quad 1.4168 E-02 \quad 7.1603 E-02 \quad 0$.

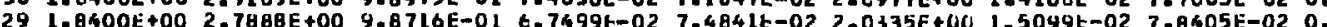
201002 . 27 27 Lat 26 L.8400E+00 2.41

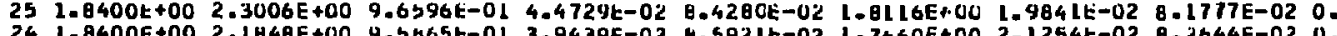

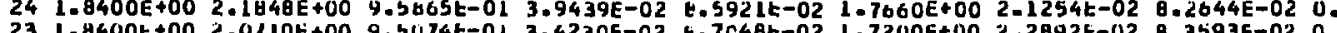

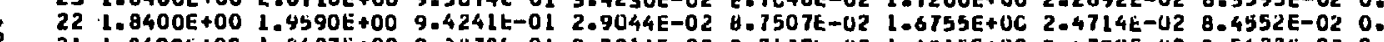
$21 \quad 1.8400 E+00$ 1.6497E+00 9.3378E-01 2.3811E-02 0.7139E-02 1.6315E+00 2.6799E-02 8.5622E-02 0. $201.8400 E+00$ 1.7399E+00 9.2503t-01 1.8271E-02 E.5849k-02 1-5861E+00 2-9292t-02 8.6839E-02 0.

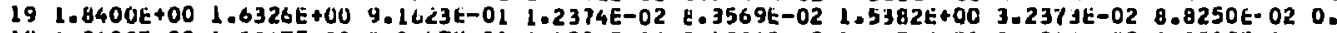

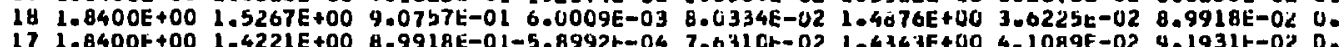

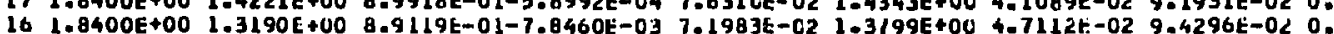
$151.8400 E+001.2171 E+00$ g. $360 E-01-1-5800 E-02$ e.7770E-02 $103244 E+005-4595 E-029.705 \theta E-020$.

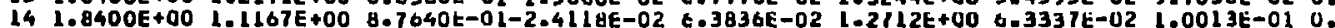
13 L 1 8400t+00 $1.0175 t+00$ 0.6458t-01-3.2777E-02 6.0025E-02

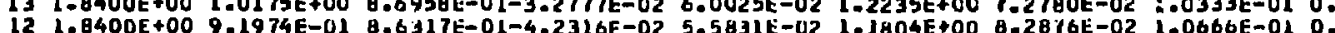
11 2. 11 1.

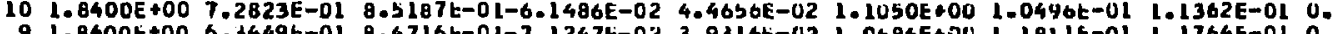
9 1.8400E+00 6. 8 I. $1400 E+00$ 3.4204E-01 B.4297E-01-7.8367E-02 3.6631E-U2 1.C334E+0D L-326EE-01 1.2201E-01 U. $71.0400 E+00$ 4.5161E-01 $8.3900 E-01-7.1161 E-02$ 3.6739t-02 9.9654E-01 L.5064t-01 1.2735t-01 0. 6 1.8400E+00 3.6526E-01 8.3486E-01-4.4296E-02 4.4540E-02 9.4245E-01 1.0081E-01 1.3630E-01 1.3551E-02 5 1.8400E+00 2.8428E-01 8.3041E-01-1.0595E-02 5.2451E-02 6.8337E-02 2-2113E-01 1.4473E-01 2.6081E-02 4 1.8400E+00 2.0923E-01 $4.2799 t-01$ 1.5653E-02 6.0525E-02 H-2492E-01 2.7446E-01 1.6432E-01 2-3015E-02

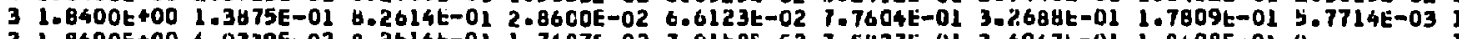
$21.8400 E+00 \quad 6.9739 E-02$ 8.2bl4t-01 1.7687E-02 7.0Lb8E-c? 7.5B37E-01 3.4947t-01 1.8608E-01 0.

0.

$1.0000 E+00$ $1.0000 E+00$ $1.0000 E+00$ 1. $0000 E+00$ $1.0000 E+00$ $1.0000 E+00$ $1.0000 E+00$ $1.0000 E+00$ $1.0000 E+00$ 1. $0000 E+00$ $1.0000 E+00$ $1.0000 \mathrm{E}+00$ $1.0000 E+100$ $1.0000 E+00$ $1.0000 \mathrm{E}+00$ $1.0000 E+00$ 1. 0000E + OO 1. $0000 E+00$ $1.0000 E+00$ $1.0000 E+00$ 1.0000E + 00 $1.00003 E+00$ 1. $0000 E+00$ $1.0000 E+U O$ $1.0000 E+U U$ $1.0000 E+00$ $.0000 E+40$ $1.0000 E+00$ $1.0000 E+00$ $1.0000 E+00$ - .000E +00 $.0000 E+00$ 1. 0000E+00 $1.0000 E+00$ $.0000 E+00$ $1.0000 E+00$
$.0000 E+00$ $.0000 E+00$
$.0000 E+00$ $.0000 E+00$
$.0000 E+00$ 1. ODOOE +00 1. $0000 E+00$ 
atist 1 I IME 1 UELIA-T
$3.676095 E-62$

1 I DEL TA-T-K

I UELTA-T-J I I SOUN

HEMP UG MAP

HEMPUG

RHO

$x(2)$

Y(R)

$x-001$

$Y-C G 1$

3. UOUOOUE+01 S.63S747E $=02$

$0.493454 E-02$

410.

$6.1350 E+00 \quad 7.6378 t-01 \quad 5.2420 E-01 \quad 3.9378 E-020$.

$\checkmark$

0.

0.

0.

40 1.8400E+00 4.948BE+00 $7.9617 E-01$ 3.1189E-01 4. U628E-02 1.7370E+02 $4-4744 E-044.2343 t-02 \quad 0$. 39 I 37 L.

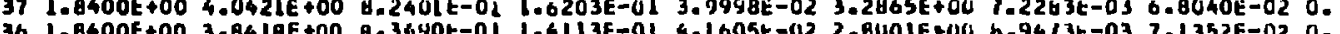
36 L.8400E+00 3.8418E+00 6.3440t-01 l.4l13E-01 4.1605t-02 2.8U01E+00 b.94/3t-03 7.1352E-02 0.

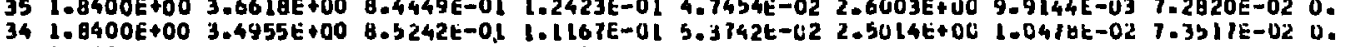
$331.8400 \mathrm{0}+00$ 3.3401E+00 6.5/52E-01 1.0112t-01 5.8324t-02 2.4046t+00 1.111bt-02 7.4245t-02 0.

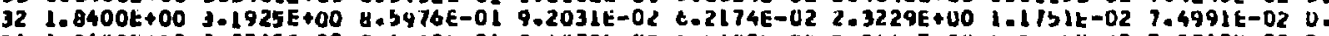

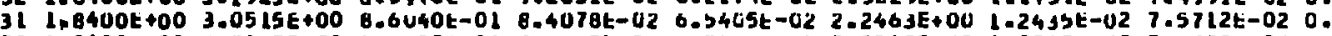

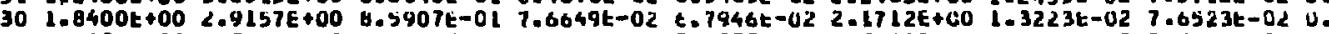
29 1.8400t+00 2.7444E+00 U.5633t-01 6.9757t-02 7.0075t-02 L.C499E+00 l.4049t-02 7.1143t-02 0. 28 1.8400E+00 2.6569E+00 H.5274E-0\} 6.3466E-02 7.1663E-U2 2.C332E+0U I.5067t-02 7.8L94E-02 U. 27 I.8400t+00 2-3327t+00 8.4616E-01 5-7480t-02 7.2434t-62 1.96f0E+0C 1-6184t-02 7.9120t-02 0.

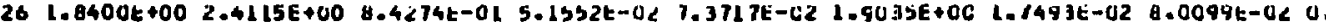

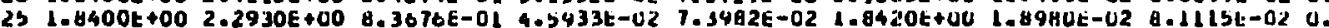

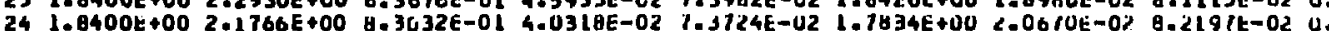

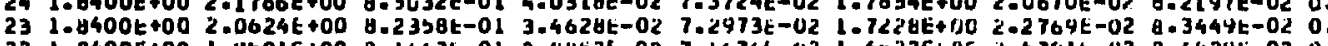

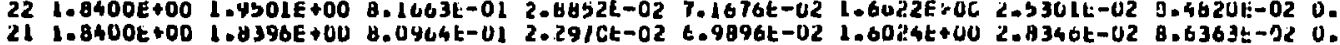

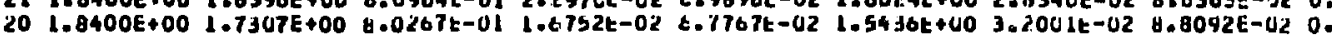

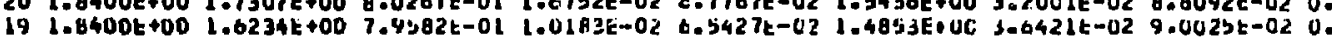

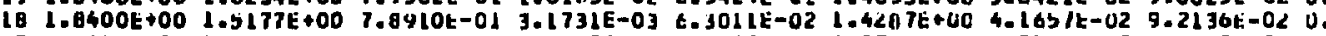
$171.8400 E+00$ 1.4134E +00 1.8CS4E-01-3.4662E-U3 t.0340E-02 1.374LE+CO 4.77SOE-02 9.4b07t-02 0.

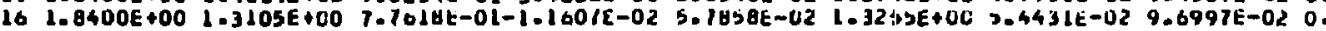
is I.8400t+00 I.2030E+00 1.7610t-01-1.4934t-02 3.4608t-C2 1.2714E+06 6.18/3E-02 9.9628E-02 0.

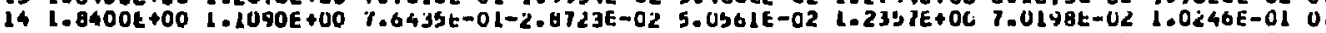
13 L.84U0E+00 L.0LU4E+U0 7.5405E-01-3.7828t-02 4.5479t-02 1.191,SE+U0 7.9372t-U2 1.0349t-01 U.

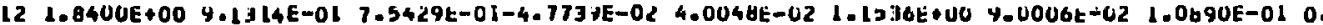

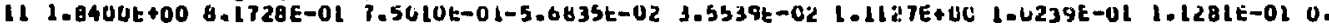

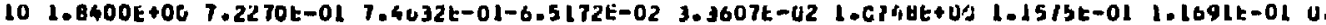
9 I. $0400 E 000$ O. 1

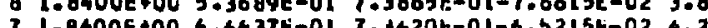
16llt-01 2.2443t-02 1.0000E+00

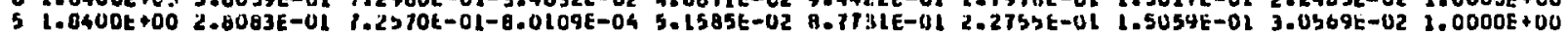
$41.8400 t+00$ 2.0 PO9E-01

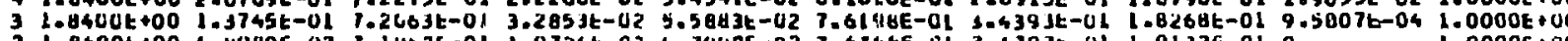
2 1. $4400 t+00$ G.4480E-02 T.1432E-01 1.9726t-02 5.7UUGE-02 T.4THEE-01 3.6397t-01 1.9132E-01 0. 1 I. $8400 E+00 \mathrm{U}$. $7.1419 E-C 1-C$.

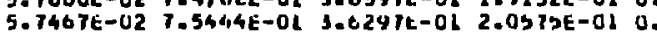

1. 00 COE + OD 
1 DELTA-I-R , I CELIA-1 CCCE FILE

HEMPOG HAP

HEMPOG EN) 1

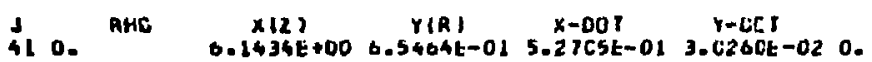

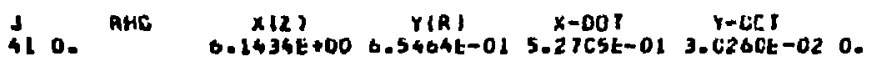

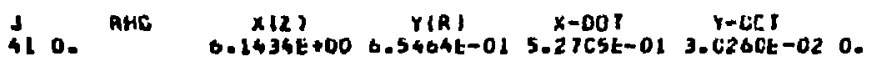

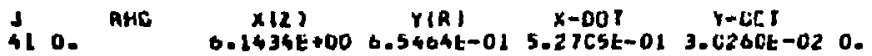

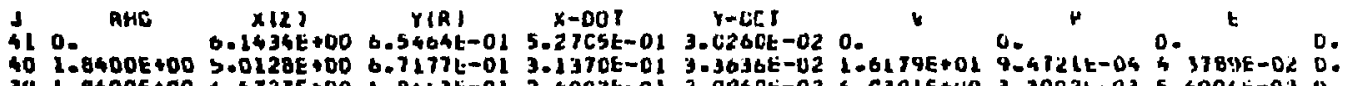

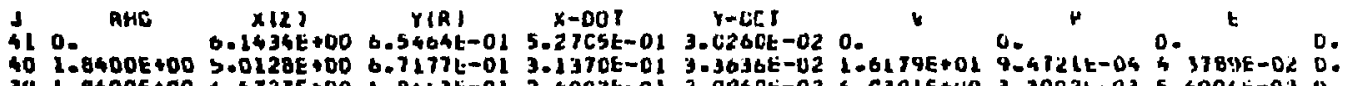

DEL Th- I-R
1. 3COCLOE+CII

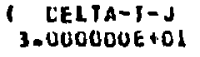

SDUNC SPEEL
S.635797E-OI

6. 2 W10IH $341.8400 E+00$ T.ST2IE+00 $6.8463 E-012.4003 t-012.9960 E-026.6301 E+00 \quad 3.3002 E-03 \quad 5.6904 E-02 \quad 0$.

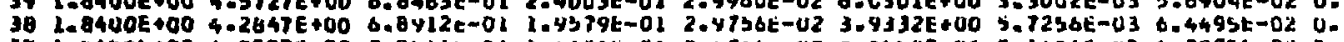

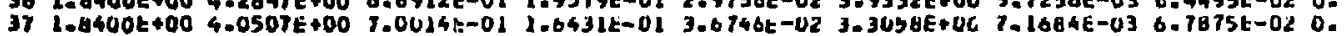

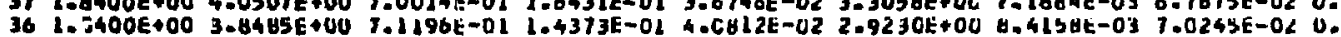

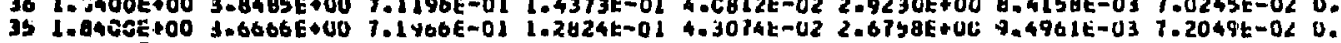

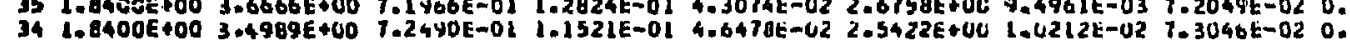

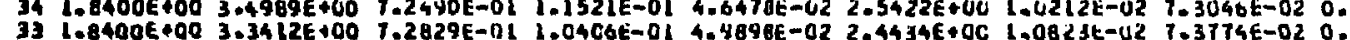

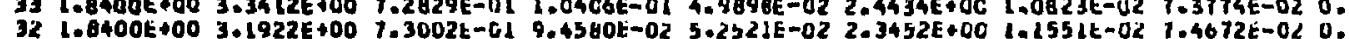

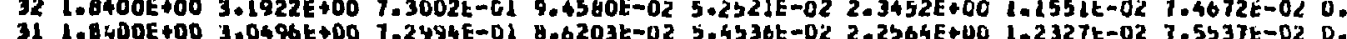
31 L.8400E+00 1.04\%t +00 1.2494E-01 8.6203t-02 $5.4336 t-02$ 2.2364E+00 1.2327t-02 7.5337t-02 D.

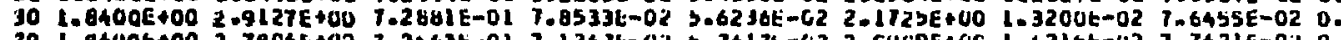
29 I.84U0E+00 2-7804t+00 7-2043t-01 7.1247t-02 3-7417t-02 2.C409E+0C 1-42LSt-02 7.7421E-02 0.

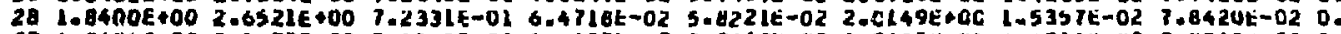

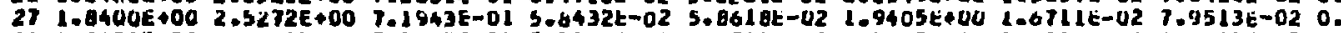

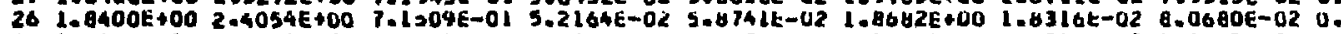

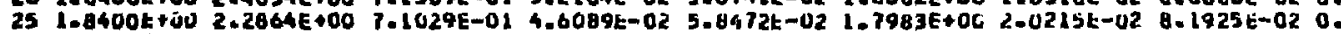

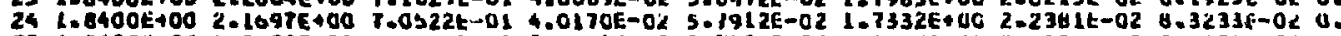
23 1.8400E+00 2.0552E+00 6.9493E-01 3.406LE-02 5.7124E-02 1.468SE+00 2.5023t-02 0.4696t-02 9.

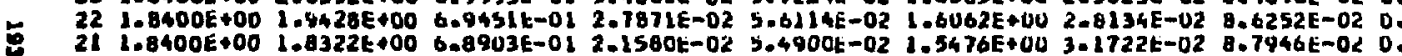
$201.8400 E+00 \quad 1.7234 E+00$ G.8 $357 E-01$ 19 I. 19 1.040E 17 I. 17 1.6400E+00 1.4065E+00 6.6779t-01-7.05RTE-03 4.6273t-02 1.3424E\$00 5.1924t-02 9.6030t-02 0. 16 l.6400E400 2.3039E+00 6.6302E-01-I.5284E-02 4.2280E-02 1-2970E+0C S-866IE-02 9.8542ti-02 0.

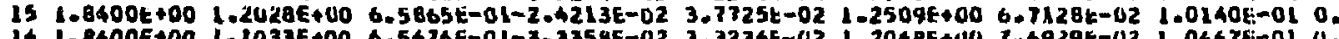

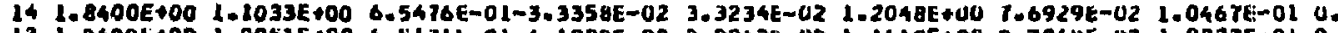

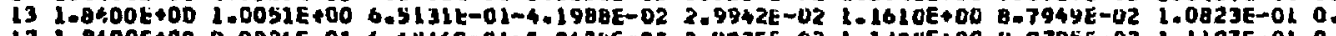
$121.8400 E \bullet 00$ 9.0826E-21 6.4414E-01-5.0428E-02 2.4075E-02 $2.1204 E+06$ 4.9795E-02 1.1197E-01 0.

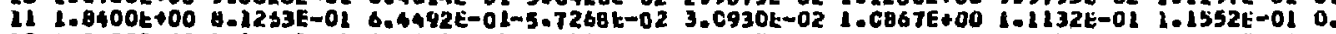
$101.6400 E+00$ 7. $1799 E-01$ 6.414LE-01-6.3146E-02 3.4717t-02 1.0619E+00 1-2072t-01 1.1437E-01 0.

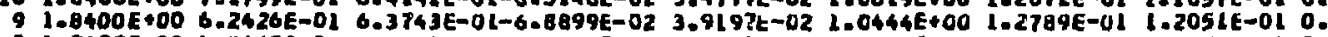

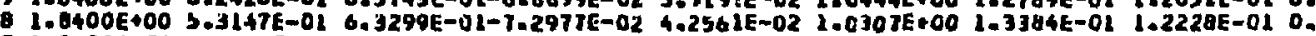

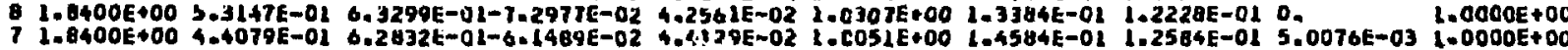

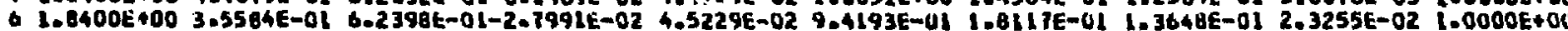

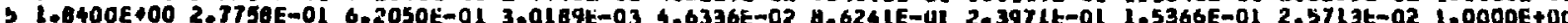
1 . 31.0400500 20 3500501 $31.8400 E+001.3590 E-01$ 6.1599E-01 3.2634E-02 4.4980E-02 7.4692E-01 3.6342t-01 1.8828E-01 0.

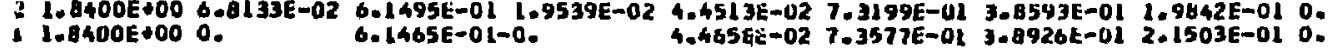
1. $0000 E+00$
$1.0000 E+00$

0.

1. 0000E + DO

$1.0000 E+00$

1. OOUNE +00

$1.0000 E+40$

$1.00 C O E+00$

1. 00 COE +00

$1.0000 E+00$

$1.0000 \mathrm{E}+00$

1. 0000E + UD

2. $00005+00$

1. $0000 \mathrm{E}+00$

L. OODOE+UO

$1.0000 E+00$

L. DODOE + 00

1.000UE + U0

$1-0000 E+00$

$1.0000 E+00$

$1.0000 E+00$

$1.0000 E+U 0$

$1.0000 \mathrm{E}+00$

$1.0000 E+00$

1. DOOOE + DO

1.0000E+00

$1.0000 E+00$

1.0000E +00

$3.0000 E+00$

1.0JDOE+OD

$1.0000 E+O D$

. J000E $\$ 00$ 


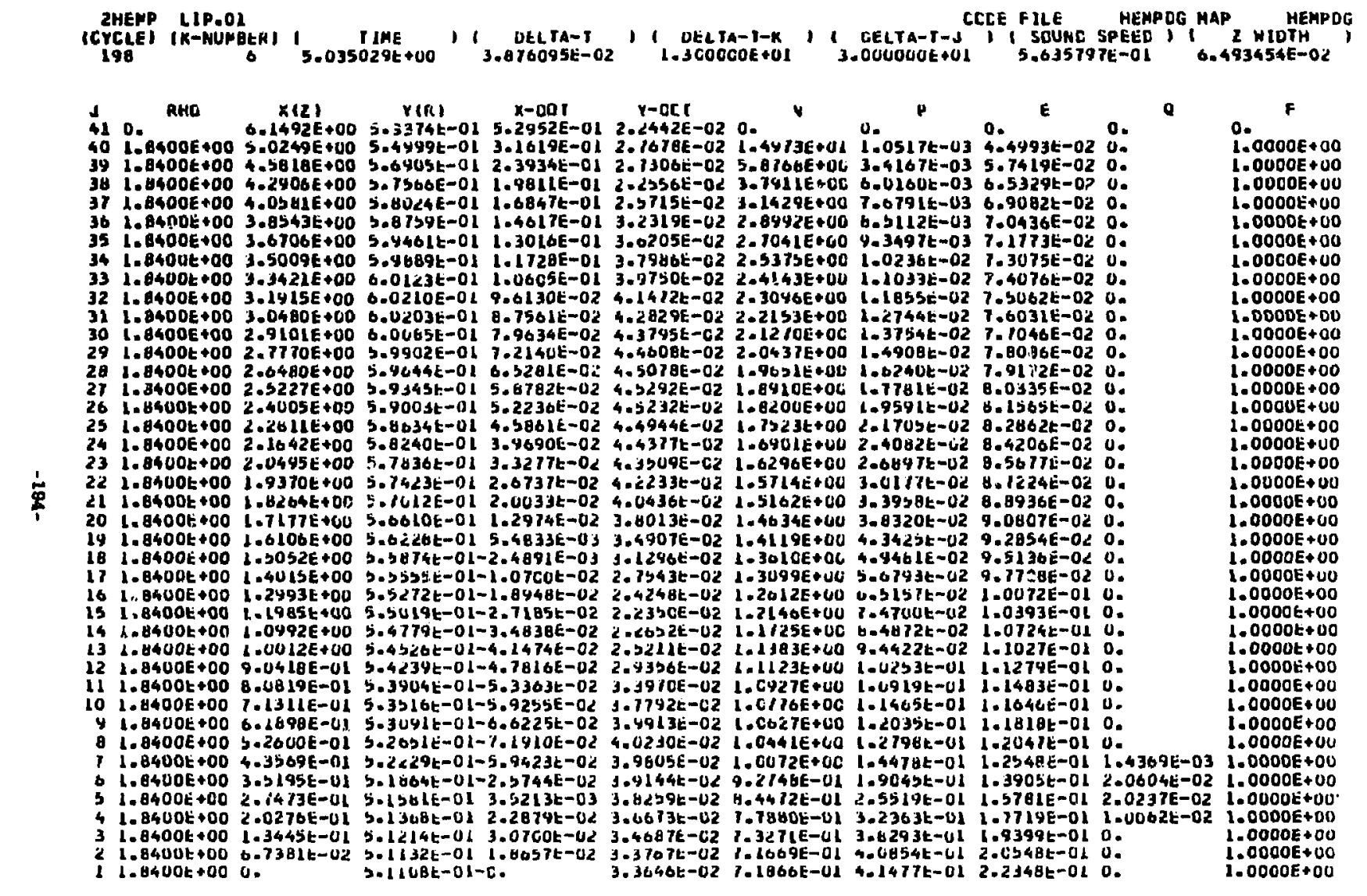


4 RHC

410. $x(2)$ $Y(R)$ $x-D 0 T$ $Y-0 C 1$ 40 L. B400E+00 $6.1525 E+00 \quad 4.1960 \mathrm{E}-015.3130 \mathrm{E}-01 \quad 1.5614 \mathrm{E}-020$. (1) 39 1.8400t+00 4.5420E+00 4.5295E-01 2.3909t-01 2.32 30t-42 5.73BOE+00 3.52B6t-03 5.7901E-02 0. 38 1. $3400 E+00$ 4.2964EtON 4.6418E-01 1.4744E-01 2.0176E-02 3.8148E+UU 5.9638E-03 6.5187E-02 0. $371.8400 t+004.0618 t+004.6762 t-01 \quad 1.7051 E-01$ 1.6334E-02 3.CS2SE+00 6-0600t-03 6.9951E-02 0.

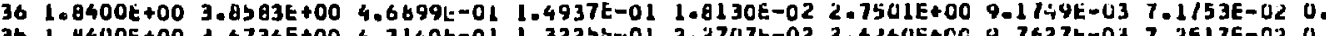
35 1. $-4400 E+00$ 1.6734E+00 4.7140t-01 1.322bt-01 2.2707t-02 2.6260E+CC 4.7627t-03 7.2517E-02 0. 34 1.8400E +00 3.5025E+00 4.7391t-01 1.1873E-01 2.01b1t-02 2.509LE+0U 1.0418t-02 7.3366E-02 0. 33 I. $8400 t+00$ 3.1423t+00 4.7542t-01 L.0730t-01 2.7989t-02 2.3874E+00 1.1234t-02 7.4366t-02 0.

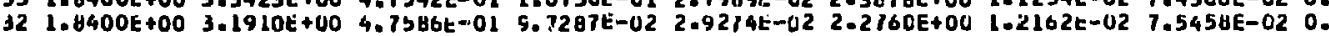
31 I. $8400 E+00$ 3.0465E+C0 4.7bG3E-01 B.B388E-02 3.0268E-J2 2-1793E+00 1-3142E-02 7.6489E-02 0.

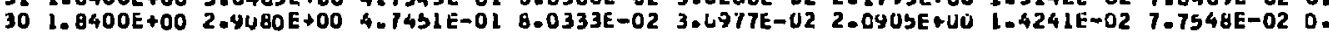
$241.8400 E+002.7743 E+00$ 4.7298E-01 $7.2642 t-02$ 3.1365E-02 2.0U72E+0C 1.5503E-02 7.0633E-02 0. $281.8400 E+002.6449 t+00 \quad 4.1112 L-016.5575 E-02$ 3.1564t-02 1.9289E+0C 1.6954t-02 7.9761E-02 0.

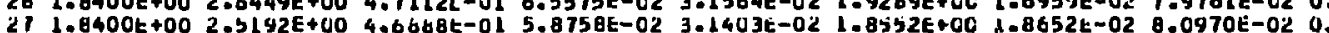

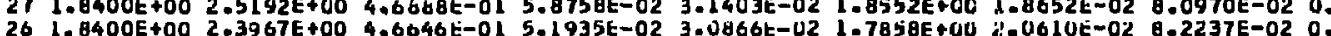

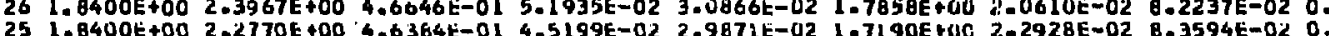

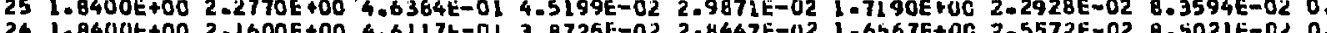
24 1.84UUE +00 2.1600E+00 4.6117E-01 3.8725E-02 2.8447E-02 1.6567E+0C 2.5572E-02 $9.5021 E-02 \quad 0$.

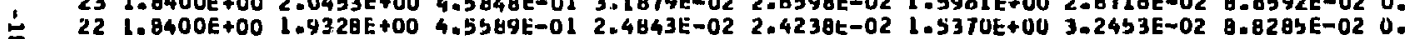

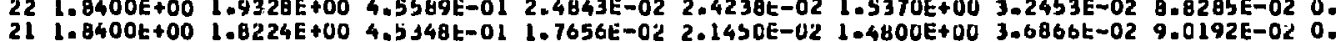
$201.8400 E+00$ 1.7L38E+00 4.513LE-01 l.0187E-02 1.8413E-02 1.4247E+00 4.2010E-02 9.233bE-02 0. $191.8400 t+00 \quad 1.6070 E+00 \quad 4.4941 E-01 \quad 2.502 \theta E-03 \quad 1.5685 E-021.3711 E+00 \quad 4.0203 t-02 \quad 9.4701 E-02 \quad 0$.

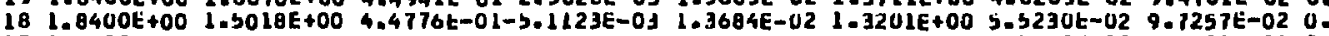
$171.8400 t+00$ 1.3983E+00 4.4626E-01-1.2372E-02 1.3215E-02 1-2725E+00 6-3093E-02 1.0001t-01 0. $161.8400 E+00$ 1.2963E+00 4.4474E-01-1.9190E-02 1.4690t-02 1.2317E+00 J-1022E-02 1.02IIE-01 0. $151.8400 t+00$ 1.1955E+00 4.4300t-01-2.5664E-02 1.7914E-02 1.1977E+00 7.8600Em02 1.0519E-01 0. $141.8400 E+00$ 1.0460E+00 4.4090t-01-3.1564t-02 2.2333t-02 1.1707E+00 \&-5332Em -02 1.0736E-01 0. $131.0400 t+00$ 9.9755E-01 4.3430E-01-3.7199t-02 2.7116E-02 1.1303E+00 9.0916t-02 1.0912E-01 0.

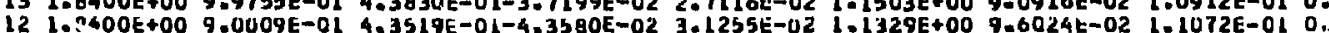
11 L 10 1. 10 1.0400E+00 7.0823E-01 4.2790E-01-5.7410E-02 3.5396E-02 1.0962E+00 1.0793E-01 1.1437t-01 4

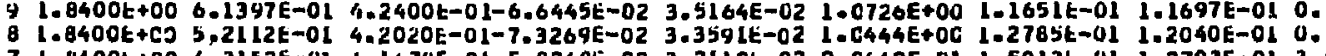

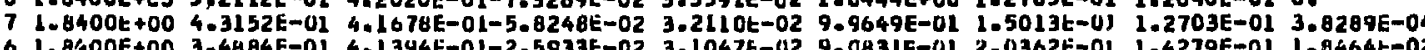
6 1.8400E+00 3.4684E-01 4.1344E-01-2.5933E-02 3.1047E-02 9.083LE-01 2.0362E-01 1.4279E-01 1-8464E-02

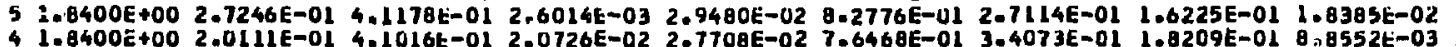

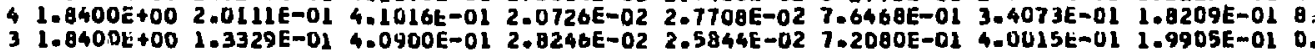
2 1.8400E+00 6.6789E-02 4.0437E-01 1.7525E-02 2.4811E-02 7.0389E-01 4.2844E-01 2.1159E-01 0.

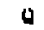
4
0.

1. 0000E+ OO 1. 0000E+UO $1.0000 E+00$ $1.0000 E+0 D$ 1. $0000 \mathrm{E}+00$ $1.0000 E+00$ $1.0000 E+00$ $1.0000 E+U 0$ 1. $0000 E+00$ i. 00DOE +00 1. $0000 E+00$ 1. $0000 \mathrm{E}+00$ $1.0000 E+00$ 1. $0000 E+00$ $1.0000 \mathrm{E}+00$ $1.0000 E+00$ $1.0000 E+00$
$1.0000 E+00$ $1.0000 E+00$
$1.0000 E+00$ $1.0000 E+00$
$1.0000 E+00$ $1.0000 E+00$ $1.0000 E+00$ $1.0000 E+00$ $1.0000 E+0$ (1 1. $0000 \mathrm{E}+00$ $1.0000 E+00$
$1.0000 E+00$ $1.0000 E+00$ 1.0000E + 00 1. 0000E+ $1.0000 E+00$ $1.0000 E+00$ $1.0000 E+00$
$1.0000 E+00$ - 0000E+O气 1.0000E+00 1. $0000 E+00$ $1.0000 E+00$ 


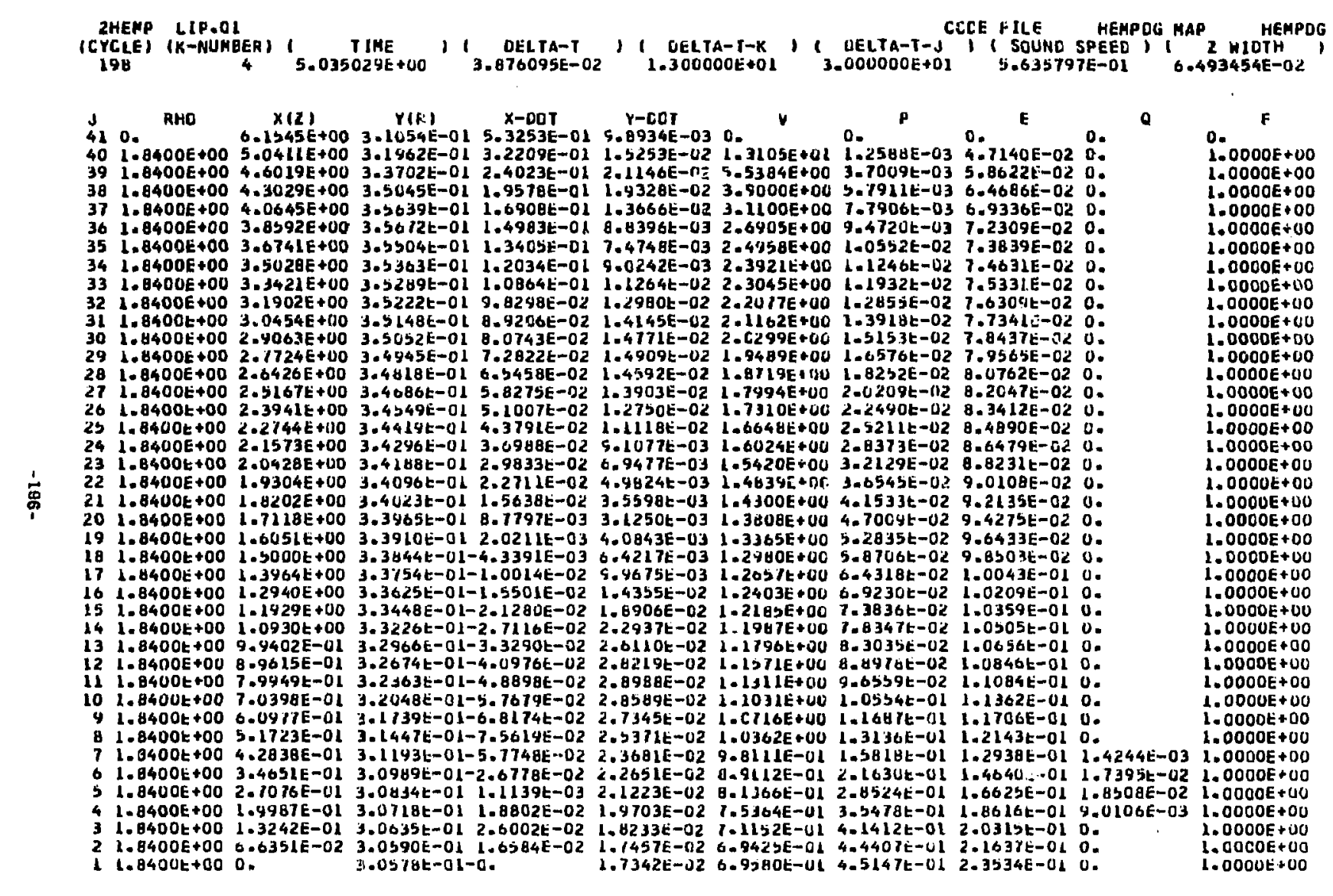


2HENP LIP.OI

CECE FILE

HEMP DU MAP

HEMPDL (CYCLE)
198

$J$

RHO

$x(2)$

$Y(R)$

$x-00 t$

$r-n D T$

b. $1555 E+00$ 2.0S24E-01 5.3327E-01 5.5794E-03 0.

$v$

u.

40 1.8400E+00 5.0453E+00 2.1069E-01 3.243bE-01 5.4406E-03 1.2438E+01 l-3419E-03 4.7983E-02 0. $391.8400 E+00$ 4.6098E+00 2.2289t-01 2.4205E-01 1.4979t-02 5-3100E+00 3.9164t-03 5.9492E-02 0.

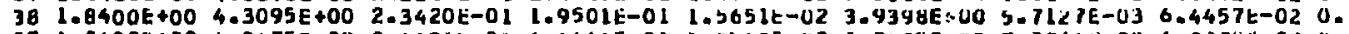
37 1.8400E +00 4.0675E+00 2.4101E-01 1.6664E-01 l.2342E-02 3.2833E+00 7.2346E-03 6.803JE-02 0. $361.8400 E+00 \quad 3.8595 E+00 \quad 2.4303 E-01 \quad 1.4738 E-01 \quad 7.6972 t-03 \quad 2.8322 E+00 \quad 6.7911 t-03 \quad 1.1016 t-02 \quad 0$.

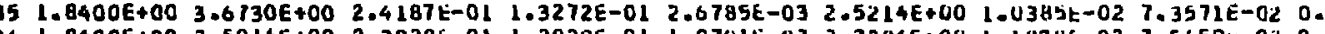
34 I. $8400 E+00$ 3.50 L4E+00 2.3928E-01 1.2029E-0I-1.0701E-03 2.3204E+00 1-1834E-02 7.5459E-02 0. $33 \quad 1.6400 t+003.3407 E+002.3653 E-01 \quad 1.09 C 6 E-01-2.9444 E-03 \quad 2.1912 E+00 \quad 1.3072 t-02 \quad 7.6745 E-02 \quad 0$. $321.6400 E+003.18 \theta 9 E+002.3432 E-01$ 9.901bE-02-3.3621t-03 2.CO19E+0C 1.4241t-02 7.7117tE-02 0.

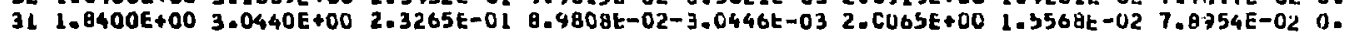

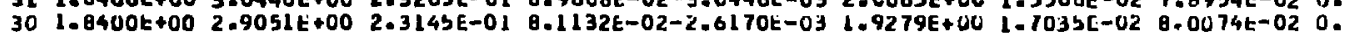
$291.8400 E+002.7710 E+002-3053 E-017.2735 E-02-2-4980 E-03 \quad-8529 E+00$ 1-8759E-02 8.1258E-02 0. $26 \quad 1.8400 t+002.6413 E+00 \quad 2.2964 t-01 \quad 6.5060 t-02-2.4061 E-03 \quad 1.7819 t+00 \quad 2.0713 t-02 \quad 0.2 b 15 E-02 \quad 0$. $271.8400 E+002.5153 E+00 \quad 2.2925 t-015.7515 t-02-3.4368 t-03 \quad 1.7146 t+00 \quad 2-3133 t-02 \quad 8.38765-02 \quad 0$. $261.8400 E+002.3928 E+00 \quad 2.2683 E-01 \quad 4.9984 E-02-4.2094 E-03 \quad 1.61322 E+00 \quad 2.5822 E-02 \quad 8.5308 E \cdot 020$. $231.8400 E+002.2732 E+002.2639 E-01 \quad 4.2568 E-02-4.9177 E-03 \quad 1.5434 E+00$ 2.8968E-02 8.5B18E-02 0. $241.8400 E+002.1363 E+00 \quad 2.2651 E-01 \quad 3.5740 E-02-5.4194 E-03 \quad 1.5397 E+00 \quad 3.2305 E-02 \quad 0.8375 E-02 \quad 0$. $231.8400 E+002.0418 E+002.2855 E-012.8871 E-02-5.6429 E-03$ 1.4B96E+00 3.6099t-02 9.0016E-02 0.

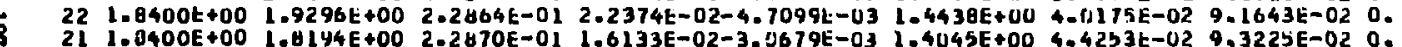
$201.8400 E+00$ 1.7110E+00 2-2864E-01 1.0402E-02-5.2906E-04 1.3717E+00 4-8134E-02 9.4700E-0 0.

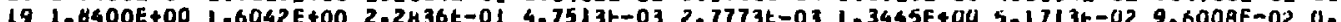
191.04000 17 l. 17 1. 16 1. $151.8400 E+001.1905 E+002.2397 E-01-1.7530 E-02$ 2.6554E-02 1.2346E+00 $6.6342 E-021.0104 E-010$. $141.8400 E+002.0902 E+002.2208 E-01-2.4238 E-02$ 1.8728E-C2 1.2288E+00 7.15902-02 1.0278E-01 0. 13 1.8400E+00 9.9102E-01 2.2000E-01-3.13LEE-02 2.0073E-02 1.2016E+00 T.7648E-02 1.047BE-01 0. $121.8400 E+00$ 8.9294E-01 2.1.781E-01-4-0046E-02 2.0726E-02 1.1707E+00 8.5315E-02 $1.0727 E-010$. 11 1.8400E+00 1.9623E-01 2.1356E-01-4.9262E-02 2.0580E-102 1.1359E+00 9.5091E-02 1.2037E-01 0. $101.8400 t+00$ 7.007BE-01 2.1335E-01-5.4874E-02 $1.9715 E-C \cdot 2 \quad 1.2014 E+001.0622 E-01 \quad 1.1379 E-01 \quad 0$. 9 1.8400E+00 6.0671E-01 2.1125t-01-7.01C6E-02 1.8399E-02 1.0638E+00 1.1914t-01 1.1775t-01 0. $1.8400 E+00$ 5.1444E-01 2.0911E-01-7-7746E-02 1.6822E-02 1.C268E+00 1.3557E-01 1.2268E-01 0. $71.8400 E+00 \quad 4.2623 E-01 \quad 2.0765 t-01-5.7721 E-02 \quad 1.5502 t-02 \quad 9.6701 E-01 \quad 1.6600 E-01 \quad 1.3165 E-01 \quad 3.1674 E-03 \quad 1.0000 E+00$ $61.8400 E+00 \quad 3.4489 E-01 \quad 2.0633 E-01-2.7600 E-02 \quad 1.4694 E-02 \quad 0.7$ U32E-01 $2.2629 E-01 \quad 1.4924 E-01 \quad 1.7173 E-02 \quad 1.0000 E+00$ $51.8400 t+00$ 2.6958E-0I 2.0533E-01-1.8119E-04 1.3693E-02 8-0340E-01 2.06112E-01 1.6933E-01 $1.9055 E-02 \quad 1-0000 E+00$ 4 1. B400E +00 1 $9901 E-0120454 E-01$ l $7275 E-02$ l

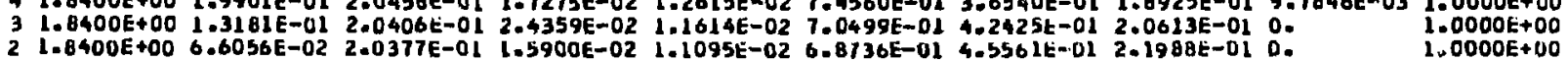

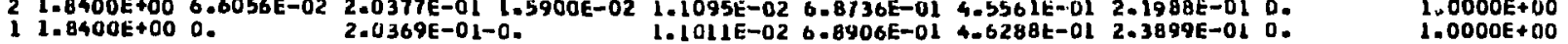


2HENP LIP.OI

CYCLE) IK-NUMEER

RHC

410 .

40 1.8400E+00

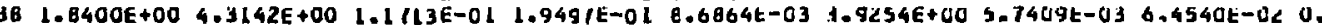
$371.6400 E+00 \quad 4.0703 E+00 \quad 1.2142 t-01 \quad 1.6527 t-01 \quad 7.7205 t-03 \quad 3.4163 t+60 \quad 6.8561 E-03 \quad 6.7094 E-02 \quad 0$. $36 \quad 1.8400 t+00 \quad 3.8601 E+00 \quad 1.2337 t-01 \quad 1.4512 t-01 \quad 5.7030 E-03 \quad$ J.C362t+00 $7.9819 t-03 \quad 0.9308 t-02 \quad 0$. $351.8400 t+003.6722 t+00 \quad 1.2349 E-01 \quad 3015 E-013.0172 E-032-7106 E+0 C-4.2864 E-03 \quad 7.1656 E-02 \quad 0$. 35 $\begin{array}{ll} & \end{array}$ $33 \quad 1.8400 E+00 \quad 3.3390 E+001.2 C 80 E-01 \quad 1.0756 E-01-3.0413 E-032.2599 E+00 \quad 1.2551 E-02 \quad 7.6122 E-02 \quad 0$. $321.8400 E+003.1872 E+00$ 1.1907E-01 9.8369E-02-3.1828E-03 2-C762E+00 L.45U3E-02 7.8103E-02 0.

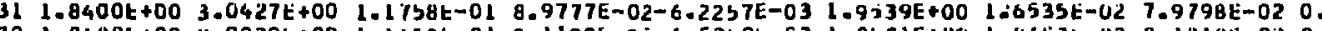
$301.0400 t+002.9039 t+00$ l.1652t-01 8.1190E-02-6.53b9t-03 1.8b81E+UC 1.665t-02 8.131日t-02 0.

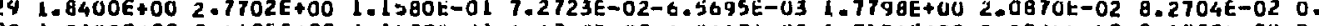

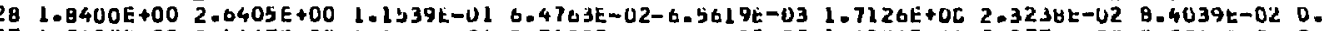

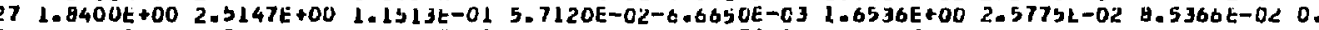

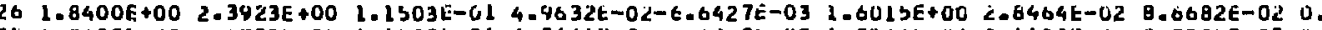
$251.8400 t+002.2729 t+00$ 1.1SO2t-01 4.244LE-02-6.4010t-0J 1.5366t+LC 3.1185E-02 $0.7923 E-02 \quad 0$.

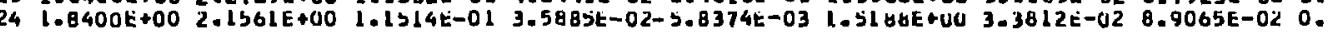
$231.8400 t+002.0417 t+00$ L.LS24t-U1 2.9662E-02-4.6503E-03 L.4859E+00 3.64U0E-02 9.0147t-02 0. $221.8400 E+00 \quad 1.9295 E+00$ l.1S44E-01 2.3846L-02-3.3169E-03 L.4b66E+6C 3.8962t-02 9.1134E-02 0.

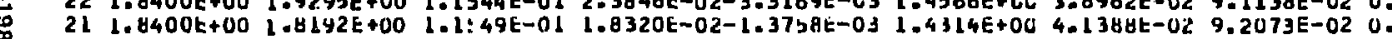

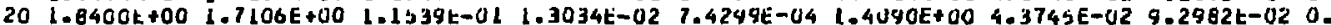

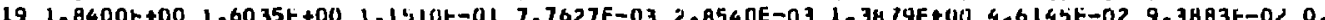
101084005400106039

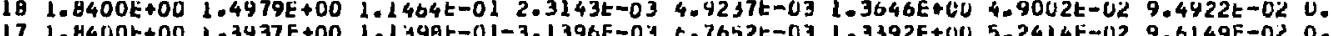
$171.8400 E+00 \quad 1.3937 E+00$ 1.1 $398 E-01-3.1396 E-03$ E.7652E-03 1.3392E+00 5.2414E-02 9.6149E-02 0.

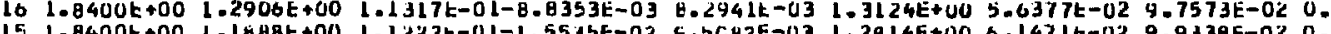

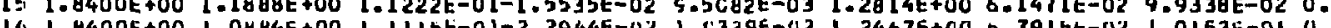

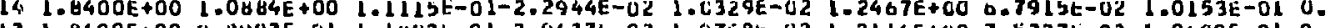

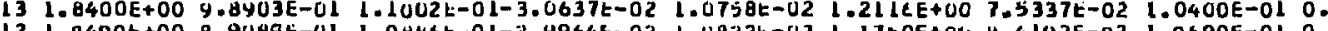

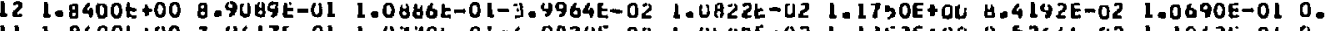
11 1.8400t +00 7.44L7E-01 1.0770t-01-4.983UE-02 L.US42E-02 1.1J5JE+00 9.5264t-02 1.1042E-01 0. $101.8400 E+00$ 6.984LE-01 1.0057t-01-6.0010t-02 9.5956t-03 1.CY72E+CO 1.0753t-01 1.1423E-01 0.

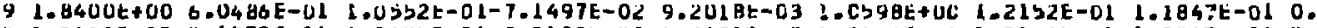

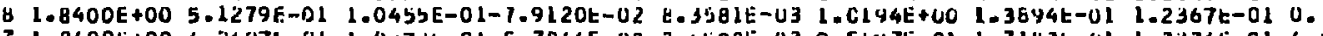
$1.8400 t+00$ 4.2497t-01 $1.0373 t-01-5.7844 E-02 \quad 7.0508 E-03 \quad 9.5647 E-01 \quad 1.7143 t-01 \quad 1.3334 t-014.06$ $1.8400 E+002.6869 E-01 \quad 1.0260 t-0 L-1.0224 t-03 \quad 6.7037 E-03 \quad 1.9679 t-0 L$ 3.0318E-01 1.7138t-01 1.9550t-02 4 1.8400t+00 1.9451t-01 1.0223t-01 1.6300t-02 0.1542t-03 1.4044E-01 3.7240t-01 1.9130E-01 1.0404t-02

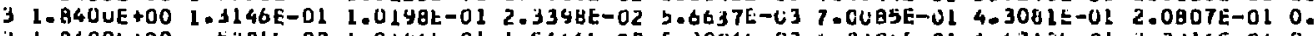

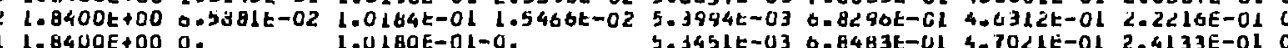

HEMPDG MAP

HEMPOG EEC 112 WIDTH 


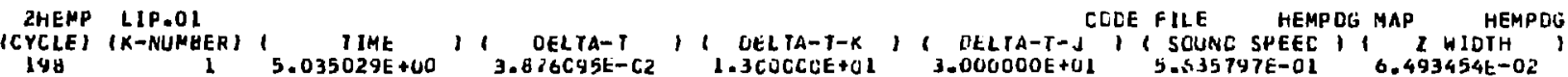

4.

$J$

RHO

(II)

$0.1561 E+000$.

$40 \quad 1.8400 E+00 \quad 3.0482 E+00$ o.

39 I. B4ODE+OD $4.6163 E+00$ U.

$38 \quad 1.8400 t+004.3154 E+00$ O.

$371.8400 t+004.0713 E+000$.

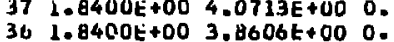

3b $1.8400 t+003.8606 t+000$.

$\begin{array}{llll}3 b & 1.8400 t+00 & 3.6719 t+00 & 0 . \\ 34 & 1.8400 t+00 & 3.4943 E+00 & 0 .\end{array}$

$331.8400 E+D 0$ 3.3381E+00 0.

32 I. $8400 E+00$ 3.1866E+00 0.

31 1. $840 O E+003.0420 E+00$ O.

$301.8400 t+002.9036 t+000$.

$291.8400 t+002.7698 E+00$ 0.

$281.8400 E+003.6404 E+000$.

$211.8400 E+002.4145 t+000$.

$261.8400 E+002.3922 E+000$.

25 1.

$251.8400 E+002.2728 E+000$.

$241.8400 E+00 \quad 2.1261 E+000$.

$231.8400 E+00 \quad 2.0417 t+000$.

药 22 1.8400E+00 $1.9295 E+000$.

$211.8400 E+001.8191 \mathrm{E}+000$.

$201.8400 E+00 \quad 1.7105 E+000$.

$191.8400 E+001.6033 E+000$.

1B $1.8400 t+00 \quad 1.4976 E+000$.

$171.8400 t+001.3932 t+00$ 0.

$161.8400 t+001.2901 E+000$.

$151.8400 E+00 \quad 1.2882 E+400$.

$14 \quad 1-8400 E+00 \quad 1.0877 E+000$

$131.8400 E+00 \quad 9.8432 E-010$.

$121.8400 E+00 \quad 8.4021 E-010$.

11 1. 8400E+00 $7.9346 \mathrm{t}-0 \mathrm{~L}$.

$101.0400 \mathrm{t}+006.9816 \mathrm{E}-010$.

$91.8400 E+006.0424 E-010$.

$81.8400 t+00 \quad 5.1224 \mathrm{E}-01 \mathrm{O}$.

$71.8400 \mathrm{E}+00$ 4.2456E-01 0 .

$61.9400 E+003.4363 t-010$.

3 1.8400t+00 2.6866E-01 D.

$41.8400 \mathrm{t}+00$ 1.9835E-01 0 .

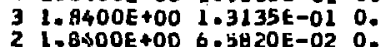

(CYCLE) (X-NUMEER) ( TIME
$Y(A)$

$x-$ - $\cup 1$ r-uct

$5.3379 E-O L-C$.

$3.2622 \varepsilon-01-C$.

$2.4419 \mathrm{t}-01-C$.

$1.9507 t-01=5$

$1.6486 \mathrm{E}-0 \mathrm{~L}-\mathrm{C}$.
$1.4443 \mathrm{t}-0 \mathrm{I}-\mathrm{C}$.

$1.4443 \mathrm{t}-0 \mathrm{i}-\mathrm{C}$.
$1.2940 \mathrm{E}-01-\mathrm{C}$.

1. 1689 t $-01 \cdots \mathrm{C}$.

1.0641E-01-C.

$9.7110 \mathrm{t}-02-\mathrm{C}$.

8.948BE-02-C.

8.111 EE-02-C.

$7.27285-02-c$.

$6.4724 E-02-C$.

5. $7070=-02-C$.

4.9688t-02-0.

4. $2623 \mathrm{E}-02-C$.

$3.6243 t-02-C$.

$3.0296 E-02-0$.

$2.4764 E-02-C$.

$2.4764 \mathrm{E}-02-\mathrm{C}$.
$1.9413 \mathrm{E}-02-\mathrm{C}$.

$1.4154 E-02-C$.

8.8790E-03-C.

$3.4144 \mathrm{E}-0 . \mathrm{B}-\mathrm{C}$.

$-2.2419 E-03-C$.

$-8.0528 t-03 . C$.

$-1.4973 E-02-C$.

$-2.2584 \mathrm{t}-02-\mathrm{C}$.

$-3.0506 E-02-C$.

$-4.0029 \mathrm{E}-02-\mathrm{C}$.
$-5.0050 \mathrm{E}-02-\mathrm{C}$.

$-6.04736-02-c$

- $7.04790-02-0$.

$-7.1978 E-02-C$.
$-7.9604 E-02-C$.

$-7.9604 E-02-C$.
$-5.7893 E-02-C$.

$-2.8364 E-02-C$.

$-1.3174 E-03-C$.

1.5974E-02-C.

2. $3086 E-02-C$.

, $1^{-0}$ Delta-t ${ }^{-6} ;$

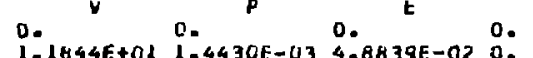

$1.1044 E+02$ 1.44.30E-03 $4.88396-020$

S.C1

$3.9021 E+00$ 5.7871E-03 $0.4674 E-02$ O.

3.4734E+00 6.7042E-03 $0.6712 E-02$ O.

3.15CAE+UC T.3854E-03 $6.8415 t-020$

$2.8665 E+0 C$ 0.5996E-03 7.03LTE-02 0 .

$2.6084 E+00 \quad 9-8116 t-03 \quad 7.2362 k-020$.

$2.3807 E+00 \quad 1.1290 \mathrm{E}-02 \quad 7.4448 E-02 \quad 0$.

$2 . C 23 L E+0 G \quad 1.5292 E-02 \quad 7.8704 E-02$ b. $3825 E-04 \quad 1.0000 E+00$

$1.8997 t+0 d 1.7654 t-02 \quad 8.0575 t-02 \quad 9.2900 t-04 \quad 1.0000 t+00$

$1.8050 E+00$ 2.0092t-0? B.2.203t-02 $1.0356 E-03 \quad 1.0000 E+00$

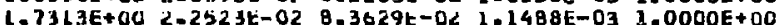

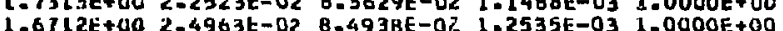

$1.6712 E+00$ 2-493E-02 B-4938E-OL I.

$1.62105+002.73645-02$ O.6L

$1.5796 E+00$ 2.972uL-02 $1.5466 \mathrm{E}+0 \mathrm{O} 3.1832 \mathrm{t}-02$ B.8163E-02 1.2985E-03 1.0000E +00 $1.3107 E+00$ 3. $3804 E-02$ 8.9001E-02 $1.0013 E-03$ 1.00DOE+00 $1.4934 E+00$ 3.5757E-02 $8.9766 E-02$ 4.9469t-04 $1.0000 E+00$ $2.4704 E+00$ 3.7692E-02 9.0b33k-02 0. $1.0000 E+00$ L. 44 13E+UU 3.981OE-02 9.1382E-02 0. 1.000UE+00

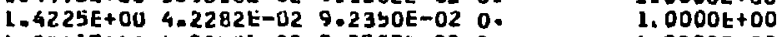
1.344 LE+00 4.534 Jt $-029.3527 \mathrm{t}-02$ 0. $1.0000 \mathrm{E}+00$ $1.3626 \mathrm{E}+00$ 4.9250t-02 $9.4962 \mathrm{E}-02 \mathrm{0} \quad 1.0000 \mathrm{E}+00$ L.3293t+UC S.3823t-02 9.6640E-02 $0 . \quad 1.0000 E+00$ $1.2933 E+005 . \$ 444 E-029.0619 E-02 \mathrm{G}$. $\quad 1.0000 E+00$ $1.2536 E+006-6564 t-02 \quad 1.0106 E-010$. $1.0000 E+00$ $1.2149 E+007.4600 E-02$ 1.0375E-01 0 . $1.1153 E+00$ H-411UE-0Z 1.0687E-01 Ua $1.1341 E+009.5639 E-02$ 1. $1054 E-01$ O $1.04436+041.08501-011.1455 E-010$.

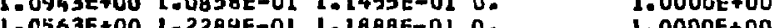
1.C563E+00 1.2289E-0I I.2888E-01 O. L.000NE+DO $1.0254 E 00$ L $1.0000 E+00$ 9.5170E-01 1.7486E-OL L.342LE-01 3.4678E-03 1.0000E+00 $8.6609 \mathrm{E}-01 \quad 2.363 \mathrm{Jt}-01 \quad 1.5210 \mathrm{E}-01 \quad 1.7370 \mathrm{E}-02$ 1.0000E+OO 7.935TE-01 3.0675E-01 1.7241E-01 1.9798E-02 1.0000E+00 7.3795E-OL 3.75B4E-01 1.9231E-02 1.0732E-02 1.0000E+UO $6.9482 E-01$ 4-3406E-01 2.0902E-01 $0 . \quad 1.0000 E+00$ $3.8094 E-01$ 4.6663E-02 2.2324E-01 $0 . \quad 1.0000 E+0 C$ $6.8279 E-01$ 4.7380E-01 2.424TE-02 0. $1.0000 E+0 C$ OELTA-T-K, OELTA-T-J, (SOUNO SPEEC, I I WIOTH, 
ZHEMP LIP.OL

(CYCLE) (K-N

198

IIME
I

1 DELTA-I

DELTA-T
$.876095 E-C$

I DELIA-T-K

1. $400000 E+01$

1 delta-t -

CCCE FILE

HEMPDG MAP

$1.400000 E+01$

$5.635797 \mathrm{E}-01$

2 WIOTH

\begin{tabular}{|c|c|c|c|c|c|}
\hline $\begin{array}{c}\text { (TOTAL E) } \\
1.749545 E+00\end{array}$ & $\begin{array}{c}\text { (E-LERO) } \\
1.757432 E+00\end{array}$ & $\begin{array}{c}\text { (t-CHANGE) } \\
-4.487919 E-C 1\end{array}$ & $\begin{array}{c}\text { (K.E.SUF) } \\
4.328246 E-01\end{array}$ & $\begin{array}{c}\text { (I.E.SUP' } \\
1.316720 E+00\end{array}$ & $\begin{array}{c}\text { (MASS-SUM) } \\
1.178223 t+02\end{array}$ \\
\hline $\begin{array}{c}\text { (MATERIAL) } \\
\text { IO } \\
l\end{array}$ & $\begin{array}{r}\text { (MAS5) } \\
9.47001 \text { IE+01 } \\
2.312212 E+01\end{array}$ & $\begin{array}{c}\text { (TOTAL E) } \\
3.043768 E-01 \\
1.445168 \mathrm{0}+00\end{array}$ & $\begin{array}{l}\text { (KINE IIC E) } \\
2.560245 \mathrm{~L}-01 \\
1.7600 \mathrm{~L}-01\end{array}$ & $\begin{array}{l}\text { IIATERnAL El } \\
4.435223 \mathrm{~B}-02 \\
1.268368 \mathrm{0}+00\end{array}$ & \\
\hline
\end{tabular}




\section{Appendix F \\ Flow Charts}

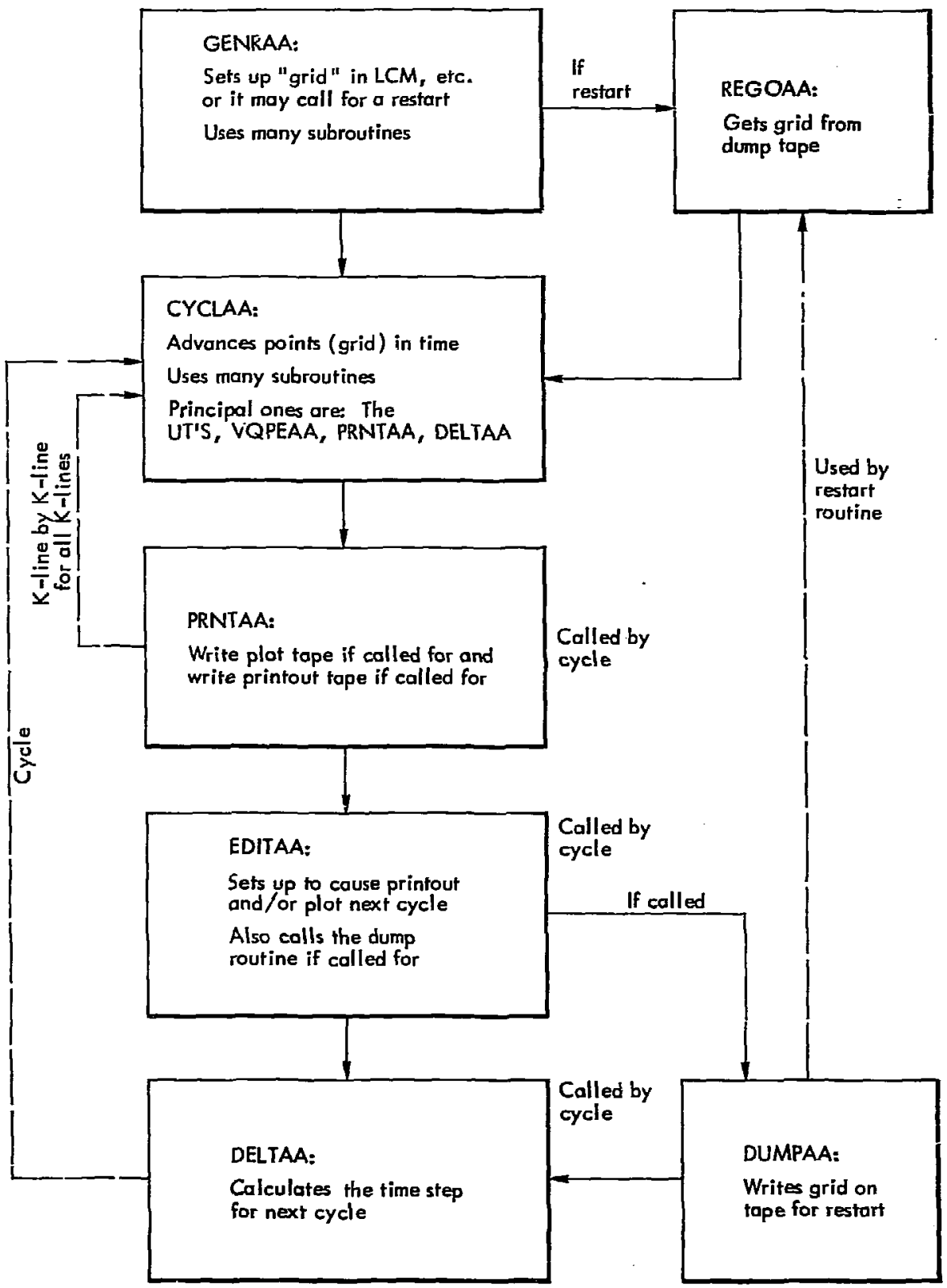

Fig. F-1. Relationship of principal subrcutines. 


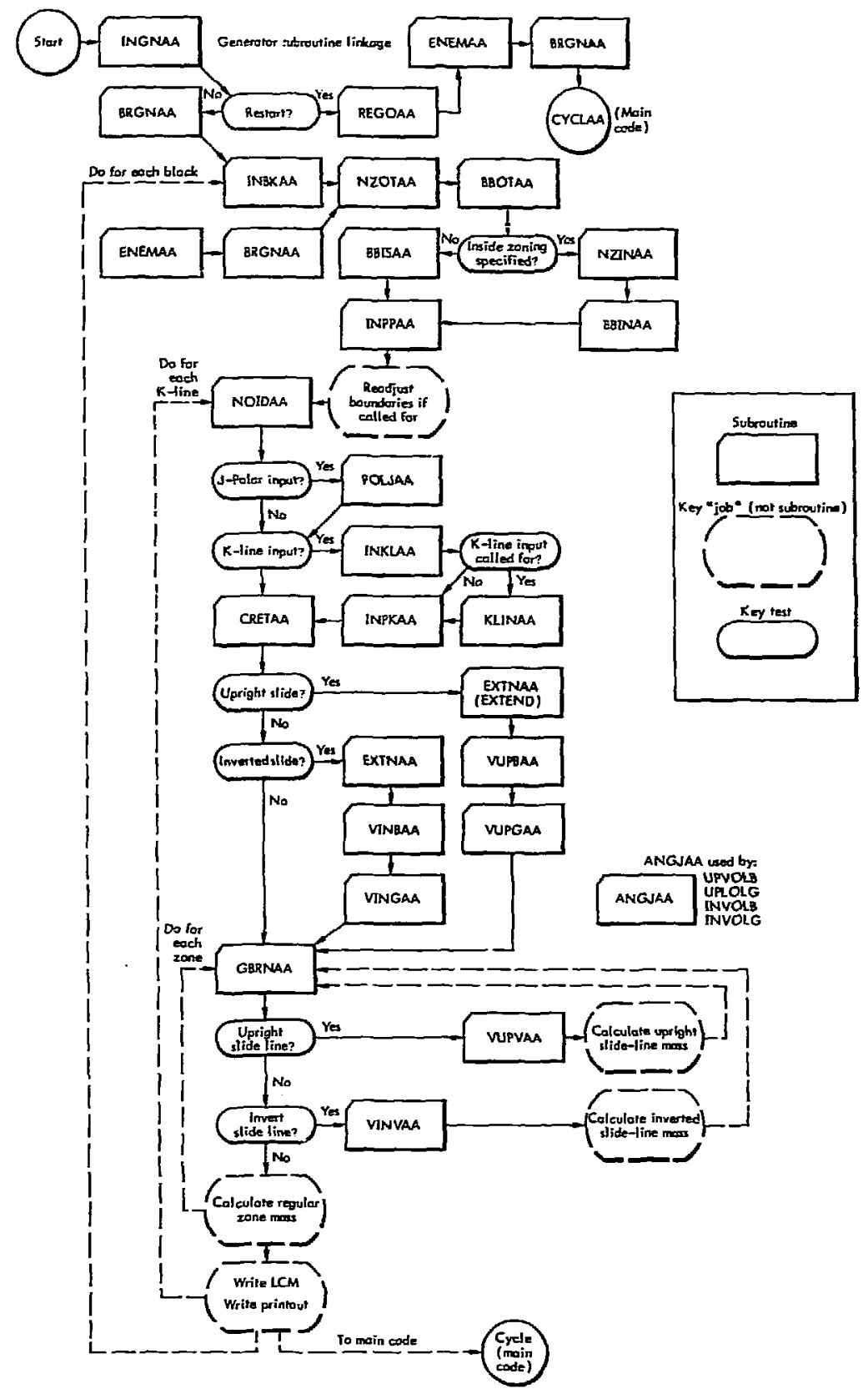

F.g. F-2. Chart of subroutine linkage and main branch points for generator GENLAA Bubroutine. 


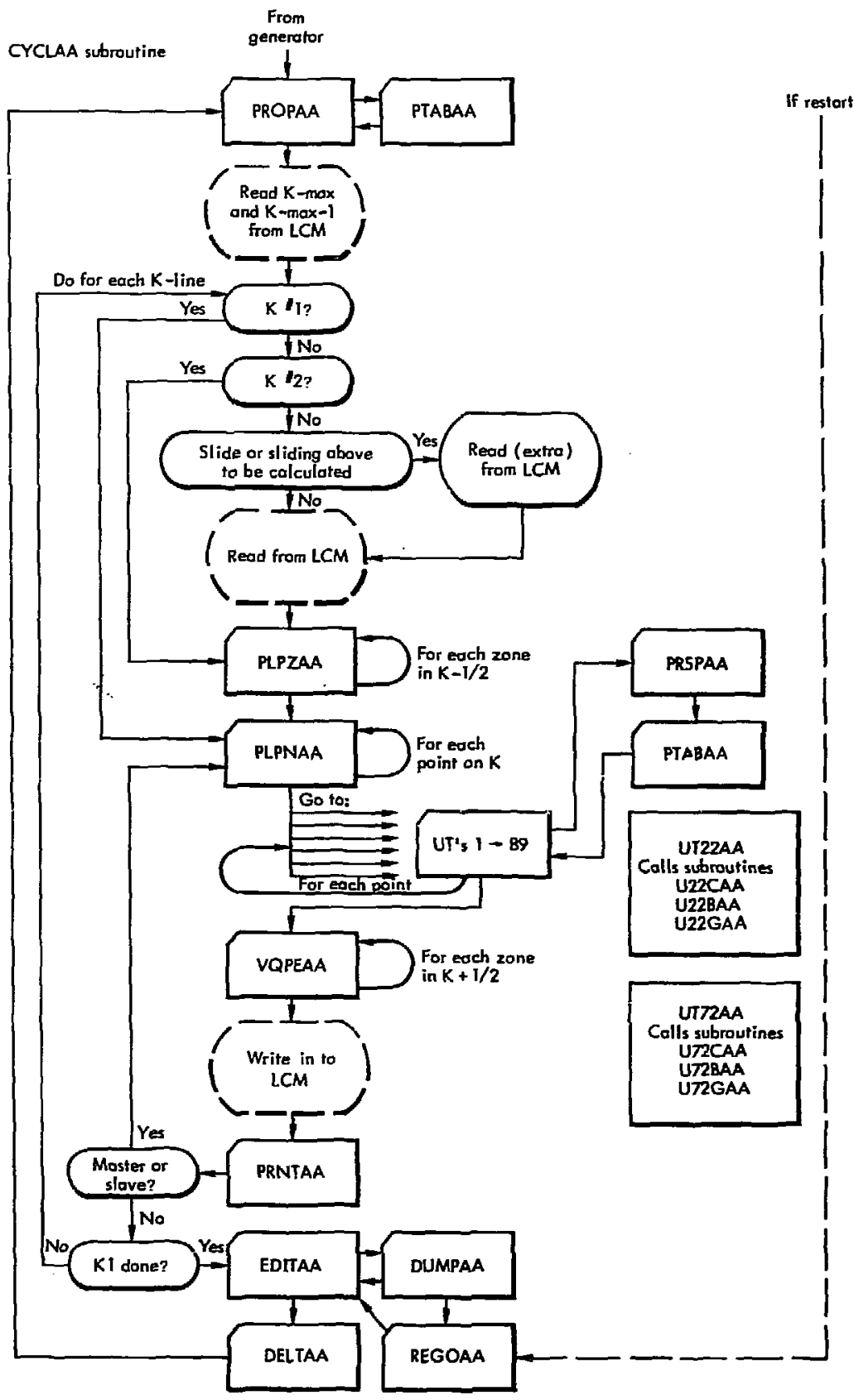

Fig. F-3. Chart of subroutine linkage and main branch points for cycling CYCLAA subroutine. 


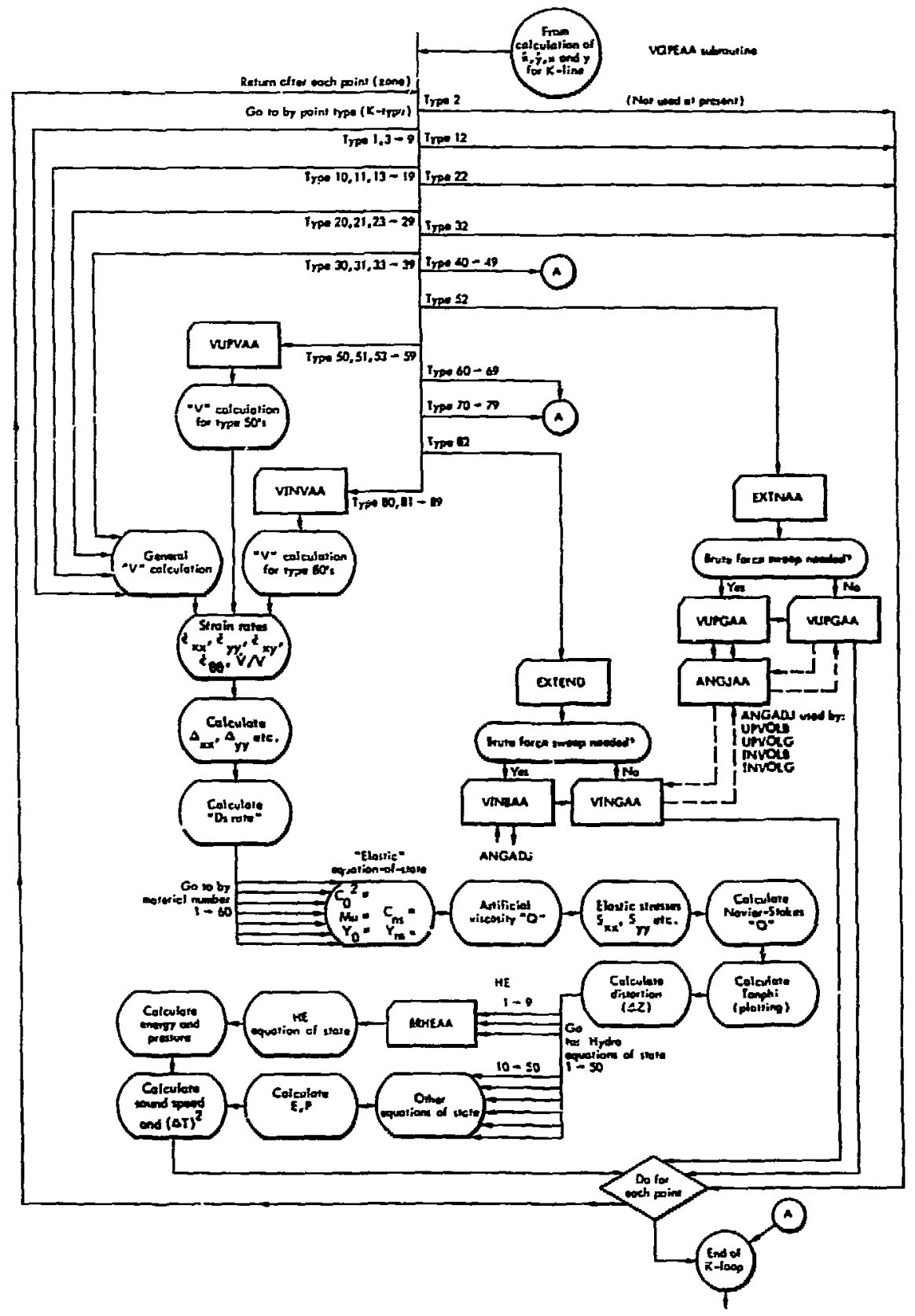

Fig. F-4. Chart of gubroutine linkage and malo branch points for VQPEAA subroutine. 